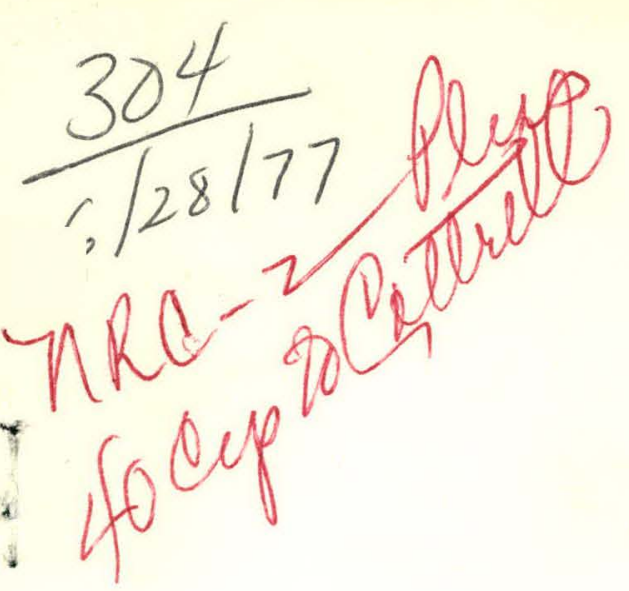

4.1173

TREE-NUREG-1083

for U.S. Nuclear Regulatory Commission

\title{
LOFT FACILITY PSS EXPERIMENTS: ANALYSIS OF WET WELL VERTICAL \\ LOADS RESULTING FROM TRANSIENT INITIATION
}

VICTOR T. BERTA

NOTICE

PORTIONS OF THIS REPORT ARE ILLEGIBLE. It has been reproduced from the best avallable copy to permit the broadost possible avallability.

May 1977
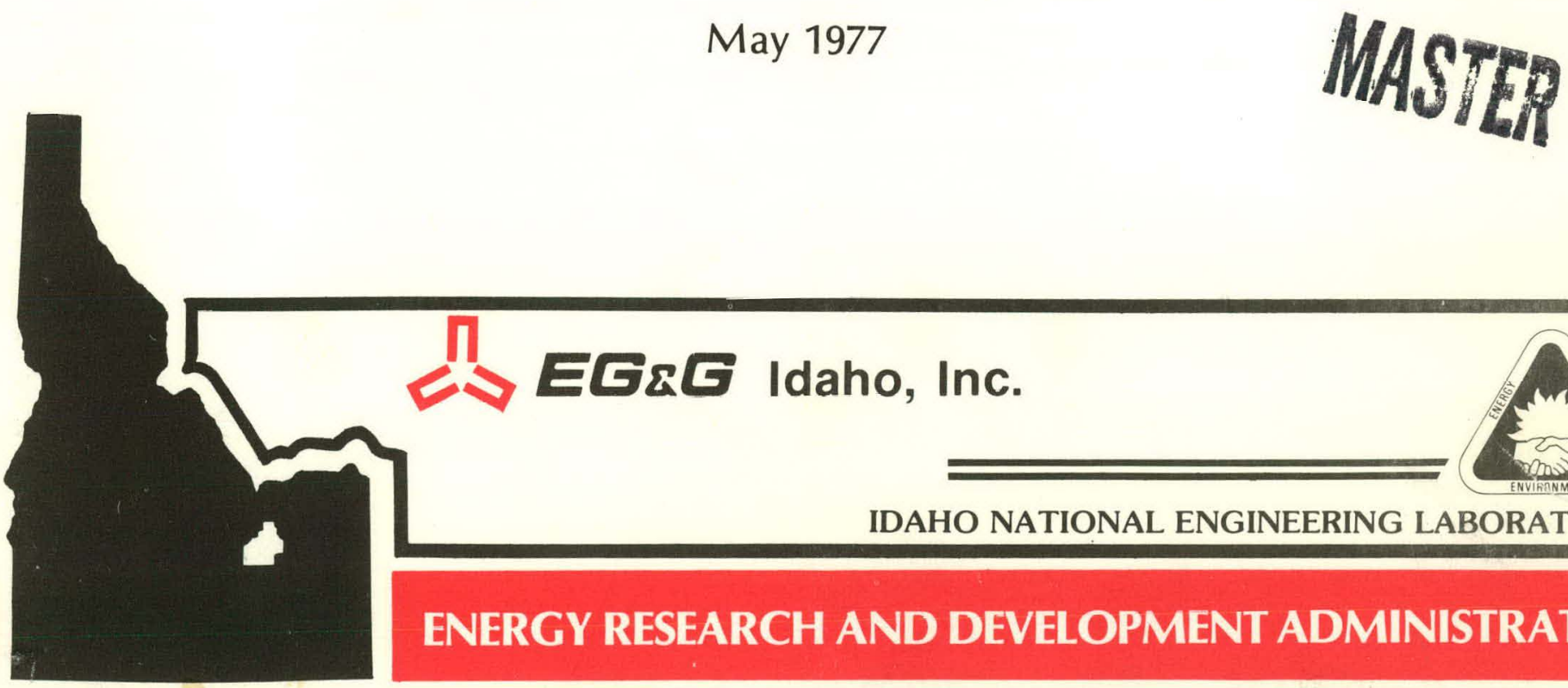

EG\&G Idaho, Inc.

IDAHO NATIONAL ENGINEERING LABORATORY

ENERGY RESEARCH AND DEVELOPMENT ADMINISTRATION

IDAHO OPERATIONS OFFICE UNDER CONTRACT EY-76-C-07-1570 


\section{DISCLAIMER}

This report was prepared as an account of work sponsored by an agency of the United States Government. Neither the United States Government nor any agency Thereof, nor any of their employees, makes any warranty, express or implied, or assumes any legal liability or responsibility for the accuracy, completeness, or usefulness of any information, apparatus, product, or process disclosed, or represents that its use would not infringe privately owned rights. Reference herein to any specific commercial product, process, or service by trade name, trademark, manufacturer, or otherwise does not necessarily constitute or imply its endorsement, recommendation, or favoring by the United States Government or any agency thereof. The views and opinions of authors expressed herein do not necessarily state or reflect those of the United States Government or any agency thereof. 


\section{DISCLAIMER}

Portions of this document may be illegible in electronic image products. Images are produced from the best available original document. 
Printed in the United States of America

Available from

National Technical Information Service

U.S. Department of Commerce

5285 Port Royal Road

Springfield, Virginia 22161

Price: Printed Copy $\$ 11.00$; Microfiche $\$ 3.00$

"The NRC will make available data tapes and operational computer codes on research programs dealing with postulated loss-of-coolant accidents in light water reactors. Persons requesting this information must reimburse the NRC contractors for their expenses in preparing copies of the data tapes and the operational computer codes. Requests should be submitted to the Research Applications Branch, Office of Nuclear Regulatory Research, Nuclear Regulatory Commission, Washington, D.C. 20555."

This report was prepared as an account of work sponsored by the United States Government. Neither the United States nor the Energy Research and Development Administration, nor the Nuclear Regulatory Commission, nor any of their employees, nor any of their contractors, subcontractors, or their employees, makes any warranty, express or implied, or assumes any legal liability or responsibility for the accuracy, completeness or usefulness of any information, apparatus, product or process disclosed, or represents that its use would not infringe privately owned rights. 
LOFT FACILITY PSS EXPERIMENTS:

ANALYSIS OF WET WELL VERTICAL LOADS

RESULTING FROM TRANSIENT INITIATION

by

Victor T. Berta

EG\&G Idaho, Inc.

May 1977

PREPARED FOR THE

U.S. NUCLEAR REGULATORY COMMISSION AND

ENERGY RESEARCH AND DEVELOPMENT ADMINISTRATION

IDAHO OPERATIONS OFFICE

UNDER CONTRACT NO. EY-76-C-07-157.0 
LOFT FACILITY PSS EXPERIMENTS:

ANALYSIS OF WET WELL VERTICAL LOADS

RESUI_TING FROM TRANSIENT INITIATION

Approved:

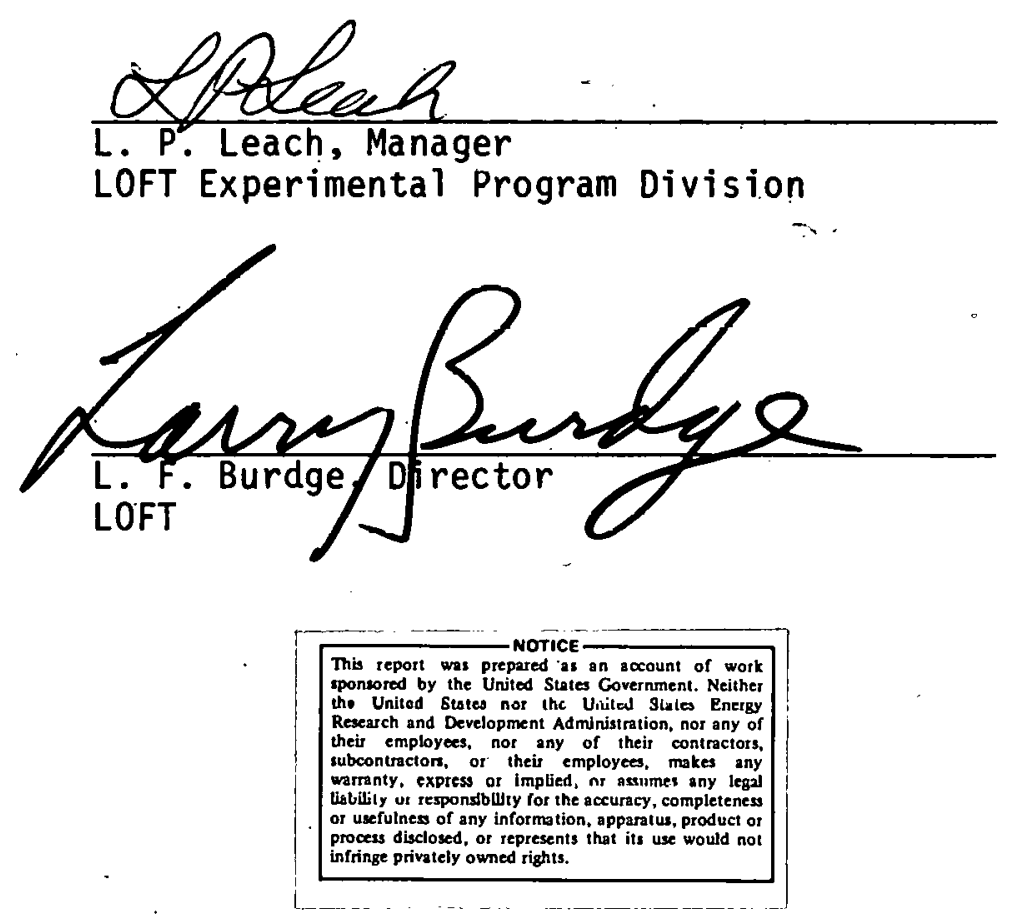

DISTRIBUTION OF THIS DOCUMENT IS UNLIMITED 


\section{ACKNOWLEDGMENTS}

Appreciation is expressed to E. C. Lemmon and K. M. Peery for experiment analysis assistance and to H. A. Hardy for data processing assistance. 
Fourteen experiments on the Loss-of-Fluid Test (LOFT) facility pressure suppression system (PSS) are analyzed in relation to the vertical load generated on the suppression tank in the first $0.5 \mathrm{sec}$ of the transient. Variations in principle parameters affecting the generation of vertical loads were included in the experiments. The internal and external vent submergences are identified from the analysis as being parameters which are first order in influencing the magnitude of the vertical load. These parameters are geometric in nature and depend only on PSS design. Physical parameters of total energy input and rate of energy input to the dry well, which influence the dry well pressurization, also are identified as being first order in influencing the magnitude of the vertical loads. The vertical load magnitude is a direct function of these geometric and physical parameters. The analysis indicates that a small value in any one of the parameters will cause the vertical load to be small and to have little dependence on the magnitude of the other parameters. In addition, the phenomena of nonuniform nonsynchronized vent inlet pressures, which have origins that are either geometric, physical, or a combination of both, act as a significant vertical load reduction mechanism.

The experimental data obtained from each experiment are included in an appendix. The appendices constitute experimental data reports that can be used in conjunction with the dimensional information of the PSS contained in the report for containment code verification studies. 
SUMMARY

The vertical loads on the LOFT suppression tank (pressure suppression system wet well) were influenced by both geometric and physical parameters. Principle geometric parameters were the vent external submergence and the vent internal submergence (which is also discussed in terms of vent preclearing). Principle physical parameters were the total energy input to the dry well and the rate of energy input to the dry well (dry well rate of pressurization). An additional parameter, which has both geometric and physical origins, is the nonuniform nonsynchronized vent pressure behavior which acts as a load magnitude reduction mechanism.

The maximum vertical loads in the suppression tank occurred within the first $0.5 \mathrm{sec}$ of the transient initiation for all experiments. The magnitude of the vertical load was found to be strongly dependent on the energy input to the dry well in this time interval. Of special significance is the strong dependence on the rate of energy input or the rate of pressurization at the inlet of the vents to the wet well suppression pool. Changes in the opening rates of the quick-opening valves (which relate to the rate of dry well pressurization above the vent.s) on a millisecond time scale basis resulted in large differences in the magnitudes of the vertical load on the suppression tank. The minimum magnitude of the vertical load on the suppression tank, which is that required to. clear the vents, could be approached at still relatively high area opening rates of the quick-opening valves (or at relatively high dry well pressurization rates).

Shallow vent submergences resulted in early bubble breakthrough of the suppression pool surface. Early bubble breakthrough acted as a vertical load reduction mcchanism. Deeper vent submergences delayed bubble breakthrough permitting larger vertical loads. Reduction of the vent internal submergence (vent preclearing) by maintaining a higher dry well pressure also is a vertical load reduction mechanism. Internal and 
external vent submergences appeared to affect the magnitude of the vertical load to the same degree.

The geometry of the dry well of the LOFT PSS is such that the four vents into the suppression pool are subjected to nonuniform nonsynchronized pressure as a function of time. Different vent pressure behavior resulted in a reduction of the vertical load magnitude in both up and down directions. Theoretical calculations which used the measured dry well pressures gave vertical load results which agreed much more closely with experimental values than did theoretical calculations which assumed uniform synchronous vent pressure behavior.

The LOFT suppression tank (wet well) is structurally stiff in the vertical direction compared to the frequency content of the pressure data in the experiments. The measured natural frequency in the vertical direction was $60 \pm 7 \mathrm{~Hz}$. Power spectral density analysis of the pressure data showed that, for all experiments, the frequency content was below $20 \mathrm{~Hz}$ with greater than $95 \%$ of the power below $10 \mathrm{~Hz}$. As a result, there was essentialiy no dynamic response of the PSS to the pressure loading.

The vertical load magnitudes were never greater than $25 \%$ of the design limits of $-13 \times 10^{6} \mathrm{~N}$ in the down direction and $-5 \times 10^{6} \mathrm{~N}$ in the up direction. The magnitude of the up-load exceeded the weight of the wet well and water pool in only three of the 14 experiments. The upload was not sufficient to cause measurable deflection in any of the three experiments. Two of the three experiments were the "miniblowdown" type in which a fixed amount (96.2 liters) of water was injected. The other experiment was a full system blowdown experiment in which 198 liters of water were injected and followed rapidly by the blowdown of the PCS water. The mini-blowdown experiment produces a pulse-type dry well pressurization as opposed to a step-type dry well pressurization in a full system blowdown experiment.

The pressure data within the wet well indicated that bubble condensation occurred primarily directly below the vents. Pool pressures from 
the pool surface down to approximately the elevation of the vent exits are very similar to gas volume pressures. Bubble phenomena in venting from the vent exits through the pool to the gas volume appeared to preclude formation of bubbles large enough to include more than one vent (minimum vent separation in LOFT is $1.82 \mathrm{~m}$ ).

The magnitudes of the principle parameters affecting vertical loads in the LOFT PSS do not have the same relationship in other systems, such as the MARK I PSS, as they do in the LOFT PSS. Therefore, directly applying the vertical load results tu other systems is not recommended unless the scaling laws are fully understood. The 14 LOFT PSS experi-. ments can be considered to be sets of parameter values for use in general containment code verification. A complete set of data is contained in this report on each experiment for this purpose. 


\section{NOMENCLATURE}

Broken Loop

$\mathrm{CV}$

FSO

LO-

LI-

LOCE

LOFT

LPWR

LVDT

Mini-Blowdown

PCS

PDE

PE

PSD

PSS

QOBV

ST

SV
The loop in which the pipe break occurs. In the LOFT system, the broken loop consists of two piping lines terminated in isolation valves. One piping line is the inlet line to the reactor vessel, and the other piping line is the outlet line from the reactor vessel. Refer to Reference 1 for additional detail.

Control valve

Full scale output (of a detector)

Designation of the mini-blowdown experiment series

Designation of the LOFT nonnuclear LOCE series

Loss-of-coolant experiment

Loss-of-fluid test

Large pressurized water reactor

Linear voltage differential transformer

The name used for an experiment in which only the coolant volume between the broken loop isolation values and the downstream QOBVS is vented into the PSS

Primary coolant system

Differential pressure element

Pressure element

Power spectral density

Pressure suppression system

Quick-opening blowdown valve

Suppression tank

Suppression vessel 


\section{CONTENTS}

ABSTRAC广 . . . . . . . . . . . . . . . . . . .

SUMMARY. . . . . . . . . . . . . . . . . . . . iv

NOMENCLATURE . . . . . . . . . . . . . . . . . . . . vii

I. LOFT SYSTEMS. . . . . . . . . . . . . . . . . . . 1

1. Description. . . . . . . . . . . . . . . . . . . . 1

2. Qualification By Experiment. . . . . . . . . . 8

II. EXPERIMENTS AND RESULTS . . . . . . . . . . . . . . . . . 11

1. Vertical Load Calculation. . . . . . . . . . . . 11

2. Experimental Vertical Loads............... 13

3. Pressure Data Characteristics. . . . . . . . . . . 27

4. Systems Response to Loading. . . . . . . . . . . . . . . 29

5. Relevance to MARK Pressure Suppression Systems . . . . . 36

II I REFERENCES. . . . . . . . . . . . . . . . . . . 38

APPENDIX A Mini-Blowdown LO-02 Experimental Data . . . . . . 39

APPENDIX B Mini-Blowdown LO-03 Experimental Data . . . . . 63

APPENDIX C Mini-Blowdown LO-3A Experimental Data . . . . . 87

APPENDIX D Mini-Blowdown LO-3B Experimental Data . . . . . . 111

APPENDIX E Mini-Blowdown LO-3C Experimental Data . . . . . 135

APPENDIX F Mini-Blowdown LO-04 Experimental Data . . . . . 159

APPENDIX G Mini-Blowdown L0-05 Experimental Data . . . . . 183

APPENDIX H Mini-Blowdown LO-08 Experimental Data . . . . . 207

APPENDIX I Mini-Blowdown L0-09 Experimental Data . . . . . 229

APPENDIX J Mini-Blowdown L0-10 Experimental Data . . . . . 253

APPENDIX K LOCE LI-01 Experimental Data. . . . . . . . . 277

APPENDIX L LOCE LI-02 Experimental Data............... 301

APPENDIX M LOCE LI-03 Experimental Data. . . . . . . . . . . 325

APPENDIX N LOCE LI-3A Experimental Data. . . . . . . . . 349 


\section{FIGURES}

1. Component Assembly Connecting PCS Broken Loop to the PSS. . 2

2. Quick-Opening Blowdown Valve Schematic Diagram. . . . . . . 3

3. LOFT PSS Header (dry wel1). . . . . . . . . . . . . 4

4. PSS Suppression Tank and Pressure Instrumentation . . . . . 5

5. PSS Vacuum Relief System. . . . . . . . . . . . . 6

6. Normalized Vertical Loads - Single QOBV Mini-Blowdown
Experiments............................. 21

7. Normalized Down-Loads - Double QOQBV Mini-Blowdown Experiments..................... . 22

8. Normalized Up-Loads - Double QOBV Mini-Blowdown Experiments................. . . 23

9. Normalized Down-loads - Ll Series Experiments . . . . . . . 24

10. Normalized Up-Loads - Ll Series Experiments . . . . . . . 25

11. PSD of PE-SV-01 Data in Experiment LO-04. . . . . . . . . 30

12. PSD of PE-SV-02 Data in Experiment LO-04. . . . . . . . 30

13. PSD of PE-SV-14 Data in Experiment LO-04. . . . . . . . . 31

14. PSD of PE-SV-55 Data in Experiment LO-04. . . . . . . . . 31

15. PSD of PE-SV-01 Data in Experiment LI-3A. . . . . . . . 32

16. PSD of $P[-5 V=02$ Ddta in Experiment L1-3A. . . . . . . . 32

17. PSD of PE-SV-14 Data in Experiment L1-3A. . . . . . . . . 33

18. PSD of PE-SV-55 Data in Experiment L1-3A. . . . . . . . 33

\section{TABLES}

I. Physical Parameters of the LOFT PCS and PSS. . . . . . 7

II. Suppression System Measurement Summary . . . . . . . 10

III. Experiment Initial Conditions. . . . . . . . . 12 
IV. Vertical Load Calculation Values . . . . . . . . . . 14

V. Mini-Blowdown Experiment Results........... 15

VI. Full System Blowdown Experiment Results. . ...... 16

VII. Vertical Load Normalized Values. . . . . . . . . . 20

VIII. Maximum Up-Load versus Wet Well Weight . . . . . . . . 34

IX. PSS Characteristics of LOFT and MARK I . . . . . . . 37

A-I. Experiment L0-02 Data Summary. . . . . . . . . . . 42

R-I. Experiment LO-03 Data Summary: . . . . . . . . . . 66

C.I. Experiment LO-3A Data Summary. . . . . . . . . . . 90

D-I. Experiment L0-3B Data Summary. . . . . . . . . . 114

E-I. Experiment LO-3C Data Summary. . . . . . ... . 138

F-I. Experiment L0-04 Data Summary. . . . . . . . . . 162

G-I. Experiment L0-05 Data Summary. . . . . . . . . . . 186

H-I. Experiment LO-08 Data Summary. . . . . . . . . . 210

I-I. Experiment L0-09 Data Summary. . . . . . . . . . . 232

.]-I. Experiment L0-10 Data Summary. . . . . . . . . . 256

K-I. Experiment LI-Ül Data Suniriary. . . . . . . . . . . 280

L-I. Experiment L1-02 Data Summary. . . . . . . . . 304

$M=I$ Experiment L1-03 Data Summary. . . . . . . . . 328

N-I. Experiment LI-3A Data Summary. . . . . . . . . 352 
LOFT FACILITY PSS EXPERIMENTS: ANALYSIS OF WET WELL

VERTICAL LOADS RESULTING FROM TRANSIENT INITIATION

I. LOFT SYSTEMS

1. DESCRIPTION

The LOFT facility is a scale model of a large pressurized water reactor (LPWR) and is designed to contain fully operational systems for the study of primary system coolant loss phenomena and plant recovery mechanisms. The pressure suppression system experiments, which are the subject of this report, involve the LOFT facility components shown schematically in Figures 1 through 5 . These figures contain relevant dimensional information in supplement of the experiments described in Section II. A detailed description of the components appears in the LOFT description document ${ }^{[1]}$.

Figure 1 shows the component assembly for initiation of loss-ofcoolant experiments (LOCE) and routing of the effluent into the header of the pressure suppression system (PSS). The header serves as the dry well of the PSS. The two upstream flanges mate with those on the ends of the broken loop piping lines (Figures 4, 44, and 45 of Reference 1). A LOCE is initiated by a controlled rate of opening of each quickopening blowdown vaive (QOBV). The schematic diagram of the QOBVs is shown in Figure 2. Venting the rear chamber of each valve simultaneously by opening control valve CV-P138-99 will cause the sleeve-piston assembly lo open. The rate of opening is controlled by the size of orifices XRO-96 and XR0-97. The shortest time for the valves in the tandem mode of operation shown in Figure 2 to open an area equal to the inlet area of the valves $\left(0.05 \mathrm{~m}^{2}\right)$ is approximately $14 \mathrm{msec}$. 


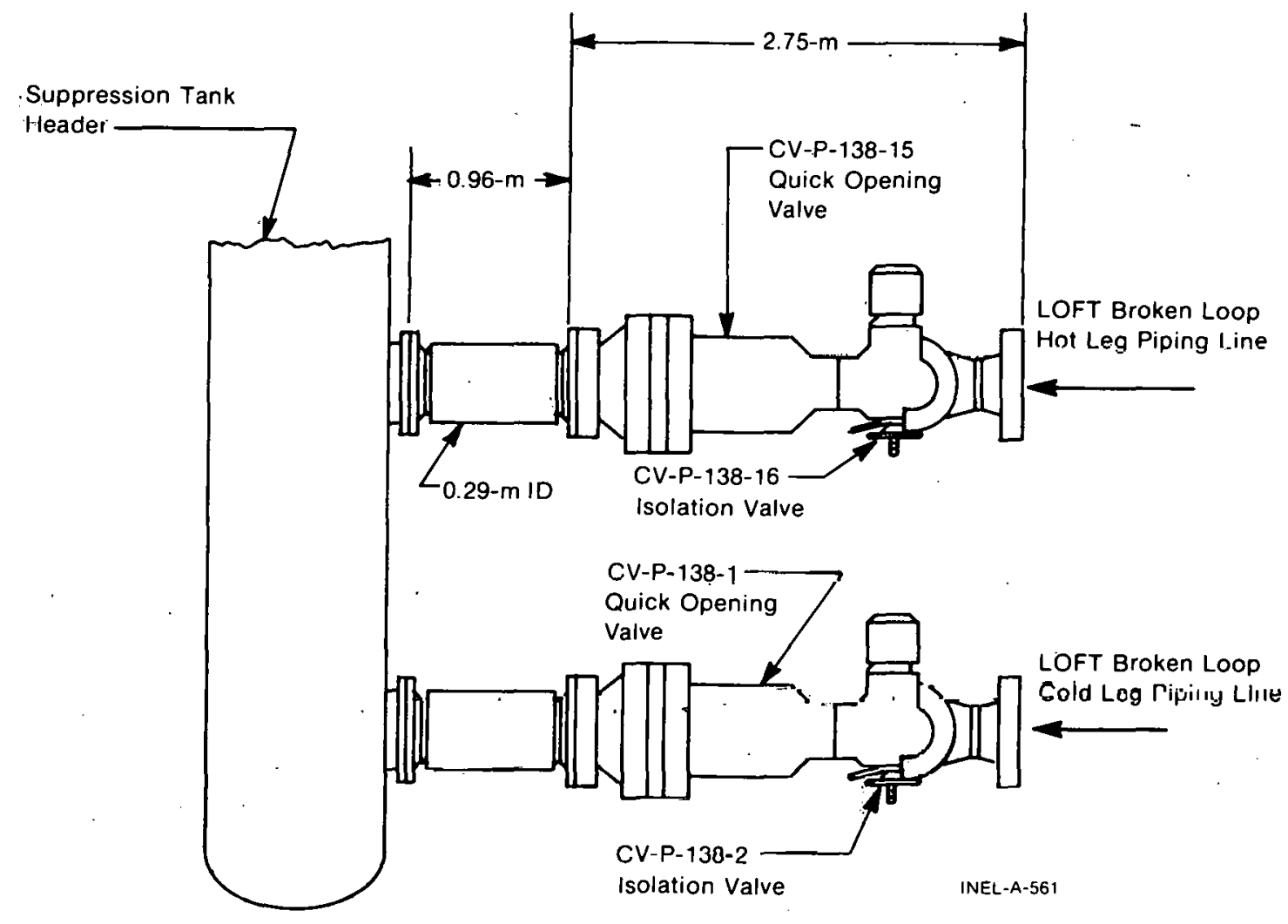

Fig. 1 Component Assembly Connecting PCS Broken Loop to the PSS.

Figures 3, 4, and 5 show the geometry of the PSS and also the location and desiunation of pressure measurements oli lihe PSS. Figure 3 shows the header or dry well nf the PSS. Four vents ruute effluent from the header to the suppression tank (ST), which is the wet well of the PSS. The four vents enter the ST on an angle of 33 degrees from the vertical. The vents extend to the horizontal centerline of the tank and then turn vertical for effluent injection into the water volume of the lank as shown in Figure 4. A vacuum relief system is shown in Figure 5 which connects the dry well to the gas volume of the wet well. This system prevenls backflow through the vents in the event the tank gas space pressure exceeds the dry well pressure. The check valve is set to open at a pressure difference of approximately 0.035 bar.

Physical parameters of the LOFT PSS and primary coolant system (PCS) are shown in Table I. The PSS is designed to contain the effluent from the LOFT PCS and to fit into the LOFT containment building, as 
$x$

$\omega$

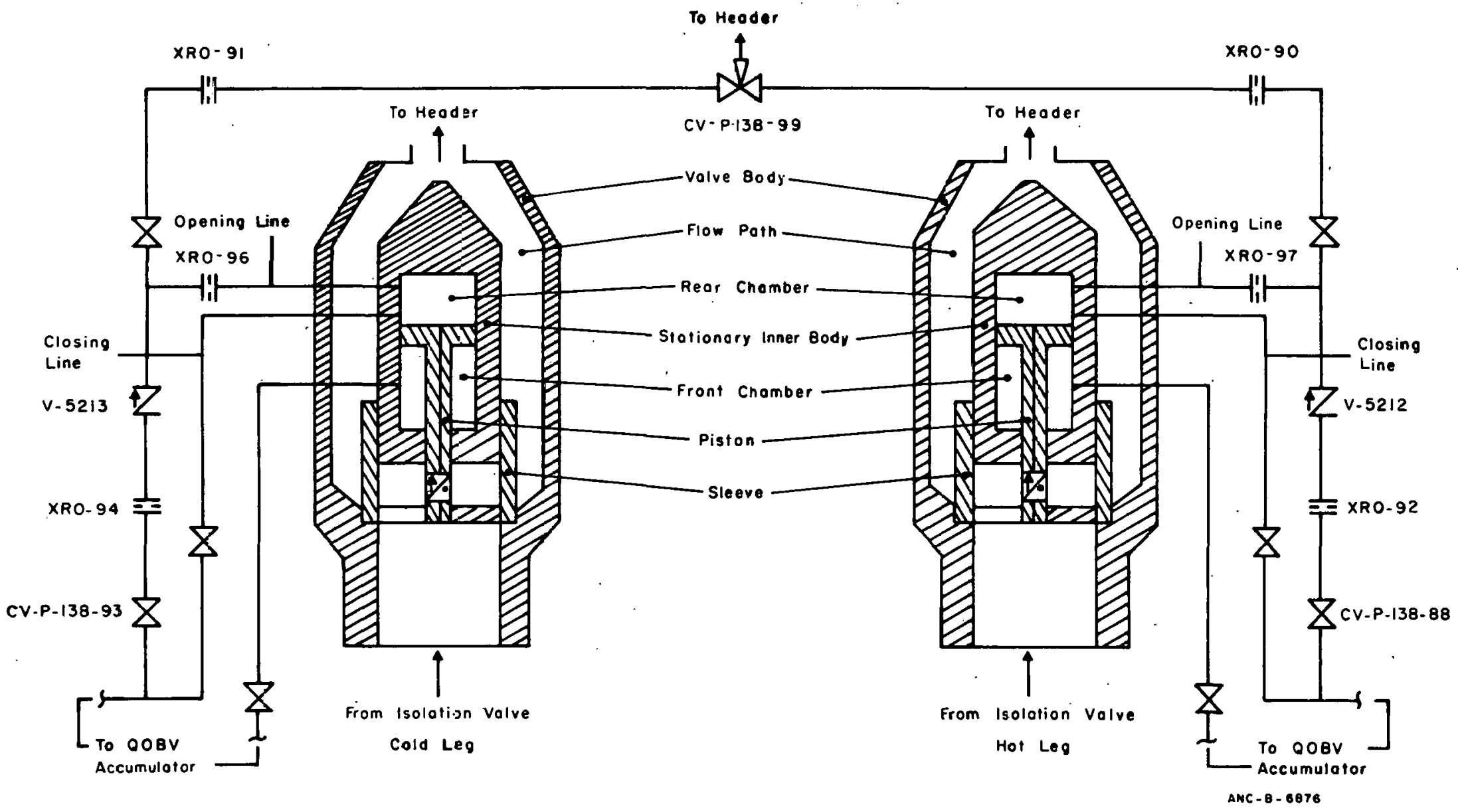

Fig. 2 Quick-Opening Blowdown Valve Schematic Diagram. 


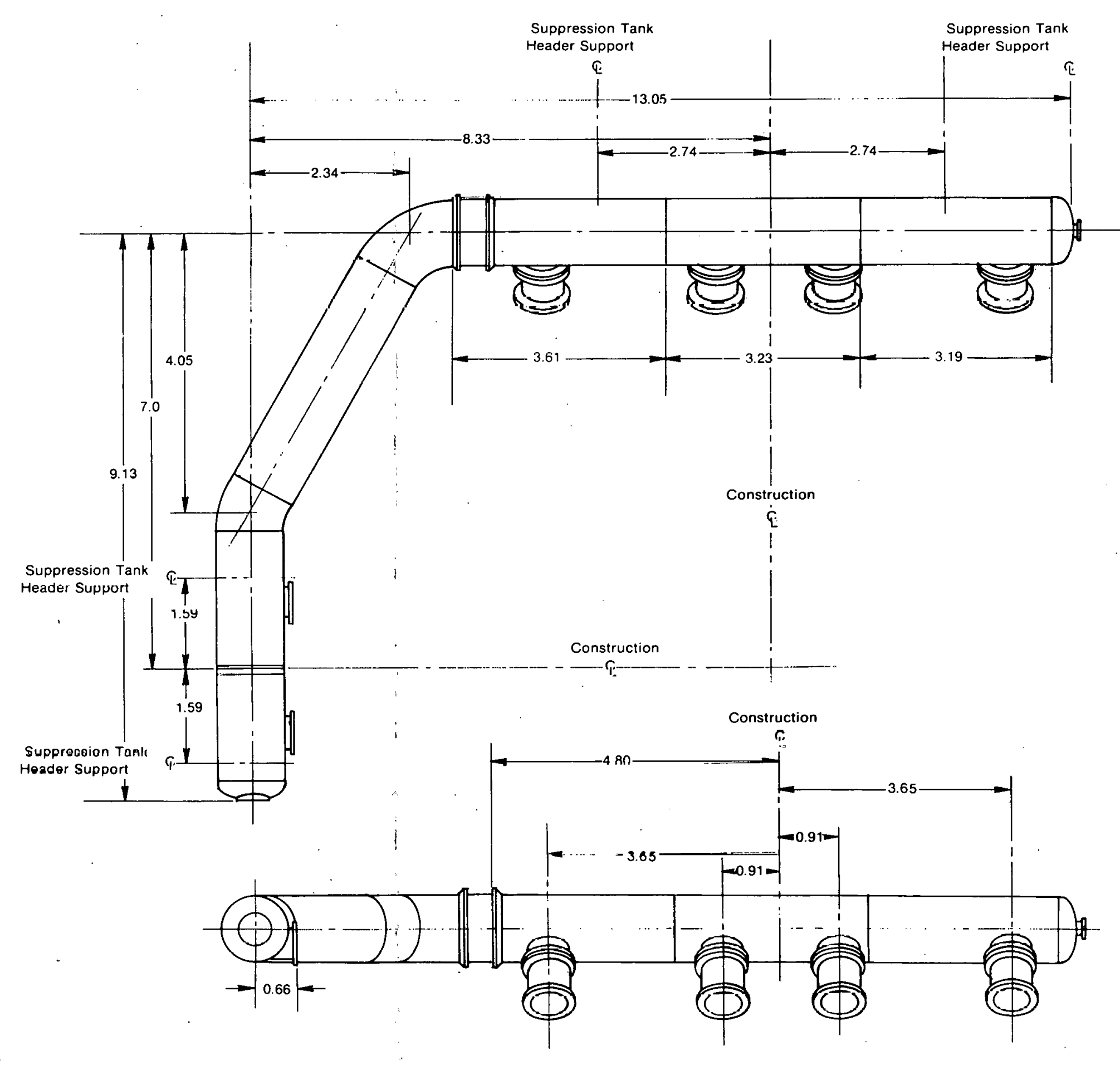

Fig. 3 LOFT PSS Header (Dry Well).
All Dimensions are in Meters

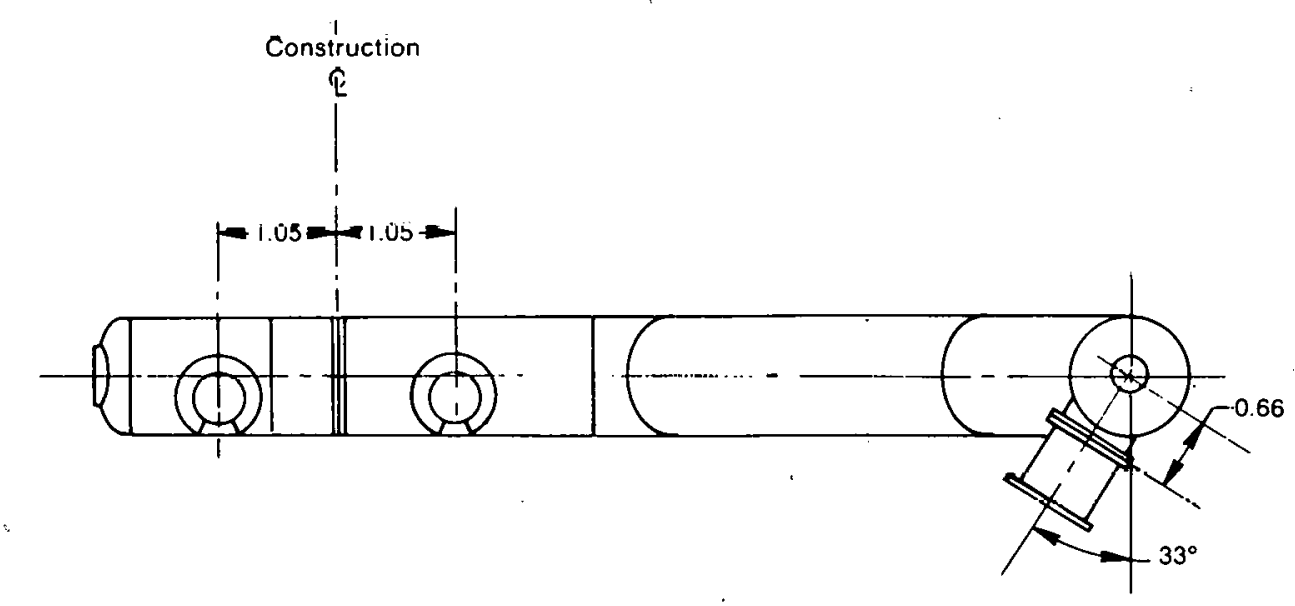

EGQ-8-522 


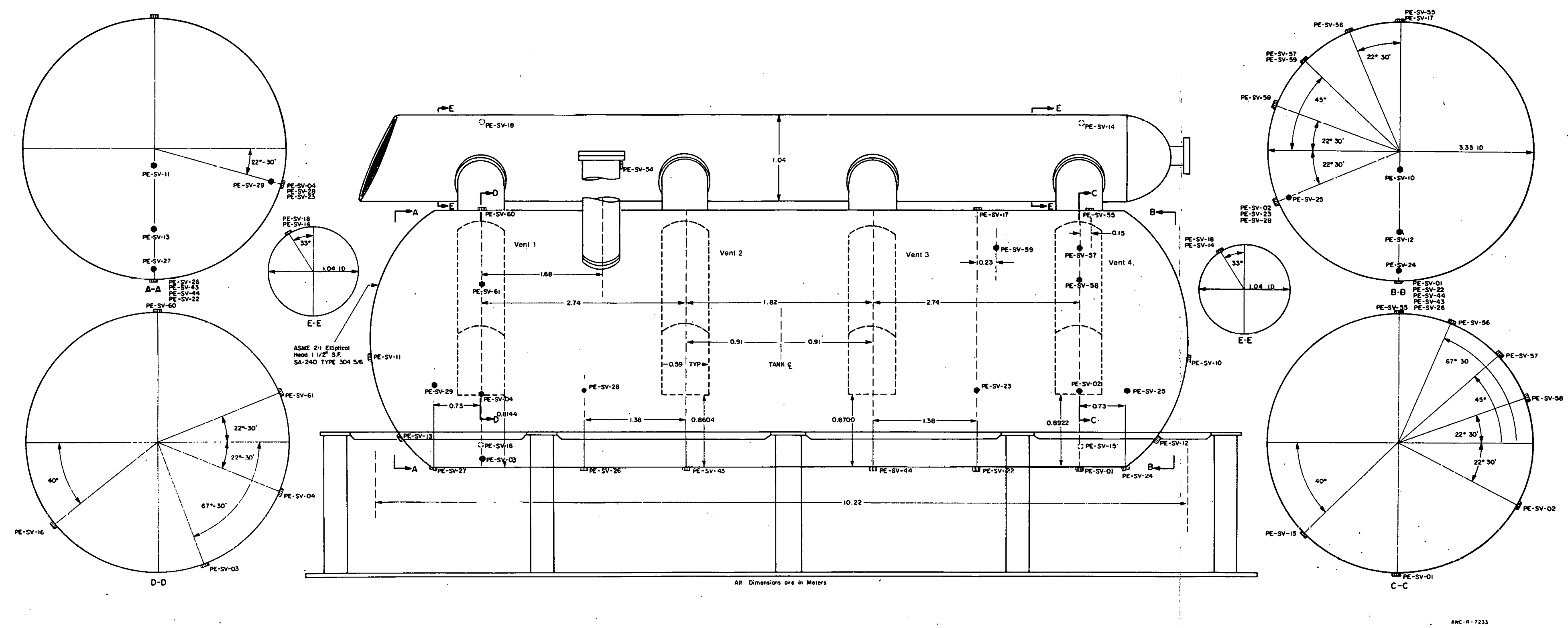

Fig. 4 PSS Suppression Tank and Pressure Instrumentation. 


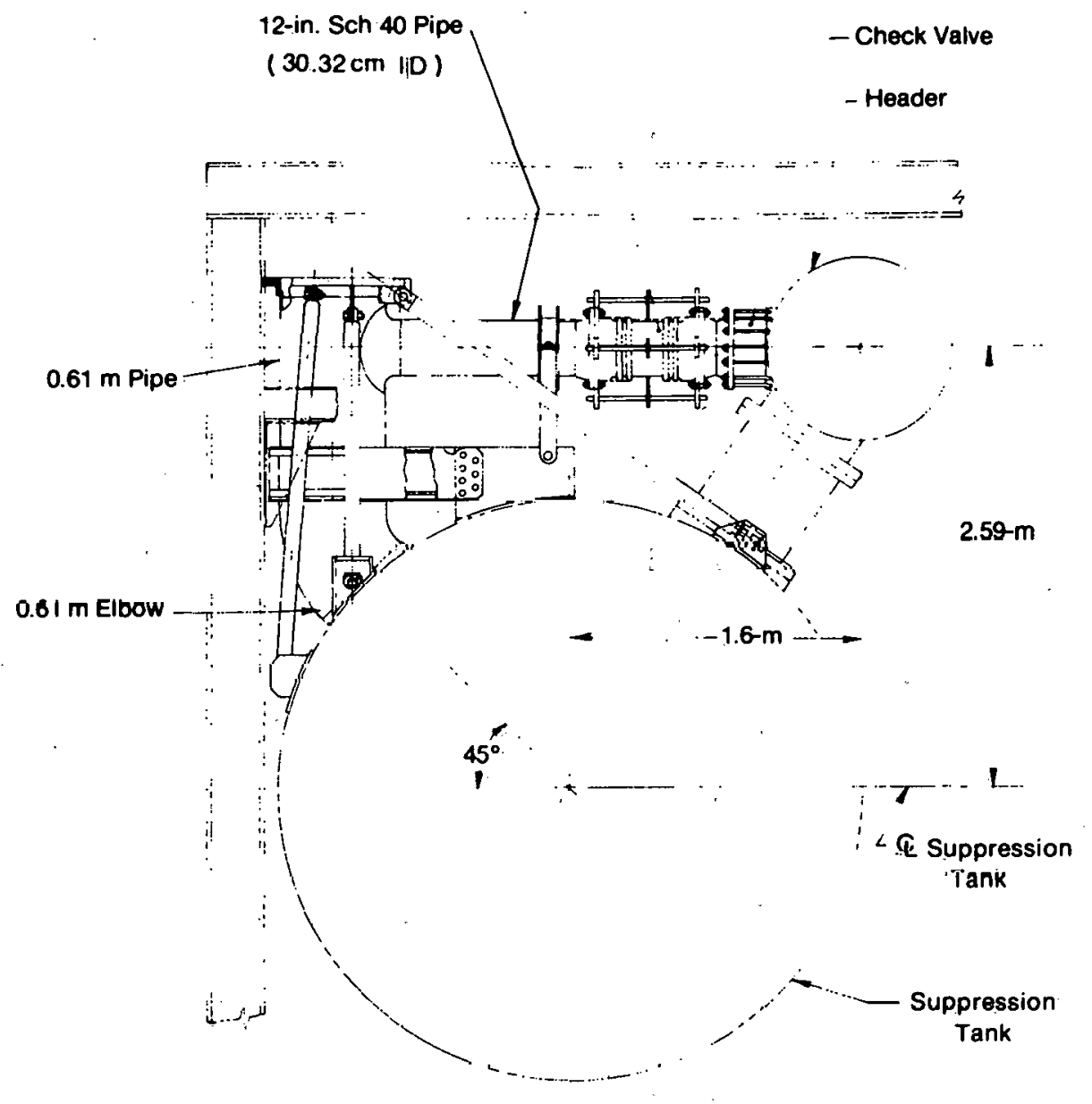

vạçưựṇ Hệliẹt Sìștẹnn

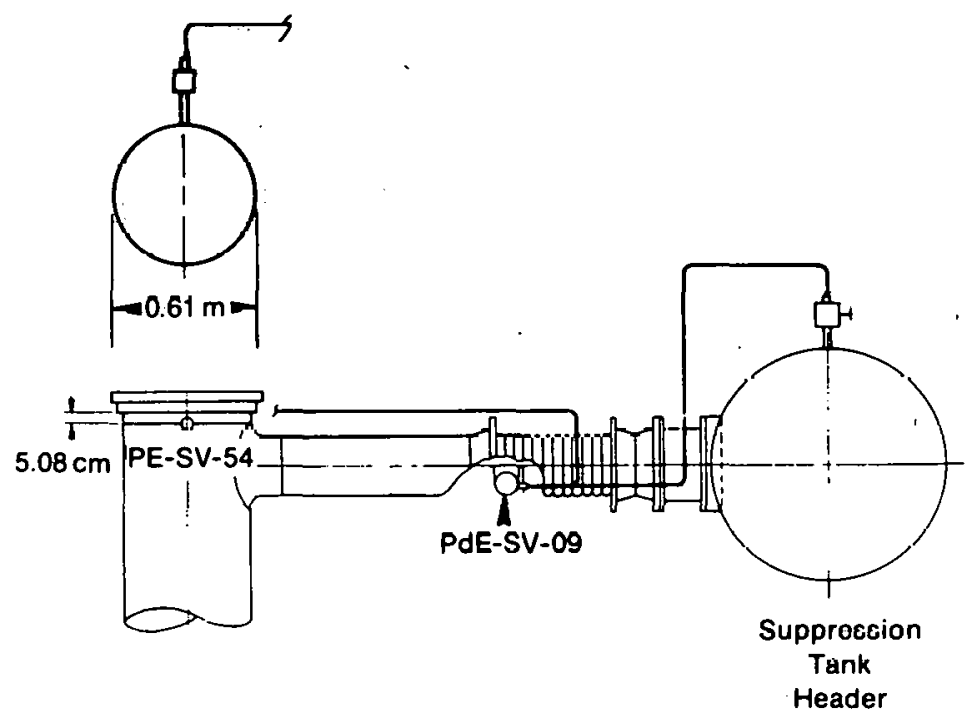

Fig. 5 PSS Vacuum Relief System.

EGG-A-521 
TABLE I

PHYSICAL PARAMETERS OF THE LOFT PRIMARY COOLANT SYSTEM AND PRESSURE SUPPRESSION SYSTEM

\begin{tabular}{|c|c|c|c|}
\hline Suppression System Parameters & Value & Primary Coolant System Parameters: & Value \\
\hline Wet well total volume & $84.9 \mathrm{~m}^{3}$ & Total system volume & $7.73 \mathrm{~m}^{3}$ \\
\hline Dry well volume & $19.2 \mathrm{~m}^{3}$ & Operating pressure & 155 bar \\
\hline Dry well inside diameter & $1.04 \mathrm{~m}$ & Operating temperature & $282{ }^{\circ} \mathrm{C}$ \\
\hline Wet well length & $10.22 \mathrm{~m}$ & \multirow{3}{*}{$\begin{array}{l}\text { Volume between quick-opening valve } \\
\text { and upstream block valve (each) } \\
\text { Flow area of quick-opening valve } \\
\text { Minimum opening time of quick- } \\
\text { opening valve }\end{array}$} & 48 liter \\
\hline & & & $0.05 \mathrm{~m}^{2}$ \\
\hline $\begin{array}{l}\text { Clearance of vent exit from wet } \\
\text { well wall (nominal) }\end{array}$ & $0.86 \mathrm{~m}$ & & 214 msec \\
\hline Weight of wet well (dry) & $23,914 \mathrm{~kg}$ & i & \\
\hline Design pressure & $10.3 \mathrm{bar}$ & $\vdots$ & \\
\hline Design temperature & $205^{\circ} \mathrm{C}$ & & \\
\hline
\end{tabular}


shown in Figure 3 of Reference 1. As a result, the LOFT PSS is not a scaled version of a MARK series PSS. The relevance of the information obtained from the LOFT PSS experiments to the MARK PSS series is discussed in Section II-5.

\section{QUALIFICATION BY EXPERIMENT}

After assembly of the LOFT facility was completed, qualification of the systems began through prescribed functional testing programs. "Two areas of qualification were required on the systems' components shown in Figures 1 through 5 . before loss-of-coolant experiments could be conducted. Qualification was required on:

(1) The components and operational procedures for providing a simultaneous opening of the QOBVS

(2.) The ability of the PSS to withstand the structural loading caused by the PCS coolant injection. The LOFT PSS is designed for a maximum up-load of $\sim 5 \times 10^{6} \mathrm{~N}$ and a maximum down-load of $-13 \times 10^{6} \mathrm{~N}$.

Experiments were designed which would provide information relevant to both qualification areas. The experiments were called "miniblowdown" experiments and were given the designation LO series experiments in keeping with the already designated $L I$ and $L 2$ series of planned full system biowdown experiments. Calculations showed that with the isolation valve upstream of each QOBV closed, the QOBV would still open in the intended manner with the opening time only a few milliseconds longer. Colosing the isolation valves also halver the volume of coolant which causes the structural loading in the PSS. Thus, qualification of the QOBVS and the associated operational procedures could be done with experiments in which only the coolant between the isolation valve and QOBV would be vented into the PSS. Additionally, these same experiments could be used to qualify the PSS loading capability, since the amount of fluid (and, hence, energy) available for 
causing structural loading would be half the maximum if both QOBVs were opened or one-fourth the maximum if only one QOBV was opened. The name mini-blowdown was based on these considerations. An additional advantage of these experiments is that the LOFT plant can be readied, or cycled, within a minimum time of about four hours once hot standby conditions are reached. This capability makes parametric studies realistically feasible which permits quantitative evaluation of the paralleler's which influence fSS structural loading.

The PSS was instrumented with pressure detectors as shown in Figures 4 and 5. Also, each QOBV was instrumented with a linear voltage differential transformer (LVDT) for measurement of the opening characteristics of the valves. The specifications of these measurements, including the data recording channels, are listed in Table II. In addition to these measurements, strain measurements were made on the suppression tank and on the support structure; temperature measurements were made in the air and water volumes in the suppression tank; and acceleration measurements were made on the outside surface of the suppression tank. The reasons for not including a description of these measurements are clarified in Section II-4: 
TABLE II

SUPPRESSION SYSTEM MEASUREMENT SUMMARY

\begin{tabular}{|c|c|c|c|c|}
\hline Measurement & 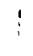 & QOBV Position & PDE-SV-09 & $P E-S V-(a 11)$ \\
\hline Detector & & Schacv1tz 503X5-A & BLH Type HLD & V1atrán Model 'Z2'2 \\
\hline Range & & $0-100 \%$ & $0-254 \mathrm{~cm} \mathrm{H}_{2} \mathrm{O}$ & $0-7.75$ bar \\
\hline Uncertainty, \% FSO & & 0.5 & 0.25 & 6 \\
\hline Linearity, \% FSO & , & 0.5 & 0.5 & 0.5 \\
\hline $\begin{array}{l}\text { Temperature effect } \\
\% \mathrm{FSO} / 100^{\circ} \mathrm{F}\end{array}$ & 1 & - & 1 & $<2$ \\
\hline Detector response, $\mathrm{Hz}$ & & $50-5000$ & $\sim 25$ & 700 \\
\hline Repeatability, \% FSO & & - & 0.1 & 0.1 \\
\hline Hysteresis, \% FSO & & - & 0.2 & 0.25 \\
\hline $\begin{array}{l}\text { Data channel } \\
\text { band width, HL }\end{array}$ & & 100 & 10 & 100 \\
\hline $\begin{array}{l}\text { Data channel } \\
\text { sampling raté, sps }\end{array}$ & & 500 & 50 & 500 \\
\hline
\end{tabular}




\section{EXPERIMENTS AND RESULTS}

Ten mini-blowdown experiments were conducted which provided the required systems qualification prior to performance of the first lossof-coolant experiment, LOCE LI-01. Subsequent to the mini-blowdown experiments, four LI series experiments were conducted. The results of the 14 experillenls are discussed in the succeeding scctions rclative to the PSS loading and structural response. The experimental data obtained with the measurements, shown in. Figures 4 and 5 and listed in Table II, and also the vertical load calculated from the pressure measurements are contained in the appendices. Each appendix contains the data for one experiment. As such, the appendices represent data reports for the experiments and can be used, in conjunction with the dimensional information contained in Figures 1 through 5, for computer code and model verification studies. The initial conditions for the experiments, which are contained in the appendices, are presented collectively in Table III for reference. The data in the appendices are to be considered as being the final form and to supercede preliminary data that have been presented previous $1 y[2,3]$.

The data contained in the appendices, and on which the PSS loading analysis is based, cover a time span of $4.0 \mathrm{sec}$. Long-term data (up to $70 \mathrm{sec}$ ) for the mini-blowdown experiments show essentially no further change after $4 \mathrm{sec}$. Long-term data for the LI series experiments show the PSS pressurization behavior resulting from the PCS blowdown. These data are included in the data report for each Ll experiment $[4,5,6,7]$.

\section{VERTICAL LOAD CALCULATION}

The pressure measured on the surface of the suppression tank in both the gas and water volumes is used to calculate the vertical load as a function of time. The suppression tank is divided into elemental areas that are polygon-shaped and have vertices defined by real pressure 
TABLE III

EXPERIMENTAL INITIAL CONDITIONS

\begin{tabular}{|c|c|c|c|c|c|c|c|}
\hline \multirow[b]{2}{*}{ Experiment } & \multicolumn{2}{|c|}{$\begin{array}{l}\text { QOBV Fluid Temperature } \\
\left({ }^{\circ} \mathrm{C}\right)^{[\mathrm{a}]}\end{array}$} & \multicolumn{2}{|c|}{$\begin{array}{c}\text { Suppression Tank } \\
\text { Temperature } \\
\left({ }^{\circ} \mathrm{C}\right)^{[\mathrm{a}]} \\
\end{array}$} & \multirow{2}{*}{$\begin{array}{c}\text { Suppression Tank } \\
\text { Pressure } \\
\text { (bar) }{ }^{[b]} \\
\end{array}$} & \multirow{2}{*}{$\begin{array}{c}\text { Water Depth Above } \\
\text { Vent Exit } \\
(\mathrm{cm})^{[\mathrm{c}]} \\
\end{array}$} & \multirow{2}{*}{$\begin{array}{c}\text { Internal Vent } \\
\text { Submergence } \\
(\mathrm{cm})[\mathrm{d}] \\
\end{array}$} \\
\hline & QOBV -1 & QOBV -15 & Gas & Water & & & \\
\hline L0-02 & 233.3 & 230.6 & 33.7 & 33.7 & 2.27 & 13.5 & 13.5 \\
\hline L0-03 & 228.3 & 231.3 & 33.9 & 32.6 & 2.35 & 26.7 & 20.7 \\
\hline$L 0-3 \dot{A}$ & 233.2 & 228.9 & 29.7 & 26.4 & 2.27 & 26.1 & 28.1 \\
\hline L0-3B & 233.7 & 232.1 & 28.5 & 26.5 & 2.21 & 26.7 & 26.7 \\
\hline LO-3C & 234.2 & 233.9 & 27.5 & 26.7 & 2.42 & 27.9 & 29.9 \\
\hline LO-04 & 250.0 & 250.2 & 26.9 & 26.9 & 2.14 & 38.1 & 38.1 \\
\hline LO-05 & 250.4 & 251.2 & 27.5 & 26.6 & 2.16 & 56.4 & 56.2 \\
\hline LO-08 & 232.5 & -.-- & 31.7 & 28.1 & 2.34 & 39.1 & 40.1 \\
\hline Lo-n9 & 245.3 & 237.6 & 33.6 & 33.6 & 2.34 & 27.9 & 21.9 \\
\hline$L O-10$ & 250.7 & 244.9 & 33.2 & 33.9 & 2.38 & 27.9 & 27.9 \\
\hline LI-01 & 256.6 & 241.4 & 29.4 & 30.8 & 2.36 & 24.7 & 21.8 \\
\hline L1-02 & 246.7 & 253.3 & 68.9 & 75.6 & 1.74 & 43.6 & 13.6 \\
\hline LI -03 & 250.1 & 257.2 & 82.8 & 86.7 & 1.67 & 43.0 & 27.3 \\
\hline$L 1-3 A$ & 245.3 & 257.6 & 81.7 & 85.3 & 1.56 & 38.1 & 21.3 \\
\hline \multicolumn{8}{|c|}{ [a]. Uncertainty is $\pm 1.5^{\circ} \mathrm{C}}$. \\
\hline \multicolumn{8}{|c|}{ [b] Uncertainty is \pm 0.08 bar. } \\
\hline \multicolumn{8}{|c|}{ [c] Uncertainty is $\pm 2.5 \mathrm{~cm}$} \\
\hline [d] Uncert & $3.2 \mathrm{~cm}$ & & & & & & \\
\hline
\end{tabular}


measurement locations or by "virtual" pressure measurement locations. The pressure at each virtual pressure measurement location is expressed in terms of the pressures at real measurement locations either by linear extrapolation along the suppression tank wall or by mirror imaging. The vector load on each elemental area is assumed to be equal to the scaler magnitude of the pressure on the elemental area times the projection of the elemental area onto the plane perpendicular to the load vector direction. The value of the pressure magnitude on a projected elemental arca polygon is chosen as the average valuc of the valucs at the vertices. The equation for the vertical load calculation' is expressed as

$$
F=10^{5} \sum_{i} w_{i} P_{i}
$$

where

$$
\begin{aligned}
& P_{i}=\text { real pressure measurements (bar) } \\
& w_{i}=\text { weighting factors for the } P_{i}\left(m^{2}\right) .
\end{aligned}
$$

Twenty-four pressure measurements are used in the vertical load calculation. The measurements and the weighting factors are listed in Table IV. Only four of the measurements used are in the gas volume and these four are equally weighted. Only these four were-used and were used in this manner, because the gas volume pressure did not show significant differences among the measurement locations.

\section{EXPERIMENTAL VERTICAL LOADS}

The mini-blowdown experimental results are shown in Table $V$. The experimental results for the $L 1$ series experiments are shown in Table VI. The results of the LO and LI experiments are shown separately in this manner to exemplify the different loading characteristics of each type of experiment. Details of the load as a function of time for each experiment are shown in the appendices. The general nature of a 
TABLE IV

VERTICAL LOAD CALCULATION VALUES

\begin{tabular}{|c|c|c|c|c|c|}
\hline & $\vdots$ & Vertical & $\sum_{i=1}^{24}$ & $w_{i} P_{i}$ (newtons) & \\
\hline$i$ & $P_{i}$ (bar) & $w_{i\left(m^{2}\right)}$ & $i$ & $\mathrm{P}_{\mathbf{i}(\text { bar })}$ & $w_{i\left(m^{2}\right)}$ \\
\hline 1 & PE-SV-01 & 1.3458 & 13 & PE $-S V-23$ & 2.5071 \\
\hline 2 & PE-SV-02 & 1.0400 & 14 & PE-SV-24 & 0.8103 \\
\hline 3 & PE-SV-03 & 1.4166 & 15 & $P E-S V-25$ & 0.8710 \\
\hline 4 & PE-SV-04 & 0.8277 & 16 & $P E-S V-26$ & 2.5026 \\
\hline 5 & PE-SV-10 & 0.3301 & 17 & $P E-S V-27$ & 1.2813 \\
\hline 6 & PE-SV-II & 0.3301 & 18 & $P E-S V-28$ & 2.4013 \\
\hline 7 & $P[-S V-12$ & 0.5737 & 19 & $P E-S V-29$ & 0.8710 \\
\hline 8 & PE-SV-13 & 0.3761 & 20 & PE-SV-43 & 2.0710 \\
\hline 9 & $P E-S V-15$ & 3.5168 & 21 & $P E-S V-44$ & 2.2852 \\
\hline 10 & PE-SV-16 & 3.4019 & 22 & PE-SV-54 & -7.6664 \\
\hline 11 & PE-SV-1 i & -7.6664 & 23 & PE-SV-55 & -7.6664 \\
\hline 12 & $P E=S V-22$ & 1.9690 & 24 & PE-SV-60 & -7.6664 \\
\hline
\end{tabular}


TABLE V

MINI-BLOWDOWN EXPERIMENT RESULTS

\begin{tabular}{|c|c|c|c|c|c|c|c|}
\hline \multirow[b]{2}{*}{ Experiment } & \multirow[b]{2}{*}{ QOBV Operation } & \multicolumn{2}{|c|}{$\begin{array}{l}\text { Combined QOBV } \\
\text { Area Opening Rate }\end{array}$} & \multirow{2}{*}{$\begin{array}{l}\text { Effective Fluid } \\
\text { Volume } \\
\text { (liter) } \\
\end{array}$} & \multicolumn{3}{|c|}{$\begin{array}{c}\text { Maximum Vertical Load } \\
\left(10^{6} \text { newtons }\right)\end{array}$} \\
\hline & & $\% / \mathrm{msec}$ & $\underline{2 \sigma^{[c]}}$ & & Down & Up & $2 \sigma$ \\
\hline L0-02 & Both valves fully opened ${ }^{[\mathrm{a}]} ; 3 \mathrm{msec} \Delta \mathrm{t}^{[\mathrm{b}]}$ & 4.05 & 0.15 & 96.2 & 0.4053 & 0.1081 & 0.0149 \\
\hline L0-03 & QOBV- 15 opened $60 \%$; QOBV- 1 opened $\approx 0.5 \%$ & 4.29 & 0.60 & 48.1 & 0.4360 & 0.2376 & 0.0170 \\
\hline L0-3A & QOBV-15 fully opened; QOBV-1 opened $52 \%$; $-80 \mathrm{msec} \Delta t$ & 1.91 & 0.05 & 96.2 & 0.4265 & 0.1929 & 0.0184 \\
\hline LO-3B & QOBV-15 ful1y opened; QOBV- 1 opened $\approx 2.4 \%$ & 3.96 & 0.12 & 48.1 & 0.4664 & 0.2979 & 0.0163 \\
\hline LO-3C & Both valves fully opened; $\sim 50 \mathrm{msec} \Delta t$ & 2.05 & 0.13 & 96.2 & 0.7675 & 0.3909 & 0.0168 \\
\hline L0-04 & Both valves fully opened; $\sim 4 \mathrm{msec} \Delta t$ & 3.89 & 0.06 & 96.2 & 1.8668 & 0.9947 & 0.0158 \\
\hline LO-05 & Both valves fully opened; $7 \mathrm{msec} \Delta t$ & 3.96 & 0.12 & 96.2 & 1.8782 & 0.8902 & 0.0160 \\
\hline LO-08 & QOBV-1 fully opened (single QOBV experiment) & 3.33 & 0.06 & 48.1 & 0.5758 & 0.3996 & 0.0141 \\
\hline L0-09 & Q0BV-15 fully opened; QOBV-1 opened $\approx 2 \%$ & 4.18 & 0.12 & 48.1 & 10.3862 & 0.1323 & 0.0077 \\
\hline Lo-10 & Both valves fully opened; $-4 \mathrm{msec} \Delta t$ & 4.34 & 0.12 & 96.2 & 1.0506 & 0.3827 & 0.0080 \\
\hline
\end{tabular}

[a] Full open area occurs at a sleeve position of $66 \%$ of its full travel. Area begins to open at a sleeve position of $17 \%$. Operation given as sleeve travel.

[b] Approximate difference in the times when the two valves begin to open.

[c] Estimated froiil repeated calculations from plotted QOBV sleeve travel data. 
TABLE VI:

FULL SYSTEM BLOWDOWN EXPERIMENT RESULTS

\begin{tabular}{|c|c|c|c|c|c|c|c|c|c|c|c|}
\hline \multirow[b]{2}{*}{ Experiment $^{[\mathrm{a}\rfloor}$} & \multirow{2}{*}{$\begin{array}{c}\text { Combined QOBV } \\
\text { Ared Opening Rate } \\
(\% / \mathrm{msec}) \\
\end{array}$} & \multicolumn{4}{|c|}{$\begin{array}{r}\text { Maximum Vertical Load -- First Cycle } \\
\left(70^{6} \text { newtons }\right)\end{array}$} & & \multicolumn{5}{|c|}{$\begin{array}{l}\text { Maximum Vertical Load -- Second Cycle } \\
\left(10^{6} \text { newtons }\right)\end{array}$} \\
\hline & & Down & 20 & Up & $2 \sigma$ & $\begin{array}{l}\text { Frequency } \\
(\mathrm{Hz})\end{array}$ & Down & $2 \sigma$ & Up & 20 & $\begin{array}{l}\text { Frequency } \\
(\mathrm{Hz})\end{array}$ \\
\hline LI -01 & $4.55 \pm 0.10$ & 1.0828 & 0.0074 & 0.103 & 0.008 & -7 & 0.144 & 0.008 & 0.1766 & 0.0074 & -0.8 \\
\hline L7 -02 & $4.46 \pm 0.17$ & 1.6642 & 0.0121 & 0.167 & 0.012 & $\sim 9$ & 0.228 & 0.012 & 0.2888 & 0.0121 & -0.8 \\
\hline$L 7-03$ & $4.88 \pm 0.11$ & 3.0580 & 0.0081 & 0.87 .02 & 0.0081 & $\sim 7$ & 0.212 & 0.008 & 0.361 & 0.008 & -0.8 \\
\hline L] $-3 A$ & $4.13 \pm 0.20$ & 2.5151 & 0.0094 & 0.3543 & 0.0094 & $\sim 7$ & 0.241 & 0.010 & 0.265 & 0.010 & $\sim 0.6$ \\
\hline
\end{tabular}

[a] Both QOBVs fully opened in each experiment. The effective fluid volume in each experiment is 198 liters evenly divided between the two Q0BVs. 
mini-blowdown load is that of a highly damped oscillation. The vertical load consists essentially of a single down-load followed by a single upload. The general nature of a full system blowdown ( $L l$ series). load is that of a single down-load up-load cycle at a frequency of about $7 \mathrm{~Hz}$ followed by a single up-load down-load cycle at a frequency of about $0.8 \mathrm{~Hz}$. In experiments $L 1-01$ and $L 1-02$, the up-load in the second cycle exceeds the up-load in the first cycle. The first load cycle in the Ll cxpcriments is similar iii rrequency to the load cycle in the LO experiments.

The $2 \sigma$ values $l$ isted in Tables $V$ and VI are calculated 'from the data channel noise levels. The pretransient data channel variance is given for all pressure measurements in the appendices. Three other errors are possible in the vertical load values. The first error is associated with the vertical load equation. This error is a systematic error and would affect all values in the same way. Examination of the pressure data with respect to the elemental area definition used in the vertical load equation indicates that this error is small, especially in relation to the difference between experiment values and predictions. The second error is the detector combined error of linearity, repeatability, and hysteresis ( $0.57 \%$ FSO or 0.04 bar). In-place calibration of the pressure detectors showed that this error is within this value and that all detectors exhibited similar calibration curves. Since (a) the measurements are used in opposition in the vertical load calculation, (b) the pressure values among all measurements did not show differences greater than about one bar or about 13\% FSO at any time, and (c) the frequency content of the data was very low compared to the bandwidth of the detectors, the detector error is considered to be very smal1. The third error is in initializing all pressure measurements to the same value which eliminates the detector uncertainty and temperature effect. This error was minimized by computer analysis to $1.0 \times 10^{-5}$ bar and is not significant. Thus, the principle uncertainty to be considered in analyzing vertical load parameter dependence is given by the $2 \sigma$ value listed in the tables for each vertical load. 
Preliminary plots of vertical load magnitudes revealed that the loads were highly dependent on the rate of pressurization of the dry well. Tables $V$ and $V I$ contain the behavior of the QOBVs. The experiments in Table $V$ can be divided into two groups, those in which one QOBV opened and those in which both QOBVs opened. Experiments L0-03, L0-3B, L0-08, and L0-09 were single QOBV experiments, whereas, both QOBVs opened in the other experiments. The area opening rate values listed in Tables $V$ and VI were determined from the QOBV sleeve travel as a function of time as measured by the LVDT on each QODV. These data are also contained in the appendices fnr par.h experiment. Sleeve position as a function of time is shown in percent of full sleeve travel for each QOBV and for the QOBVs combined. The QOBVs begin to open area at a sleeve position of $17 \%$ of full travel and attain full open area at a sleeve position of $66 \%$ of full travel. The open area is a linear function of the sleeve position. Note that the effective area in experiments L0-03, L0-3B, L0-08, and L0-09 is half of the effective area for the other experiments. Each listed value in Tables $V$ and $V I$ is expressed in \%/msec relative to the total area in the experiment. The area opening rate values show that differences in experiments of the same group occurred. The effects on the vertical load can be seen by comparing the down-loads in experiments L0-3C and L0-10 which are nearly identical in all other respects. The up-loads for these experiments are nearly identical as a result of the bubble breakthrough of the suppression pool surface.

The most significant aspect of the QOBV opening rate effects on vertical loads is the time scale in which the effects are observed. Changes in QOBV opening rates on a millisecond time scale basis produce large percentage differences in the loads. The down-luad decreases as the opening rate decreases, as expected. As a limit, the down-load would reach a minimum value based on the pressure required to clear the vents. The required pressure is a linear function of the vent submergence. The down-load minimum for experiments $L 0-3 C$ and L0-10 would be approximately $0.003 \times 10^{6} \mathrm{~N}$. This value could be approached with a dry well pressurization rate resulting from a QOBV opening rate that is sti.ll relatively high. 
The maximum area of the opening QOBV was not reached in experiment LO-03 nor did QOBV-1 reach maximum open area in experiment LO-3A which would also affect the rate of dry well pressurization in those experiments. The effects of QOBV open area differences can be seen by comparing the vertical load results of experiments $\mathrm{LO}-03$ and $\mathrm{LO}-3 \mathrm{~B}$ which are nearly identical experiments in al1 other respects. The vertical load is larger in experiment LO-3B, even though the QOBV opened. slightly slower than it did ill experiment L0-03. The flow area affects the suppression tank vertical loading in the same way as does the area opening rate of the QOBV, also as expected.

The differences within each group of experiments, due to the QOBV opening rate and flow area, can be reduced by normalization. One experiment within each group was selected on the basis of the largest opening rate with the least uncertainty and the full open flow area. All other experiments within the group were normalized linearly to the selected experiment. The normalization of Experiment LO-3B is shown as an example by the following equation

$($ normalized 1 oad $L 0-3 B)=\left(\frac{\text { area } L 0-09}{\text { area } L 0-3 B}\right)\left(\frac{\text { opening rate } L 0-09}{\text { opening rate } L 0-3 B}\right)($ load $L 0-3 B)$.

The normalized vertical loads are listed in Table VII. The uncertainties associated with the normalized values were determined from the QOBV opening rate uncertainties. The nominal load values of the three base experiments were used. The down-load and up-load values are plotted as a function of internal vent submergence in Figures 6 through 10.

The normalized vertical loads in the up and down direction for the single QOBV mini-blowdown experiments are shown in Figure 6 . The internal and external vent submergence values are nearly the same for these experiments. The up- and down-loads show essentially the same dependence on vent submergence. The up-load magnitudes are lower because of early bubble breakthrough of the suppression pool surface. 
TABLE VII

VERTICAL LOAD NORMALIZZED VALUES

\begin{tabular}{|c|c|c|c|c|}
\hline Experiment Type & $\begin{array}{l}\text { Experiment } \\
\text { Designation }\end{array}$ & $\begin{array}{c}\text { Normalization } \\
\text { (linear) }\end{array}$ & 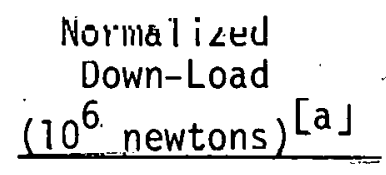 & 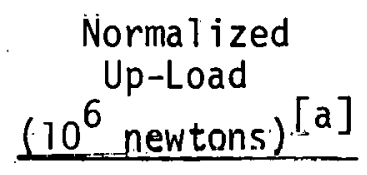 \\
\hline $\begin{array}{l}\text { Single QOBV } \\
\text { mini-blowdown }\end{array}$ & $\begin{array}{l}\text { LO-03 } \\
\text { LO-3B } \\
\text { LO-08 } \\
\text { LO-09 }\end{array}$ & $\begin{array}{l}\text { QOBV opening rate and open } \\
\text { area to L0-OY }\end{array}$ & $\begin{array}{l}0.562 \pm 0.05 \\
0.493 \pm 0.015 \\
0.649 \pm 0.01 \\
0.3862\end{array}$ & $\begin{array}{l}0.306 \pm 0.03 \\
0.315 \pm 0.012 \\
0.503 \pm 0.01 \\
0.1323\end{array}$ \\
\hline $\begin{array}{l}\text { Double QOBV } \\
\text { mini-blowdown }\end{array}$ & $\begin{array}{r}\quad 0-02 \\
\quad L 0-3 A \\
\quad L 0-3 C \\
\quad L 0-04 \\
\quad L 0-05 \\
\quad L 0=10\end{array}$ & $\begin{array}{l}\text { QOBV opening rate and open } \\
\text { area to } L 0-10\end{array}$ & $\begin{array}{l}0.434 \pm 0.016 \\
1.163 \pm 0.025 \\
1.623 \pm 0.099 \\
2.082 \pm 0.032 \\
2.057 \pm 0.061 \\
1.0506\end{array}$ & $\begin{array}{l}0.116 \pm 0.005 \\
0.494 \pm 0.011 \\
0.827 \pm 0.051 \\
1.110 \pm 0.018 \\
0.975 \pm 0.029 \\
0.3827\end{array}$ \\
\hline LOCE & $\begin{array}{l}L 1-01 \\
L 1-02 \\
L 1-03 \\
L 1-3 A\end{array}$ & QUBV opening rate to $\mathrm{Ll}=03$ & $\begin{array}{l}1.160 \pm 0.025 \\
1.820 \pm 0.068 \\
3.058 \\
2.968 \pm 0.106\end{array}$ & $\begin{array}{l}0.110 \pm 0.002 \\
0.185 \pm 0.009 \\
0.8702 \\
0.418 \pm 0.020\end{array}$ \\
\hline
\end{tabular}

[a] Uncertainties are based on opening rate uncertainty in each experiment. Uncertainties in L0-09, LO-10, and L1-03 are ignored. 


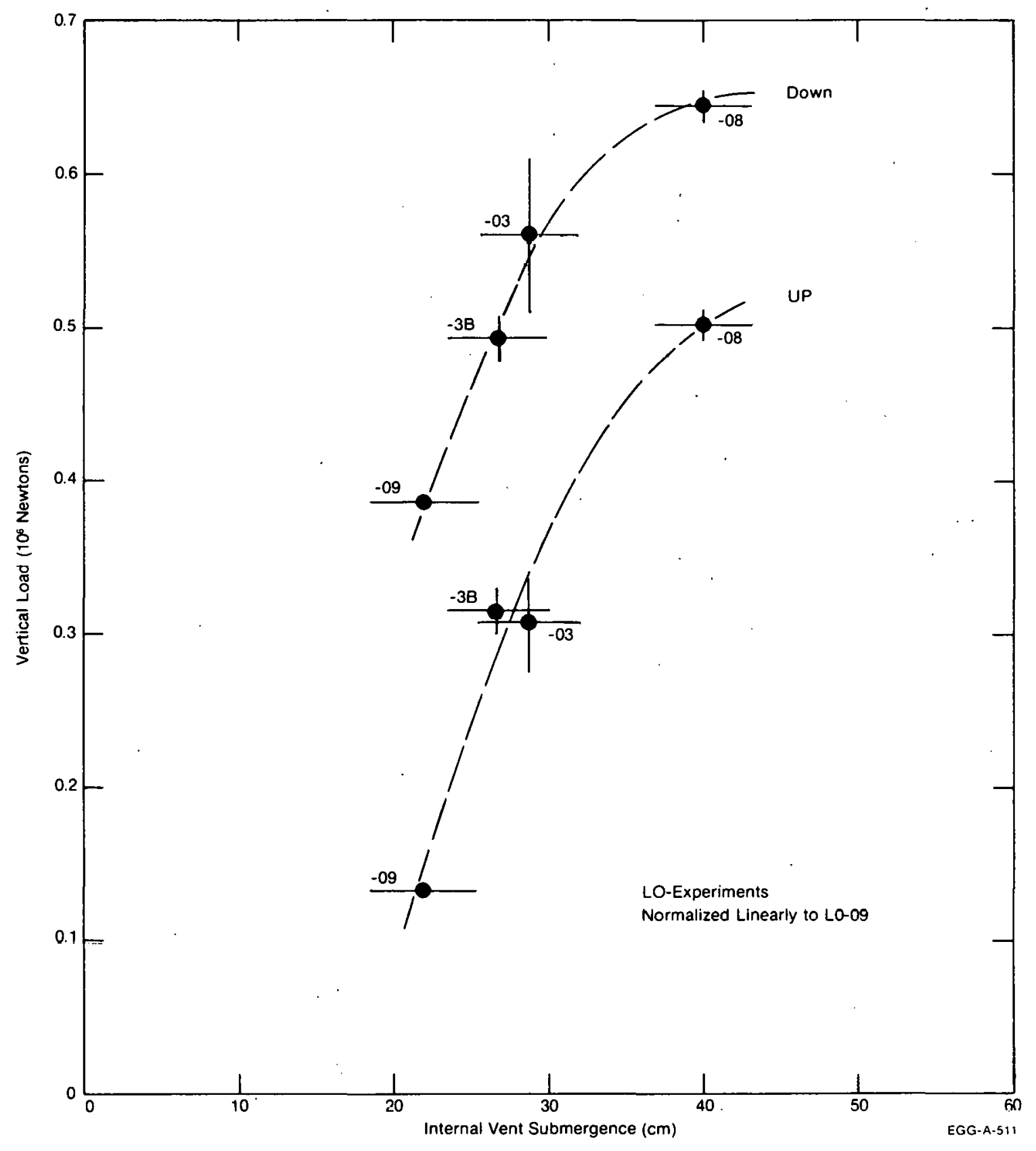

Fig. 6 Normalized Vertical Loads - Single QOBV Mini-Blowdown Experiments. 


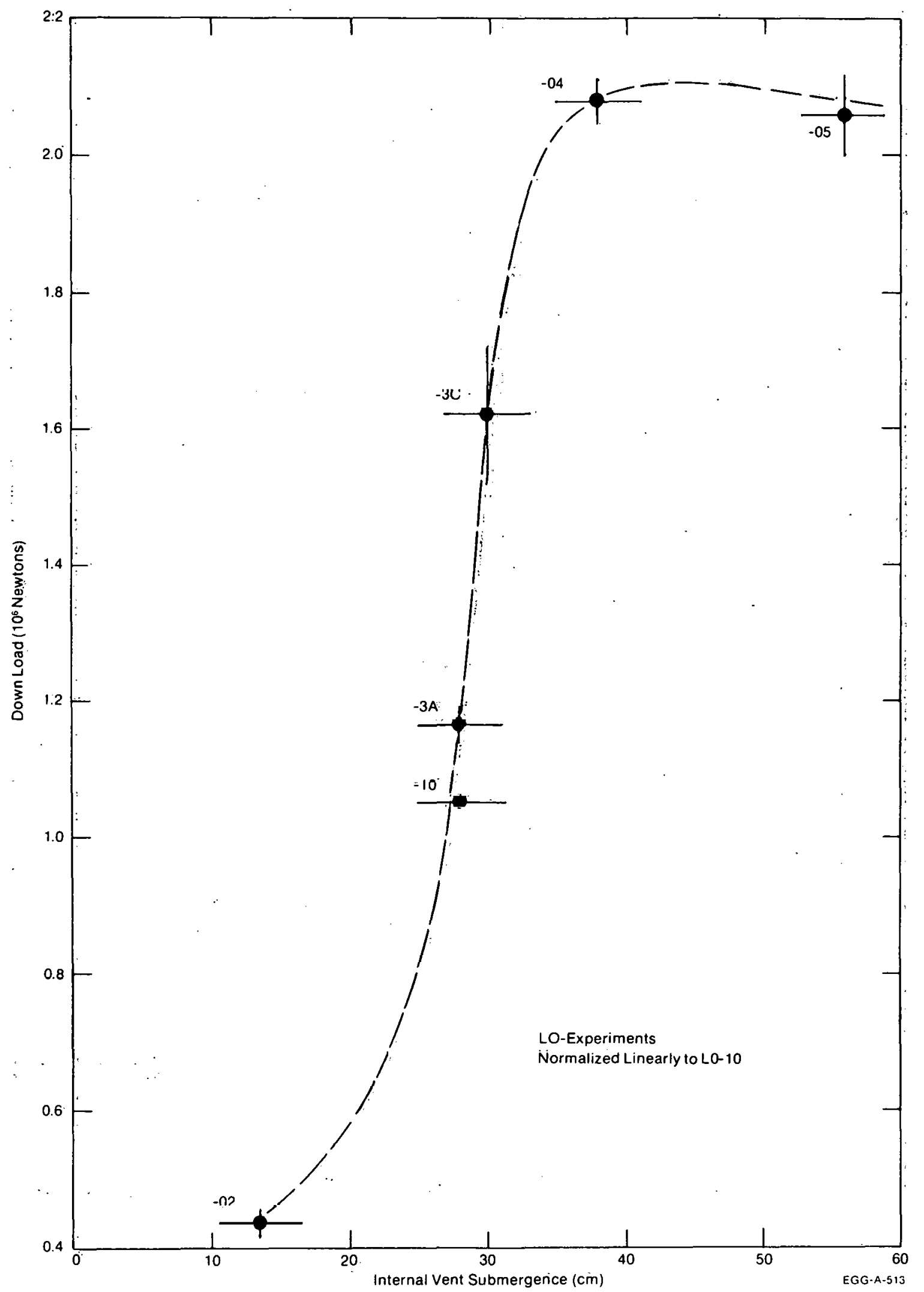

Fig. 7 Normalized Down-Loads - Double QOBV Mini-Blowdown Experiments. 


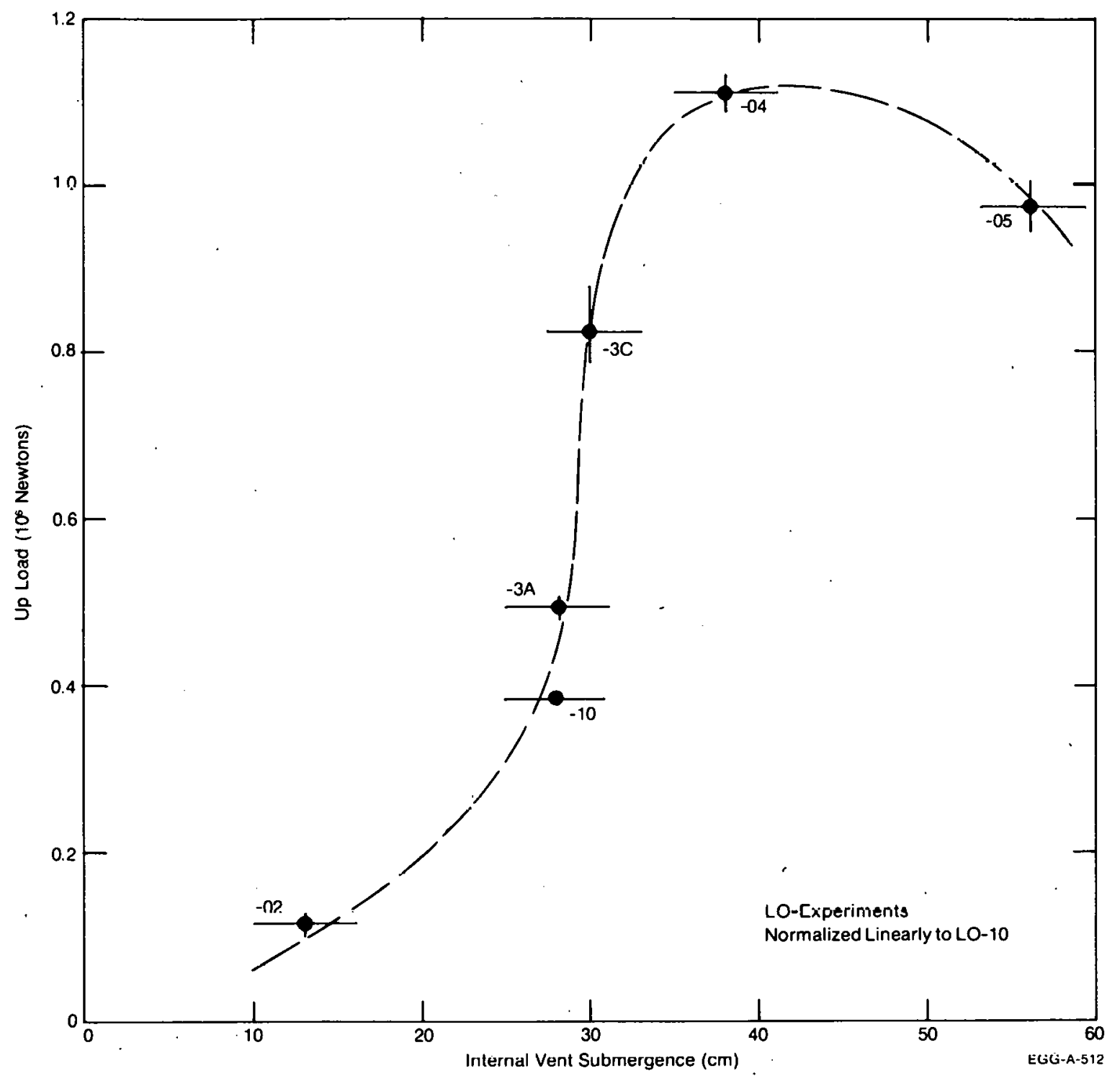

Fig. 8 Normalized Up-Loads - Double QOBV Mini-Blowdown Experiments. 


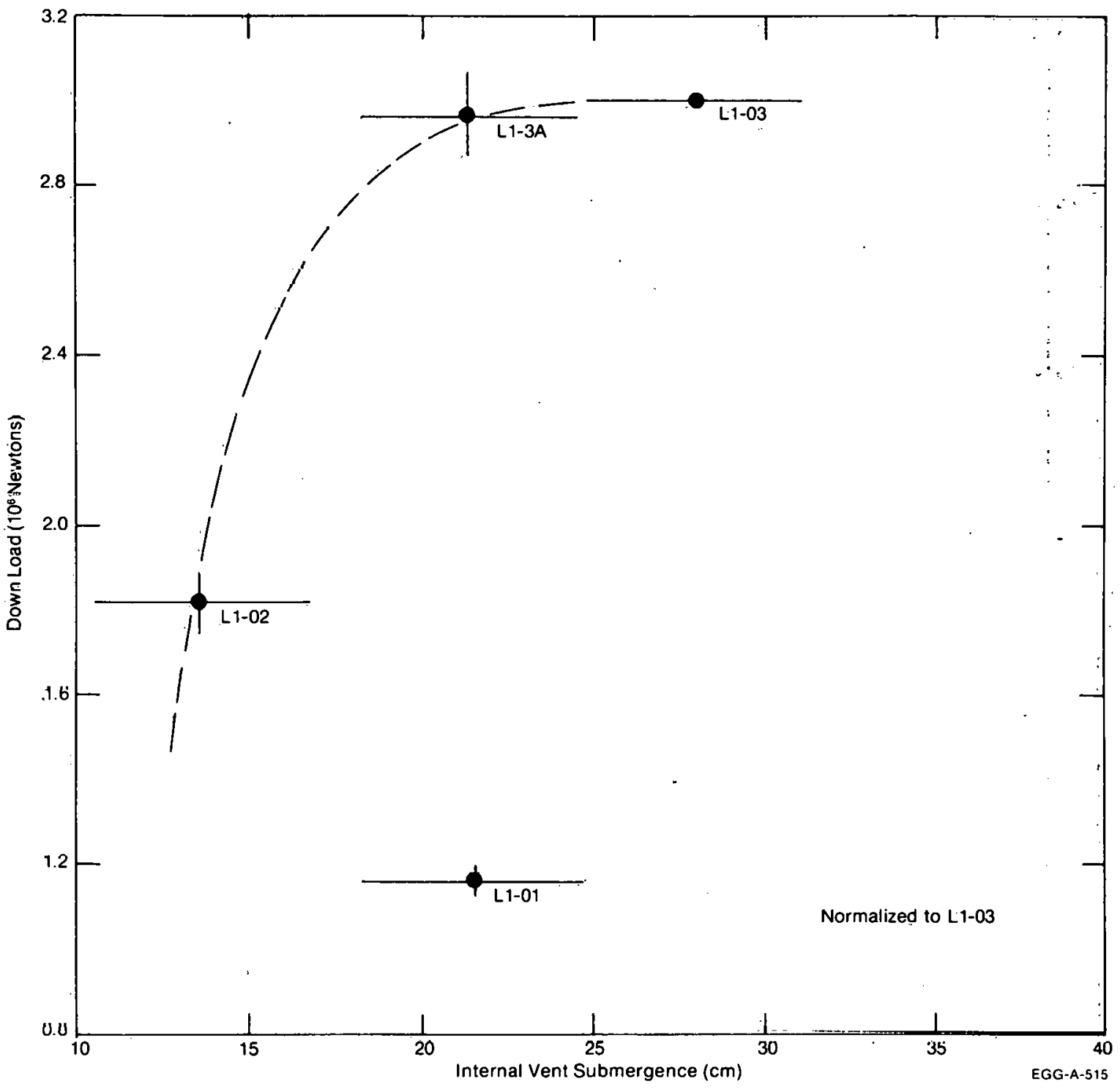

rig. 9 Normalized nown-I nads - Ll Series Experiments. 


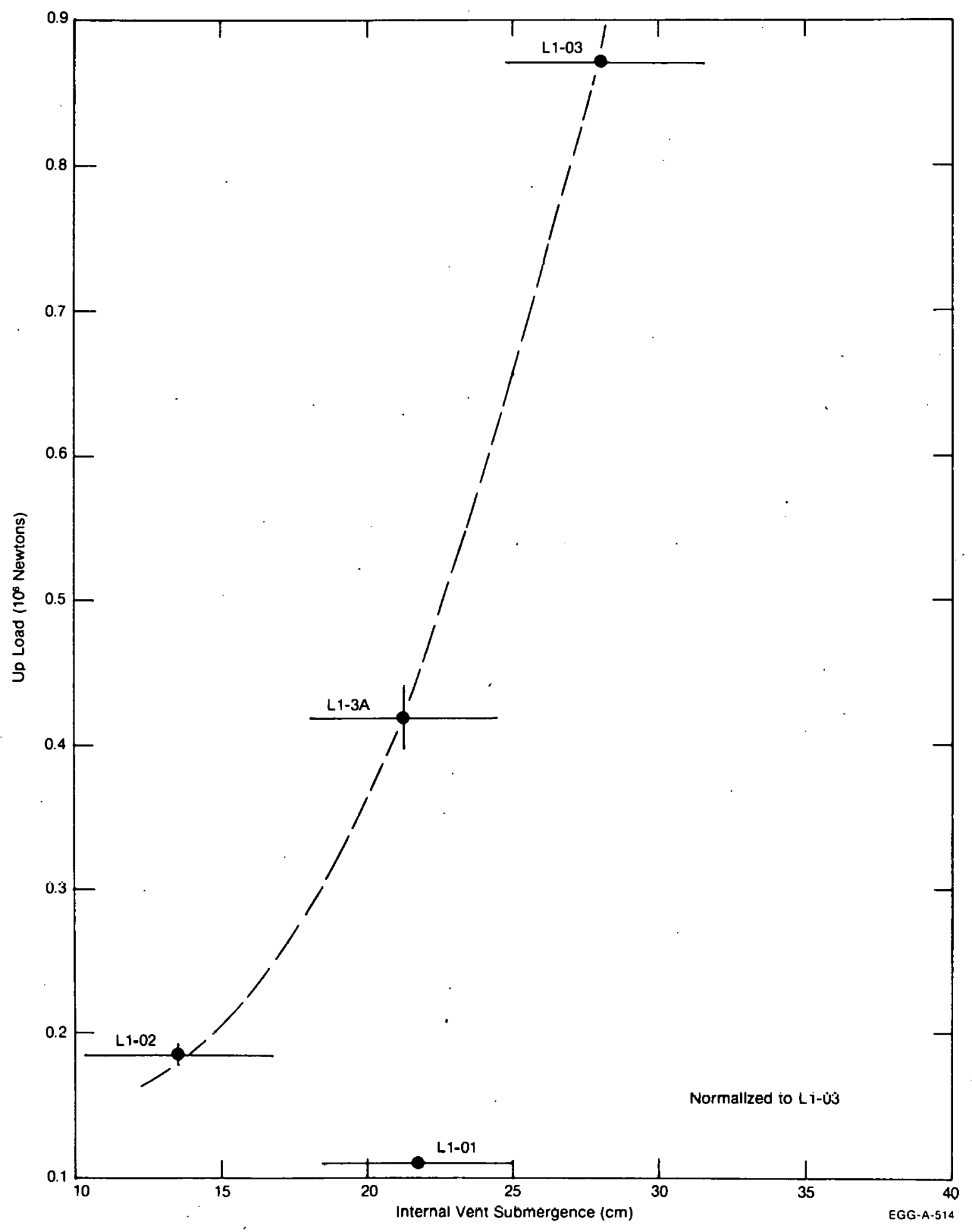

Fig. 10 Normalized Up-Loads - LI Series Experiments. 
Early bubble breakthrough occurs in the experiments in all three groups and is an up-load limiting phenomenon in the relatively shallow vent submergences in the LOFT PSS. Both curves in Figure 6 also show a trend toward less dependence on vent submergence as the vent submergence increases. This behavior is expected because, as the vent submergence increases, the mass. of water above the vent exits increases which requires more energy to move or lift it. For constant energy input to the PSS, the vertical load producing phenomena became energy limited. This energy limited behavior is more pronounced in the double QOBV miniblowdown experiments.

The normalized down-load for the double QOBV mini-blowdown experiments is shown plotted against internal vent submergence in Figure 7. The normalized up-load for these experiments is shown similarly in Figure 8 . The up-load and down-load show similar behavior as in the single QOBV experiments. The load in both directions is very sensitive to vent submergence in the range 20 to $40 \mathrm{~cm}$. The energy limitation also is evident at deeper vent submergences. The load in both directions begins to decrease beyond a vent submergence of $40 \mathrm{~cm}$.

The normalized down-load and up-load for the $L I$ experiments are similarly plotted in Figures 9 and 10, respectively. The vertical load In Lhese experillenls is quile direrint from that in the mini-blowdown experiments. The up-load is not similar to the down-load in overall dependence on internal vent submergence. The difference between the $L 1$ and LO series of experiments is the continuing input of mass to the PSS in the L1 experiments which does not occur in the LO experiments. As a result, the up-load is much less than the down-load in the Ll experiments as compared to the relative magnitudes in the LU experiments. The behavior of the data in Figures 9 and 10 is also the result of the introduction of an additional parameter - vent preclearing. Experiments L1-02, L1-03, and Ll-3A all had approximately the same external vent submergence. However, prior to the opening of the QOBVs, the vents were precleared by PCS leakage to the header which raised the pressure of the header above that in the suppression tank. Therefore, the data in Figures 9 and 10 plotted against the internal vent 
submergence represent the effect of vent preclearing on the vertical loads. Also shown is experiment L1-01 which had approximately the same internal vent submergence as experiment LI-3A. However, the external vent submergence for experiment $L I-01$ was $35 \%$ less than that for experiment LI-3A. The much smaller vertical load in experiment LI-0I compared to experiment LI-3A again demonstrates the effect of earlier bubble breakthrough.

Ihe vertical load experiment results shown in Tables $V$ through VII and Figures 6 through 10 indicate that, in the LOFT PSS for the vent submergence range investigated, the parameters which have primary influence on the vertical loads are:

(1) Physical parameters

Total energy input to the dry well

Rate of energy input to the dry well

(2) Geometric parameters

Vent internal submergence

Vent external submergence.

Suppression tank pressure and gas and water volume temperatures do not have a primary effect on vertical load. However, the effects of these parameters were not parametrically studied in the experiments. The range of PSS temperatures and pressures in the LI series of experiments were not considered to be significantly different from that in boiling water reactor (BWR) suppression systems to warrant inclusion in the overall parametric study on vertical loads.

\section{PRESSURE DATA CHARACTERISTICS}

The pressure data portrayed the phenomena involved in creating the vertical load in a consistent manner throughout the 14 experiments. The 
LOFT PSS header which acts as the dry well did not provide uniform pressure loading on the four vents. Pressure behavior below the four vents was dependent on the pressure in the header above the vents. As a result, the vertical load contributions of the four vents were not synchronized. Vent 4 cleared first because the pressure above vent 4 in the header was higher than the other vents. Vent 4 is near the end of the header and contains the compression effects resulting from impacting flow. The lack of synchronization of vent pressure behavior resulted. in. lower magnitudes of the vertical loads relative to theoretical predictions which assumed synchronization [8]. Calculations that used the header pressures above the vents to drive the PSS models gave closer agreement between experimental and theoretical vertical loads [8]." Thus an additional phenomena, statistical nonsynchronization, has a primary influence on vertical loading ${ }^{[a]}$. The nonsynchronized behavior can be observed in the pressure data contained in the appendices.

The pressure data consistently show the following scenario of events in the 14 experiments. A small acoustic pressure ( 0.2 bar) is recorded from the opening of the QOBVs. Approximately $4 \mathrm{msec}$ later the $\mathrm{N}_{2}$ gas compression begins in the header above the vents by the influx of mass from the QOBVs. The $\mathrm{N}_{2}$ gas is vented into the suppression tank for about $0.1 \mathrm{sec}$ before steam mixing reaches the vents. From this time on, an $\mathrm{N}_{2}$-steam mixturc is vantcd into the suppression tank. In the Ll experiments, continuing influx of PCS mass completely purges the header of $\mathrm{N}_{2}$ and venting into the suppression tank is pure steam. Because of the header geometry, the venting behavior is nonuniform and nonsynchronized.

The frequency content of the pressure data was studied by calculating the power spectral denstty (PSD) of the pressure dala. jirice all

[a] An interesting experiment would be to compare the vertical loading in a smal1 scale MARK I torus for the two cases where, with uniform dry well pressure, alternate pairs of vents are shortened 20 . to $30 \%$ in one case and all vent pairs are the same length in the second case. 
LO experiment pressure data were consistent, PSDs of typical pressures around vent 4 only were analyzed in experiment L0-04. PSDs of pressure data from detectors PE-SV-01 (below vent 4), PE-SV-02 (vent exit level on the side of the ST), PE-SV-14 (header above vent 4), and PE-SV-55 (ST gas space near vent 4) were made. A similar set of PSDs for experiment L1-3A was made for a typical LI series experiment. The PSDs for experiment $\mathrm{LO}-04$ are shown in Figures 11 through 14 . Figures 15 through 18 contain the set of PSDs for experiment L7-3A. Essentially all of the data of any significance lies below $20 \mathrm{~Hz}$. In both experiments the data in the header and below the vent show higher frequency content than the data in the suppression tank gas volume and in the suppression pool at the vent exit elevation on the tank wall. In both of these experiments the pool surface is initially $38.1 \mathrm{~cm}$ above the vent exit. Thus, a significant part of the suppression pool exhibits the same pressure behavior as the gas volume above the pool.

The pressure measurements located on the bottom of the suppression: tank and directly below the vents (e.g., PE-SV-01 in Figure 5) show pressure spikes caused by bubble condensation. The pressure spikes are uncorrelated and not as evident in pressure data from measurements located on the bottom of the suppression tank but between the vents (e.g. PE-SV-22). The pressure spike data indicate that the condensing bubbles are small and that the bubbles condense in close proximity to the pressure measurements. Also, the consistent absence of such pressure spikes on measurements made up the side of the suppression tank (e.g. PE-SV-02) indicates that venting through the vents and up into the suppression tank gas volume takes place in the region of the vents. This type of venting is also supported by the PSD results discussed in the previous paragraphs.

\section{SYSTEMS RESPONSE TO LOADING}

The suppression tank is mounted on four support pads which are attached to the mating pads on the support structure by bolts (see 

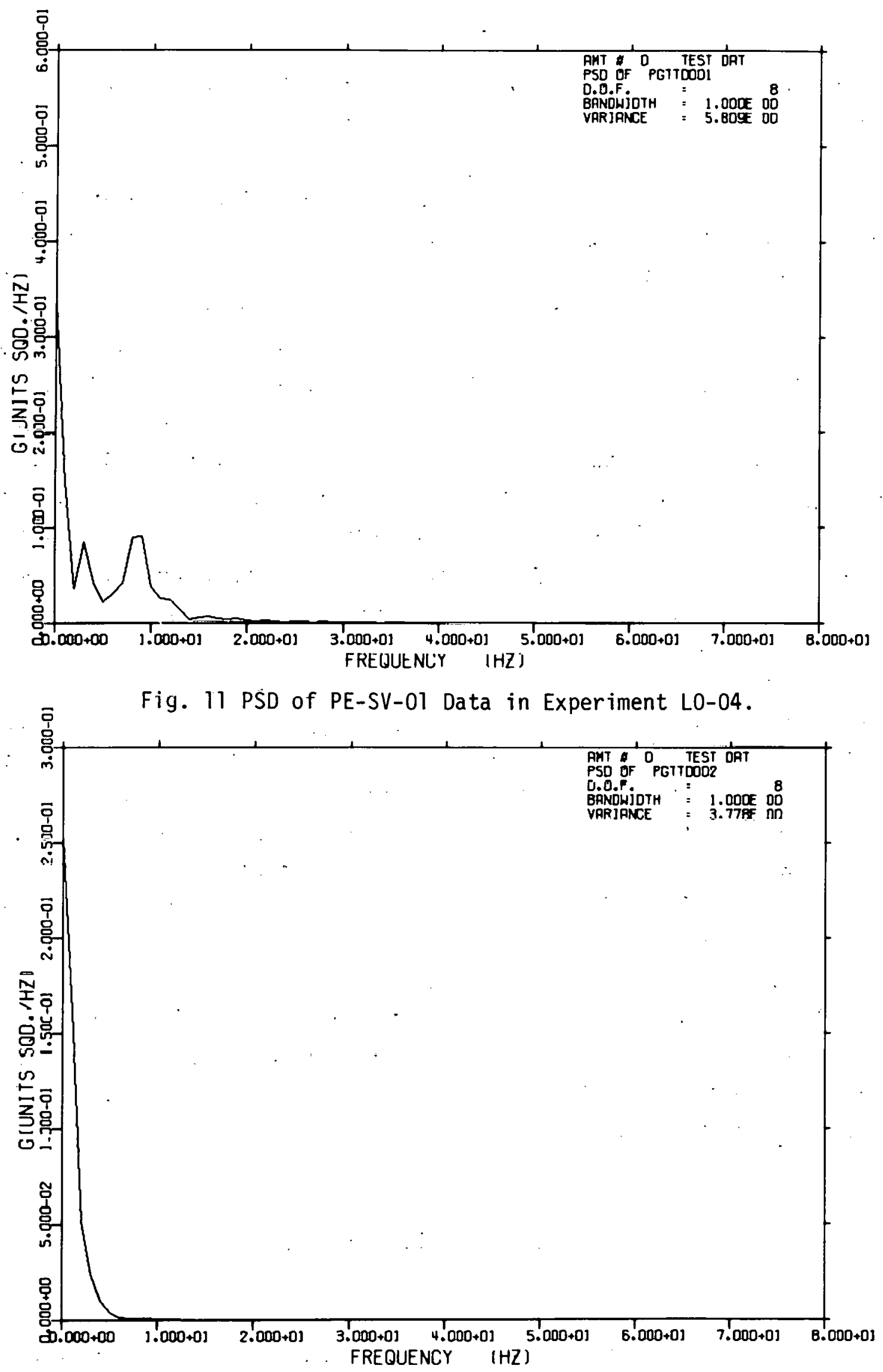

Fig. 12 PSD of PE-SV-02 Data in Experiment L0-04. 


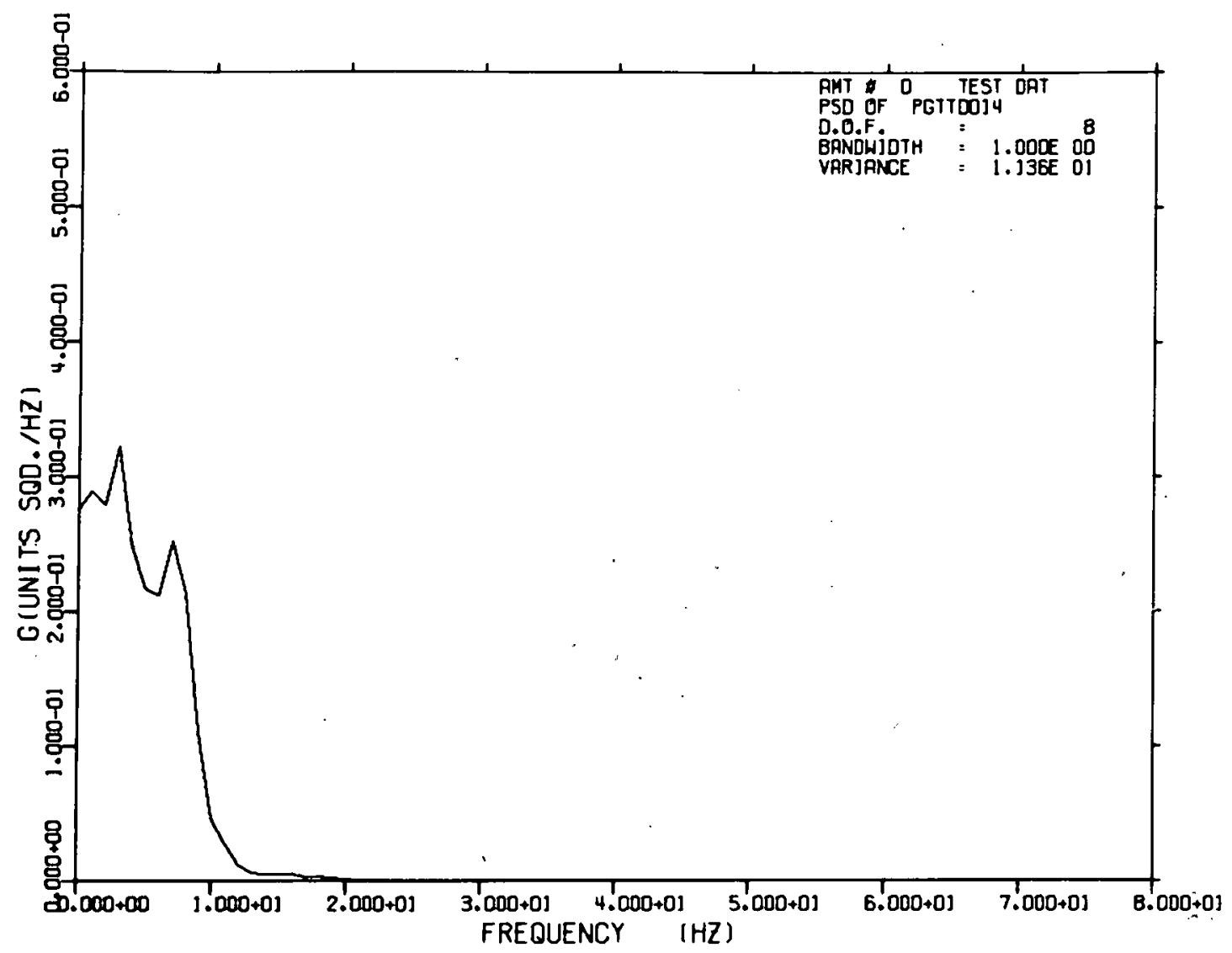

Fig. 13 PSD of PE-SV-14 Data in Experiment L0-04.

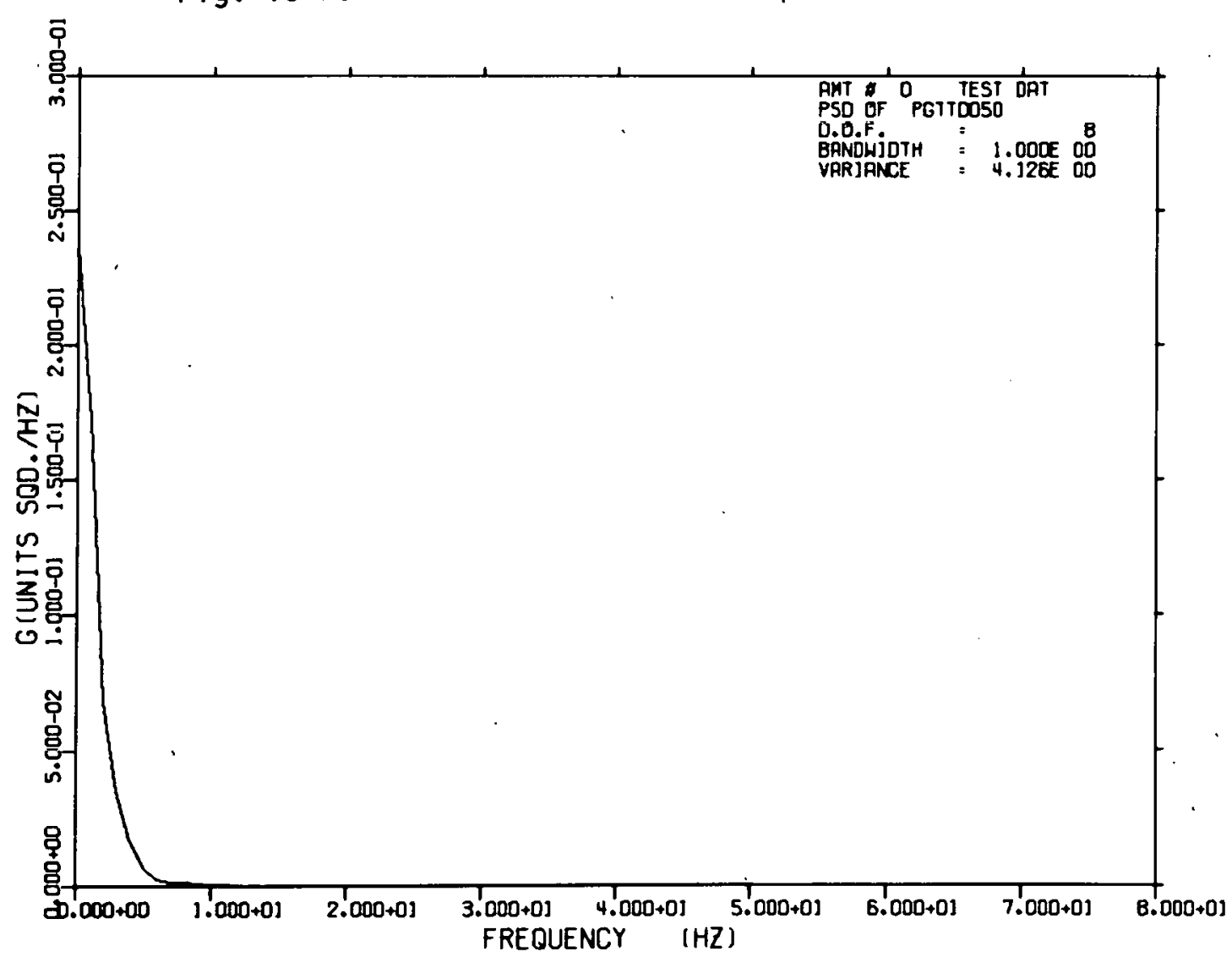

Fig. 14 PSD of PE-SV-55 Data in Experiment L0-04. 


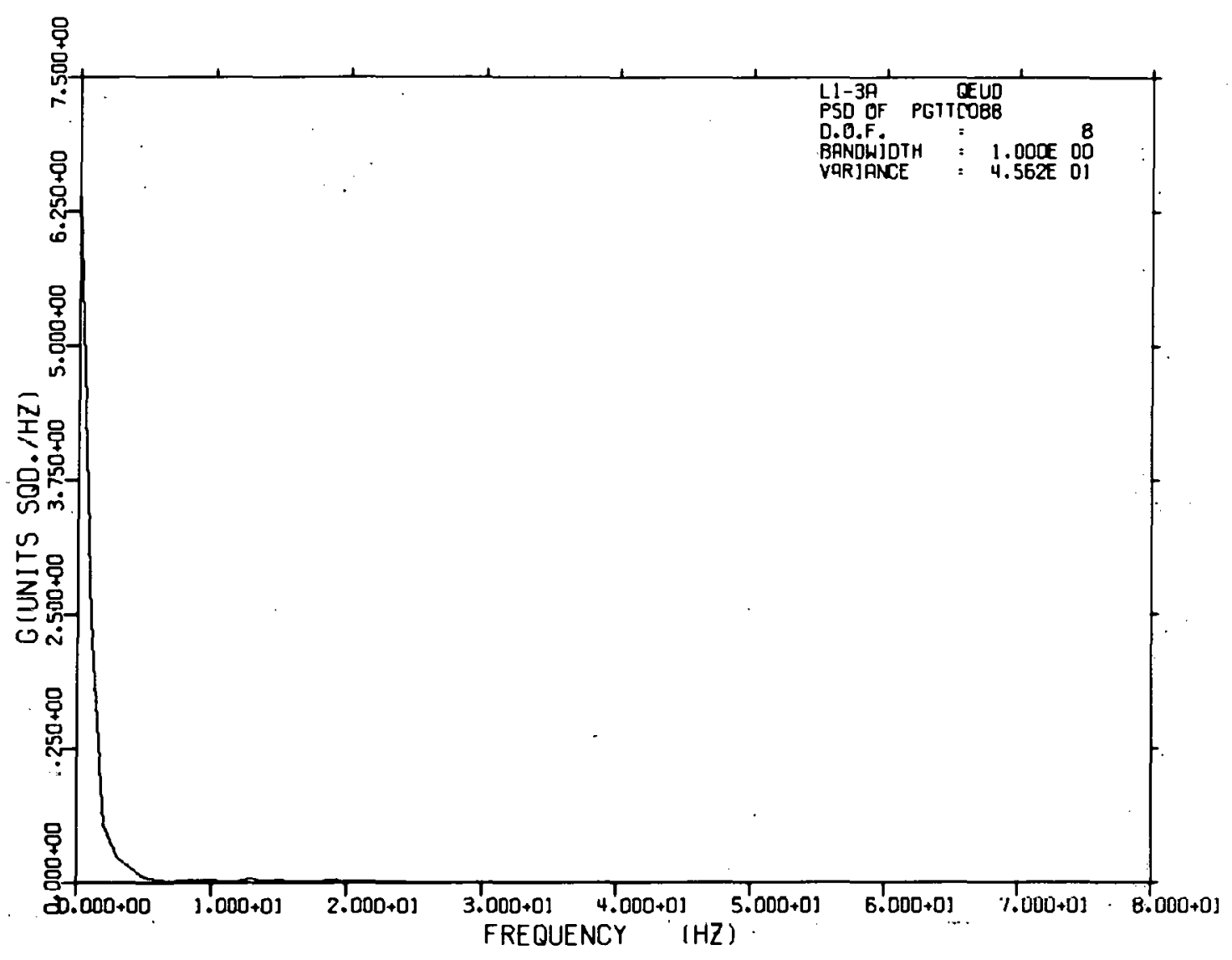

Fig. 15 PSD of PE-SV-01 Data in Experiment L1-3A.

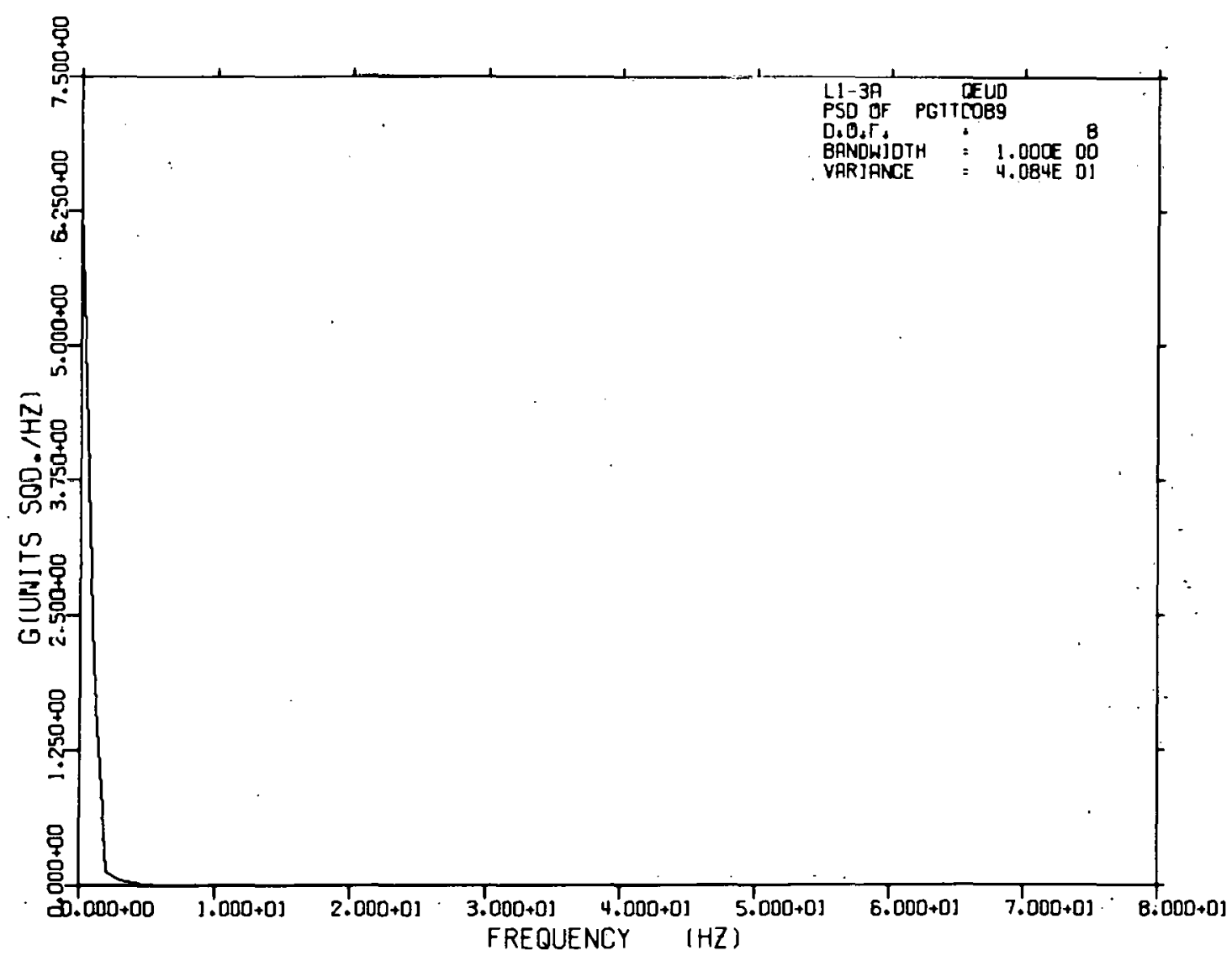

Fig. 16 PSD of PE-SV-02 Data in Experiment L1-3A. 


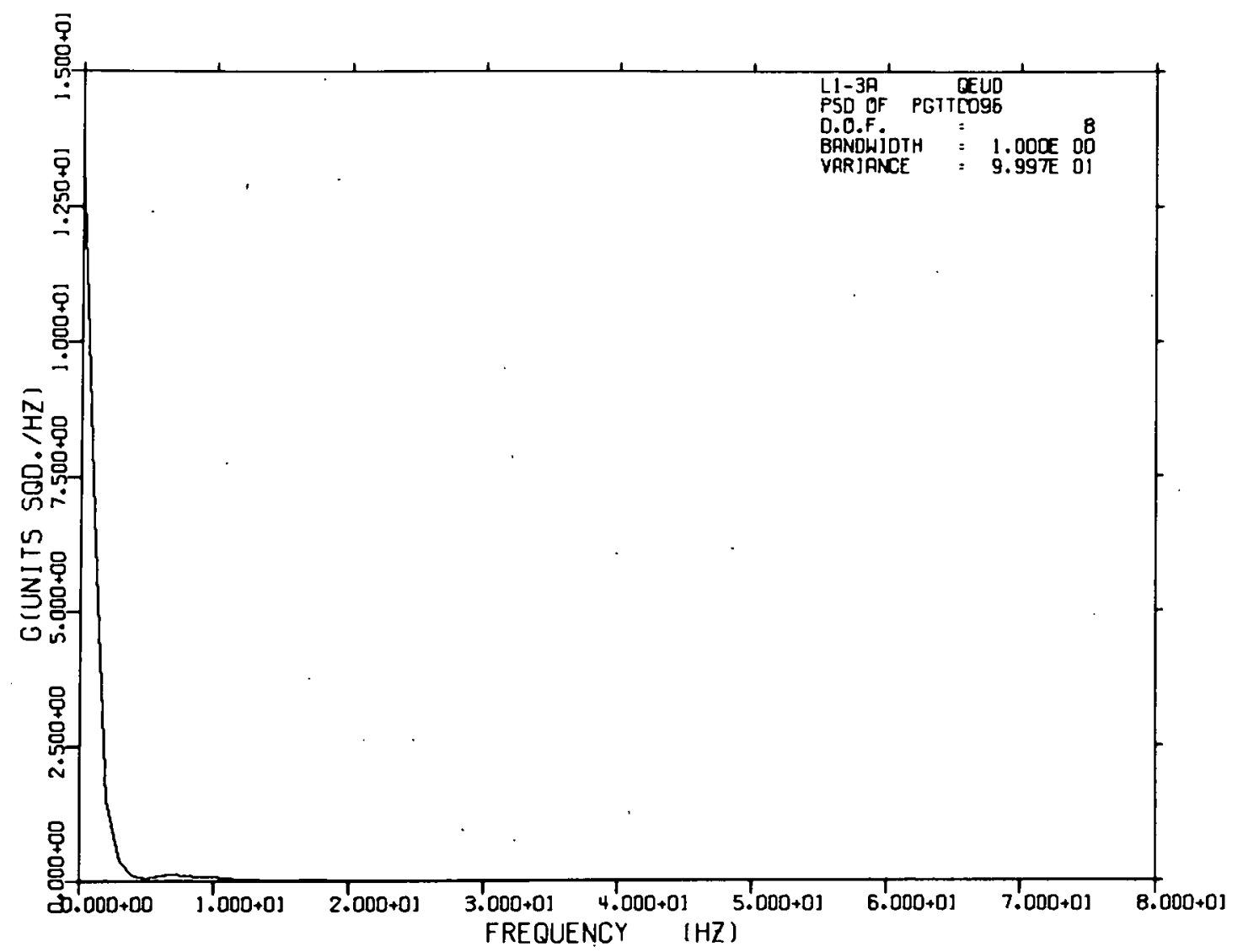

Fig. 17 PSD of PE-SV-14 Data in Experiment L1-3A.

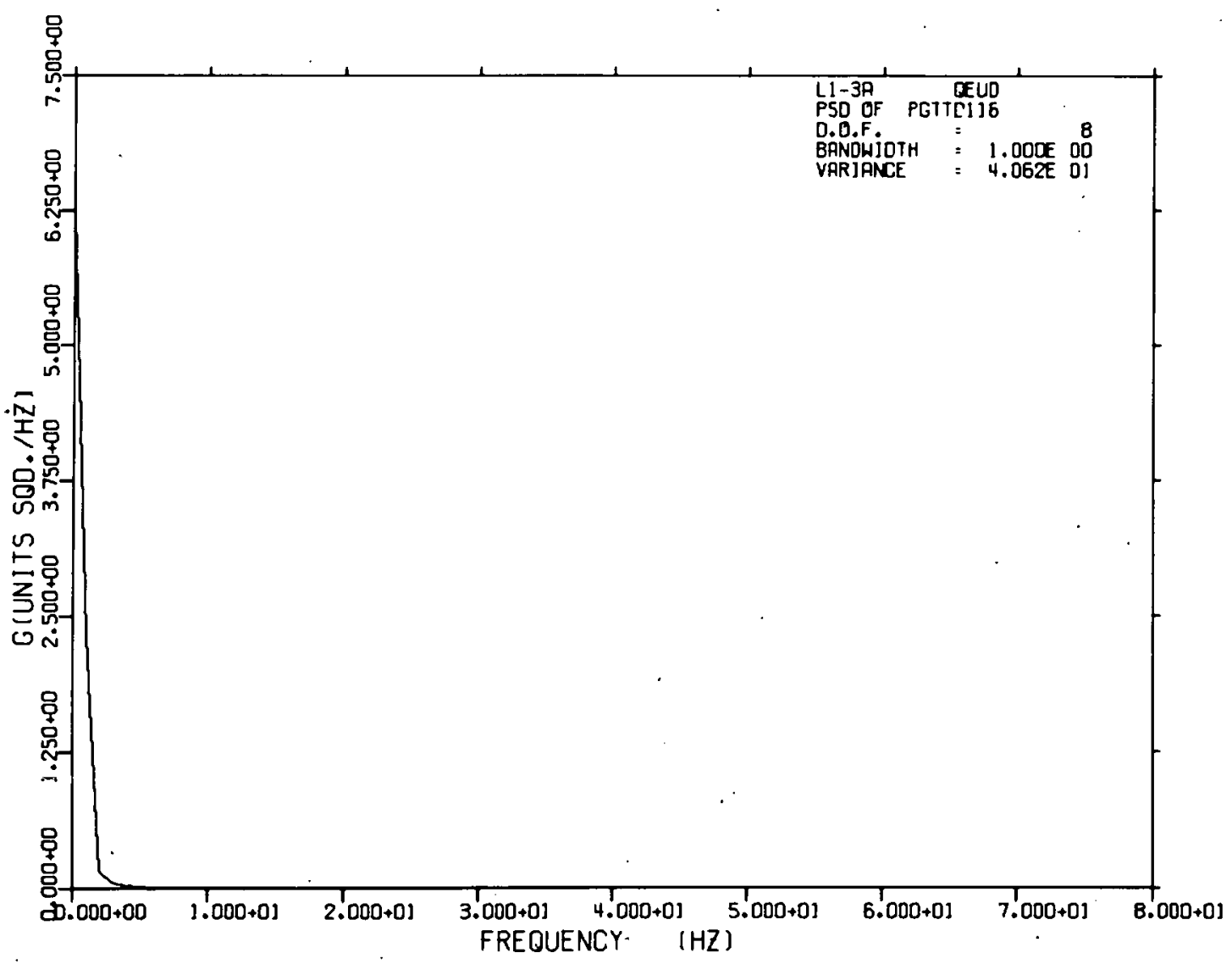

Fig. 18 PSD of PE-SV-55 Data in Experiment LI-3A. 
Figure 118, Reference 1). There are 12 bolts per support pad. The bolts are not tightly fastened and have approximately $1 \times 10^{-4} \mathrm{~m}$ clearance with the support pads to permit thermal expansion. Twelve of the 48 bolts were instrumented with strain gages to measure the up-load in the experiments. The maximum measured up-load in the experiments is tabulated along with the corresponding wet well weights for the experiments in Table VIII. In only three of the experiments did the upload exceed the wet well weight. The largest difference occurred in

TABLE VIII

MAXIMUM UP-LOAD VERSUS WET WELL WEIGHT

\begin{tabular}{|c|c|c|}
\hline Experiment & $\begin{array}{l}\text { Wet Well Weight } \\
\left.\text { (ST plus } \mathrm{H}_{2} 0\right) \\
\left(10^{6} \mathrm{~N}\right) \\
\end{array}$ & $\begin{array}{l}\text { Maximum Up-1oad } \\
\left(10^{6} \mathrm{~N}\right)\end{array}$ \\
\hline LO-02 & 0.439 & 0.1081 \\
\hline LO-03 & 0.479 & 0.2376 \\
\hline$L 0-3 A$ & 0.477 & 0.1929 \\
\hline$L O-3 B$ & 0.479 & 0.2979 \\
\hline $\mathrm{LO}-3 \mathrm{C}$ & 0.483 & 0.3909 \\
\hline LO-04 & 0.514 & $0.9947^{[a]}$ \\
\hline LO-05 & 0.572 & $0.8902^{[\mathrm{a}]}$ \\
\hline LO-08 & 0.577 & 0.3996 \\
\hline LO-09 & 0.483 & 0.1323 \\
\hline LO- 10 & 0.483 & 0.3827 \\
\hline L1-01 & 0.473 & 0.1766 \\
\hline L $1-02$ & 0.531 & 0.2888 \\
\hline$L T-03$ & 0.529 & $0.8702^{[\mathrm{a}]}$ \\
\hline$L 1-3 A$ & 0.514 & 0.3543 \\
\hline
\end{tabular}

[a] Up-load exceeds wet well weight. 
experiment L0-04 and is $0.48 \times 10^{6} \mathrm{~N}$. The support pad bolts have a modulus of $0.18 \times 10^{4} \mathrm{n} / \mu \mathrm{m}$. In order to deflect the bolts $25.4 \mu \mathrm{m}$ (1 mil) assuming the force is distributed equally among the 48 bolts, a force of $2.2 \times 10^{6} \mathrm{~N}$ must be applied. Thus, the strain gages on the support pad bolts should contain no useful data. Examination of the strain data revealed no usable information and provided support, by lack of data, that the up-loads calculated from the measured pressure were correct. Consequently, support pad strain bolt data are not included in this report.

Three other types of measurements were made which also are not included in this report. Strain gages mounted on the stiffener rings (see Figure 114, Reference 1) on the inside of the suppression tank showed that the tank flexed in response to the pressure loading; however, the amplitudes were not sufficientiy large compared to the data channel noise levels in all cases to provide additional information of good accuracy. Accelerometers (Figure 112, Reference 1) were mounted on the outside of the tank primarily to measure the vertical, longitudinal, and rocking frequencies of the tank. The results of these measurements. have been reported ${ }^{[3]}$ and tend to verify the calculated vertical and longitudinal frequencies. However, data were not obtained for all experiments and the data which were obtained were small in amplitude with large uncertainty. Of significance is the vertical frequency magnitude which was measured to be $60 \pm 7 \mathrm{~Hz}$ and calculated to be in the range 65.6 to $83.6 \mathrm{~Hz}$. This frequency is at least three times higher than that in the pressure data. The suppression tank is very stiff compared to the exciting function. Therefore, there should be very little dynamic response. The structural measurements support this.

The suppression tank gas and pool temperatures also are not reported other than in the form of initial conditions in Table III. Temperature changes in the first $0.5 \mathrm{sec}$ of the transients, in which the vertical loading occurs, are not significant. 


\section{RELEVANCE TO MARK PRESSURE SUPPRESSION SYSTEMS}

The LOFT PSS is not a scaled version of any MARK PSS. The same phenomena associated with pressure suppression will occur in all such systems; however, the geometric and structural variations among the systems will cause the phenomena to differ in magnitude and, consequently, in effect on the generation of structural loads. The results of the LOFT PSS experiments have shown that several parameters, both geometric and physical, are first order in affecting the magnitude of vertical loads. A comparison of the characteristics of the LOFI and MARK I pressure suppression systems, contained in Table IX, show that significant differences exist in the geometries. Considering the MAR̄K I values in relation to the LOFT PSS values, some of the values in MARK I would tend to decrease the vertical load, whereas other values would tend to increase the vertical load. Consequently, extrapolation of the vertical load results of the LOFT PSS experiments to other pressure suppression systems should not be attempted unless the scaling laws are known.

An additional consideration not specifically identified in Table IX is the structural stiffness of the PSS in relation to the frequency content of the pressure loading. In the LOFT PSS, little dynamic response could occur because the natural frequency in the vertical direction was several times higher than the frequency content of the pressure data. Structural dynamics may be an important consideration in other pressure suppression systems.

The LOFT PSS experiments represent specific set.s of conditions and results to which PSS computer codes can be applied for verification. Application of such codes is valid only if the LOFT. PSS geometry is within the ranges of the code parameters. The LOFT PSS experiments along with experiments in other facilities should be used to develop the definition of the physics of pressure suppression and the scaling laws which can then be applied to pressure suppression systems that will not undergo planned experiments. 
TABLE. IX

PSS CHARACTERISTICS OF LOFT AND MARK I

\begin{tabular}{|c|c|c|c|}
\hline \multirow{2}{*}{$\begin{array}{l}\text { PSS CHARACTERISTIC } \\
\text { Dry well free volume/pressure } \\
\text { suppression chamber free volume }\end{array}$} & LOFT & \multicolumn{2}{|c|}{$\operatorname{MARK} . I^{[a]}$} \\
\hline & $0.31-0.40^{[b]}$ & 1.34 & \\
\hline $\begin{array}{l}\text { Dry well free volume/pressure } \\
\text { suppression chamber pool volume }\end{array}$ & $0.89-0.56^{[c]}$ & 1.25 & \\
\hline $\begin{array}{l}\text { Dry well free volume/primary } \\
\text { system volume }\end{array}$ & 2.48 & 6.2 & \\
\hline $\begin{array}{l}\text { Primary system volume/pressure } \\
\text { suppression chamber pool volume }\end{array}$ & $0.46-0.23^{[\mathrm{c}]}$ & 0.202 & \\
\hline Break area/total vent area & 0.0445 & 0.0194 & $\therefore$ \\
\hline Vent pipe submergence, m & $0.15-0.58^{[c]}$ & 1.22 & $\therefore$ \\
\hline Vent pipe diameter, $m$ & 0.59 & 0.59 & \\
\hline Number of vent pipes & 4 & $48 \times 2$ & \\
\hline Vent pipe spacing, m & $2.74,1.82,2.74$ & 1.42 between & pairs \\
\hline $\begin{array}{l}\text { Distance from vent pipe exit to } \\
\text { bottom of suppression tank, m }\end{array}$ & 0.85 & 3.81 & \\
\hline Suppression chamber shape & Horizontal cylinder & Torus & \\
\hline $\begin{array}{l}\text { Suppression chamber cross- } \\
\text { section }\end{array}$ & Circular 3.29 dia & Circular 9.45 & dia \\
\hline $\begin{array}{l}\text { [a] Values are for the Brown's } F \\
\text { [b] Range of values in the } L 0 \text { an } \\
\text { [c] Range of values correspondin }\end{array}$ & $\begin{array}{l}\text { rry Nuclear Plant. } \\
\text { Ll experiments. } \\
\text { to the range of firs }\end{array}$ & it listed item & \\
\hline
\end{tabular}




\section{REFERENCES}

1. H. C. Robinson, LOFT Systems and Test Description (Loss-of-Coolant Experiments Using a Core Simulator), TREE-NUREG-1019 (November 1976).

2. V. T. Berta, E. C. Lemmon, and K. M. Peery, "Analys is of Blowdown Forces on LOFT Suppression Tank," Fourth Water Reactor Safety Research Information Meeting, Gaithersburg, Maryland, September $\underline{27-30,1976 .}$

3. V. T. Berta, L. P. Ledch, J. P. Kusler, "Dynamic Luadiny Exper"i= ments on the LOFT Multi-Vent Suppression. Tank," International Atomic Energy Agency Technical Committee Meeting on ThermoHydrauitic Consequences of Loss-of-Coolant Accidents Inside and Outside the Containment, Cologne, Germany, December 7-9, 1976.

4. G. M. Millar, Experiment Data Report for LOFT Nonnuclear lest LI-3A, TREE-NUREG-1027 (December 1976).

5. H. C. Robinson, Experiment Mata Report for I OFT Nonnuclear Test L1-2, TREE-NUREG-1026 (January 1977).

6. J. R. Chappel, Experiment Data Report for LOFT Nonnuclear Test L1-1, TREE-NUREG-1025 (January 1977).

7. G. M. Millar, Experiment Data Report for LOFT Nonnuclear Test L1-3, TREE-NUREG-1065 (Apri1 1977).

8. E. C. Lemmon, K. M. Peery, "Suppression Tank Loading," Two-Phase Flow and Heat Transfer Symposium-Workshop, Fort Lauderdale, Florida, October 18-20, 1976. 
APFCNDIX A

MINI-BLOWDOWN L0-02 EXPERIMENTAL DATA 


\section{THIS PAGE}

\section{WAS INTENTIONALLY \\ LEFT BLANK}




\section{APPENDIX A}

\section{MINI-BLOWDOWN LO-02 EXPERIMENTAL DATA}

Both QOBVs fully opened in this experiment. The fluid temperature was $233.3 \pm 1.5^{\circ} \mathrm{C}$ in QOBV-1 and $230.6 \pm 1.5^{\circ} \mathrm{C}$ in Q0BV-15. The suppression tank initial conditions were $2.27 \pm 0.08$ bar with identical temperatures of $33.7 \pm \overline{1} .5^{\circ} \mathrm{C}$. in the suppression pool and gas volume. The vents were submerged $13.5 \mathrm{~cm}$ with zero preclearing.

The experimental data are defined in Table A-I. The opening characteristics of the QOBVS are shown in terms of percent sleeve travel versus time. The flow area of the valve begins to open at a sleeve position of $17 \%$ of full travel and is fully open at a sleeve position of $66 \%$ of full travel. The differential pressure between the header and the tank gas volume is measured with a very sensitive device primarily to provide information on vent preclearing. The data channel for this measurement is driven to saturation in the early part of the transient. 
TABLE. A-I

EXPERIMENT LO-02 DATA SUMMARY

\begin{tabular}{|c|c|c|c|c|c|}
\hline $\begin{array}{c}\text { Measurement } \\
\text { or } \\
\text { Calculation } \\
\end{array}$ & $\begin{array}{l}\text { Pre-Transient } \\
\text { Data Channel } \\
\text { Varjance } \\
\left(10^{-4} \text { bar }^{2}\right)\end{array}$ & Figure Number & Measurement & $\begin{array}{c}\text { Pre-Transient } \\
\text { Data Channel } \\
\text { Variance } \\
\left(10^{-4} \text { bar } 2\right)\end{array}$ & Figure Number \\
\hline QOBV-1 upening & - & $A-1, A-2$ & PE-SV-22 & 0.73315 & $A-22$ \\
\hline QOBV-15 opening & - & $A-3, A-4$ & PE-SV-23 & 0.24619 & $A-23$ \\
\hline $\begin{array}{l}\text { Combined QOBV } \\
\text { opening }\end{array}$ & 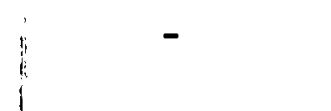 & $A-5, A-6$ & PE-SV-24 & 0.17639 & $A-24$ \\
\hline Vertical load & - & $A-7$ & $P E-S V-25$ & 0.16272 & $A-25$ \\
\hline PDE-SV-09 &. & $A-8$ & $P E-S V-26$ & 0.10138 & $A-26$ \\
\hline PE-SV-01 & 0.25361 & $A-9$ & PE-SV-27 & 0.20784 & $A-27$ \\
\hline PE-SV-02 & 0.28117 & $A-10$ & PE-SV-28 & 0.18178 & $A-28$ \\
\hline PE-SV-03 & 0.33361 & $A-11$ & PE-SV-29 & 0.20536 & $A-29$ \\
\hline PE-SV-01 & 0.32906 & $A-12$ & $P E-5 V-43$ & 0.11775 & $A-30$ \\
\hline PE-SV-10 & 0.27913 & $A-13$ & PE-SV-44 & 0.15339 & $A-31$ \\
\hline PE-SV-11 & 4.7636 & $A-14$ & $P E-5 V=54$ & 0.14935 & $A=32$ \\
\hline PE-SV-12 & 0.35920 & $A-15$ & PE-SV-55 & 0.08284 & $A-33$ \\
\hline PE-SV-13 & 0.23476 & $A-16$ & PE-SV-56 & 0.12772 & $A-34$ \\
\hline PE-SV-14 & 0.25699 & $A-17$ & PE-SV-57 & 0.07860 & $A-35$ \\
\hline$P t-S V-I b$ & 0.30590 & $A-18$ & PE-SV-58 & 0.15903 & $\Lambda-36$ \\
\hline PE-SV-16 & 0.23358 & $A-19$ & PE-SV-59 & 0.13825 & $A-37$ \\
\hline PE-SV-17 & 0.27607 & $A-20$ & $P E-S V-60$ & 0.18815 & $A-38$ \\
\hline PE-SV-18 & 0.27705 & $A-21$ & PE-SV-61 & 0.12080 & $A-39$ \\
\hline
\end{tabular}




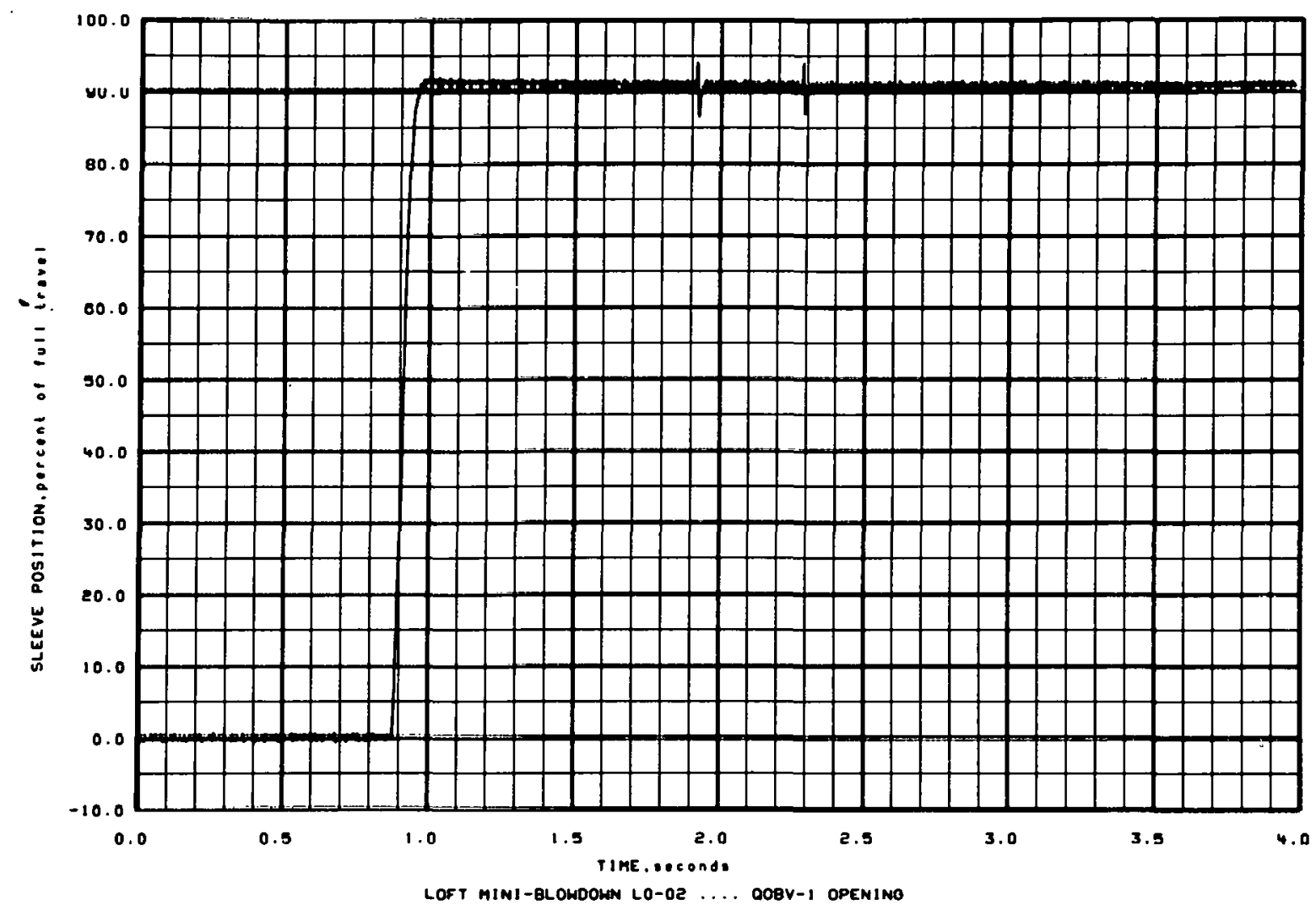

Figure A-1

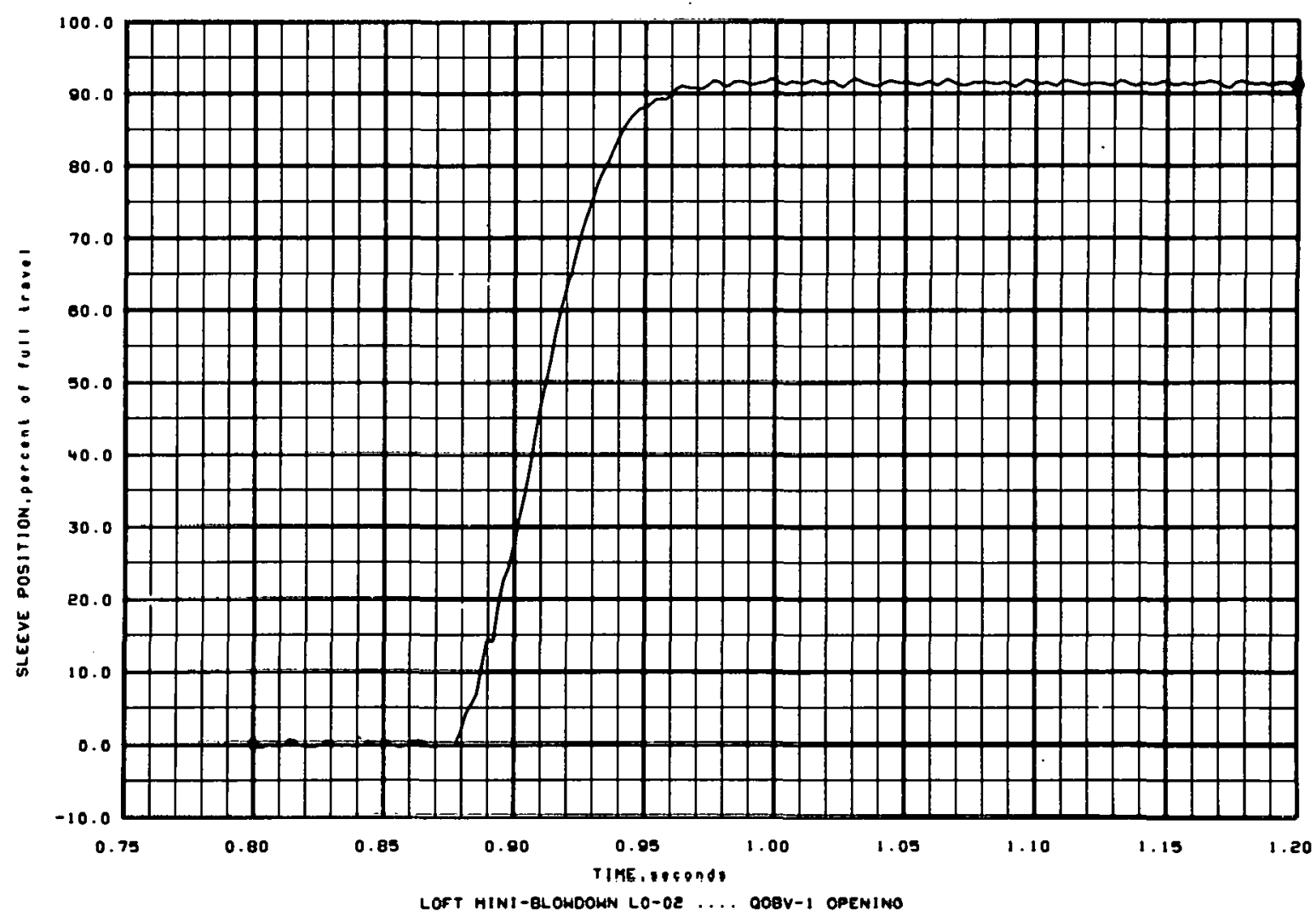

Figure A-2 


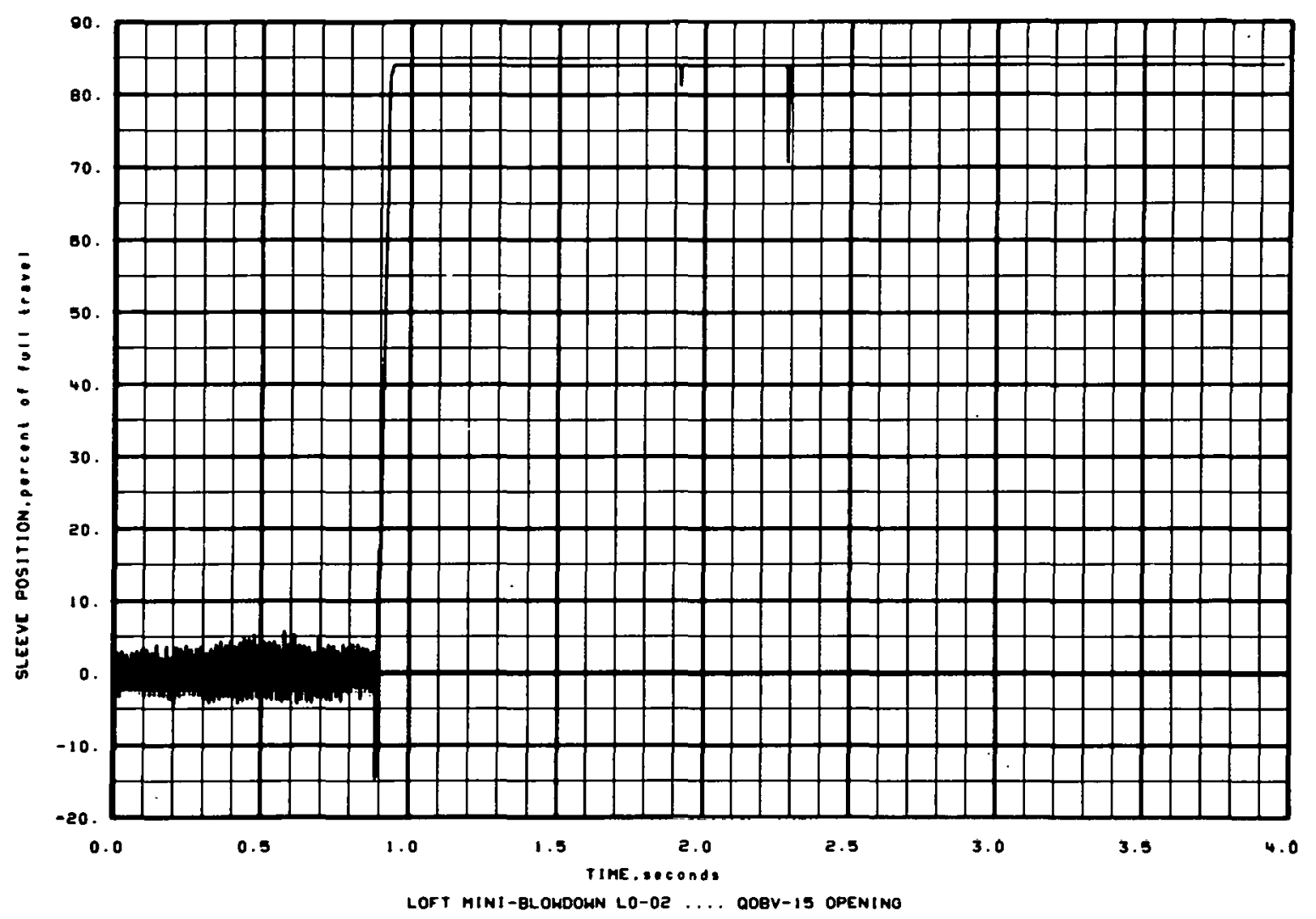

Figure A-3

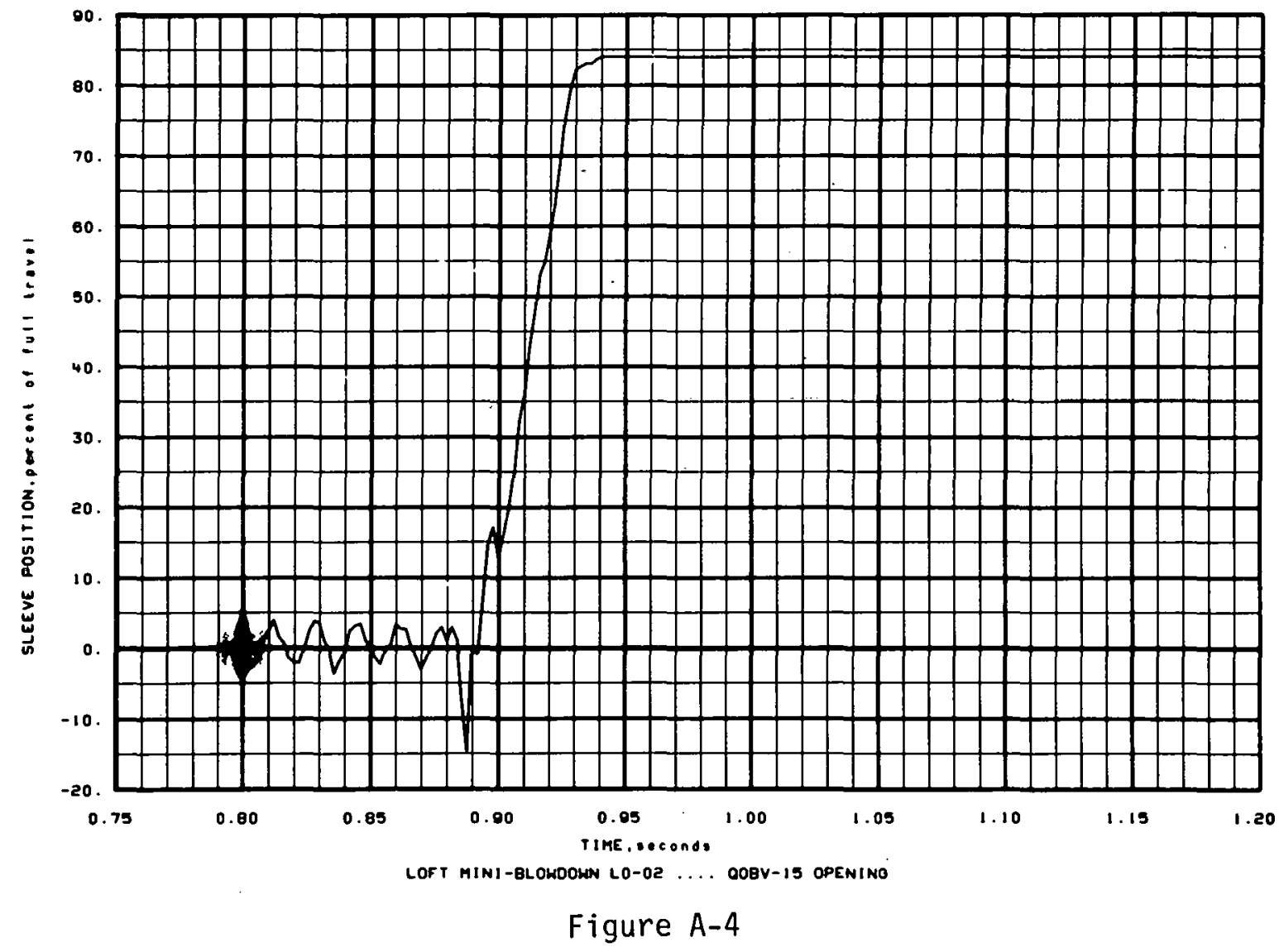




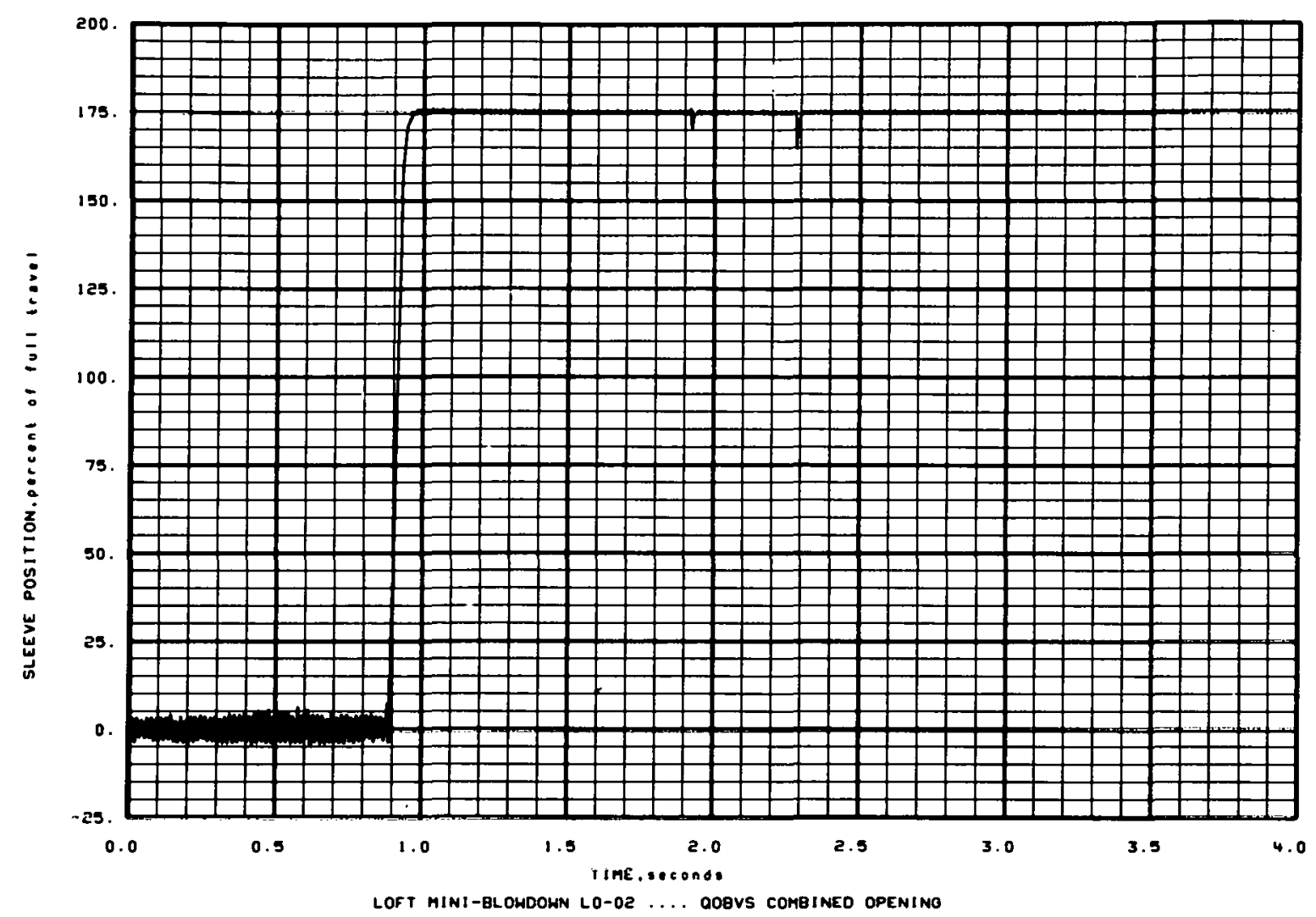

Figure A-5

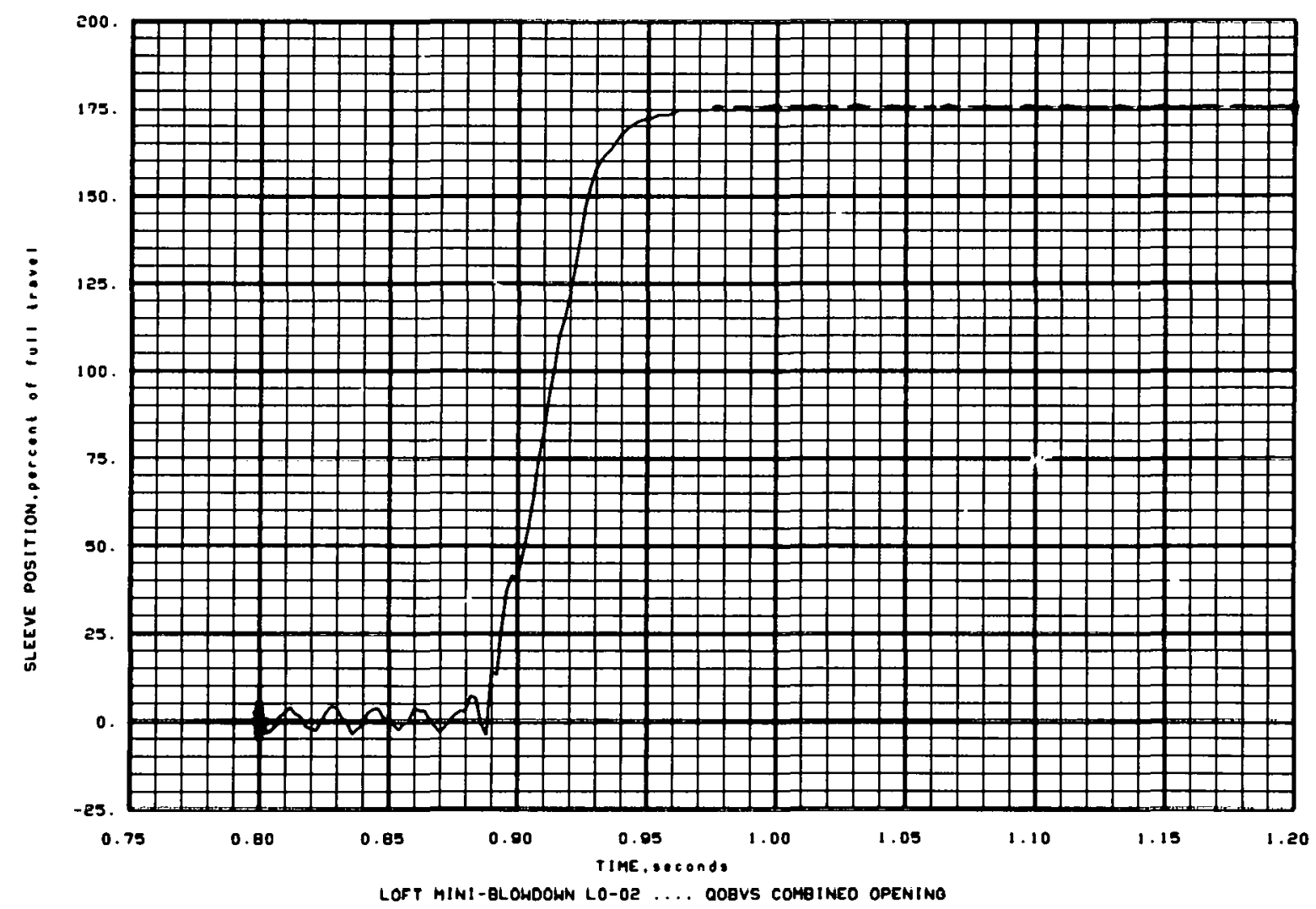

Figure A-6 


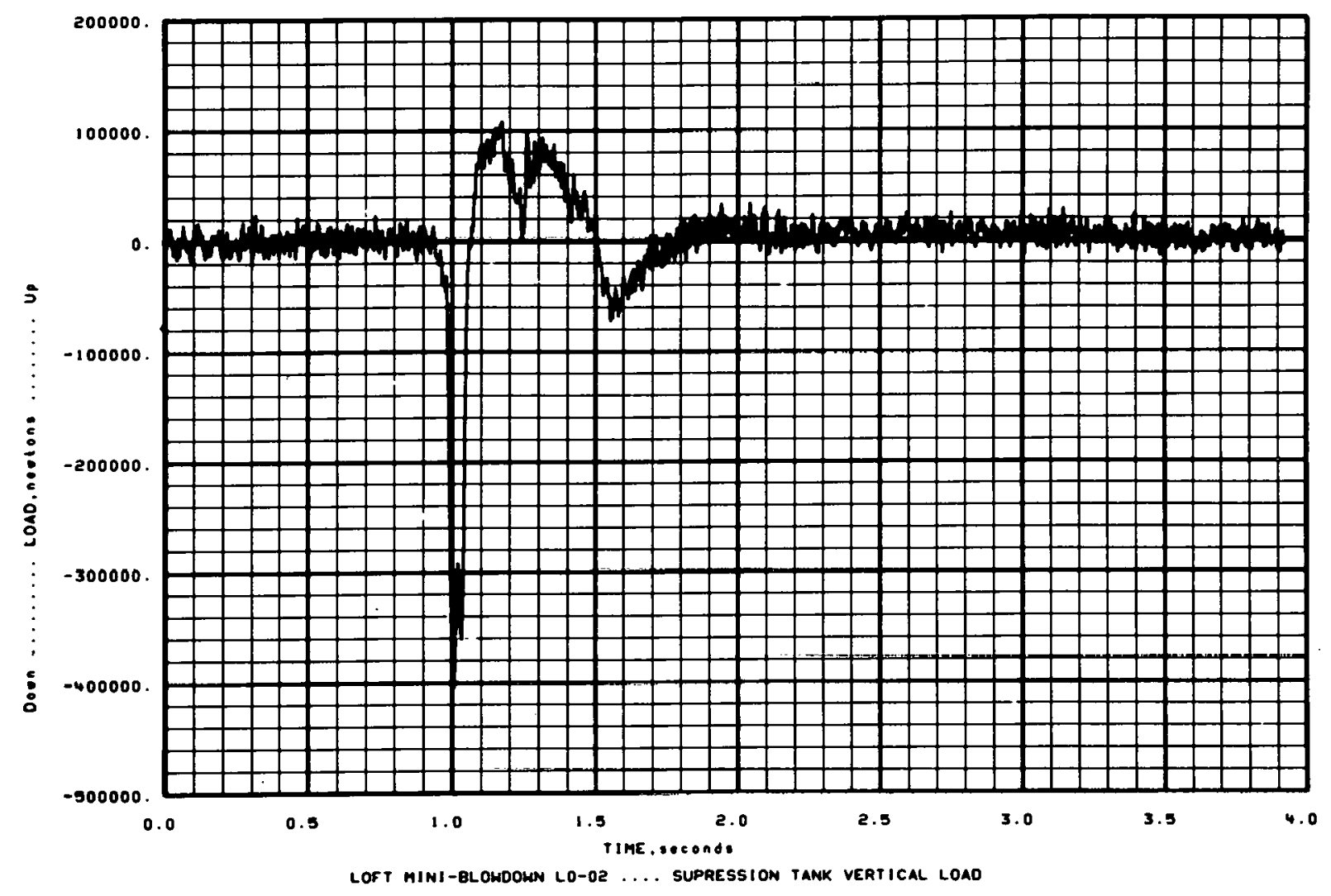

Figure A-7

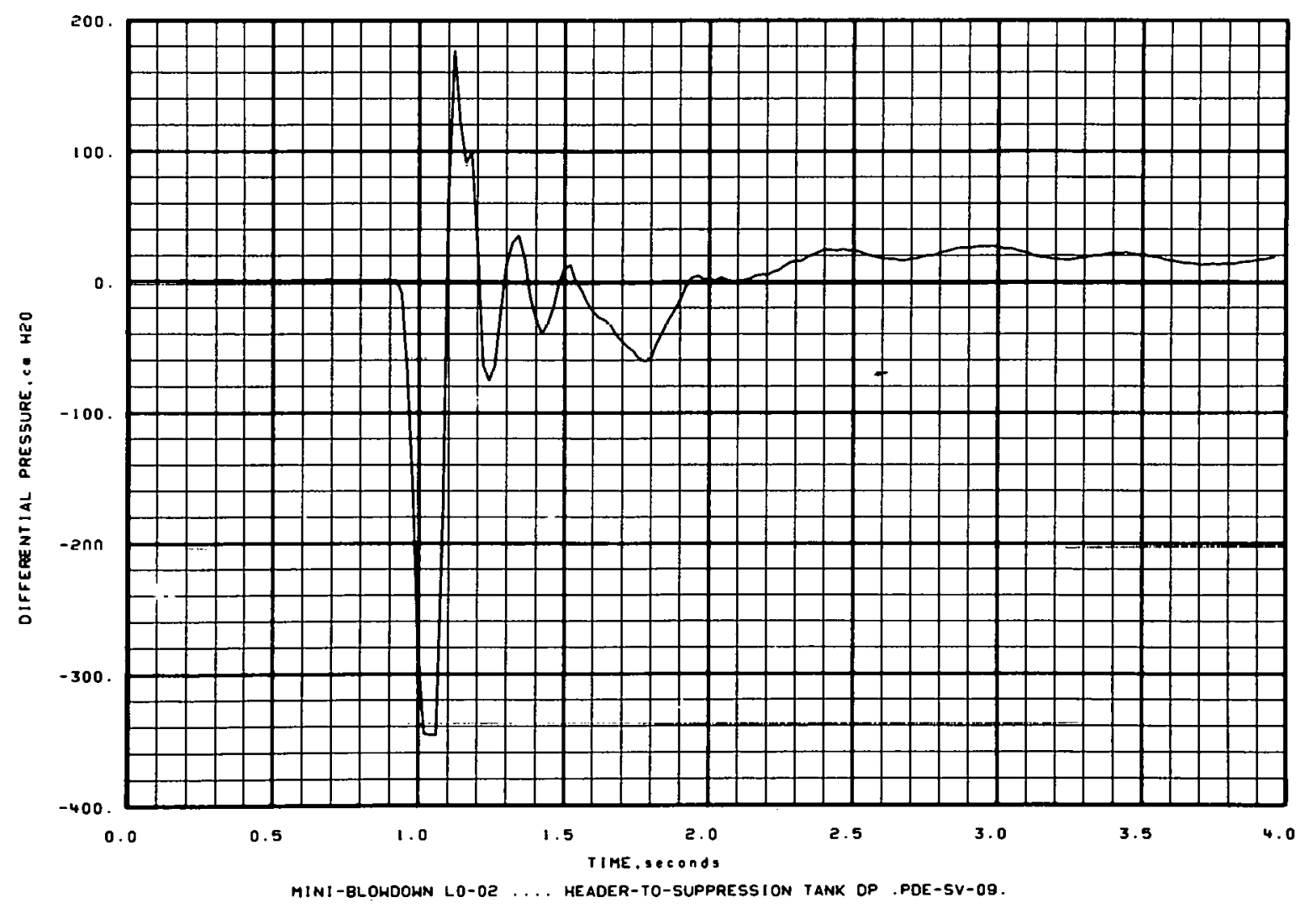

Figure A-8 


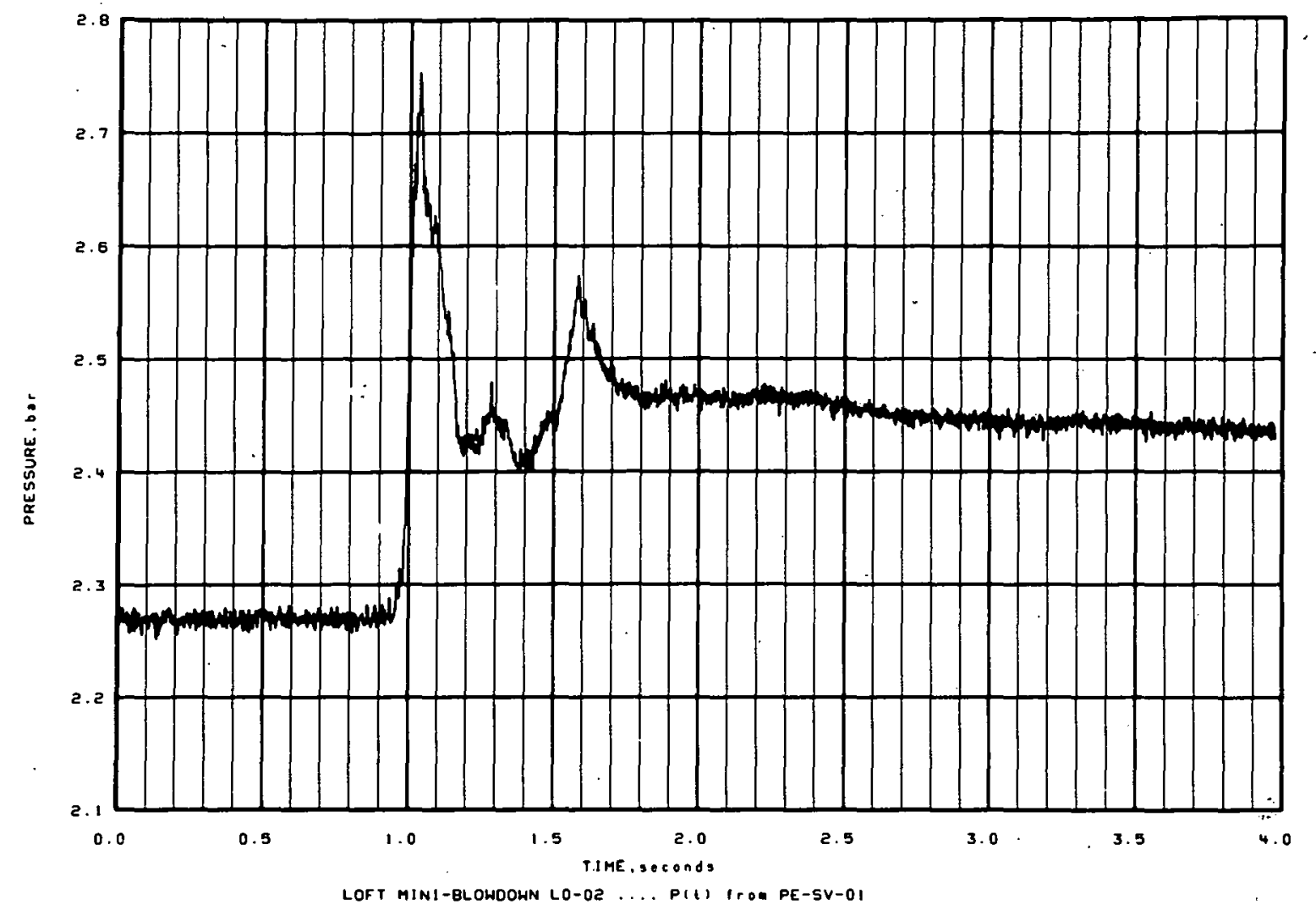

Figure A-9

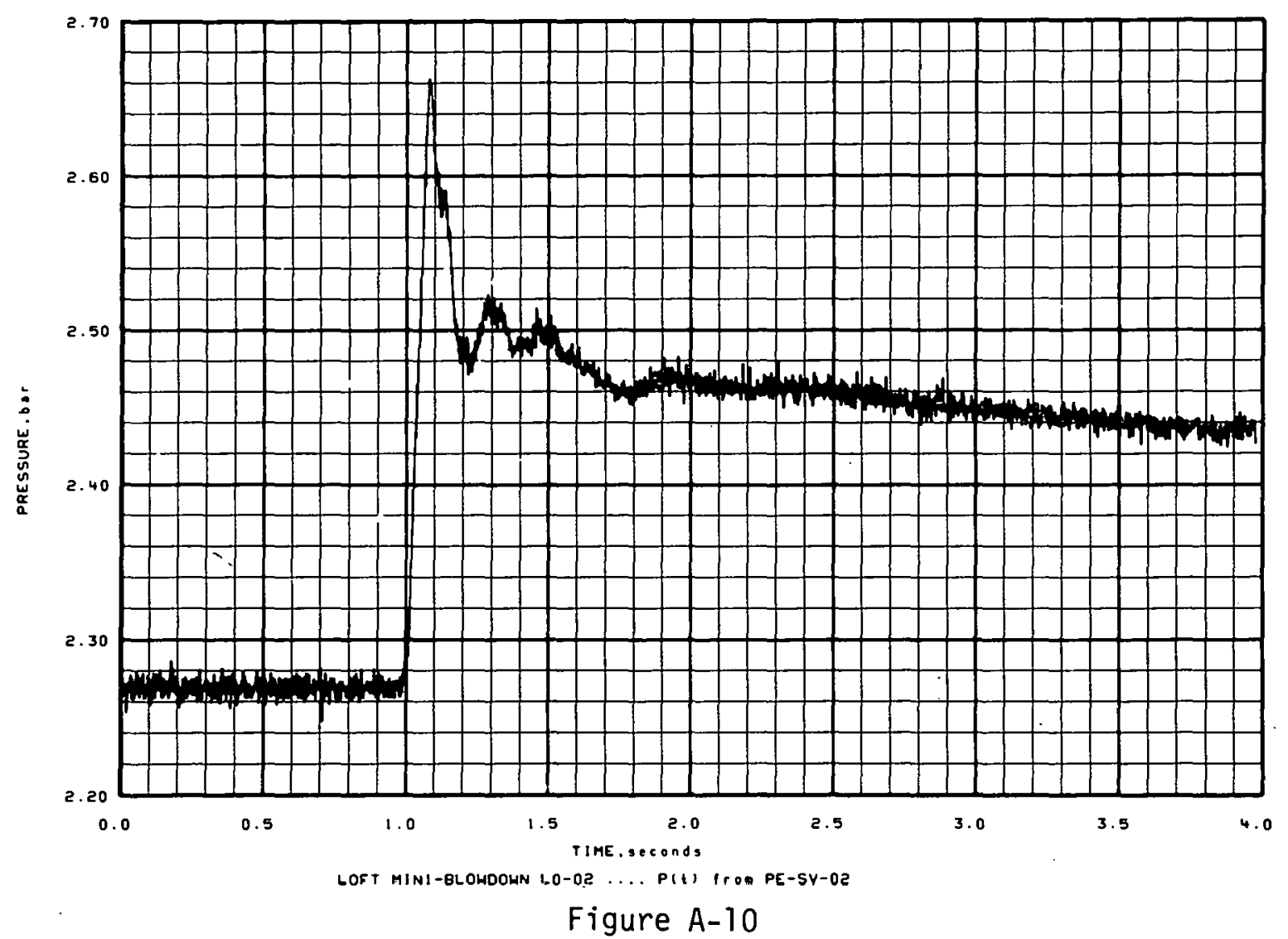




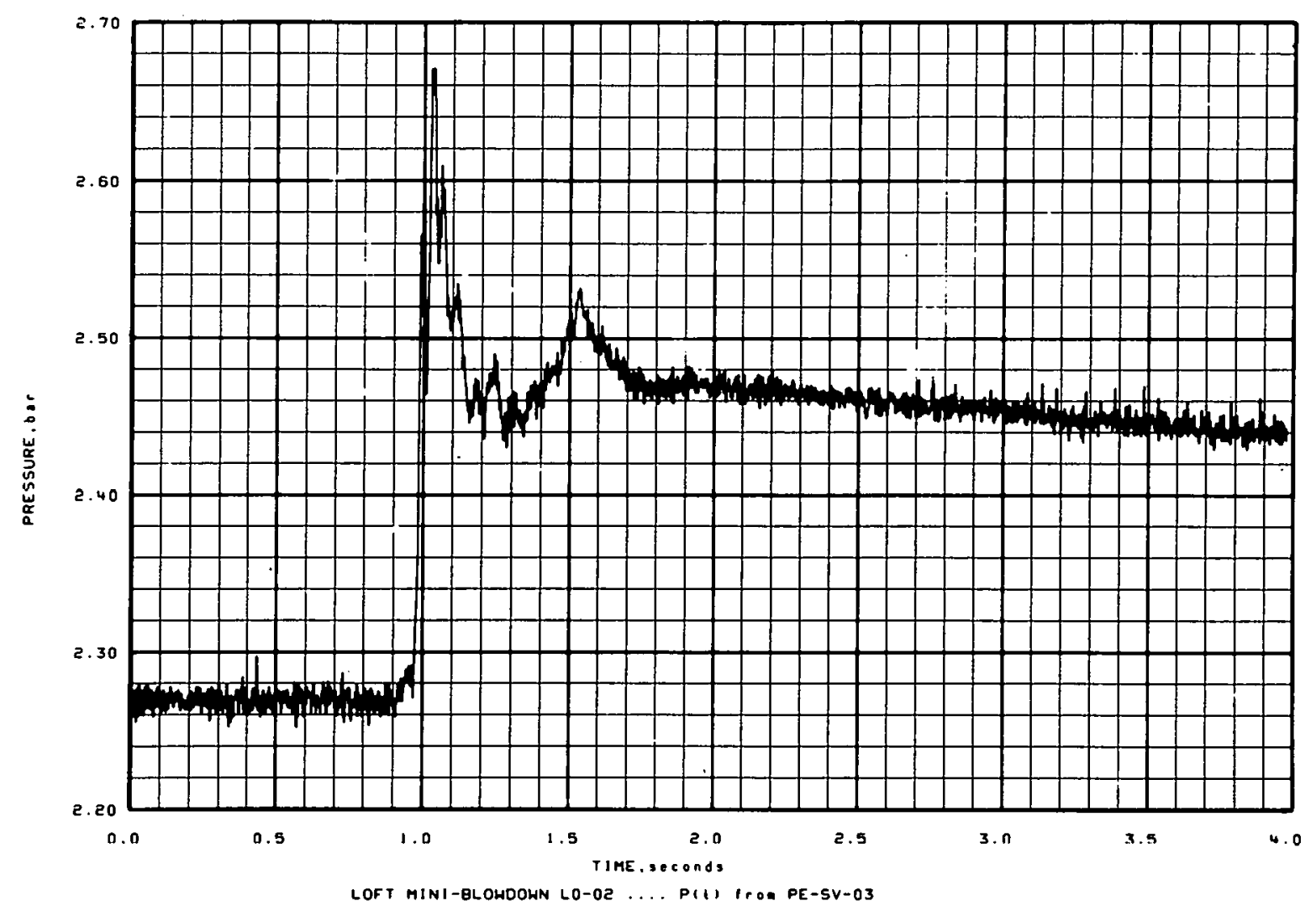

Figure A-11

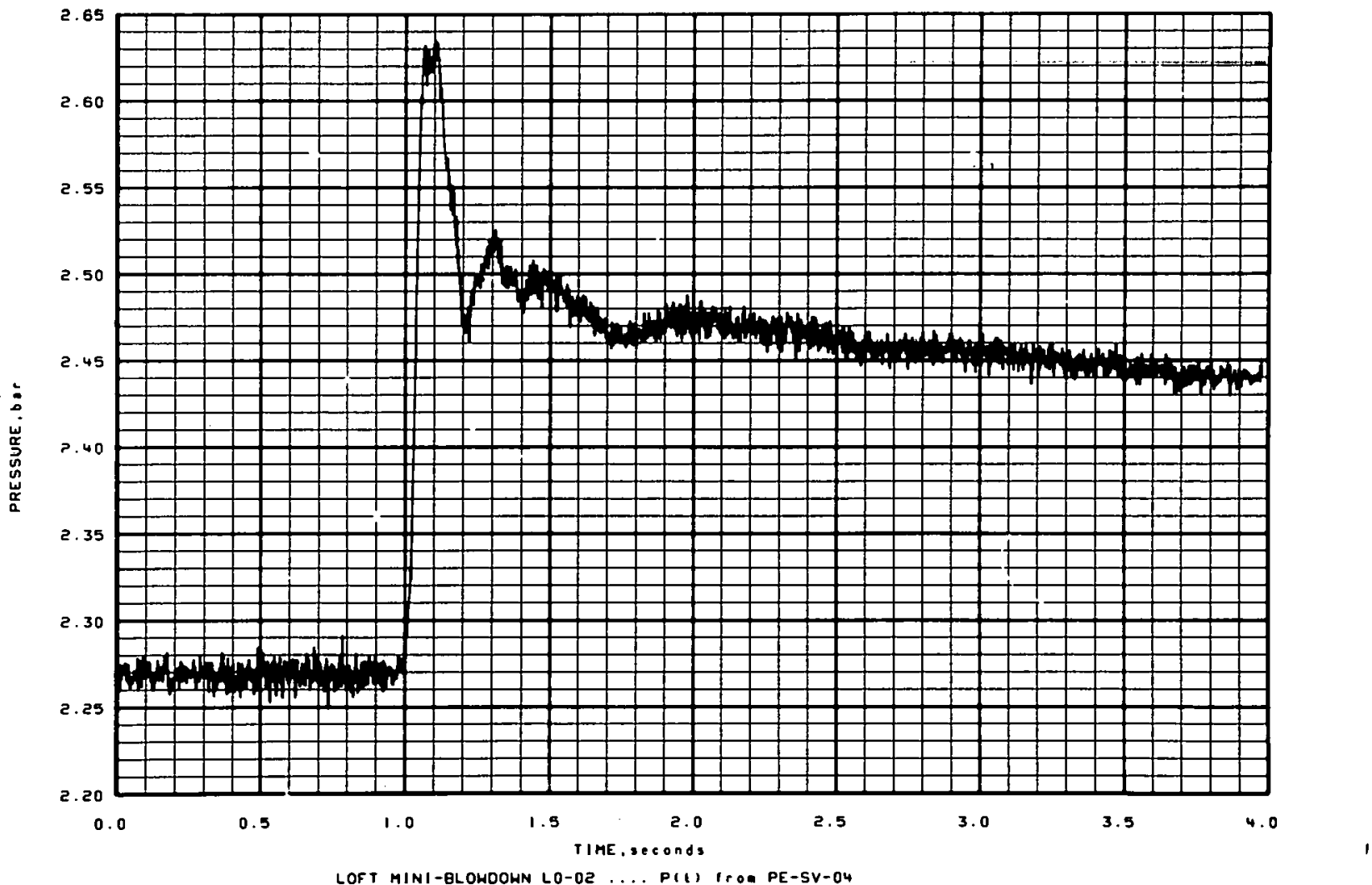

Figure $A-12$ 


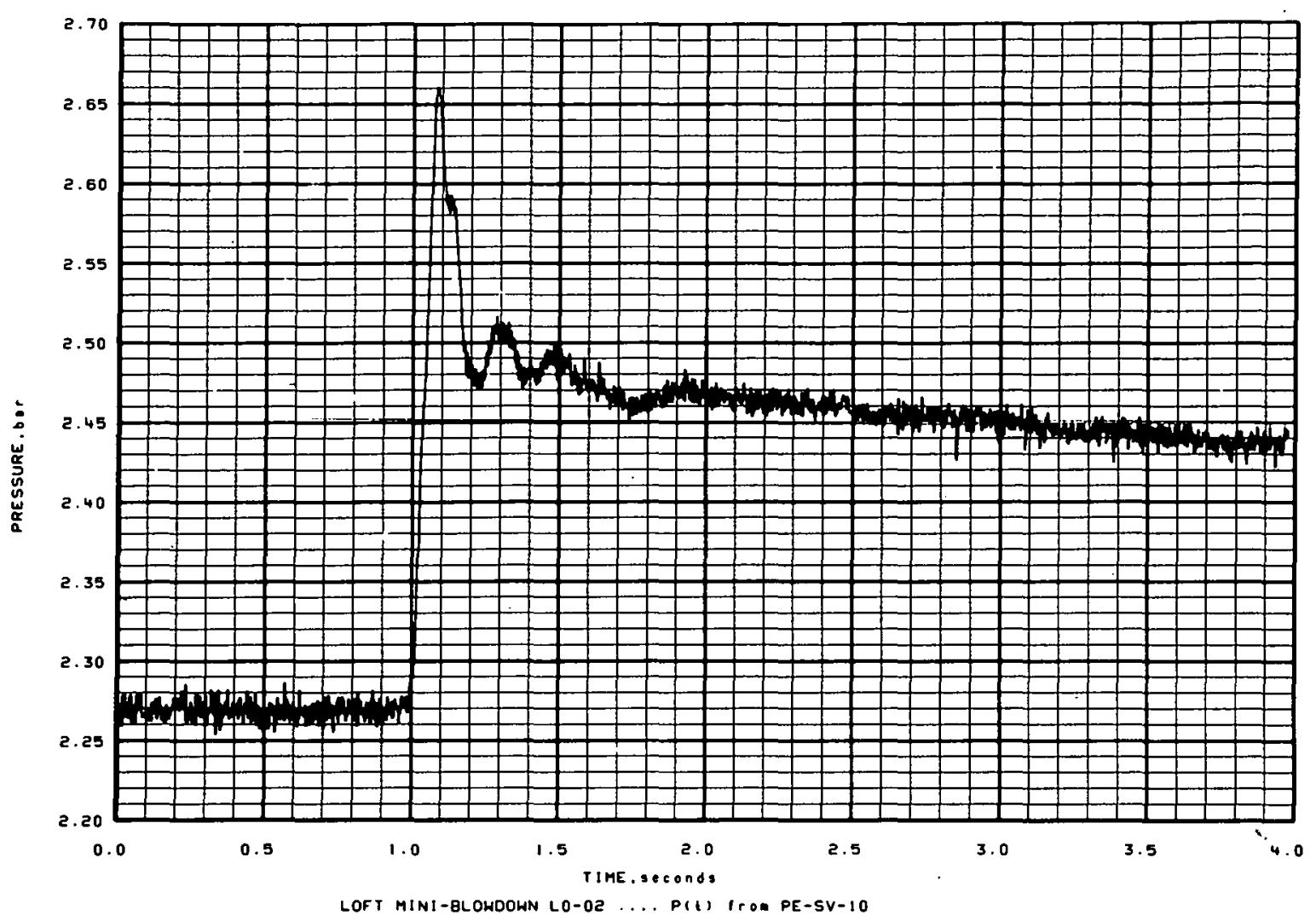

Figure $A-13$

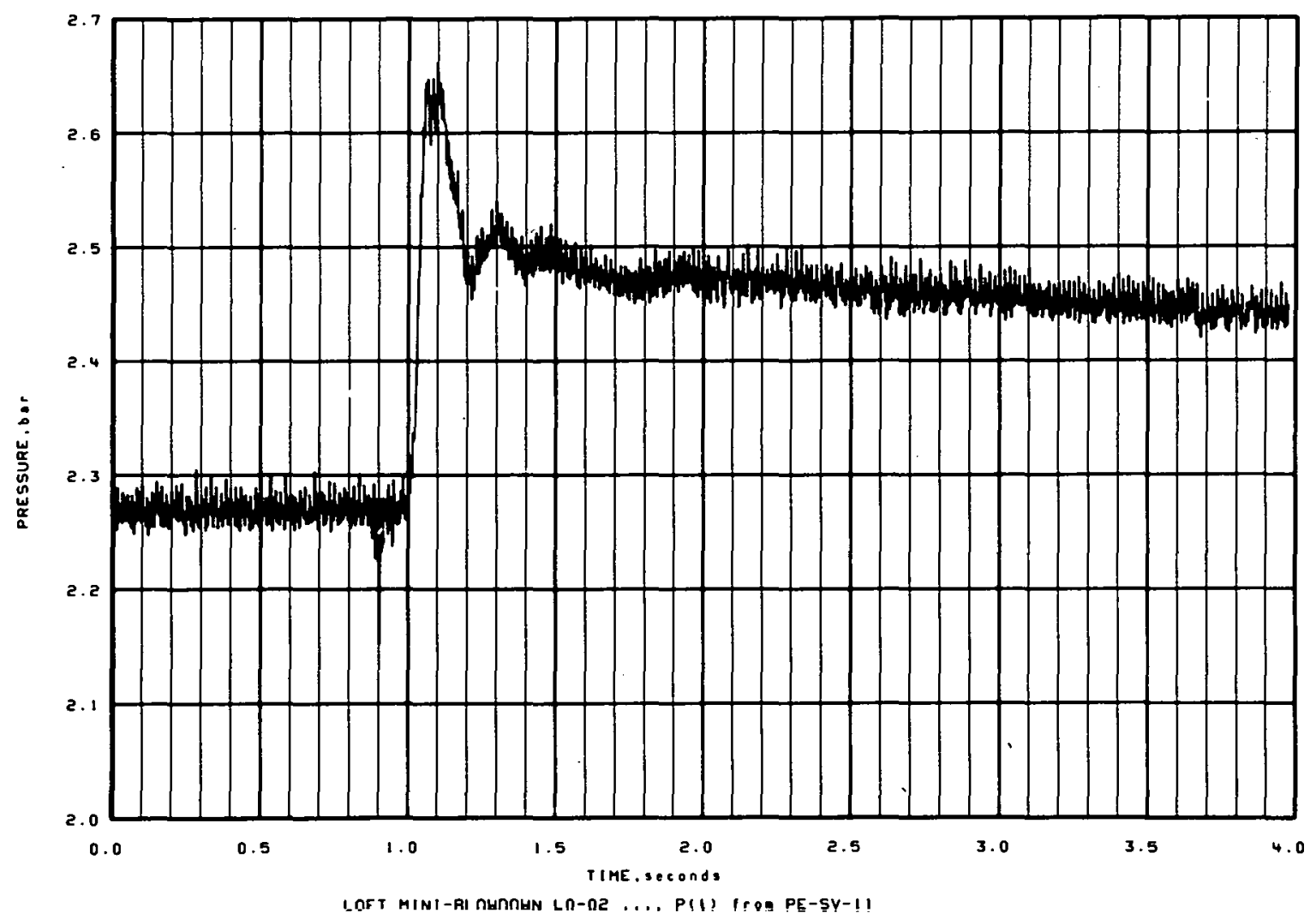

Figure A-14 


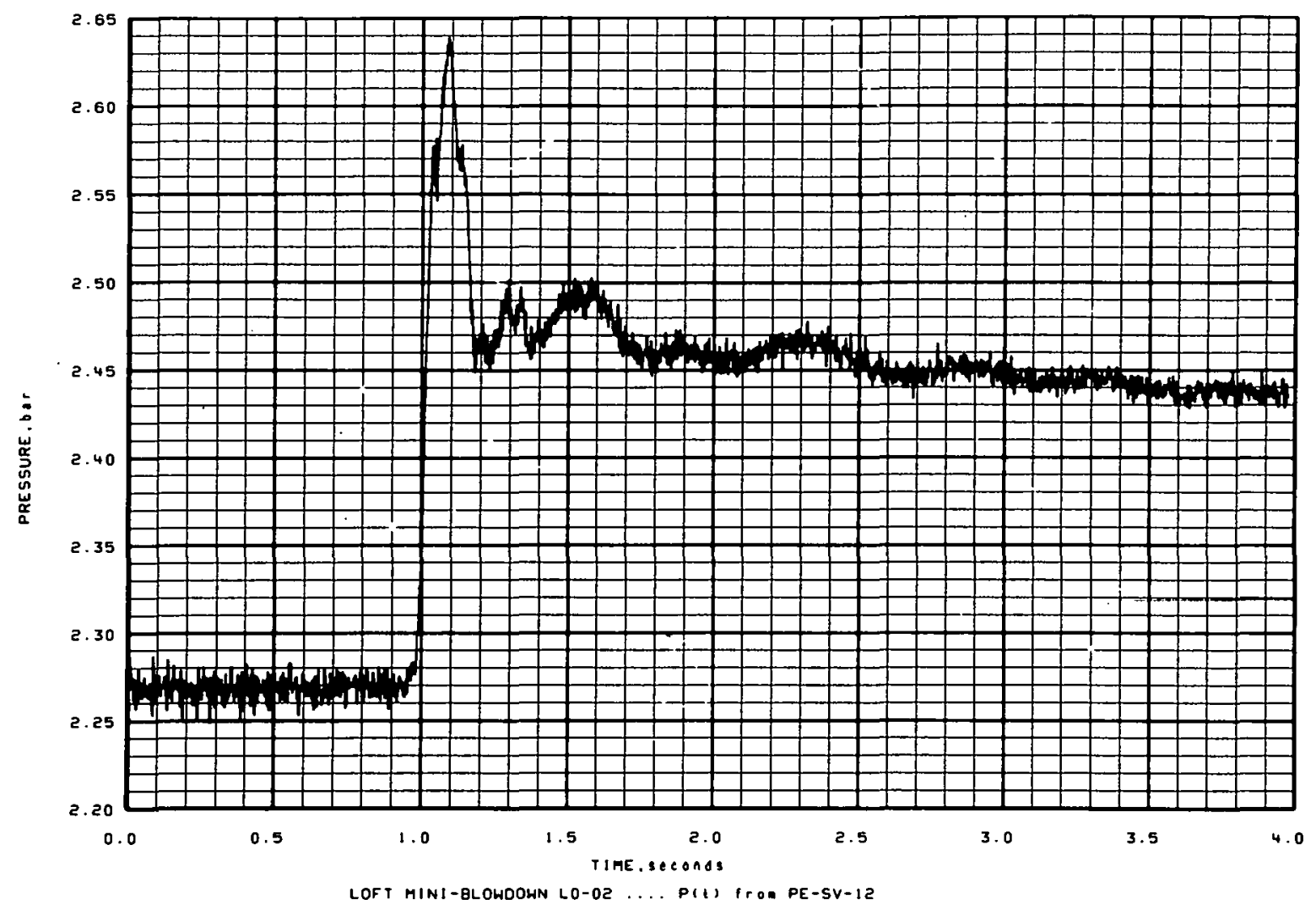

Figure A- 15

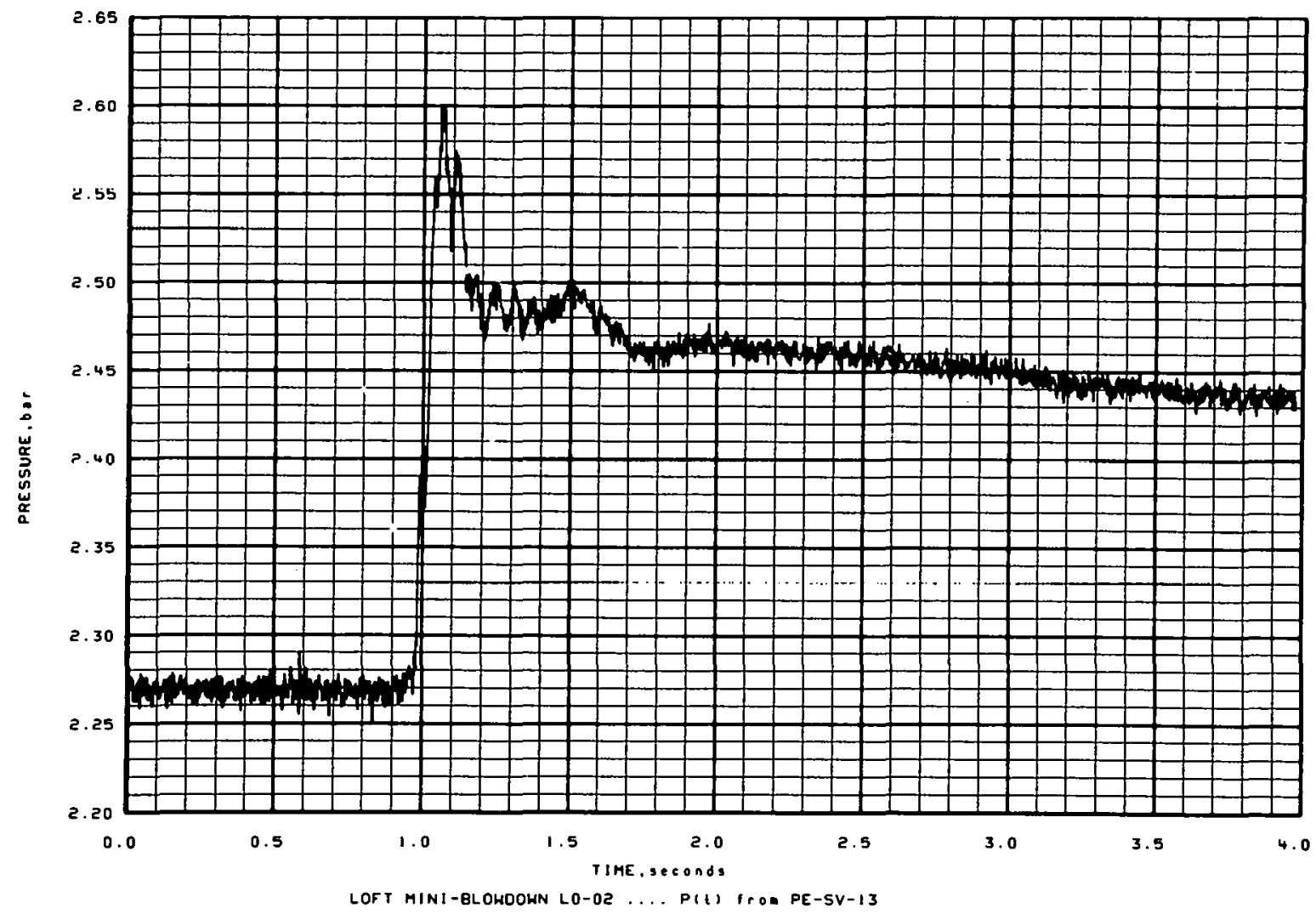

Figure A-16 

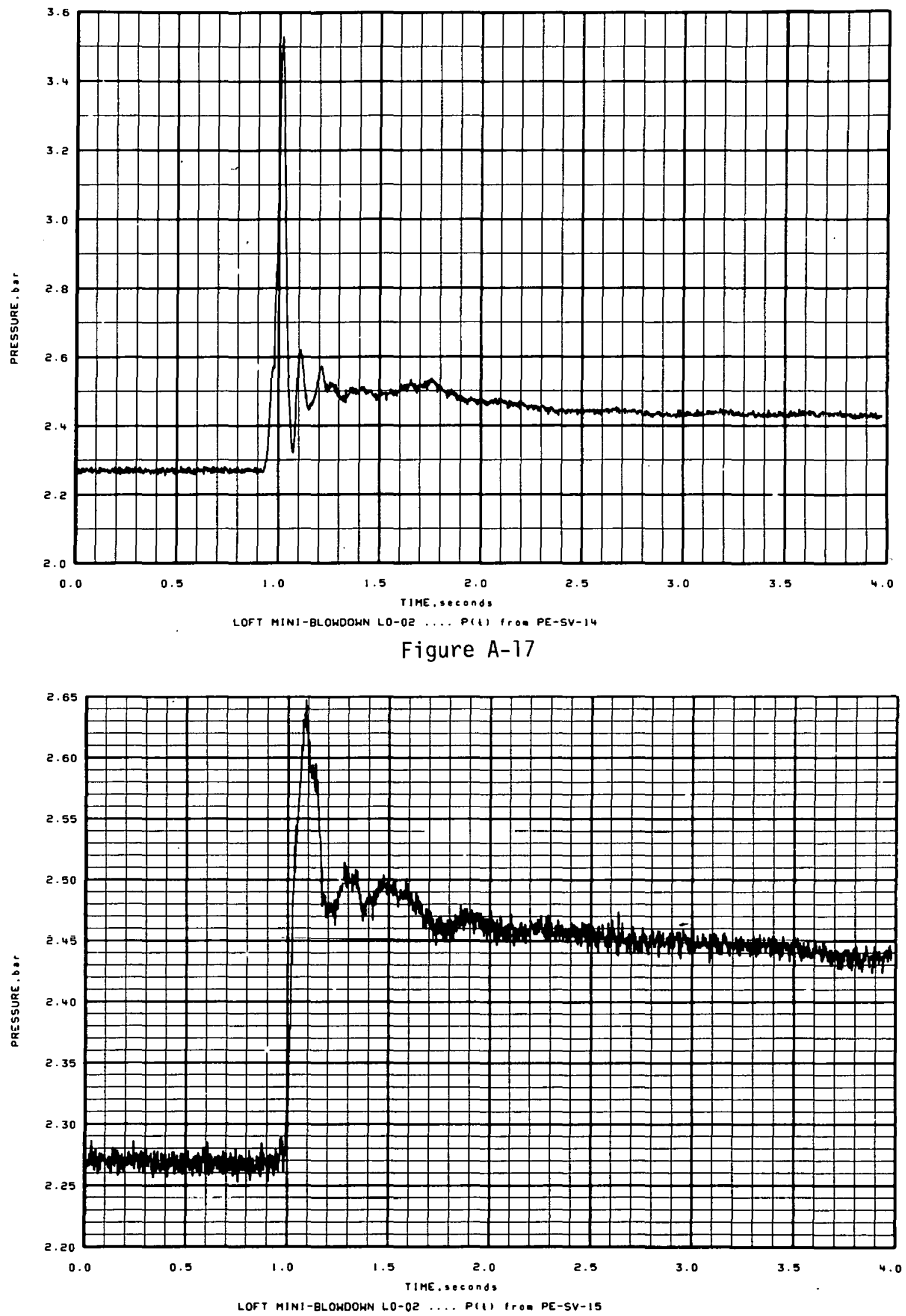

Figure $A-18$ 


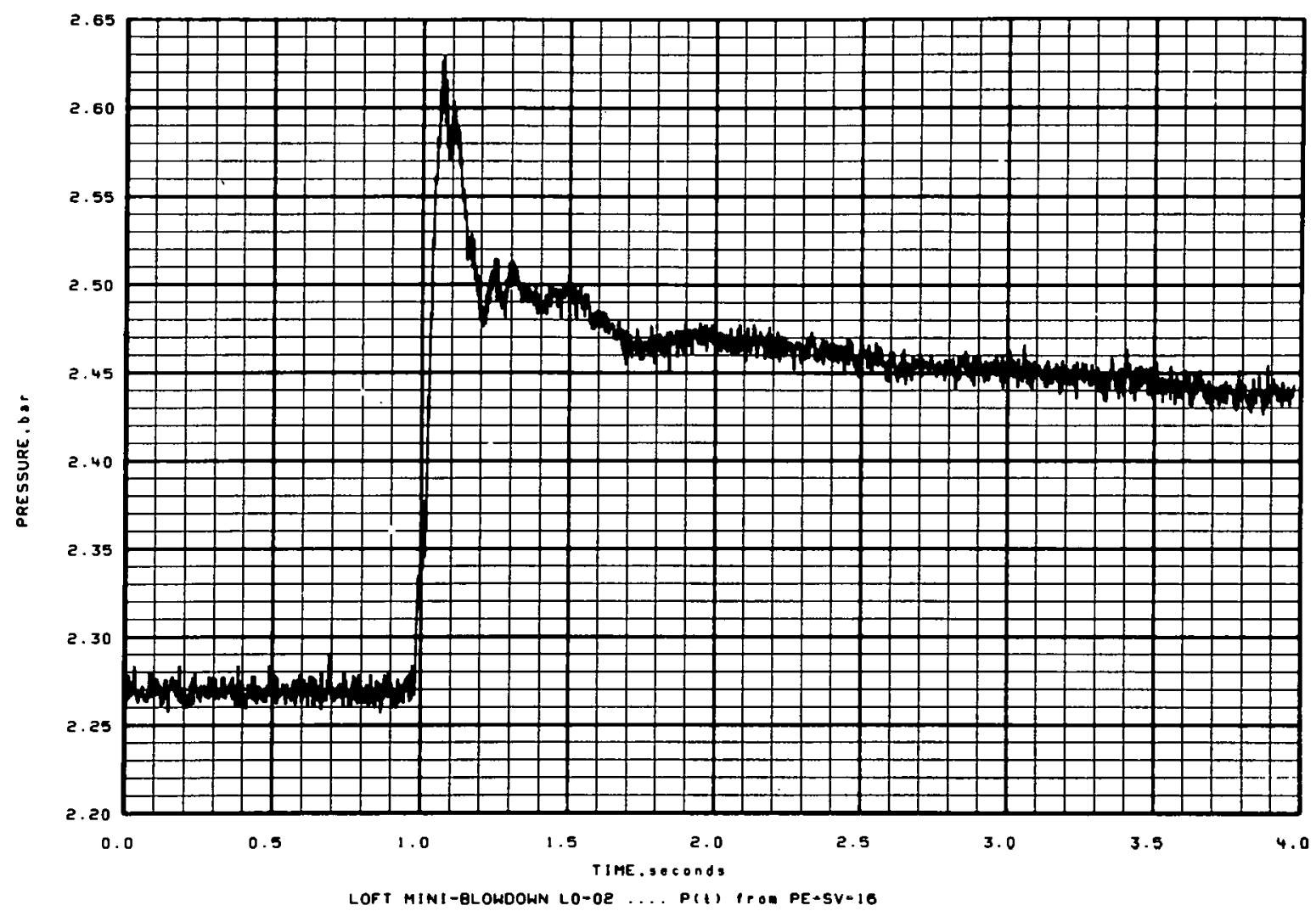

Figure A-19

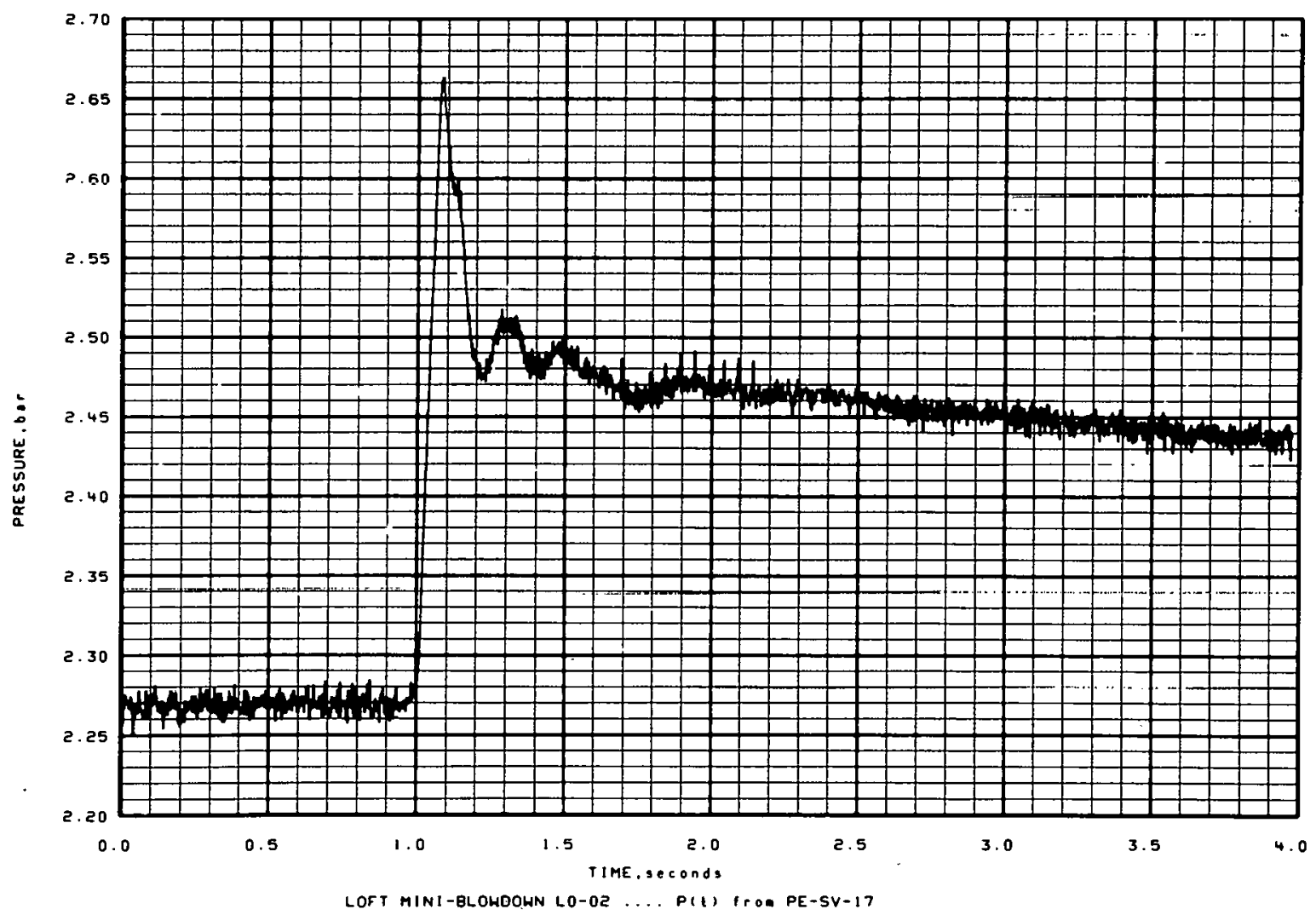

Figure $A-20$ 


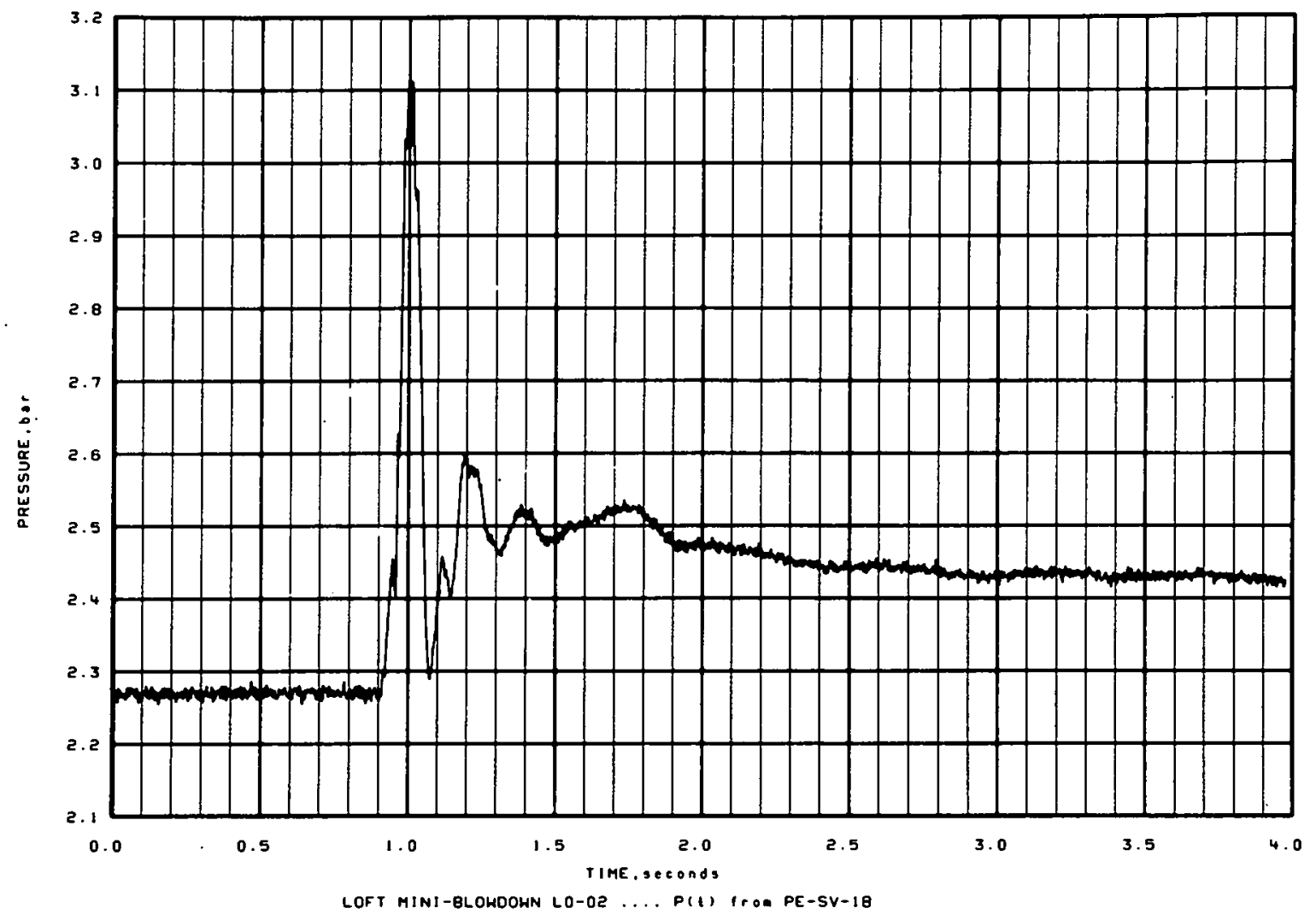

Figure A-21

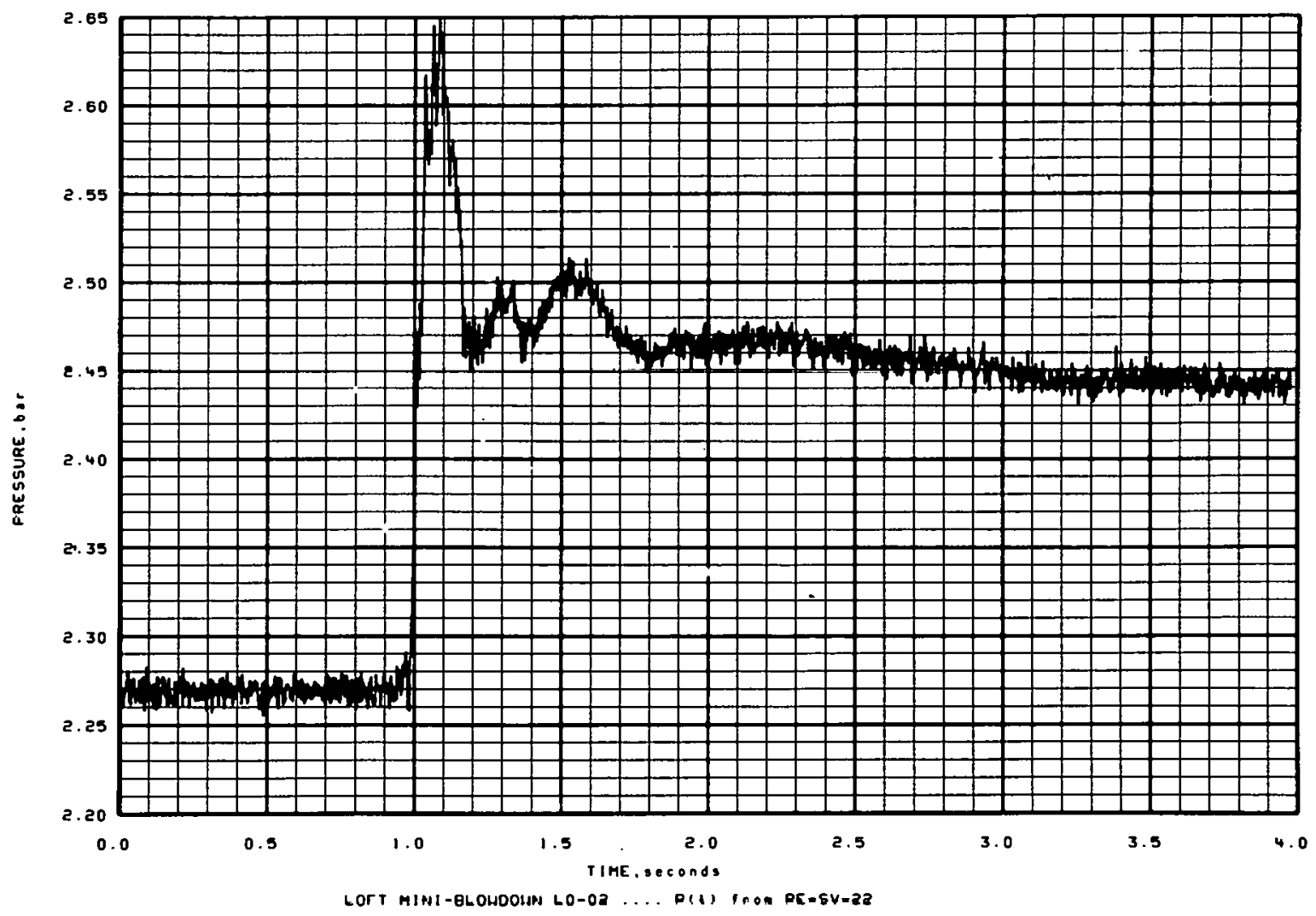

Figure A-22 


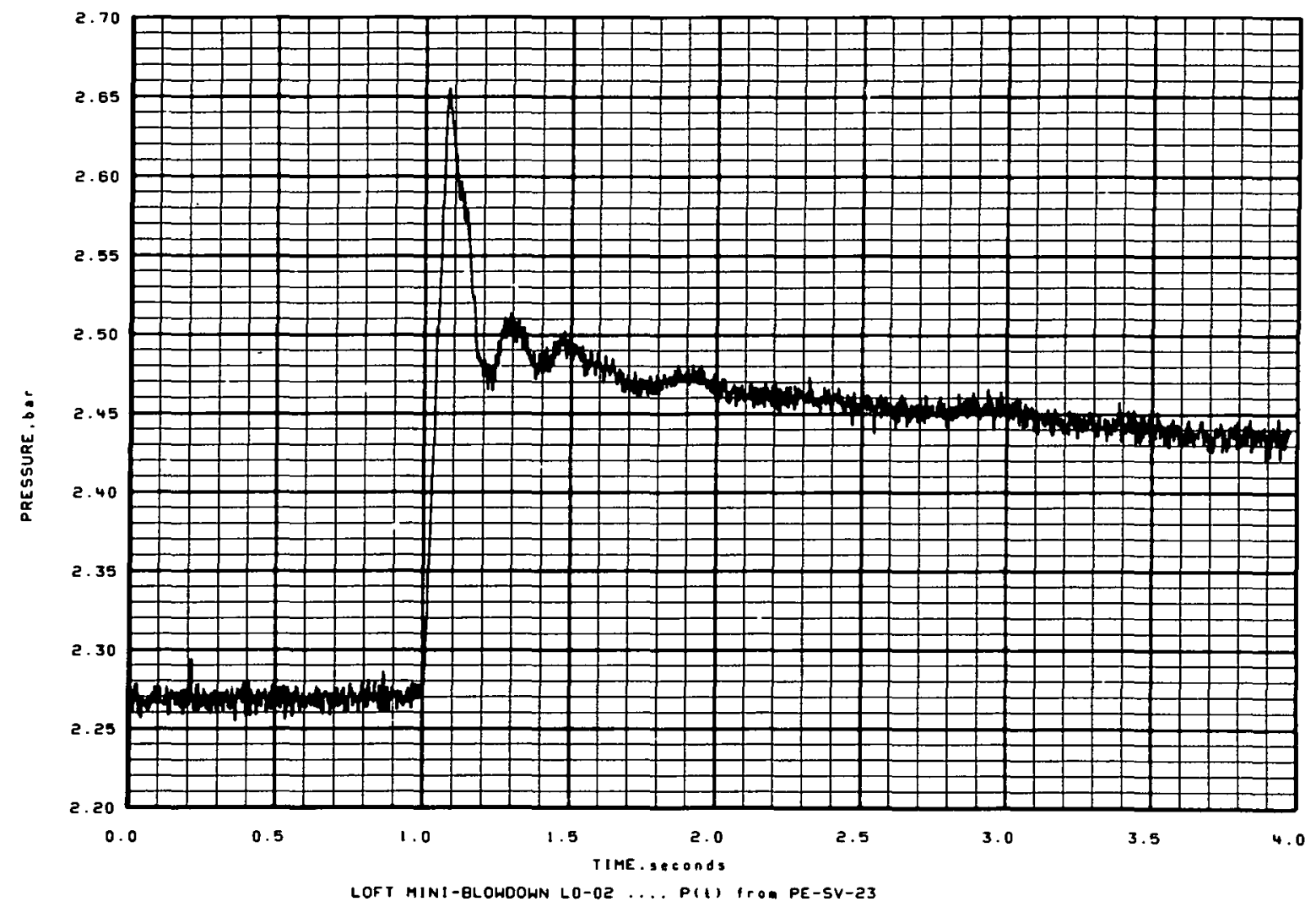

Figure $\mathrm{A}-23$

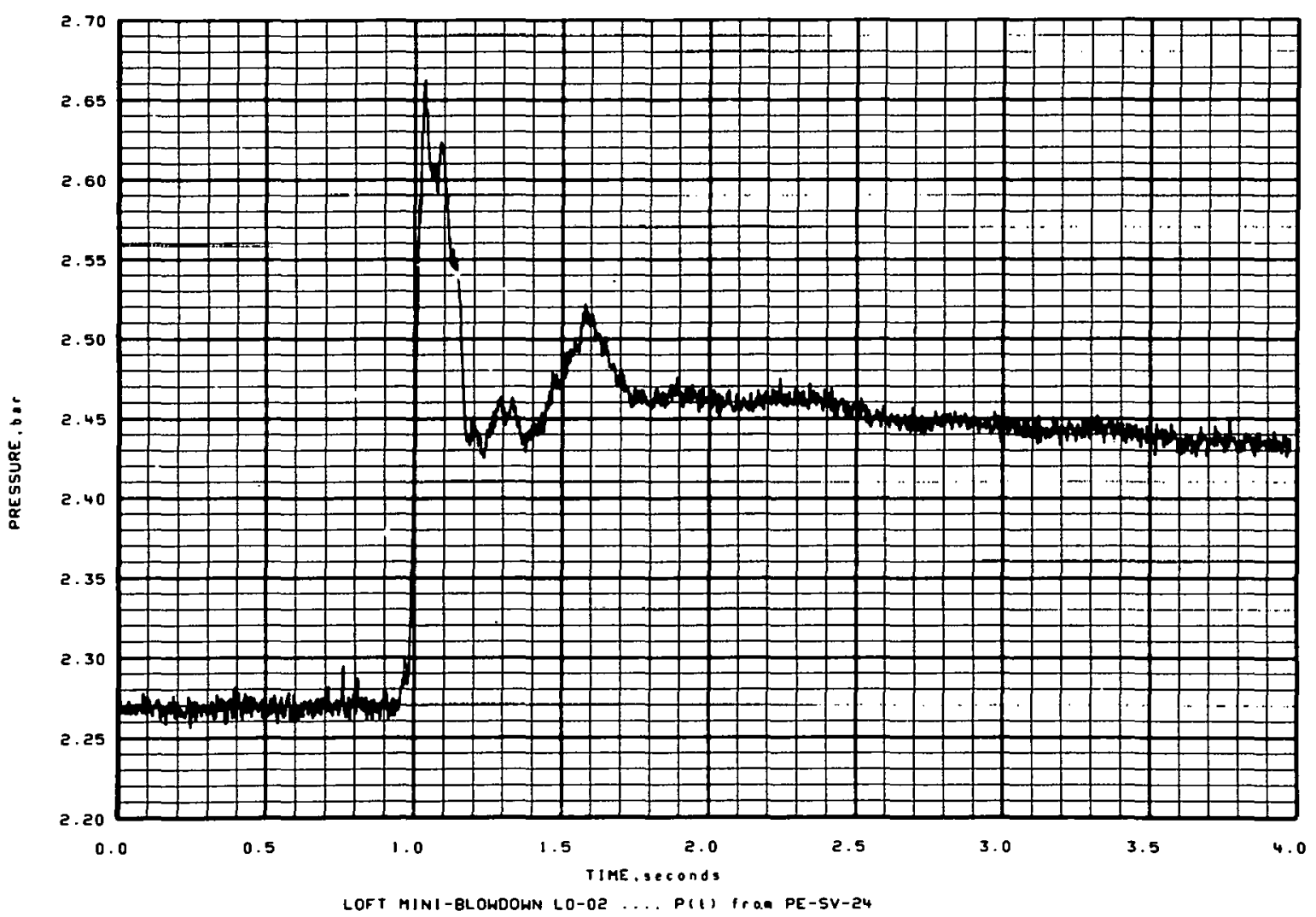

Figure A-24 


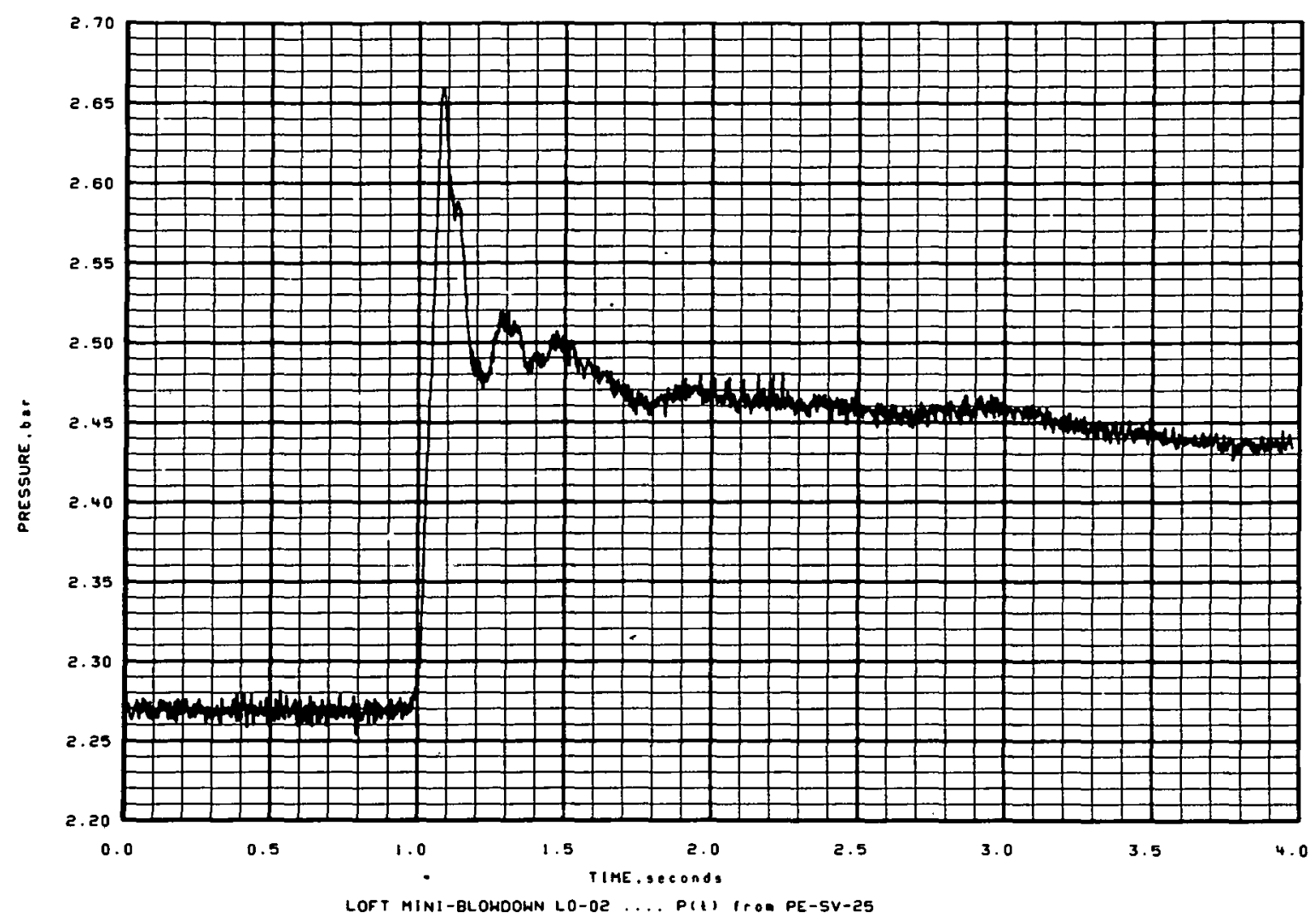

Figure A-25

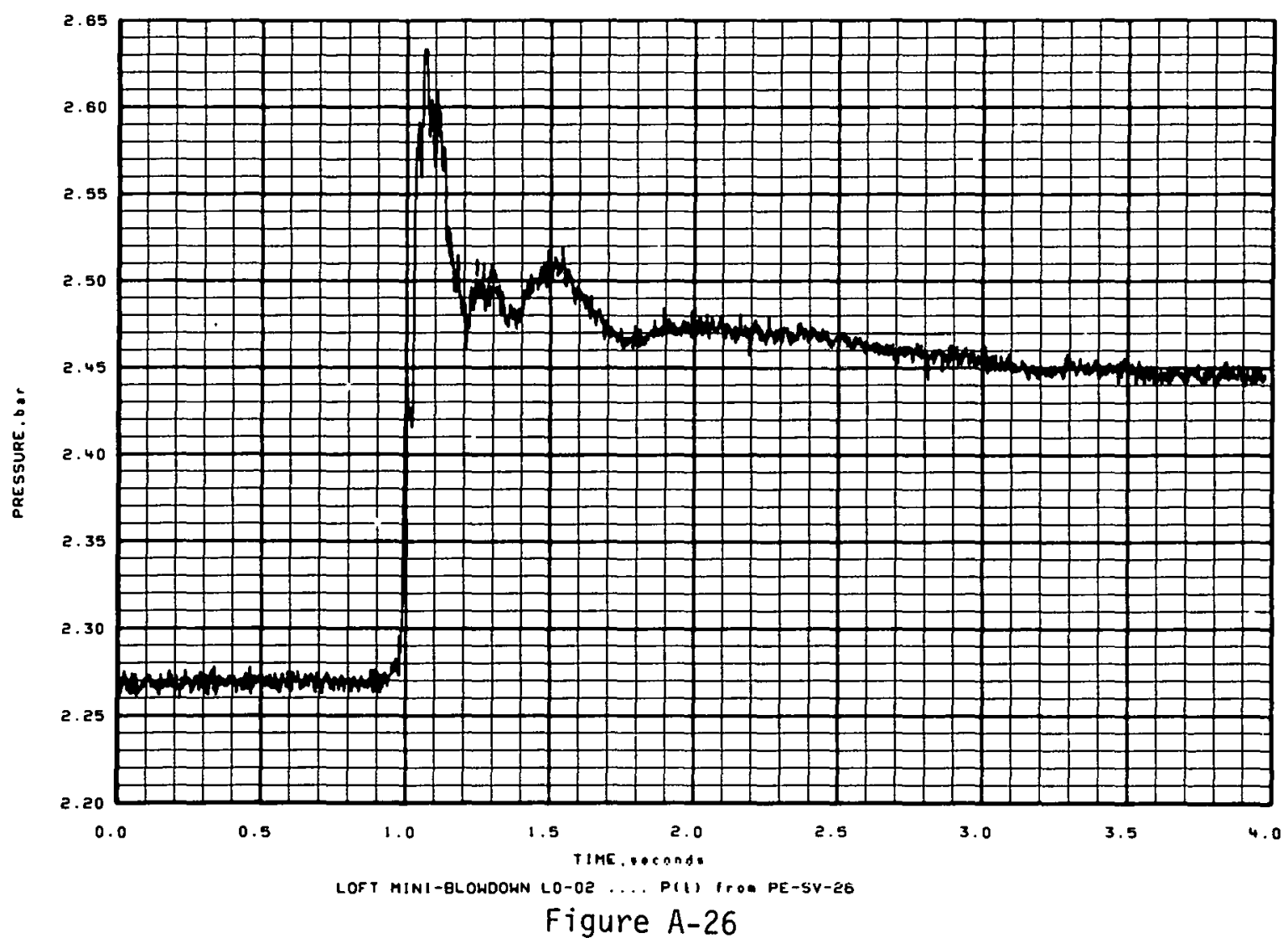




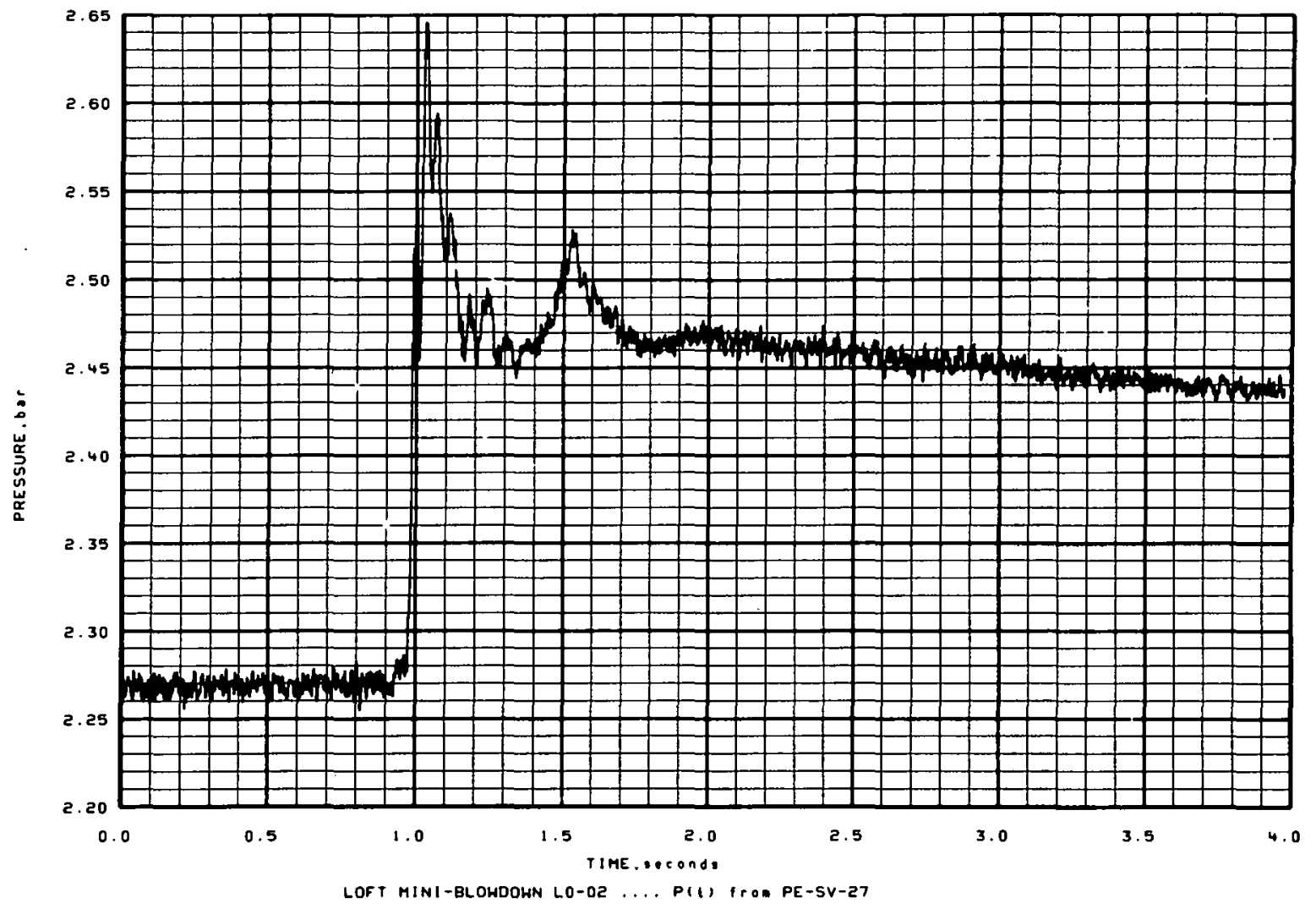

Figure $\mathrm{A}-27$

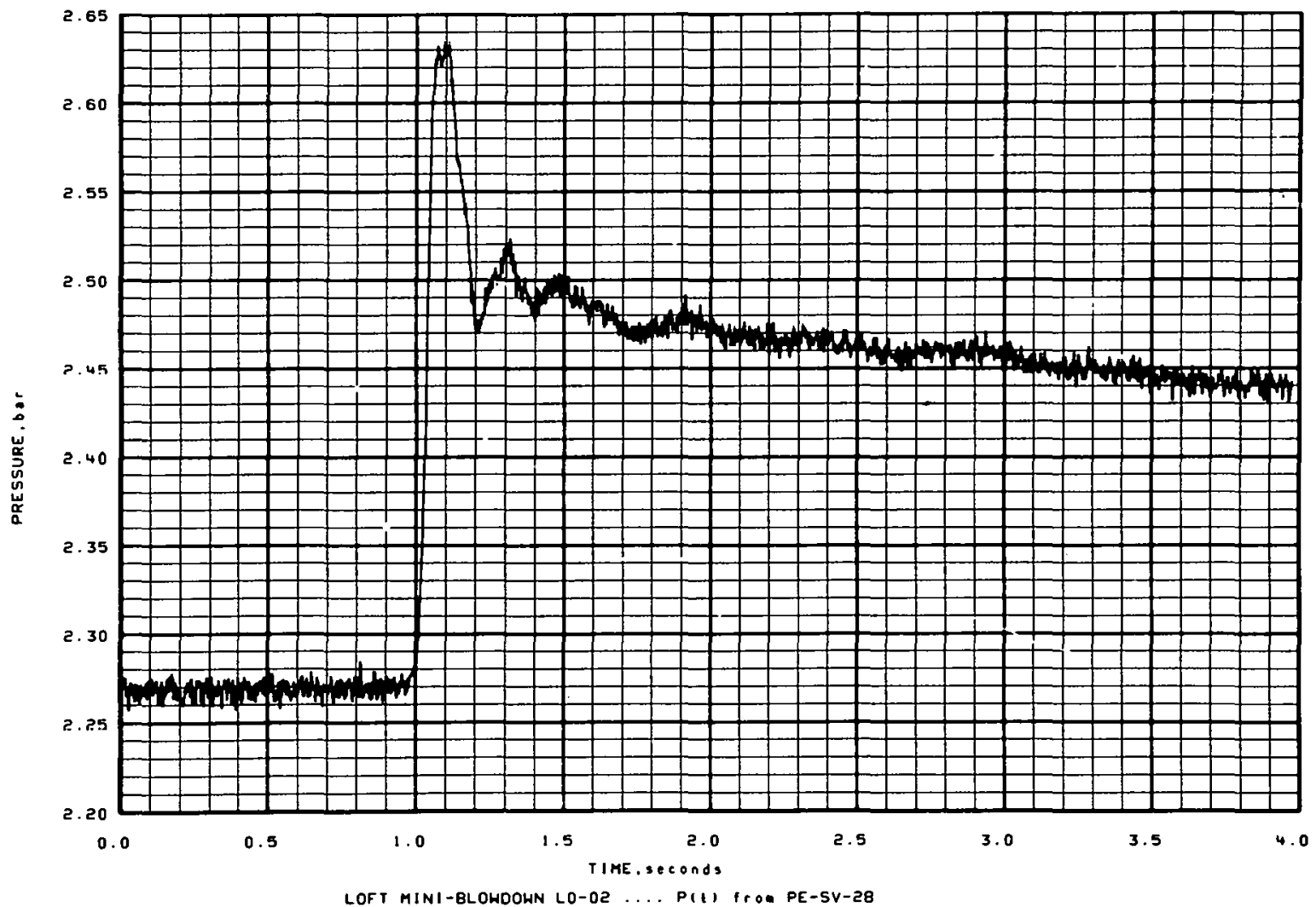

Figure $A-28$ 

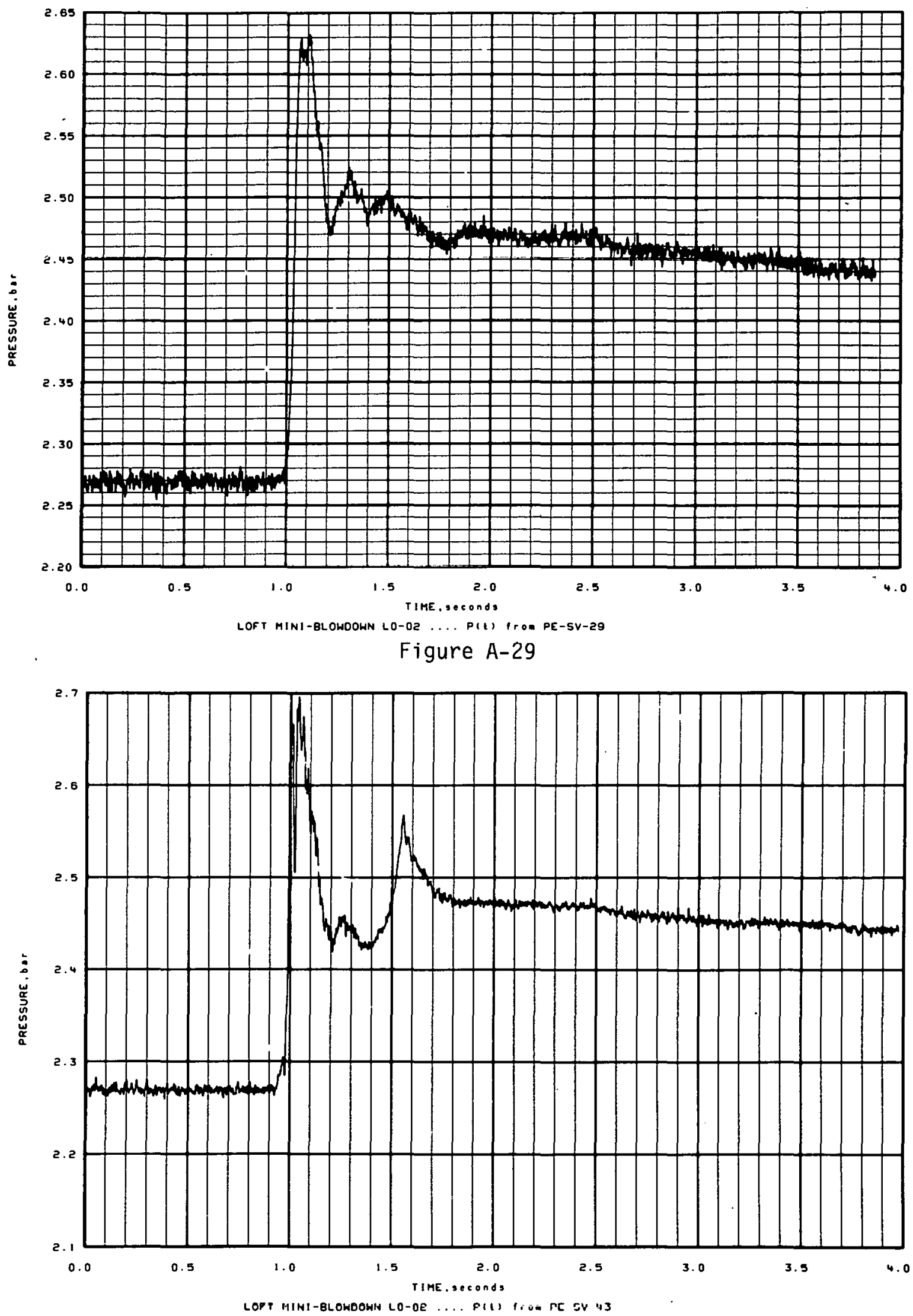

Figure $A-30$ 


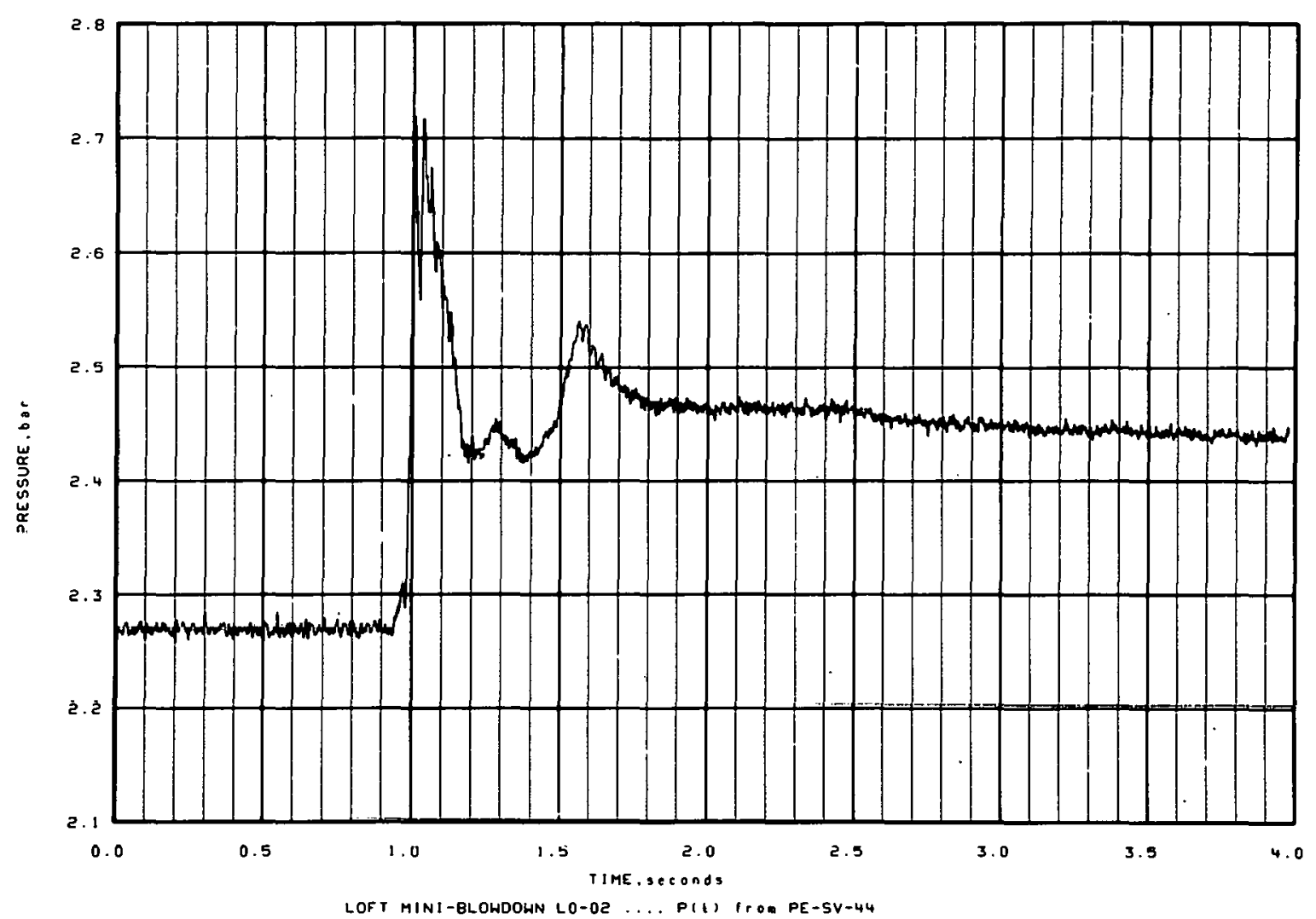

Figure A-31

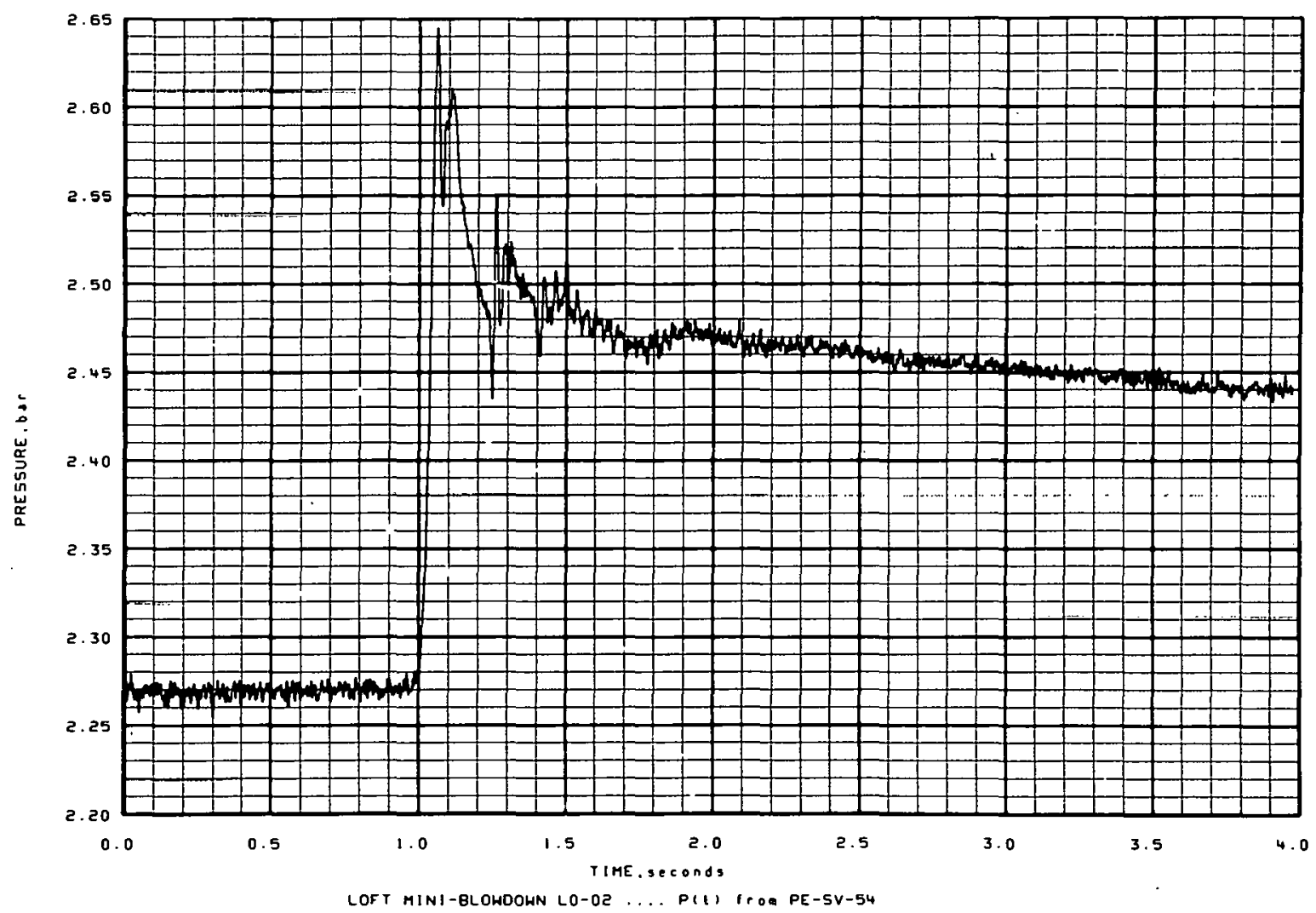

Figure A-32 


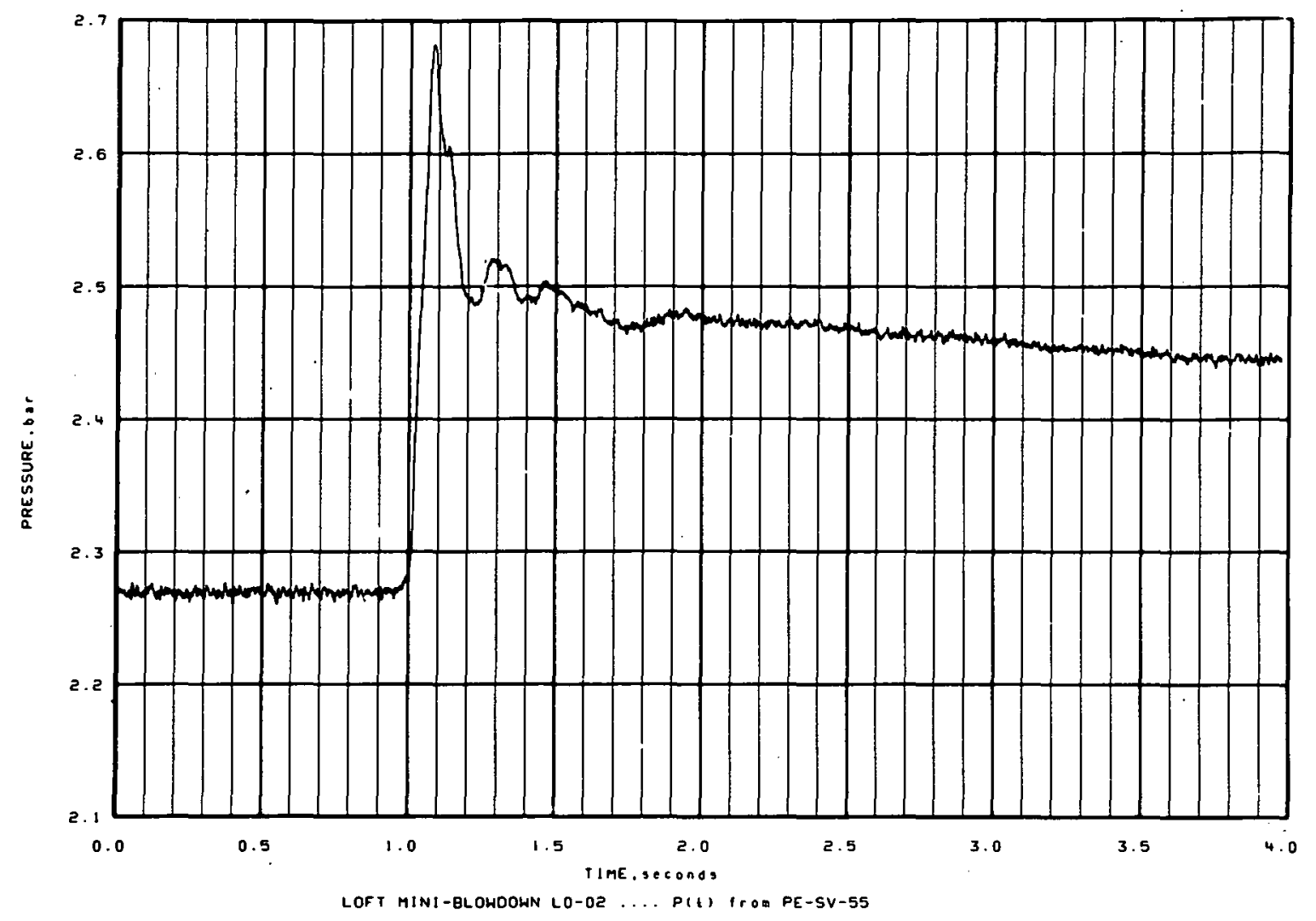

Figure A-33

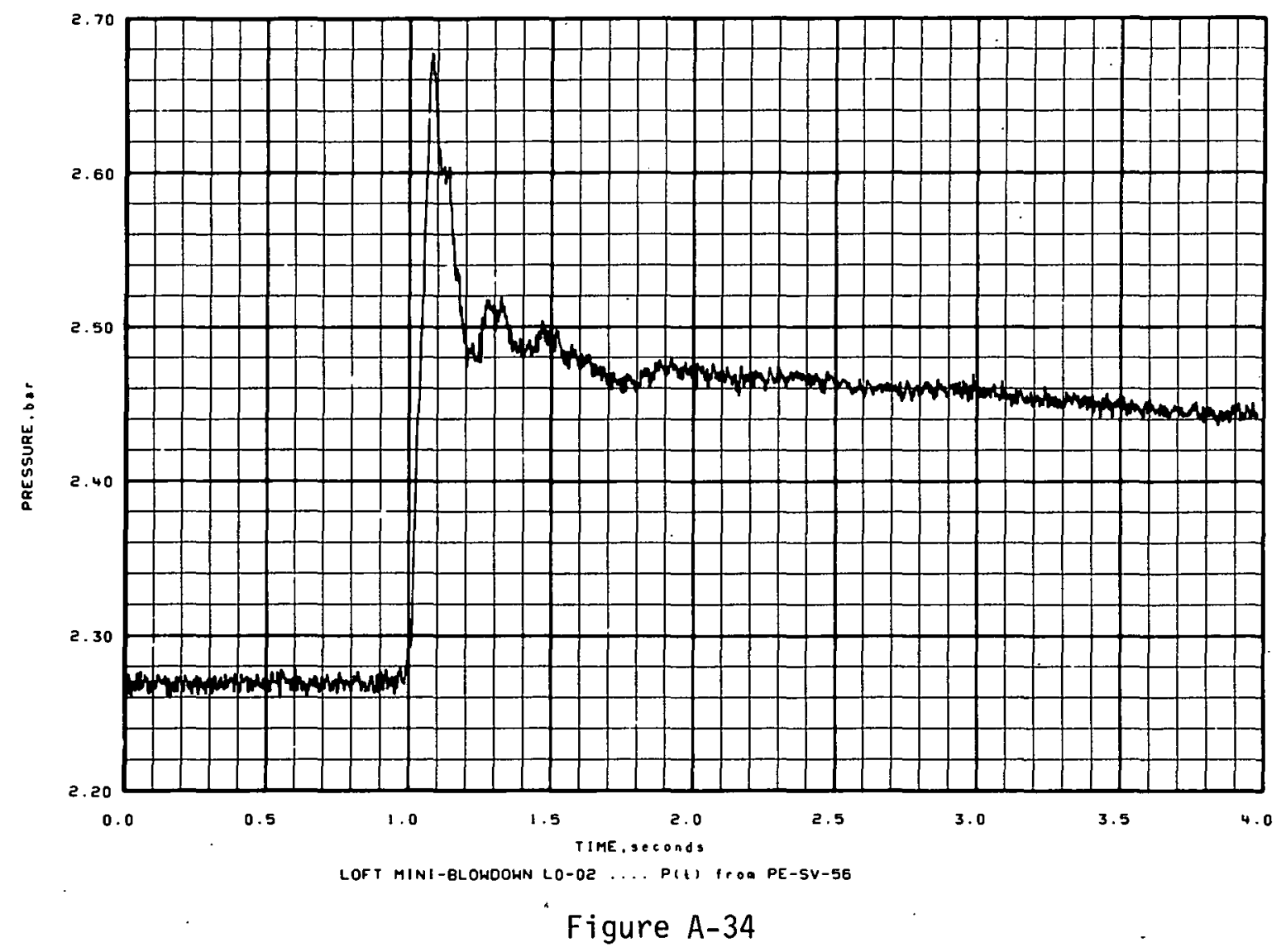




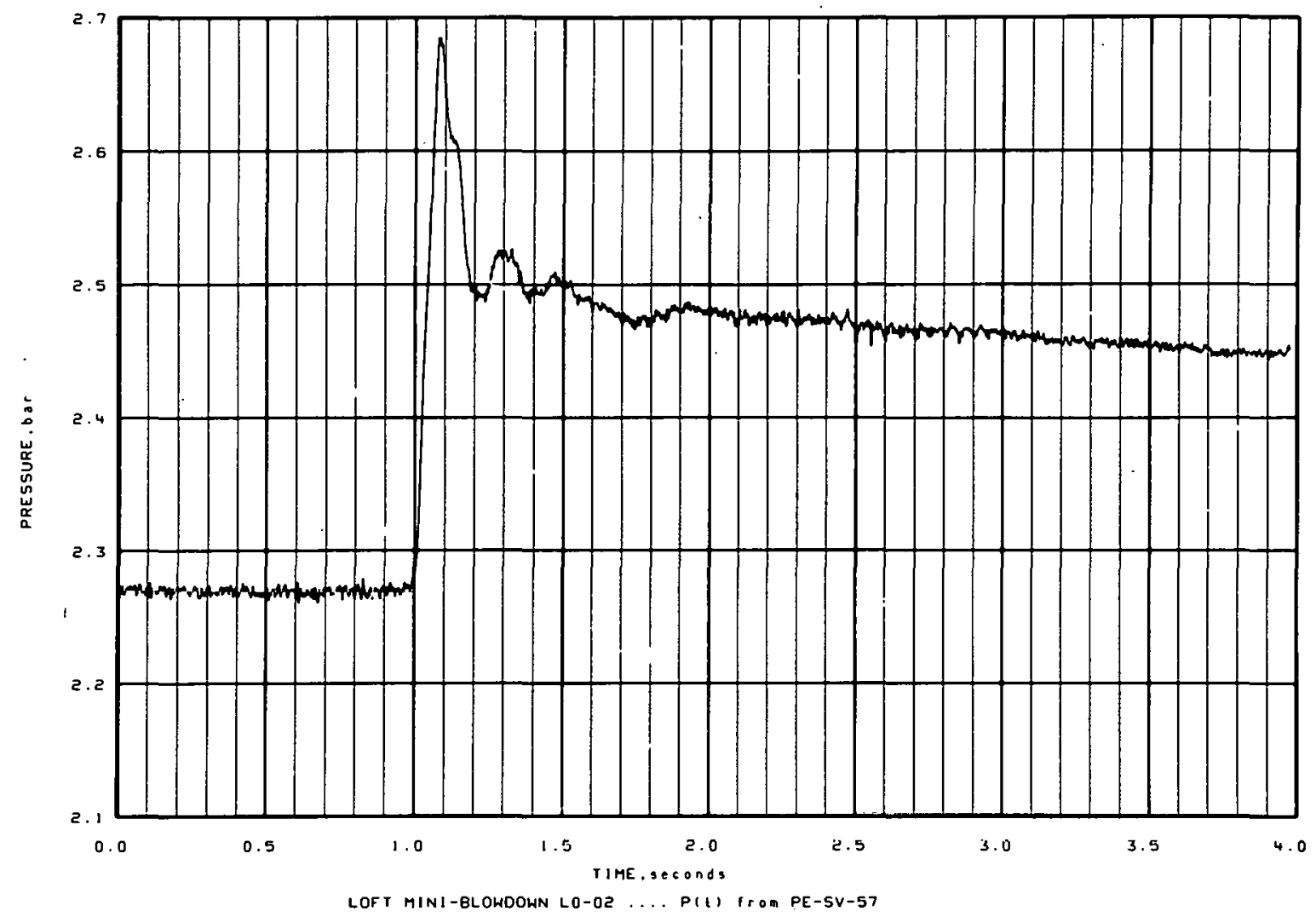

Figure $A-35$

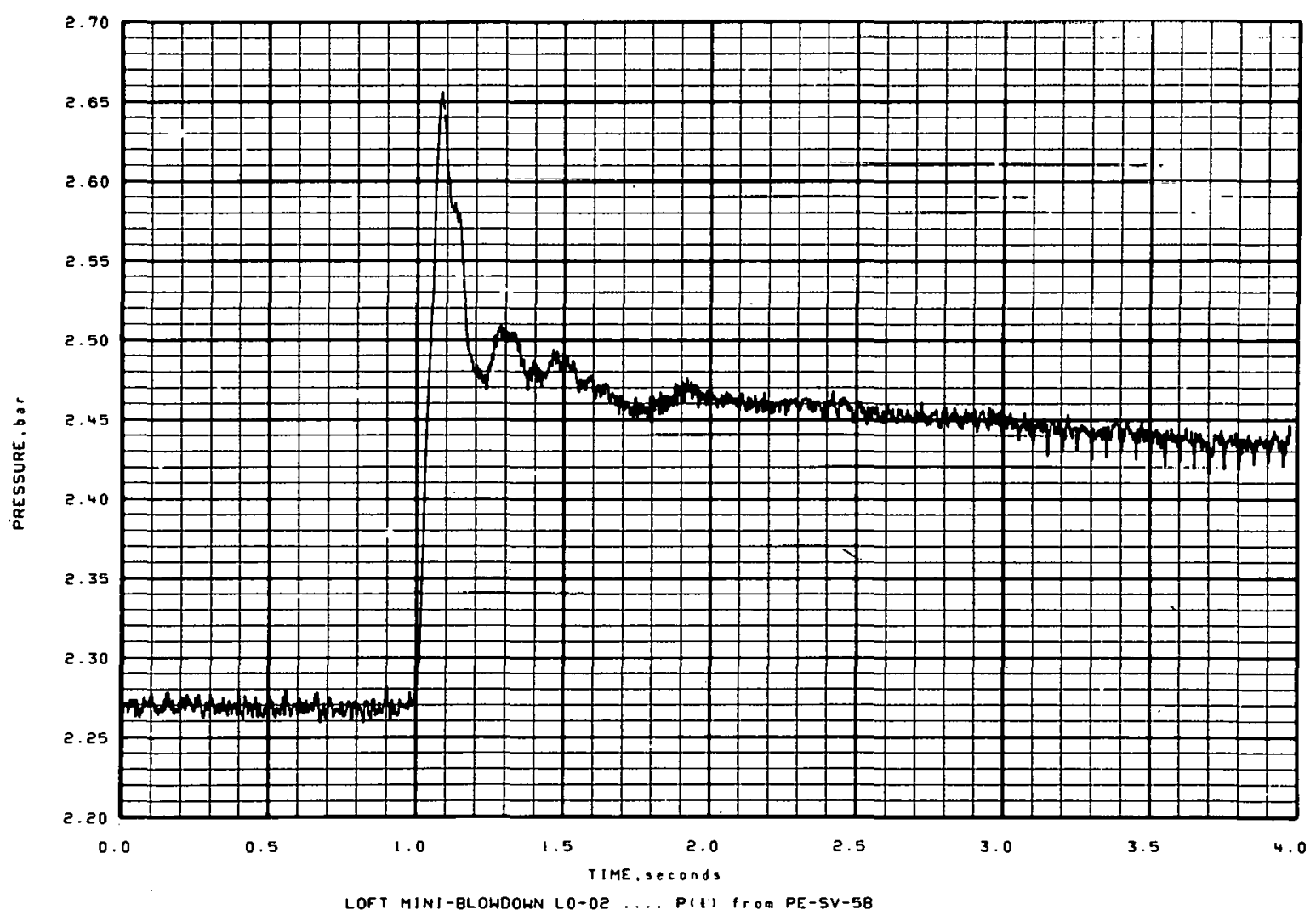

Figure A-36 


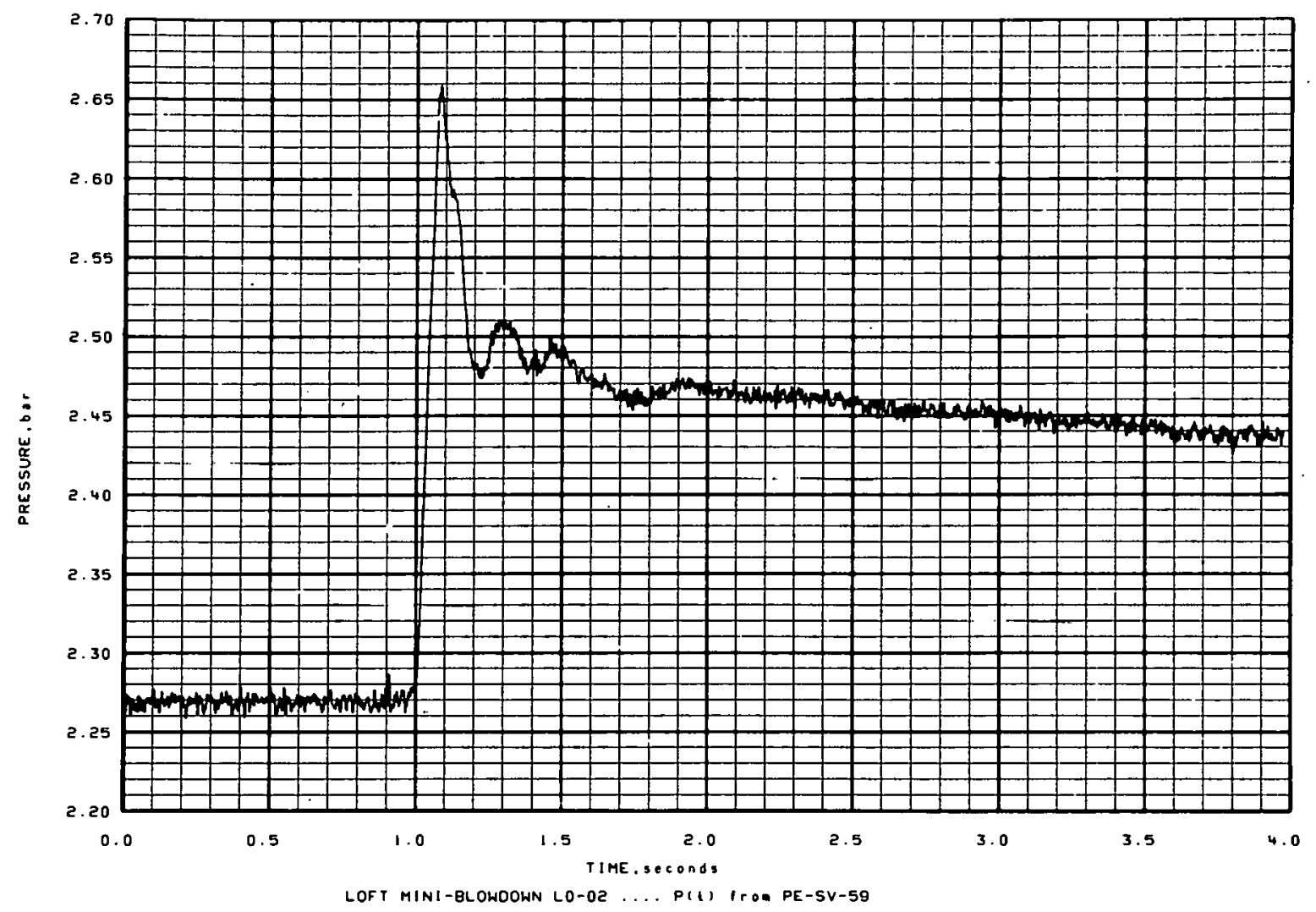

Figure A-37

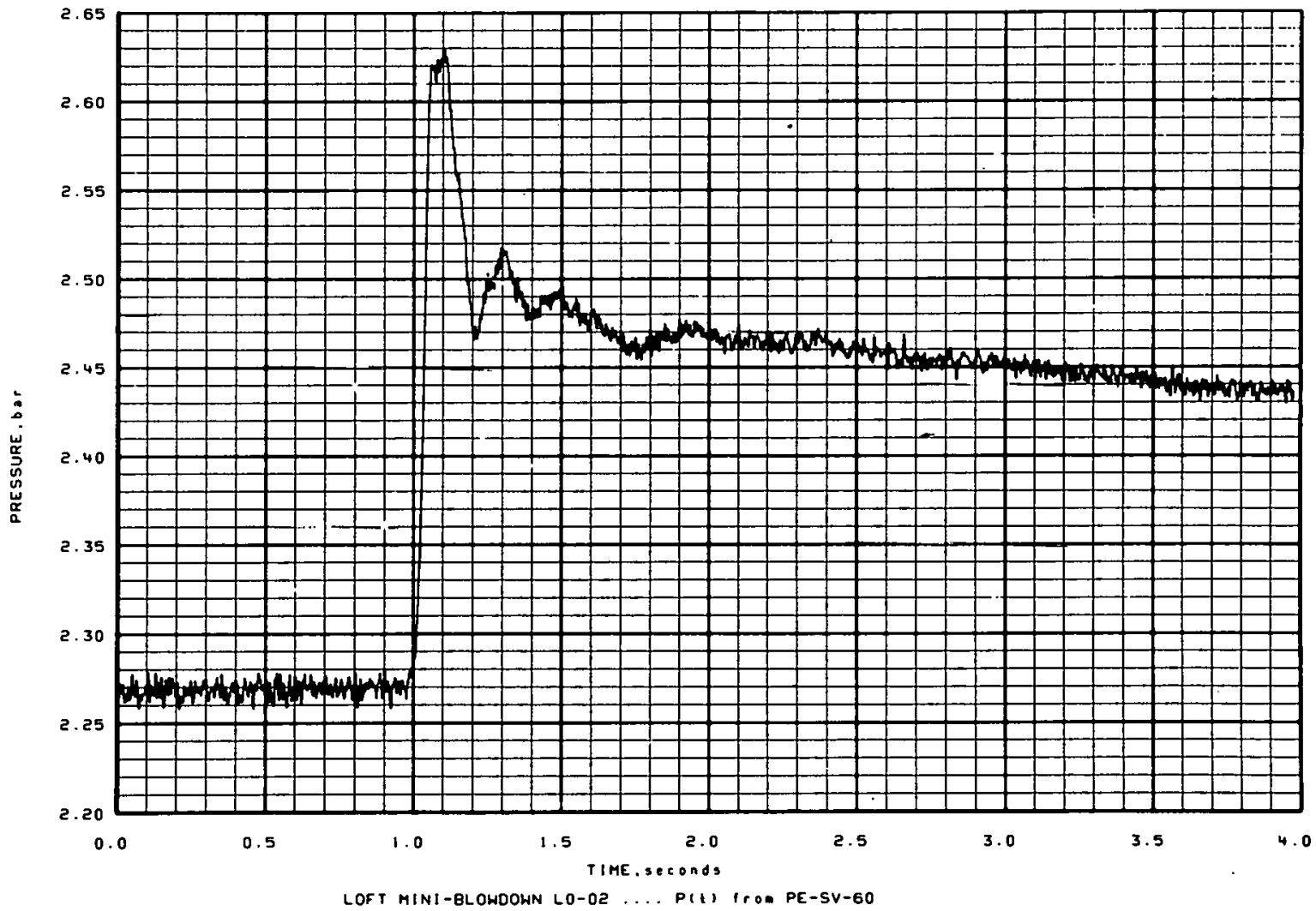

Figure A-38 


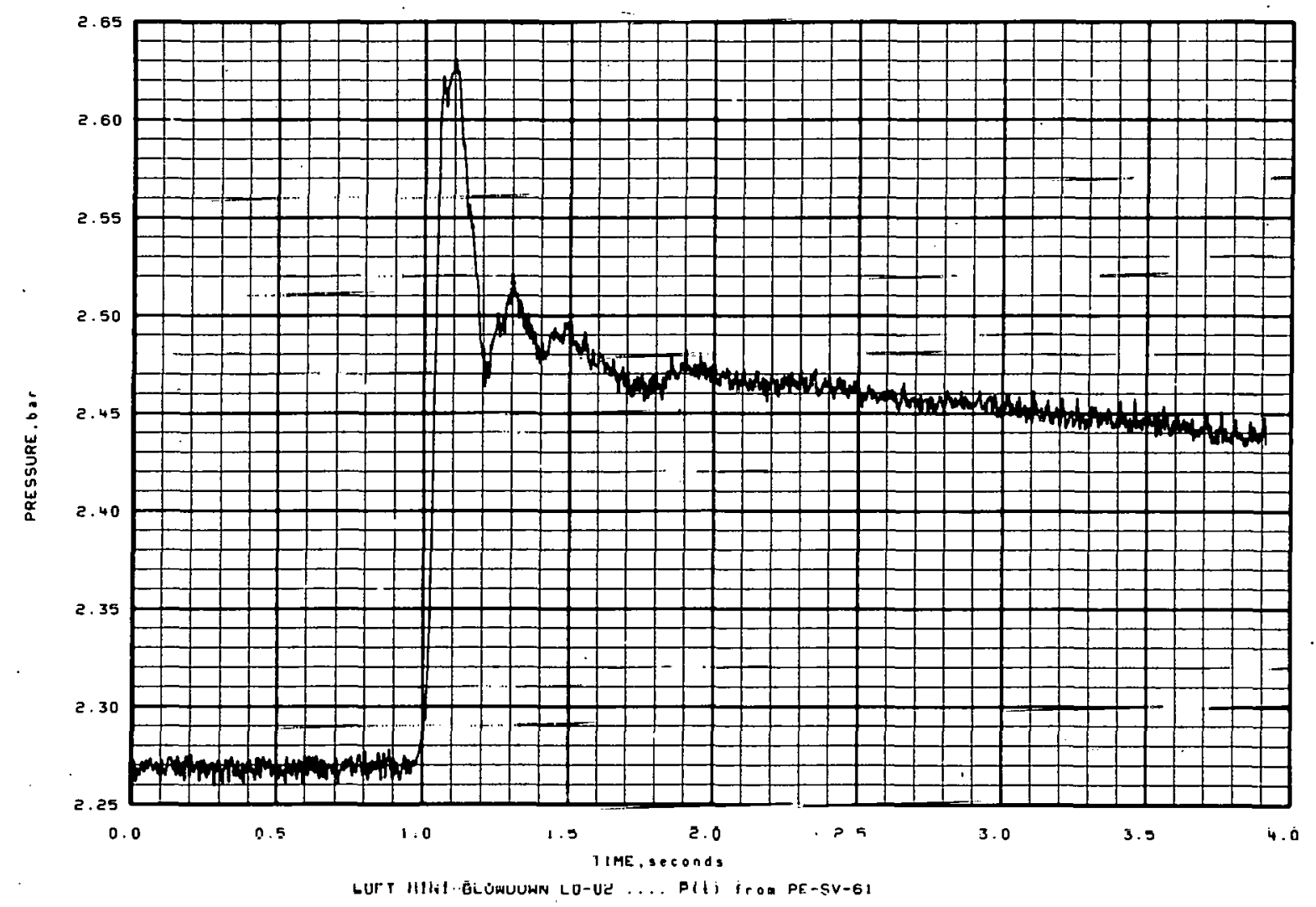

Figure A-39 
6

APPENDIX B

MINI-BLOWDOWN LO-03 EXPERIMENTAL DATA

$\because$

$<$

I

)

63 
THIS PAGE

WAS INTENTIONALLY

LEFT BLANK 


\section{MINI-BLOWDOWN LO-03 EXPERIMENTAL DATA}

Both QOBVS were to open in this experiment; however, only QOBV-15 opened. The sleeve in QOBV-15 moved only $60 \%$ of full travel. The fluid temperature in QOBV-15 was $231.3 \pm 1.5^{\circ} \mathrm{C}$. The suppression tank initial conditions wero $2.35 \pm 0.08$ bar, $3.3 .9 \pm 1.5^{\circ} \mathrm{r}$ gas vnlume temperature. and $32.6 \pm 1.5^{\circ} \mathrm{C}$ pool temperature. The vents were submerged $26.7 \pm 2.5 \mathrm{~cm}$ with an internal water level of $28.7 \pm 3.2 \mathrm{~cm}$.

The experimental data are defined in Table B-I. The opening characteristics of the QOBVs are shown in terms of percent sleeve travel versus time. The flow area of the valve begins to open at a sleeve position of $17 \%$ of full travel and is fully open at a sleeve position of $66 \%$ of full travel. The differential pressure between the header and the tank gas volume is measured with a very sensitive device primarily to provide information on vent preclearing. The data channel for this measurement is driven to saturation in the early part of the transient. 
TABLE B-I

EXPERIMENT L0-03 DATA SUMMARY

\begin{tabular}{|c|c|c|c|c|c|}
\hline $\begin{array}{l}\text { Measurement } \\
\text { or } \\
\text { Calculation }\end{array}$ & $\begin{array}{l}\text { Pre-Transient } \\
\text { Data Channel } \\
\text { Variance } \\
\left(10^{-4} \text { bar }^{2}\right)\end{array}$ & Figure Number. & Measurement & $\begin{array}{c}\text { Pre-Transient } \\
\text { Data Channel } \\
\text { Variance } \\
\left(10^{-4} \text { bar }^{2}\right) \\
\end{array}$ & Figure Number \\
\hline QOBV-1 opening & $\therefore \quad-$ & $B-1, B-2$ & PE-SV-22 & 0.45152 & $B=22$ \\
\hline QUBV-15 opening & - & $B-3, B-4$ & PE-SV-23 & 0.44105 & B-23 \\
\hline $\begin{array}{l}\text { Cumbined ROBV } \\
\text { opening }\end{array}$ & : & $B-E, D-C$ & P'E $\ldots Y-24$ & 0.26401 & $B-24$ \\
\hline Vertical load & 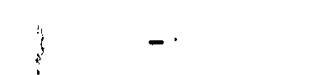 & $B-7$ & $P E-S V-25$ & 0.27930 & $B-25$ \\
\hline PDE-SV-09 & $\therefore \quad-$ & $B-8$ & $P E-S V-26$ & 0.27 .056 & $B-26$ \\
\hline PE-SV-01 & 0.56854 & $B-9$ & $P E-S V-27$ & 0.52025 & $B-27$ \\
\hline PE-SV-02 & 0.50459 & $B-10$ & PE-SV-28 & 0.44373 & $B-28$ \\
\hline PE-SV-03 & 0.45872 & $B-1.1$ & PE-SV-29 & 0.36506 & $B-29$ \\
\hline PE-SV-04 & 0.48583 & $B-12$ & PE-SV-43 & 0.21367 & $B-30$ \\
\hline$P E-S V-10$ & 0.32326 & $B-13$ & PE-SV-44 & 0.32526 & B- -31 \\
\hline PE..SV..11 & 1.0580 & $B-14$ & $P E-S V=54$ & 0.18526 & $B-32$ \\
\hline PE-SV-12 & 0.35020 & $B-15$ & PE-SV-55 & 0.07944 & B- -33 \\
\hline PE-SV-13 & 0.21353 & B- 16 & PE-SV-56 & 0.18983 & $B-34$ \\
\hline PE-SV-14 & 0.27439 & $B-17$ & PE-SV-57 & 0.17348 & B- -35 \\
\hline PE-SV-15 & 0.35717 & $B-18$ & PE-SV-58 & 0.28687 & $B-36$ \\
\hline PE-SV-16 & 0.32035 & $B-19$ & PE-SV-59 & 0.18835 & $B-37$ \\
\hline HE-SV-1/ & $0.33 \% 64$ & $B-20$ & PE-SV-60. & 0.22109 & $B-38$ \\
\hline PF-SV-18 & 0.32737 & $R-2:]$ & $P E-S V-61$ & 0.22190 & $\mathrm{~B}-39$ \\
\hline
\end{tabular}



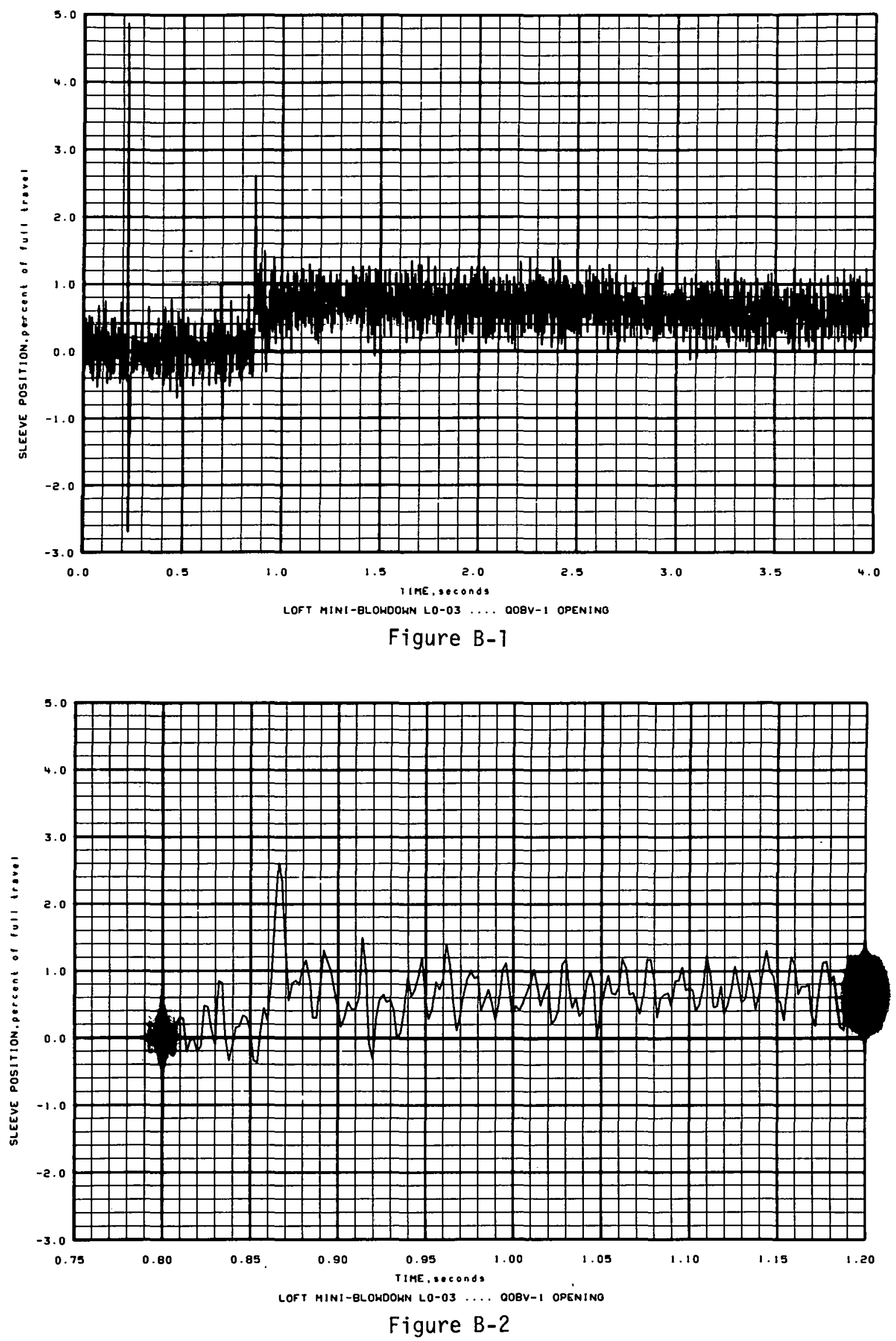

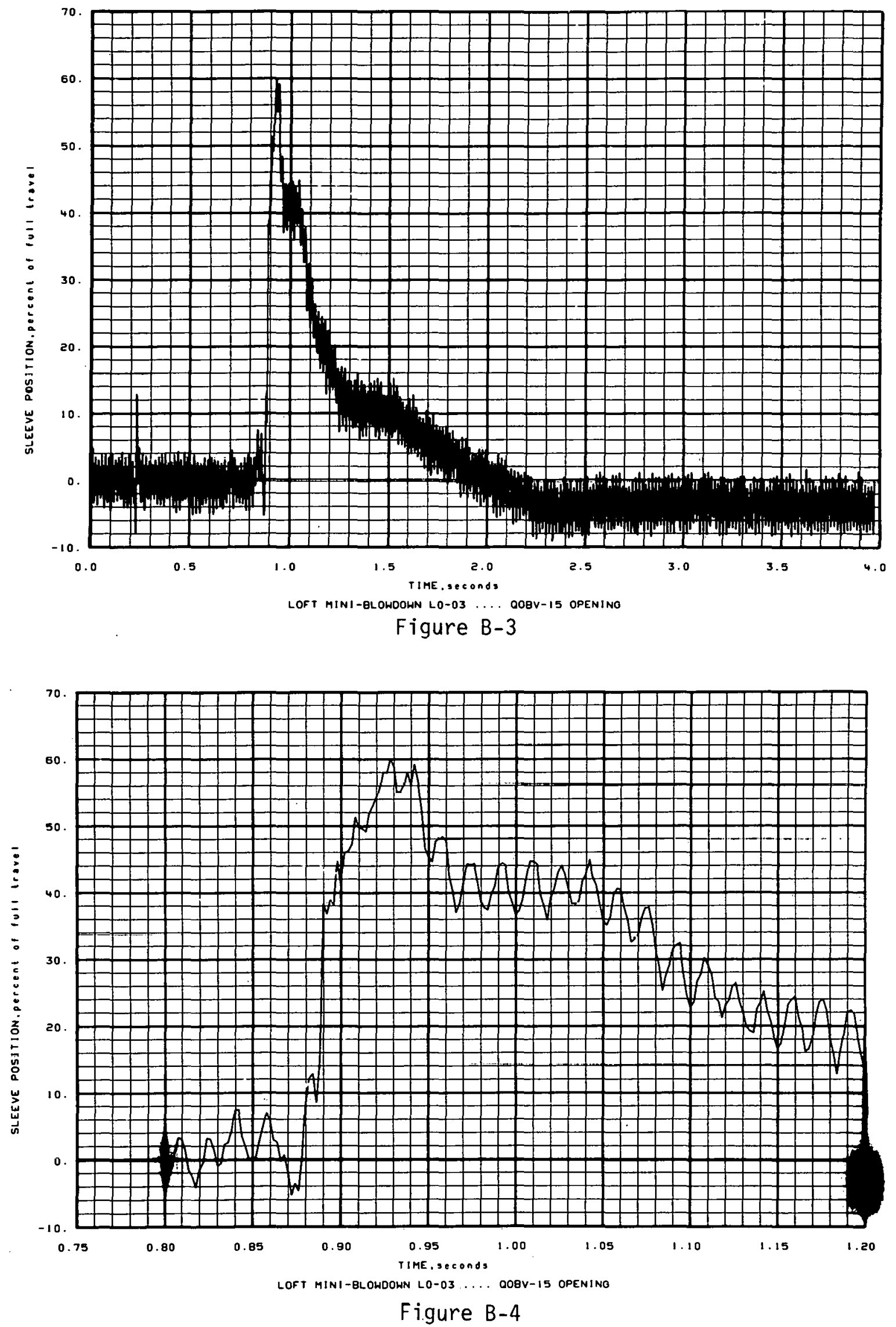


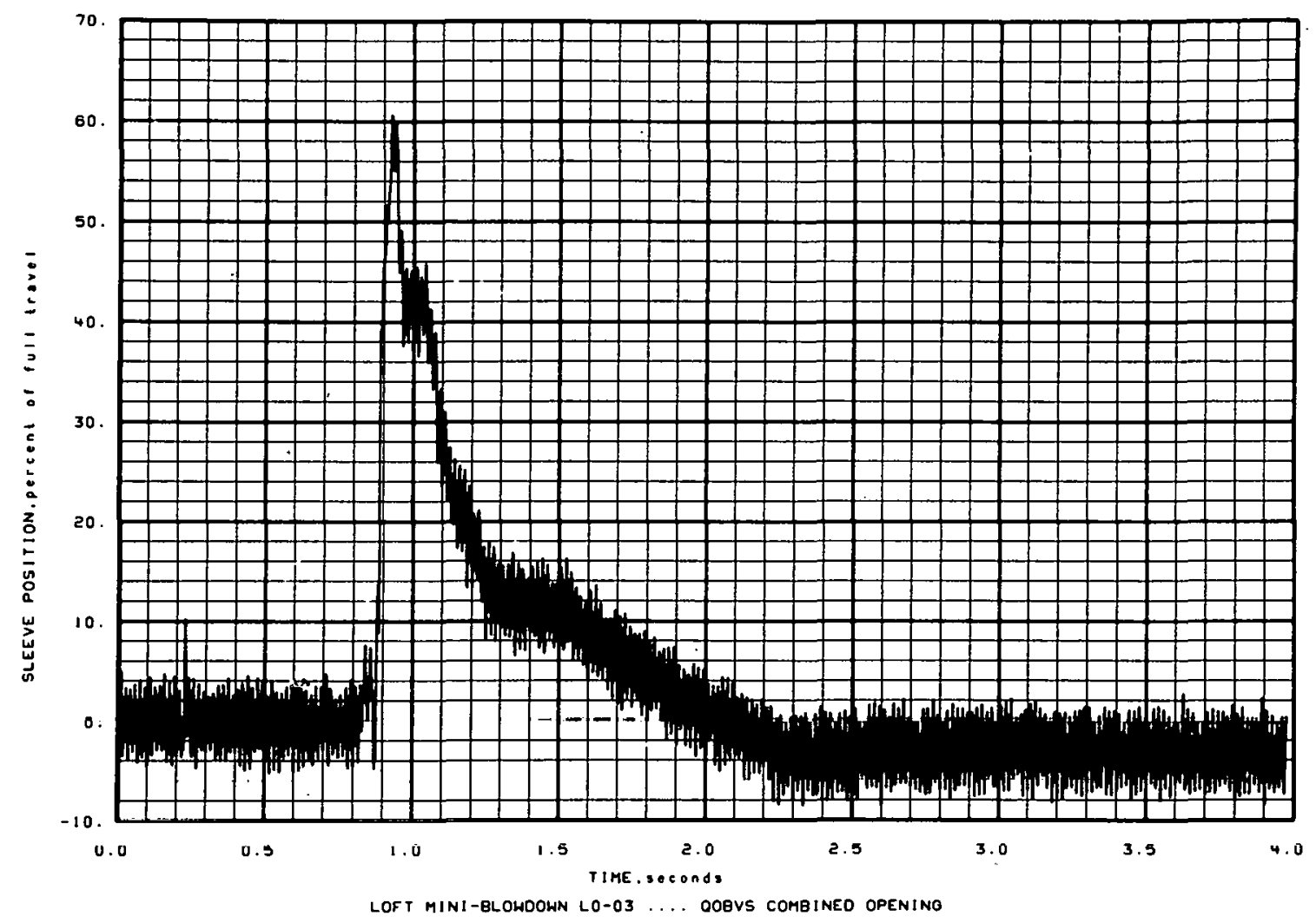

Figure B-5

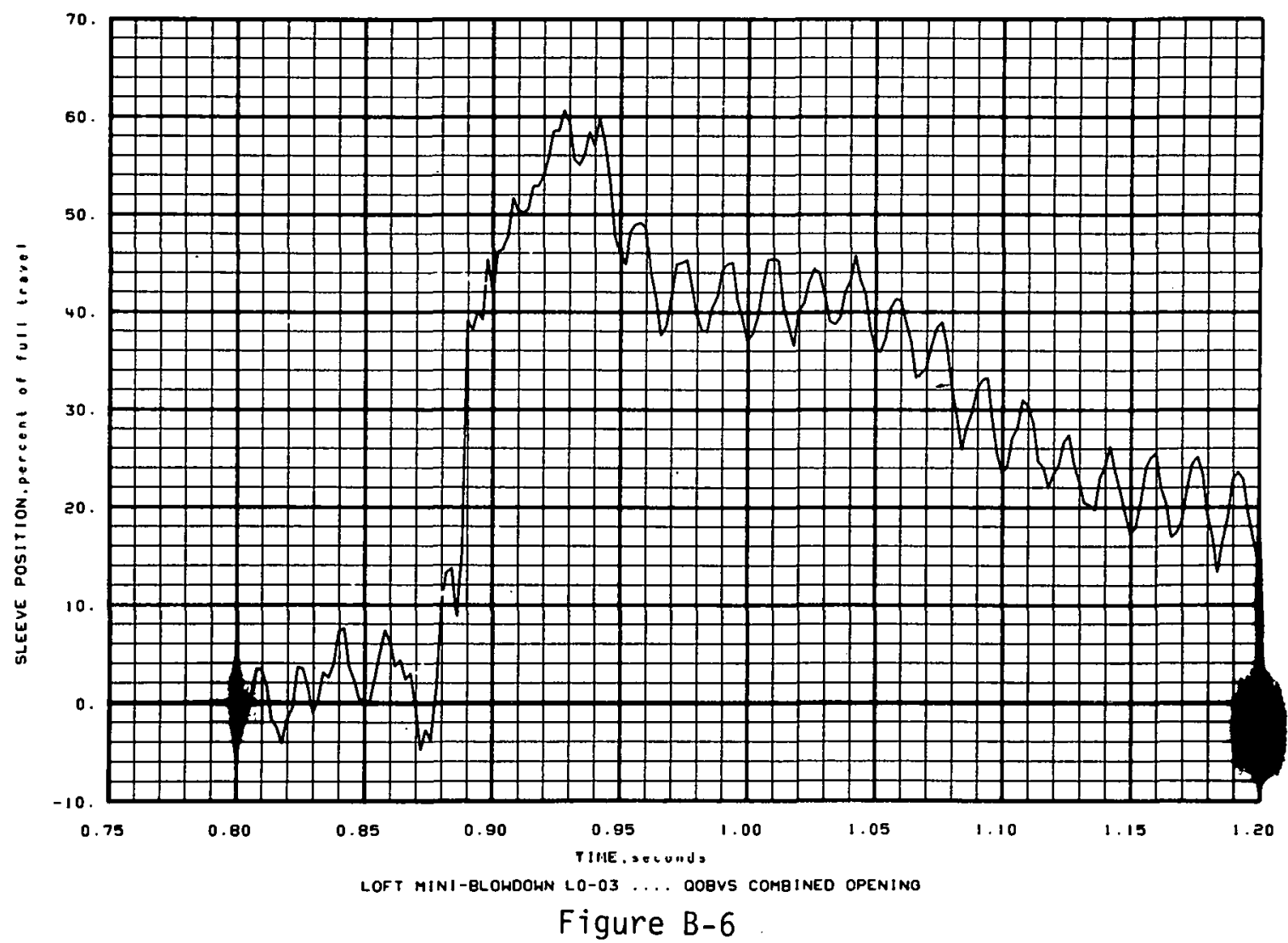




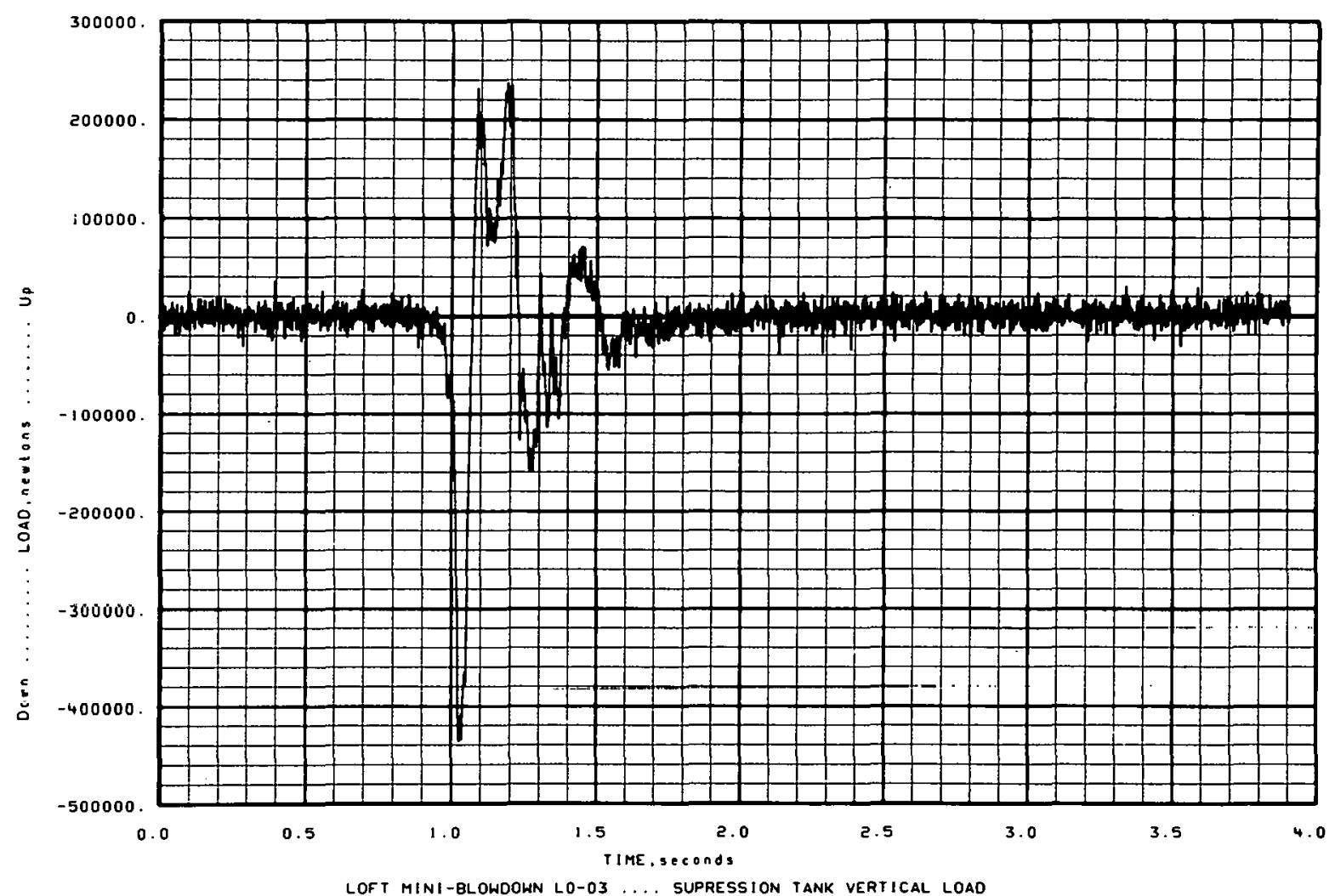

Figure B-7

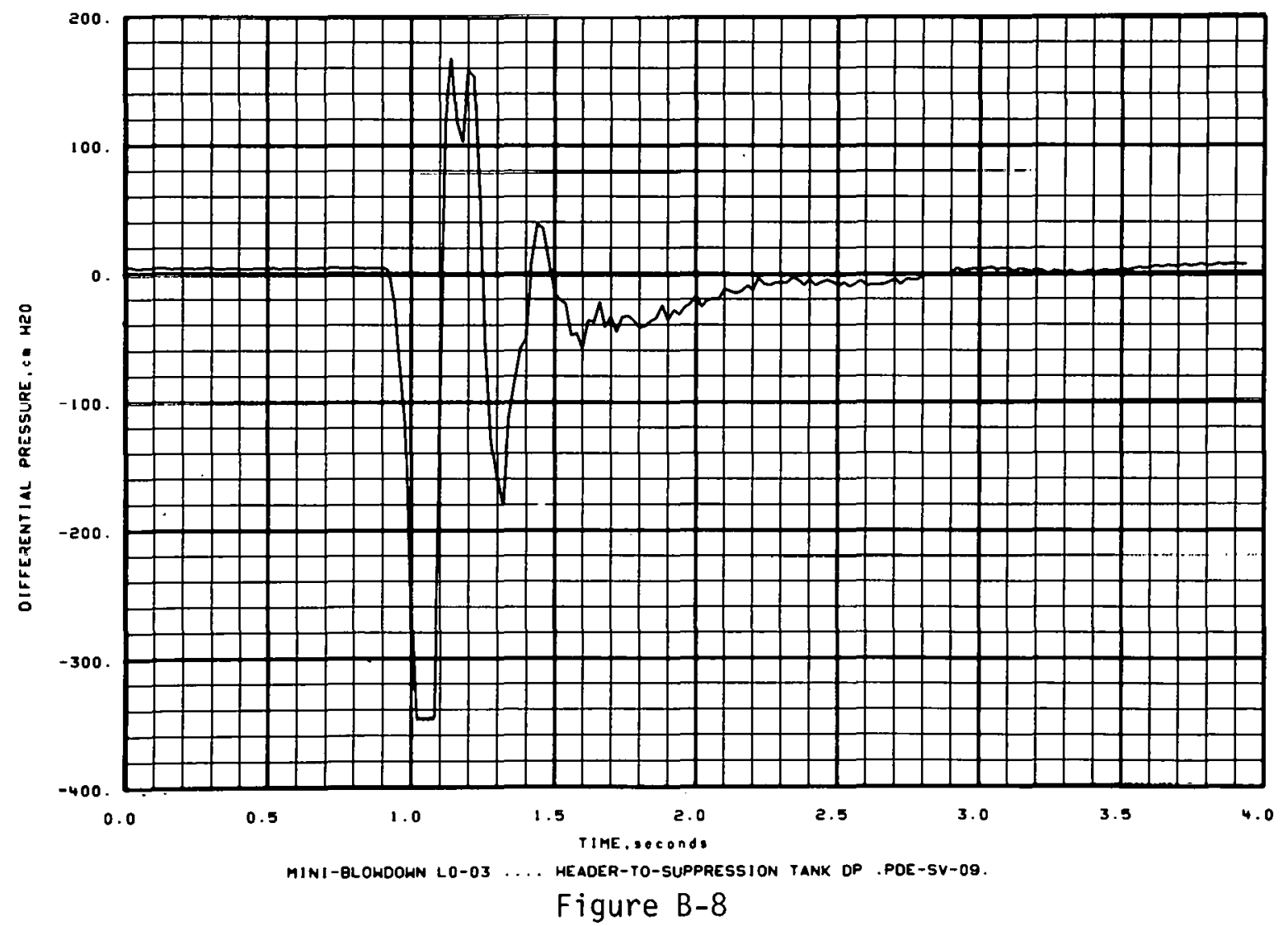



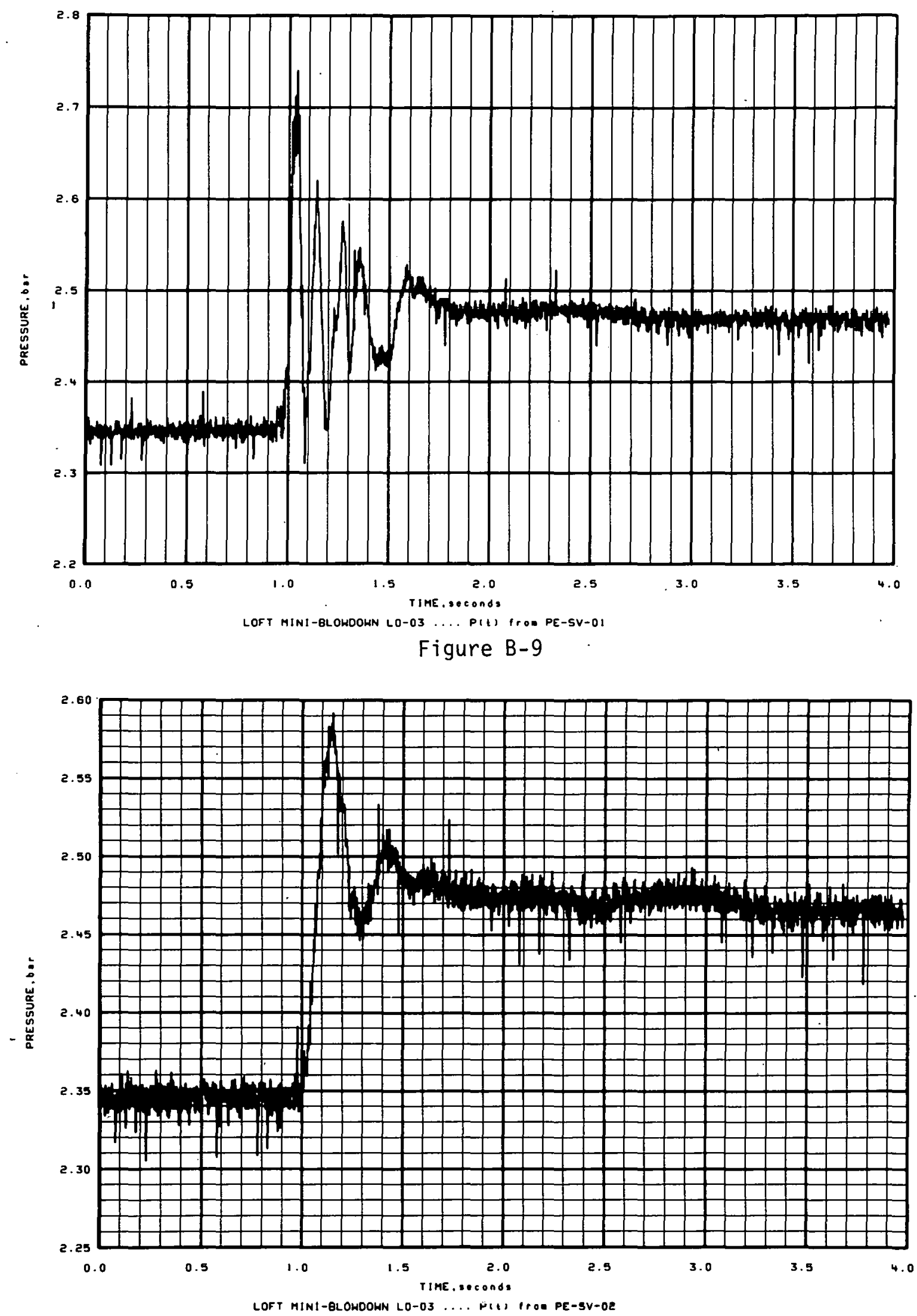

Figure B-10 

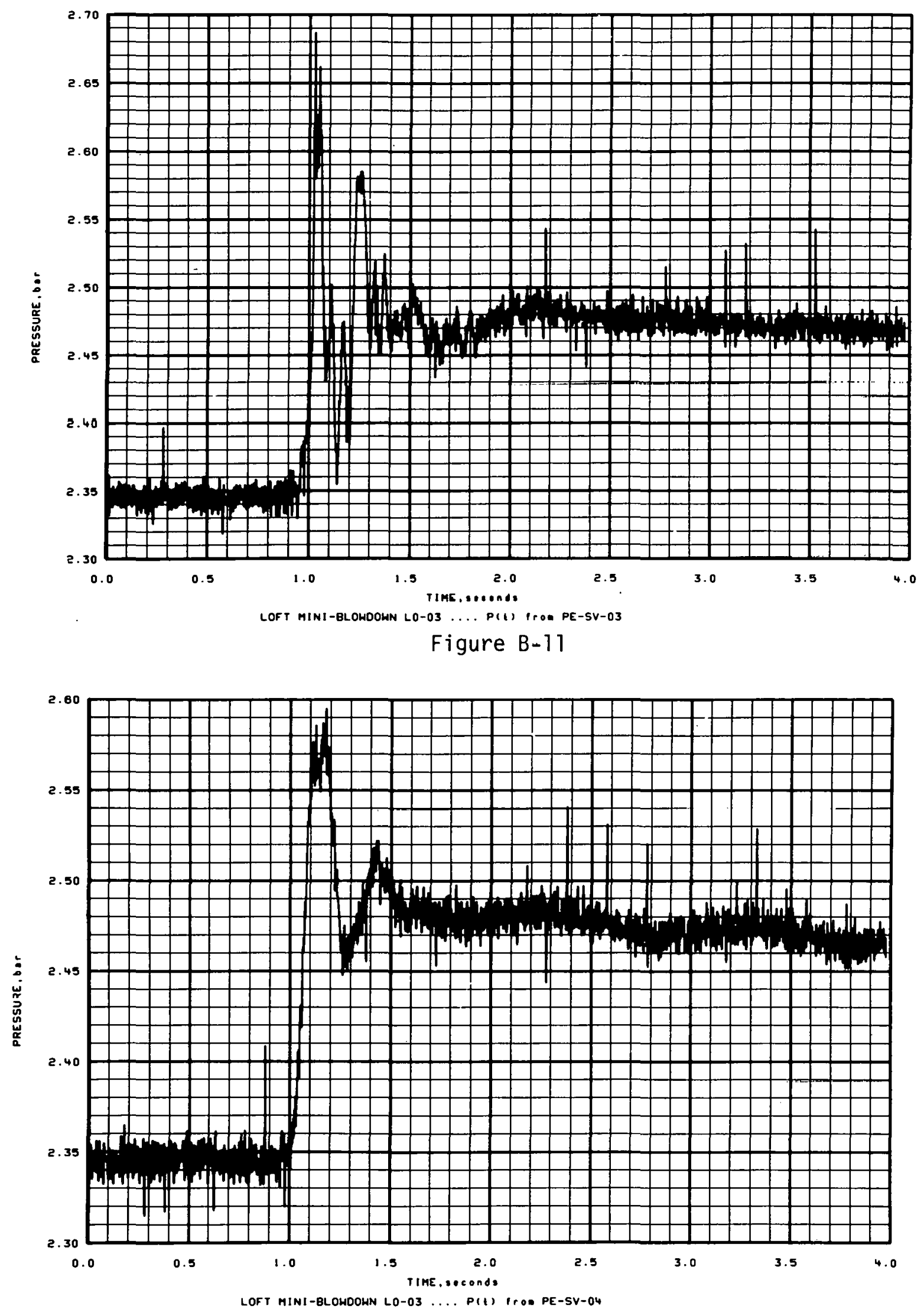

Figure $B-12$ 


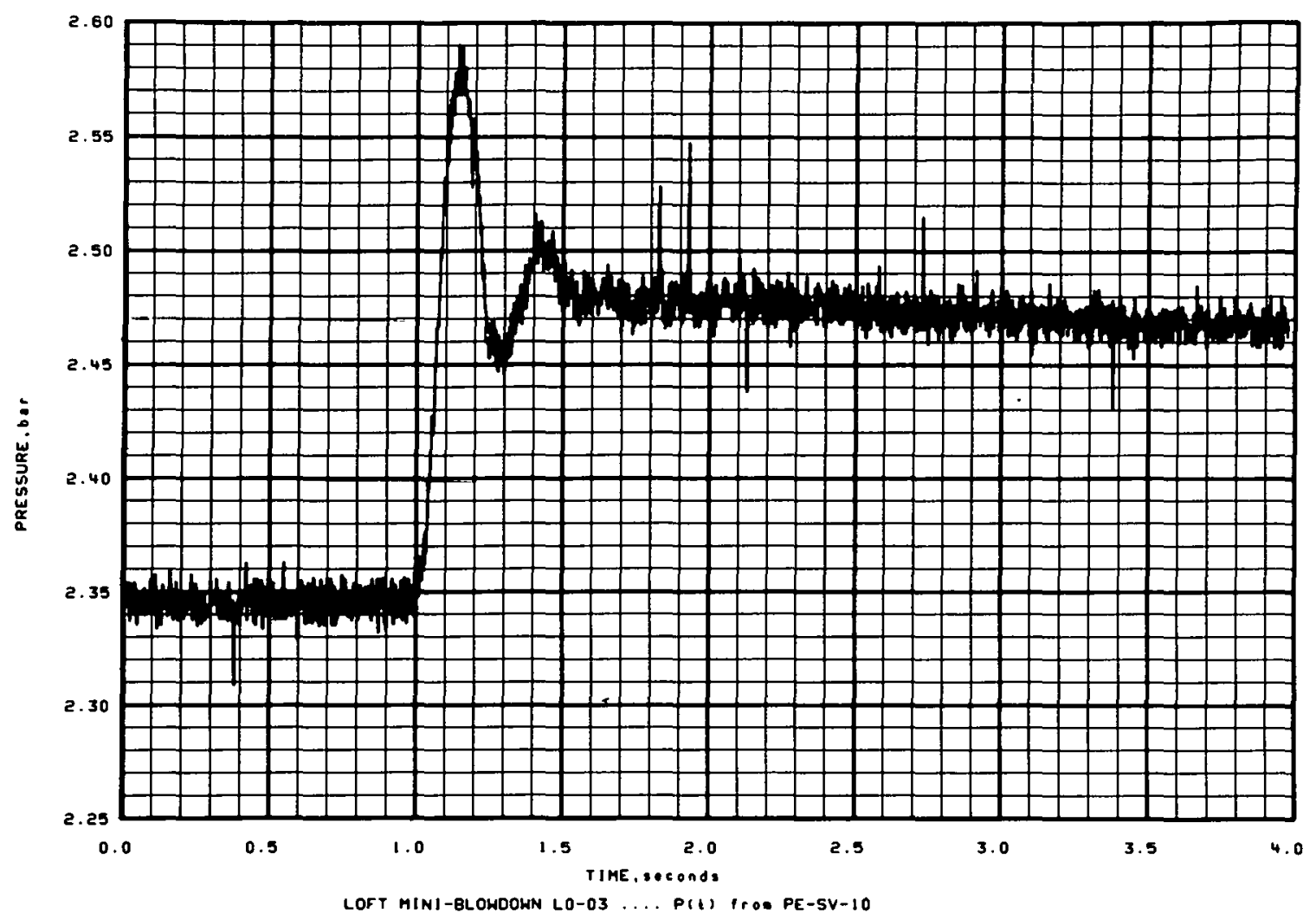

Figure B-13

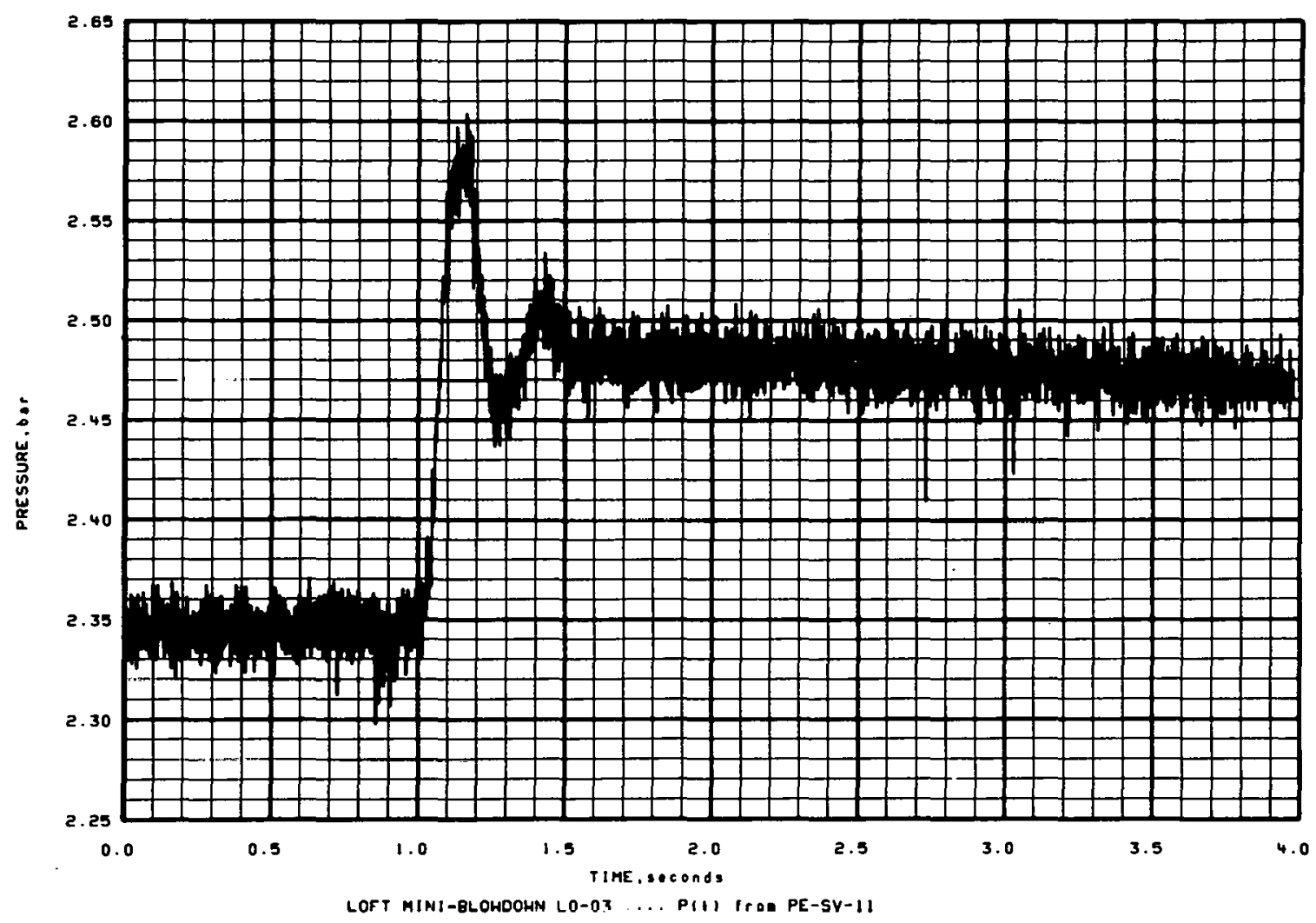

Figure B-14 


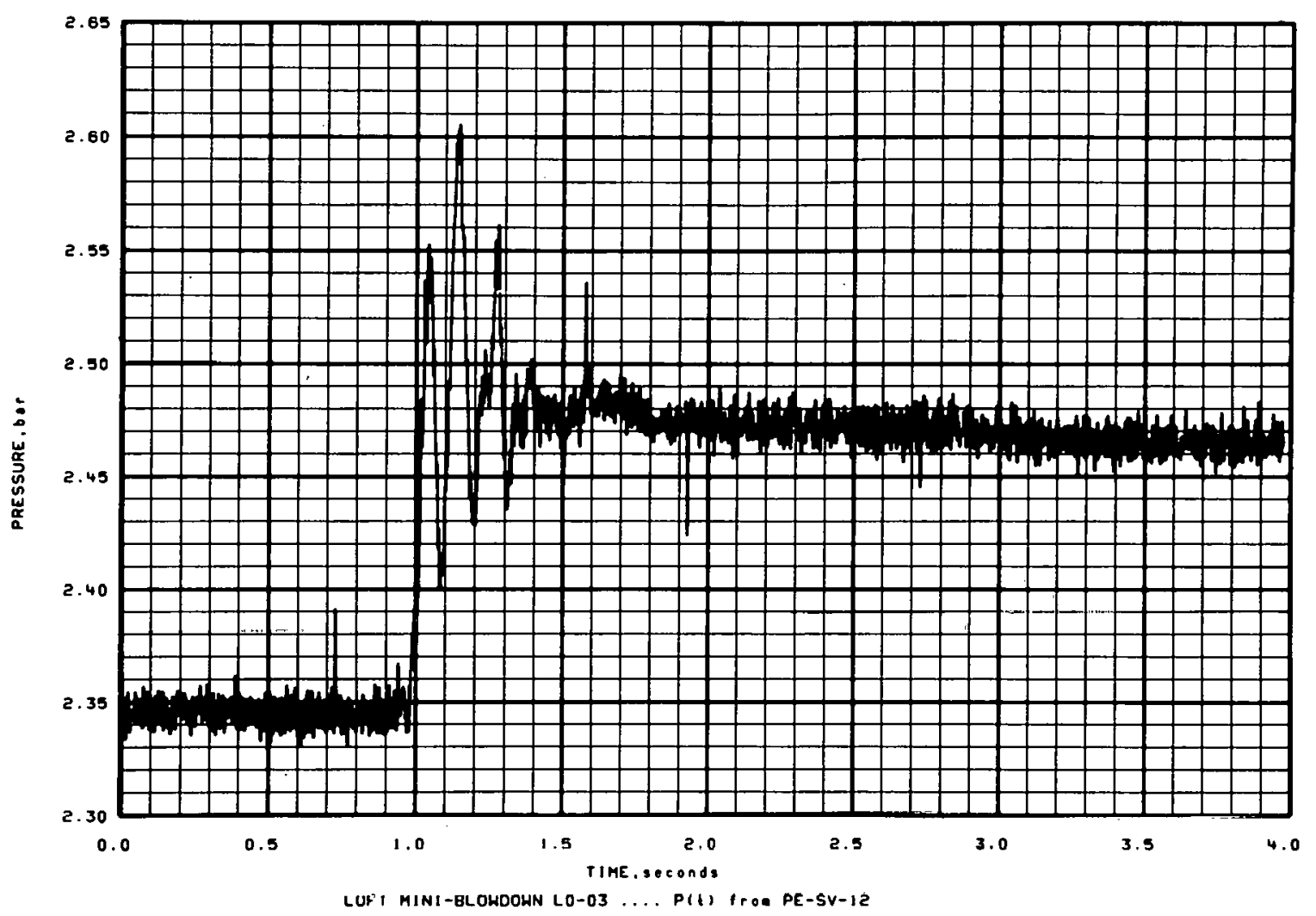

Figure $B-15$

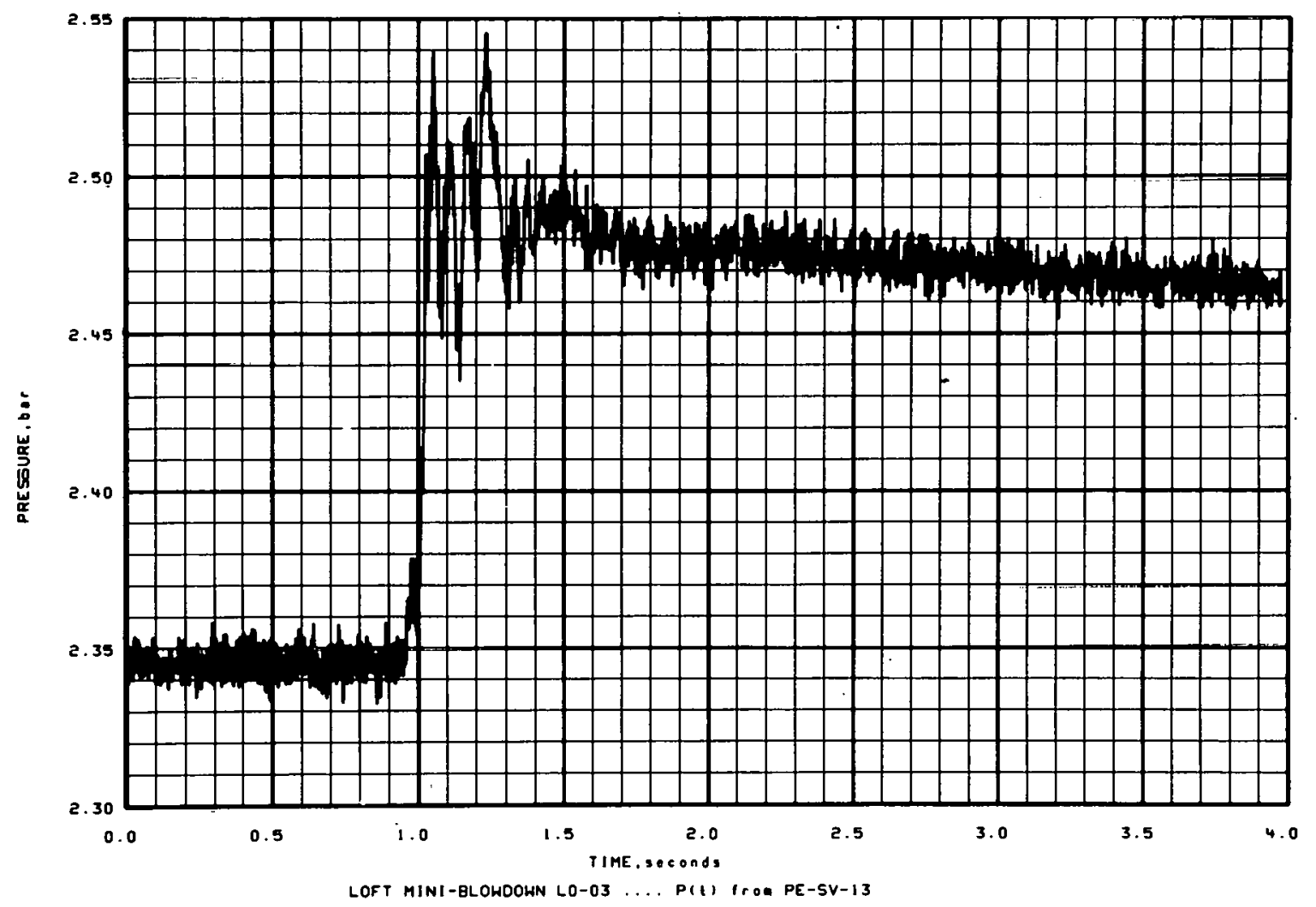

Figure B-16 


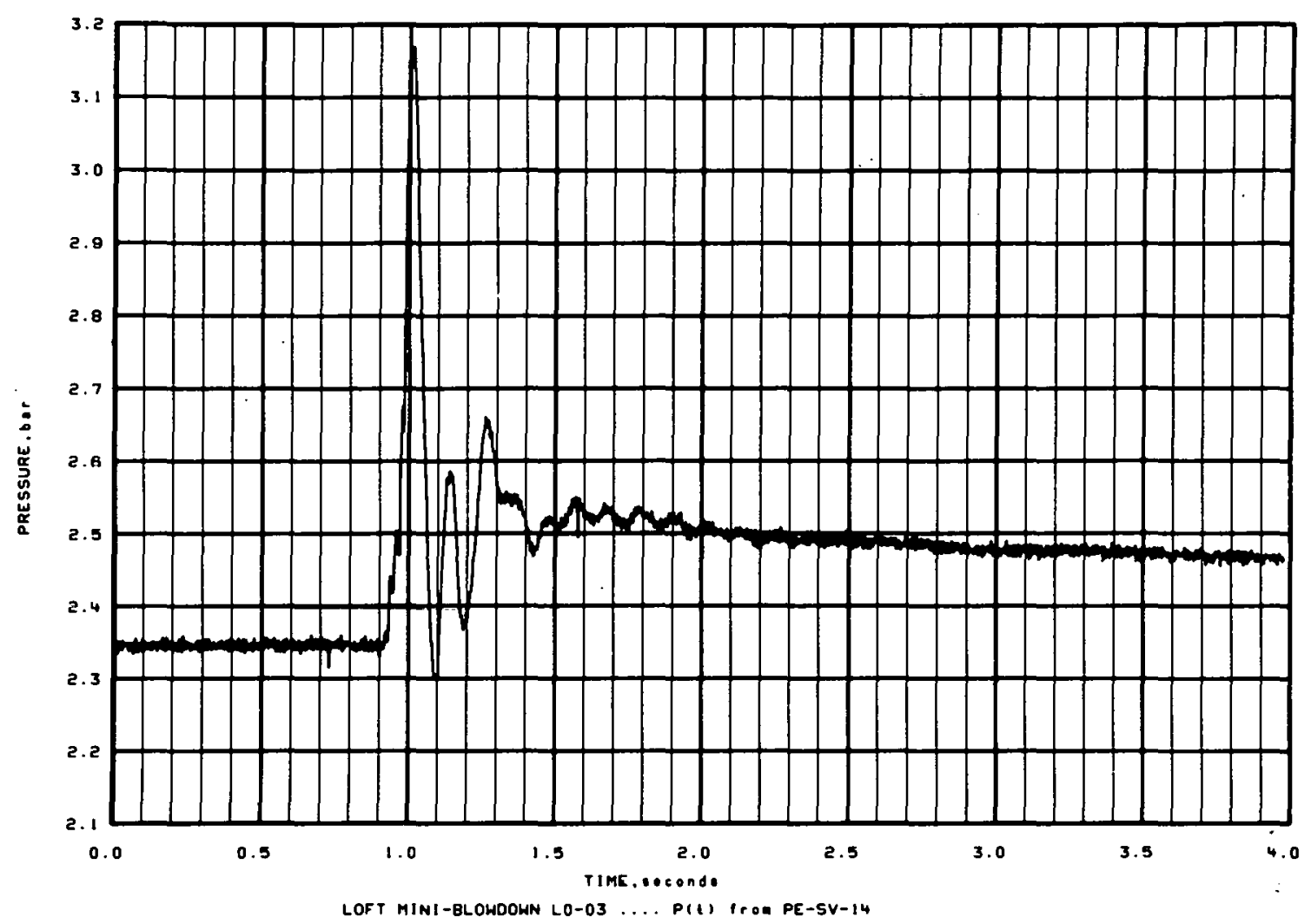

Figure $B-17$

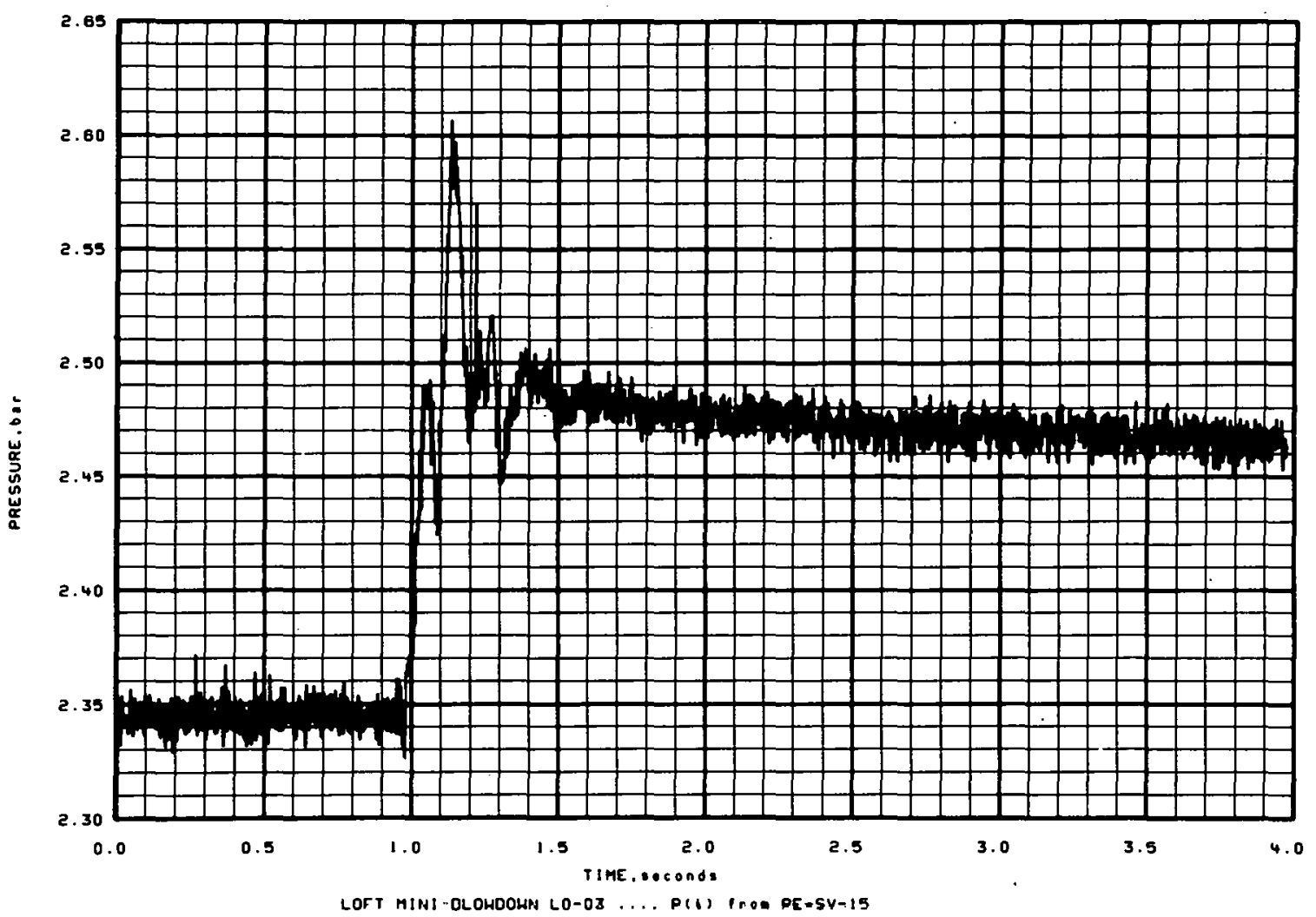

Figure B-18 


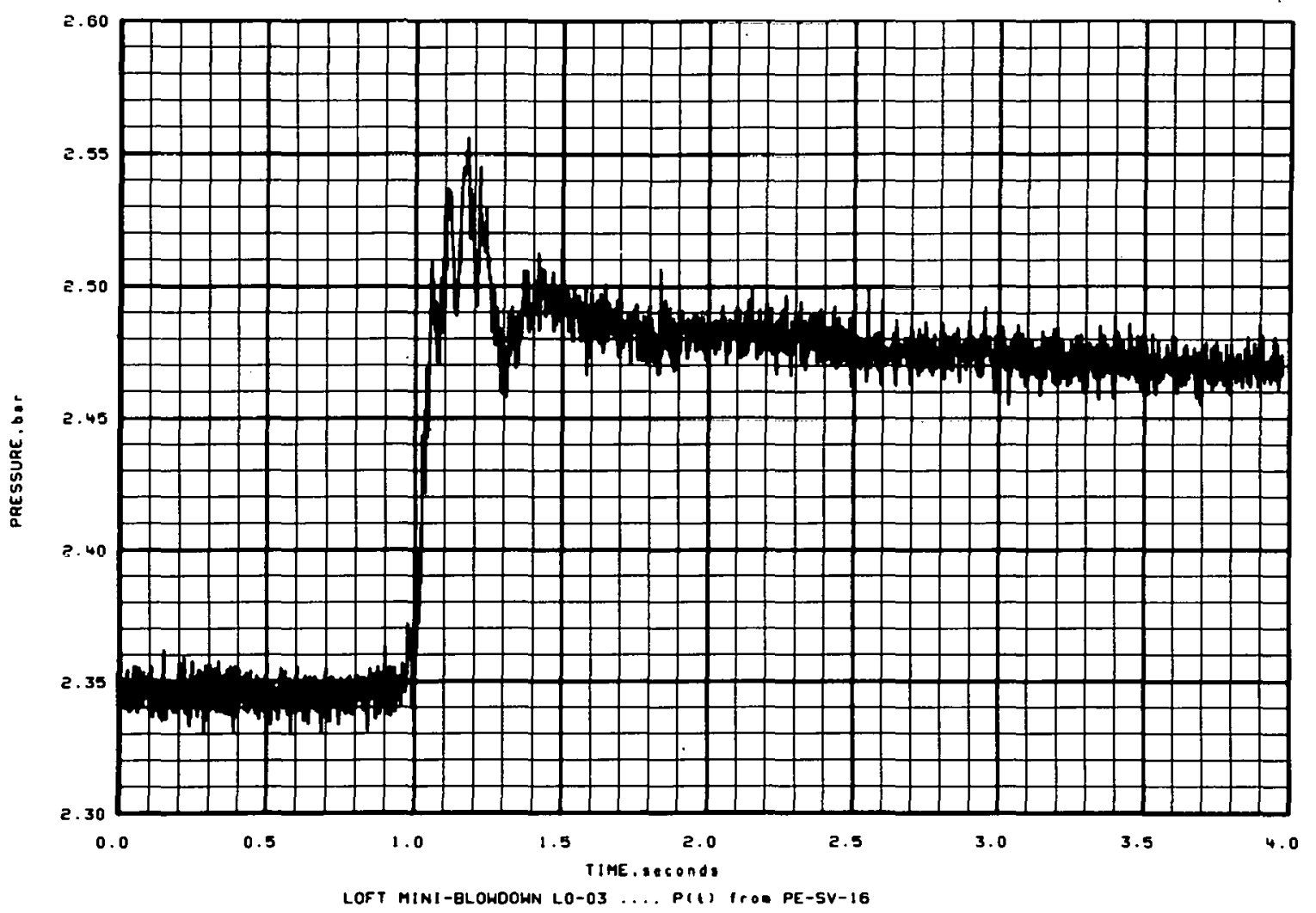

Figure B-19

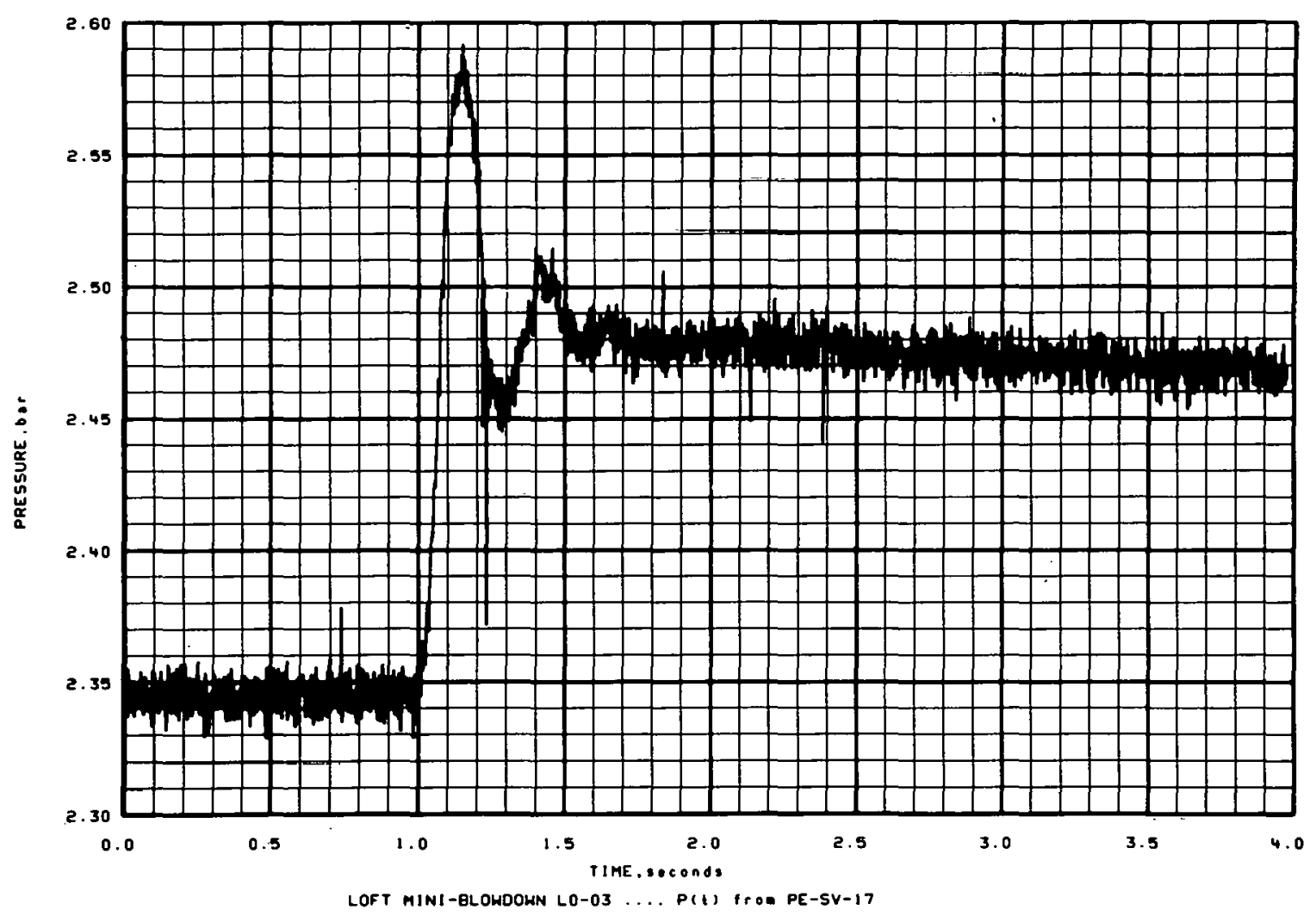

Figure B-20 


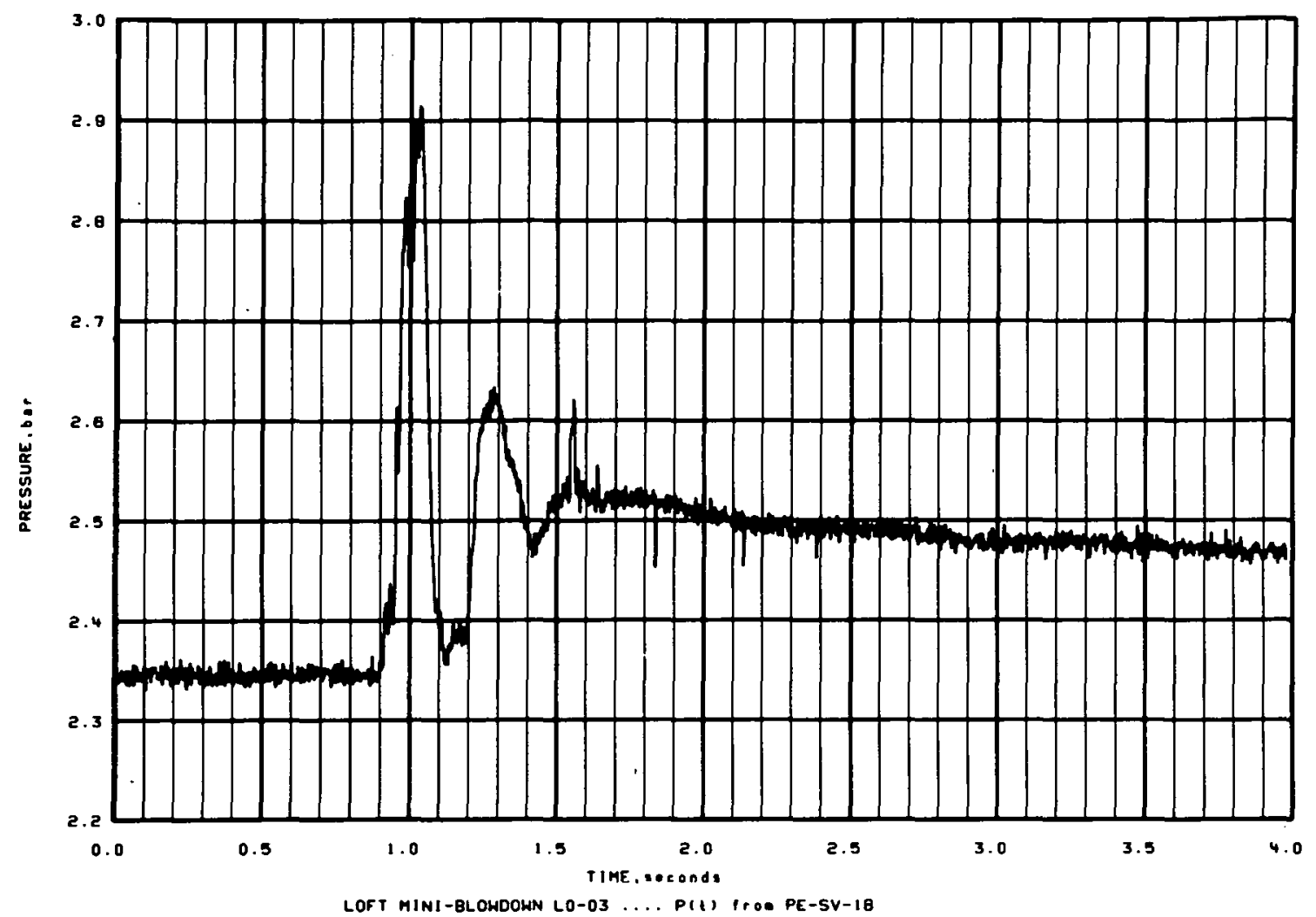

Figure B-21

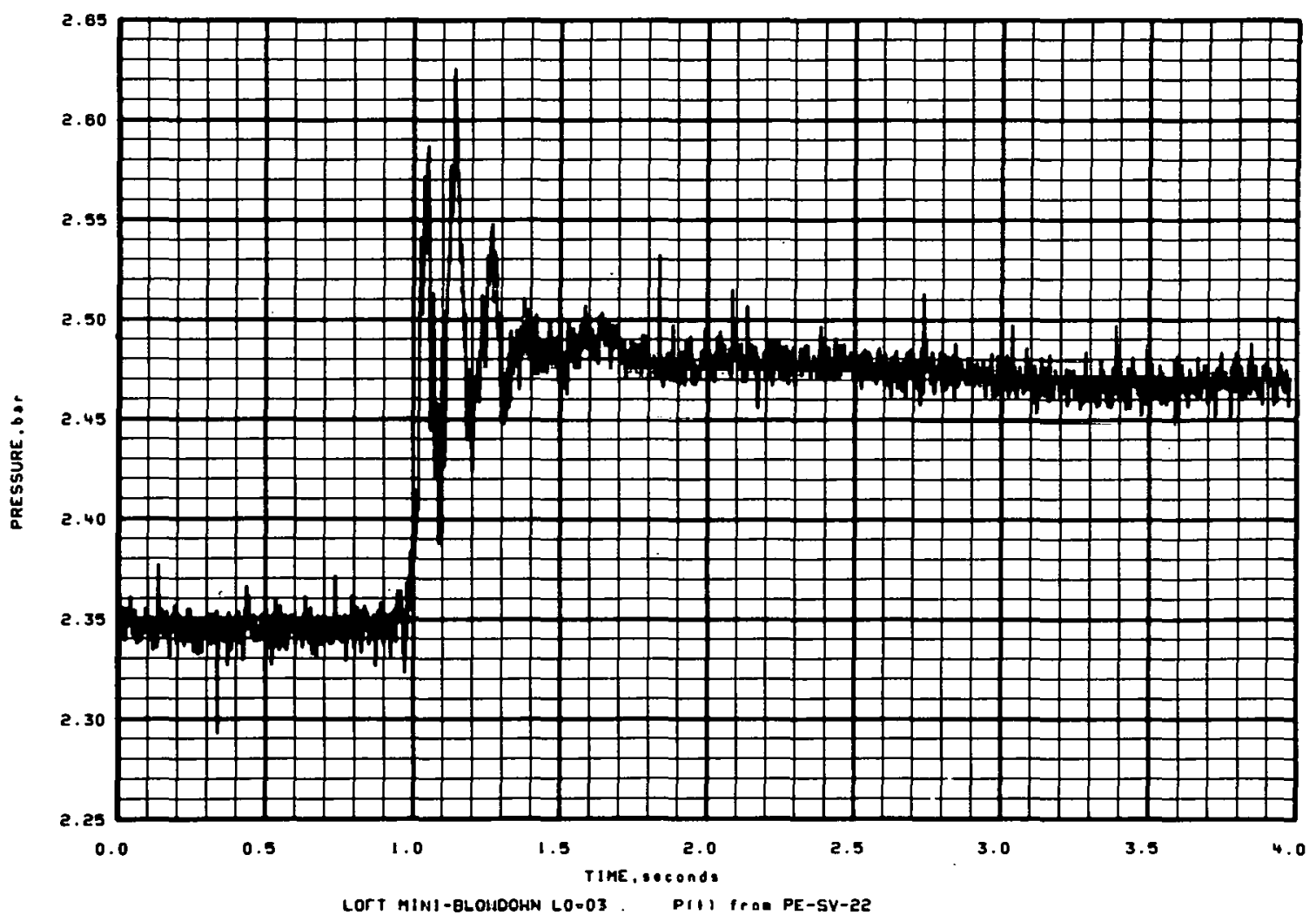

Figure B-22 


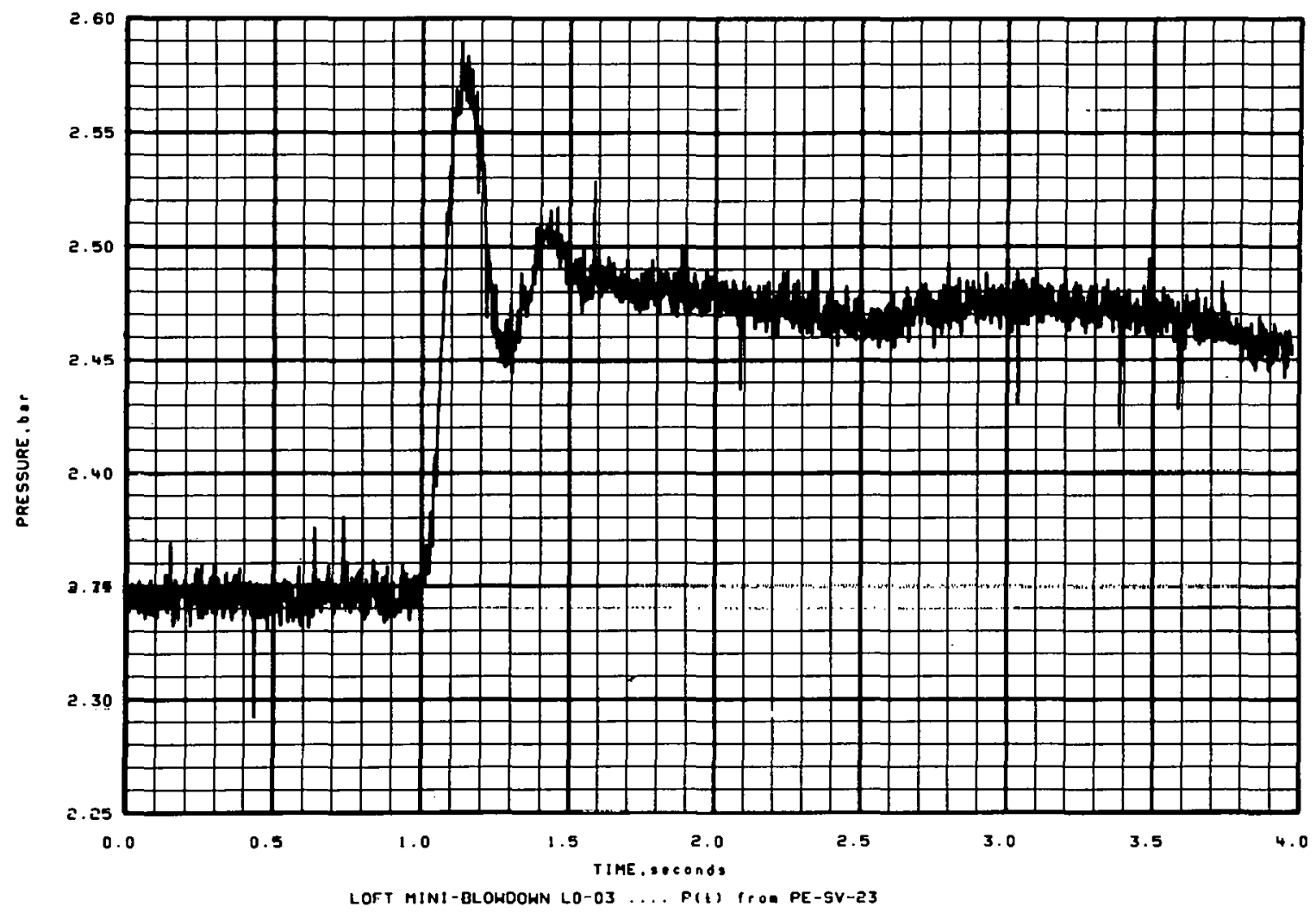

Figure B-23

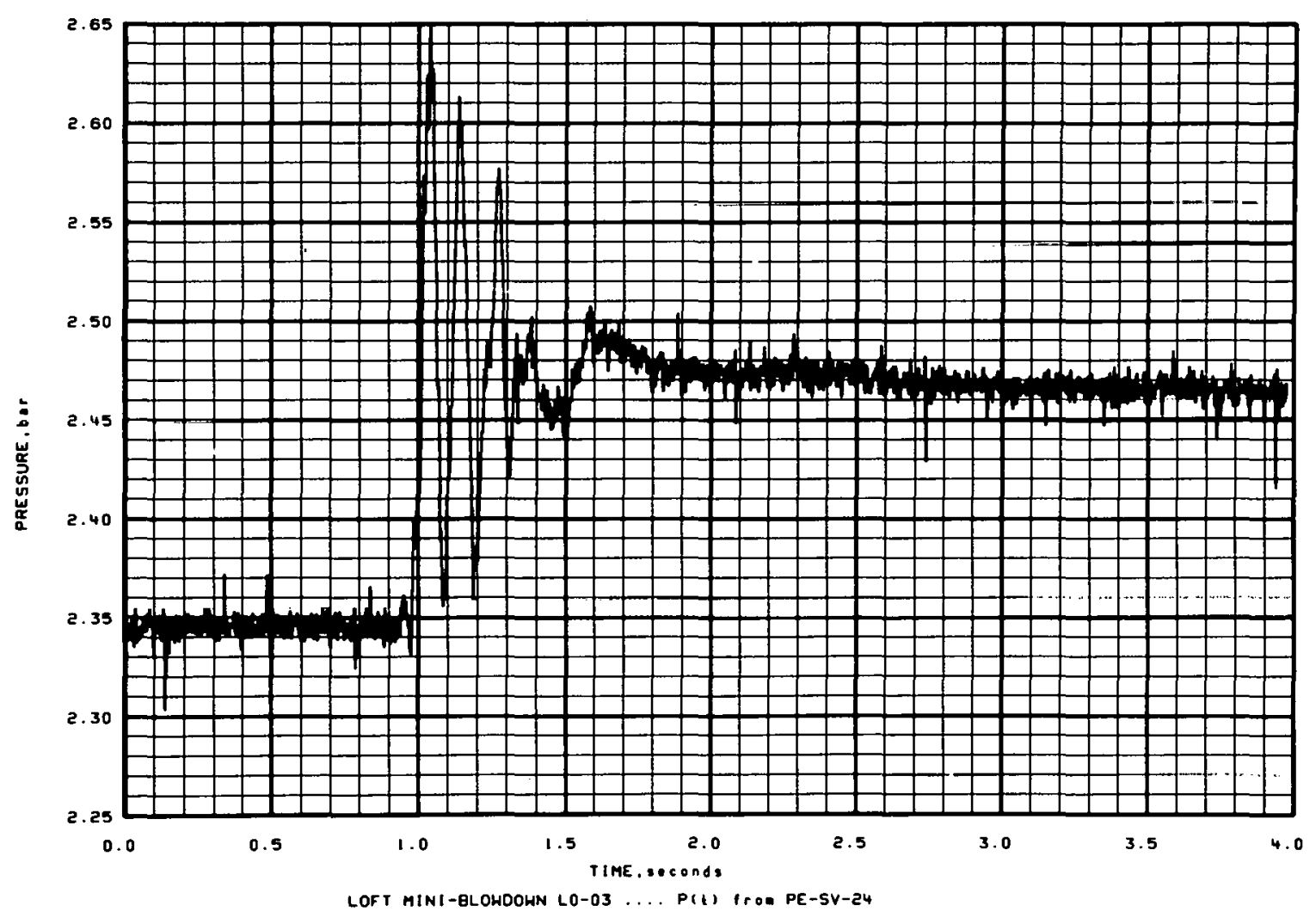

Figure B-24 

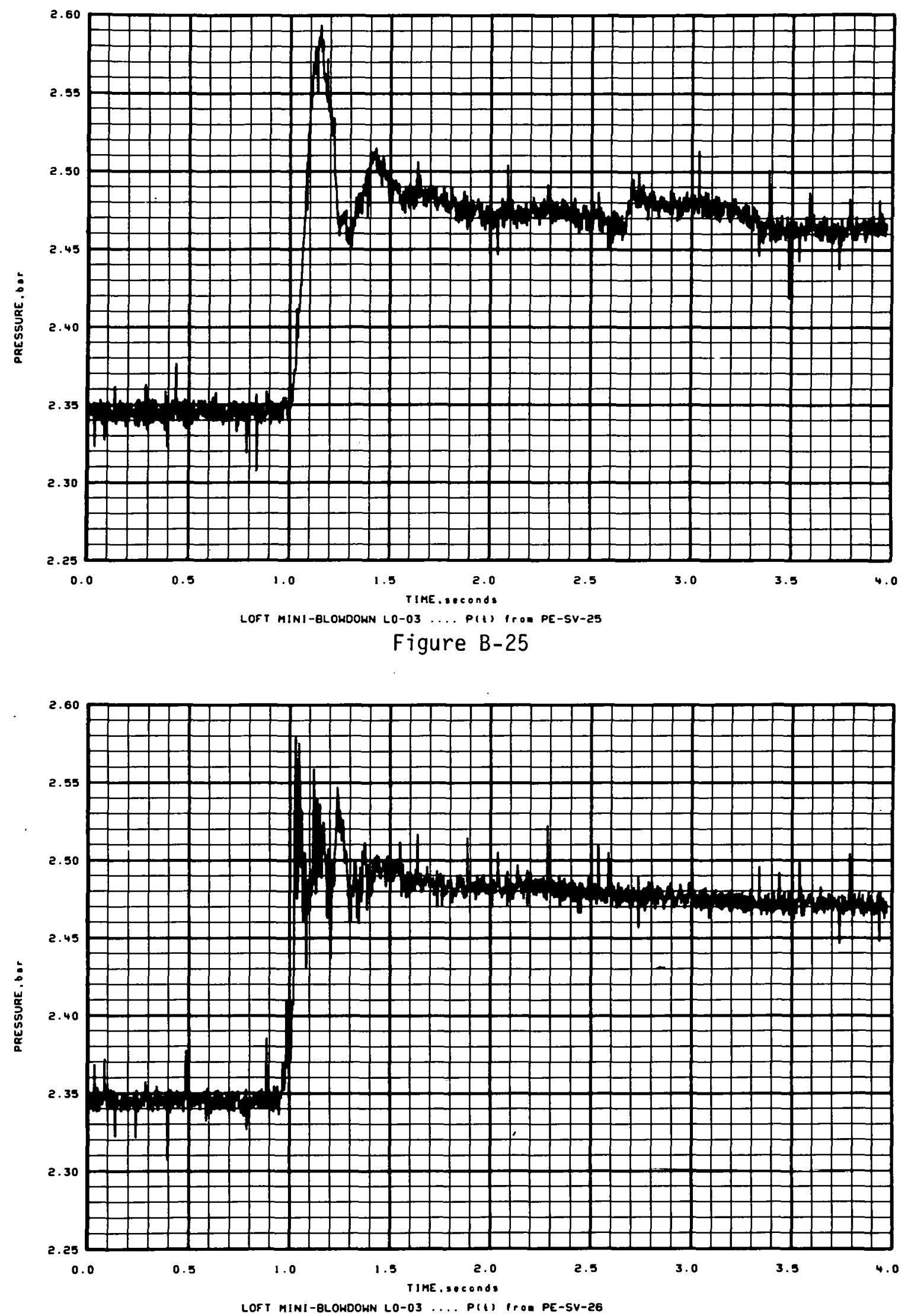

Figure B-26 

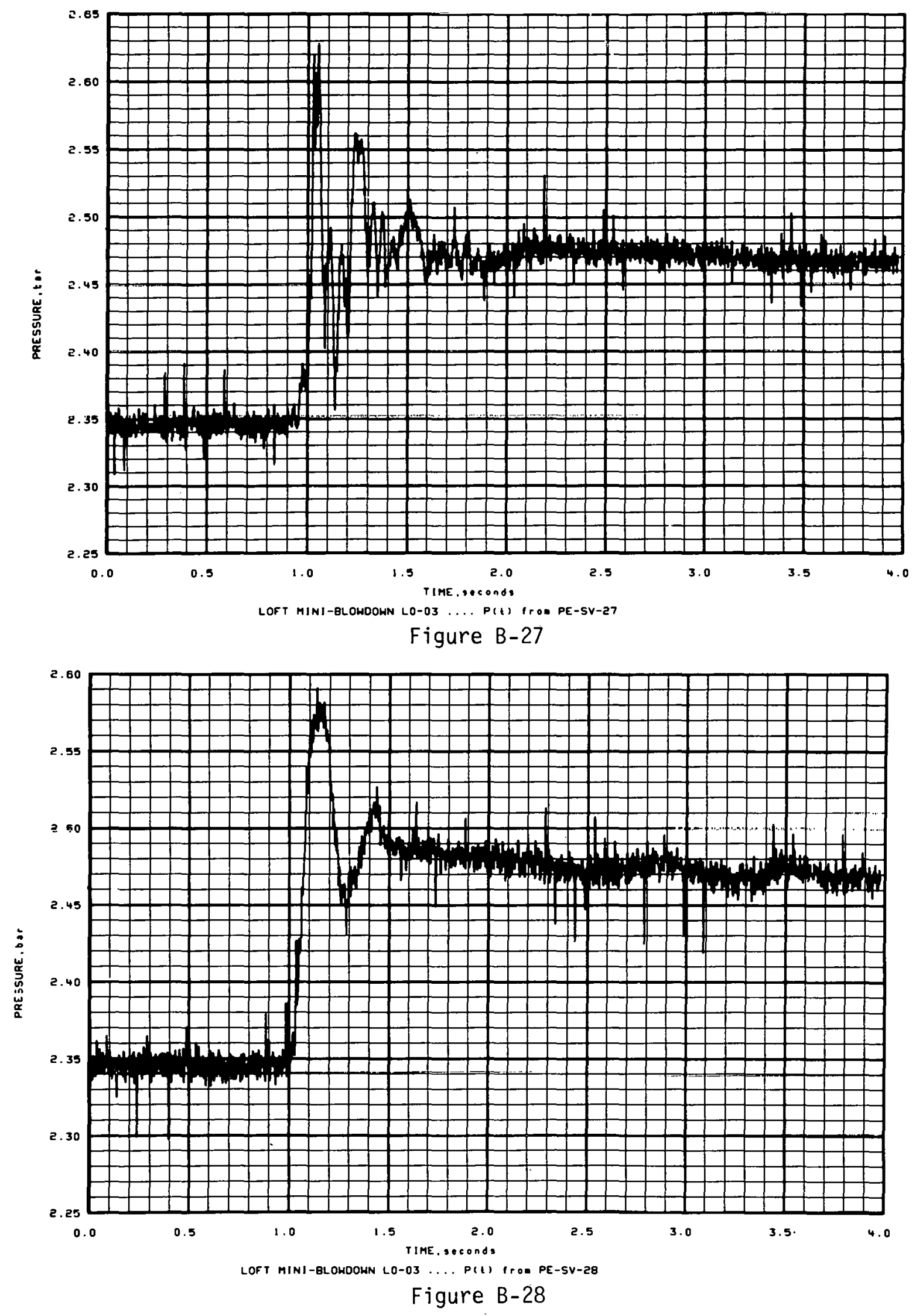


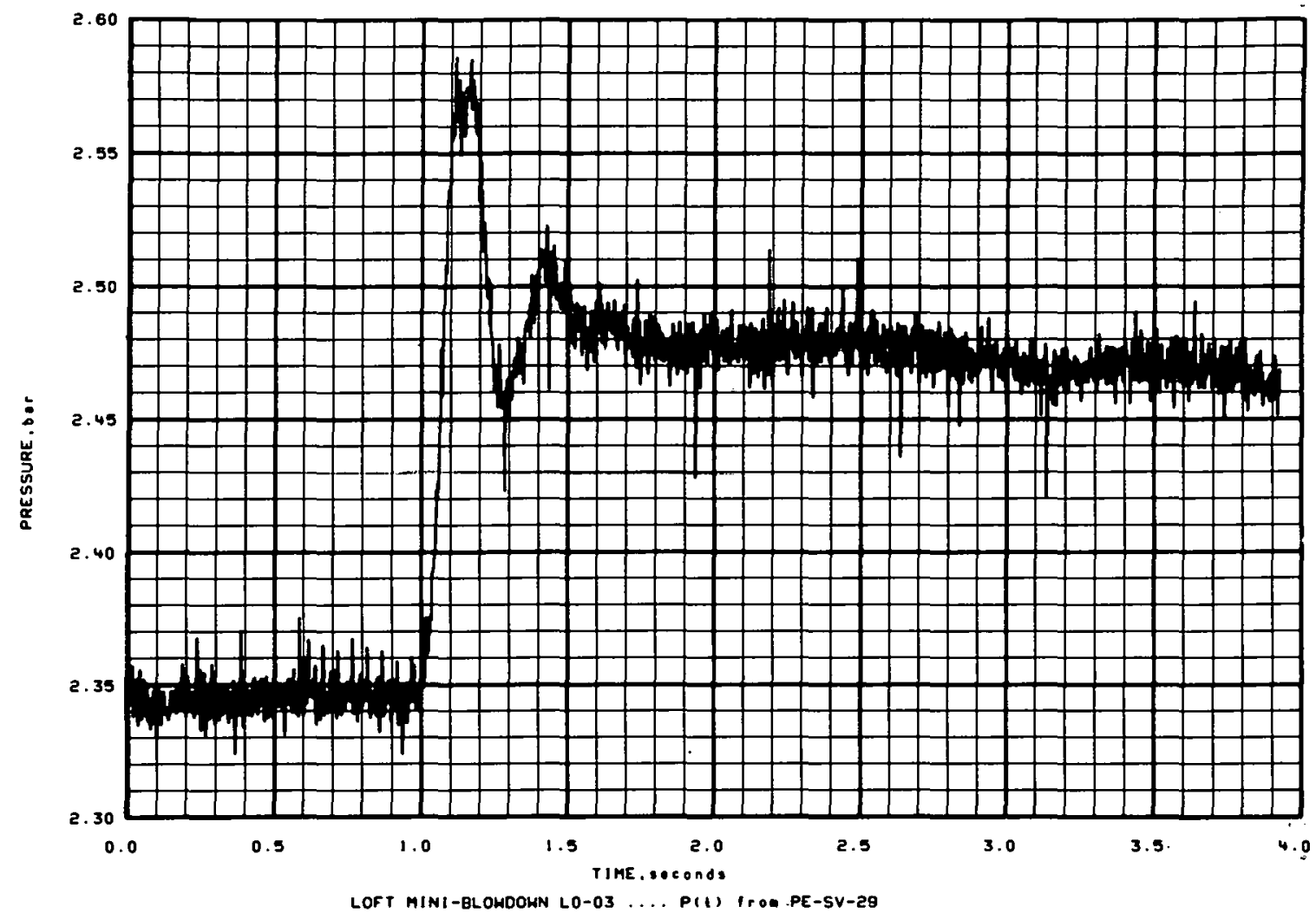

Figure B-29

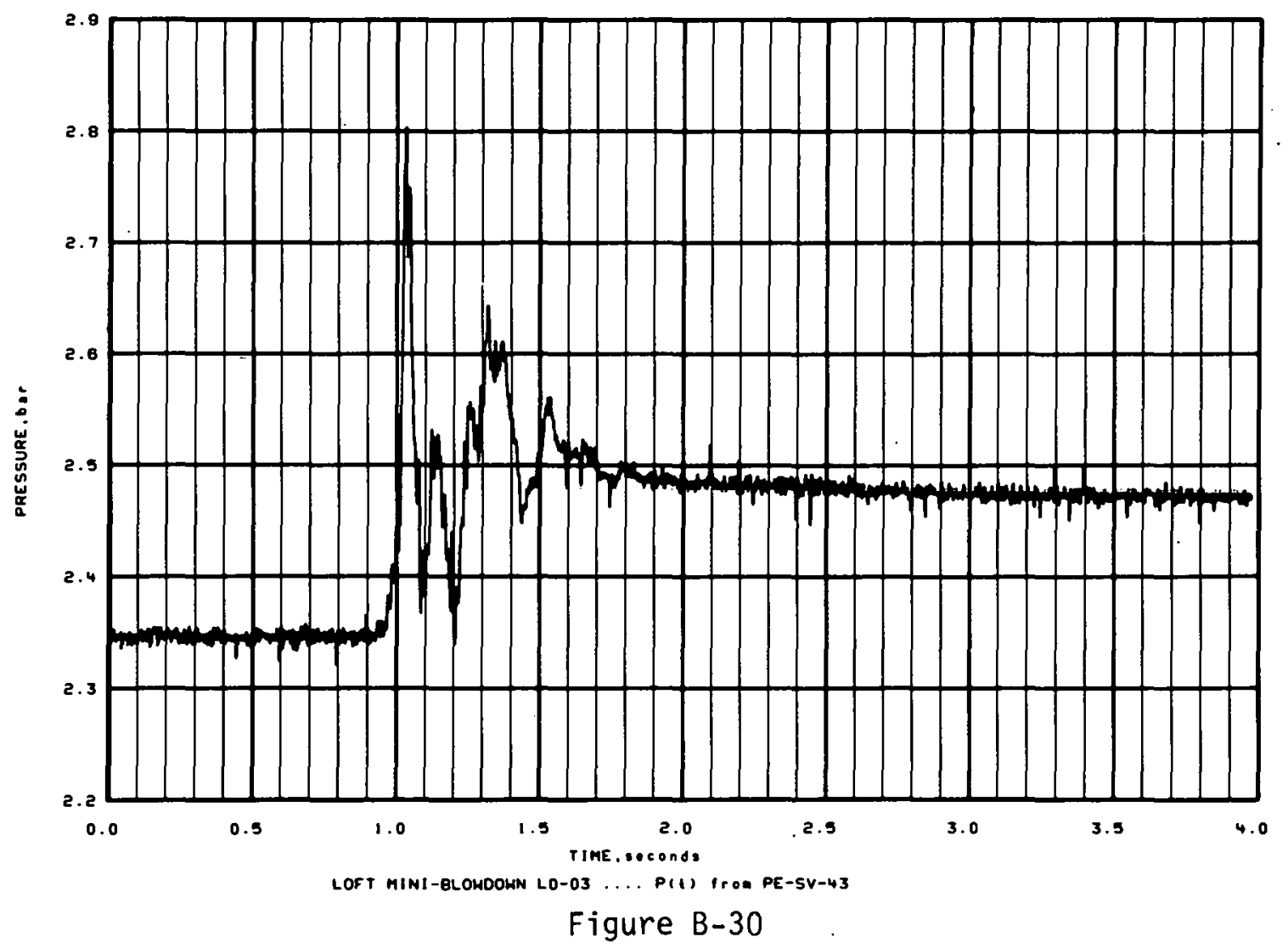




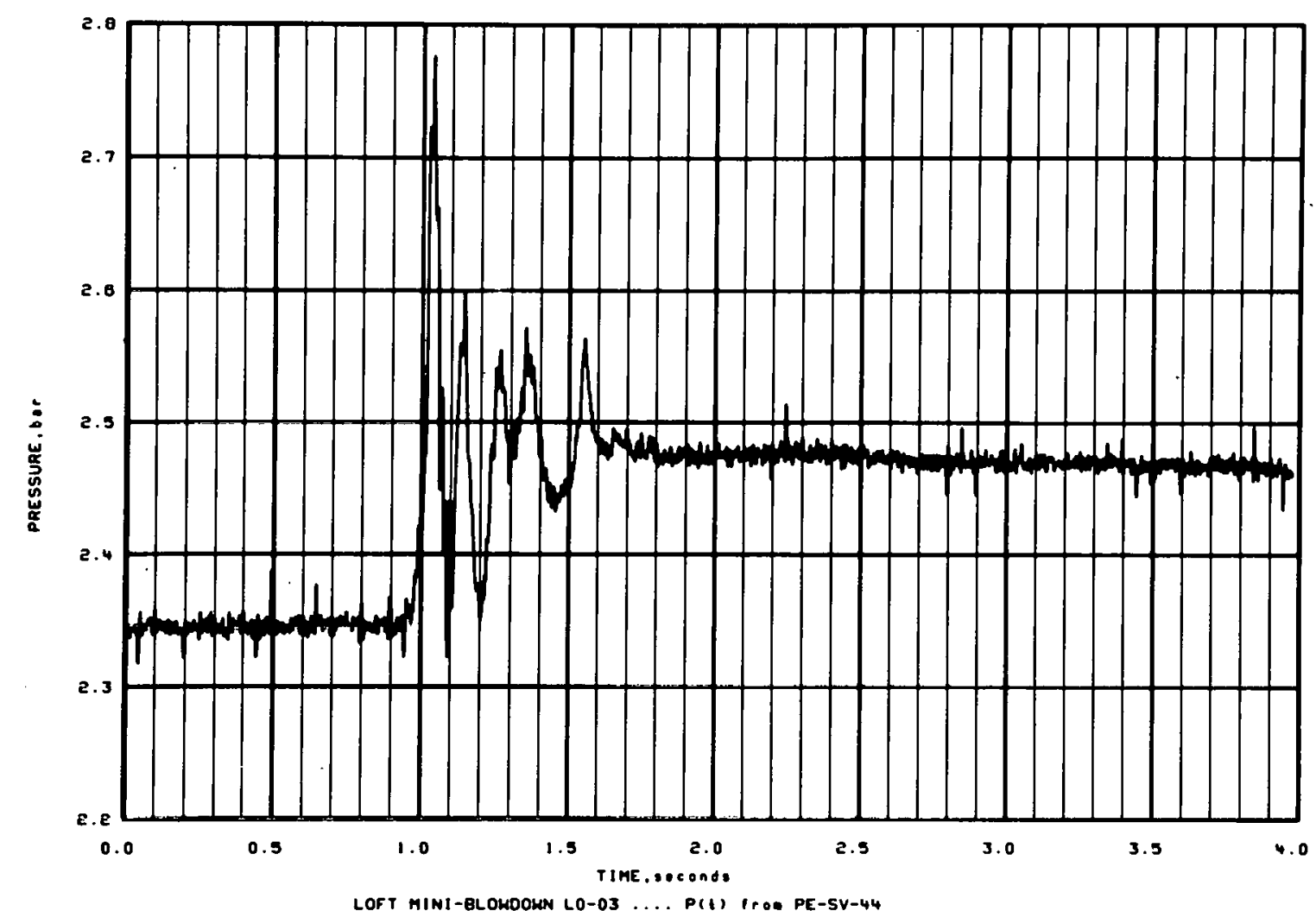

Figure B-31

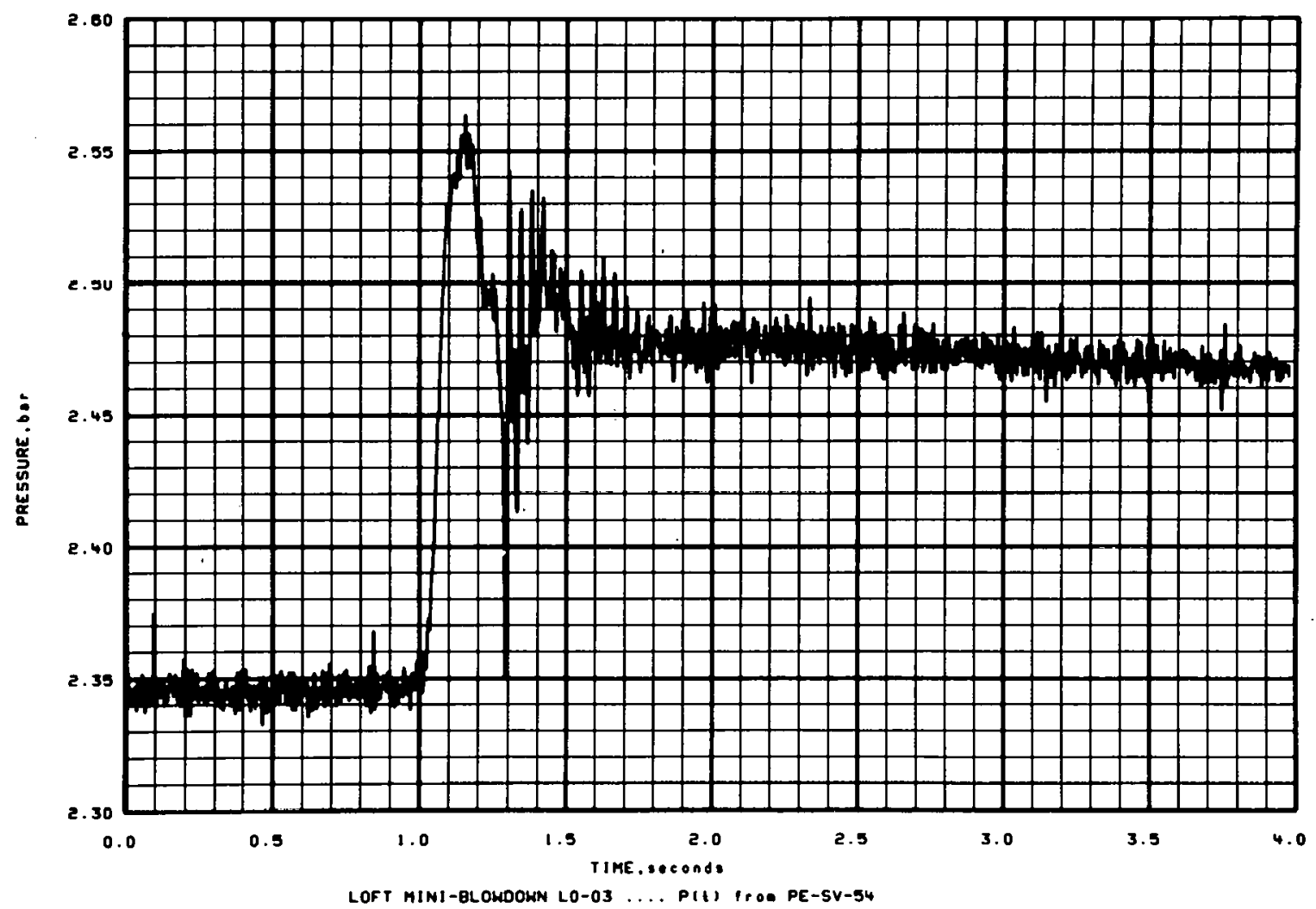

Figure B-32 

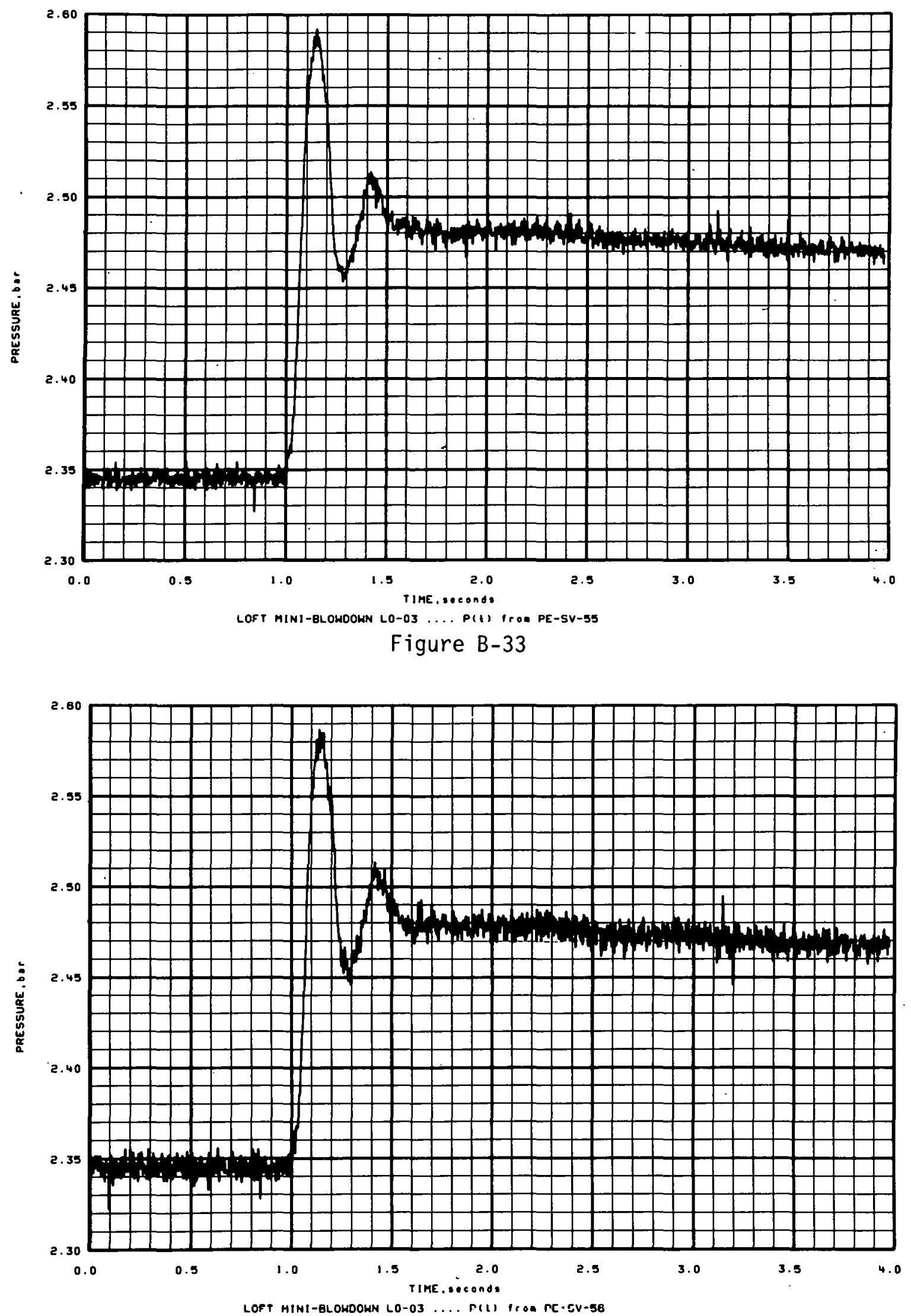

Figure B-34 


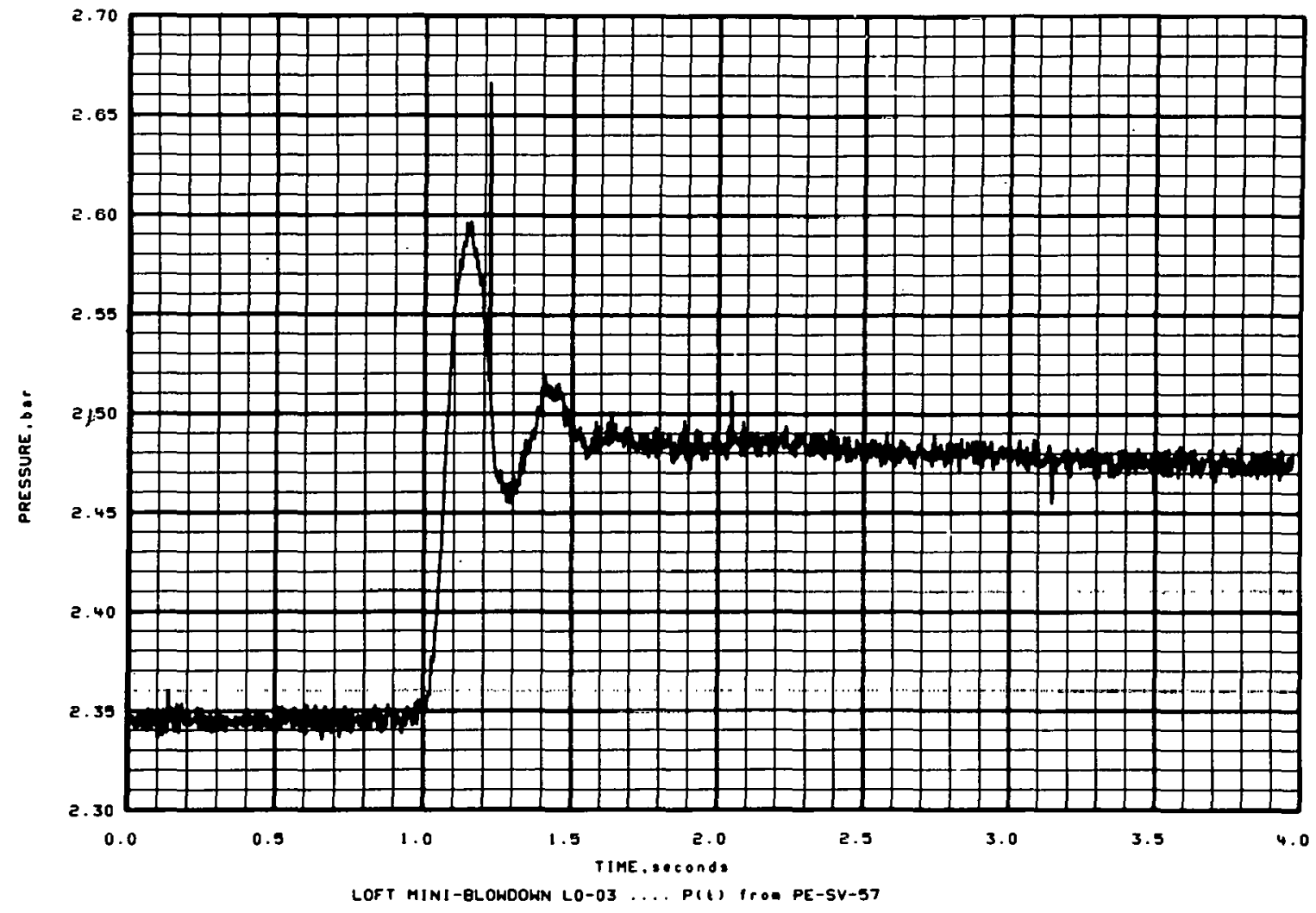

Figure B-35

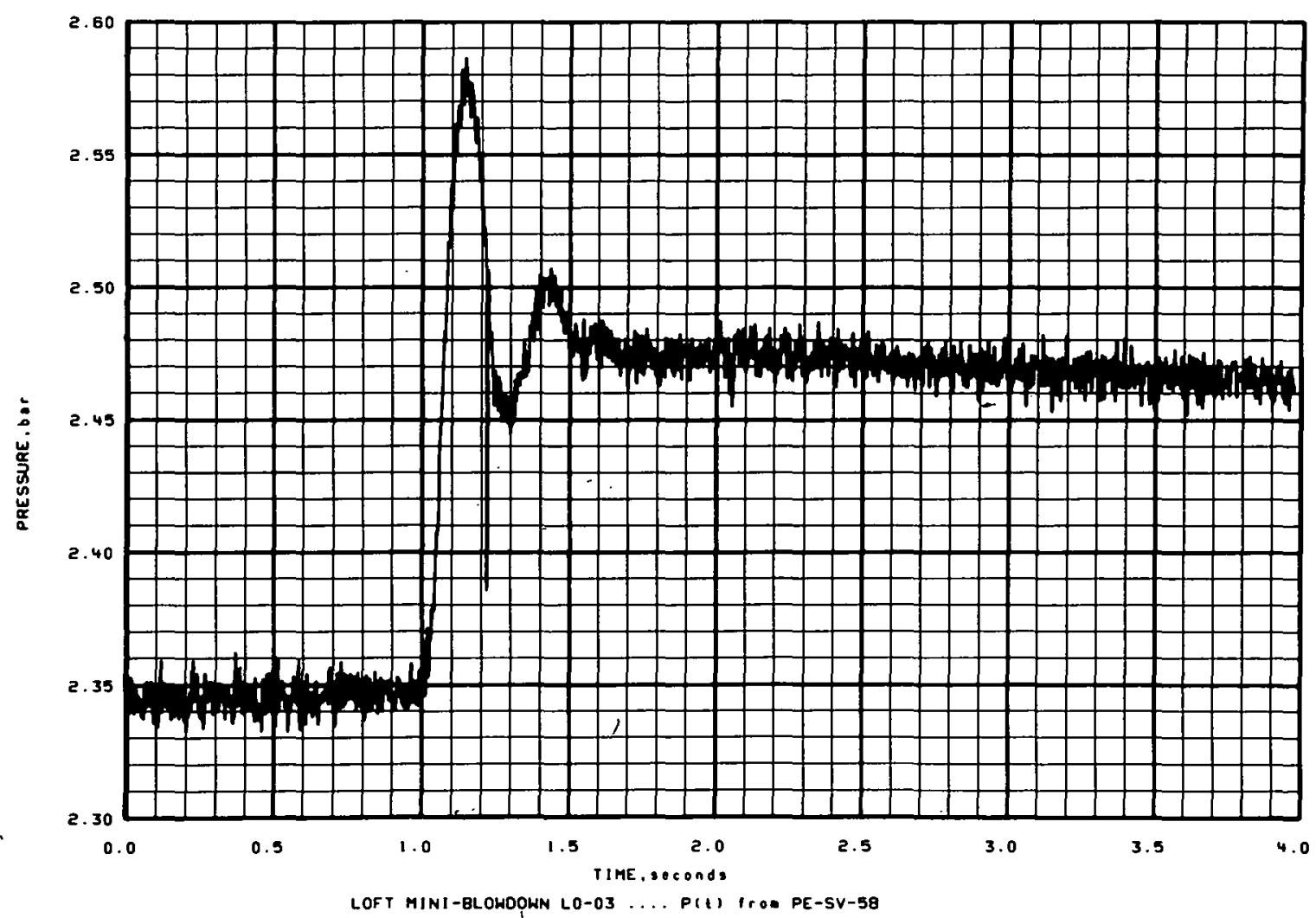

Figure B-36 

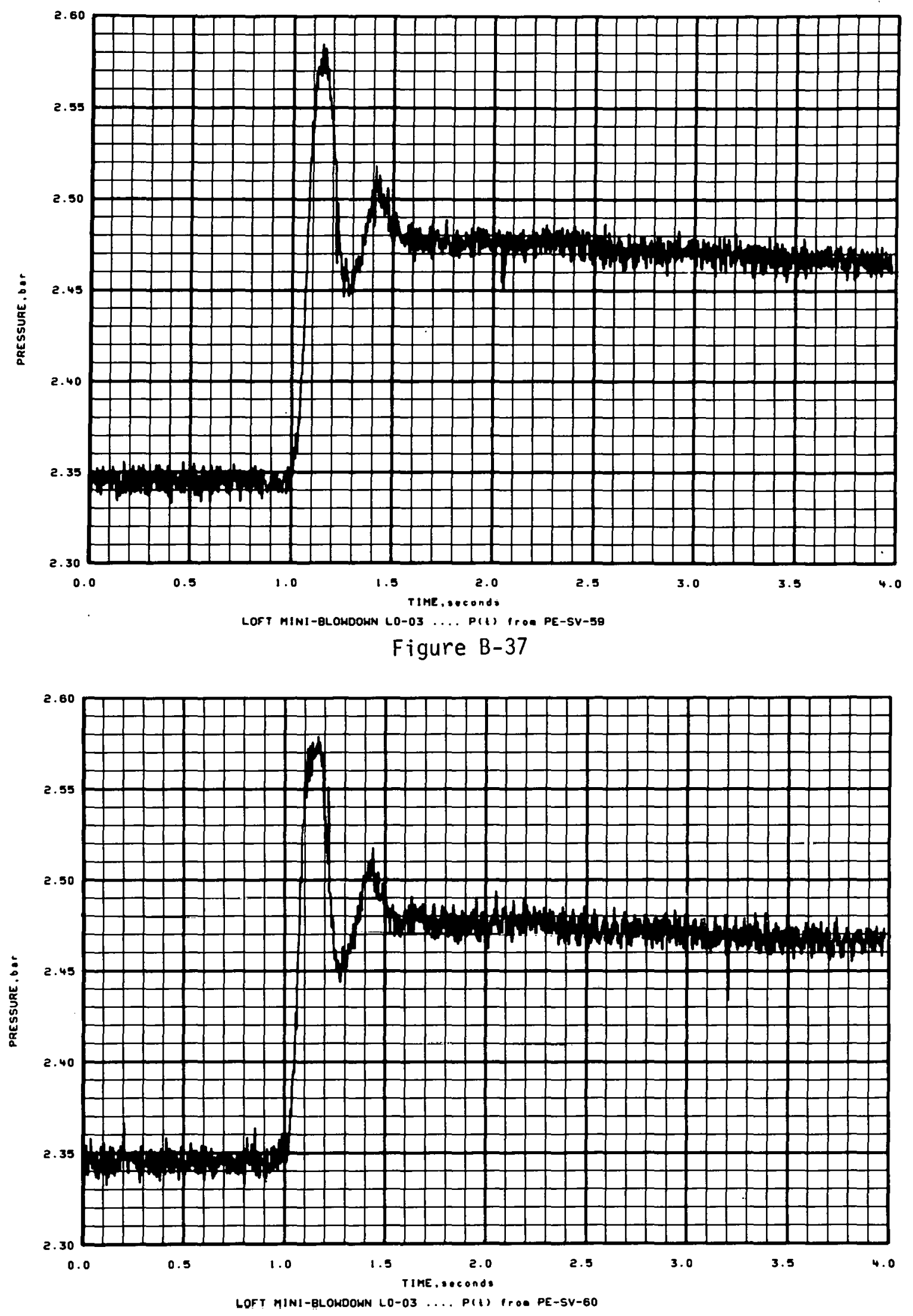

Figure B-38 


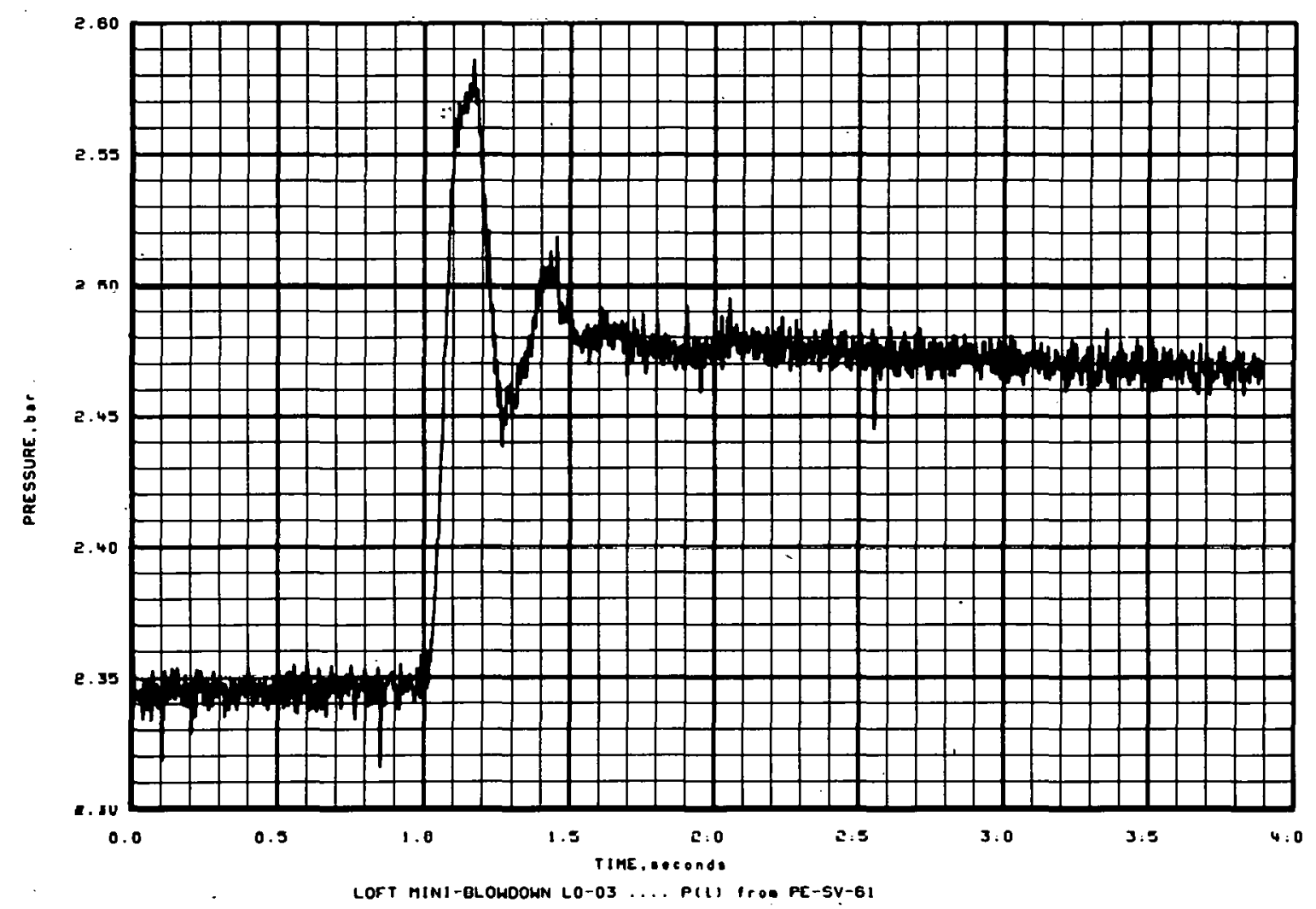

Figure B-39 
APPENDIX C

MINI-BLOWDOWN LO-3A EXPERIMENTAL DATA 
THIS PAGE

\section{WAS INTENTIONALLY LEFT BLANK}




\section{APPENDIX C}

\section{MINI-BLOWDOWN LO-3A EXPERIMENTAL DATA}

Both QOBVs opened in this experiment. QOBV-15 fully opened. The sleeve in QOBV-1 traveled only 52\% of full travel. Also, there was approximately $80 \mathrm{msec}$ difference in the times when the valves started to open the flow area. The fluid temperature was $233.2 \pm 1.5^{\circ} \mathrm{C}$ in QOBVand $2289 \pm 1.5^{\circ} \mathrm{r}$ in nnRv-15. The suppressinn tank rnnditinns were $2.27 \pm 0.08$ bar, $29.7 \pm 1.5^{\circ} \mathrm{C}$ in the gas volume, and $26.4 \pm 1.5^{\circ} \mathrm{C}$ in the pool. The vents were submerged $26.1 \pm 2.5 \mathrm{~cm}$ with an internal water level of $28.1 \pm 3.2 \mathrm{~cm}$.

The experimental data are defined in Table $\mathrm{C}-\mathrm{I}$. The opening characteristics of the QOBVs are shown in terms of percent sleeve travel versus time. The flow area of the valve begins to open at a sleeve position of $17 \%$ of full travel and is fully open at a sleeve position of $66 \%$ of full travel. The differential pressure between the header and the tank gas volume is measured with a very sensitive device primarily to provide information on vent preclearing. The data channel for this measurement is driven to saturation in the early part of the transient. 
TABLE C-I

EXPERIMENT LO-3A DATA SUMMARY

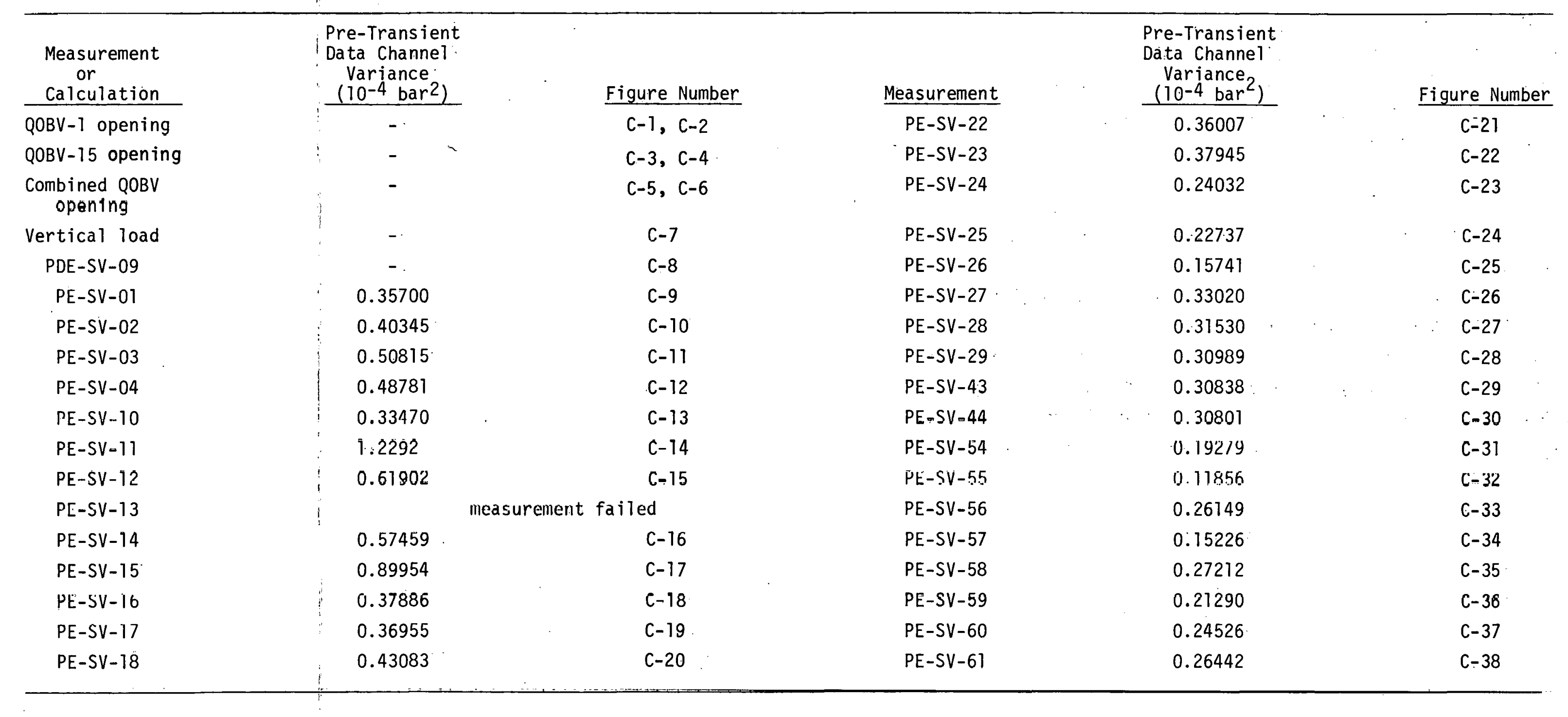



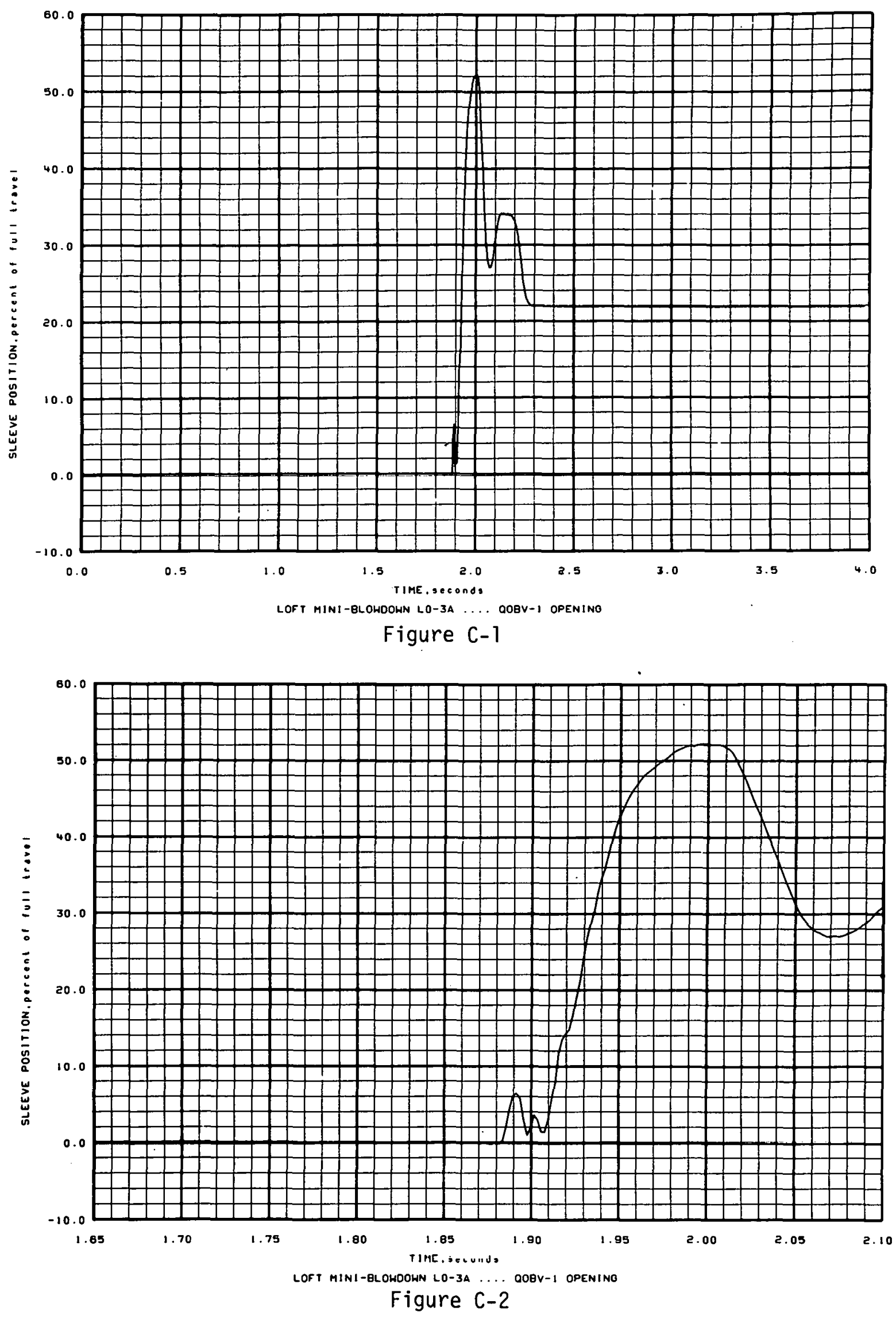

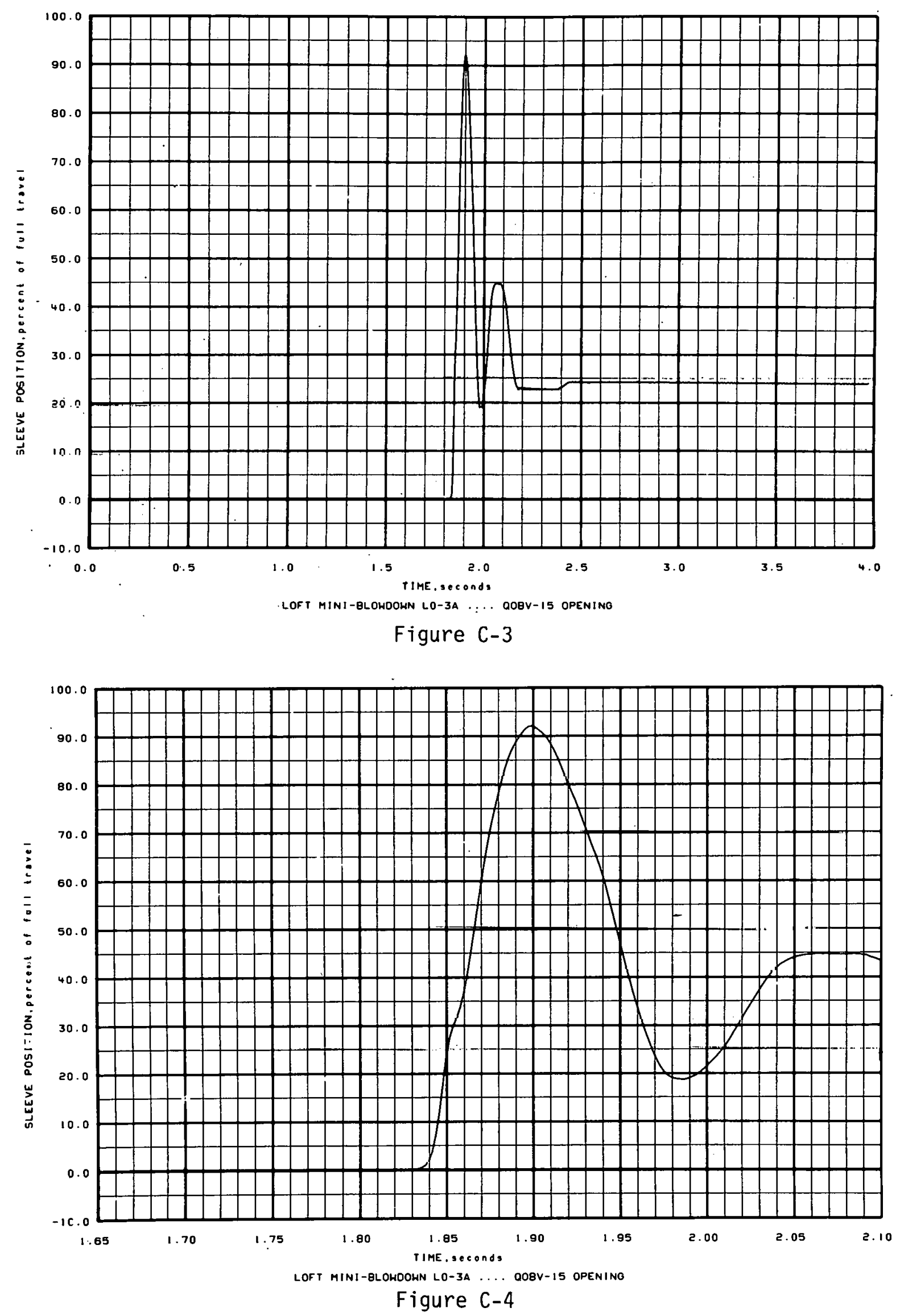


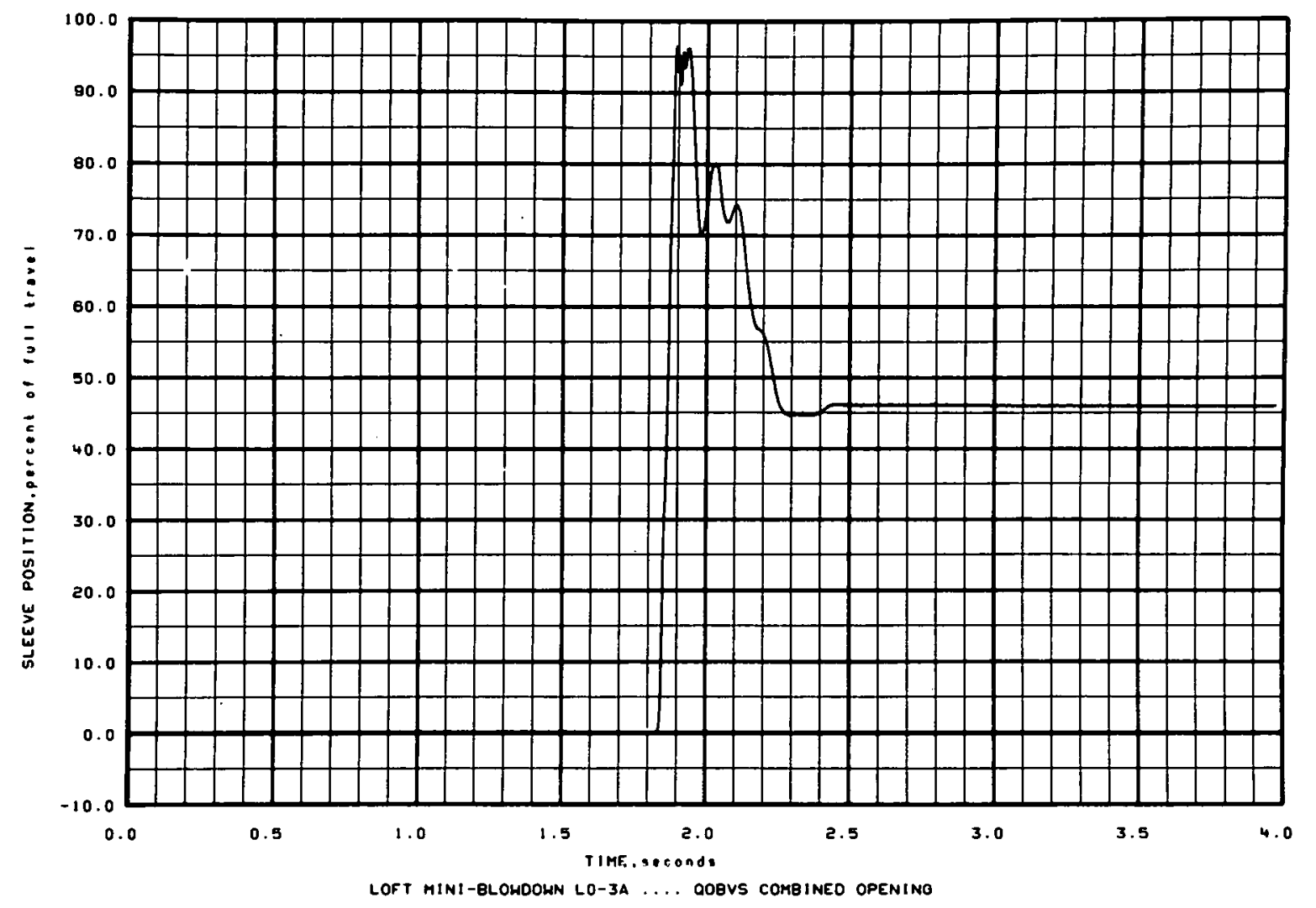

Figure C-5

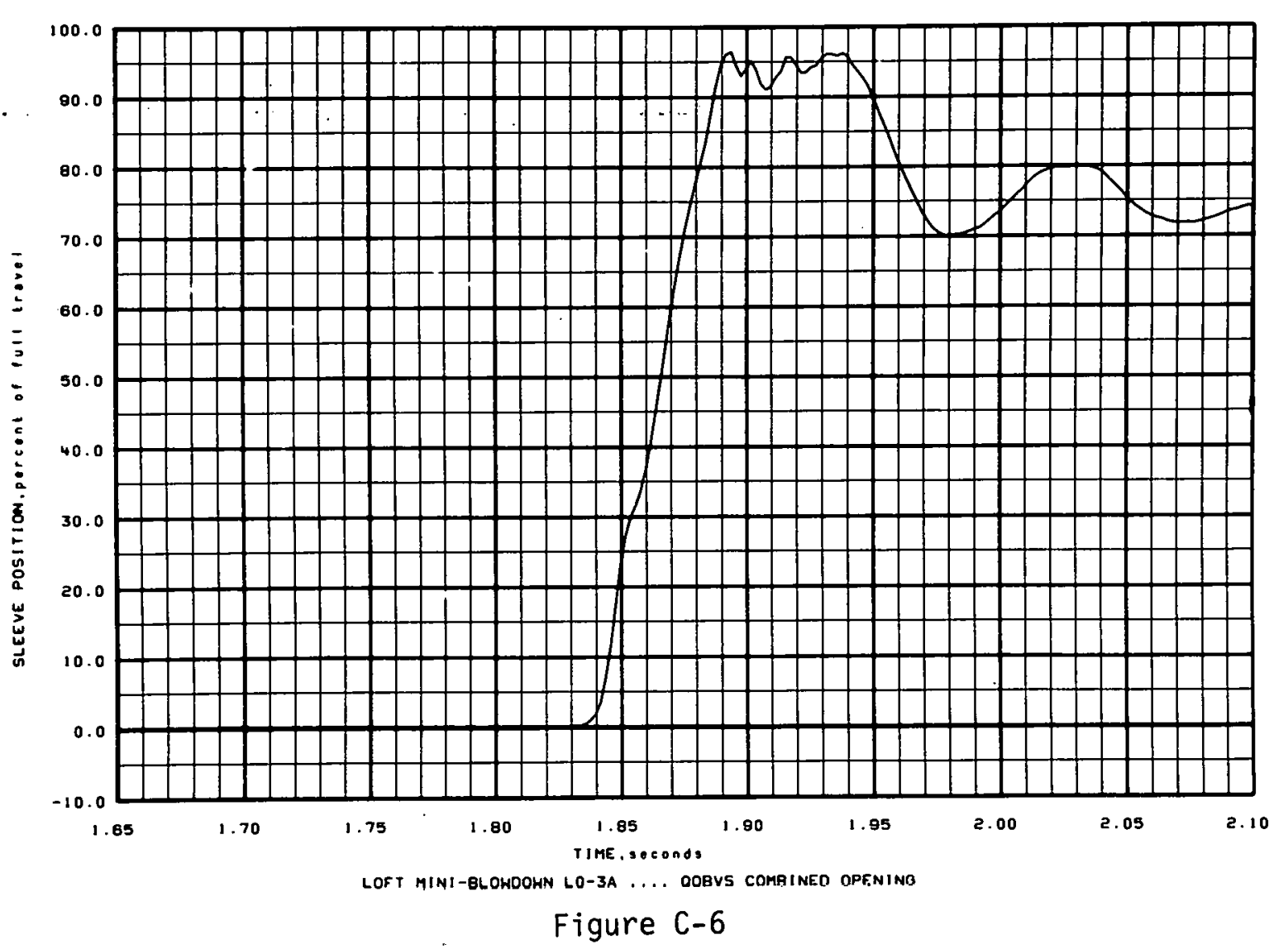



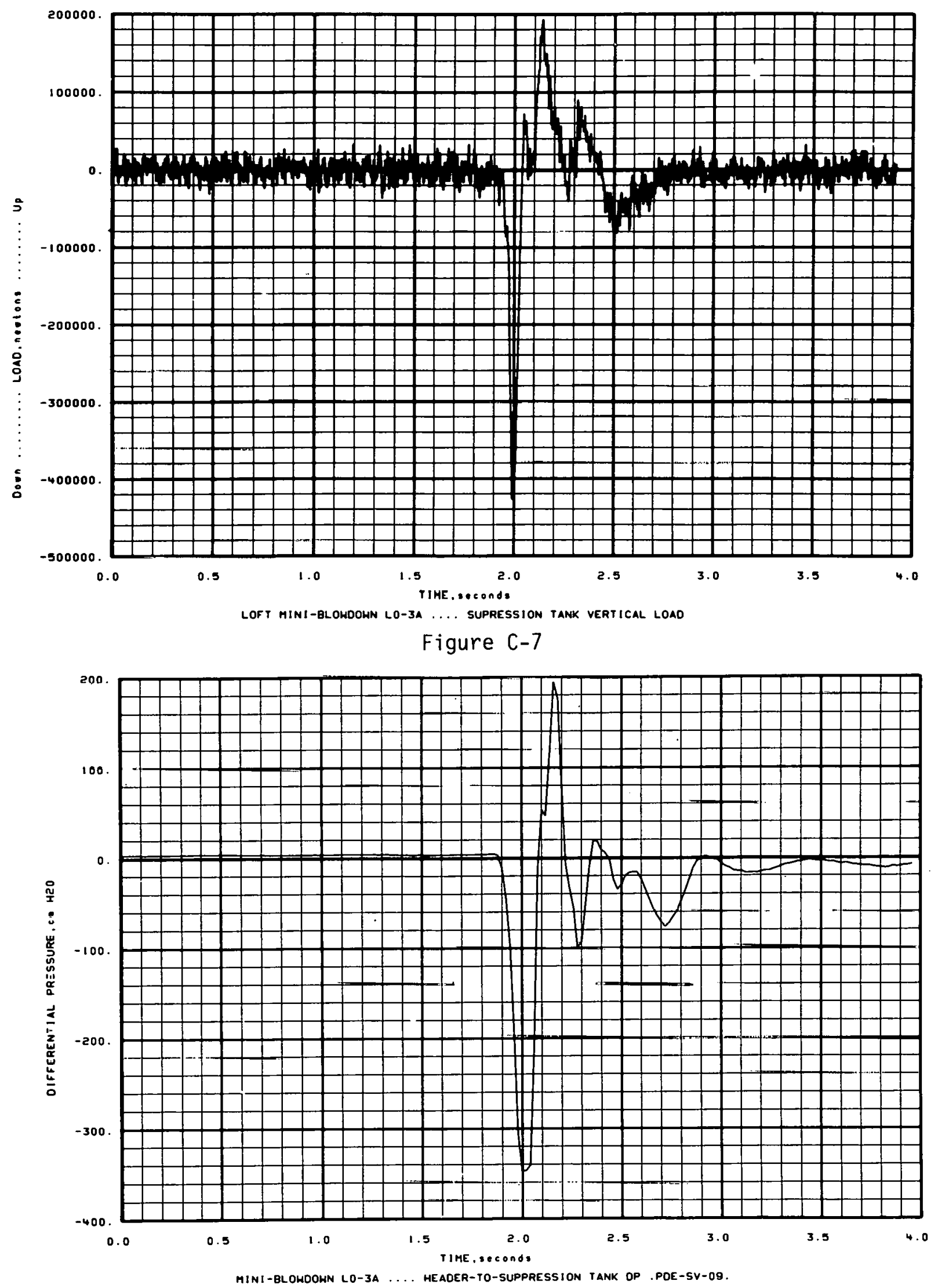

Figure C-8 


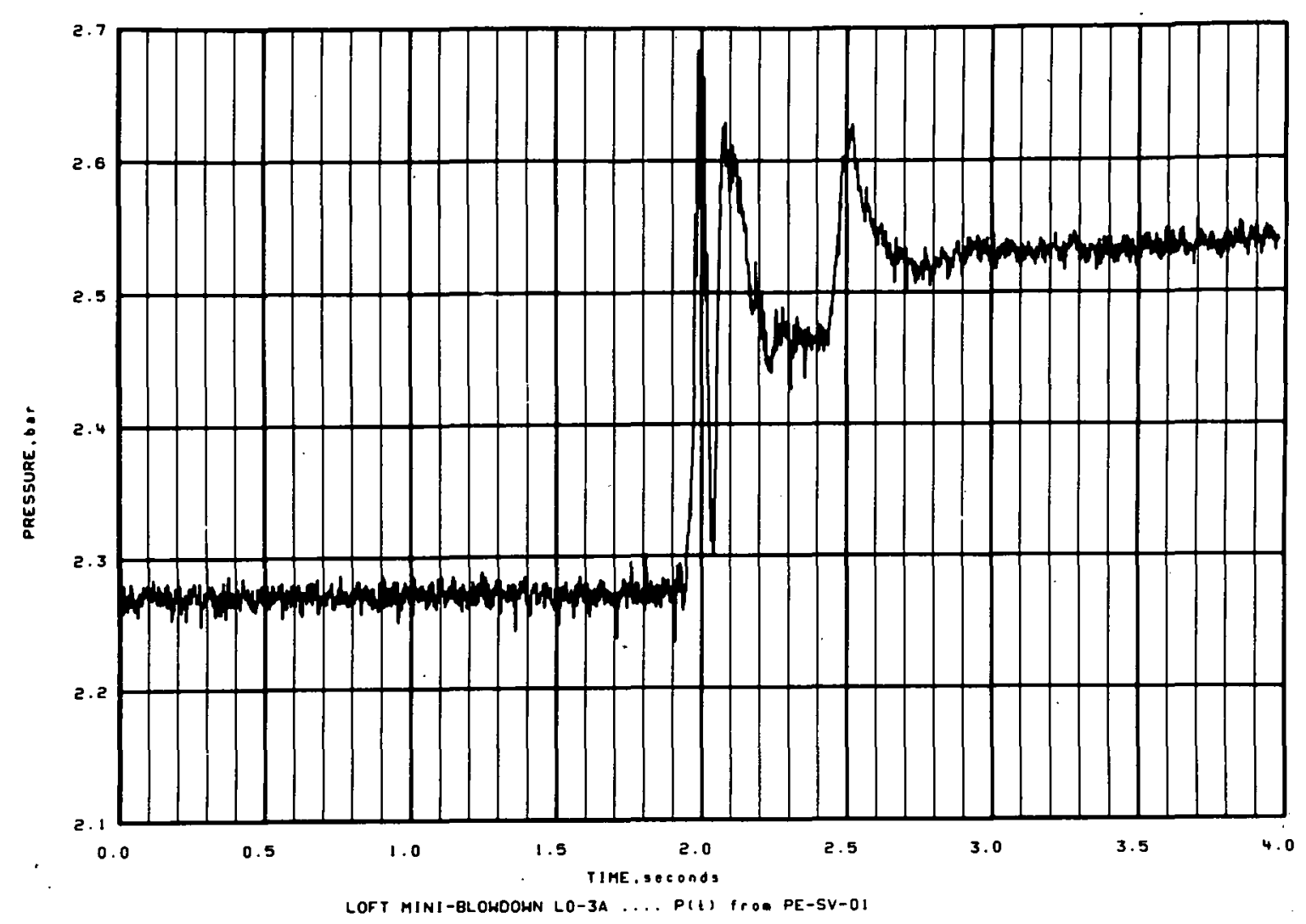

Figure C-9

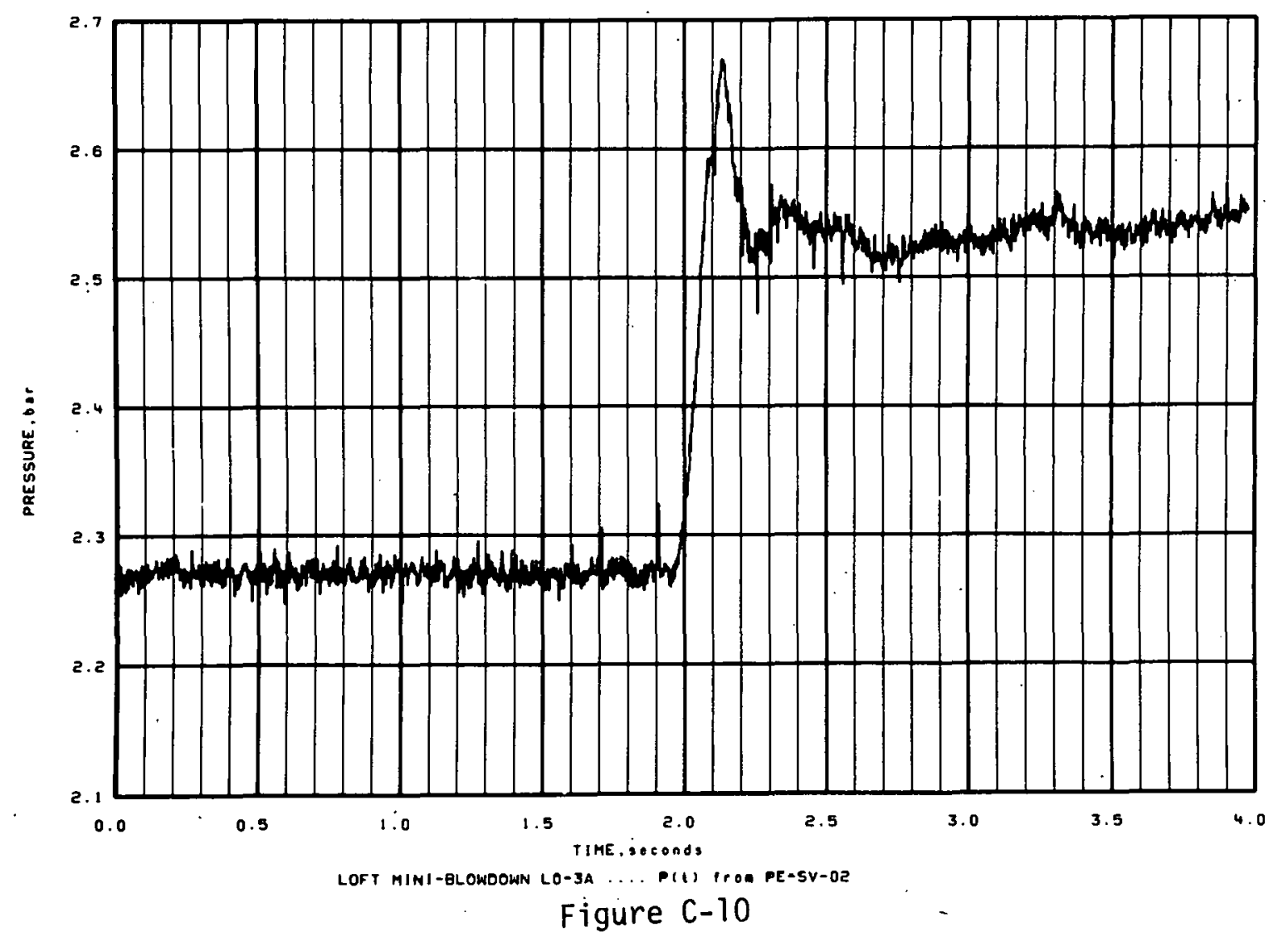




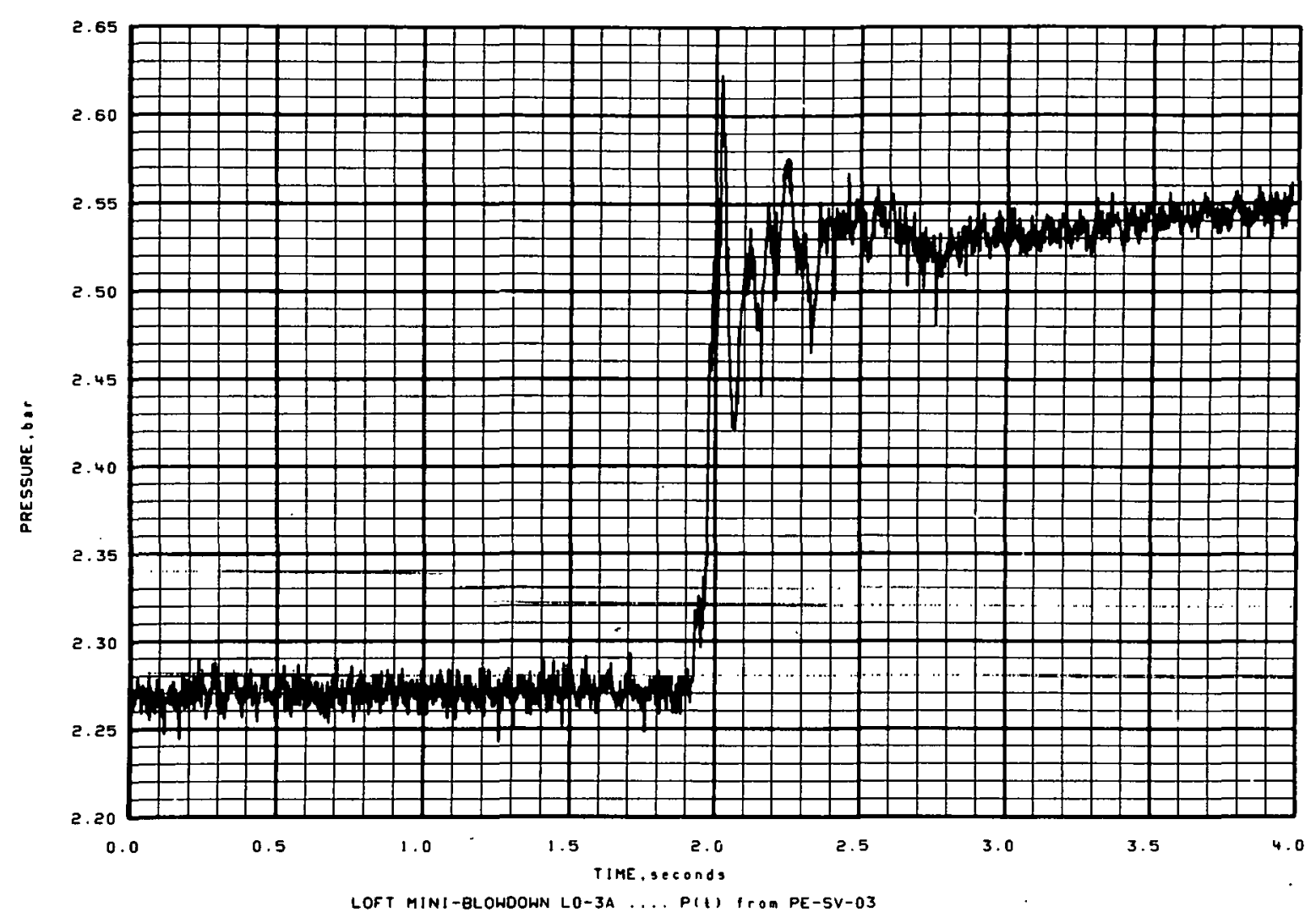

Figure $\mathrm{C}-11$

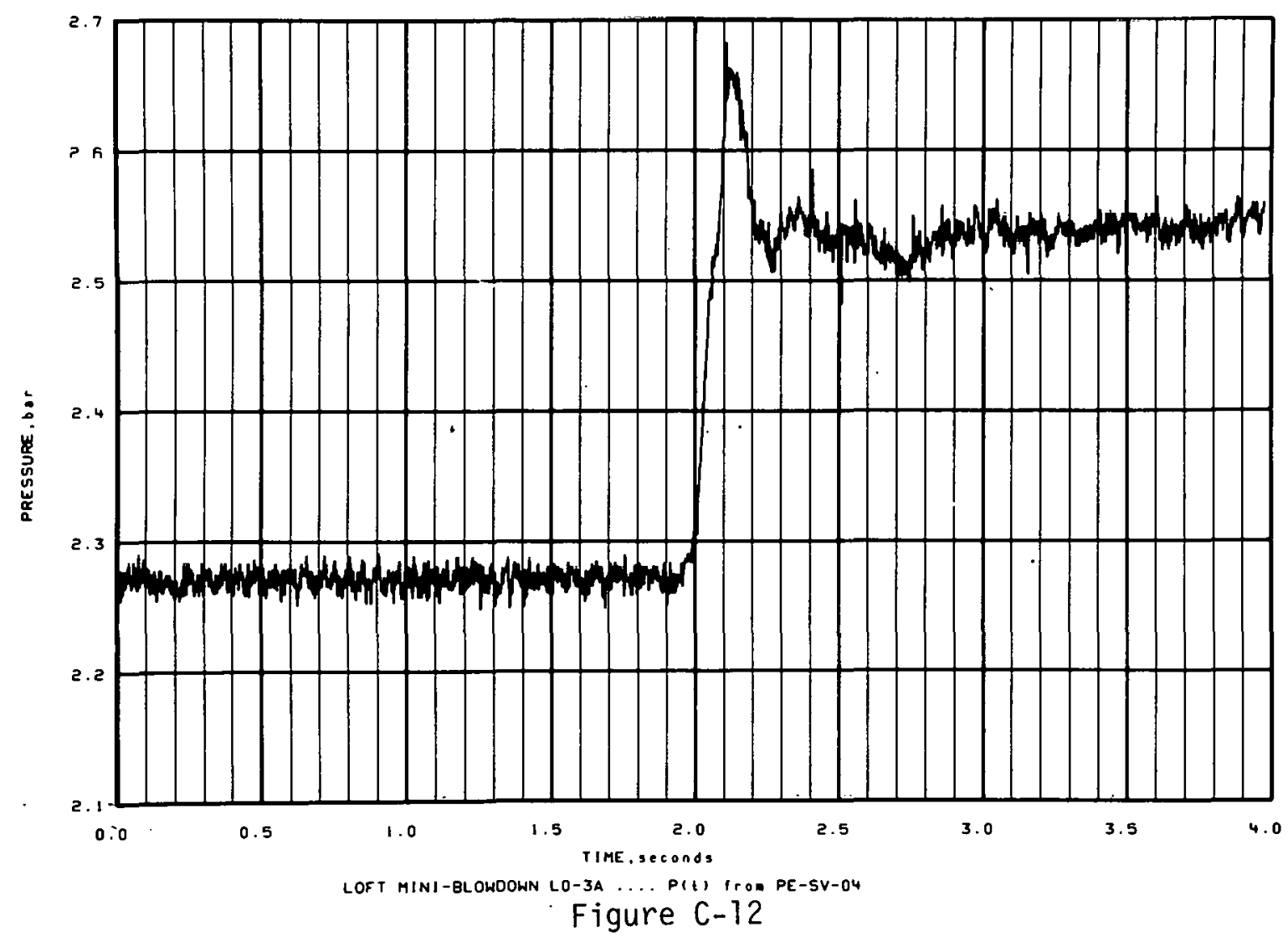




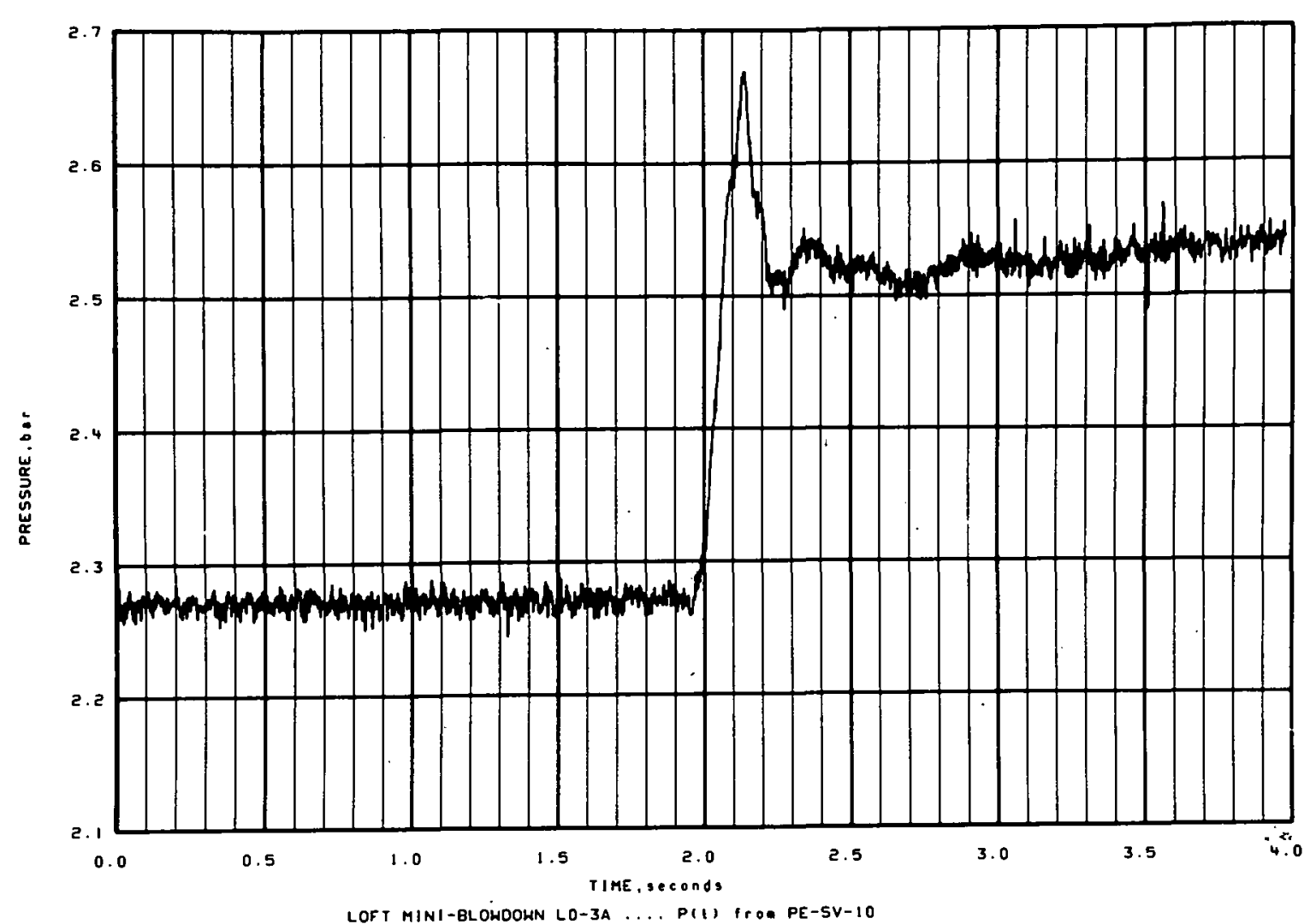

Figure $\mathrm{C}-13$

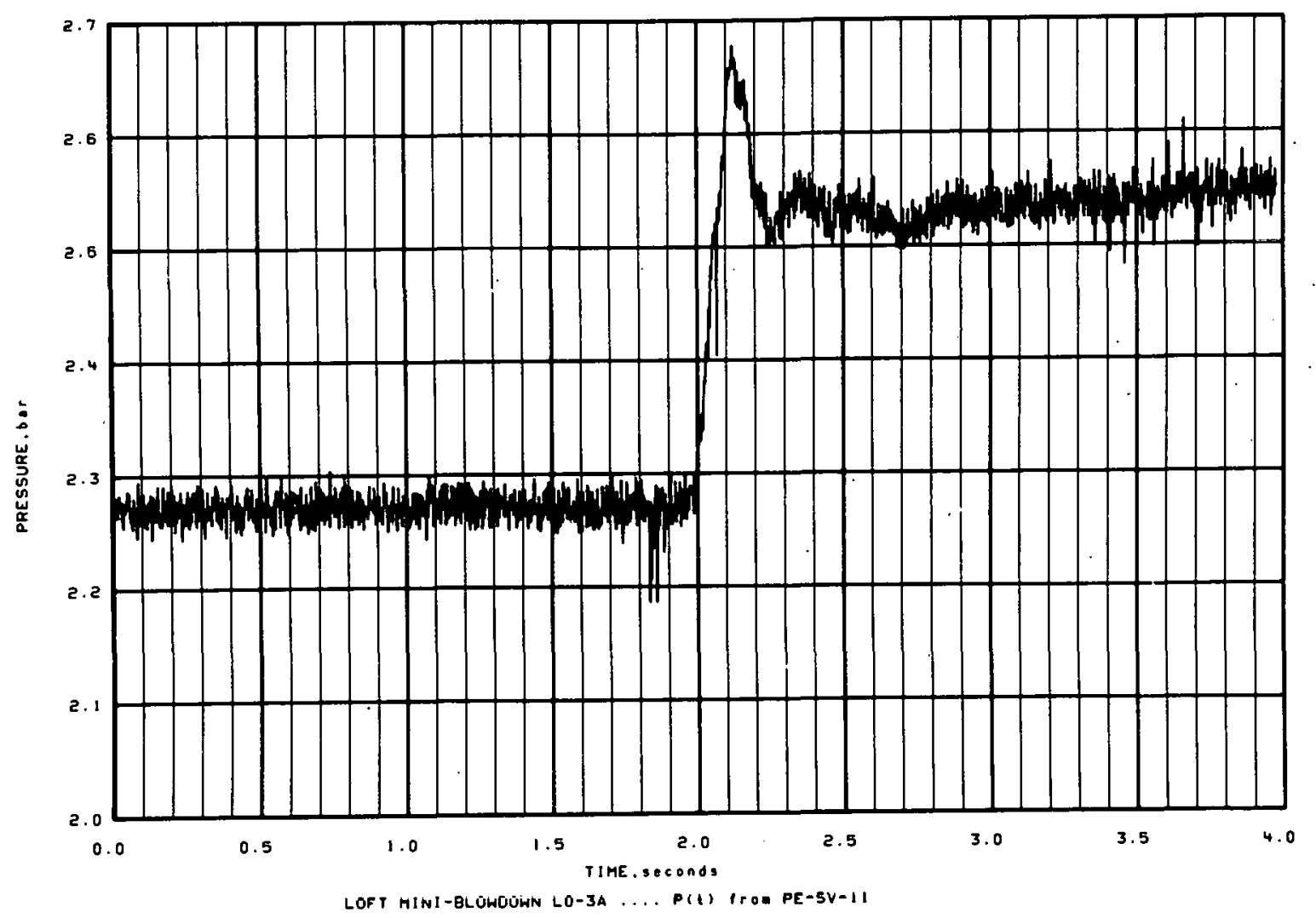

Figure $\mathrm{C}-14$ 

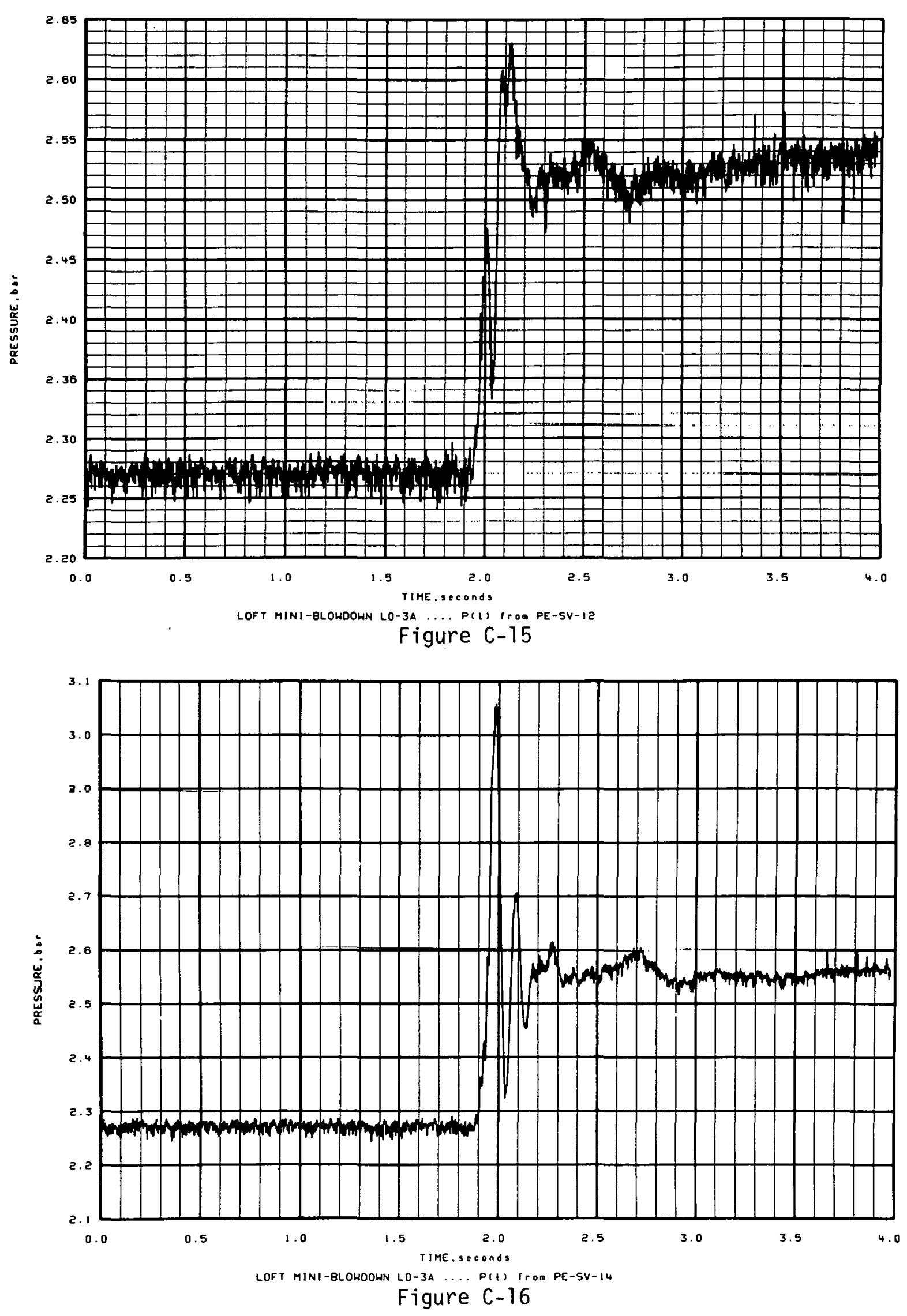

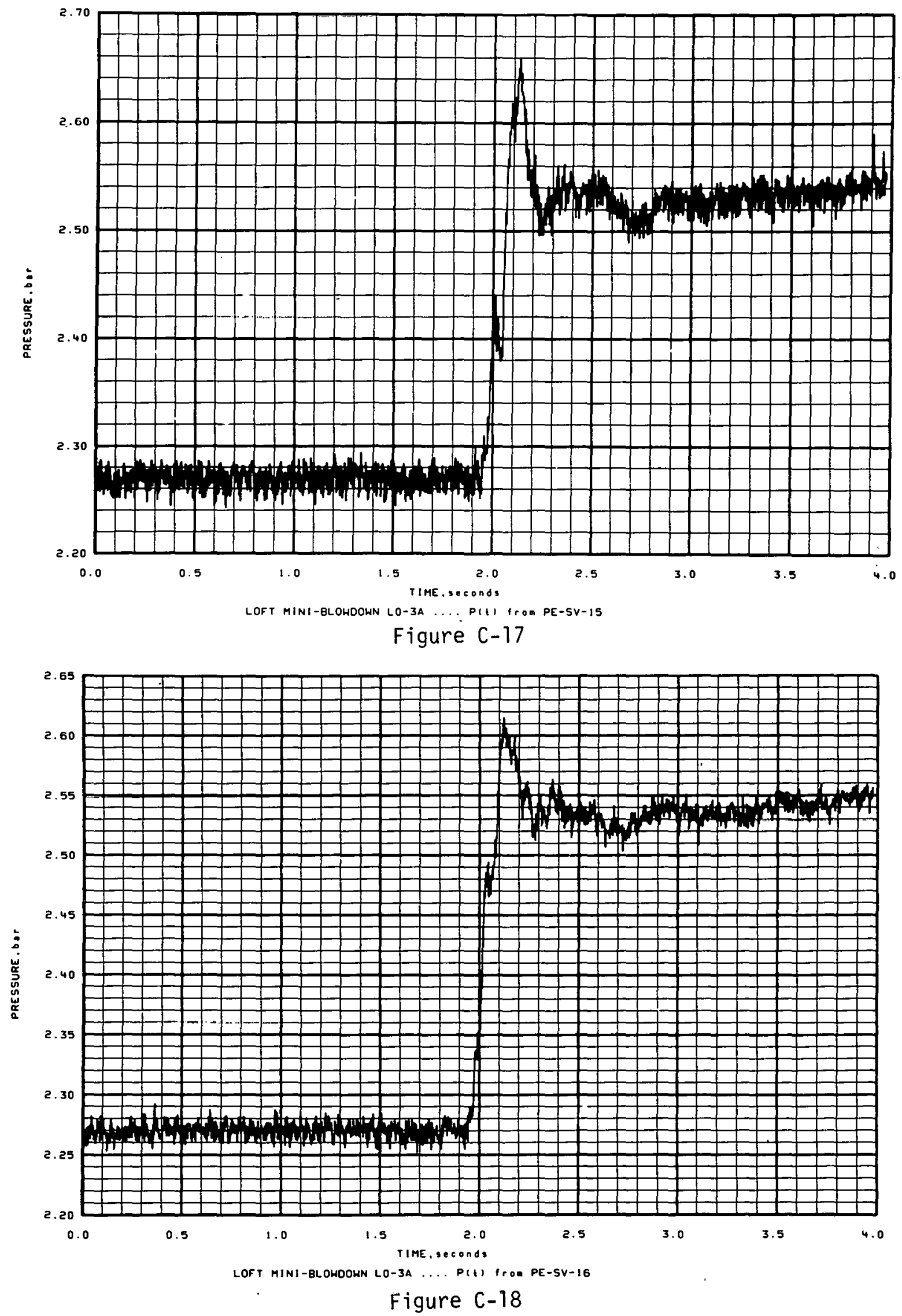


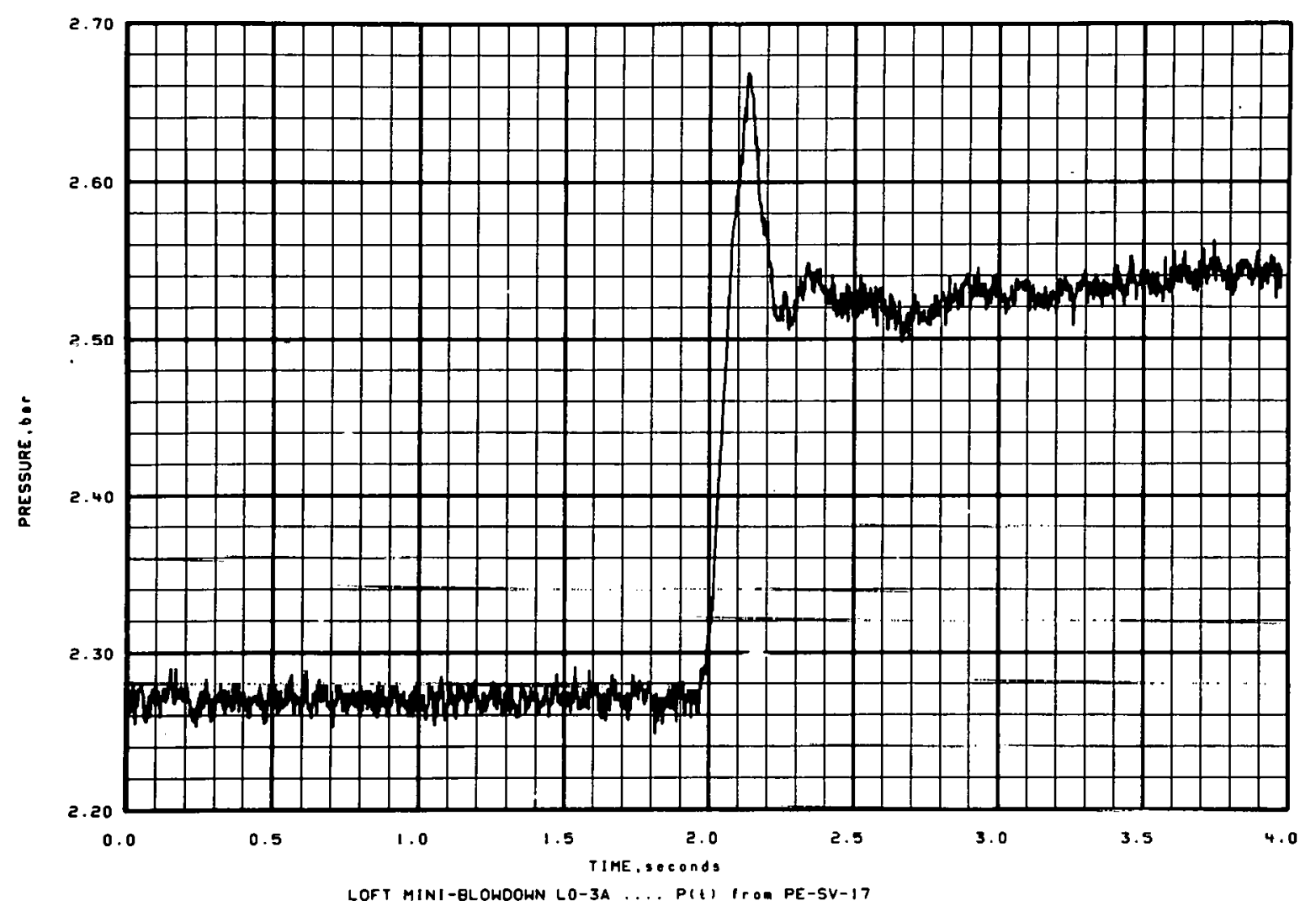

Figure $\mathrm{C}-19$

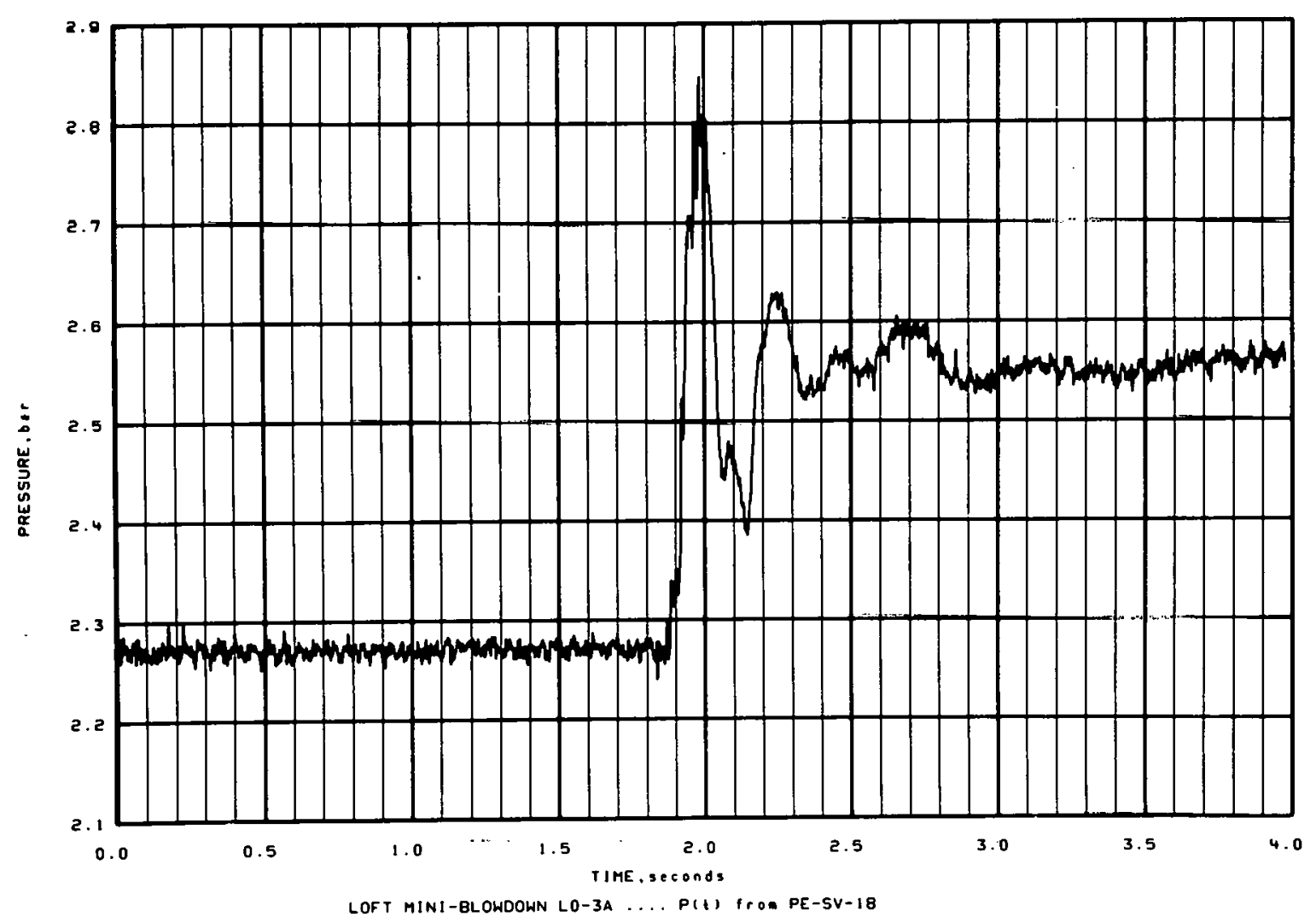

Figure $\mathrm{C}-20$ 

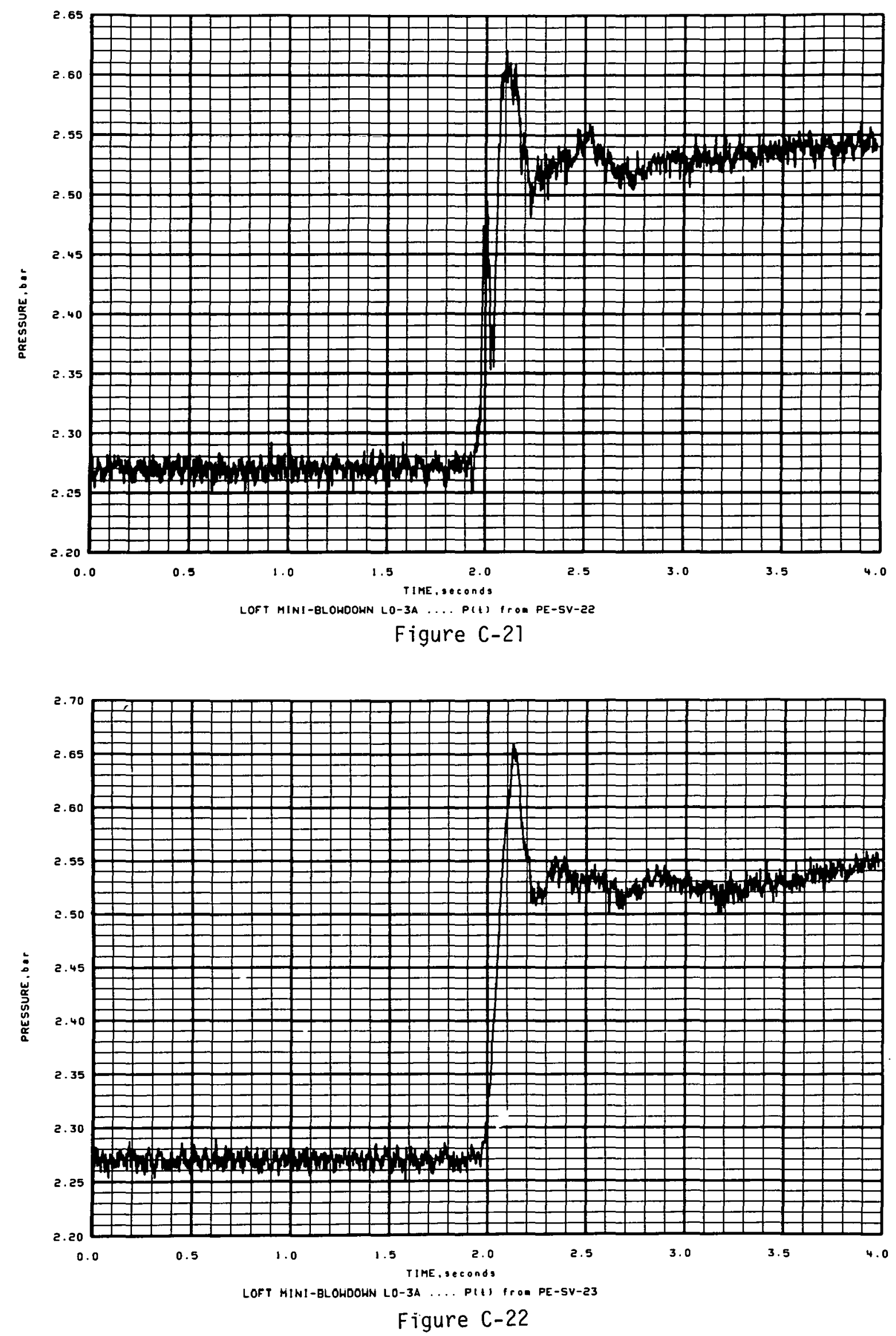


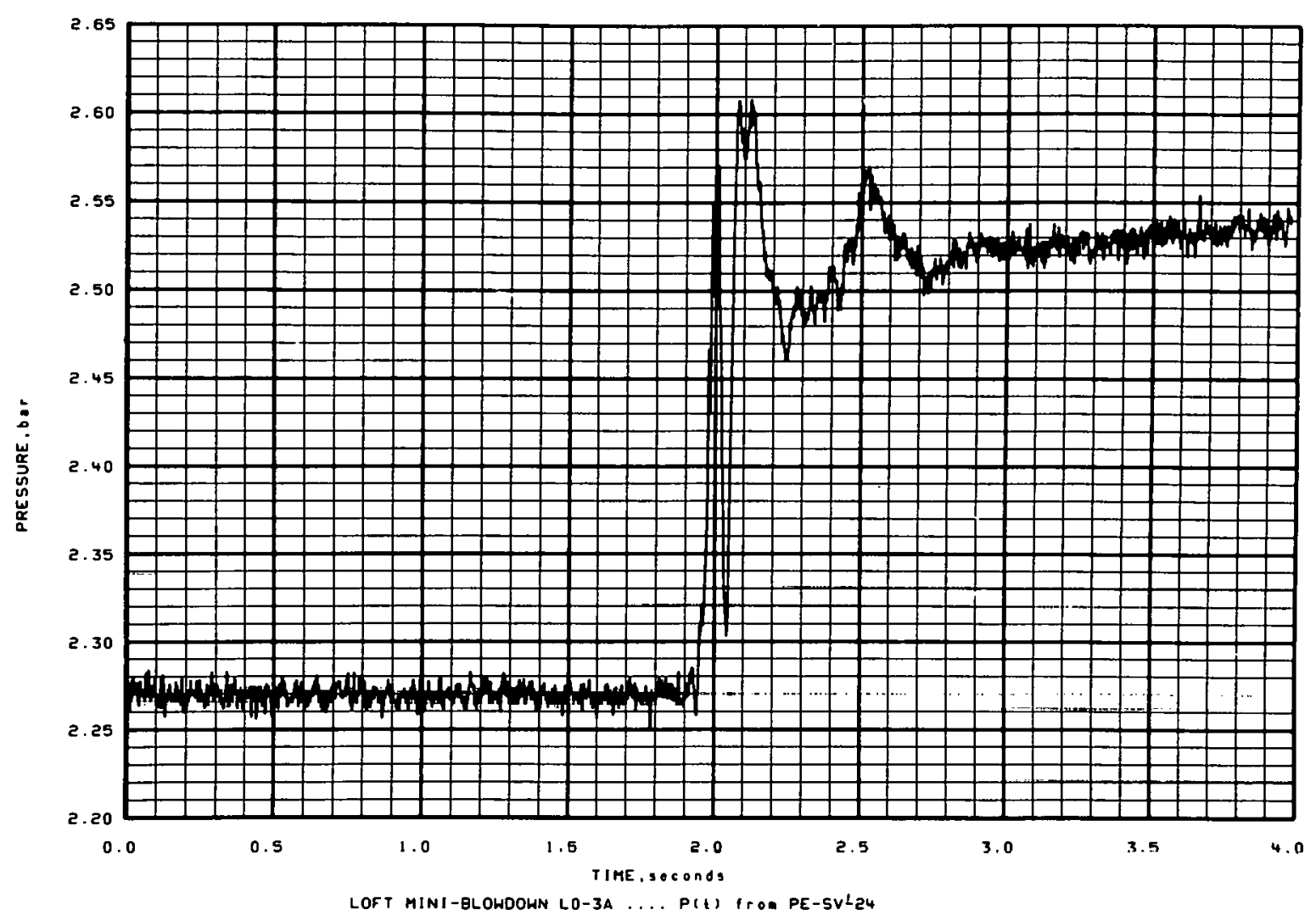

Figure $\mathrm{C}-23$

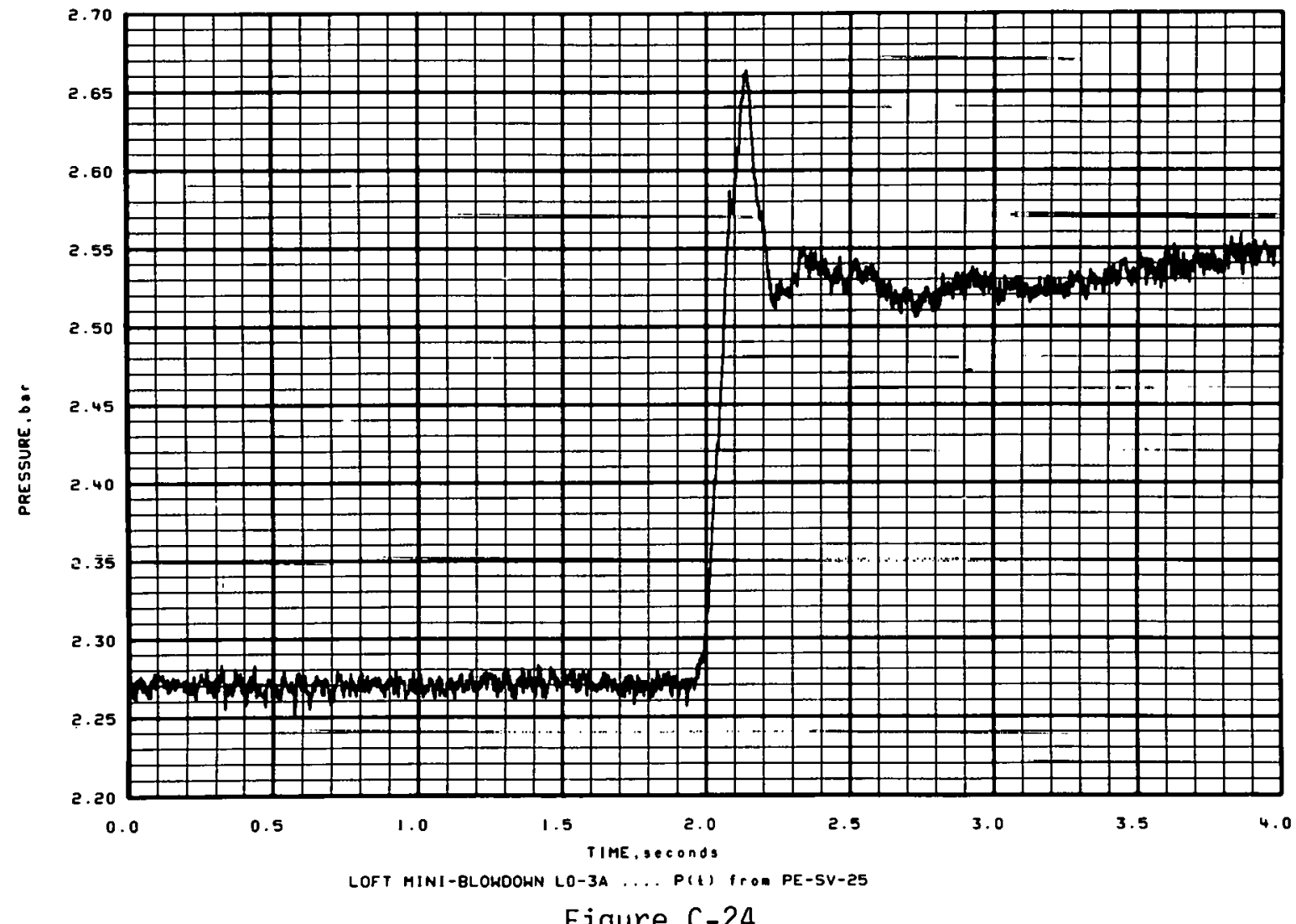

Figure $\mathrm{C}-24$ 

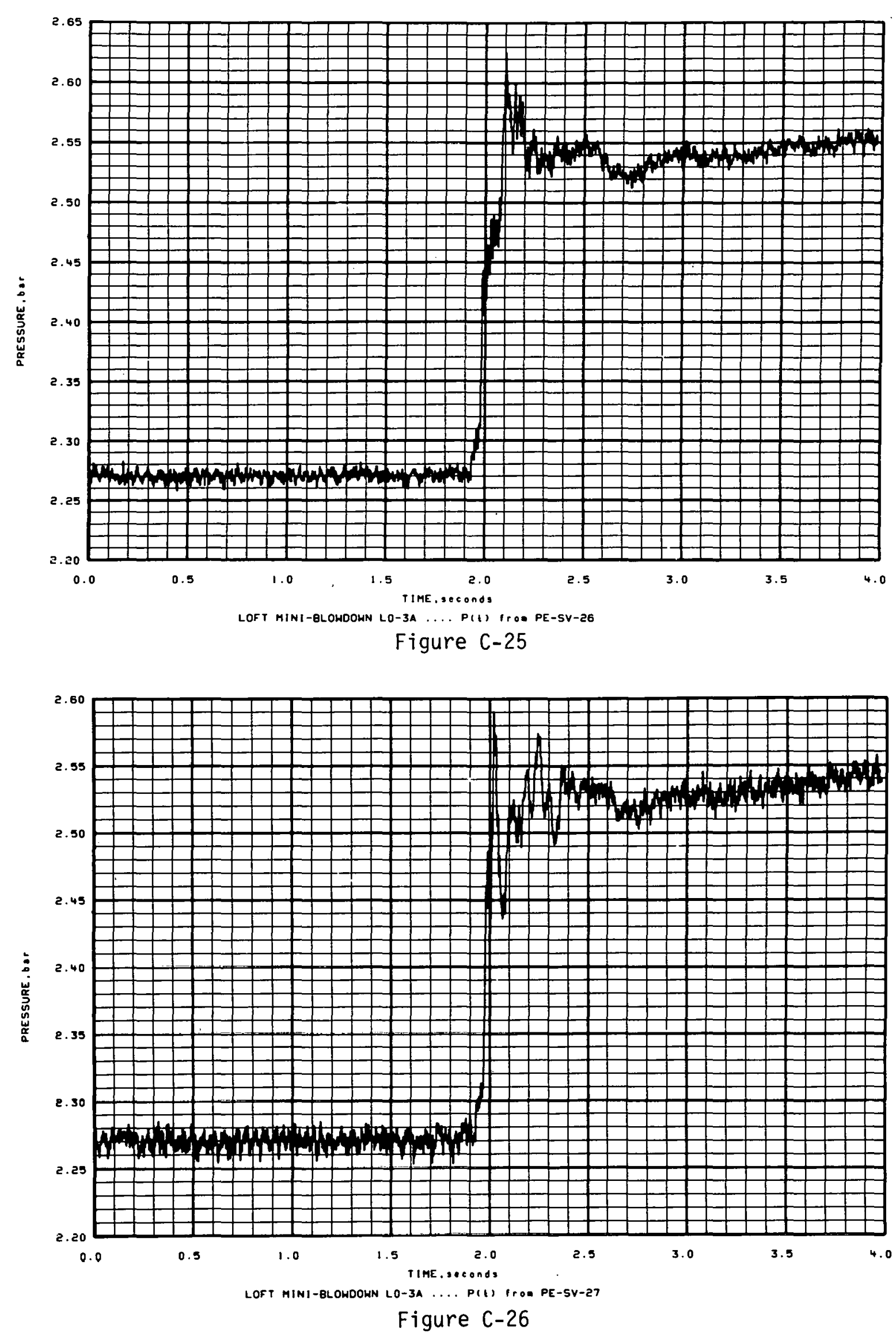

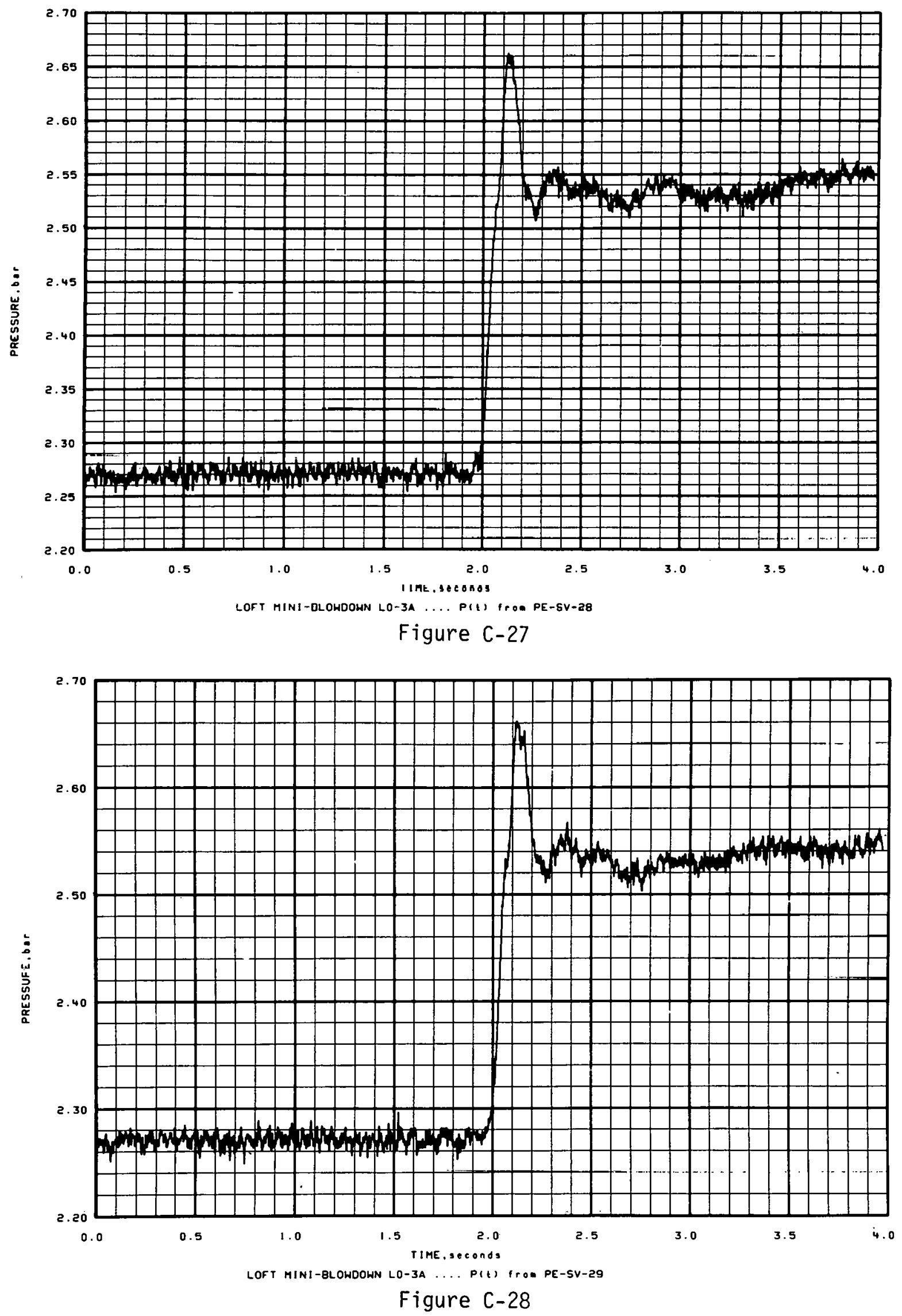


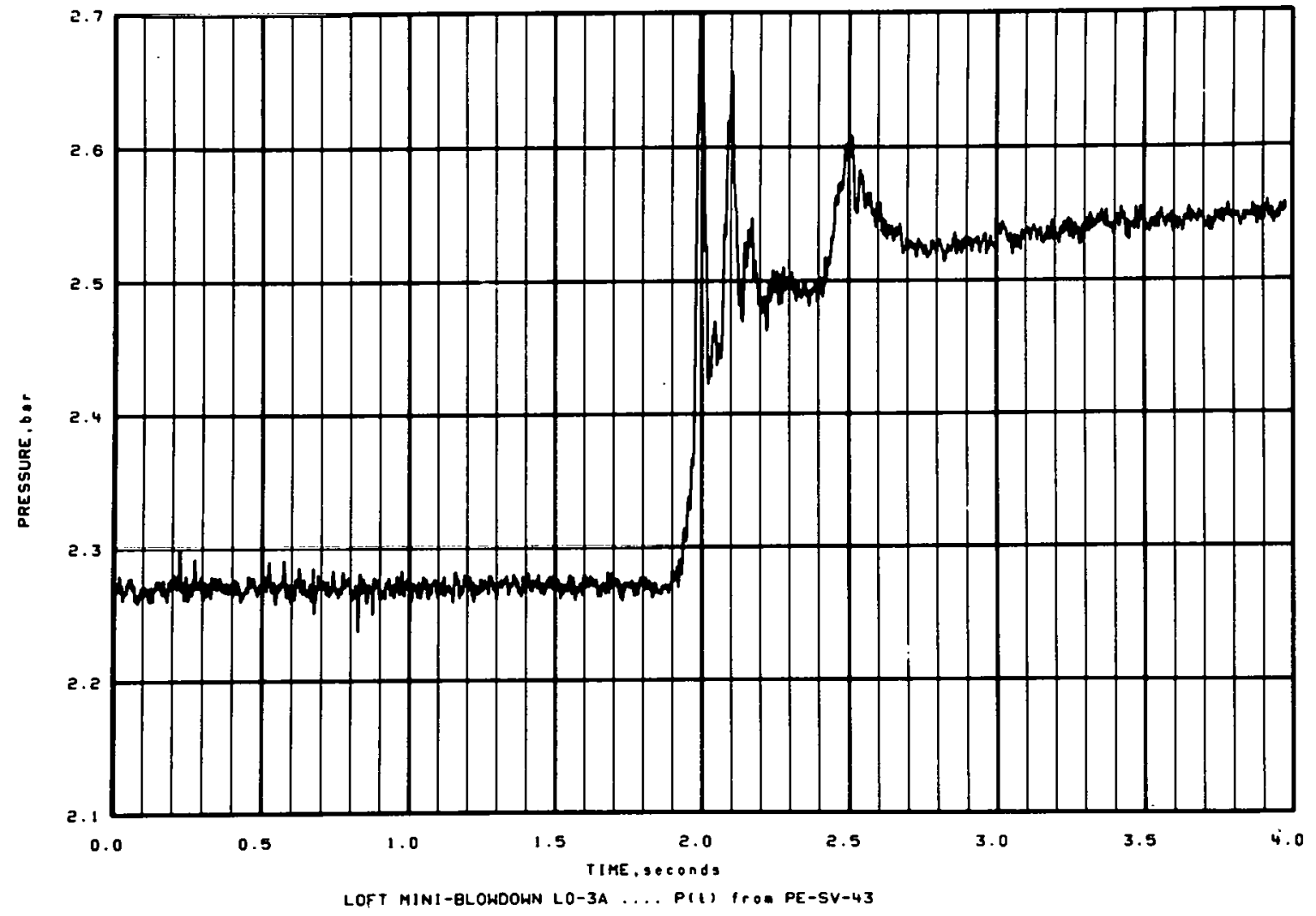

Figure $\mathrm{C}-29$

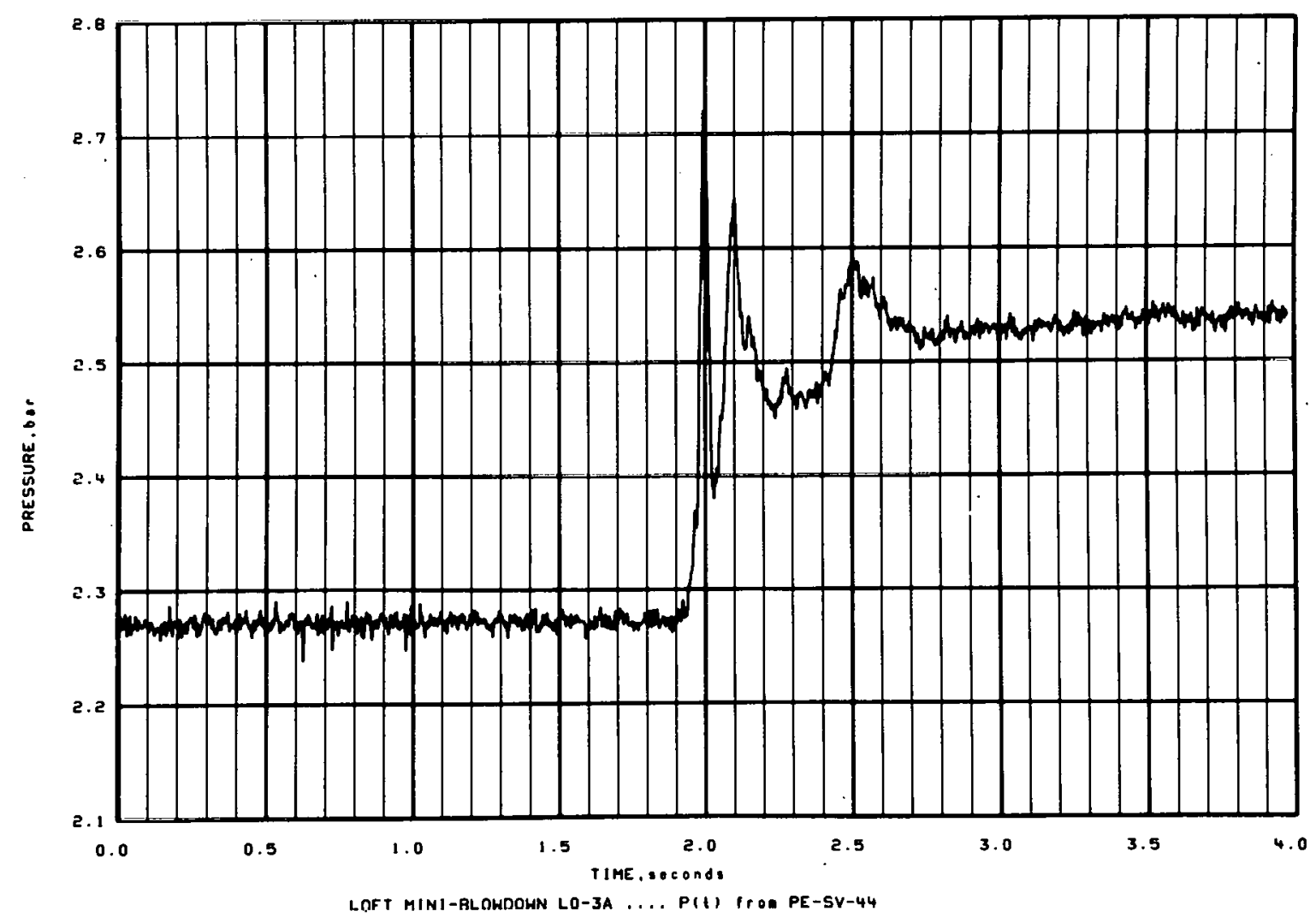

Figure $\mathrm{C}-30$ 

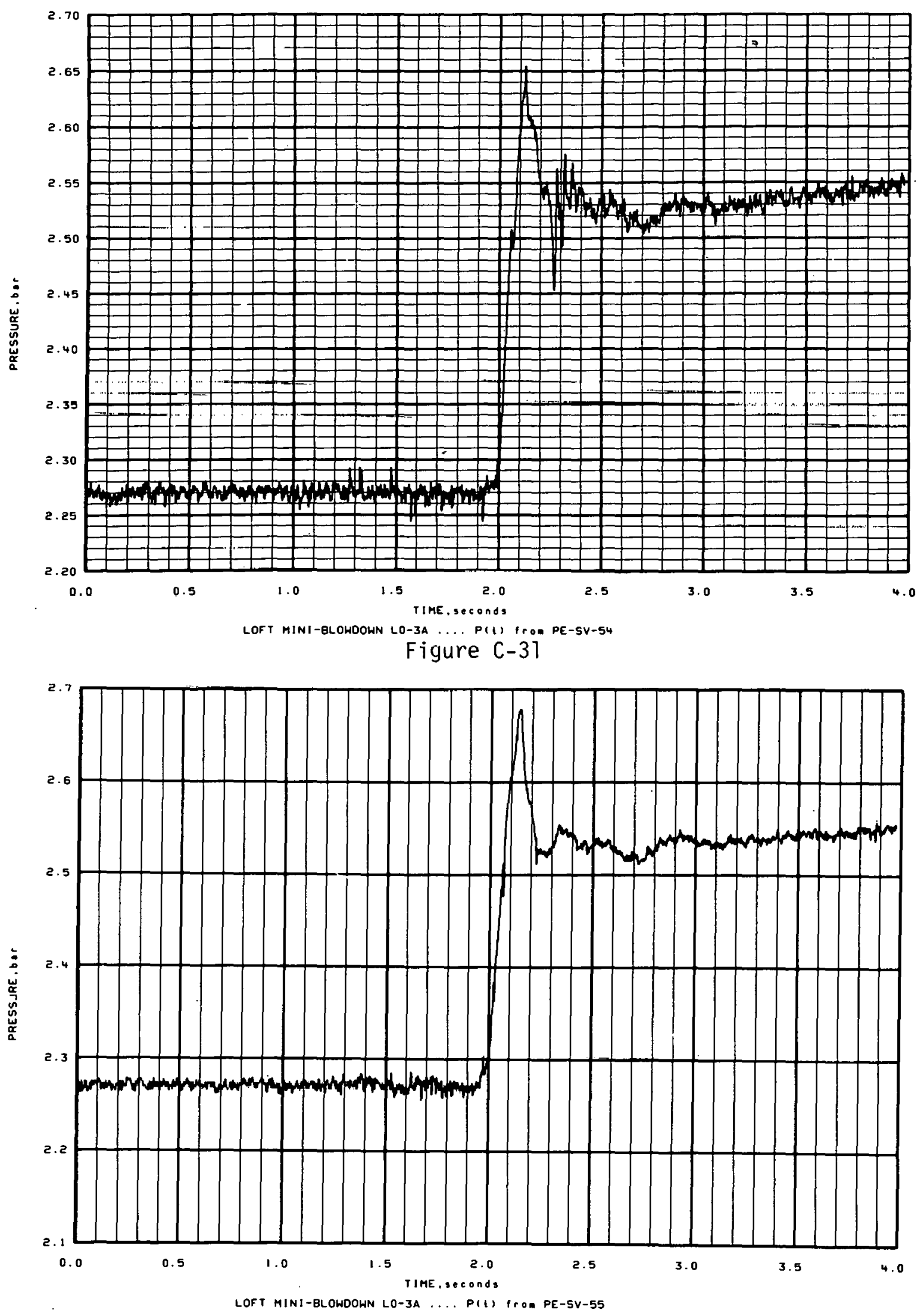

Figure $\mathrm{C}-32$ 


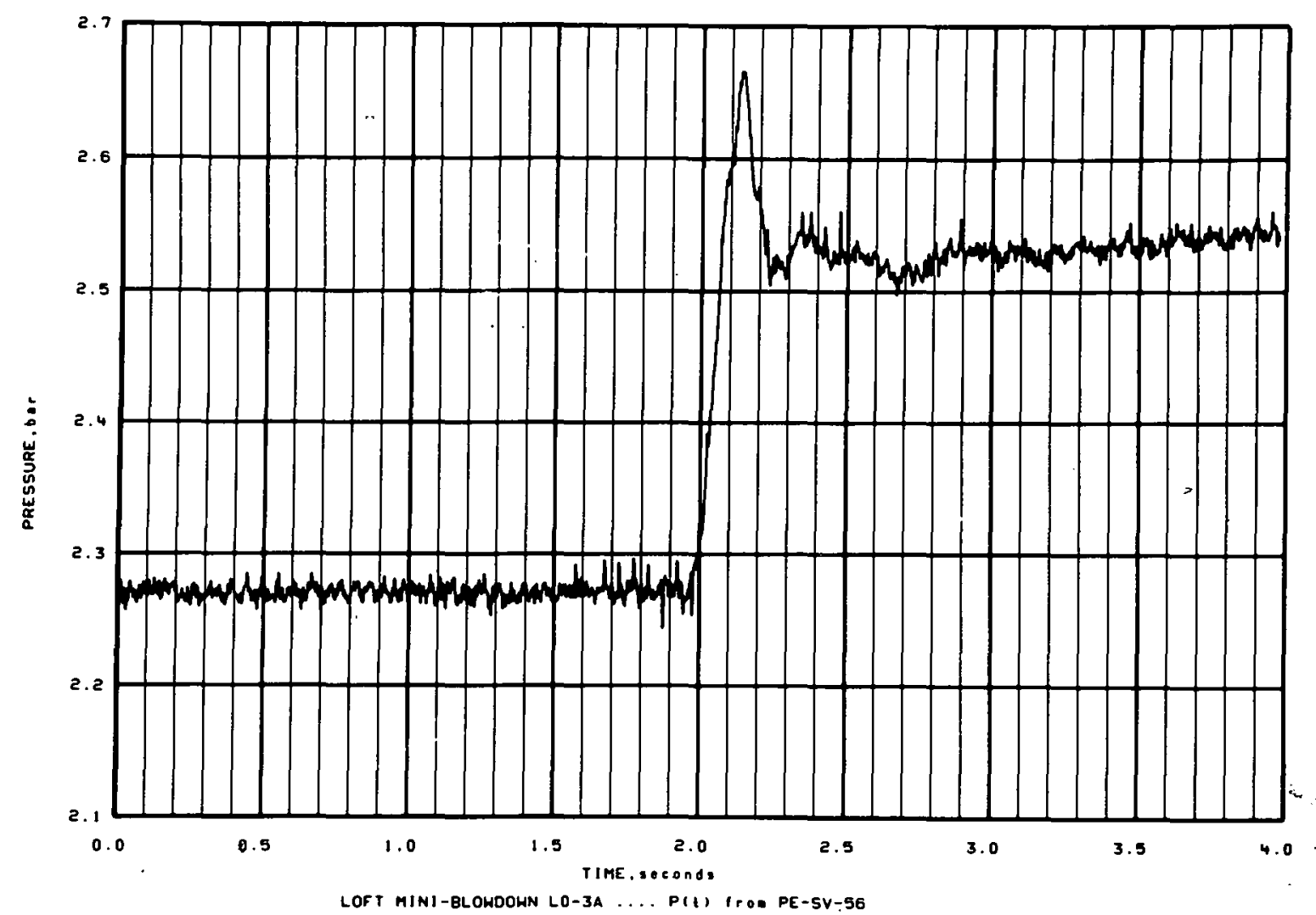

Figure C-33

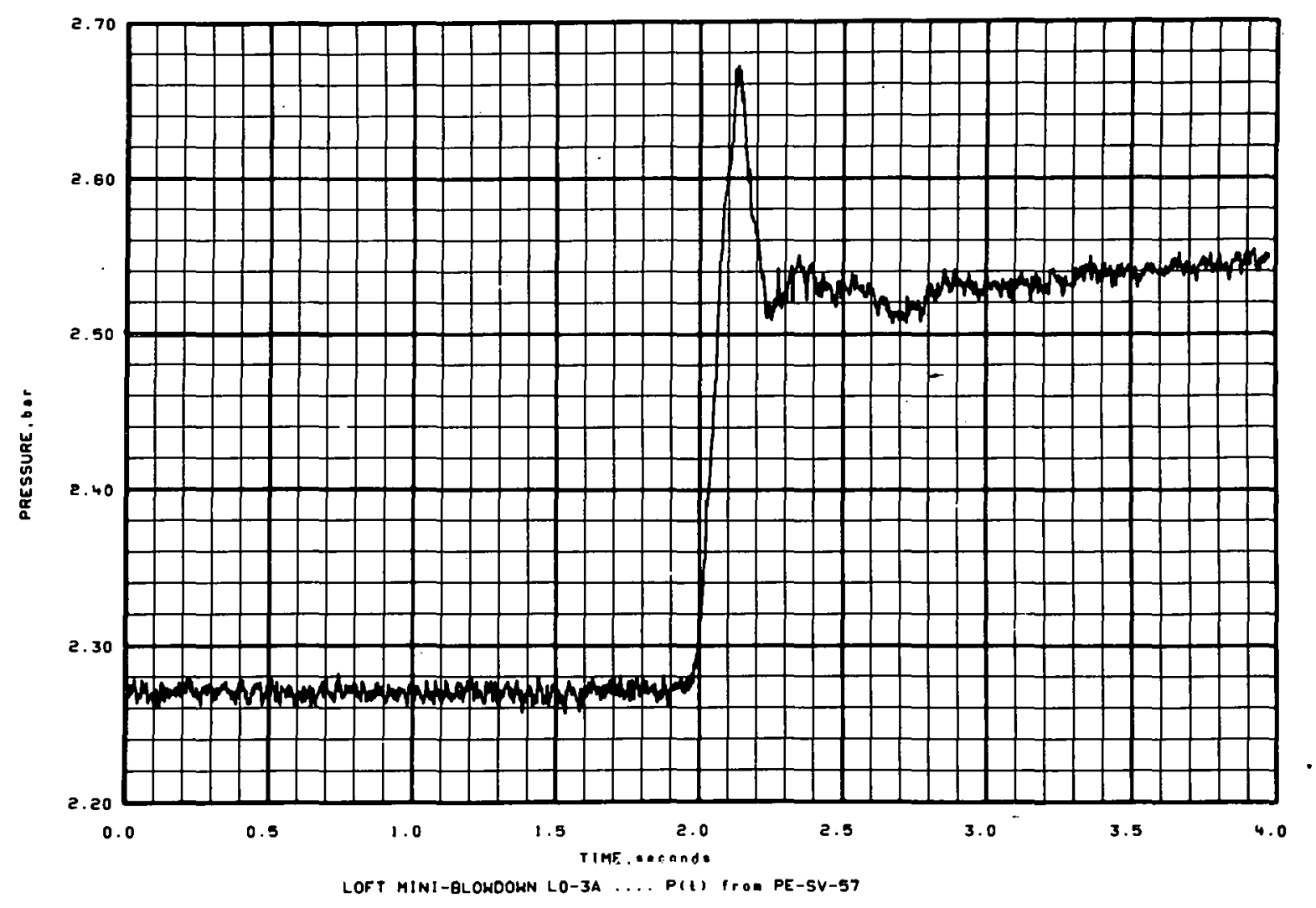

Figure $\mathrm{C}-34$ 


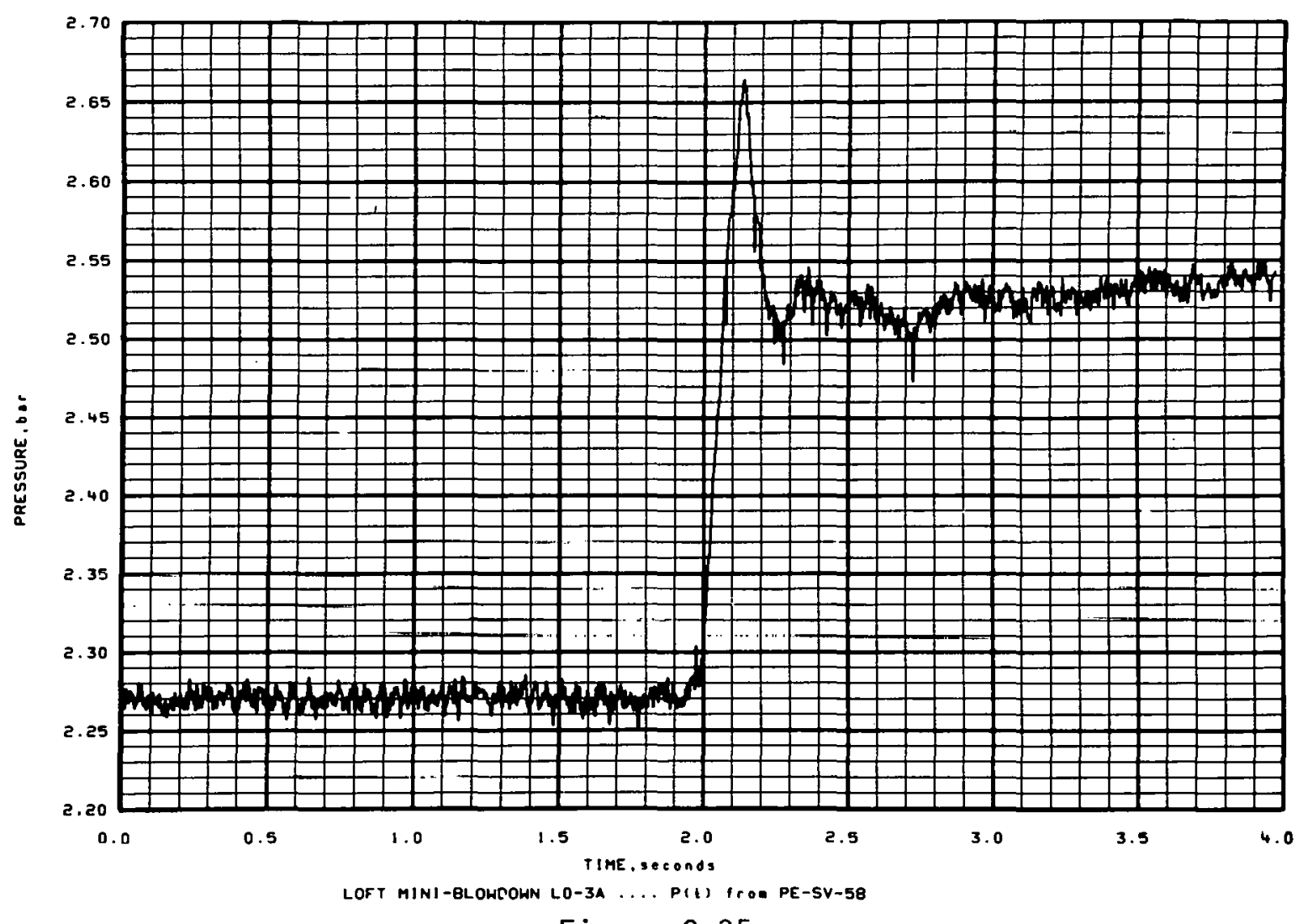

Figure $\mathrm{C}-35$

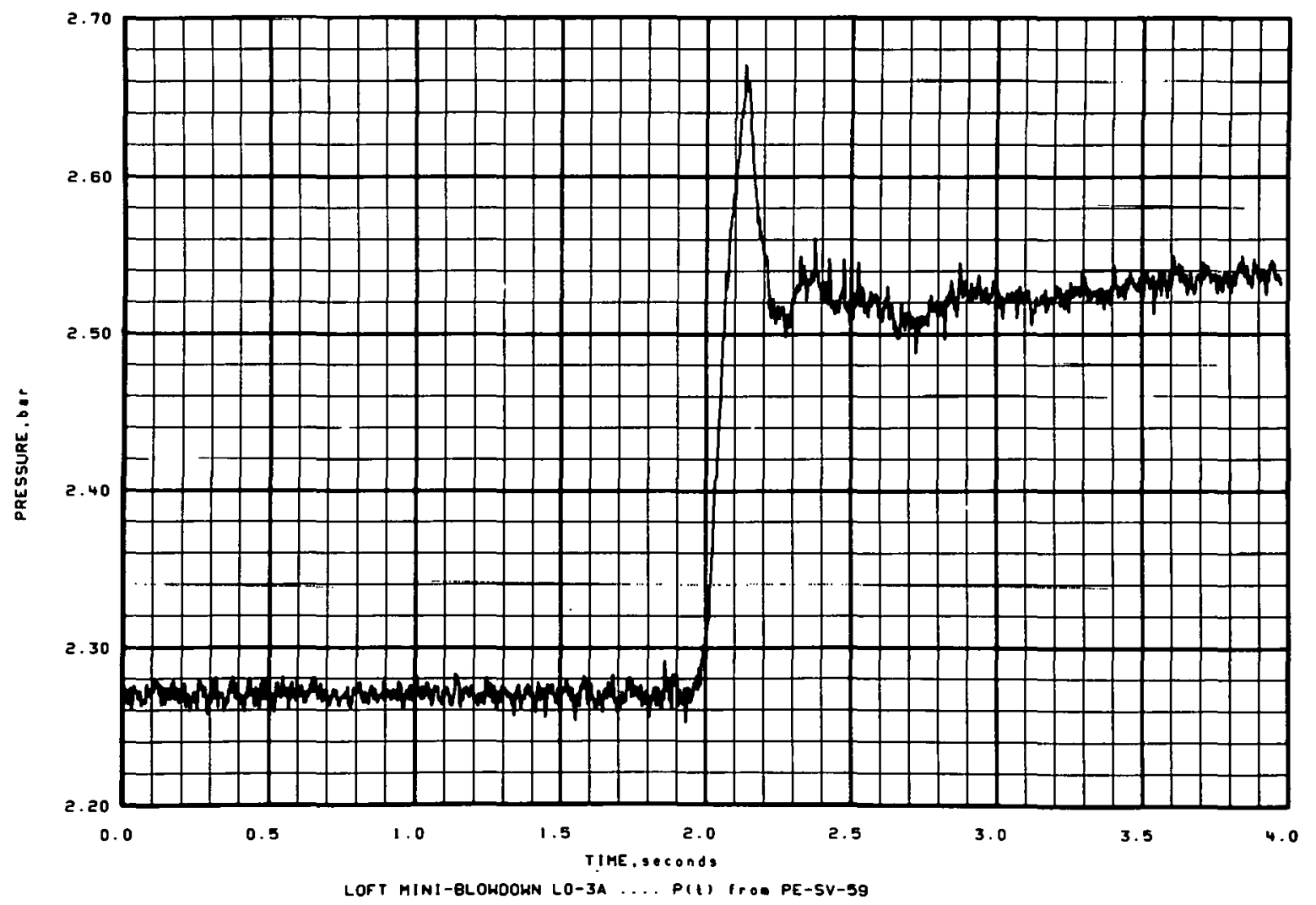

Figure $\mathrm{C}-36$ 


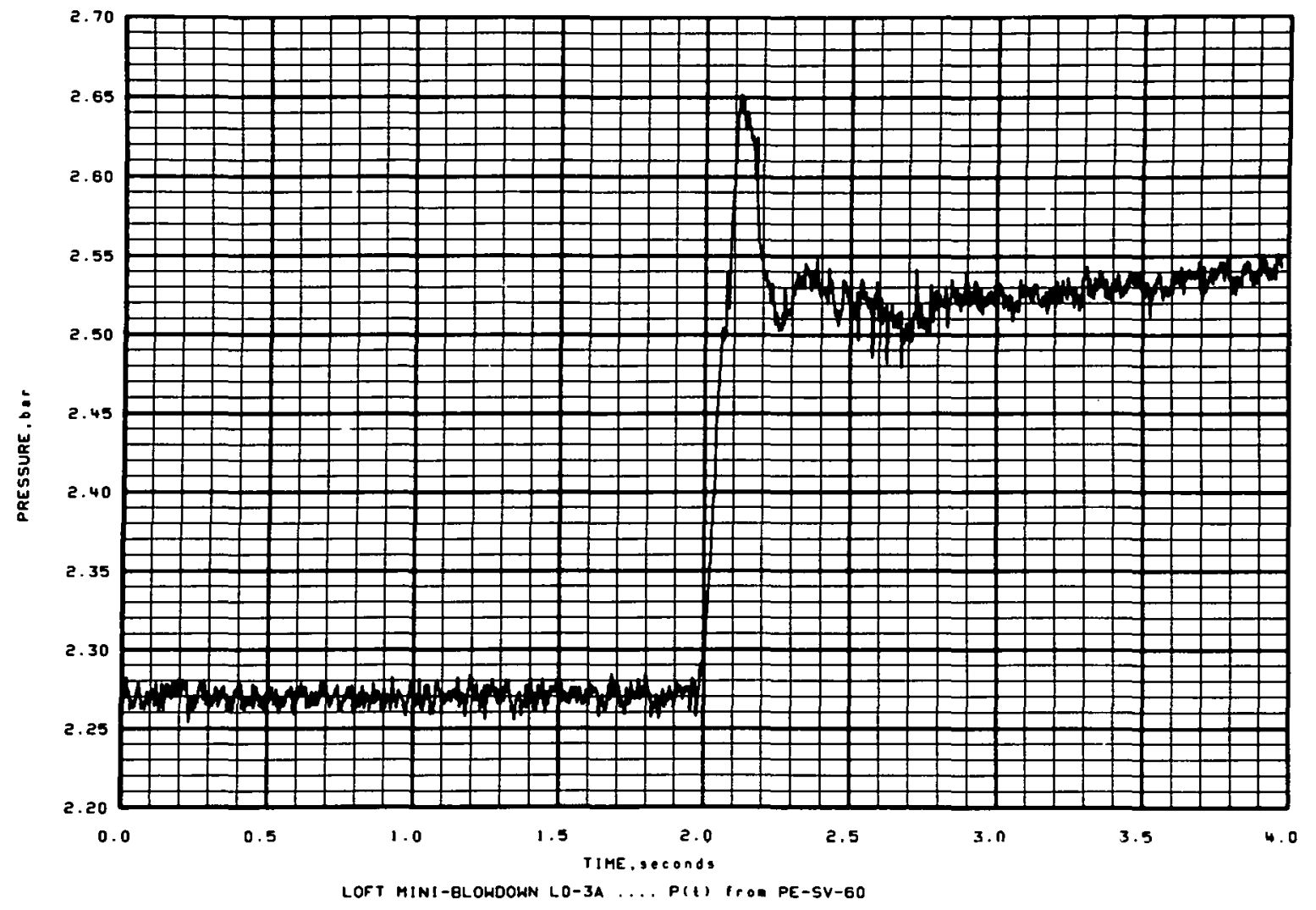

Figure $\mathrm{C}-37$

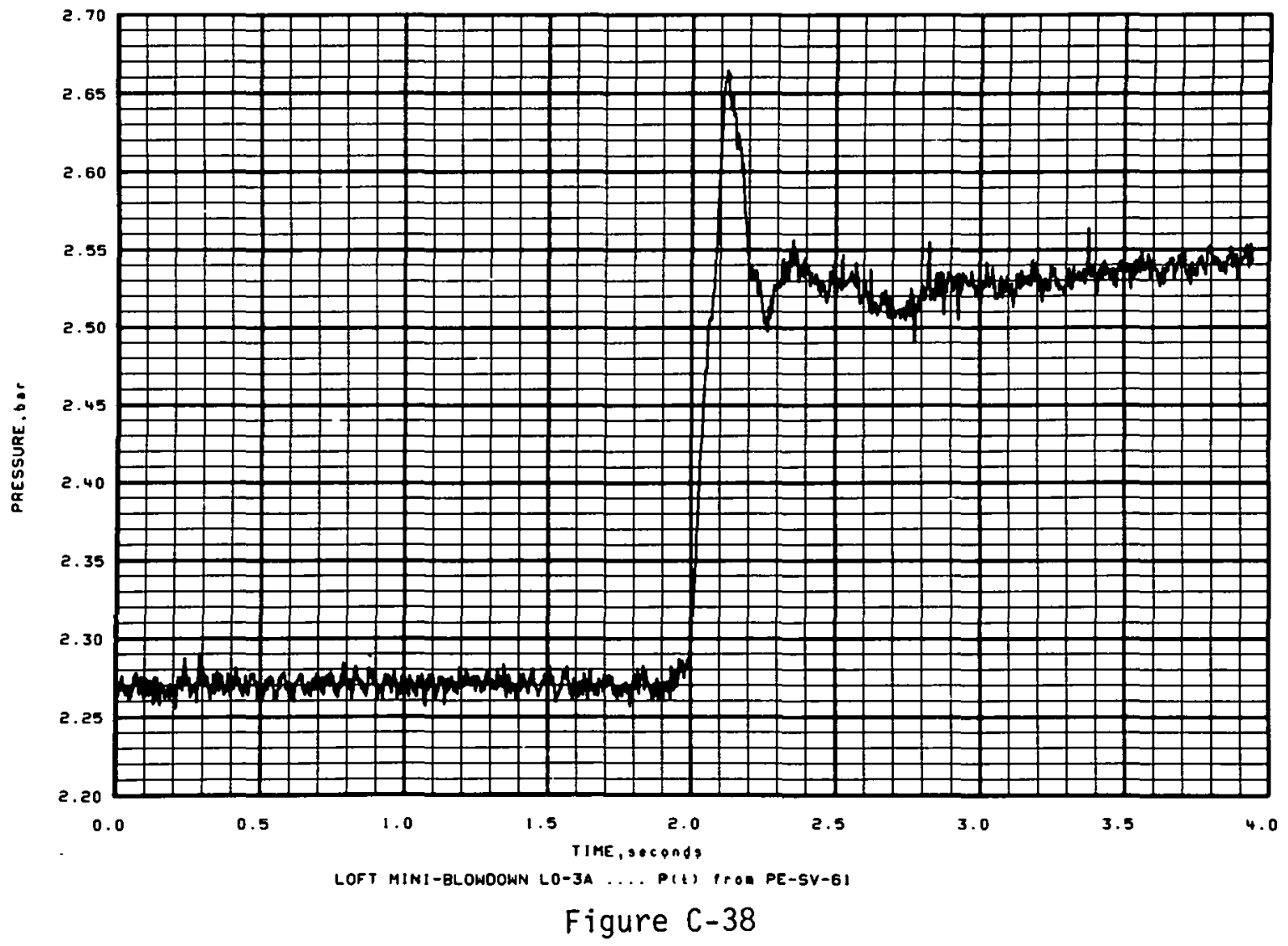


THIS PAGE

\section{WAS INTENTIONALLY}

$\because$ LEFT BLANK 
APPENDIX D

MINI-BLOWDOWN LO-3B EXPERIMENTAL DATA 
THIS PAGE

\section{WAS INTENTIONALLY \\ : LEFT BLANK}


MINI-BLOWDOWN LO-3B EXPERIMENTAL DATA

Both QOBVs were to open in this experiment; however, QOBV-1 did not open. The fluid temperature in QQBV- 15 was $232.1 \pm 1.5^{\circ} \mathrm{C}$. The suppression tank initial conditions were $2.21 \pm 0.08 \mathrm{bar}, 28.5 \pm 1.5^{\circ} \mathrm{C}$ in the gas volume, and $26.5 \pm 1.5^{\circ} \mathrm{C}$ in the pool. The vents were submerged $26.7 \pm 2.5 \mathrm{~cm}$. The internal vent submergence was essentially the same and is given as $26.7 \pm 3.2 \mathrm{~cm}$.

The experimental data are defined in Table D-I. The opening characteristics of the QOBVS are shown in terms of percent sleeve travel versus time. The flow area of the valve begins to open at a sleeve position of $17 \%$ of full travel and is fully open at a sleeve position of $66 \%$ of full travel. The differential pressure between the header and the tank gas volume is measured with a very sensitive device primarily to provide information on vent preclearing. The data channel for this measurement is driven to saturation in the early part of the transient. 
TABLE D-I

EXPERIMENT LO-3B DATA SUMMARY

\begin{tabular}{|c|c|c|c|c|c|}
\hline $\begin{array}{c}\text { Measurement } \\
\text { or } \\
\text { Calculation }\end{array}$ & $\begin{array}{l}\text { Pre-Transient } \\
\text { Data Channel } \\
\text { Variance } \\
(10-4 \text { bar } 2) \\
\end{array}$ & Figure Number & Measurement & $\begin{array}{c}\text { Pre-Transient } \\
\text { Data Channei } \\
\text { Variance } \\
\left(10^{-4} \text { bar }{ }^{2}\right) \\
\end{array}$ & Figure Number \\
\hline QOBV- 1 opening & - & $D-1, D-2$ & PE-SV-22 & 0.33337 & $D-22$ \\
\hline QOBV-15 opening & - & $D-3, D-4$ & PE-SV-23 & 0.28409 & $D-23$ \\
\hline $\begin{array}{l}\text { Combined QOBV } \\
\text { opening }\end{array}$ & 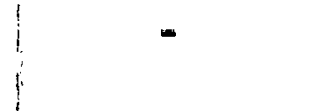 & $D-5, D-6$ & $P E-S V-24$ & 0.19333 & $\mathrm{v}-24$ \\
\hline Vertical load & - & $D-7$ & $P E-S V-25$ & 0.19770 & D-25 \\
\hline PDE-SV-09 & - & $D-8$ & PE-SV-26 & 0.11859 & $D-26$ \\
\hline PE-SV-01 & 0.33103 & D-9 & PE-SV-27 & 0.23738 & $D-27$ \\
\hline PE-SV-02 & 0.33182 & D-10 & PE-SV-28 & 0.21 .189 & $D-28$ \\
\hline PE-SV-03 & 0.36585 & D-11 & PE-SV-29 & 0.23991 & $D-29$ \\
\hline PE-SV-04 & 0.43270 & D-12 & PE-SV-43 & 0.15496 & $D-30$ \\
\hline$P E-S V-10$ & 0.27835 & $D-13$ & PE-SV-44 & 0.15816 & $D-31$ \\
\hline PE-SV-11 & 3.3539 & $0-14$ & $P E-S V-54$ & 0.15063 & $0-32$ \\
\hline PE-SV-12 & 0.27922 & $D-15$ & PE-SV-55 & 0.08894 & D-33 \\
\hline PE-SV-13 & 0.23571 & D-16 & PE-SV-56 & $0 . .23487$ & $D-34$ \\
\hline PE-SV-14 & 0.28629 & $D-17$ & PE-SV-57 & 0.12619 & $D-35$ \\
\hline PE-SV-15 & 0.32491 & D-18 & PE-SV-58 & 0.19305 & $D-36$ \\
\hline PE-SV-16 & 0.24915 & D-19 & PE-SV-59 & 0.22789 & $D-37$ \\
\hline PE-SV-17 & 0.29686 & $D-20$ & PE-SV-60 & 0.30480 & $D-38$ \\
\hline PE-SV 18 & 0.43368 & $D-21$ & $P E-S V-61$ & 0.23670 & $D-39$ \\
\hline
\end{tabular}



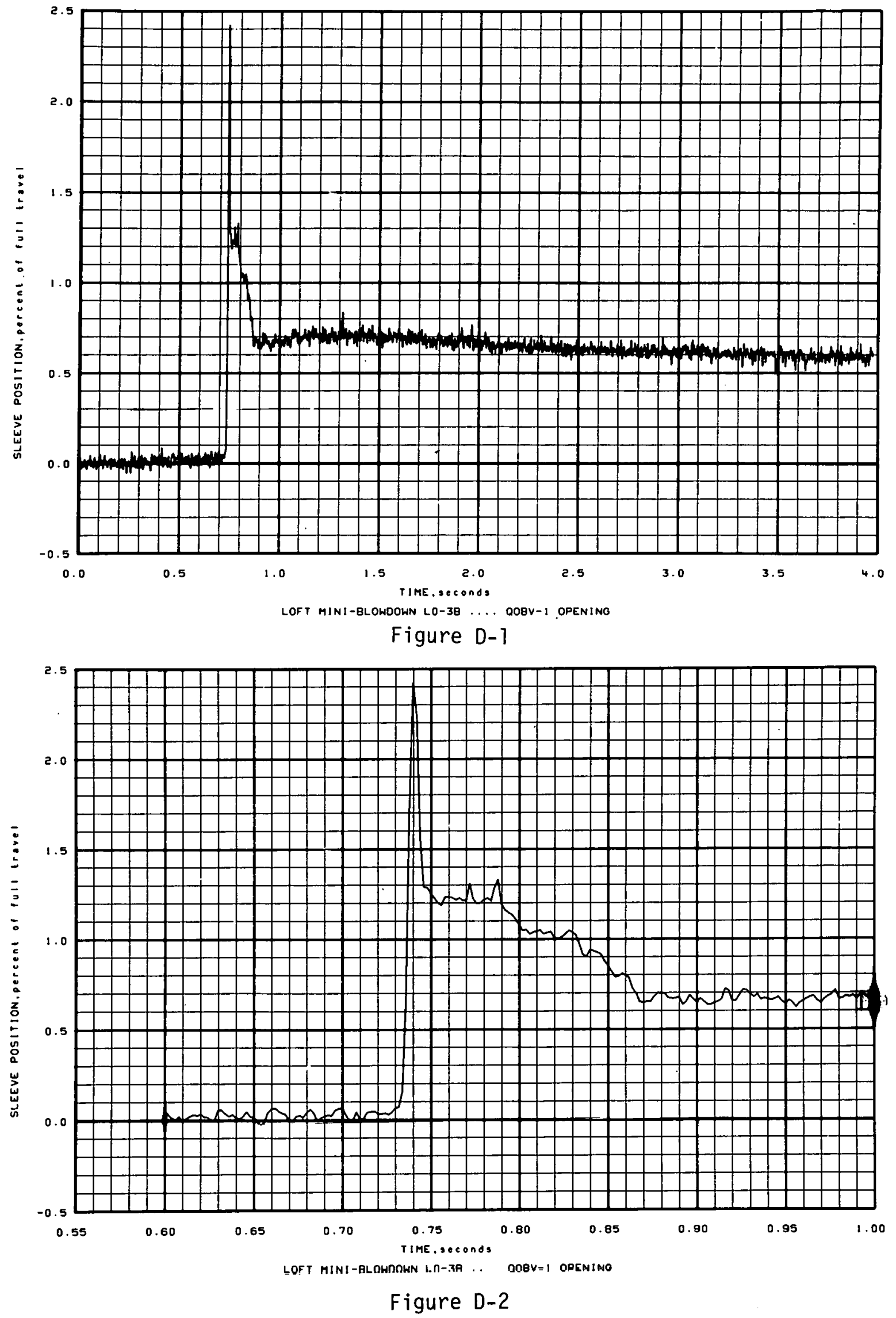

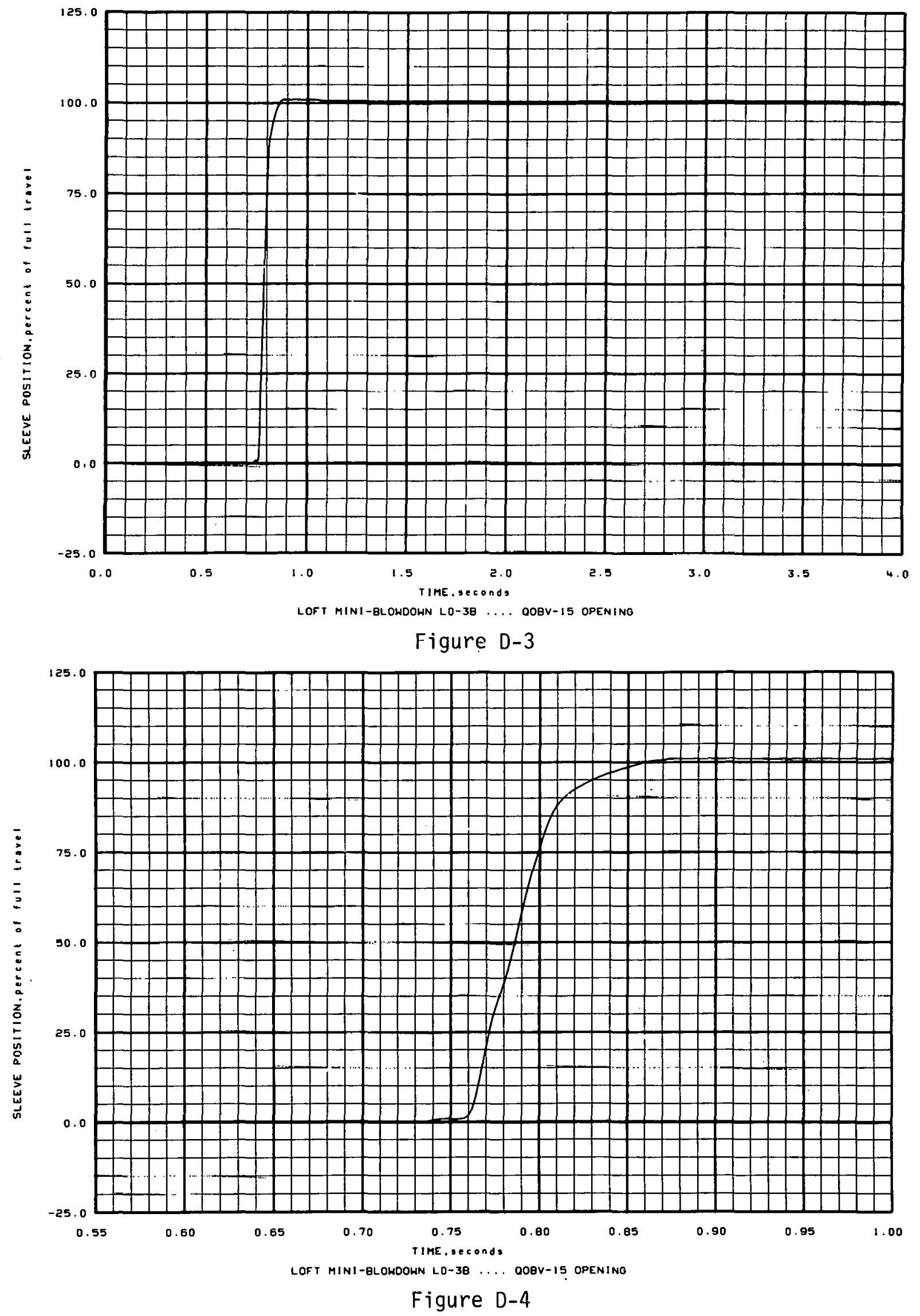


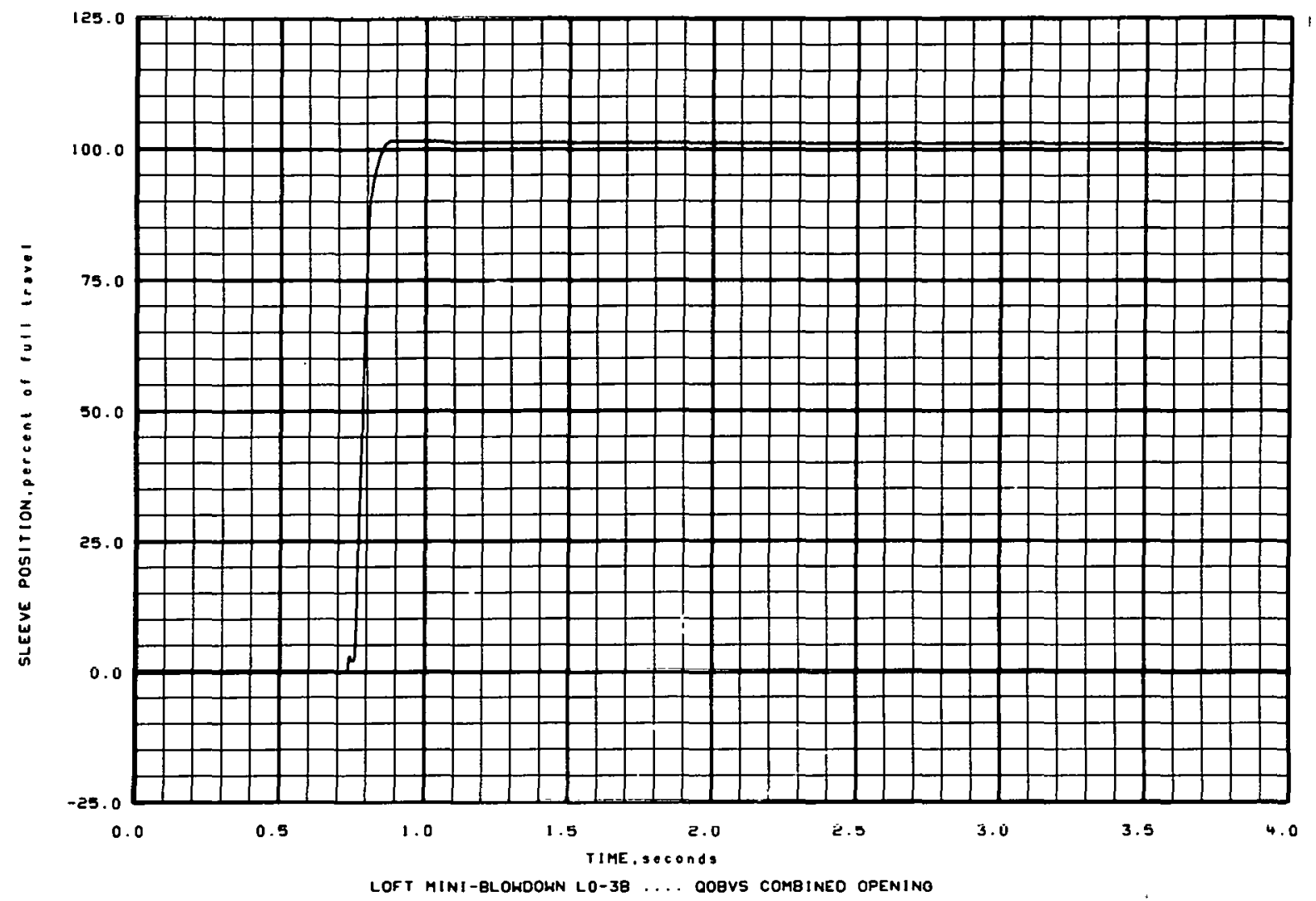

Figure D-5

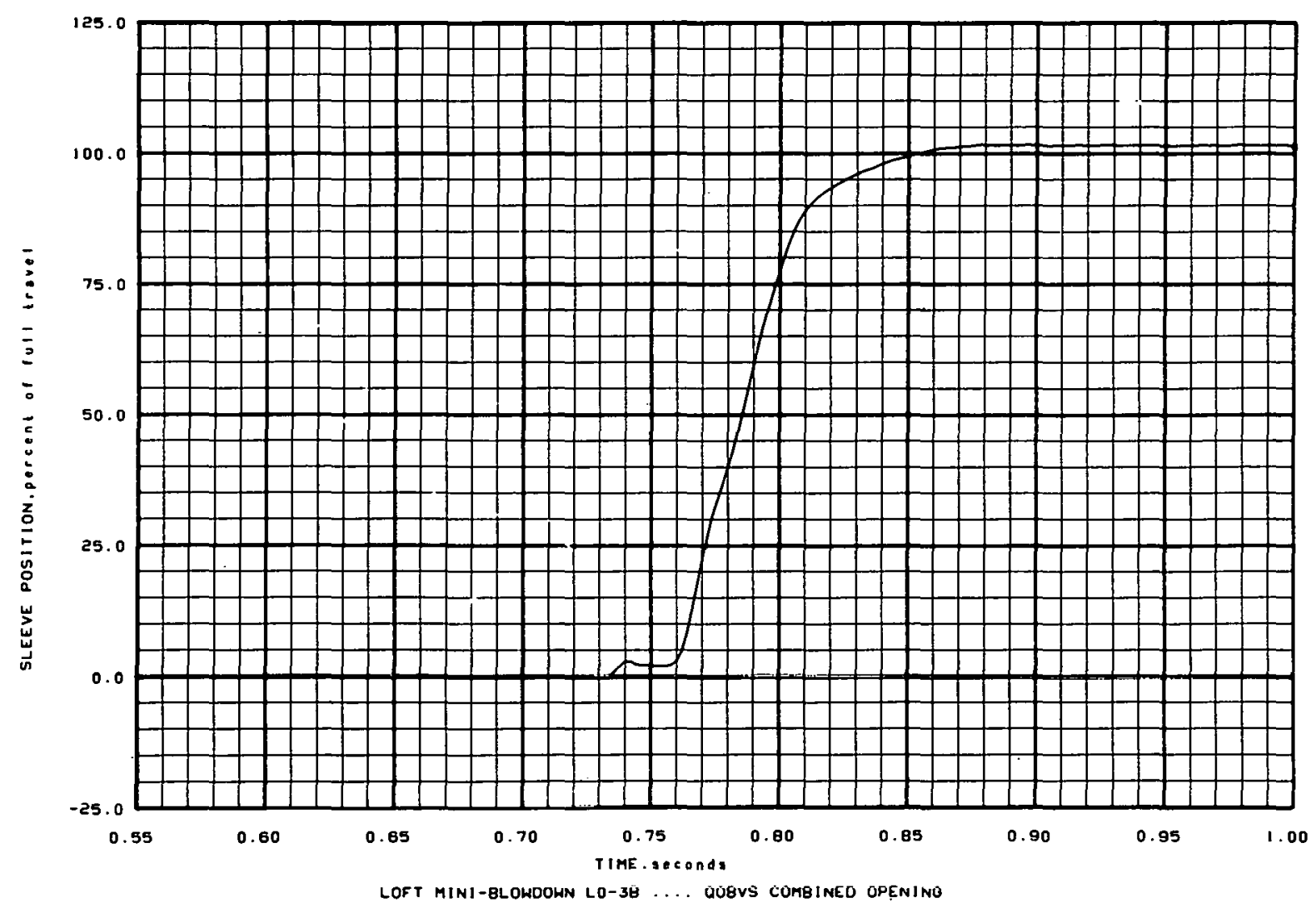

Figure D-6 

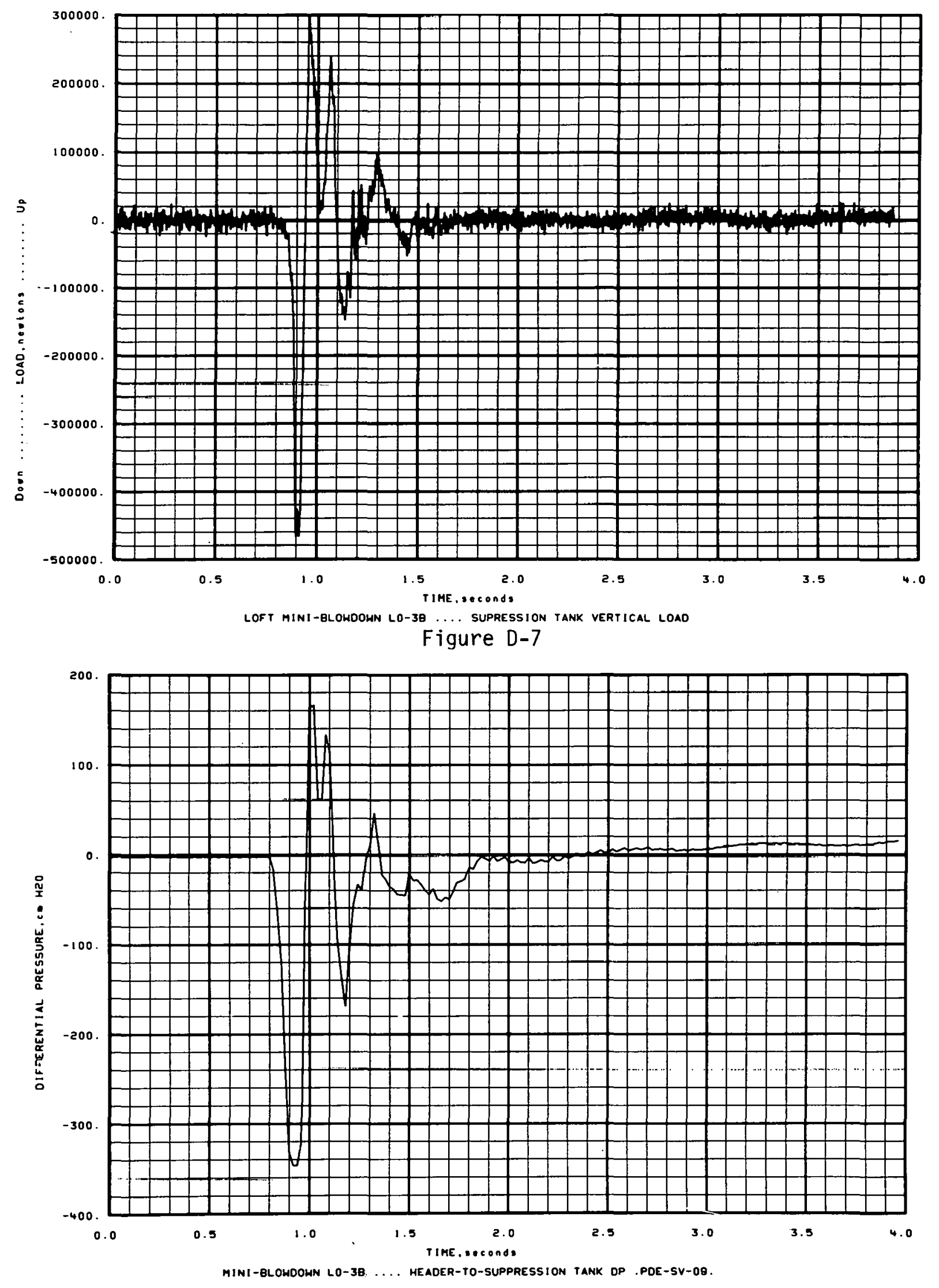

Figure D-8 


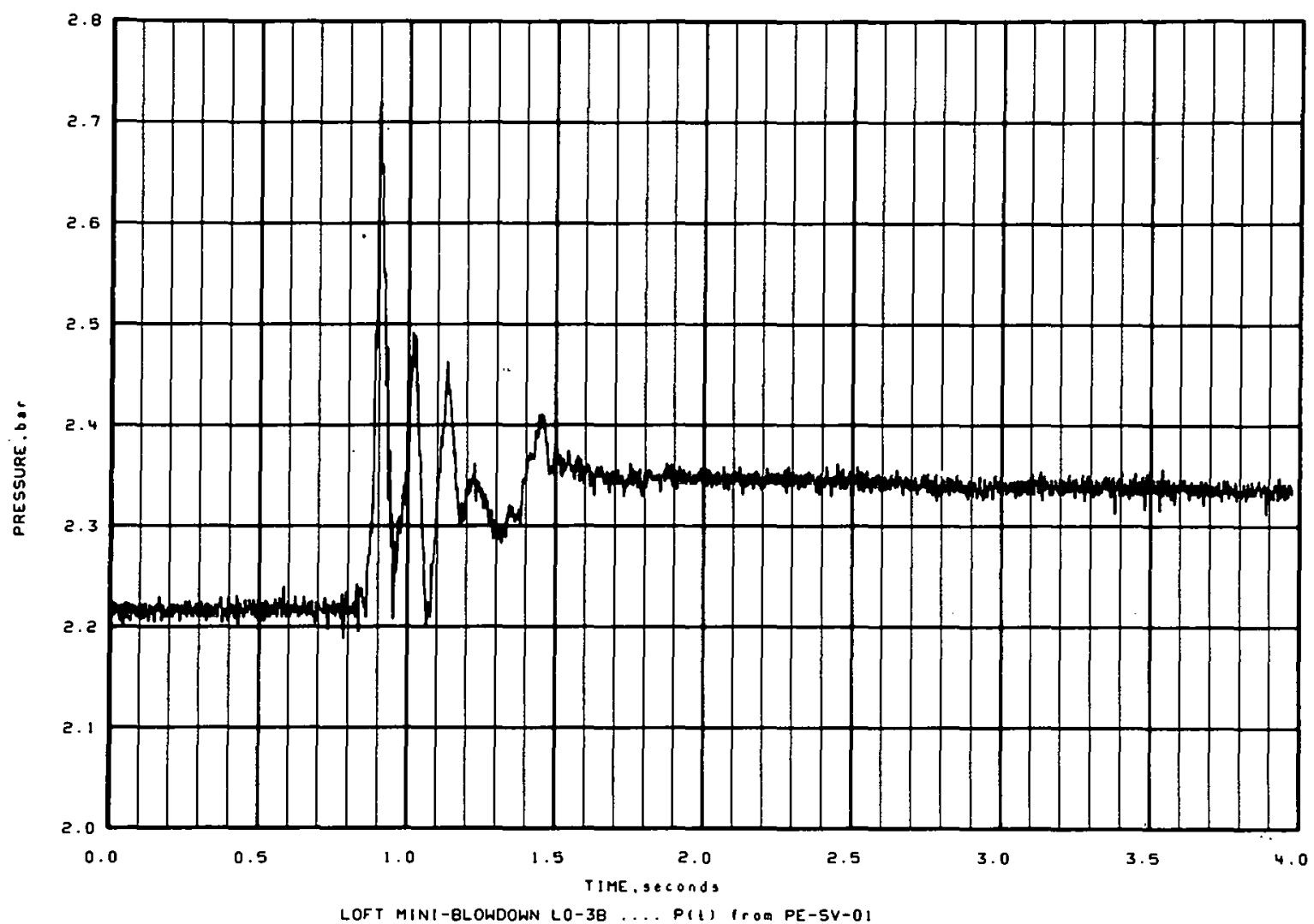

Figure D-9

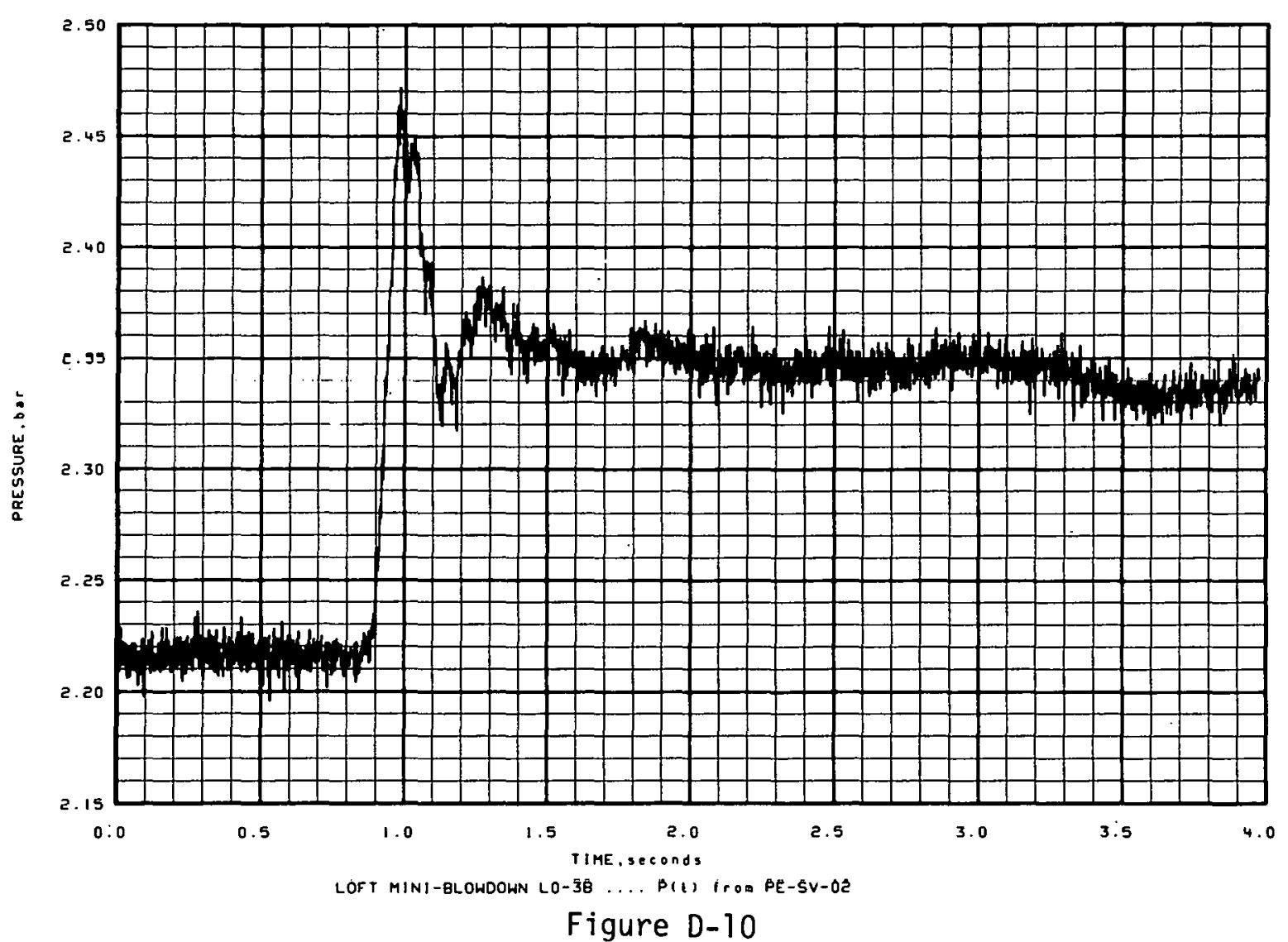



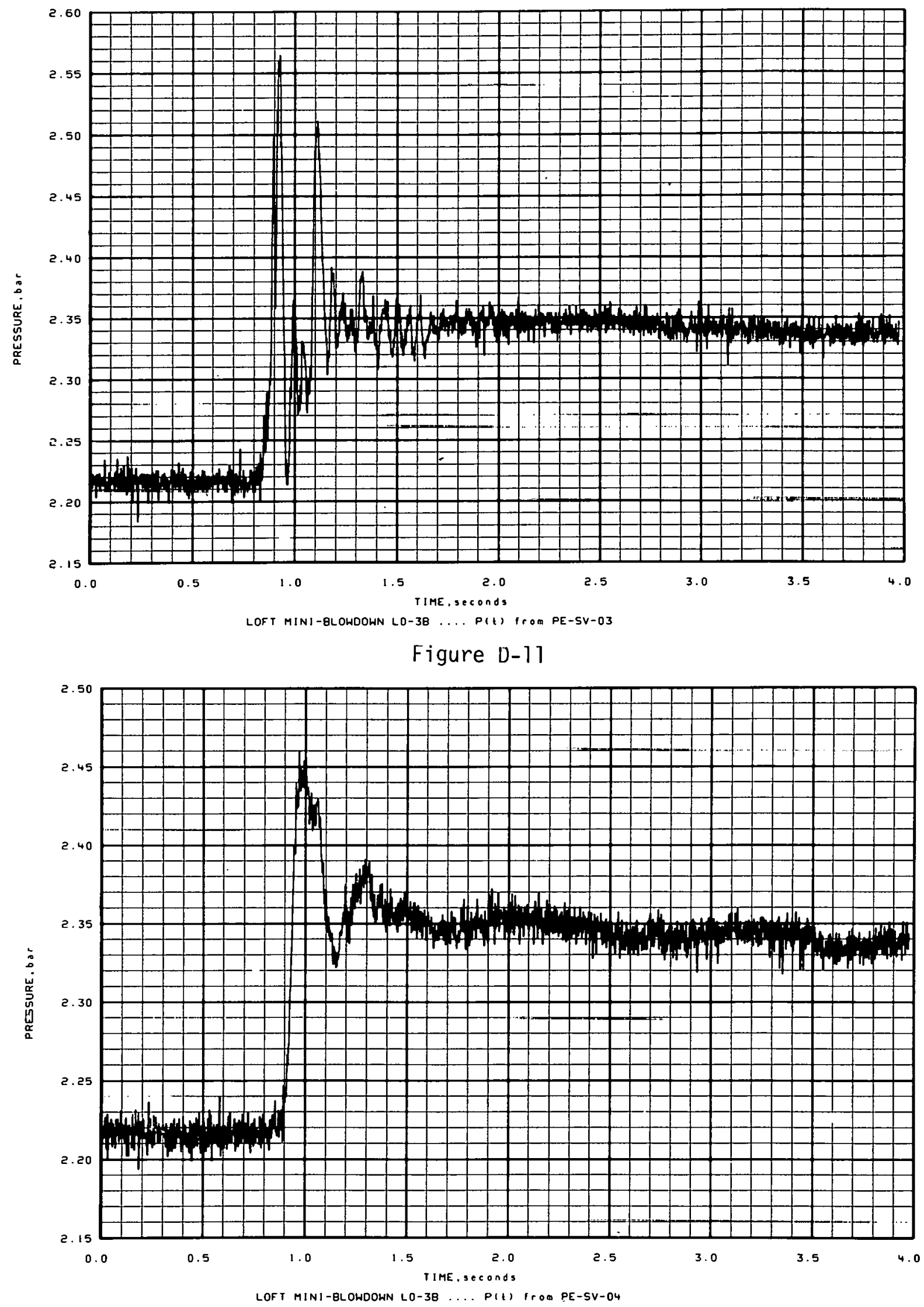

Figure D-12 


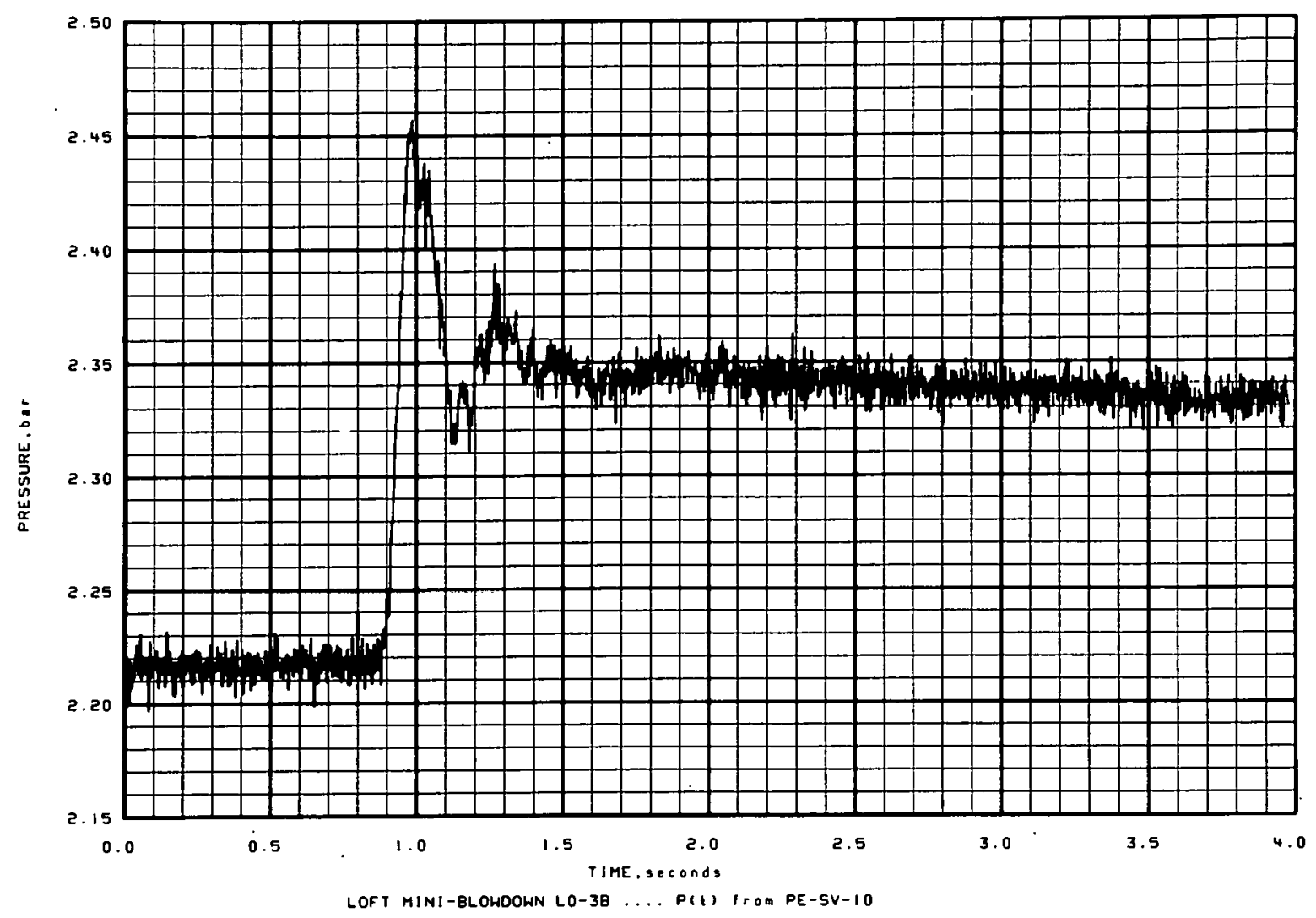

Figure D-13

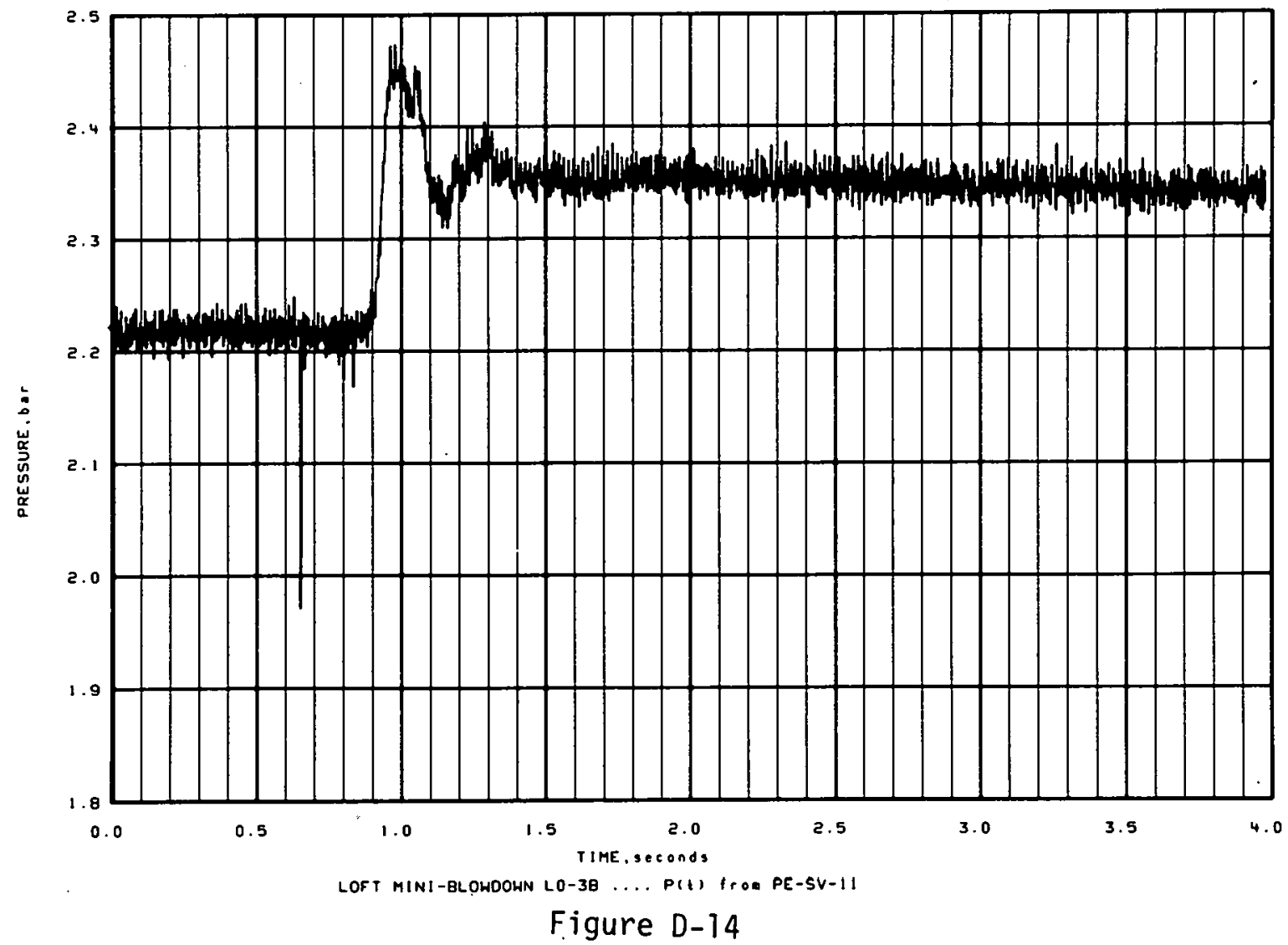



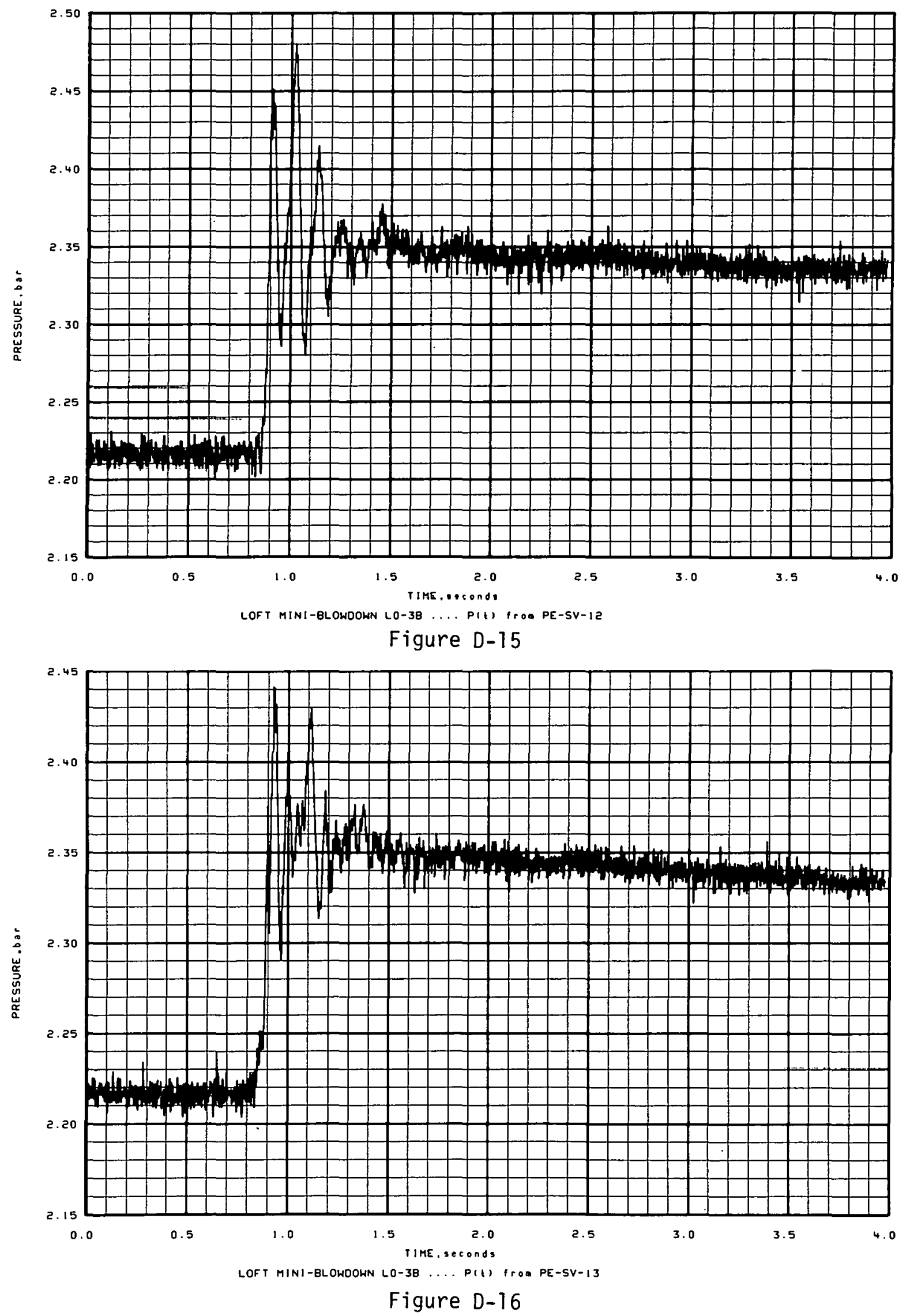


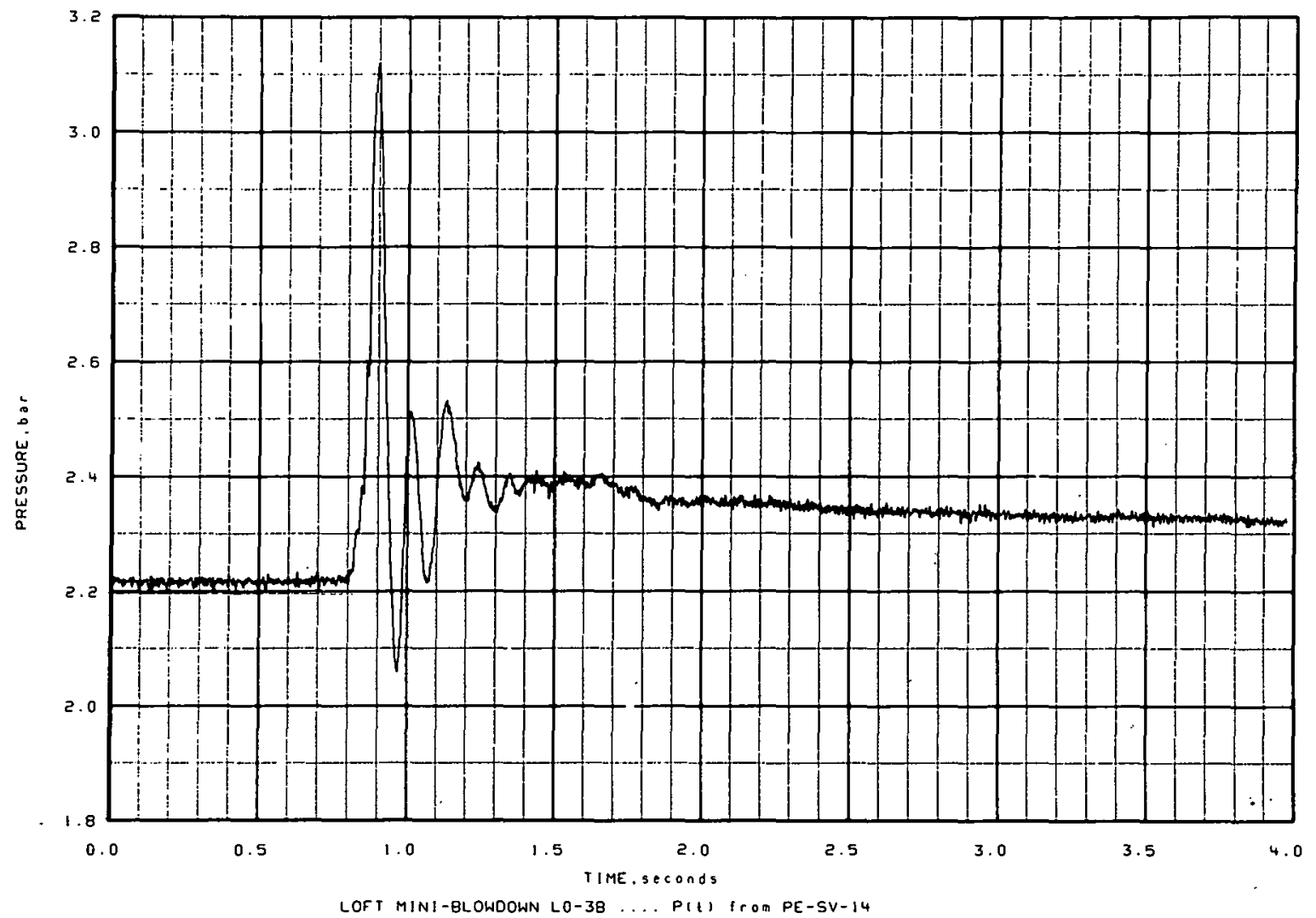

Figure $D-17$

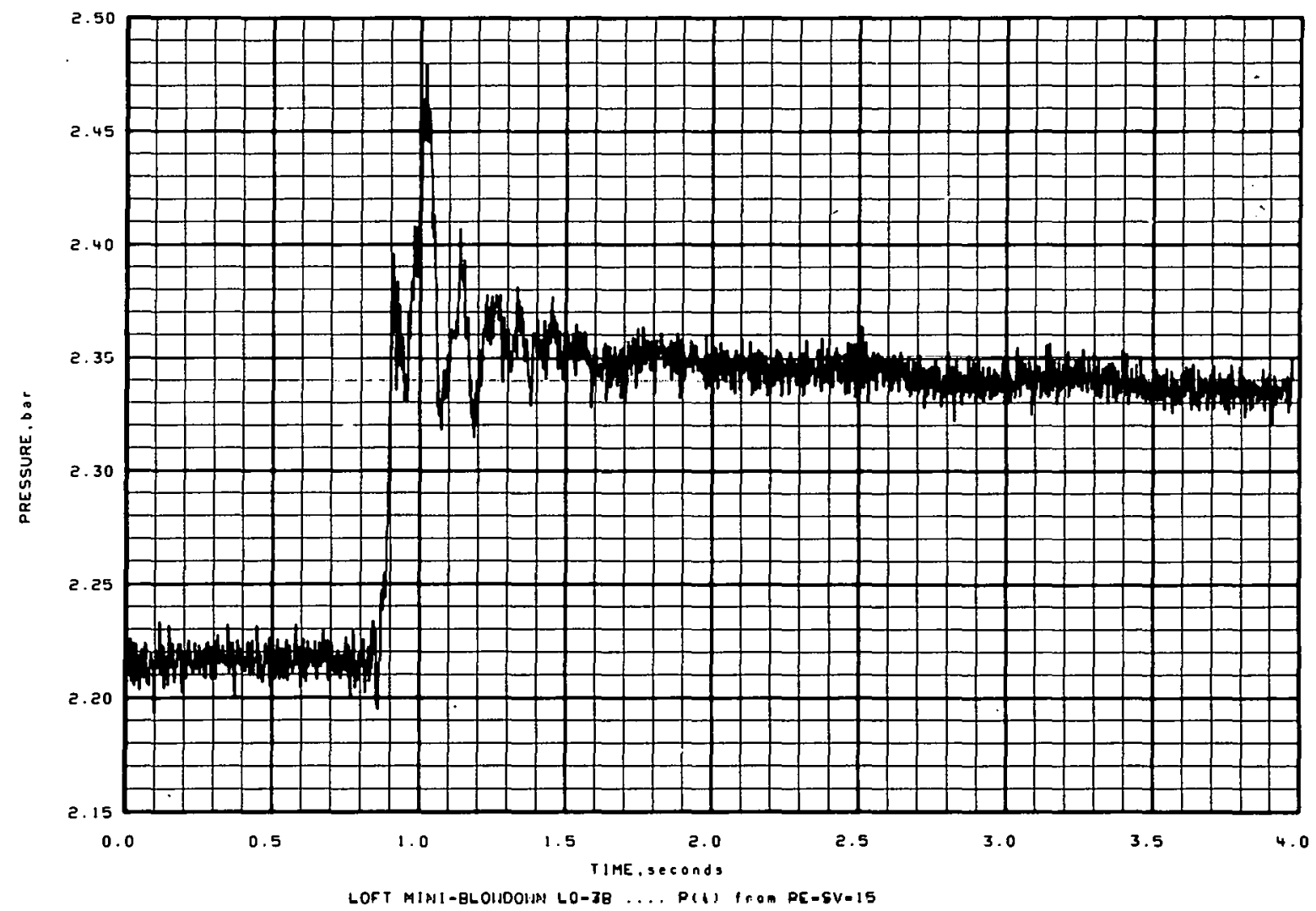

Figure D-18 

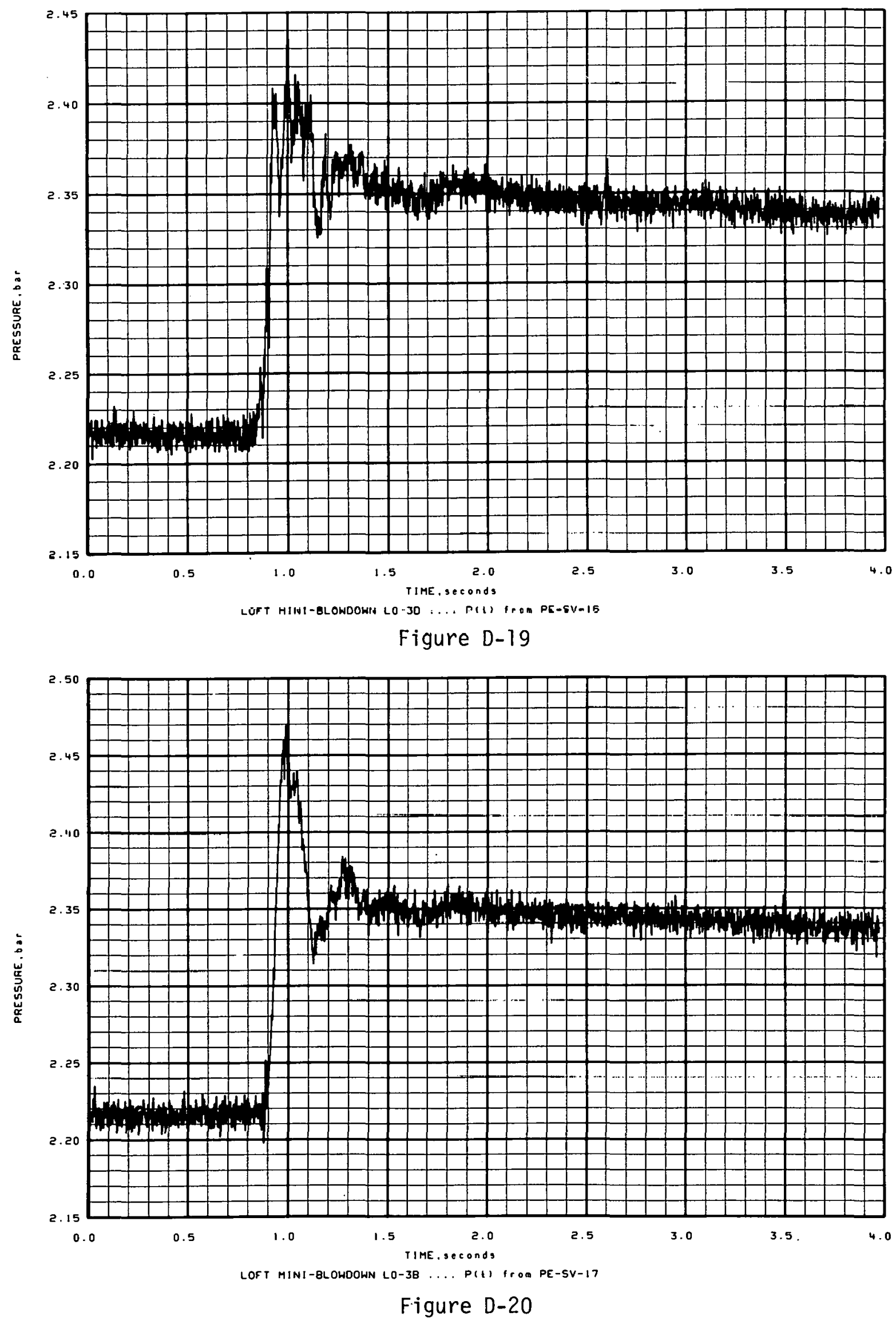


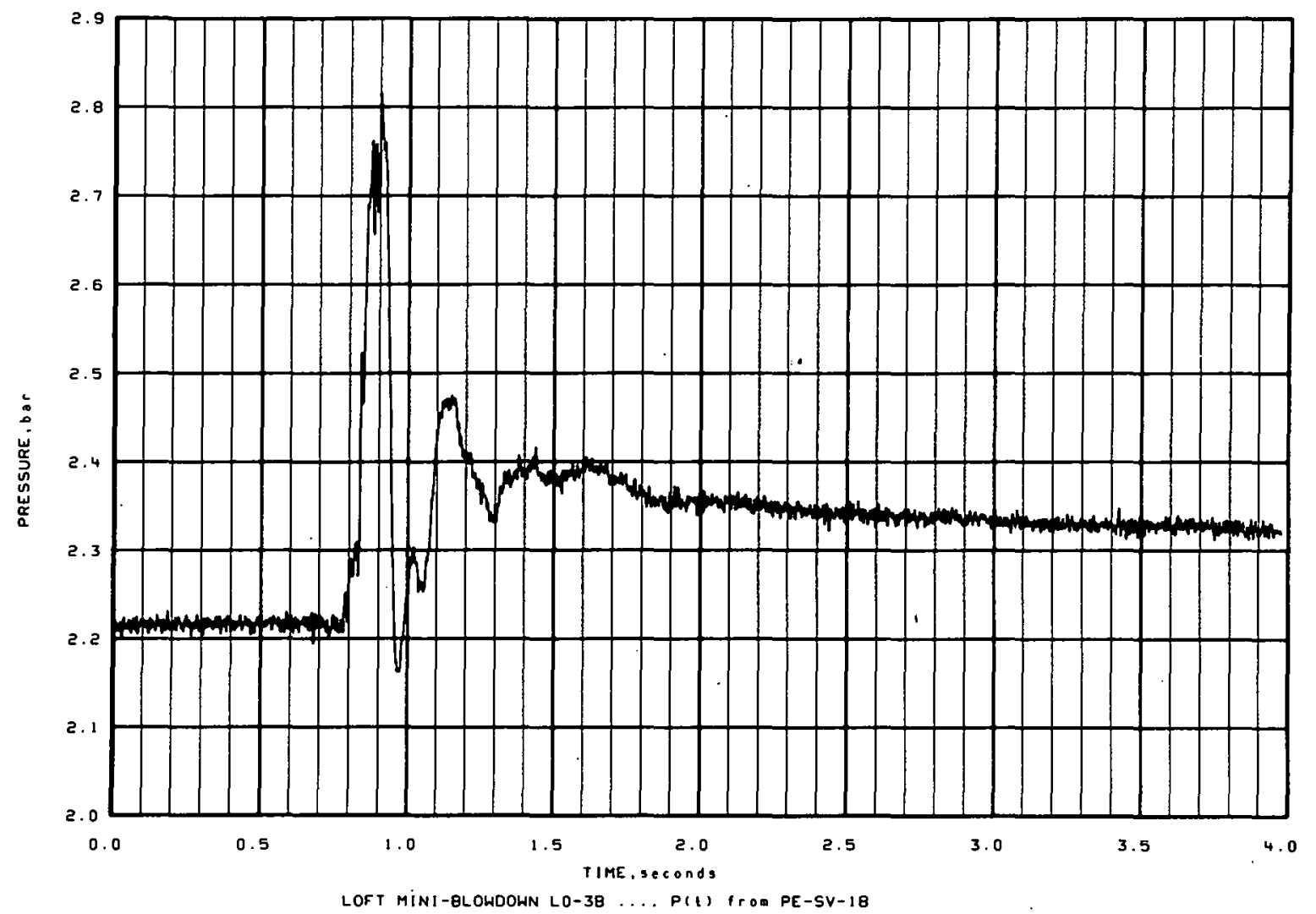

Figure D-21

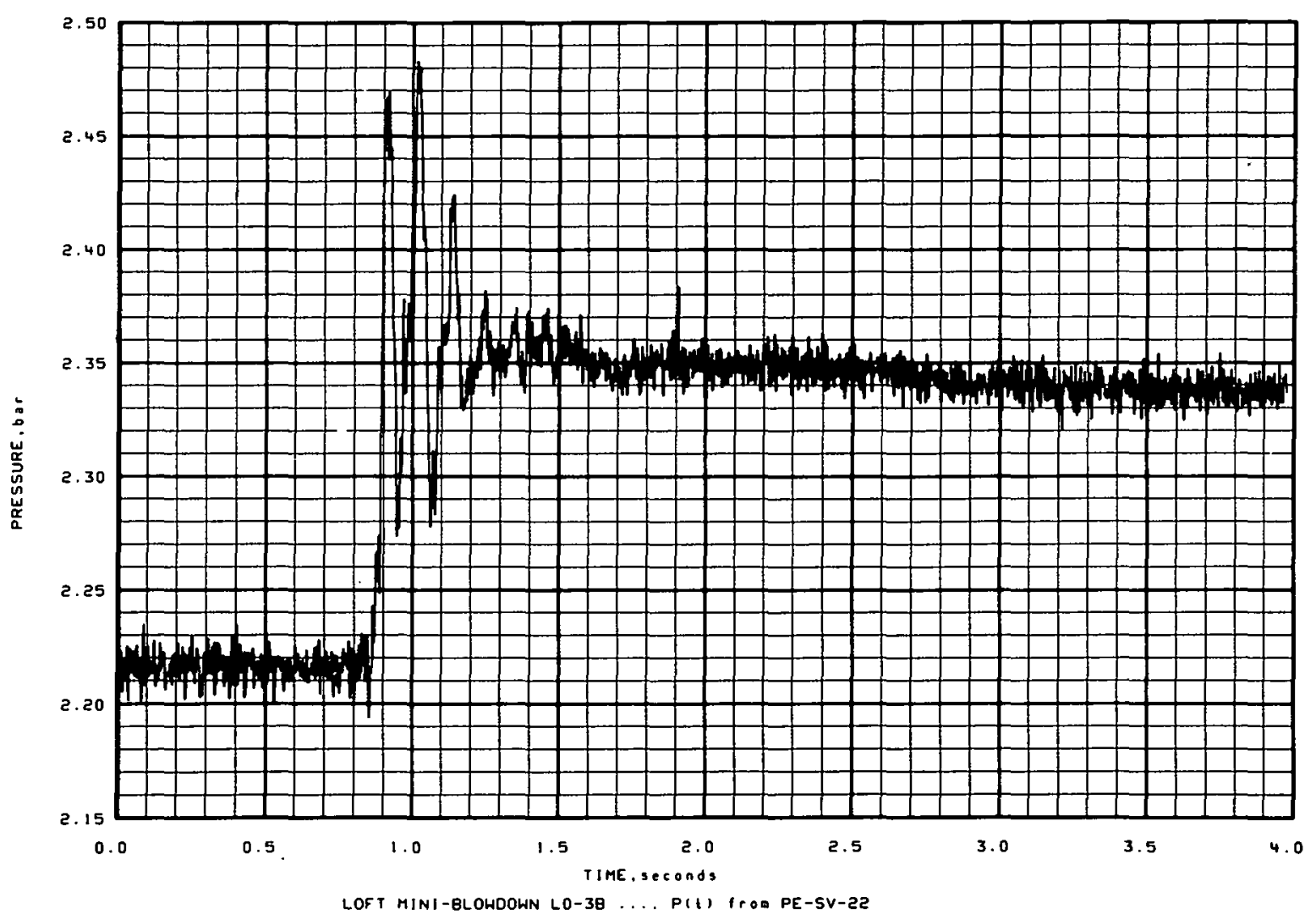

Figure D-22 

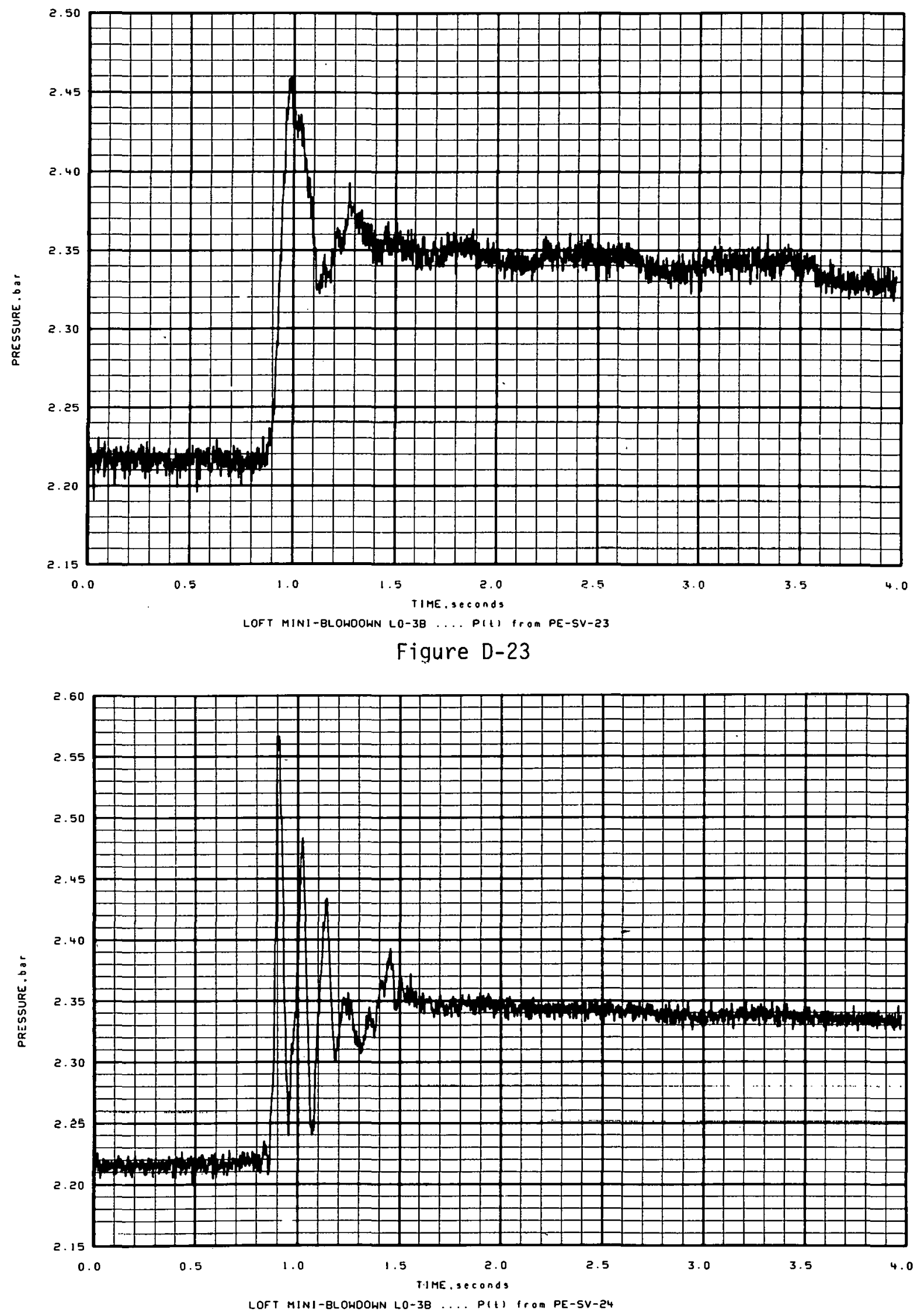

Figure D-24 


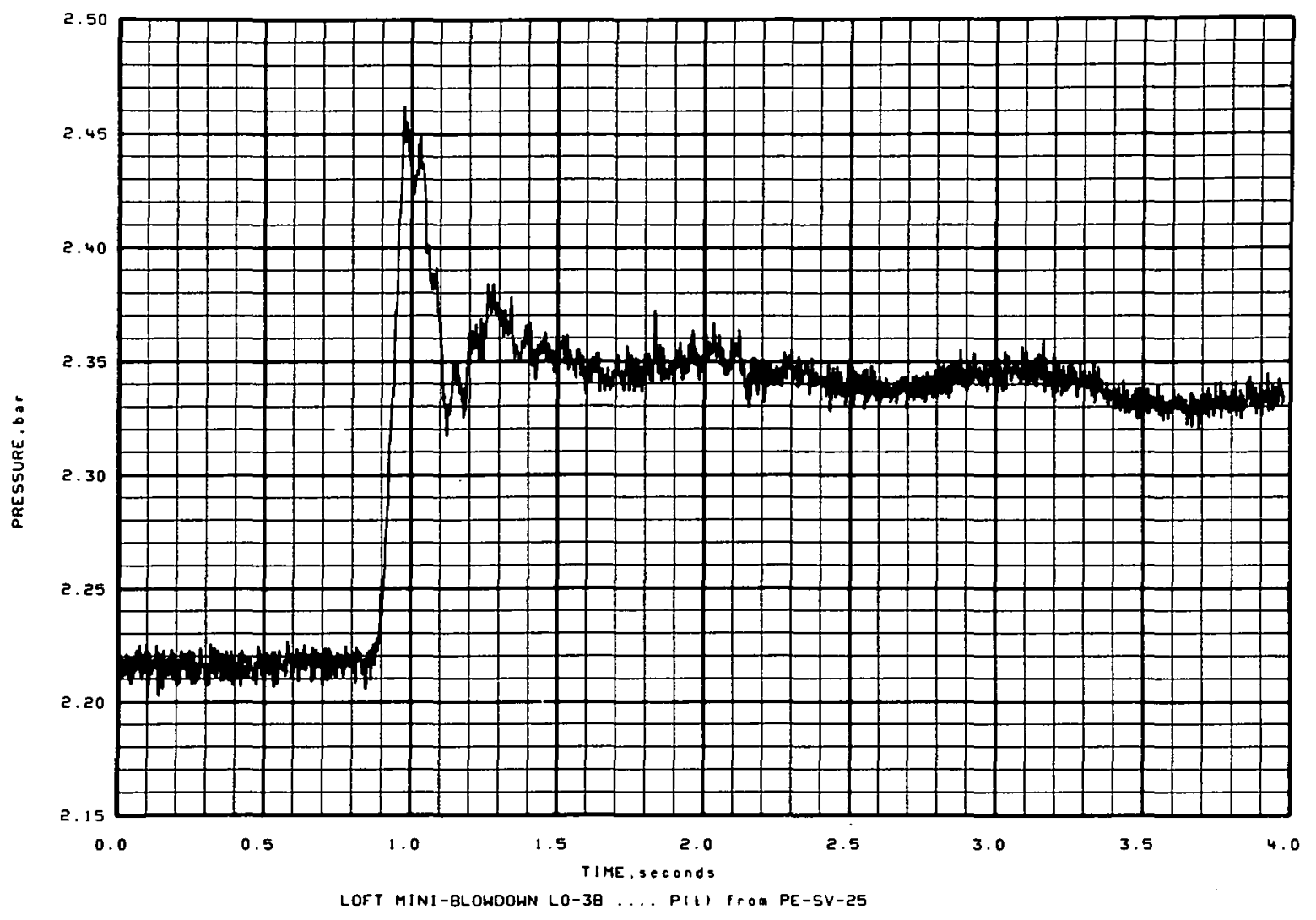

Figure D-25

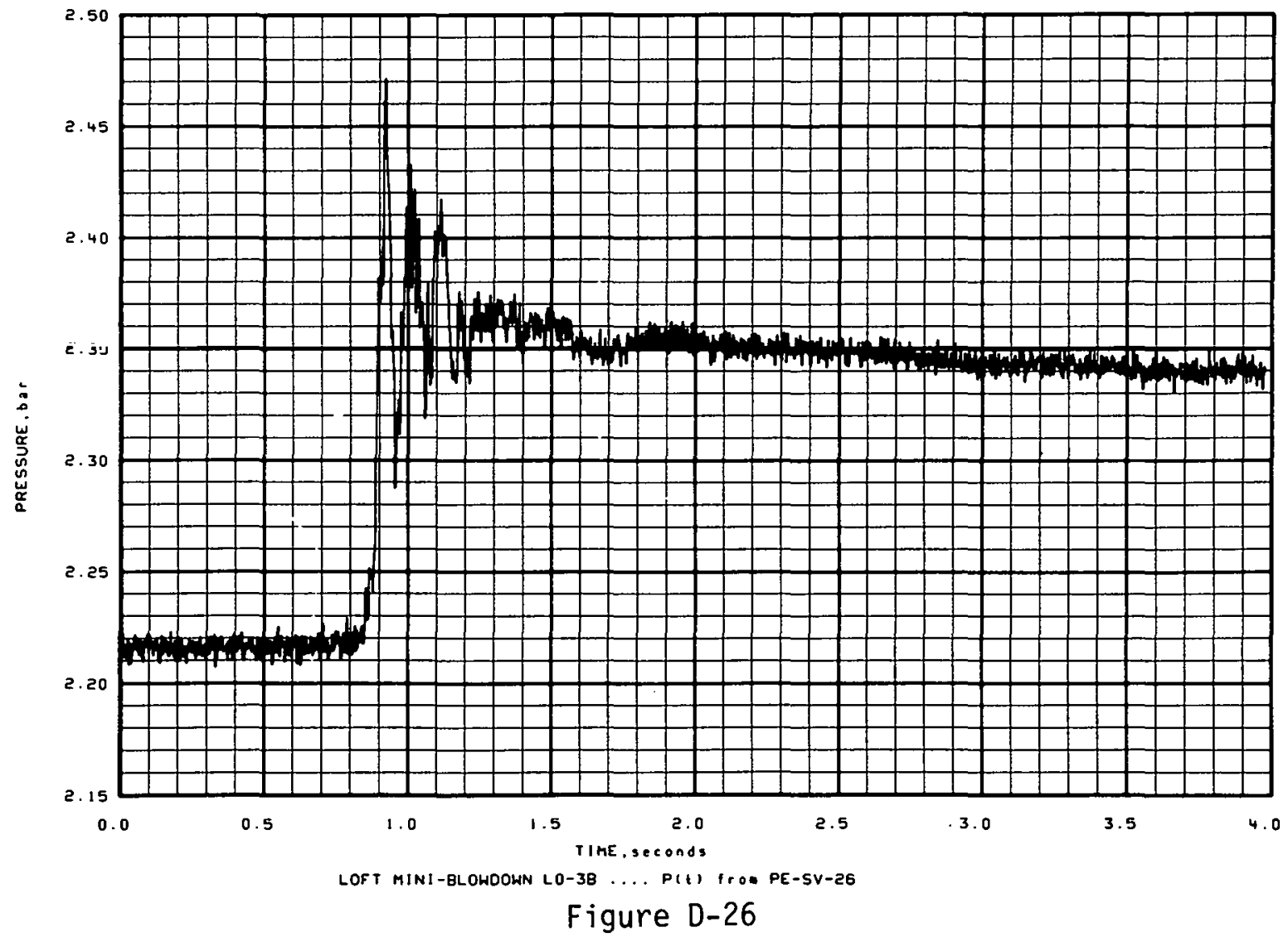



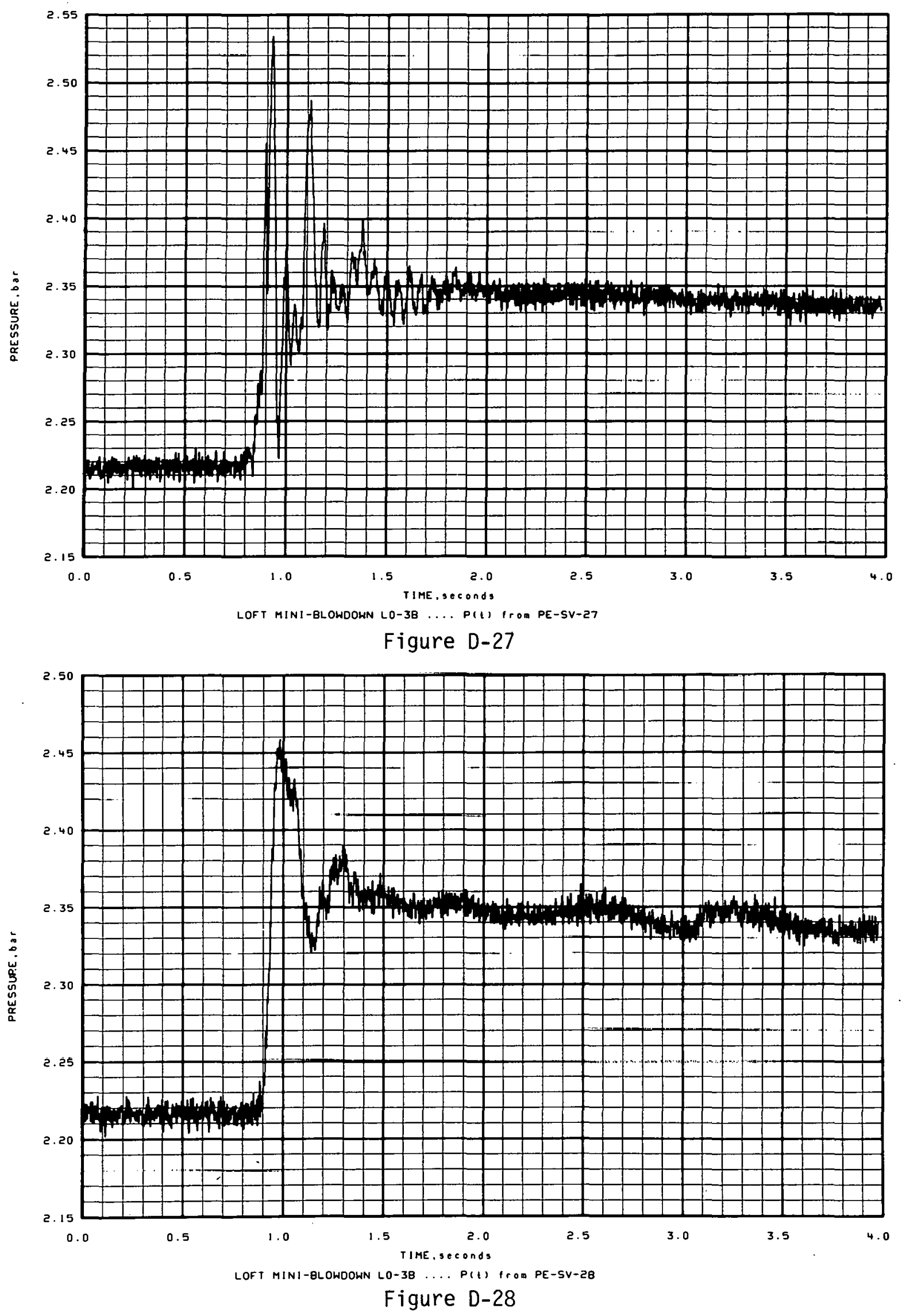


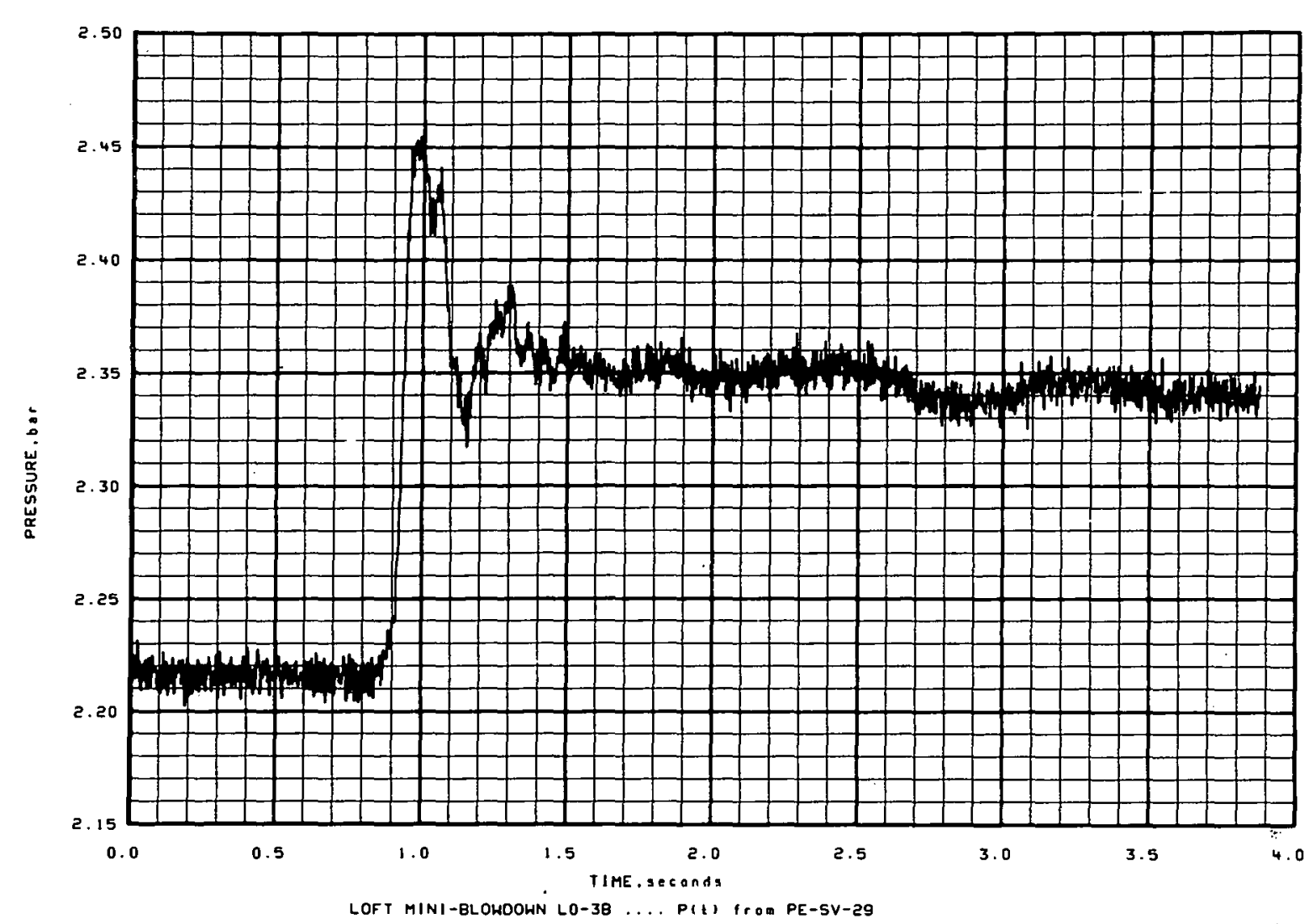

Figure D-29

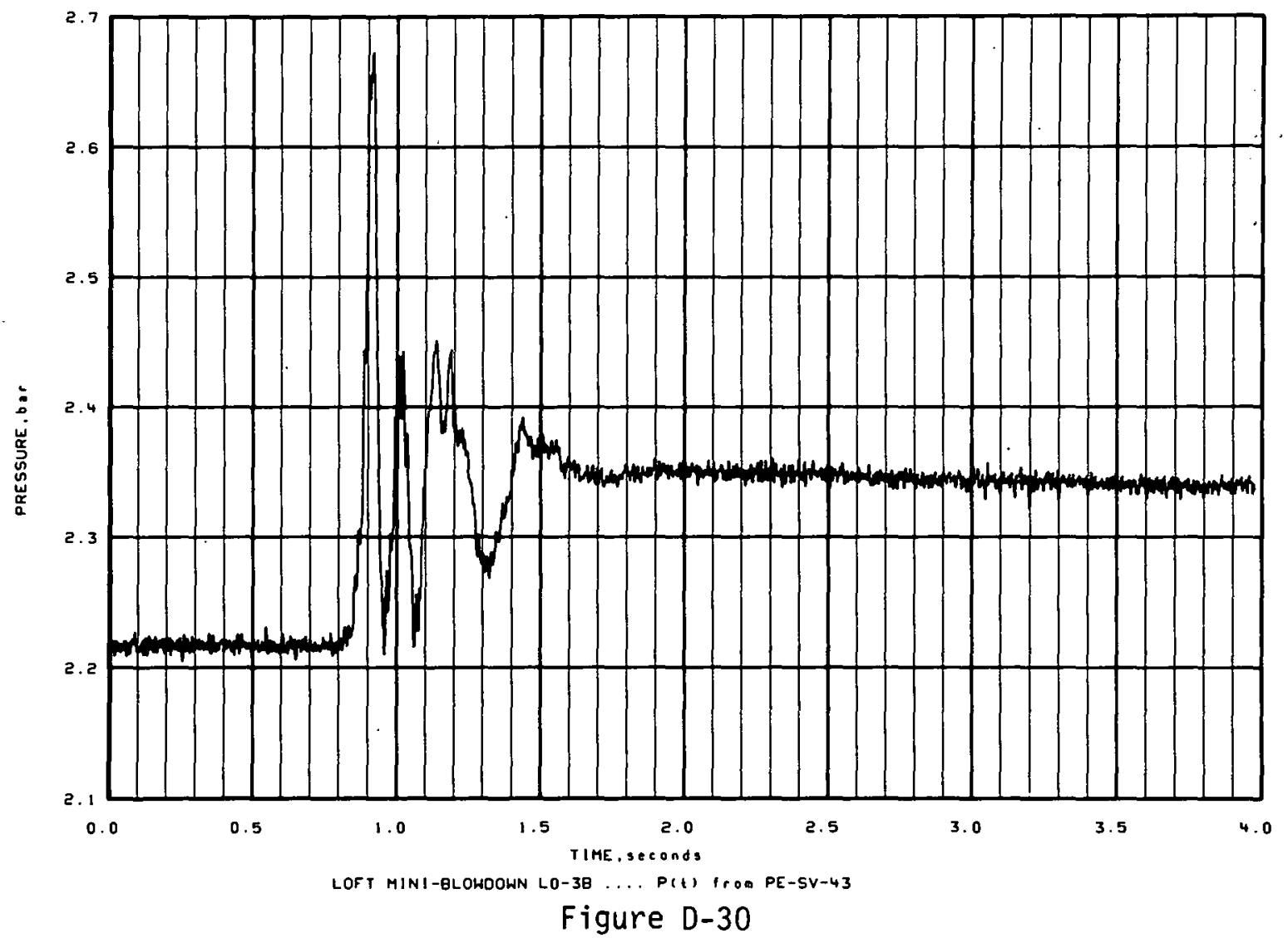




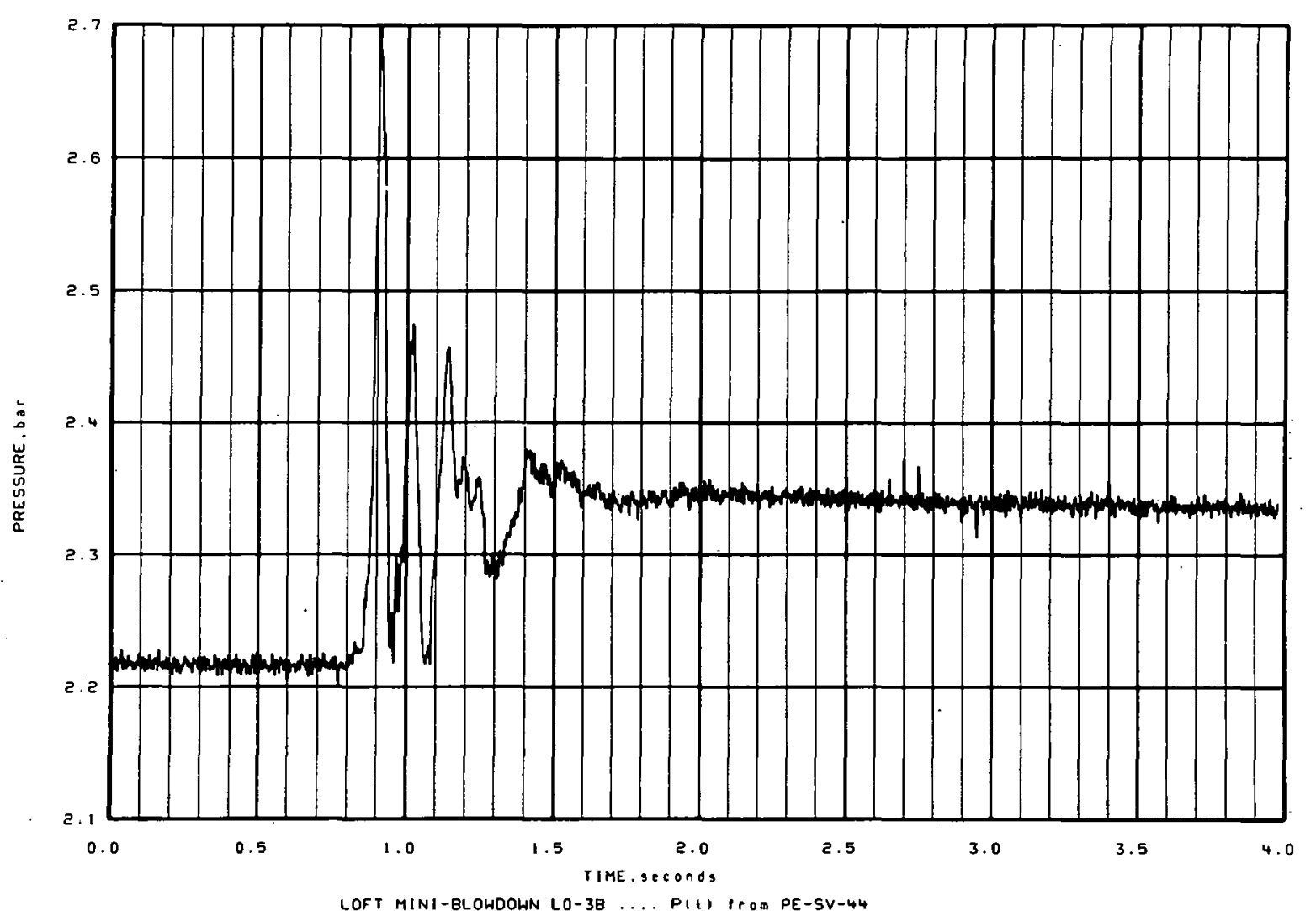

Figure D-31

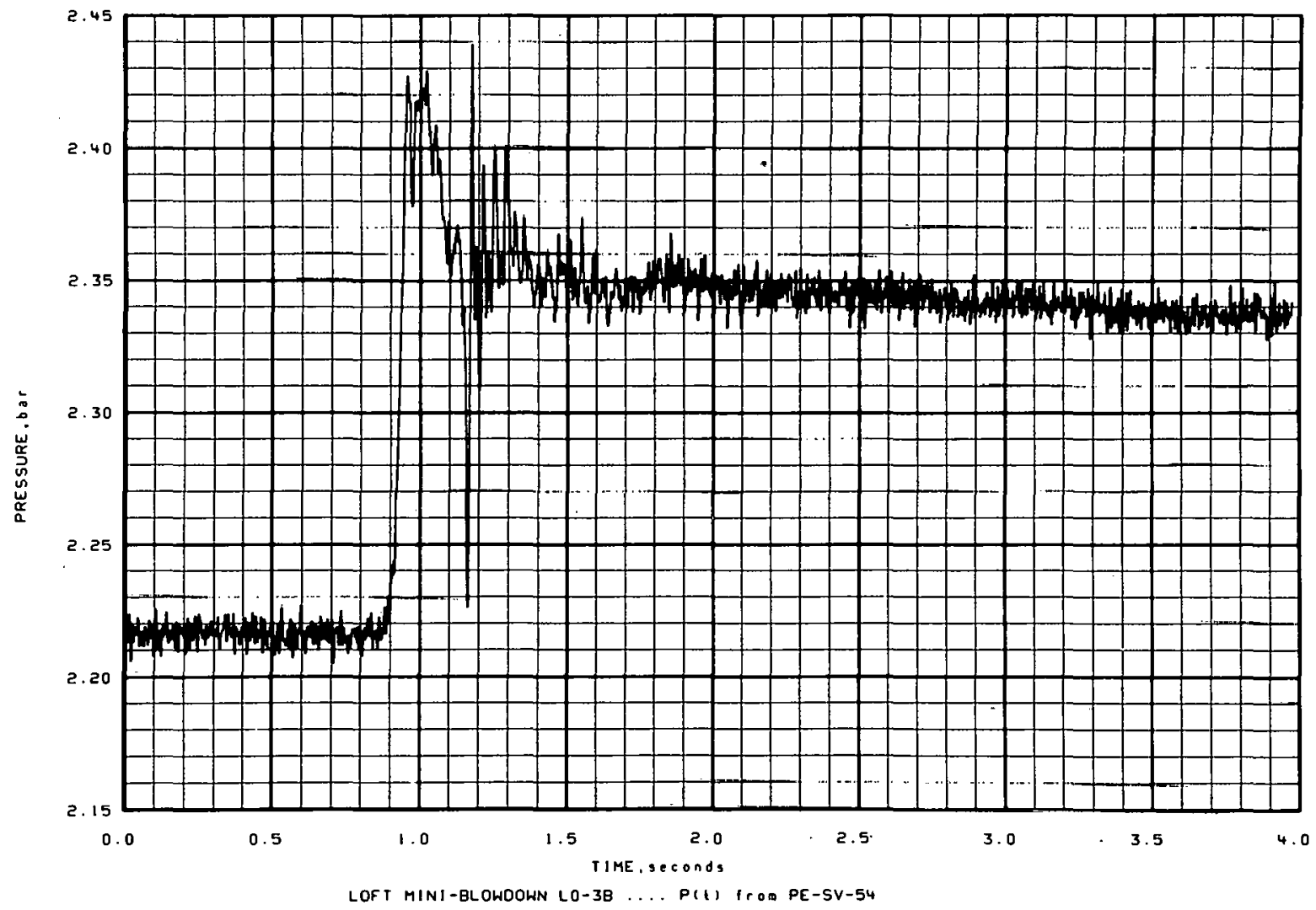

Figure D-32 


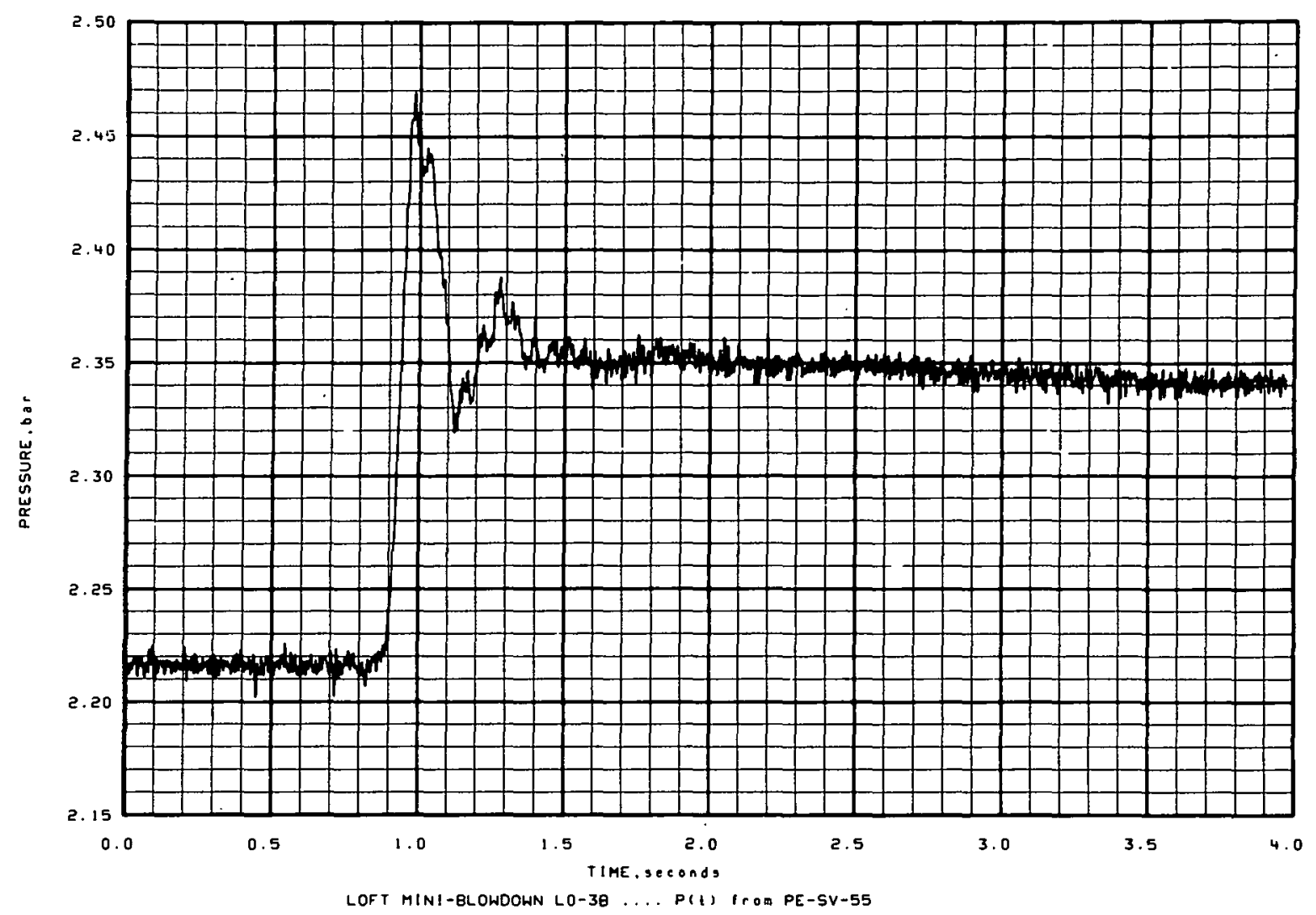

Figure D-33

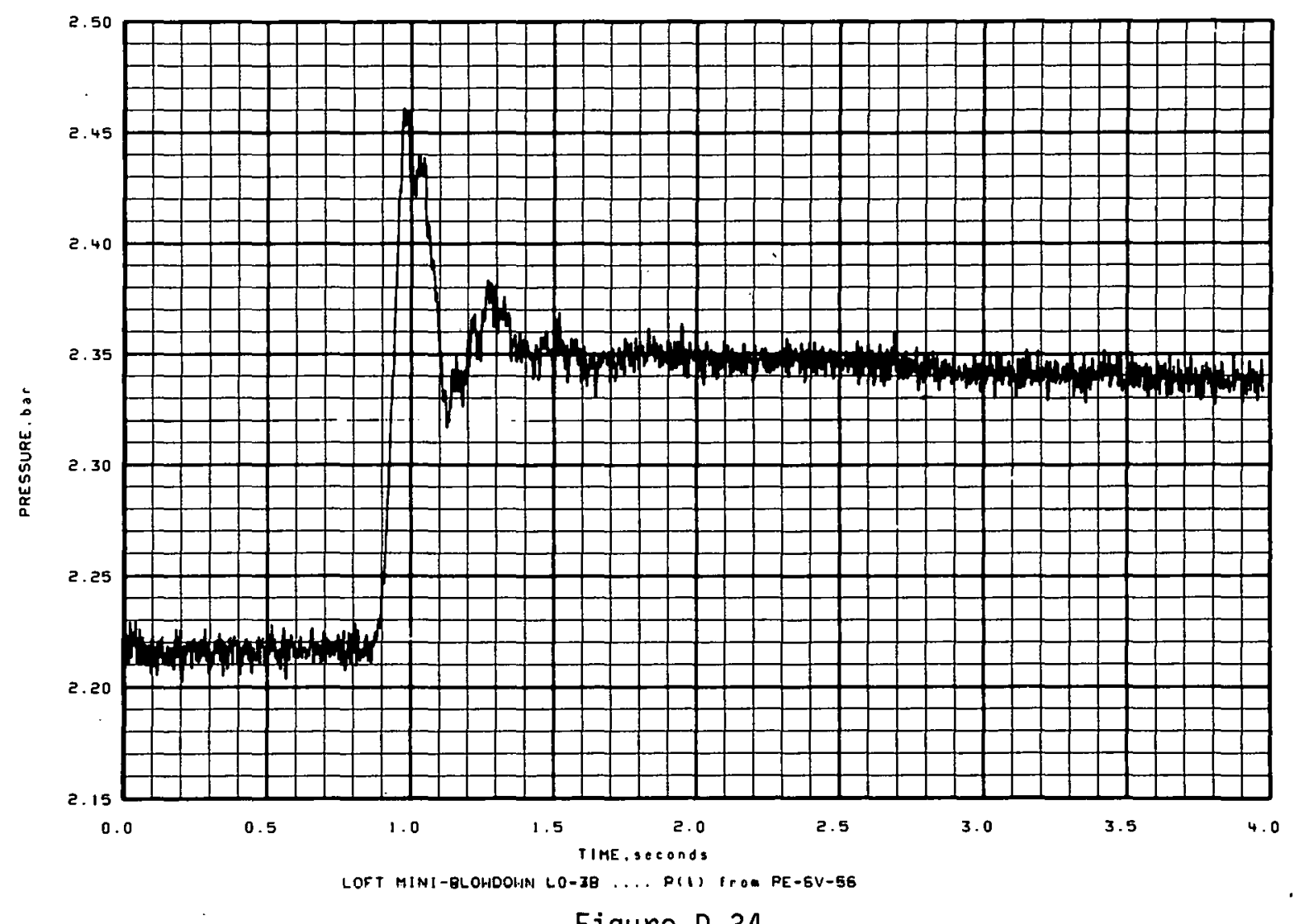

Figure D-34 

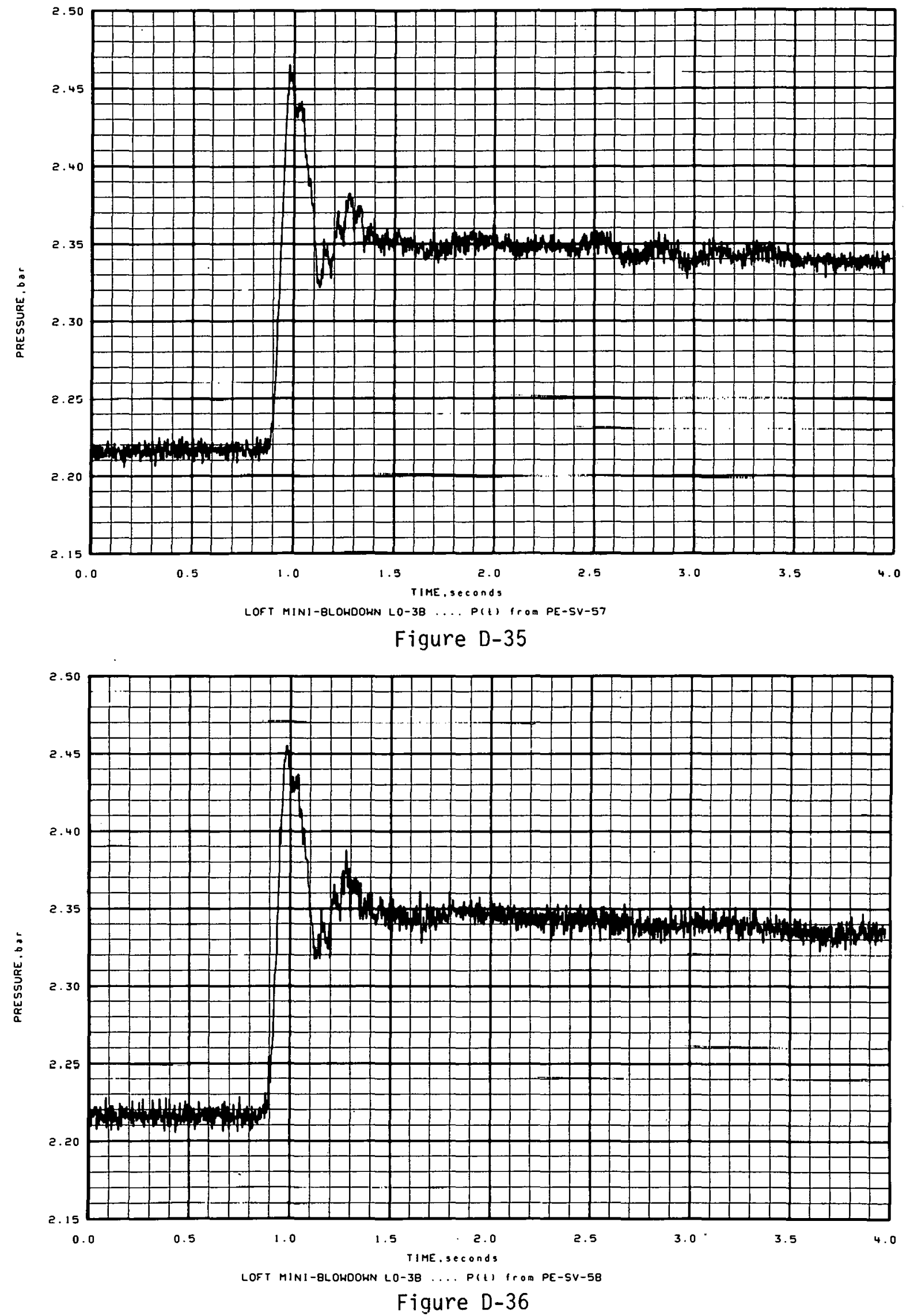


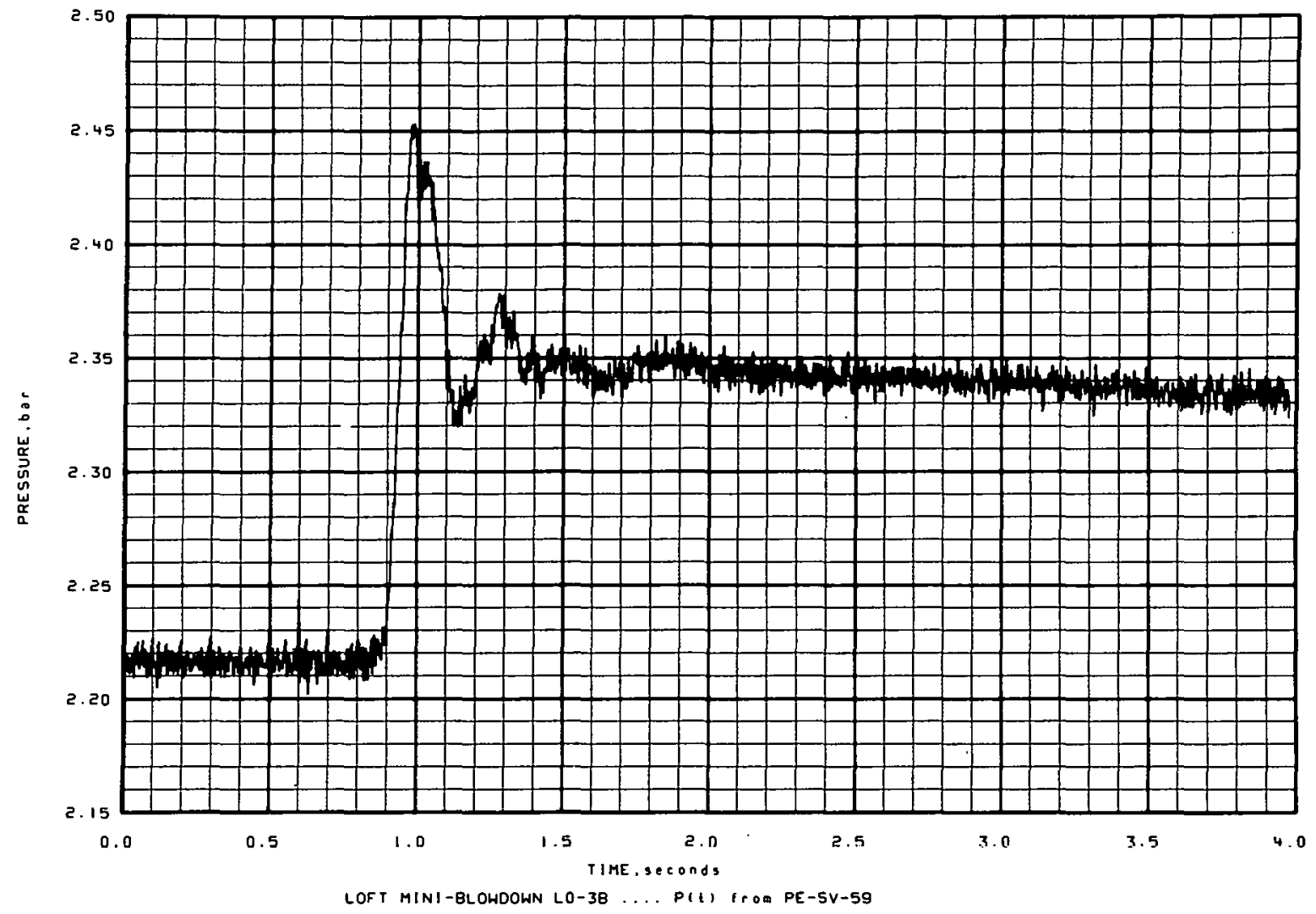

Figure D-37

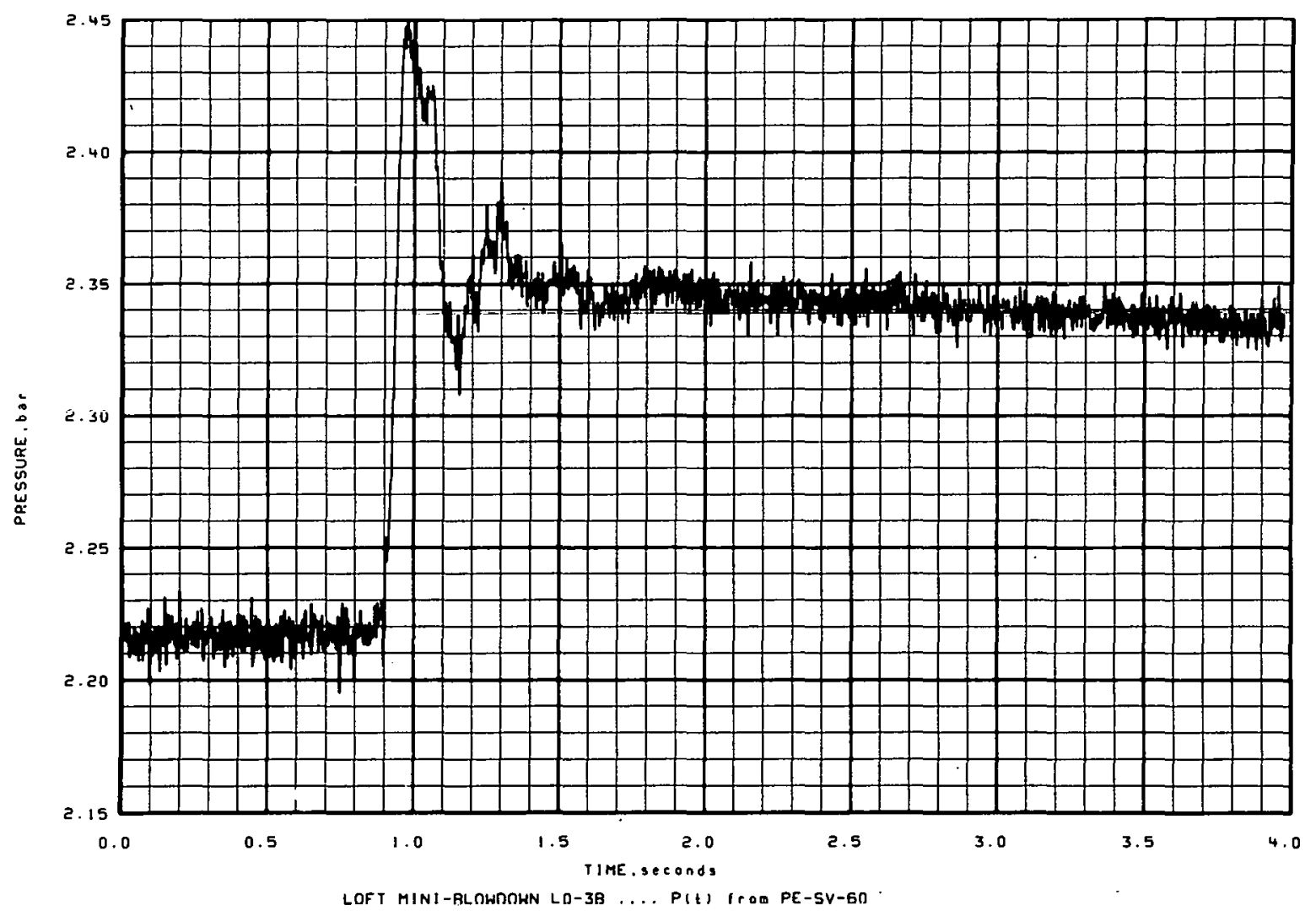

Figure D-38 


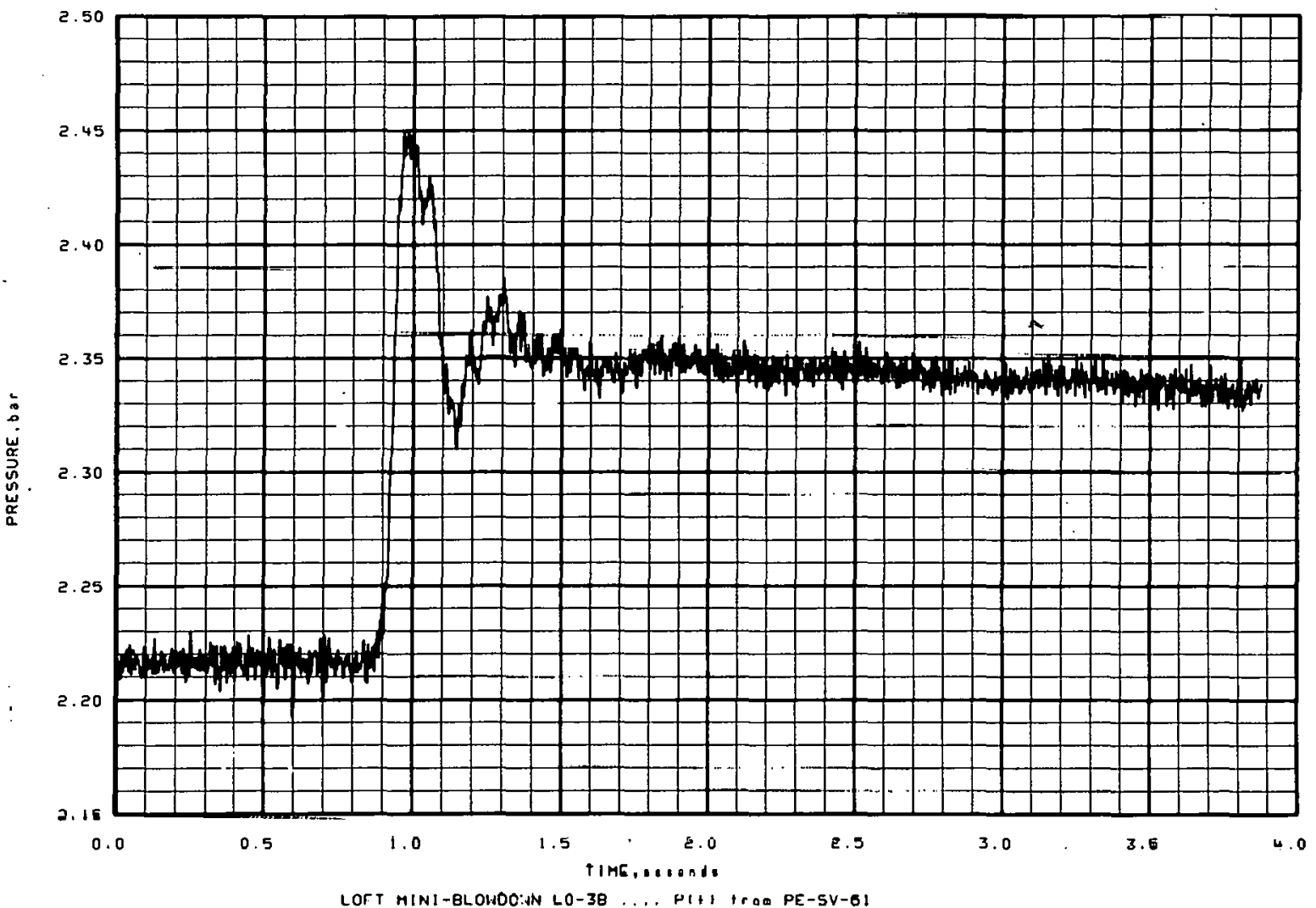

Figure D-39 
APPENDIX E

MINI-BLOWOOWN LO-3C EXPERIMENTAL DATA 
THIS PAGE

\section{WAS INTENTIONALLY LEFT BLANK}




\section{APPENDIX E}

MINI-BLOWDOWN LO-3C EXPERIMENTAL DATA

Both QOBVs fully opened in this experiment. However, there was approximately a $50-\mathrm{msec}$ time difference in the times when the valves started to open flow area. This resulted in a slower rate of pressurization in the header. The fluid temperature was $234.2 \pm 1.5^{\circ} \mathrm{C}$ in QOBV- 1 and $233.9 \pm 1.5^{\circ} \mathrm{C}$ in QOBV- 15 . The suppression tank initial conditions were $2.42 \pm 0.08 \mathrm{bar}, 27.5 \pm 1.5^{\circ} \mathrm{C}$ in the gas volume, and $26.7 \pm 1.5^{\circ} \mathrm{C}$ in the pool. The vents were submerged $27.9 \pm 1.5 \mathrm{~cm}$. The internal vent submergence was $29.9 \pm 3.2 \mathrm{~cm}$.

The experimental data are defined in Table E-I. The opening characteristics of the QOBVs are shown in terms of percent sleeve travel versus time. The flow area of the valve begins to open at a sleeve position of $17 \%$ of full travel and is fully open at a sleeve position of $66 \%$ of full travel. The differential pressure between the header and the tank gas volume is measured with a very sensitive device primarily to provide information on vent preclearing. The data channel for this measurement is driven to saturation in the early part of the transient. 
TABLE E-I

EXPERIMENT LO-3C DATA SUMMARY

\begin{tabular}{|c|c|c|c|c|c|}
\hline $\begin{array}{l}\text { Measurement } \\
\text { or } \\
\text { Cáculation }\end{array}$ & $\begin{array}{c}\text { Pre-Transient } \\
\text { Data Channel } \\
\text { Variance } \\
\left(10^{-4} \text { bar } 2\right) \\
\end{array}$ & Figure Number & Measurement & $\begin{array}{l}\text { Pre-Transient } \\
\text { Data Channel } \\
\text { Varijance } \\
\left(10^{-4} \text {. bar } 2\right) \\
\end{array}$ & Figure Number \\
\hline QOBV-1 opentry & & $E-1, E-2$ & PE-SV-22 & 0.29437 & $E-22$ \\
\hline QOBV-15 opening & - & $E-3, E-4$ & PE-SV-23. & 0.24991 & $E-23$ \\
\hline $\begin{array}{l}\text { Combined QOBV } \\
\text { opening }\end{array}$ & - & $E-5, E-6$ & PE-SV-24 & 0.17652 & $E-24$ \\
\hline Vertical load & - & $E-7$ & PE-SV-25 & 0.19996 & $E-25$ \\
\hline PDE-SV-09 & - & $E-8$ & PE-SV-26 & 0.13526 & $E-26$ \\
\hline PE-SV-01 & 0.25367 & $E-9$ & PE-SV-27 & 0.23817 & $E-27$ \\
\hline PE-SV-02 & 0.35602 & $E-10$ & PE-SV-28 & 0.23992 & $E-28$ \\
\hline PE-SV-03 & 0.32328 & $E-11$ & PE-SV-29 & 0.35763 & $E-29$ \\
\hline PE-SV-04 & 0.47519 & $E-12$ & PE-SV-43 & 0.18837 & $E-30$ \\
\hline PE-SV-10 & 0.40962 & $E-13$ & PE-SV-44 & 0.21058 & $E-31$ \\
\hline PE-SV-11 & 1.6224 & $E-14$ & PE-.SV-54 & 0.17187 & $E-32$ \\
\hline$P E-S V-12$ & 0.29861 & $E-15$ & $P[-S V-55$ & 0.10049 & $E-33$ \\
\hline PE-SV-13 & 0.17853 & $E-16$ & $P E-S V-56$ & 0.19573 & $E-34$ \\
\hline PE-SV-14 & 0.32800 & $E-17$ & PE-SV-57 & 0.12094 & $E-35$ \\
\hline$P E-S V-15$ & 0.31635 & $E-18$ & PE-SV-58 & 0.24732 & $E-36$ \\
\hline PE-SV-16 & 0.29990 & $E-19$ & PE-SV-59 & 0.25033 & $\bar{E}-37$ \\
\hline PE-SV-17 & 0.37193 & $E-20$ & PE-SV-60 & 0.25702 & $E-38$ \\
\hline PF-SV-18 & 0.35029 & $E-21$ & PE-SV-61 & 0.20165 & $E-39$ \\
\hline
\end{tabular}



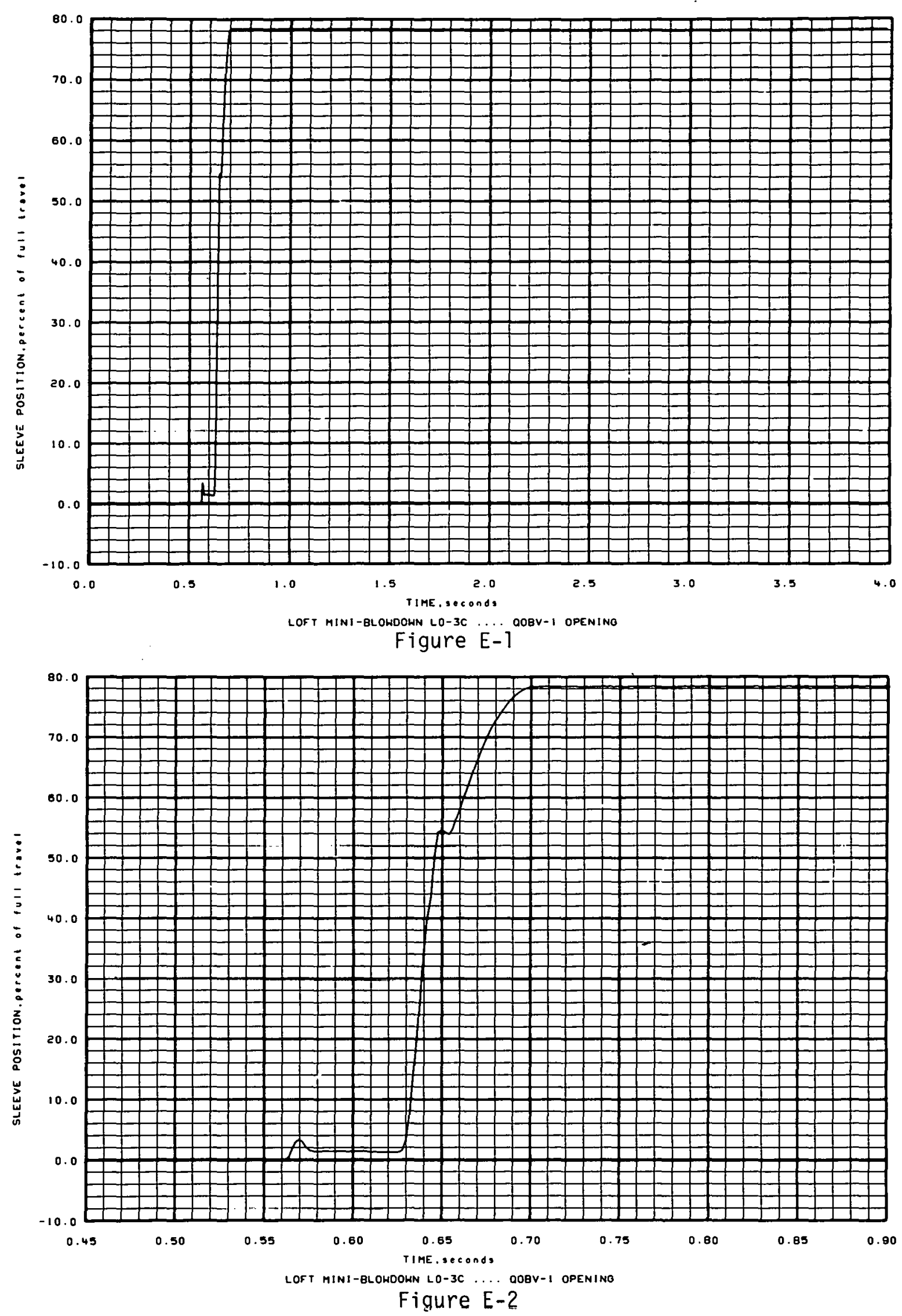

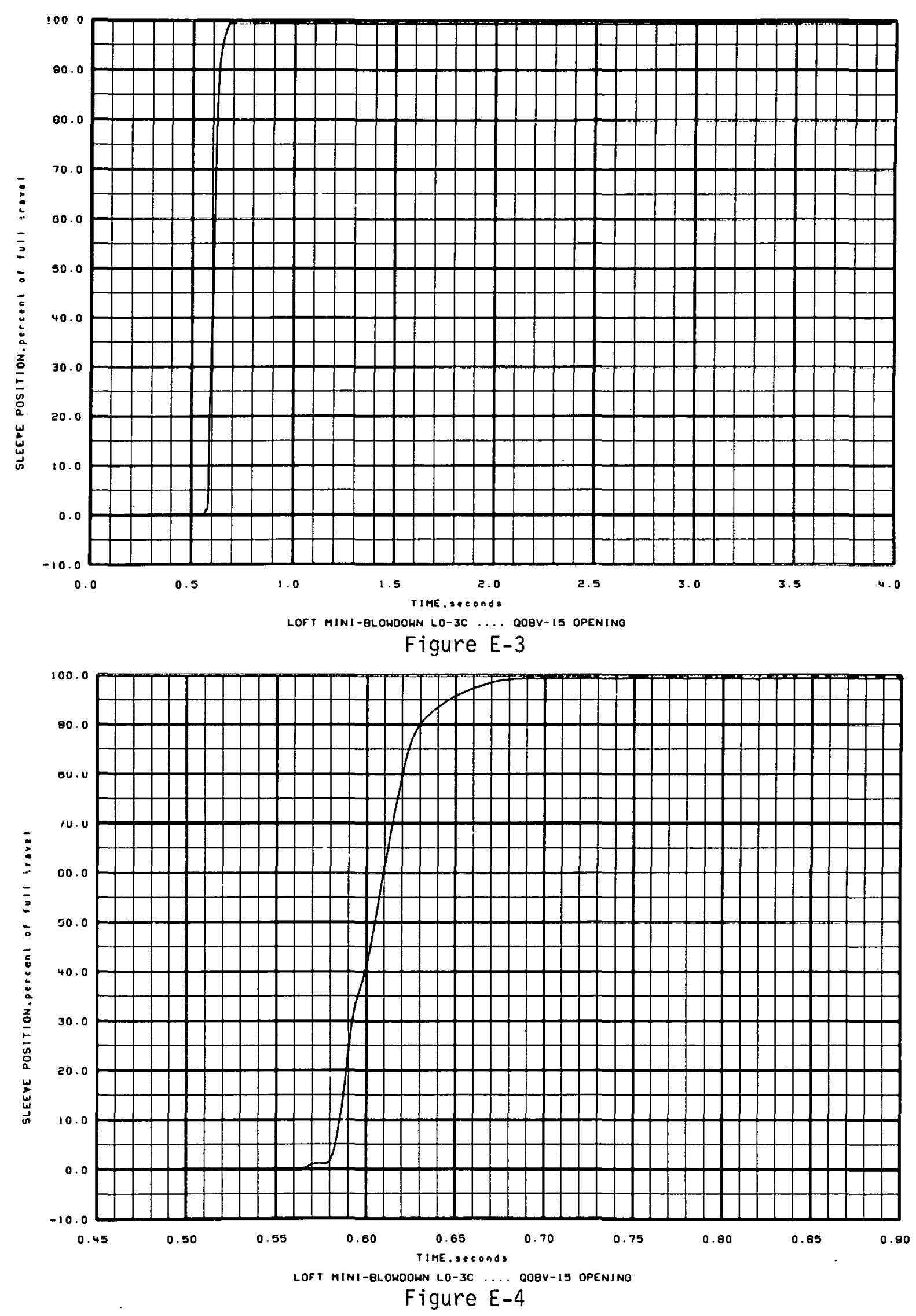

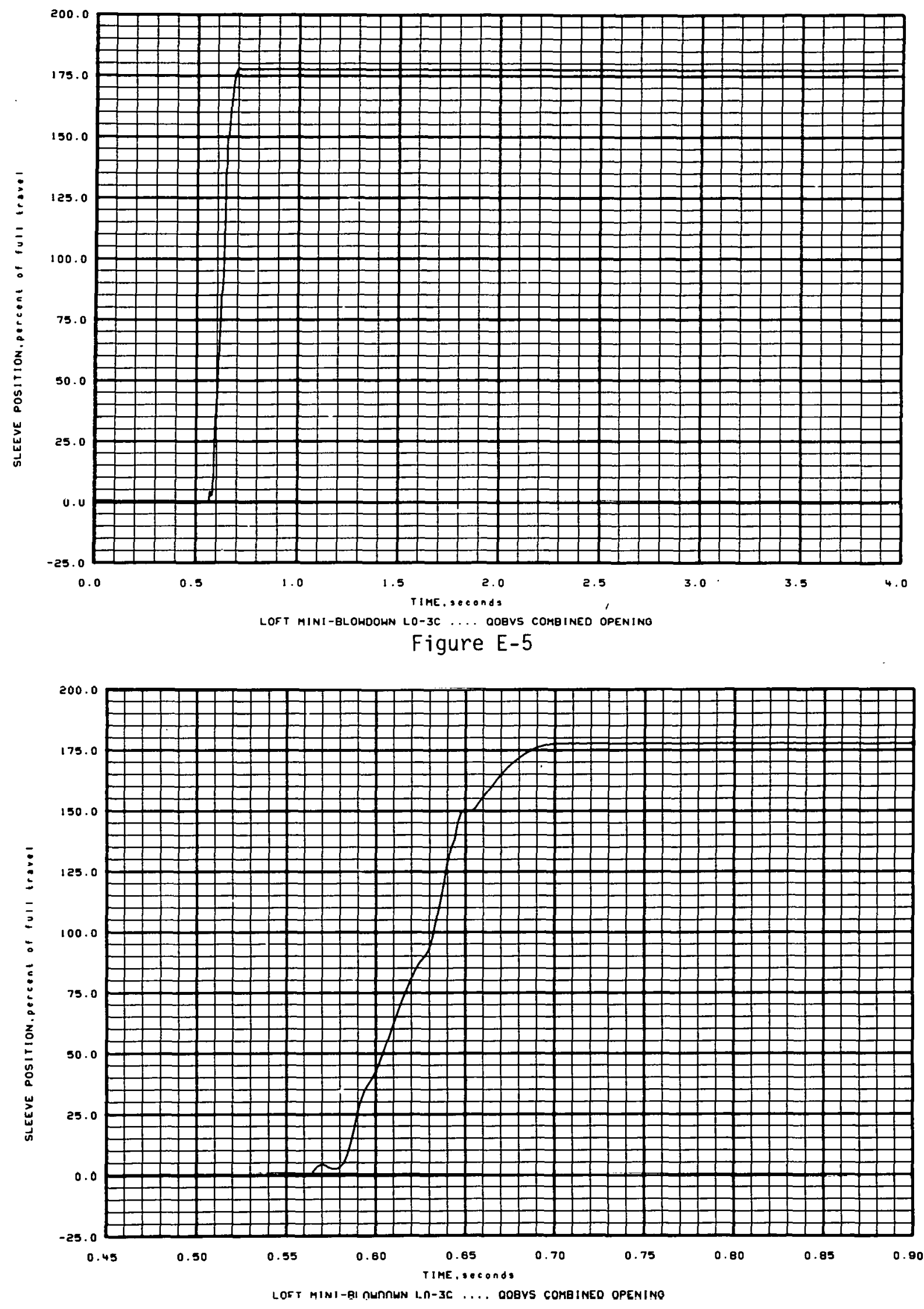

Figure E-6 

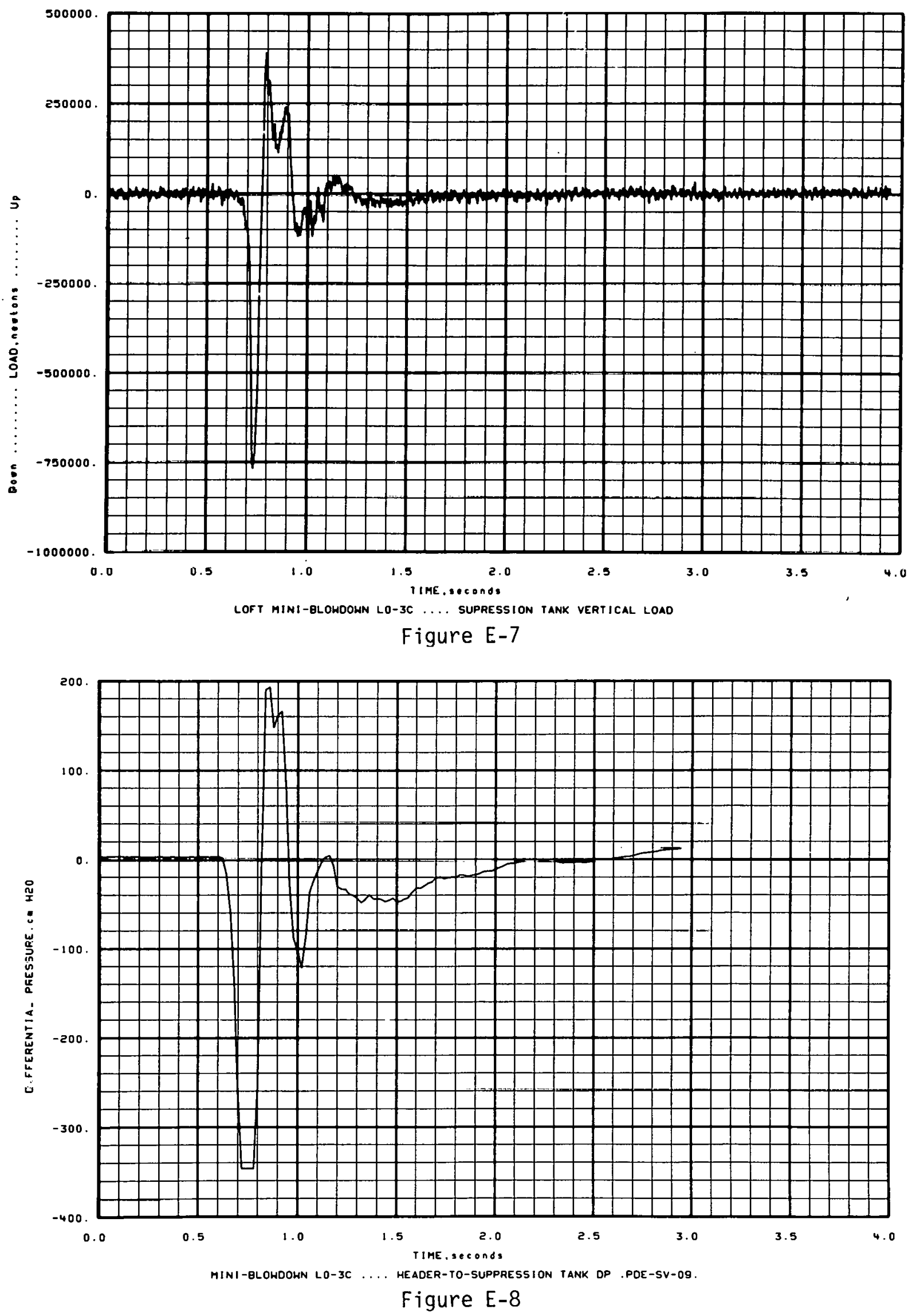


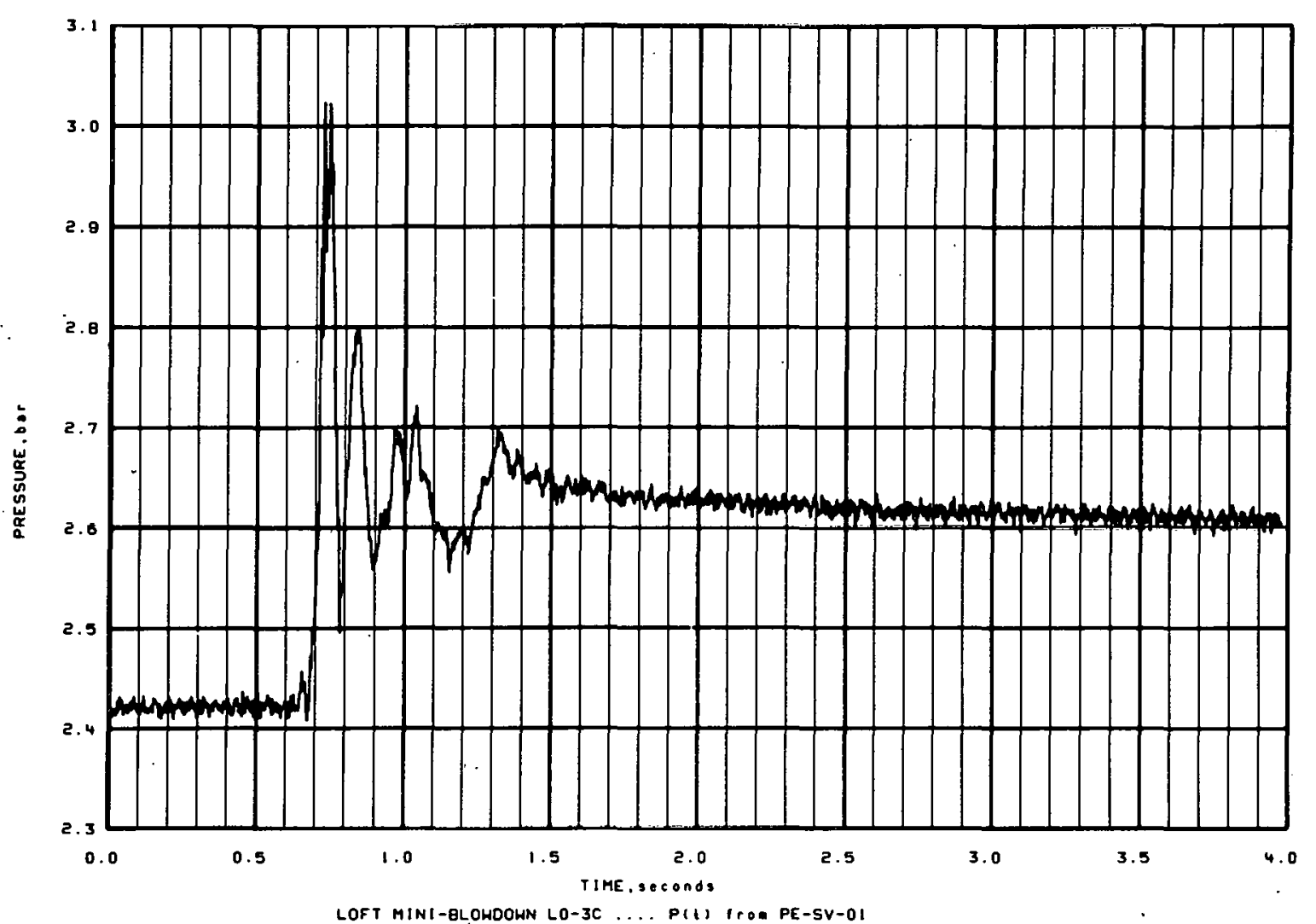

Figure E-9

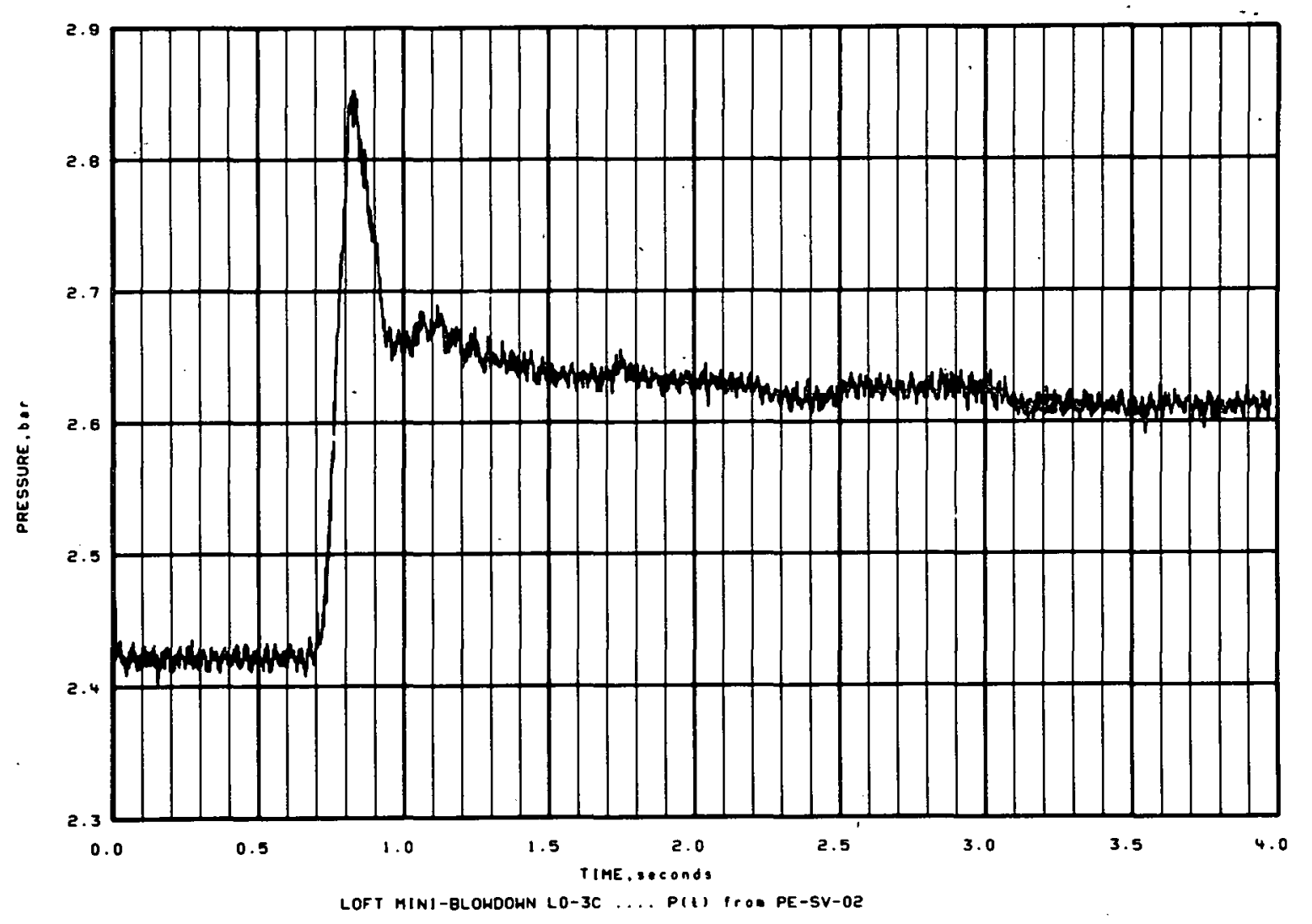

Figure E-10 


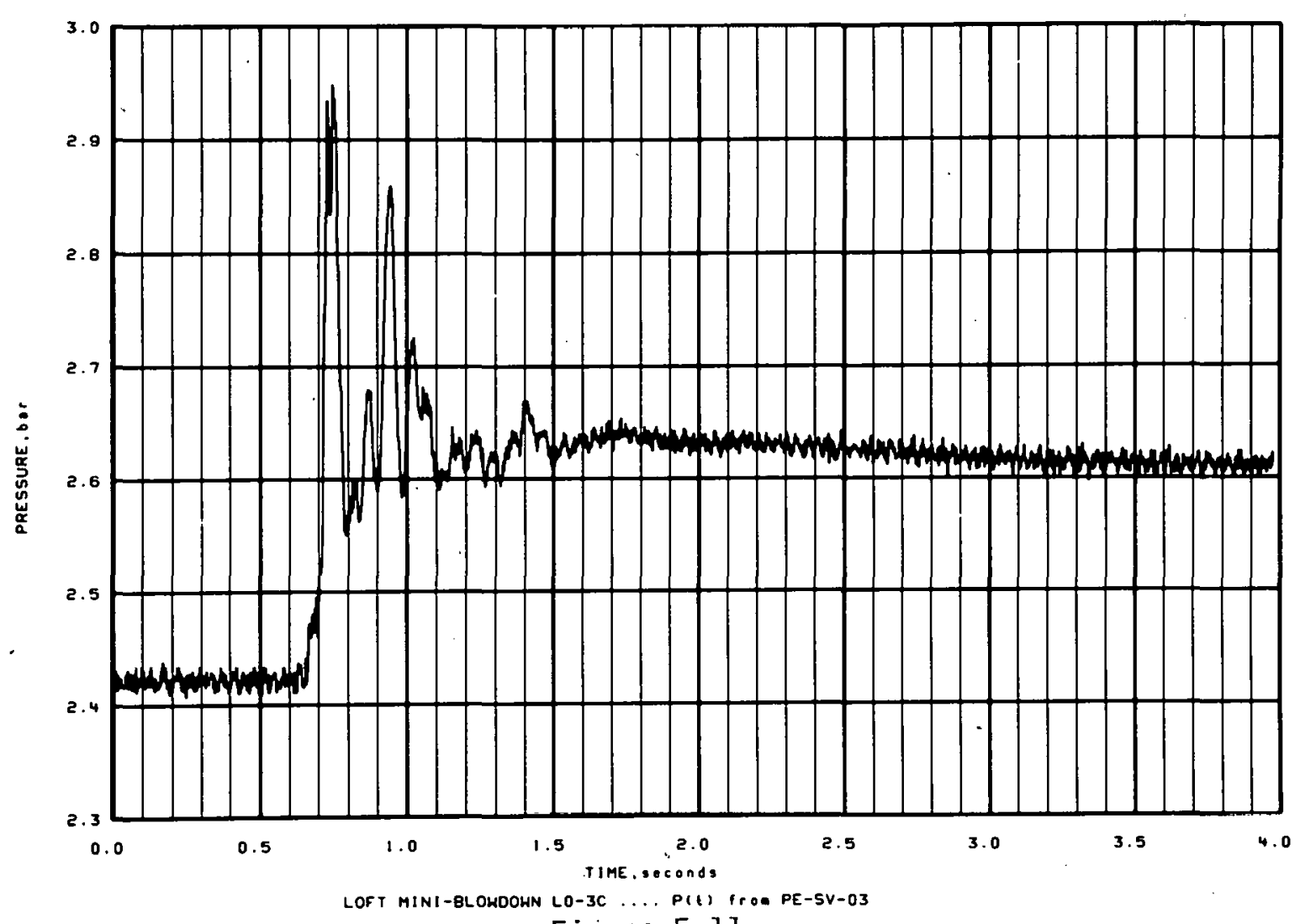

Figure E-11

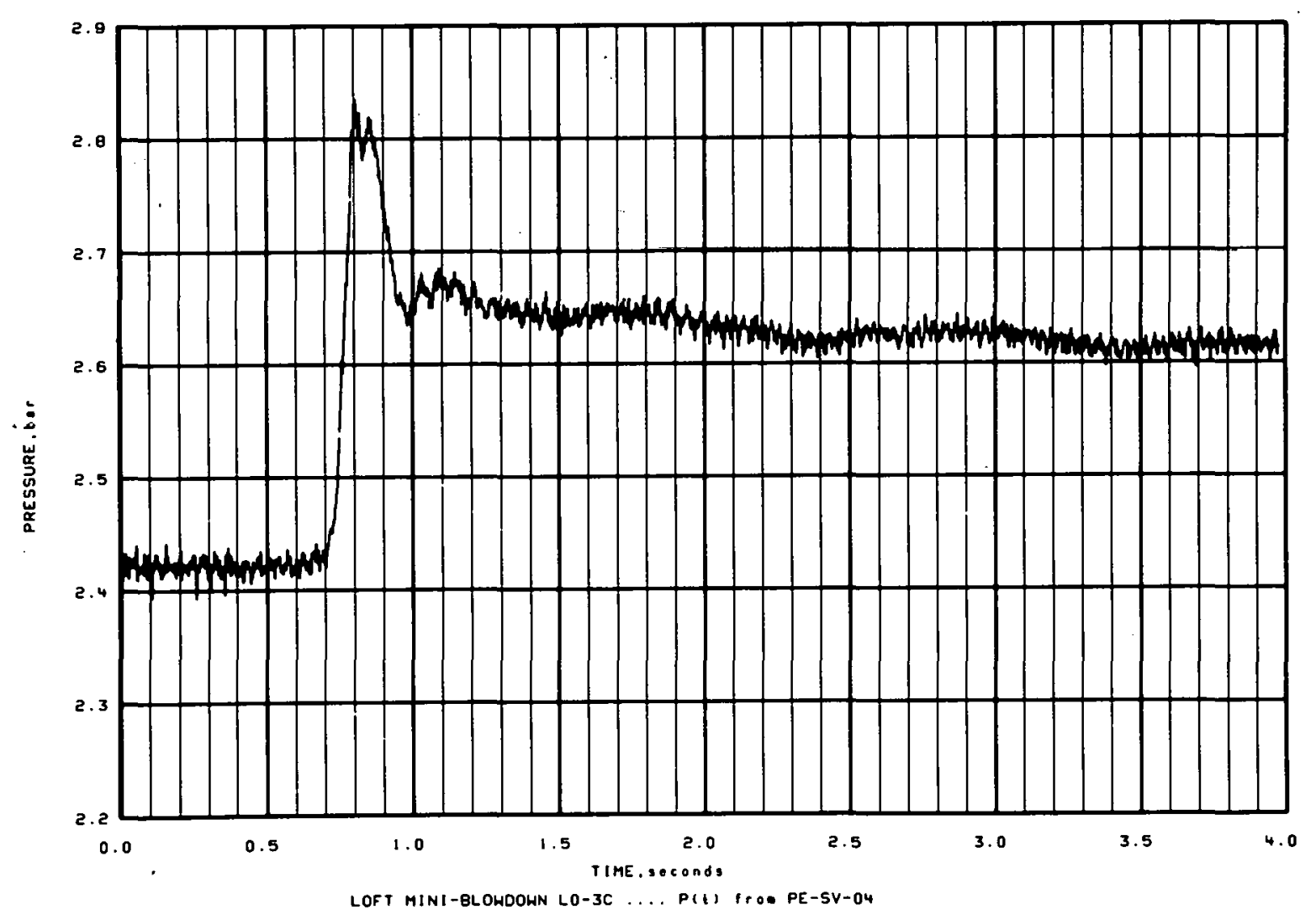

Figure E-12 


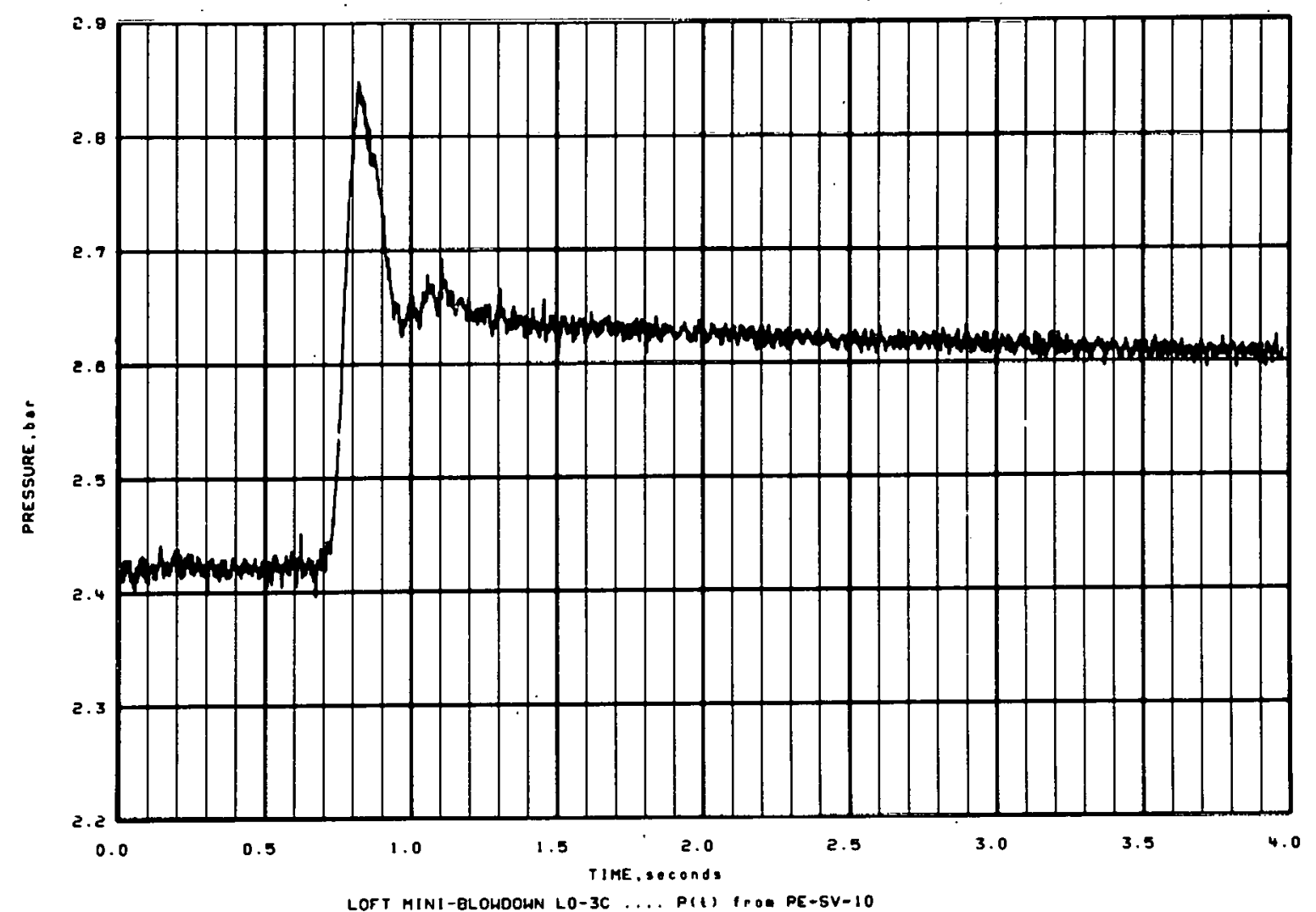

Figure E-13

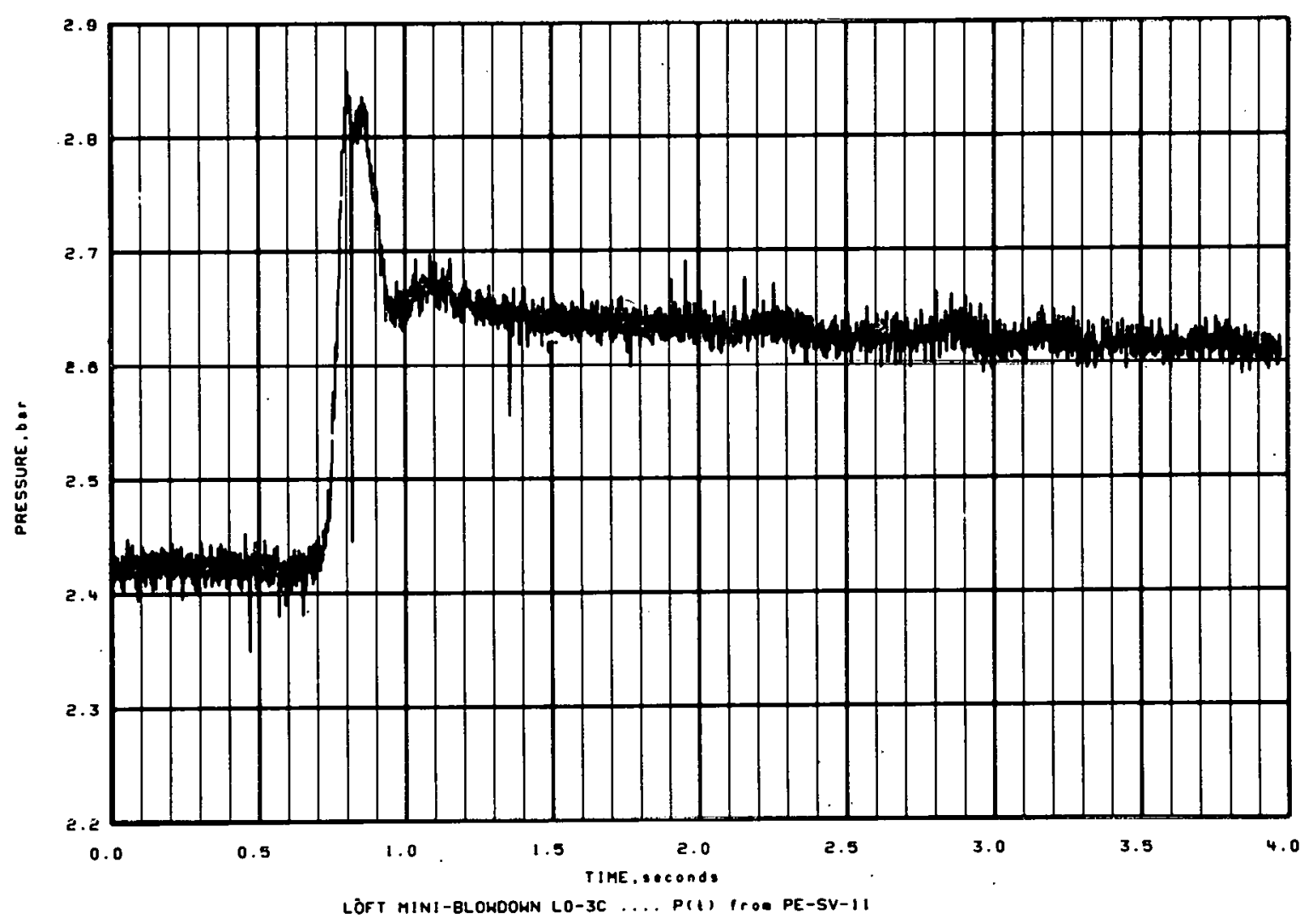

Figure E-14 


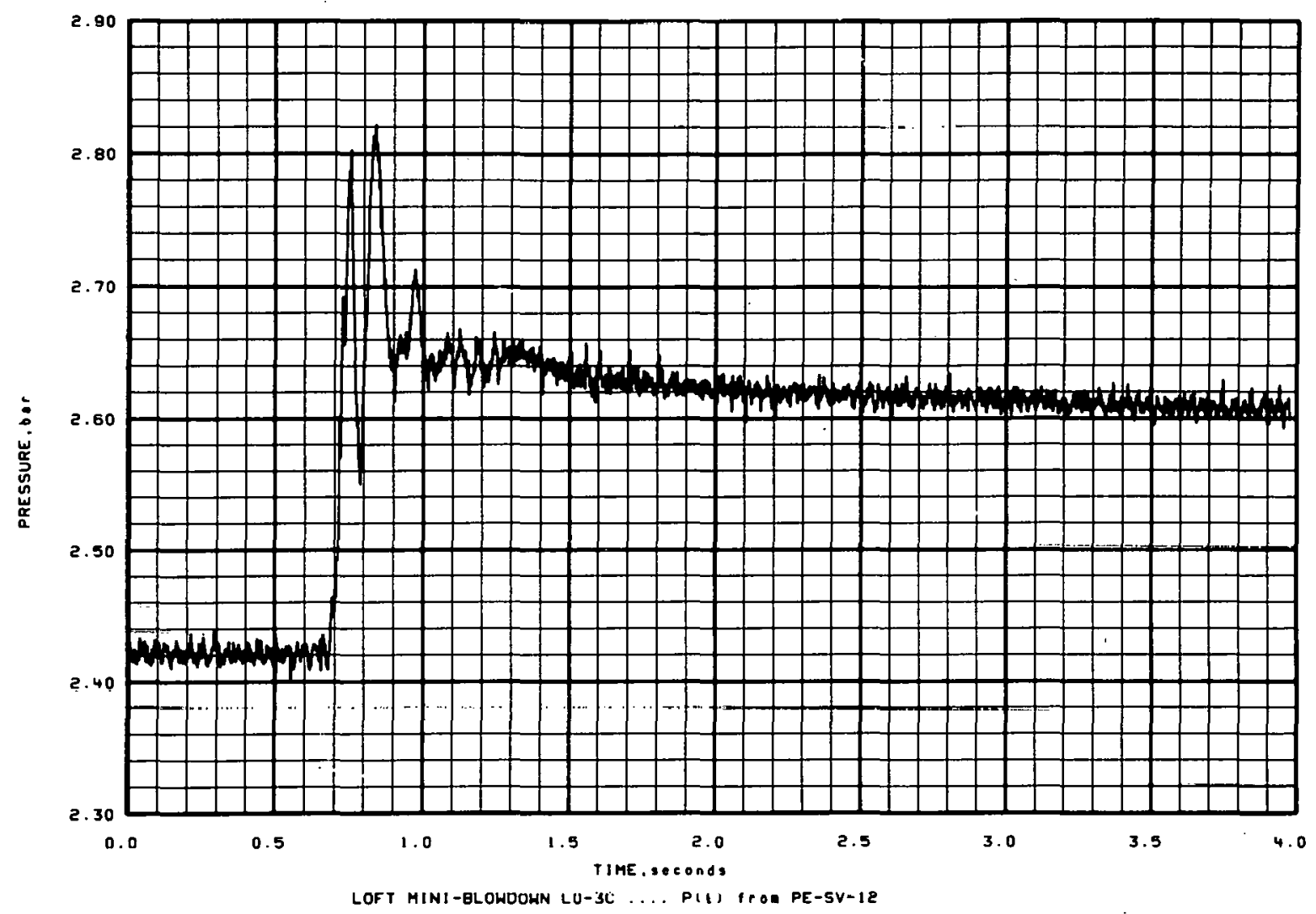

Figure E-15

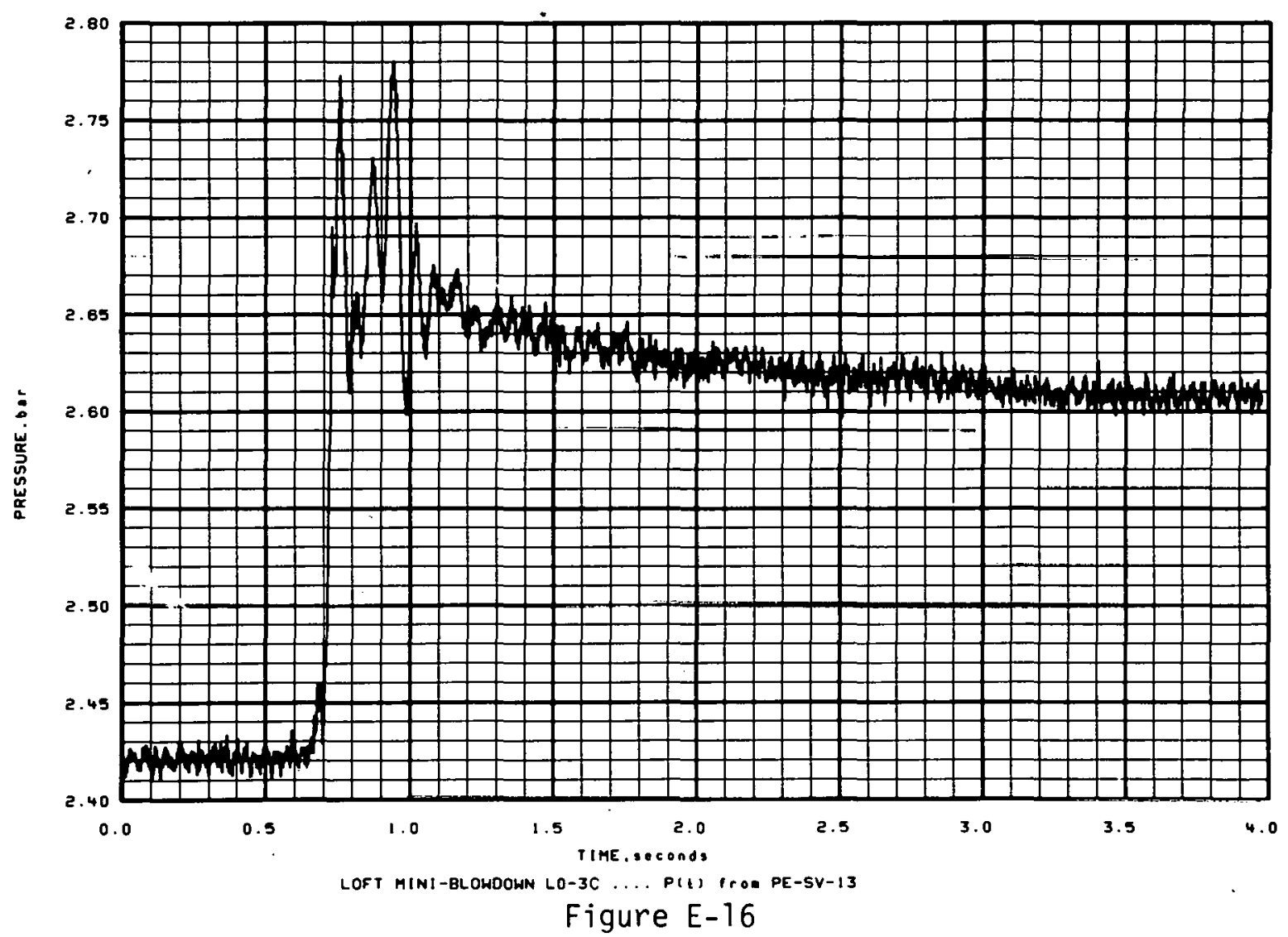




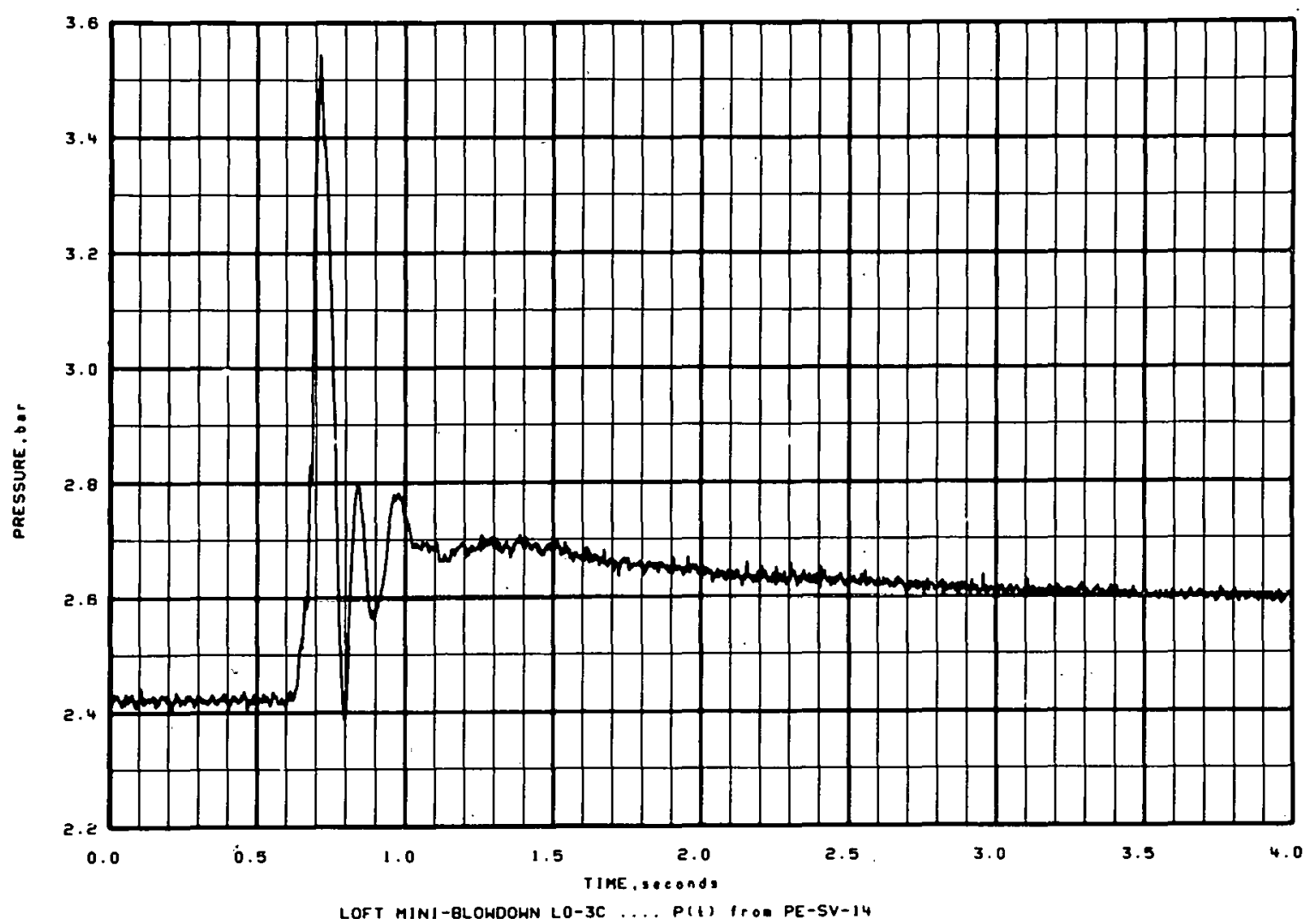

Figure E-17

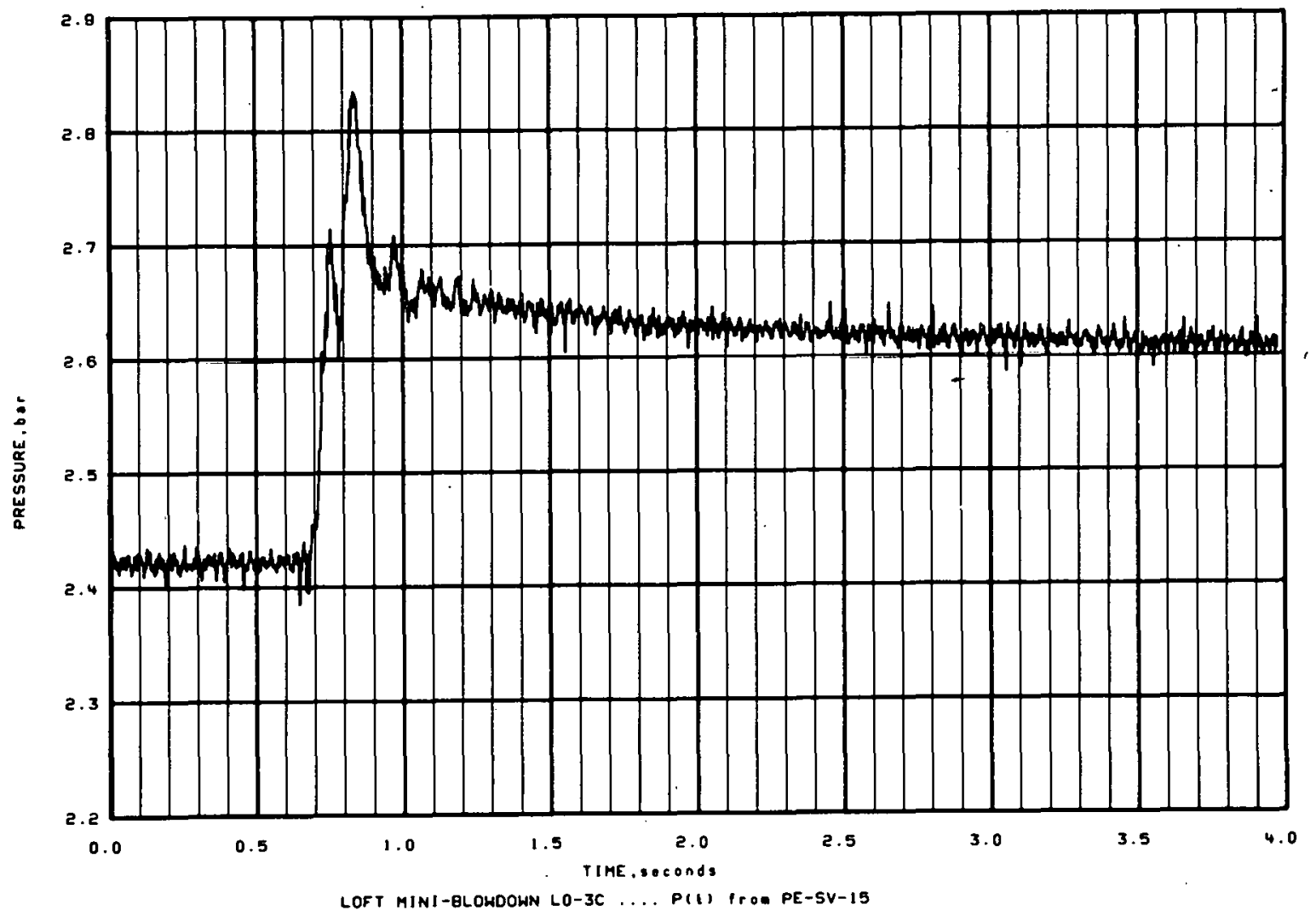

Figure E-18 

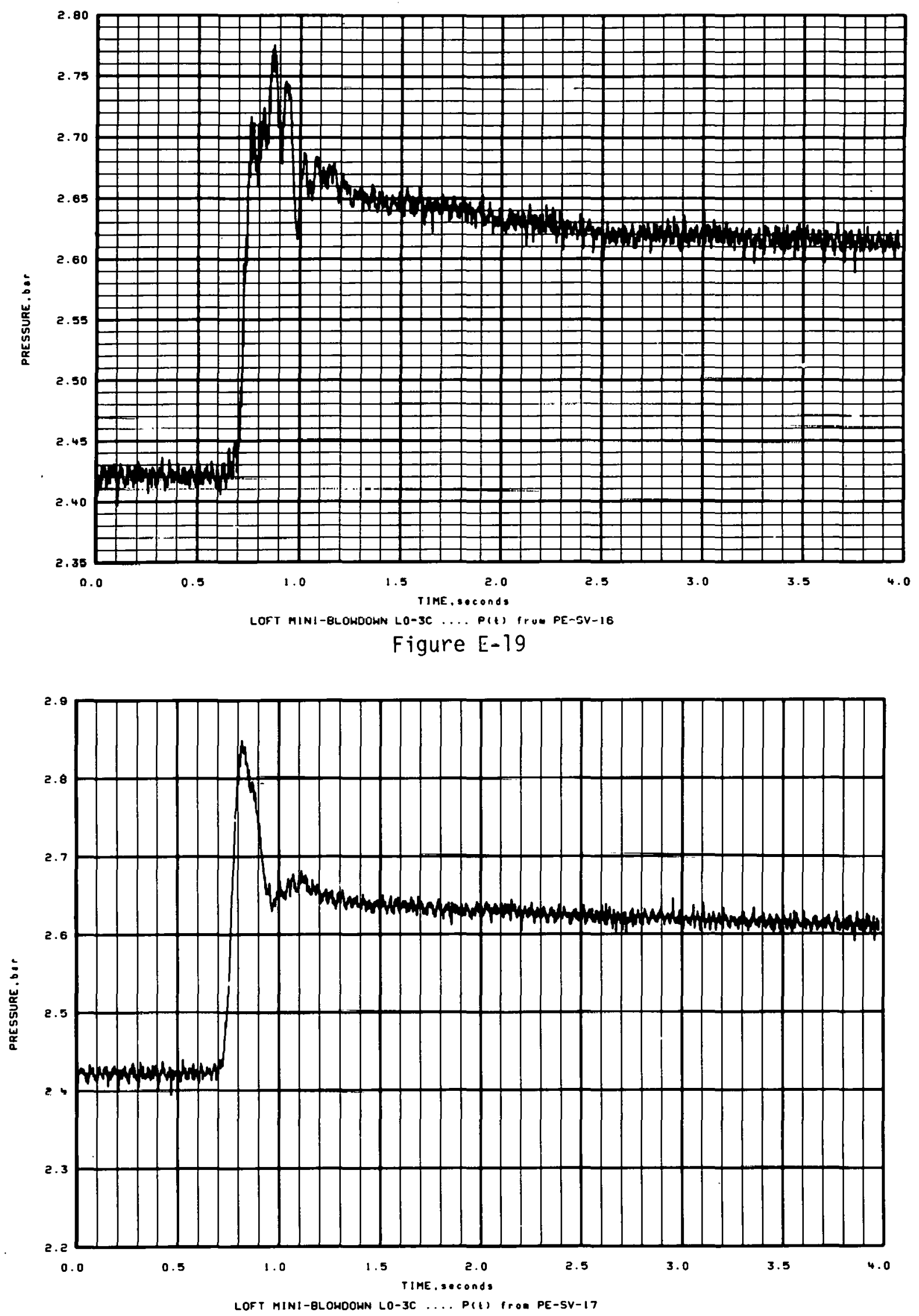

Figure E-20 

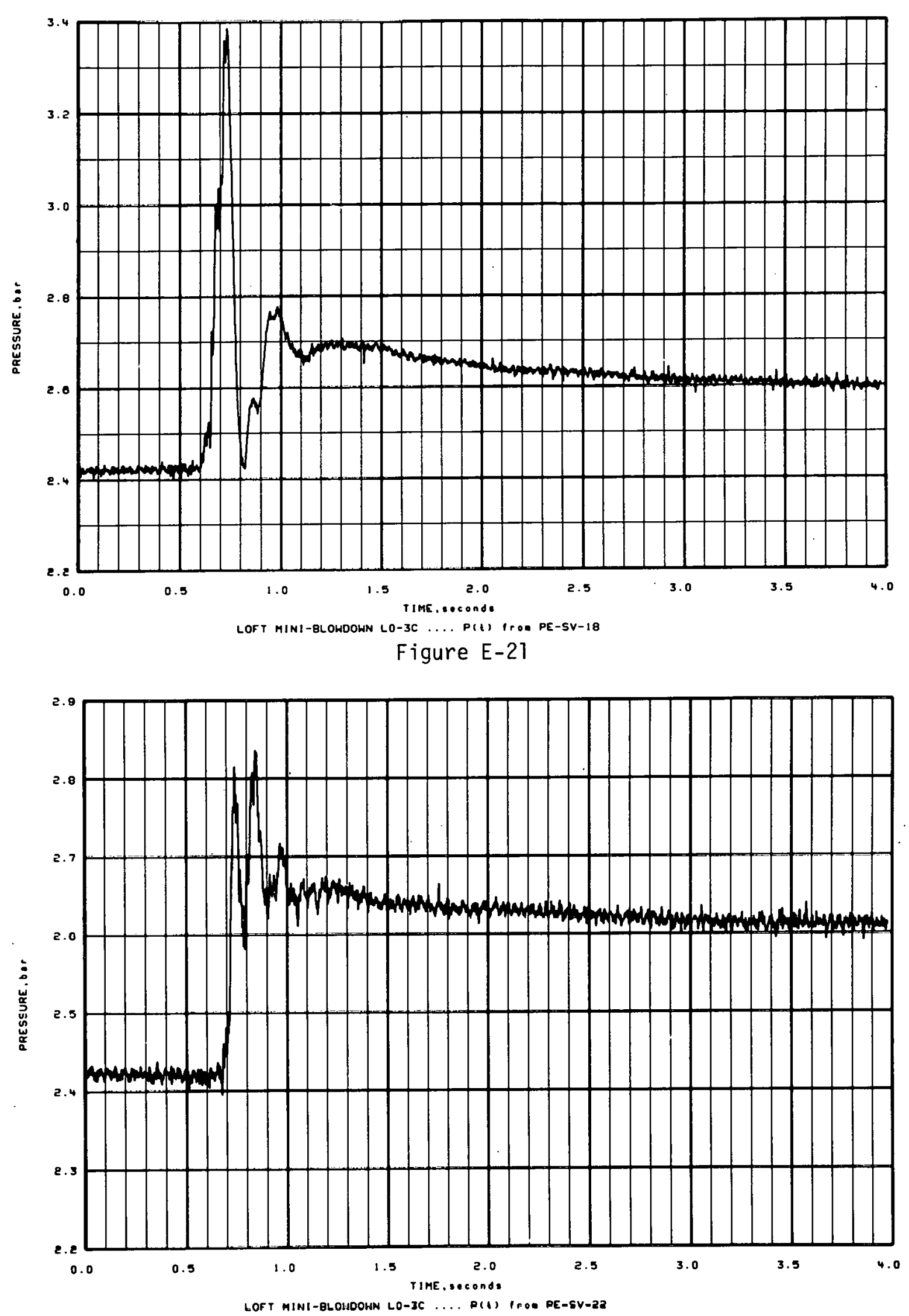

Figure E-22 


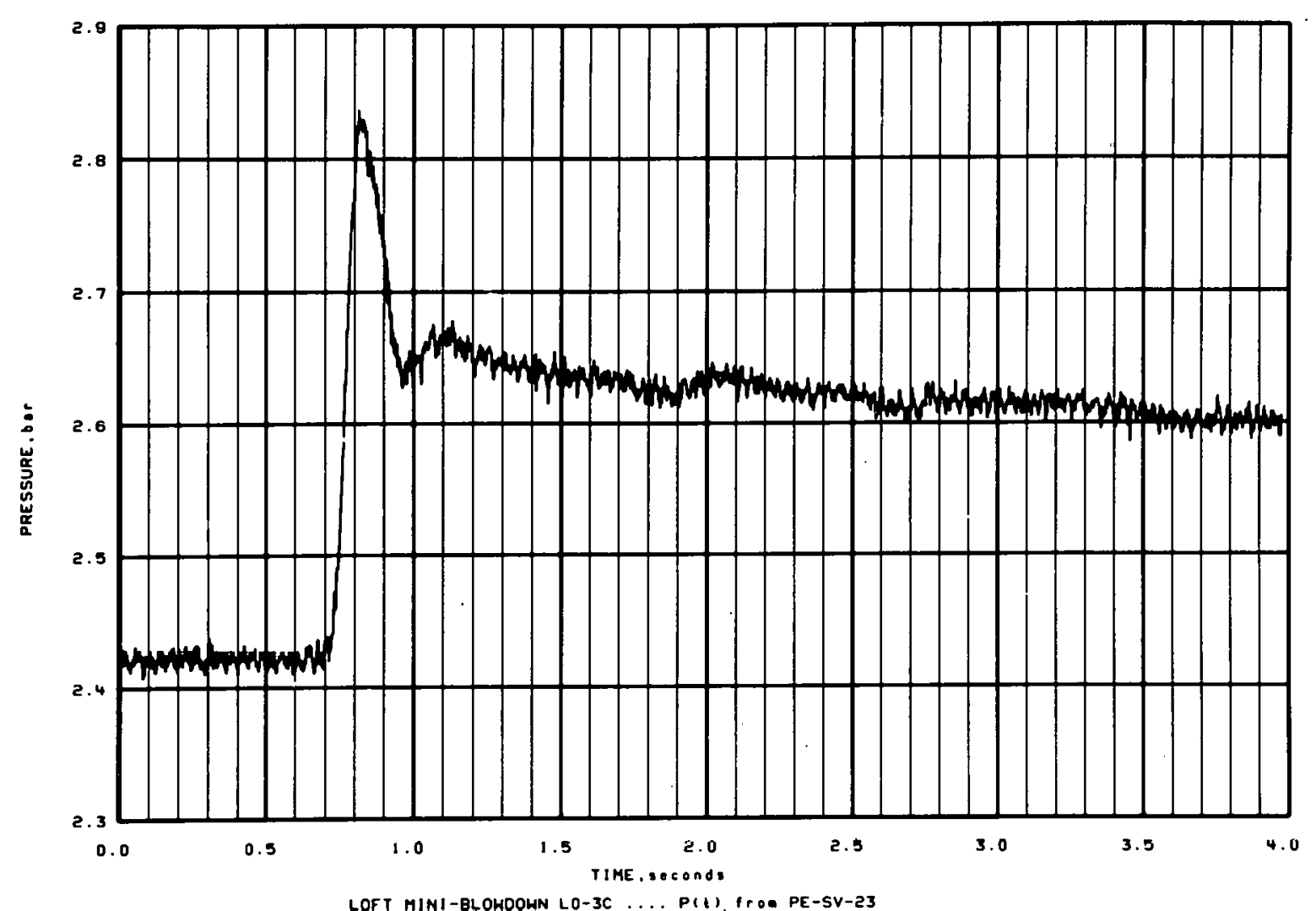

Figure E-23

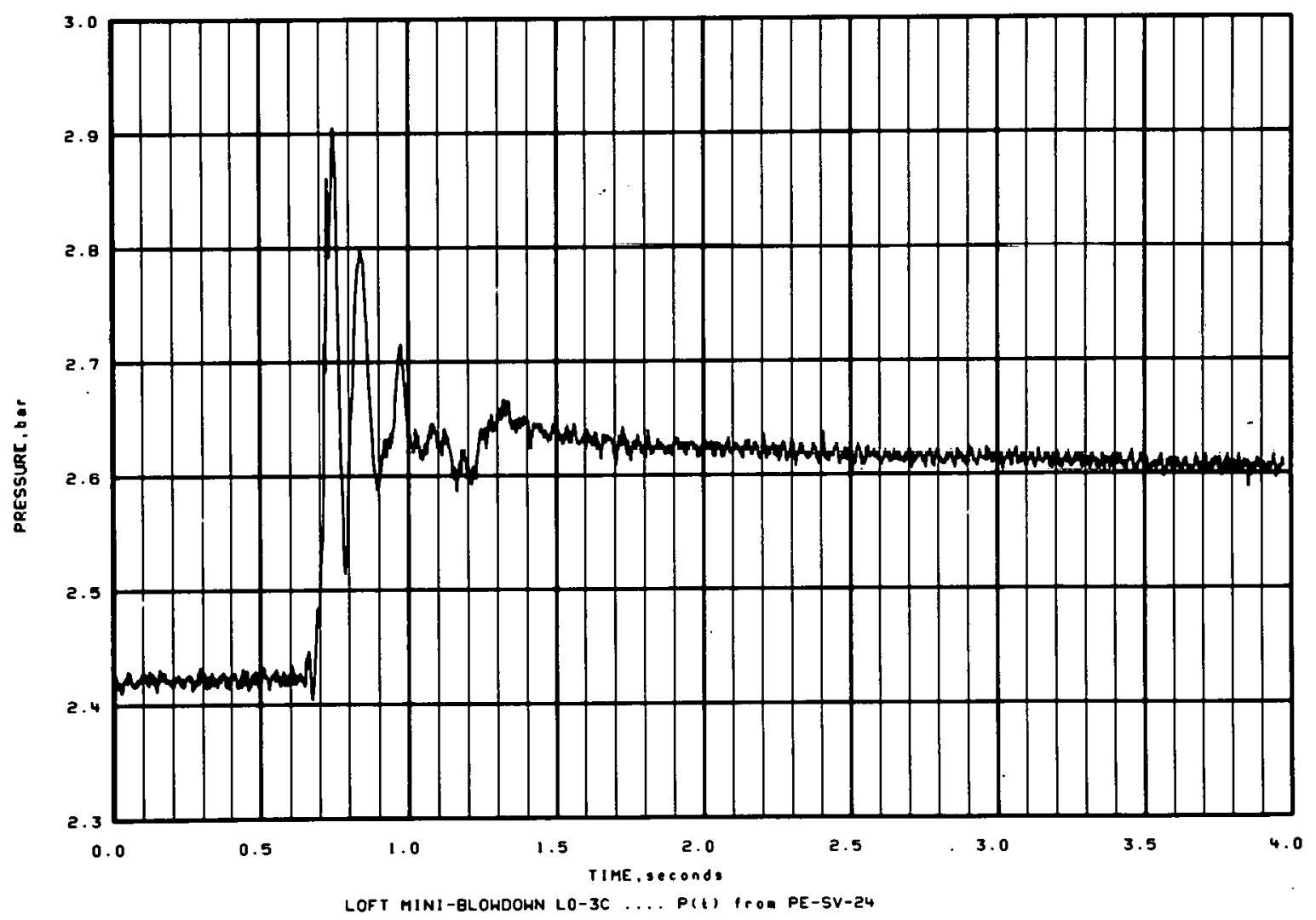

Figure E-24 


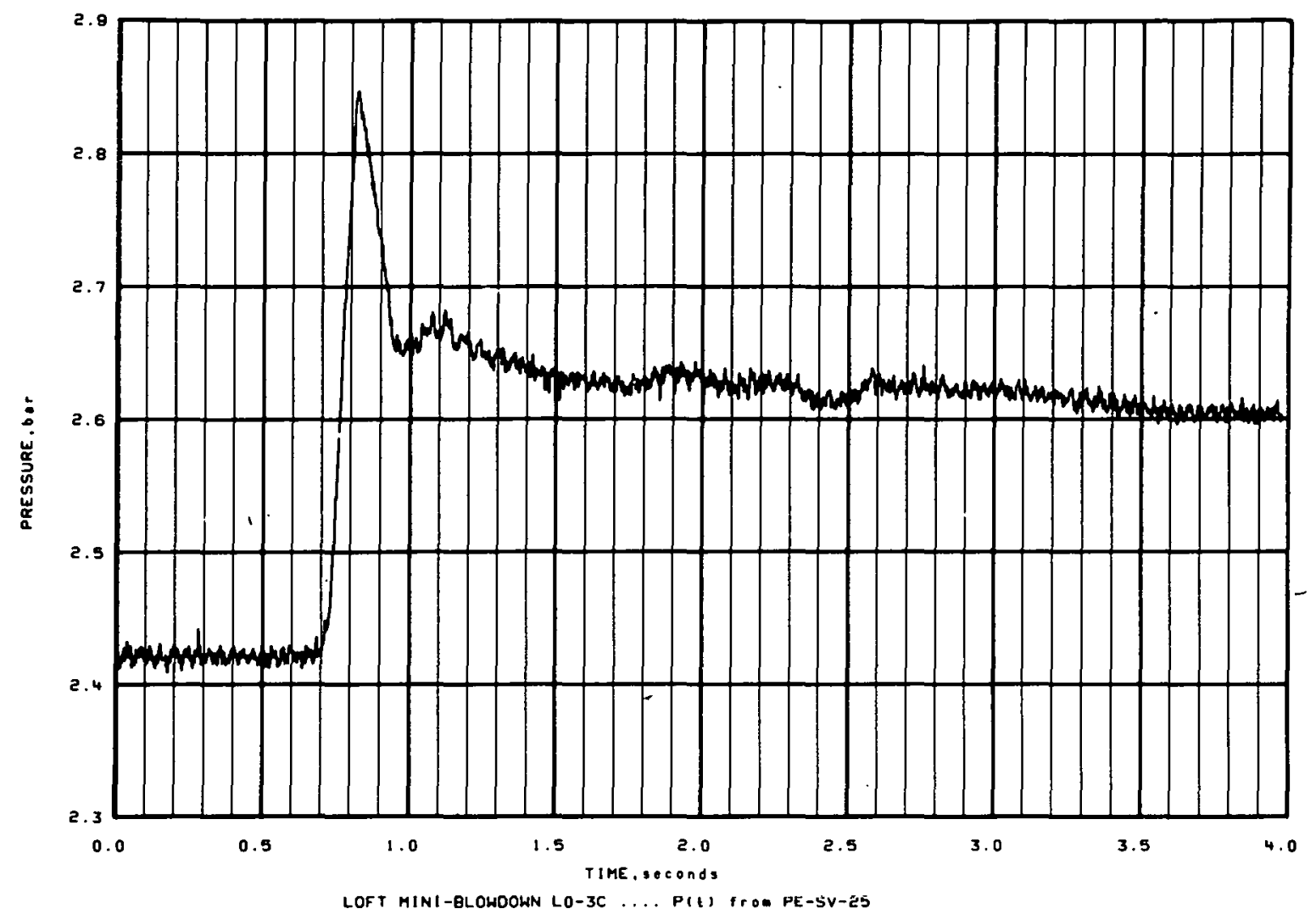

Figure E-25

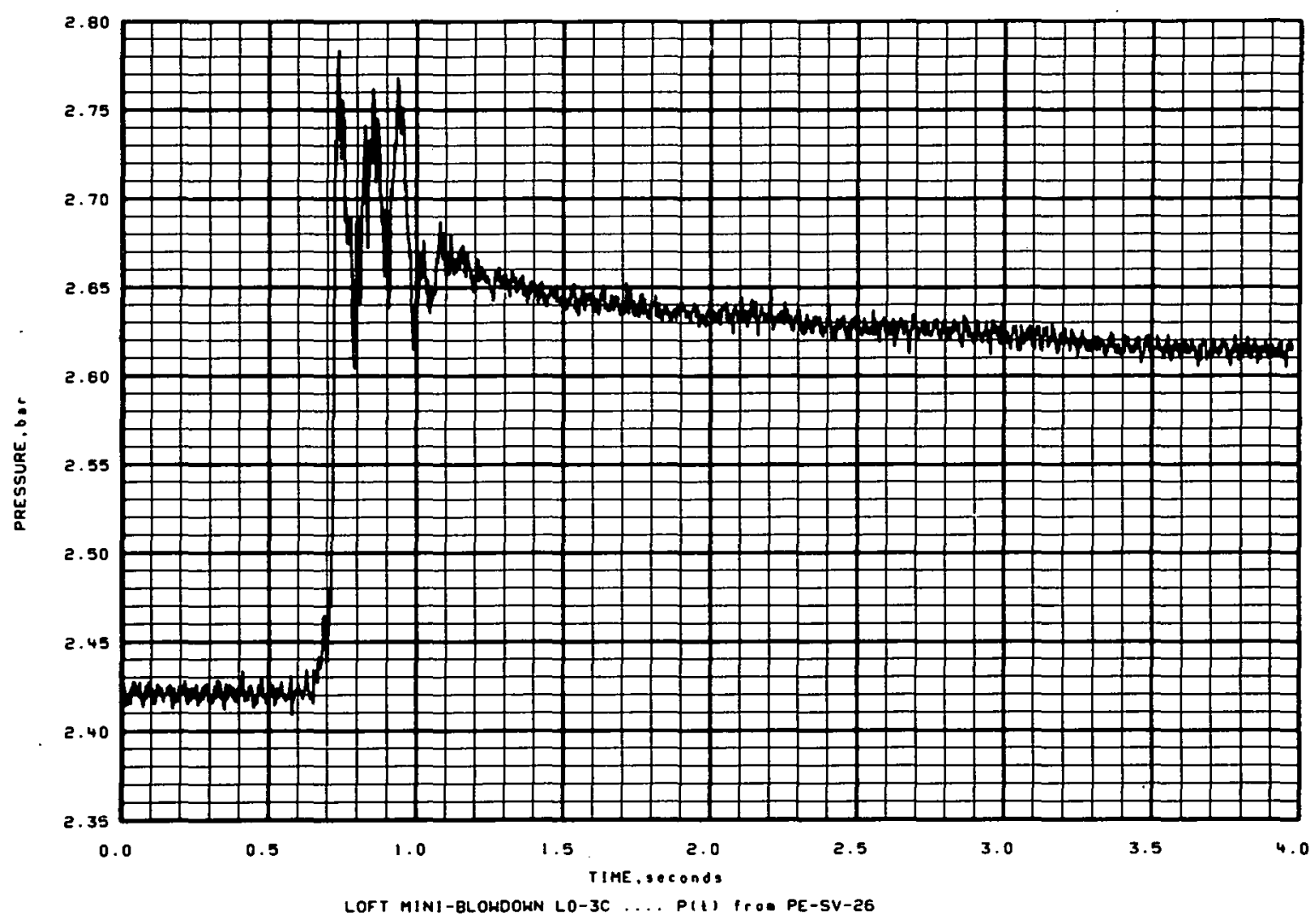

rigure $E-26$ 


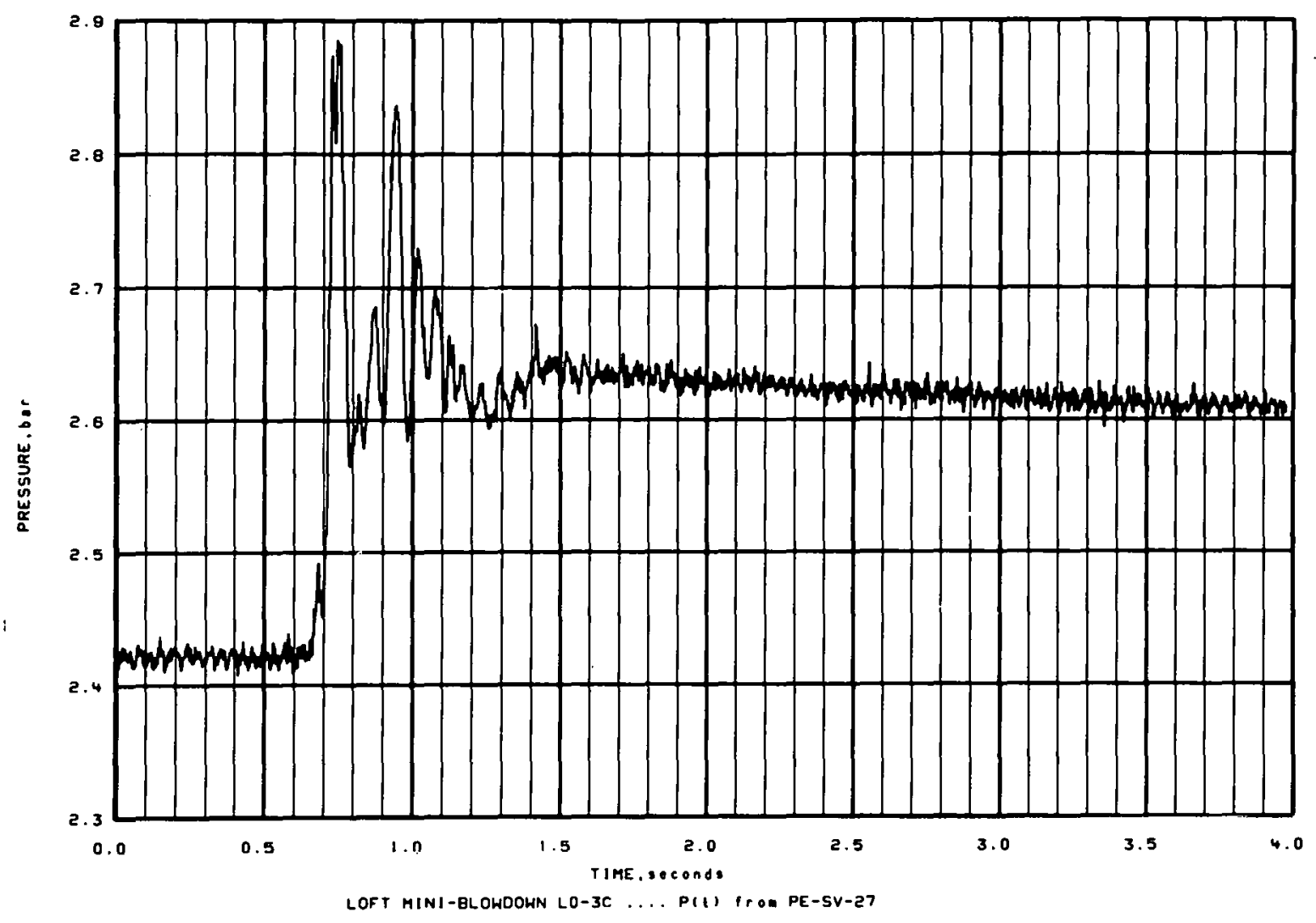

Figure E-27

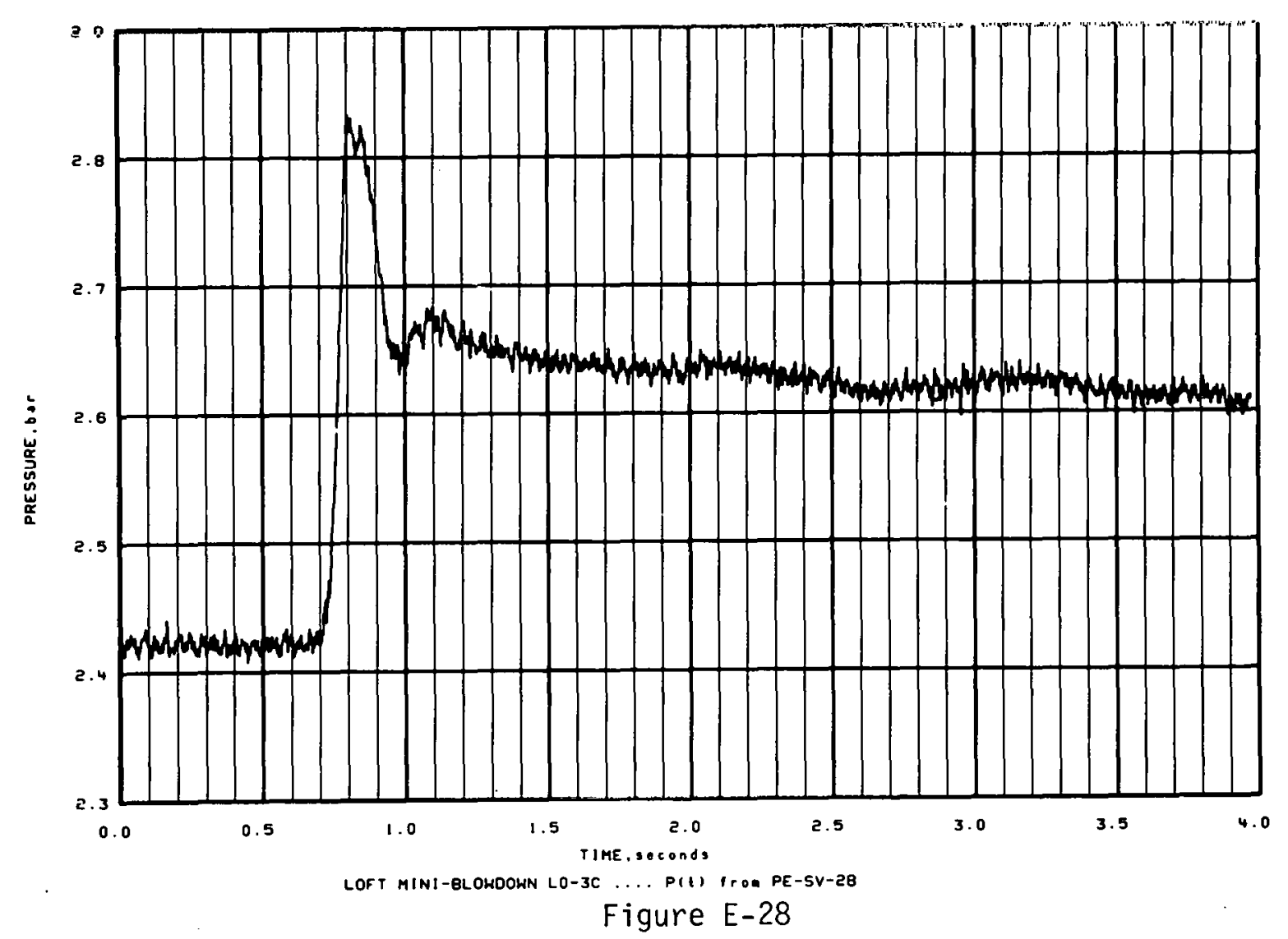




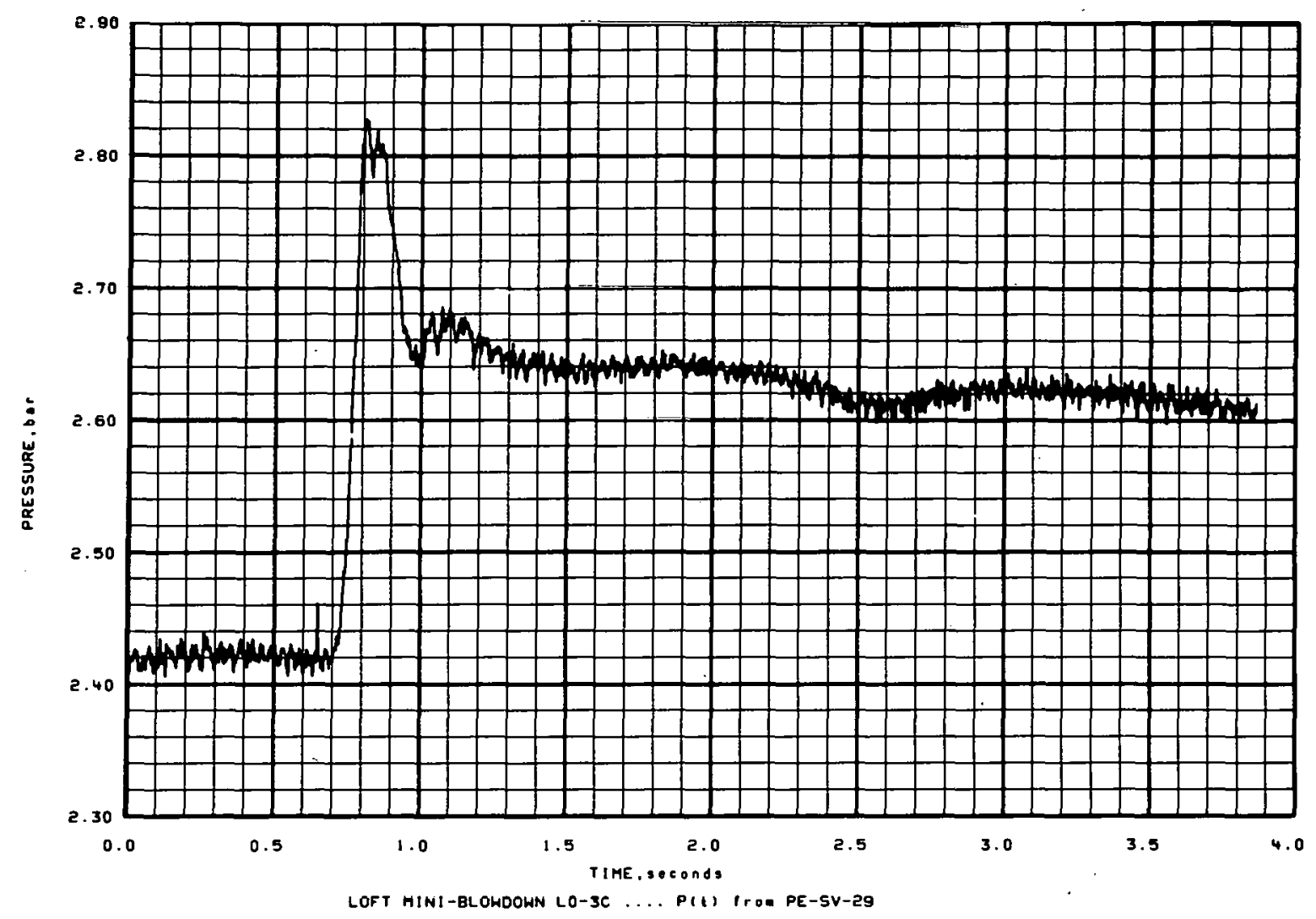

Figure E-29

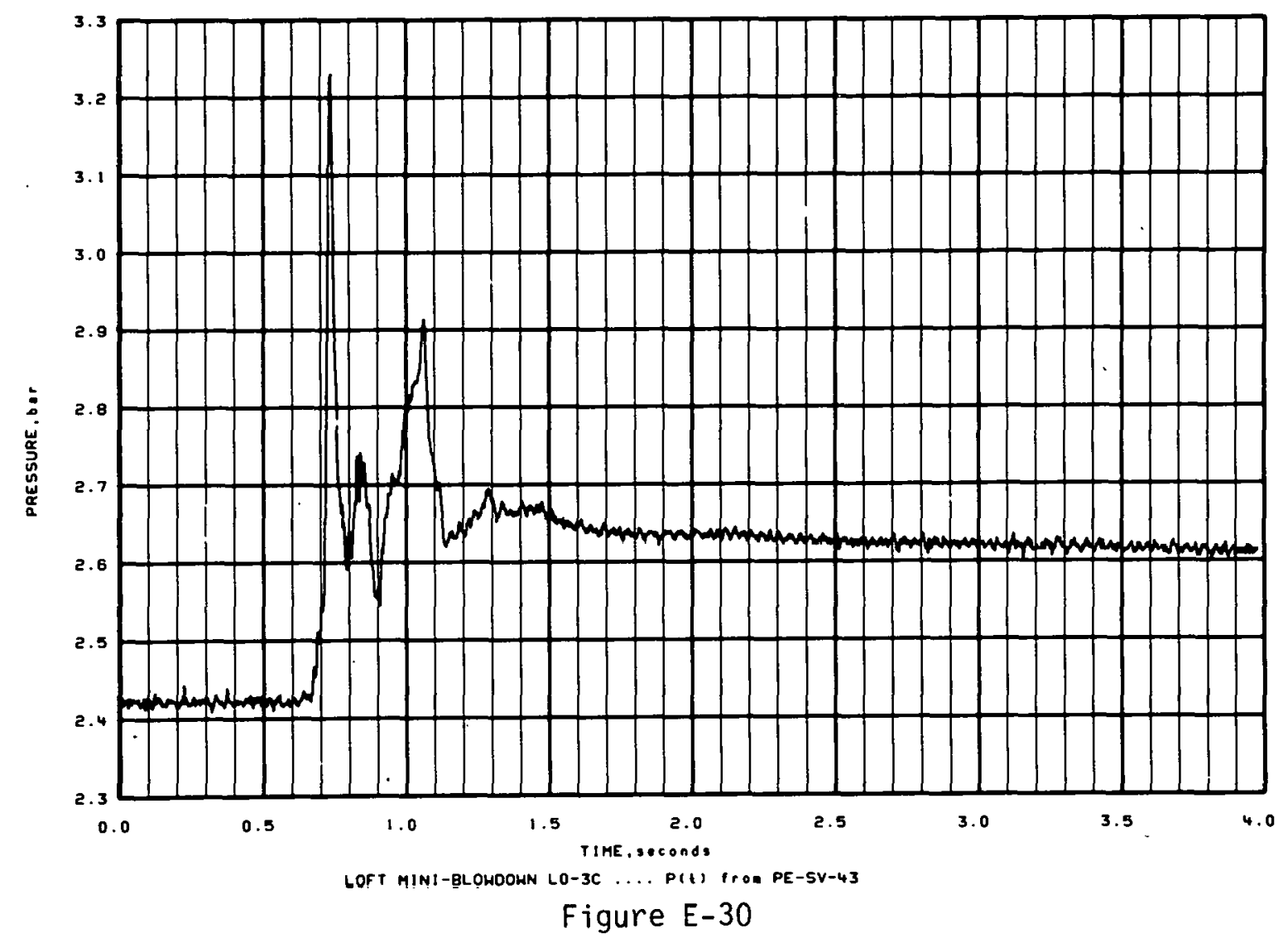




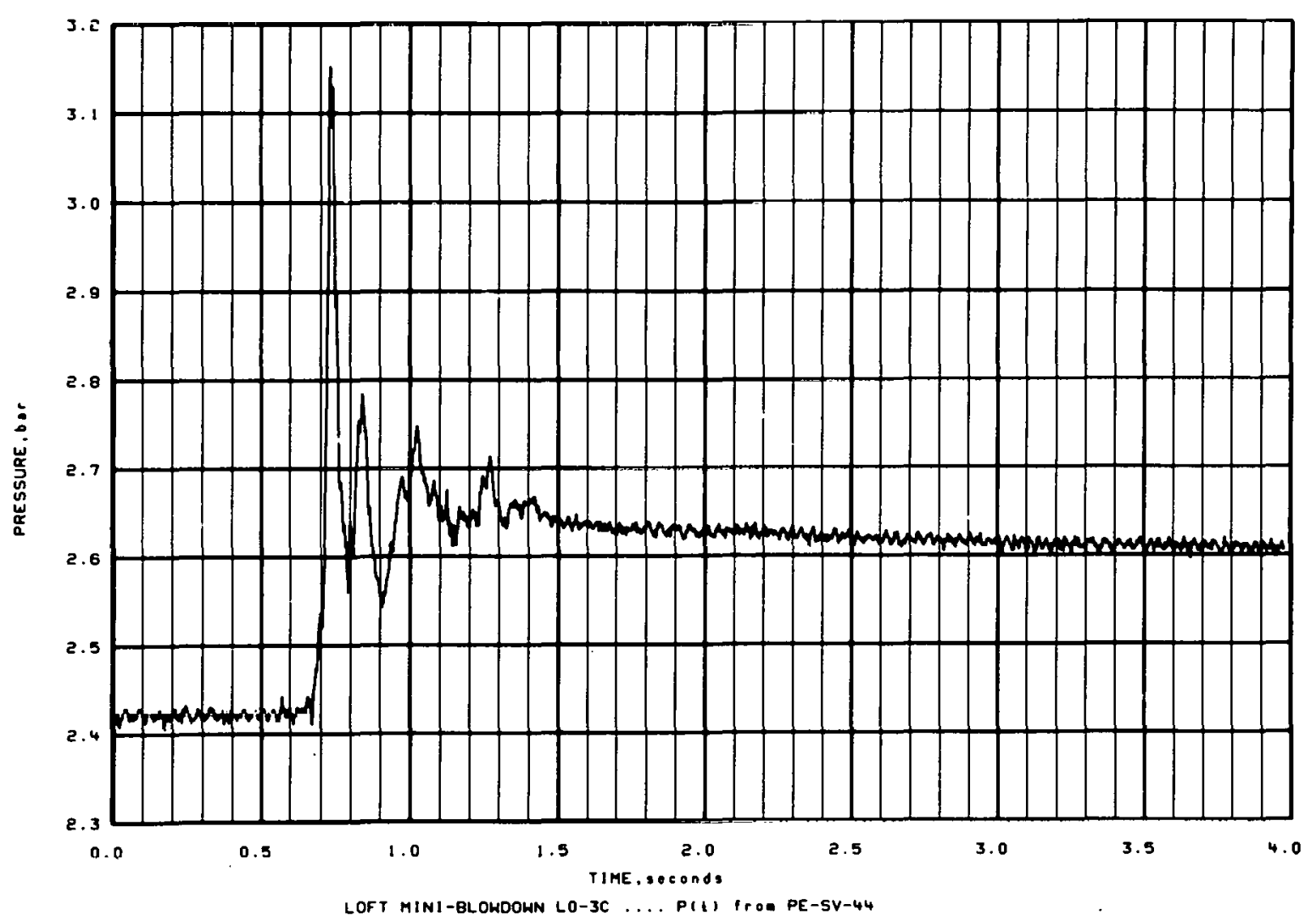

Figure E-31

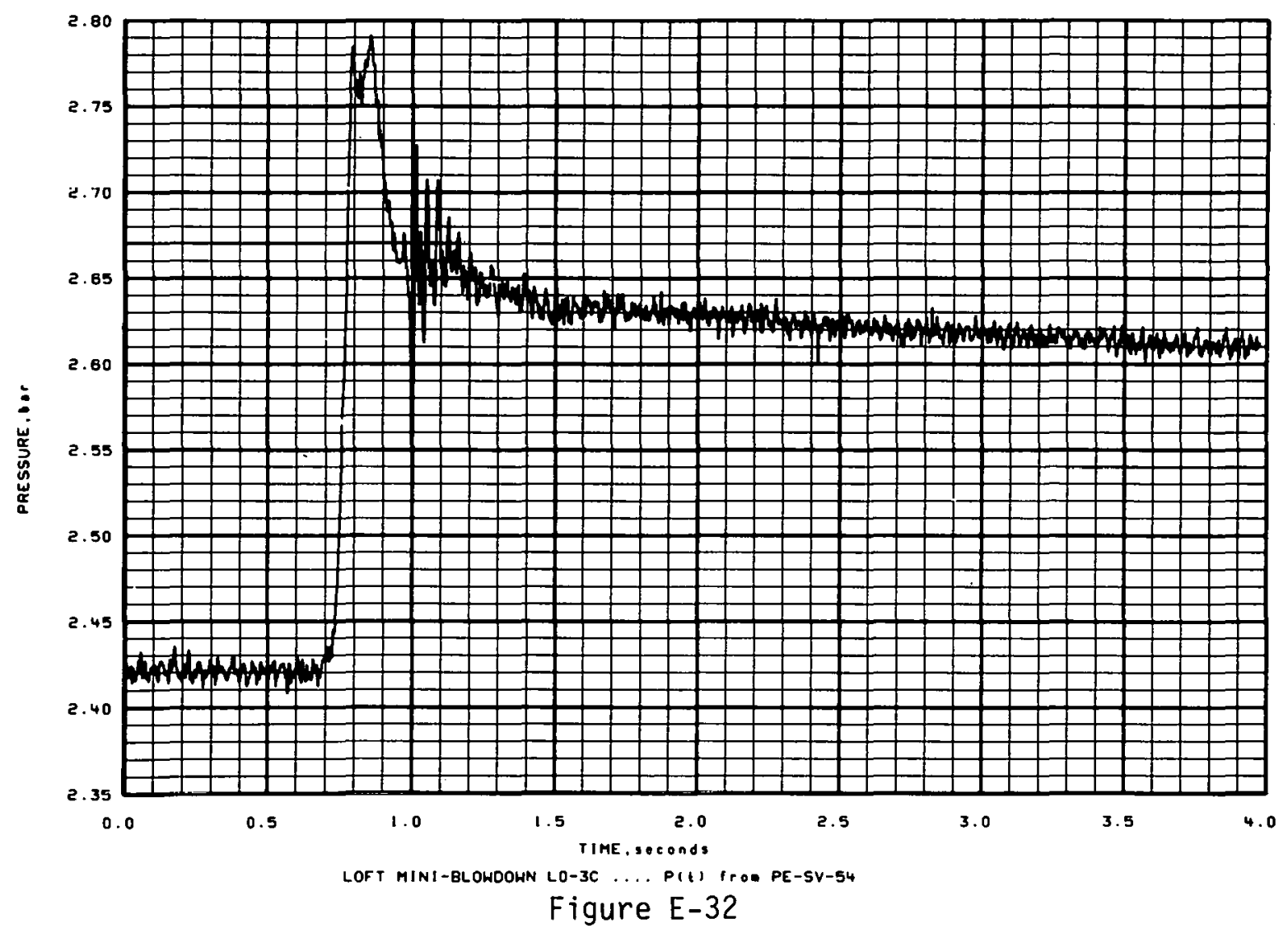




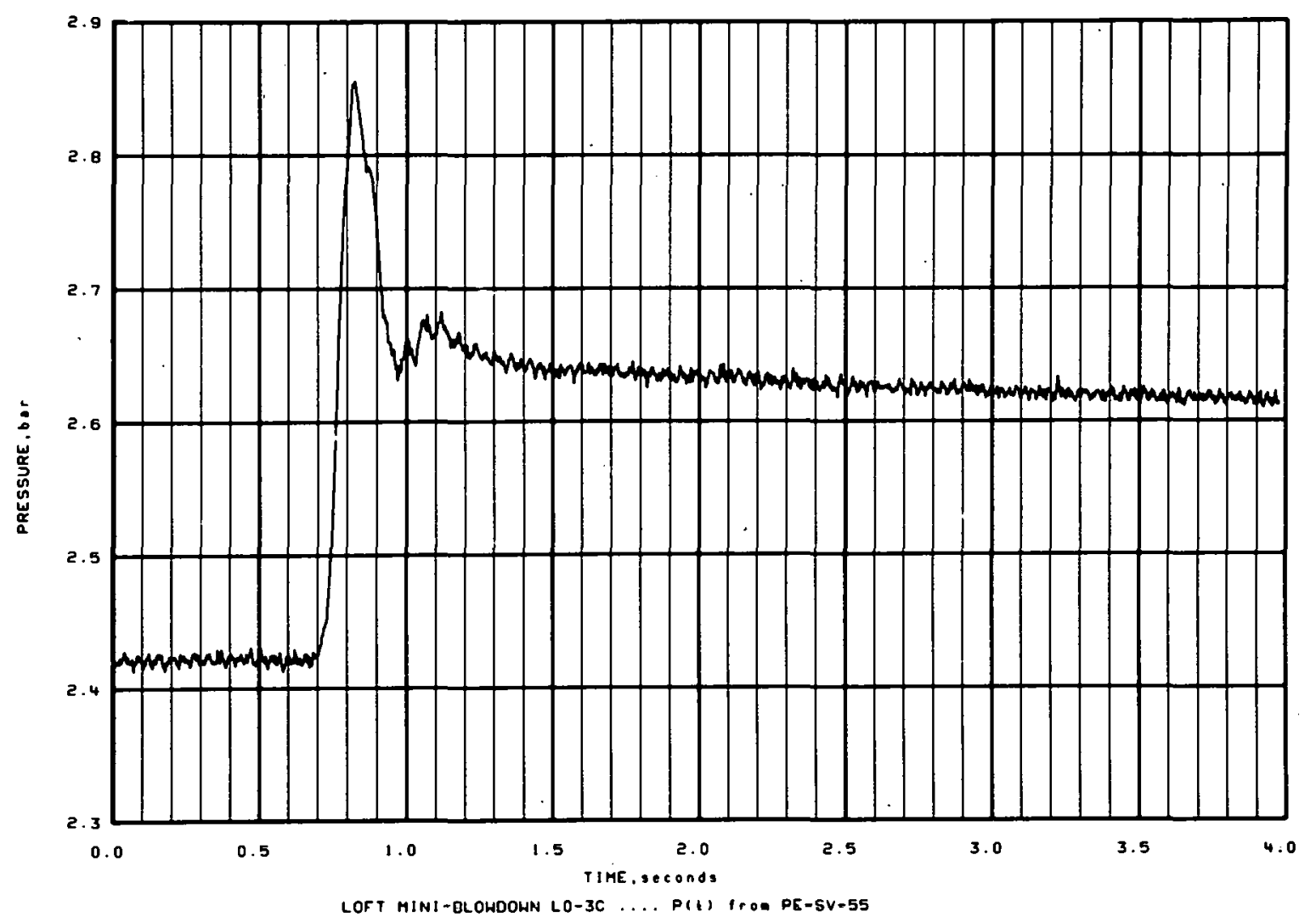

Figure E-33

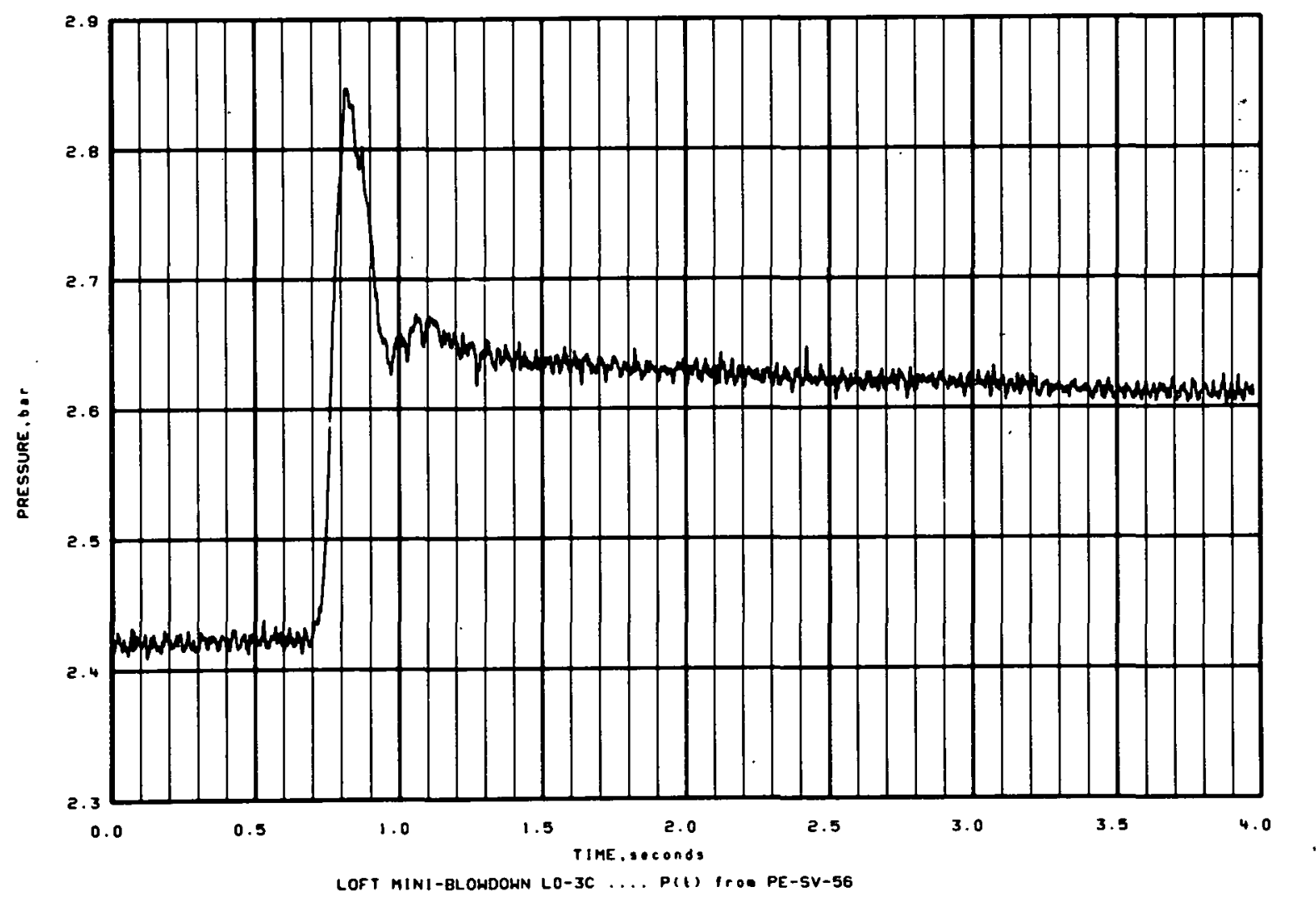

Figure E-34 


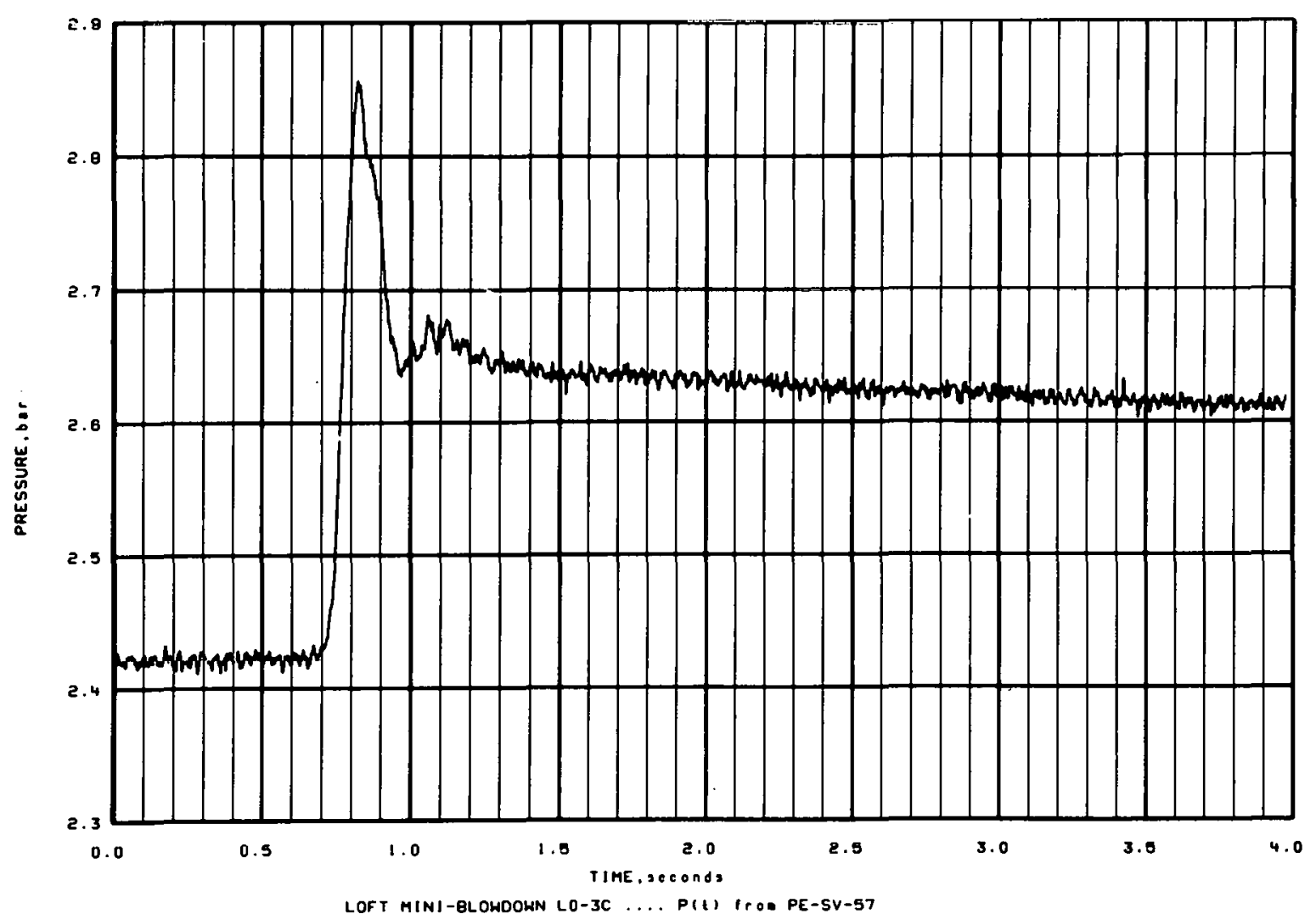

Figure E-35

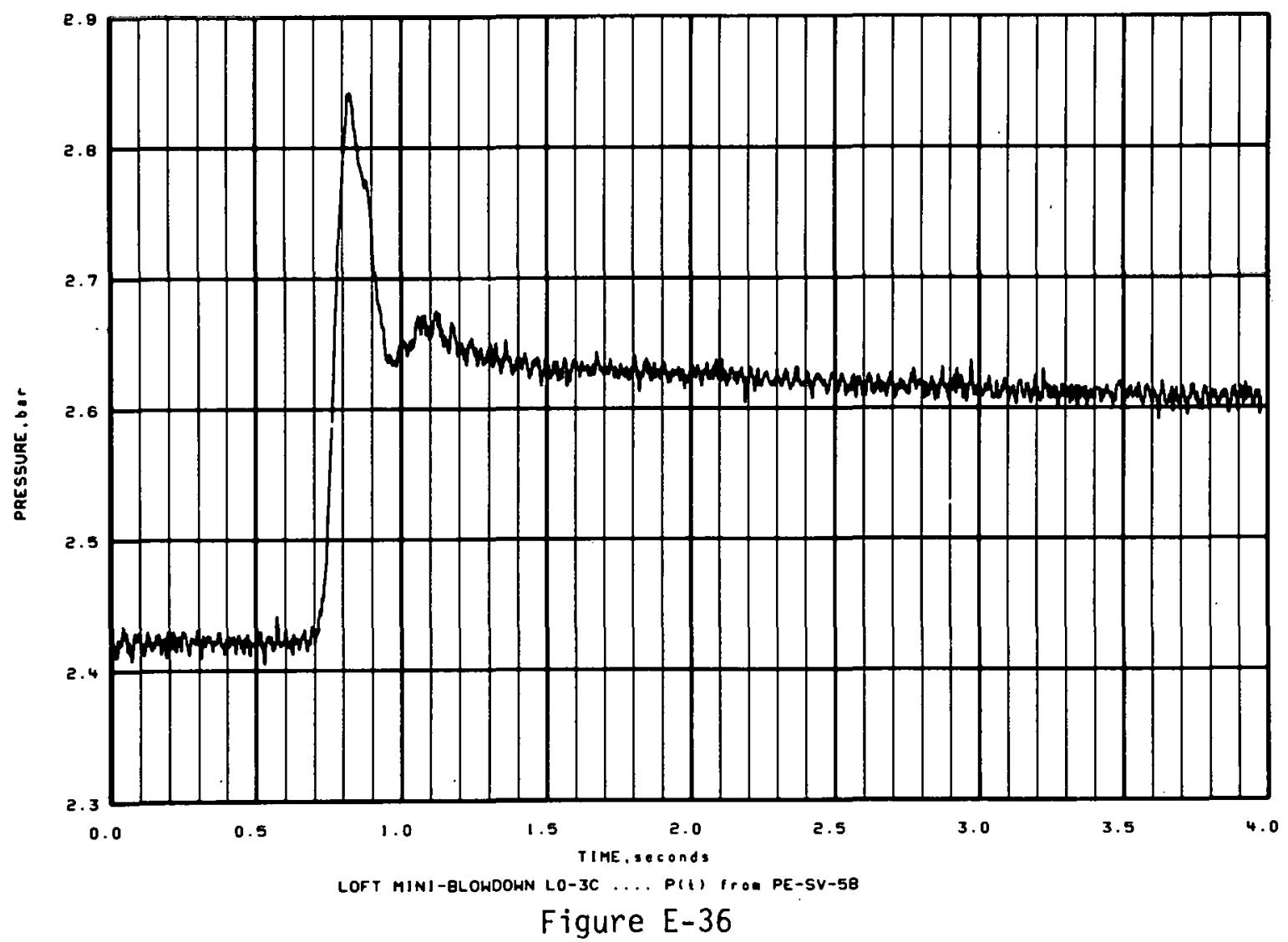




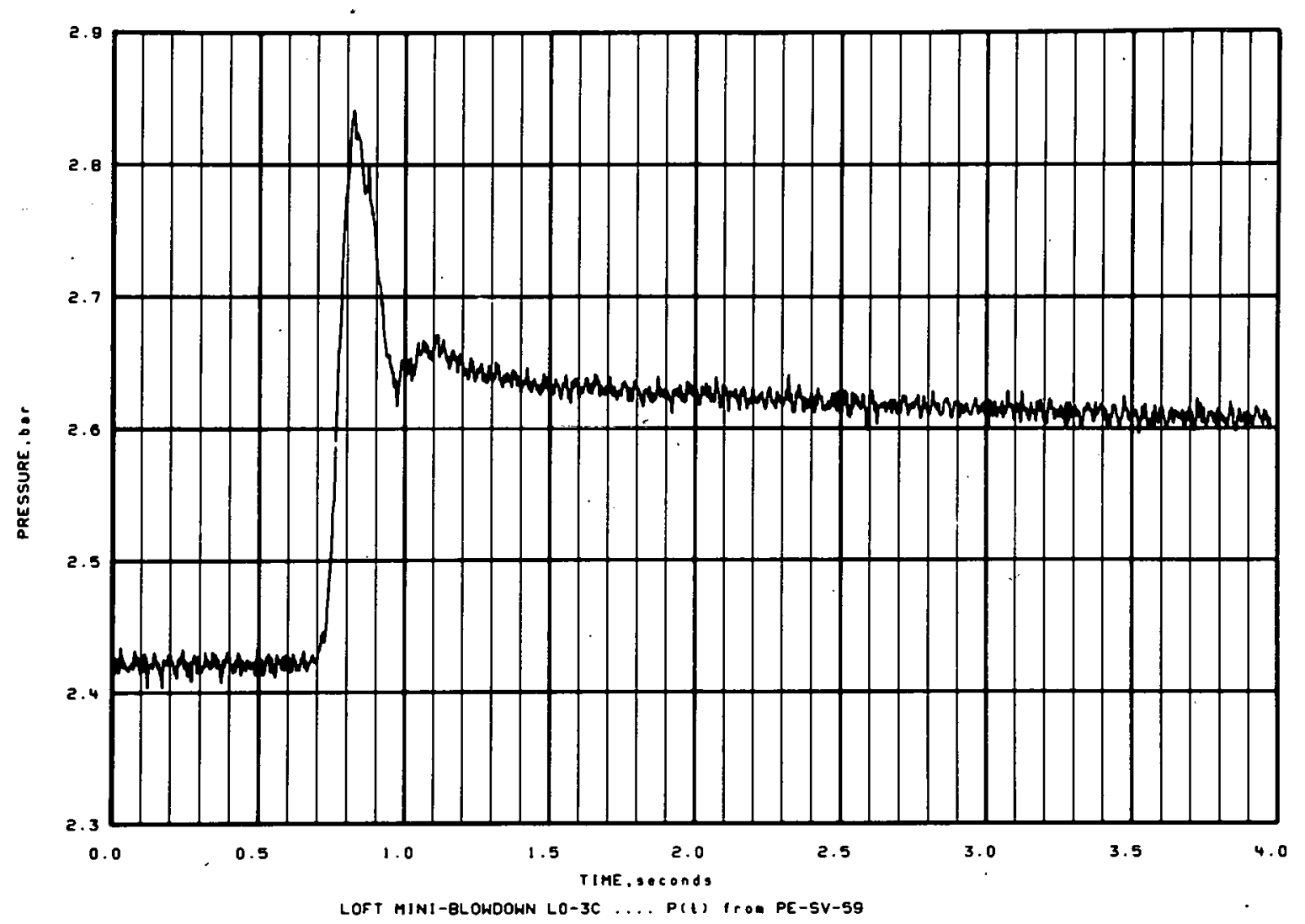

Figure E-37

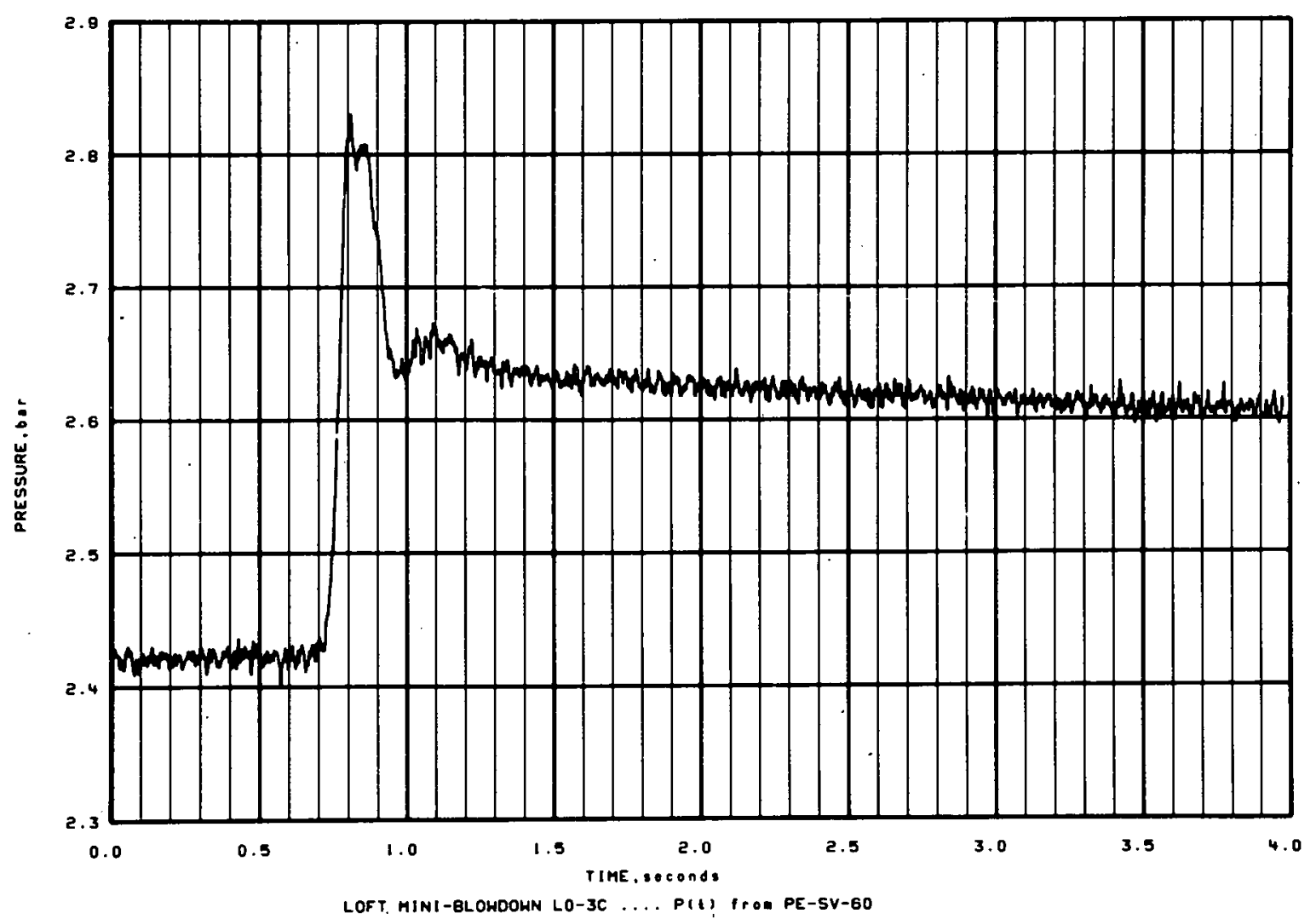

Figure E-38 


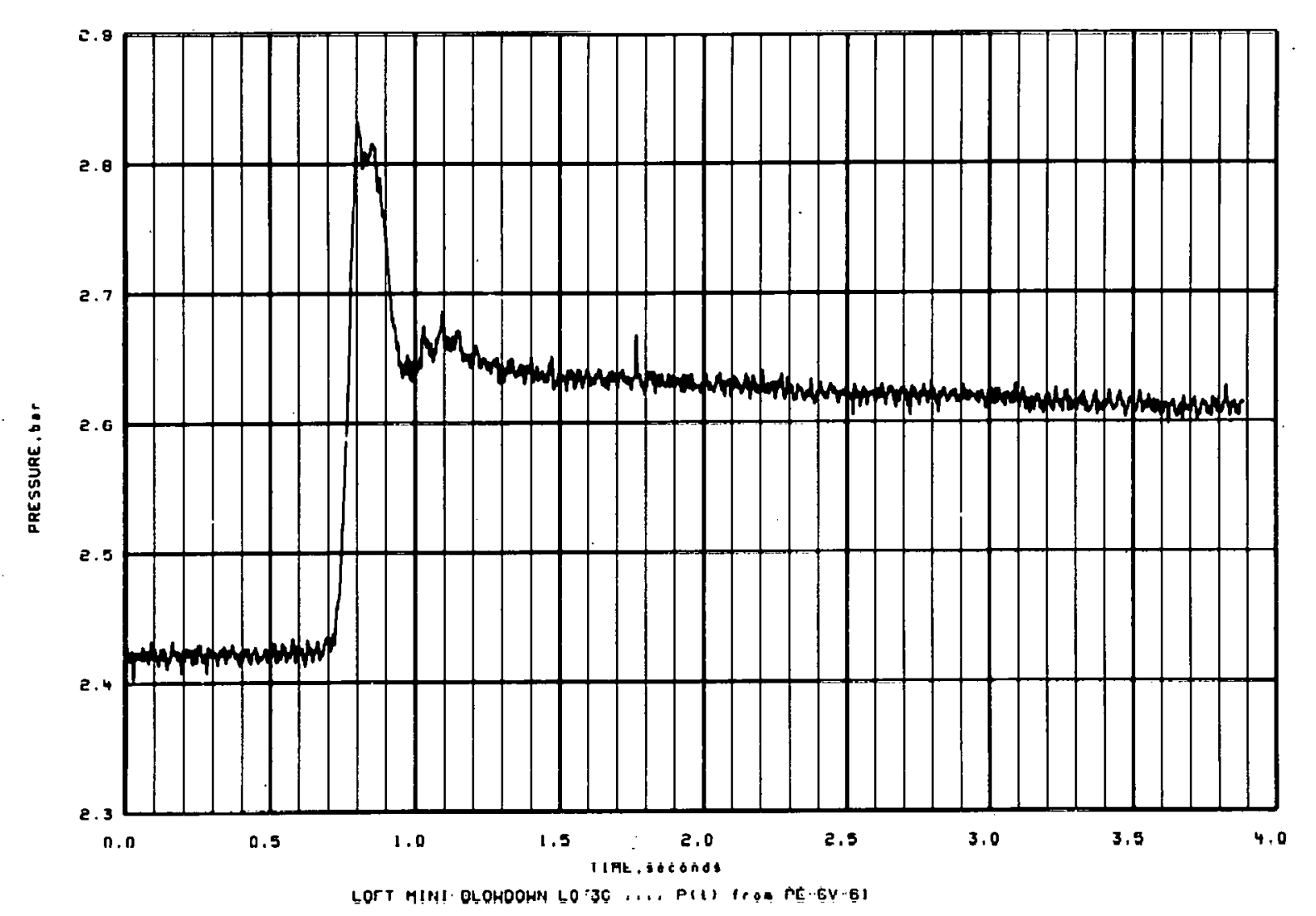

Figure E-39 
APPENDIX $\Gamma$

MINI-BLOWDOWN LO-04 EXPERIMENTAL DATA 
THIS PAGE

WAS INTENTIONALLY

LEFT BLANK 


\section{APPENDIX F}

\section{MINI-BLOWDOWN LO-04 EXPERIMENTAL DATA}

Both QOBVs fully opened with nearly the same start time (within $4 \mathrm{msec}$ ). The fiuid temperature was $250.0 \pm 1.5^{\circ} \mathrm{C}$ in QOBV-1 and $250.2 \pm 1.5^{\circ} \mathrm{C}$ in QOBV-15. The suppression tank initial conditions were $2.14 \pm 1.5^{\circ} \mathrm{C}$ in the gas vilume and pool. The vents were submerged $38.1 \pm 2.5 \mathrm{~cm}$. The internal vent submergence was the same as the external vent submergence.

The experimental data are defined in Table F-I. The opening characteristics of the QOBVS are shown in terms of percent sleeve travel versus time. The flow area of the valve begins to open at a sleeve position of $17 \%$ of full travel and is fully open at a sleeve position of $66 \%$ of full travel. The differential pressure between the header and the tank gas volume is measured with a very sensitive device primarily to provide information on vent preclearing. The data channel for this measurement is driven to saturation in the early part of the transient. 
TABLE F-I

EXPERIMENT LO-04 DATA SUMMARY

\begin{tabular}{|c|c|c|c|c|c|}
\hline $\begin{array}{c}\text { Measurement } \\
\text { or } \\
\text { Calculation }\end{array}$ & $\begin{array}{l}\text { Pre-Transient } \\
\text { Data Channel } \\
\text { Varjance } \\
\left(10^{-4} \text { bar } 2\right) \\
\end{array}$ & Figure Number & Measurement & $\begin{array}{c}\text { Pre-Transient } \\
\text { Data. Channel } \\
\text { Varjance } \\
\left(1 n^{-4} \text { bar }^{2}\right) \\
\end{array}$ & Tfgure Number \\
\hline QUBV-1 opening & $\quad-$ & $F-1, F-2$ & $P E-S V-22$ & 0.34 .370 & $F=22$ \\
\hline QOBV-15 openiny & - & $F-3, r-4$ & $P E-S V-23$ & 0.37318 & $F-23$ \\
\hline $\begin{array}{l}\text { Combined QOBV } \\
\text { opening }\end{array}$ & 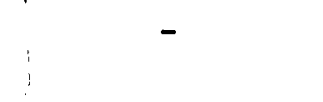 & $\Gamma-5, F-6$ & $P E-S V-24$ & 0.19351 & $F-24$ \\
\hline Vertical load & - & $F-7$ & PE-SV-25 & 0.18878 & $F-25$ \\
\hline PDE-SV-09 & - & $F-8$ & PE-SV-26 & 0.13114 & $F-26$ \\
\hline PE-SV-0I & 0.26013 & $F-9$ & PE-SV-27 & 0.21933 & $F-27$ \\
\hline Pt-SV-02 & 0.26439 & $F-10$ & $P E-S V-28$ & 0.18457 & $F-28$ \\
\hline PE-SV-03 & 0.27188 & $F-11$ & PE-SV-29 & 0.32779 & $F-29$ \\
\hline PE-SV-04 & 0.31493 & $F-12$ & PE-SV-43 & .0 .14777 & $F-30$ \\
\hline$P E-S V-10$ & 0.26178 & $F-13$ & PE-SV-44 & 0.14693 & $F-31$ \\
\hline PE-SV-11 & 3.612 .6 & $F-14$ & PE-SV-54 & 0.15678 & $F-32$ \\
\hline PF-SV-12 & 0.27708 & $F-15$ & PE-SV-55 & 0.09906 & $F-33$ \\
\hline PE-SV-13 & 0.18209 & $F-16$ & PE-SV-56 & 0.24830 & $F-34$ \\
\hline PE-SV-14 & 0.34811 & $F-17$ & PE-SV-57 & 0.13400 & $F-35$ \\
\hline PE-SV-15 & 0.30399 & $F-18$ & $P E=5 V-58$ & 0.21874 & $F-36$ \\
\hline PE-5V-18 & 0.25125 & $F=19$ & PE-SV-59 & 0.17844 & $F-37$ \\
\hline PE-SV-17 & 0.31367 & $F-20$ & $P E-S V-60$ & 0.20589 & $F-38$ \\
\hline PE-SV-18 & 0.37693 & $F-21$ & PE-SV-61 & 0.15667 & $F-39$ \\
\hline
\end{tabular}




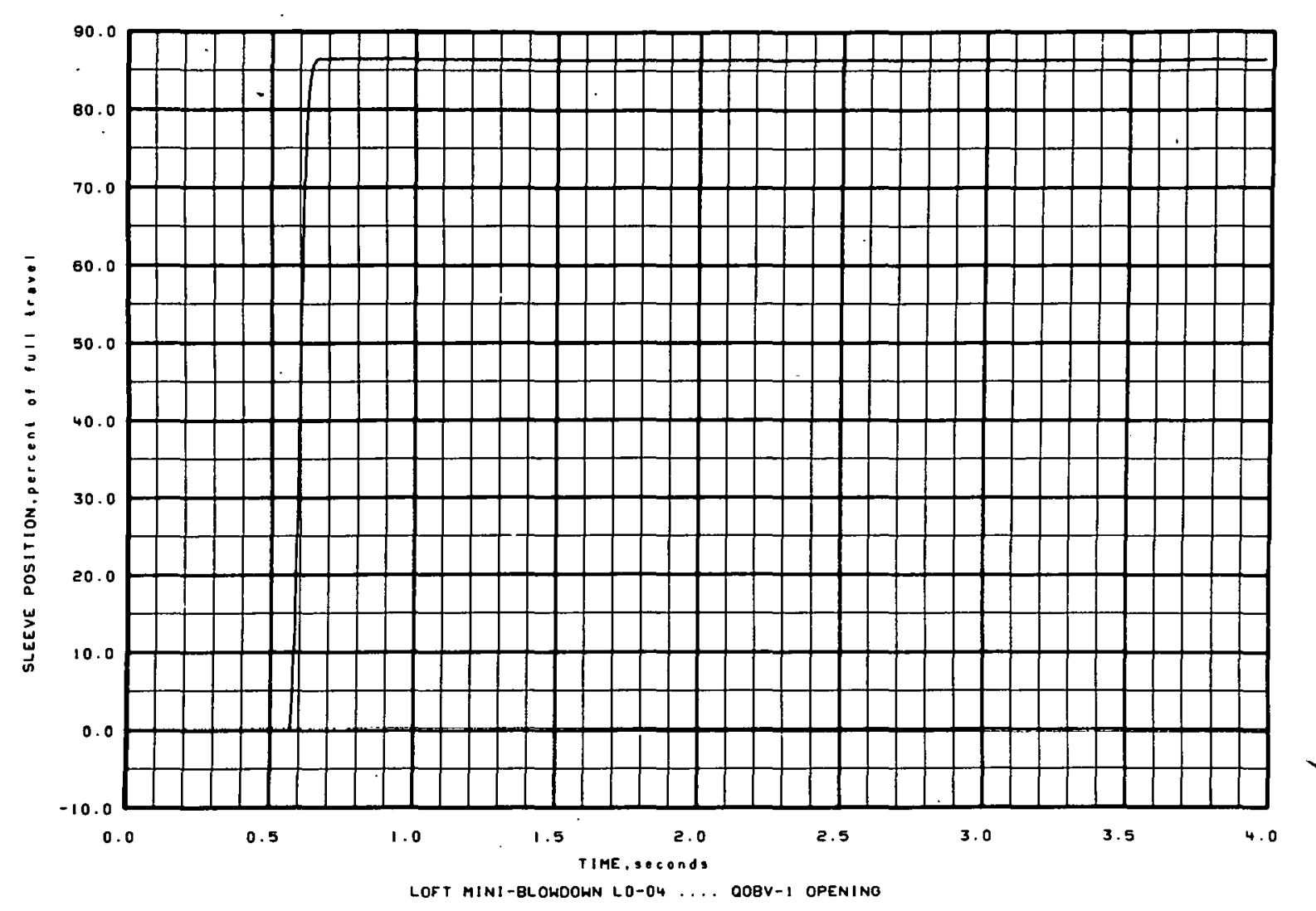

Figure F-1

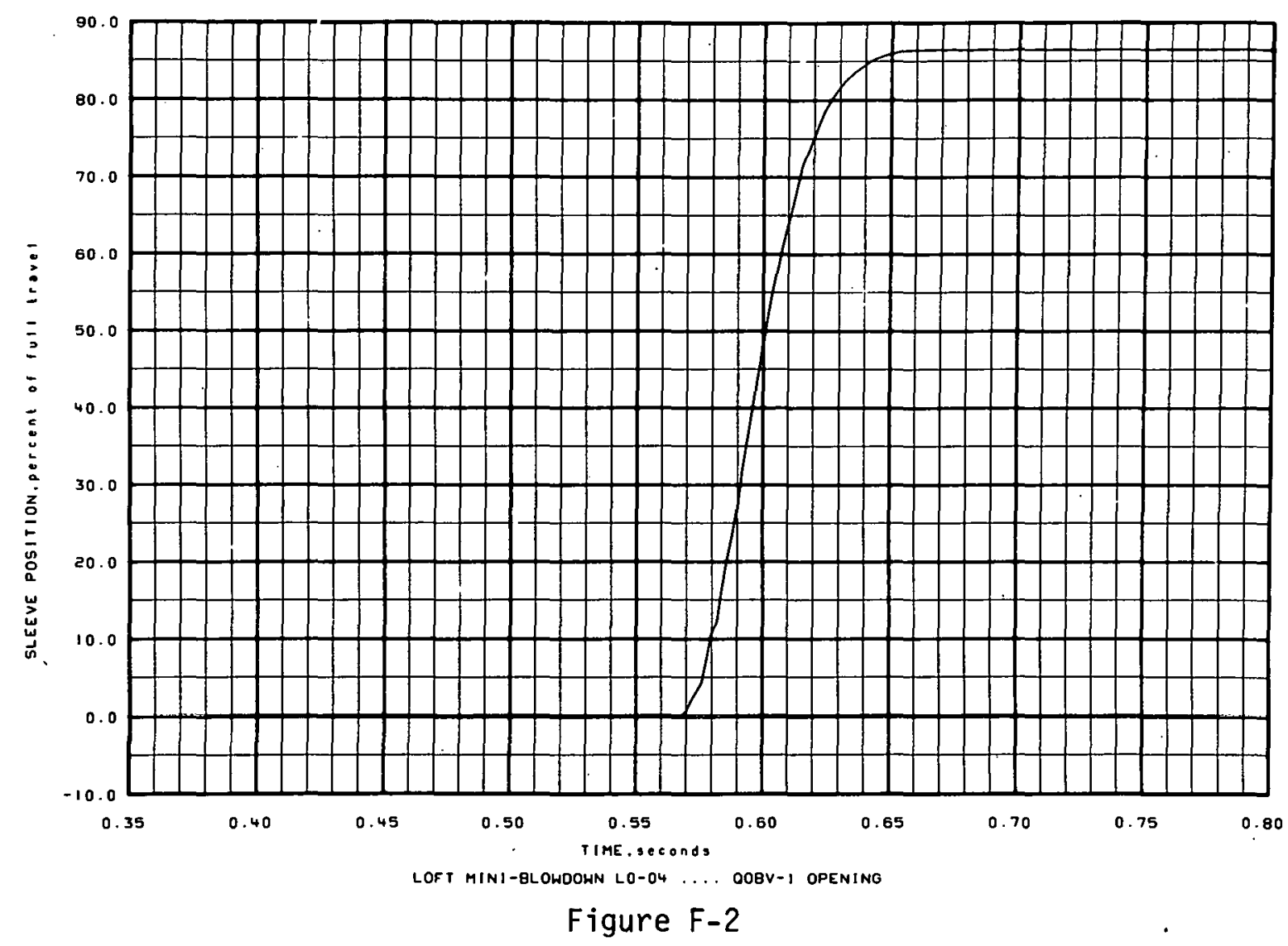



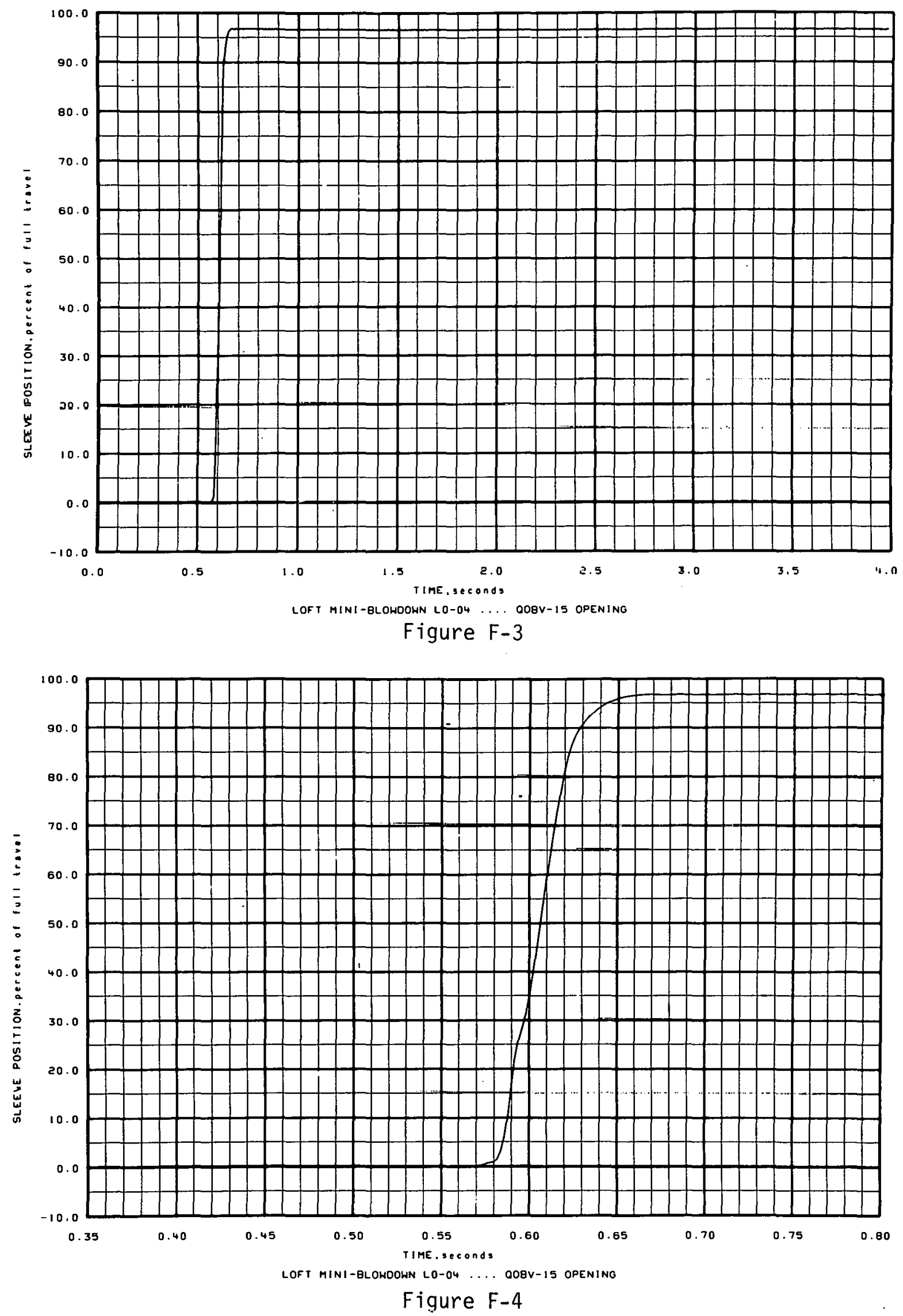

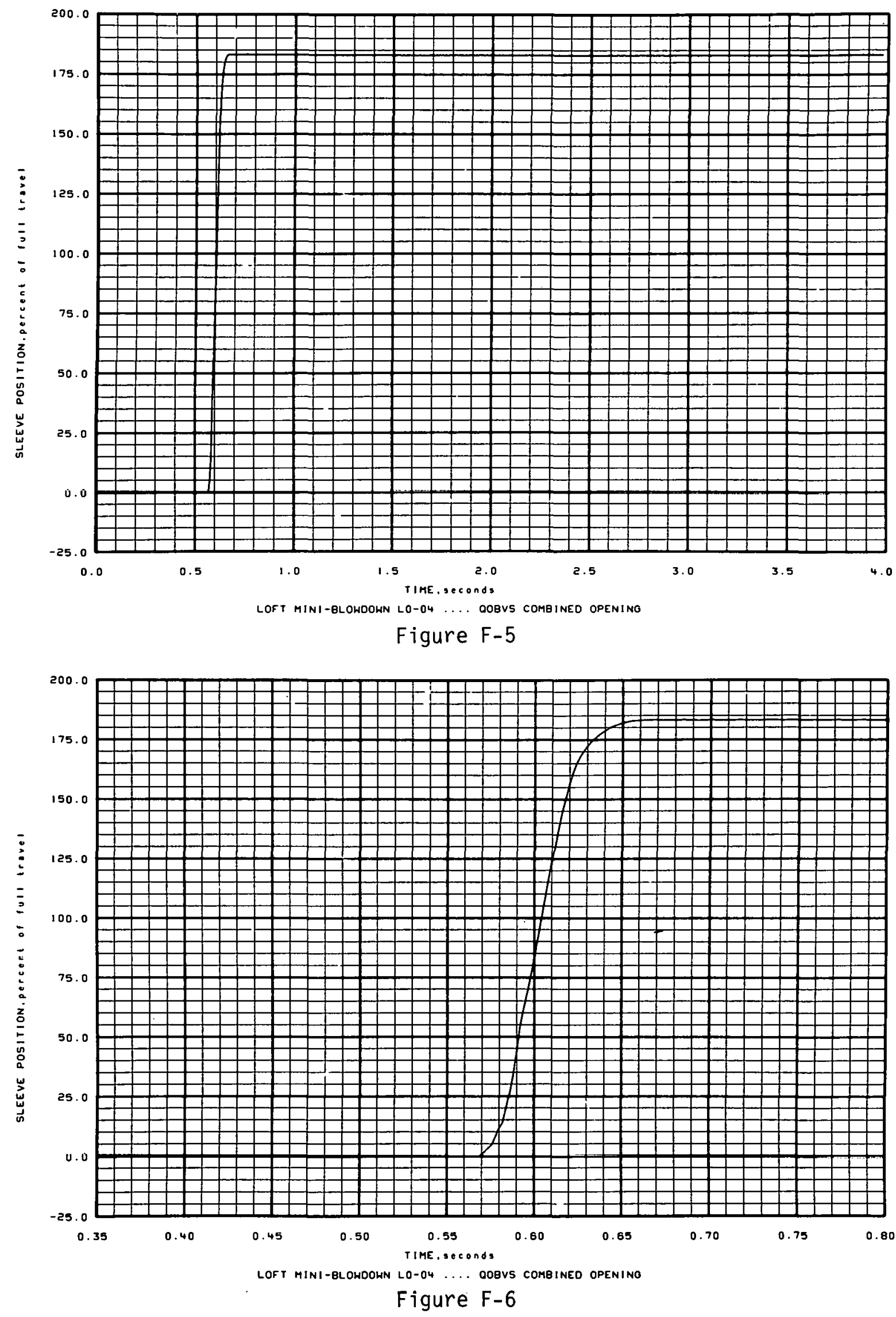

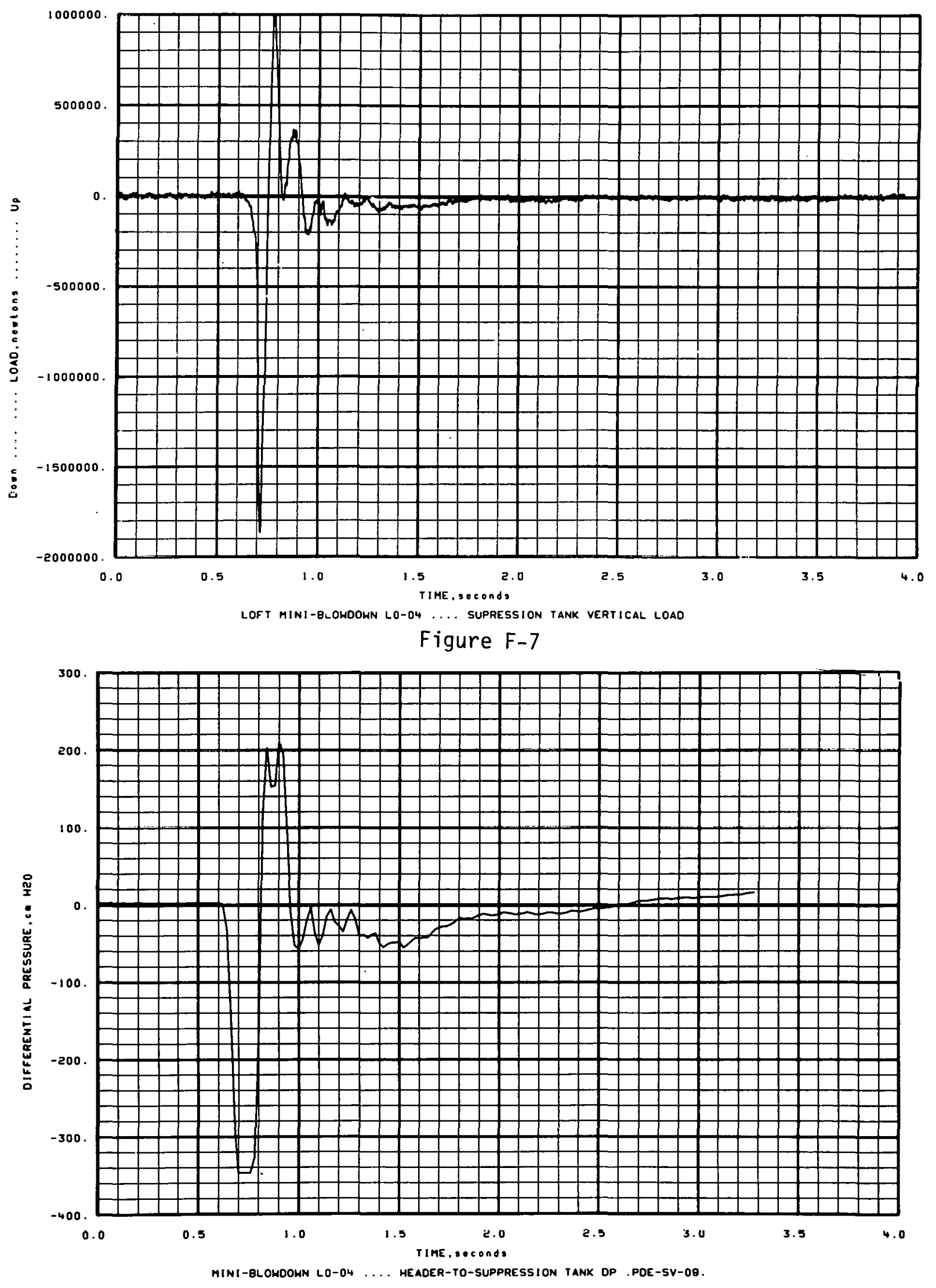

Figure F-8 


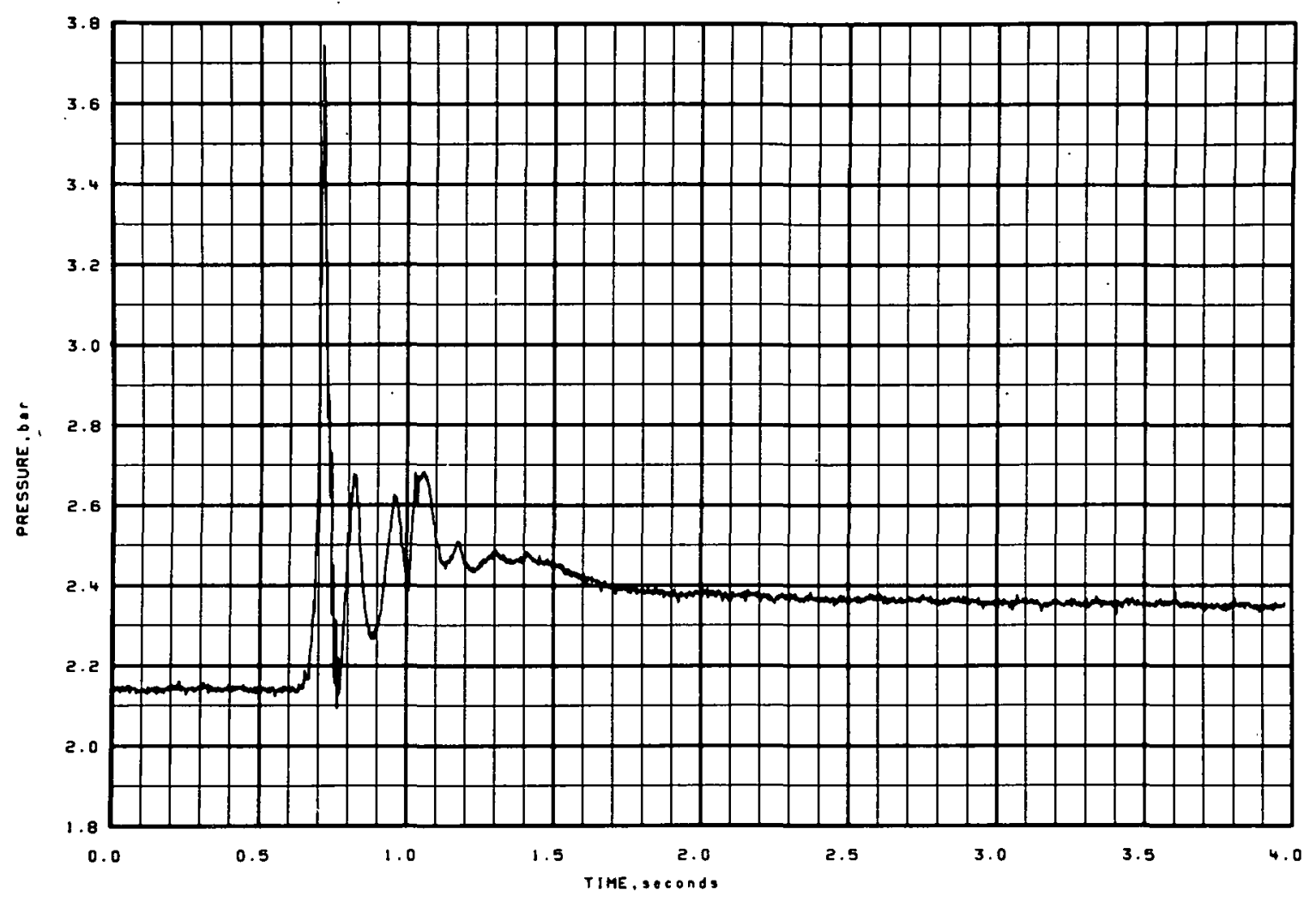

LOFT MINI-BLOHDOWN LO-04 .... P(t) frOA PE-SV-0I

Figure F-9

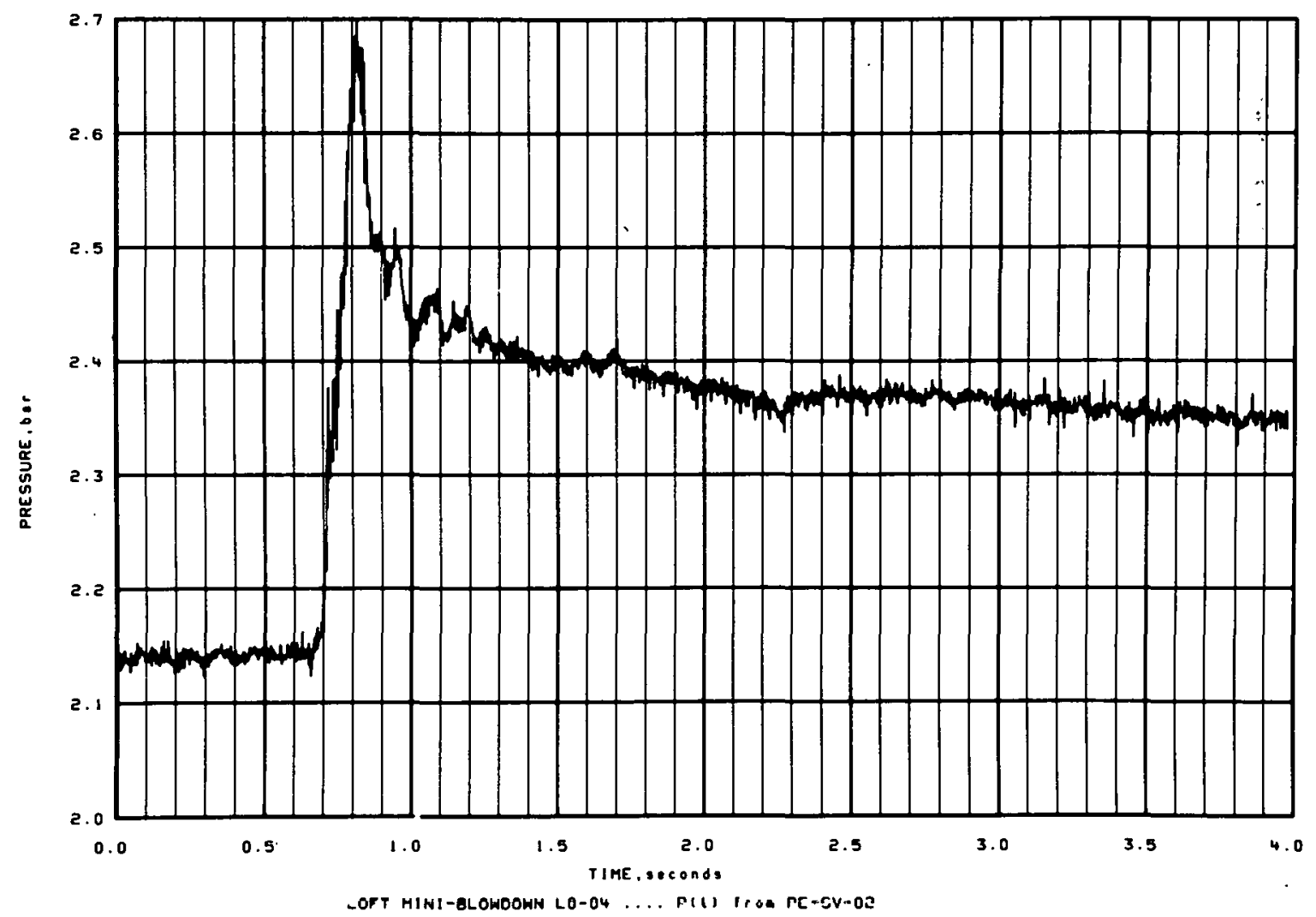

Figure F-10 

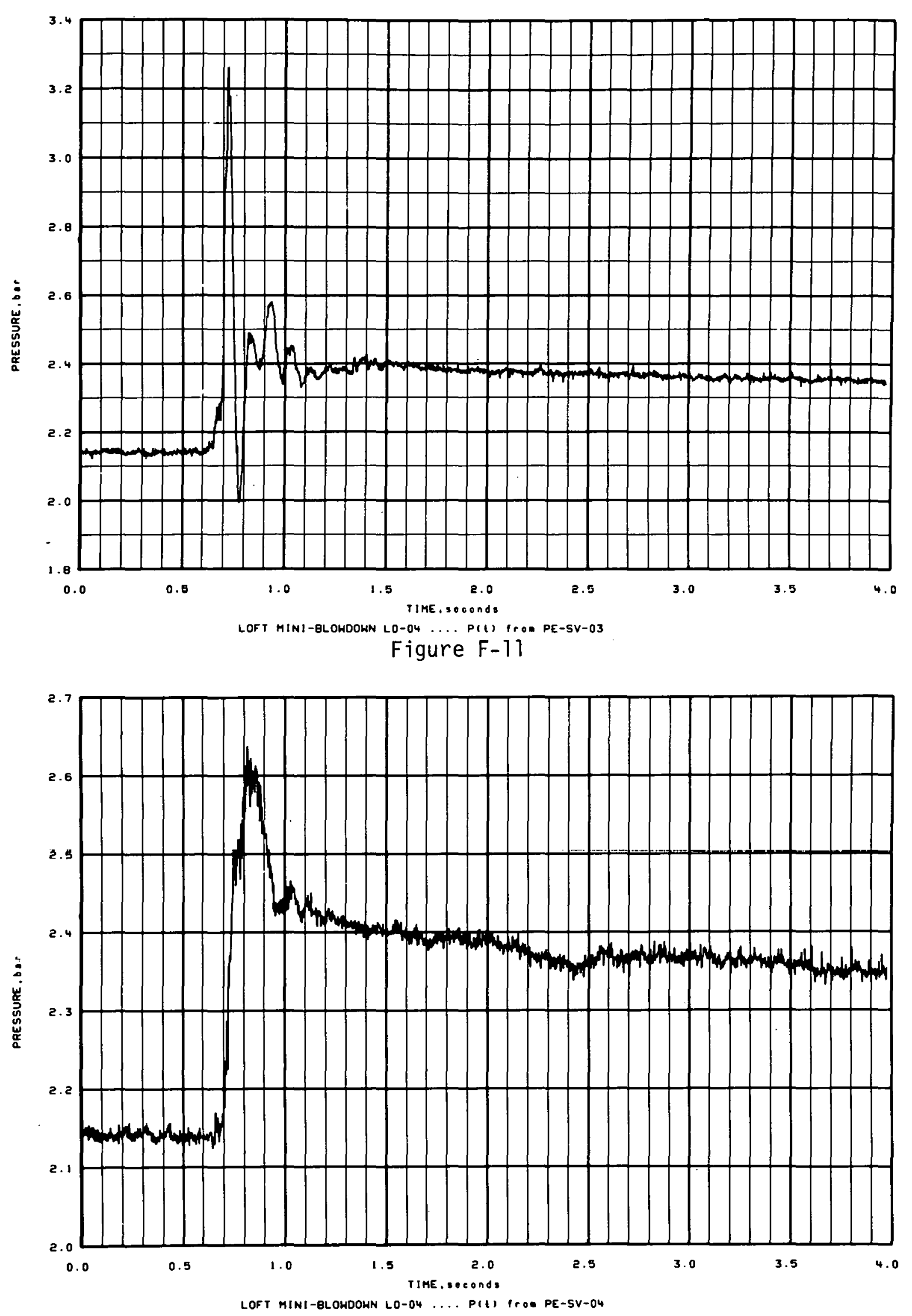

Figure F-12 


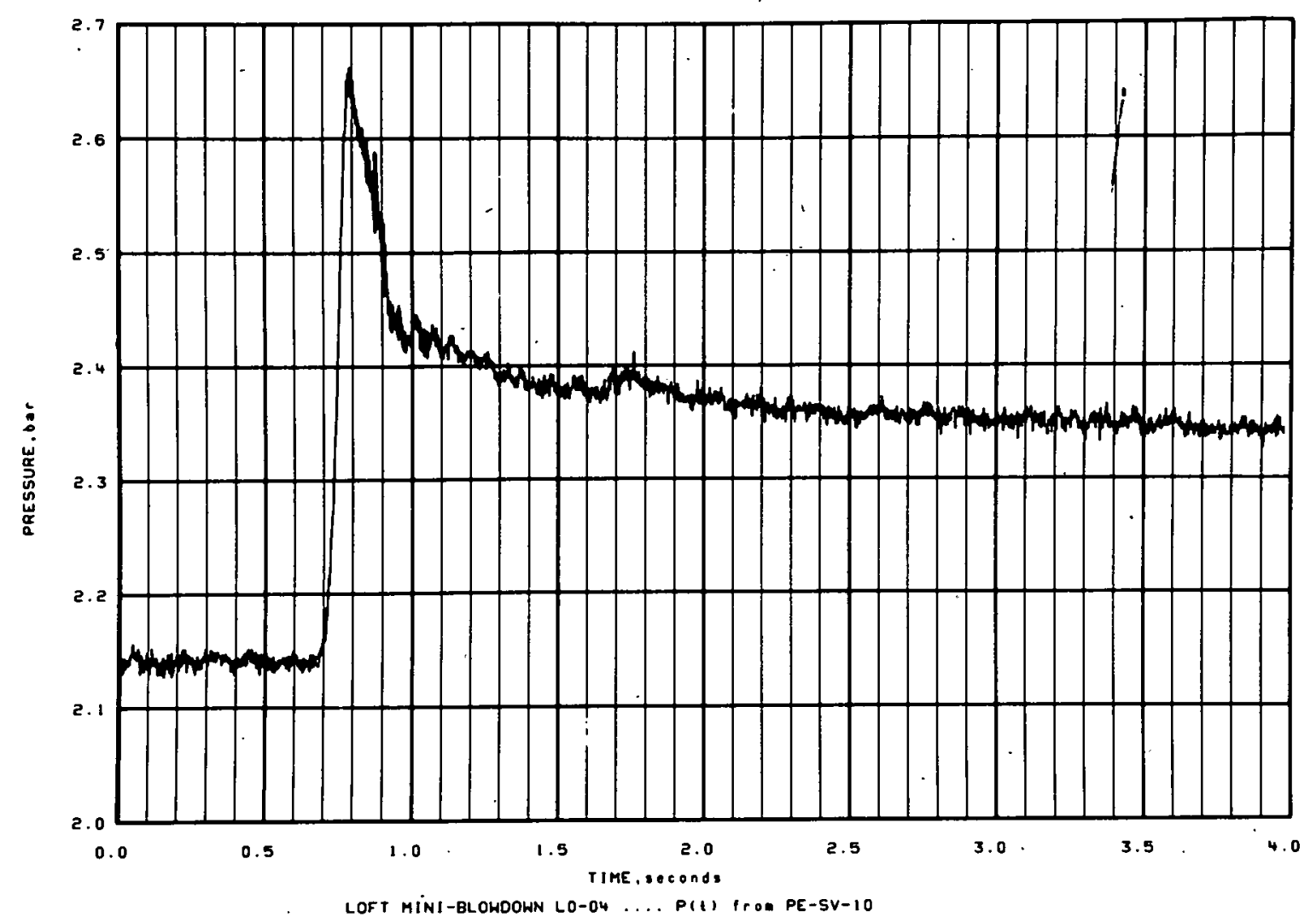

Figure F-13

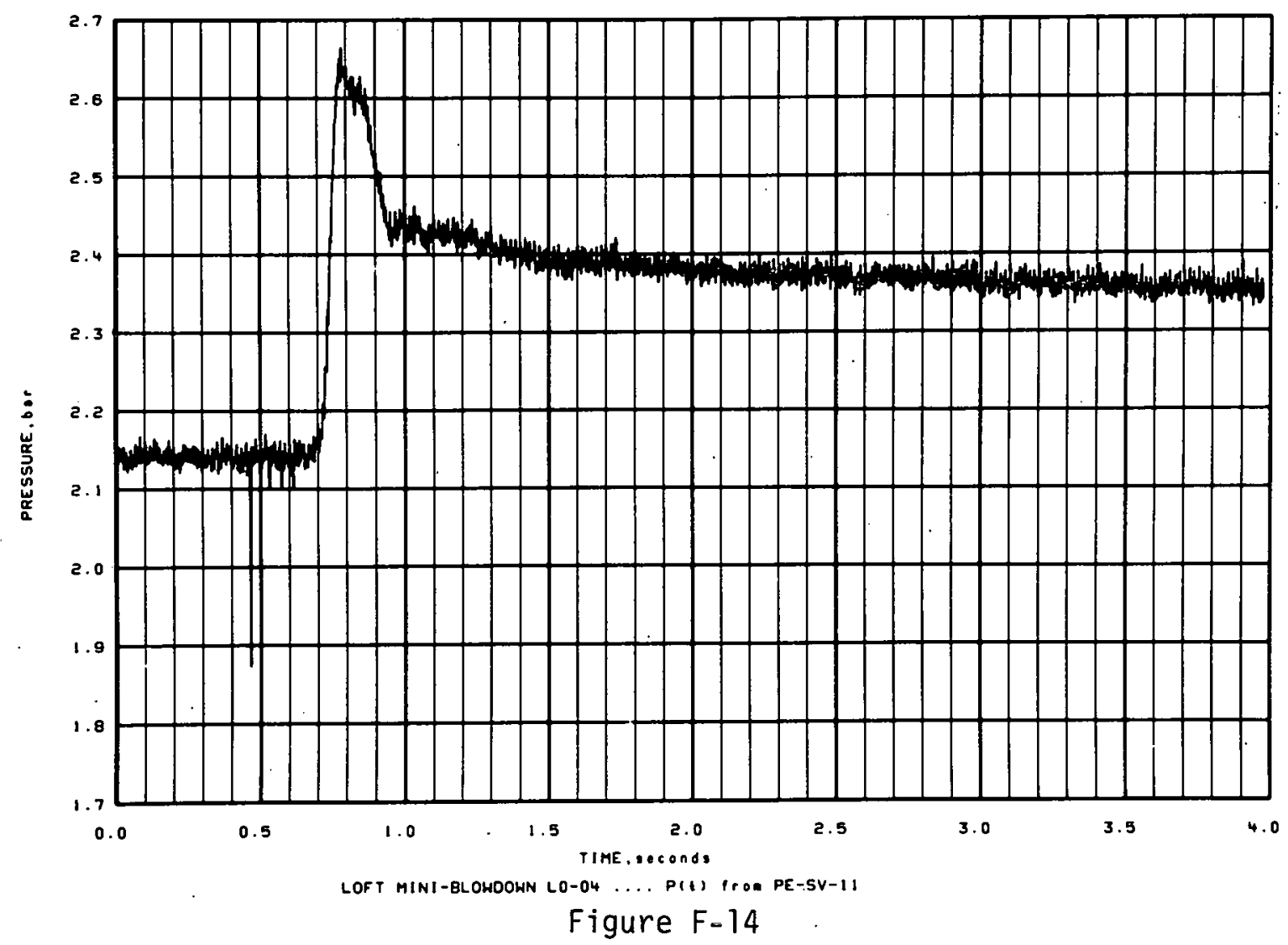




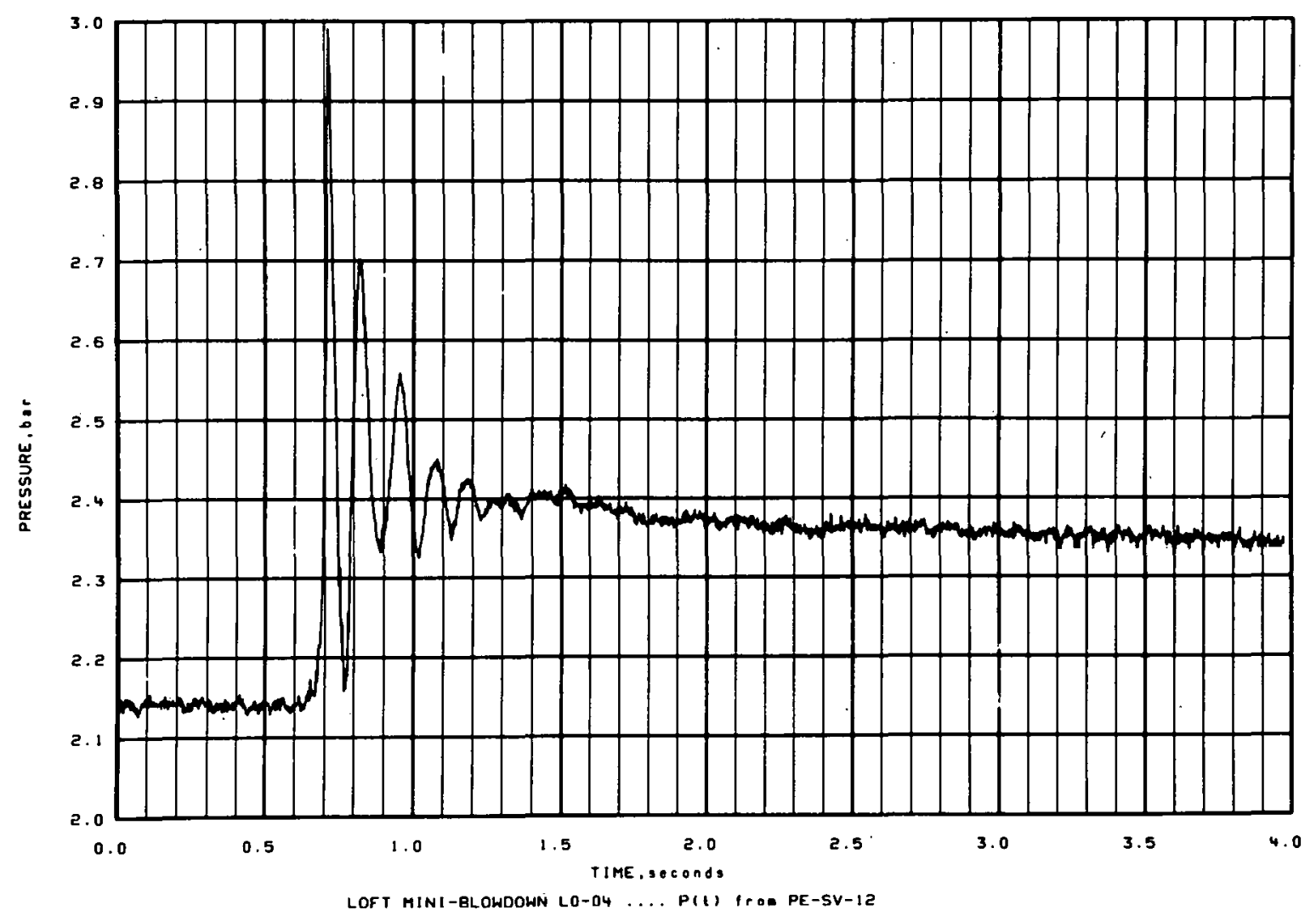

Figure F-15

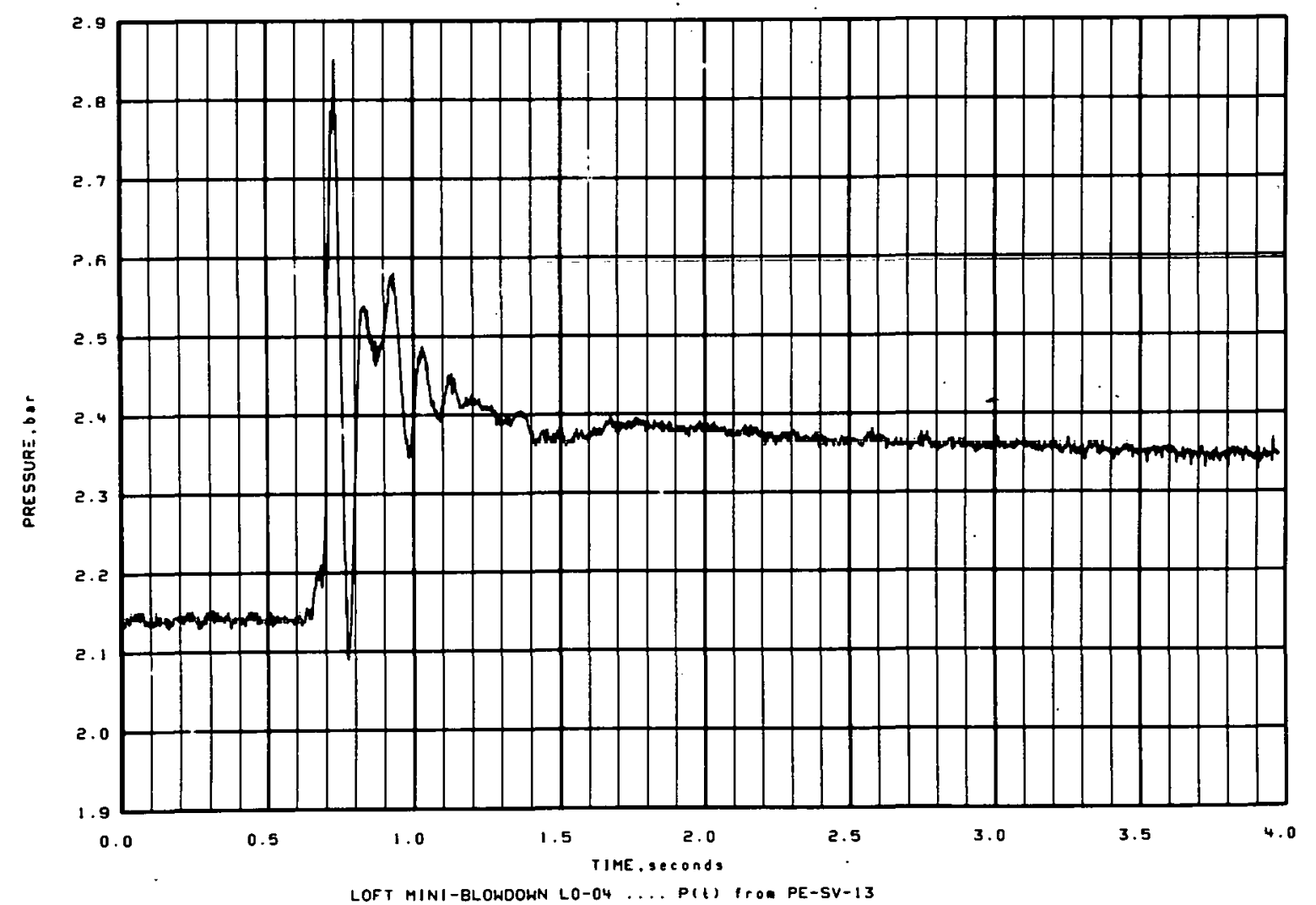

Figure $\mathrm{F}-16$ 


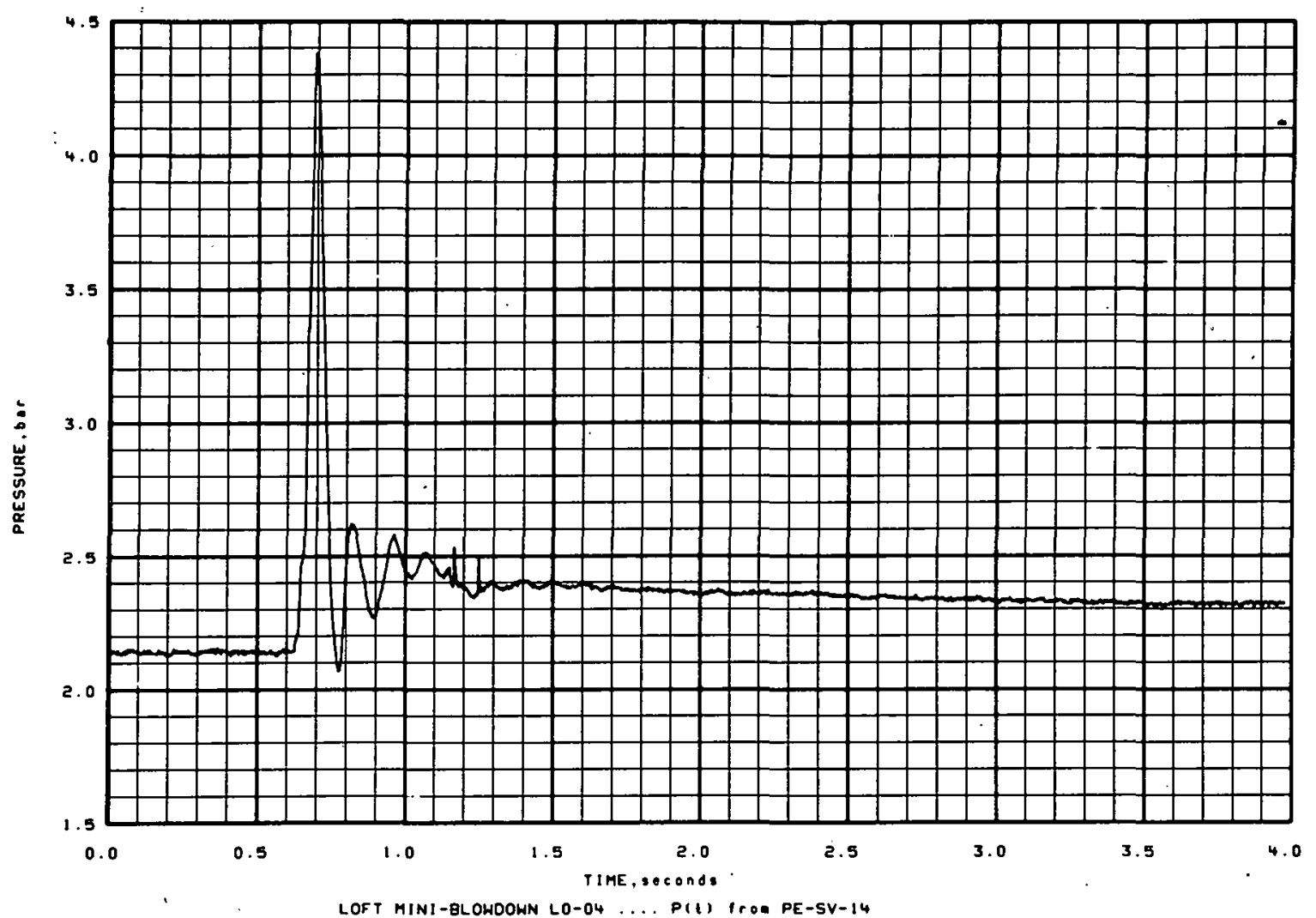

Figure $\mathrm{F}-17$

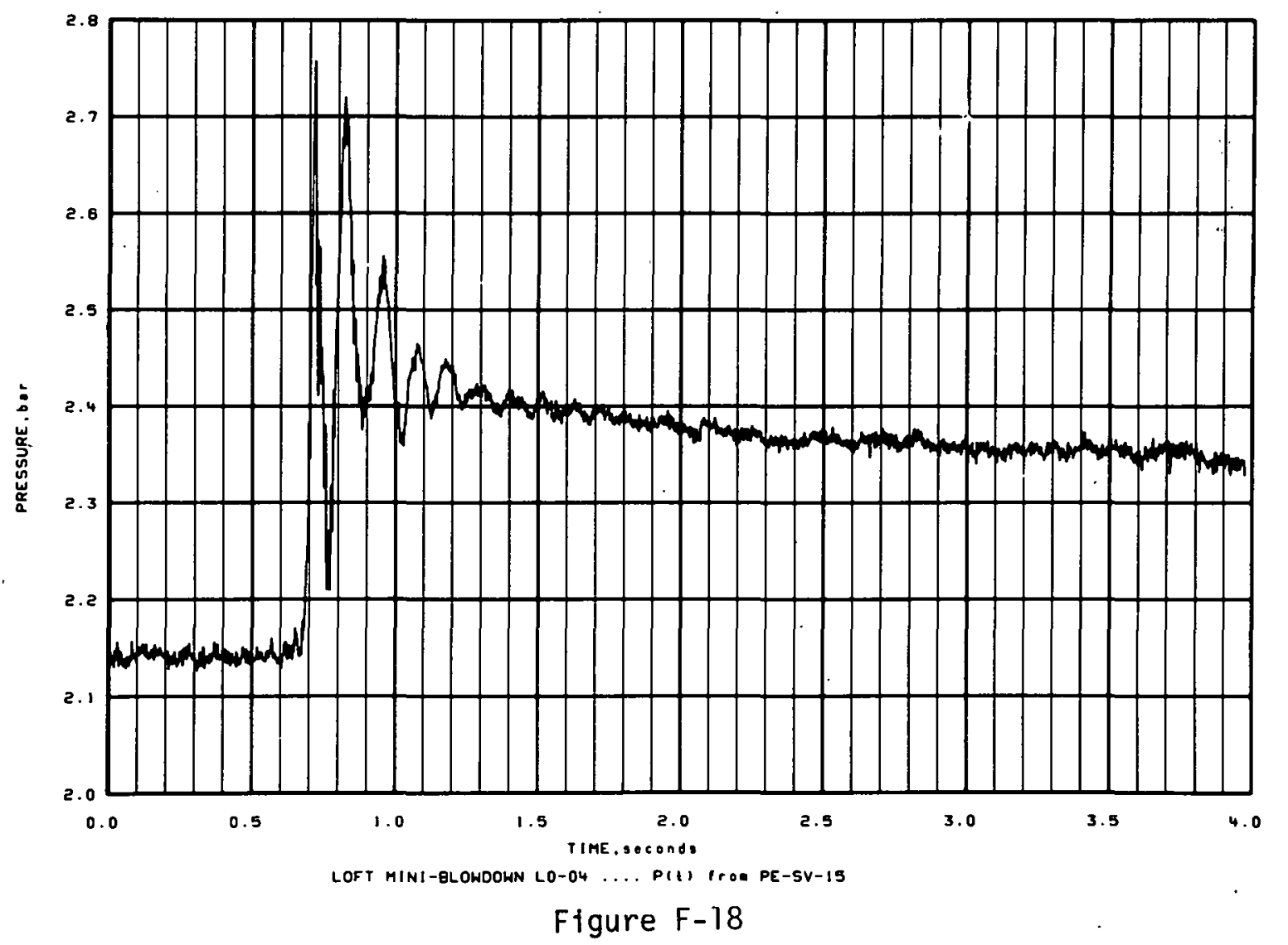




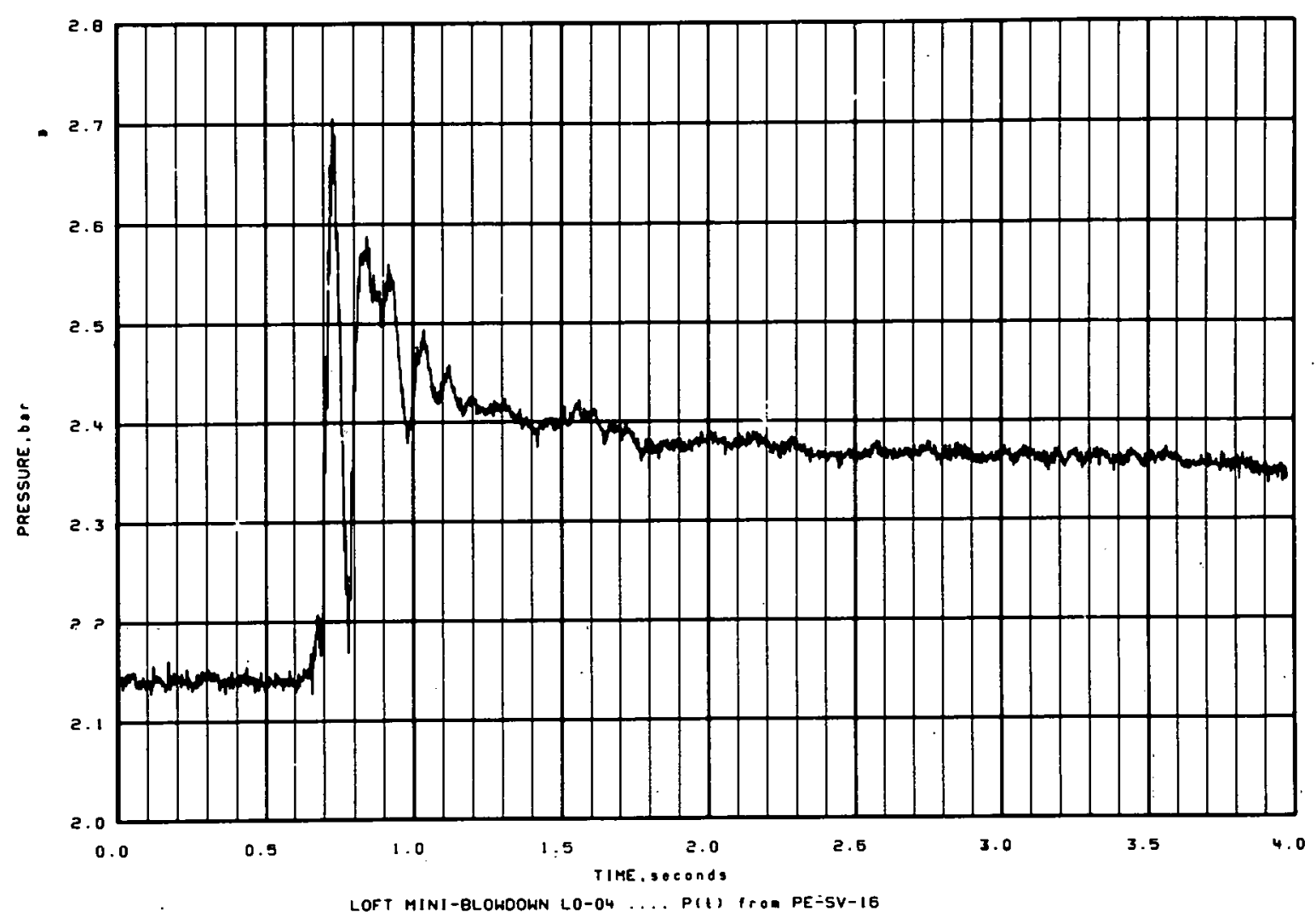

Figure F-19

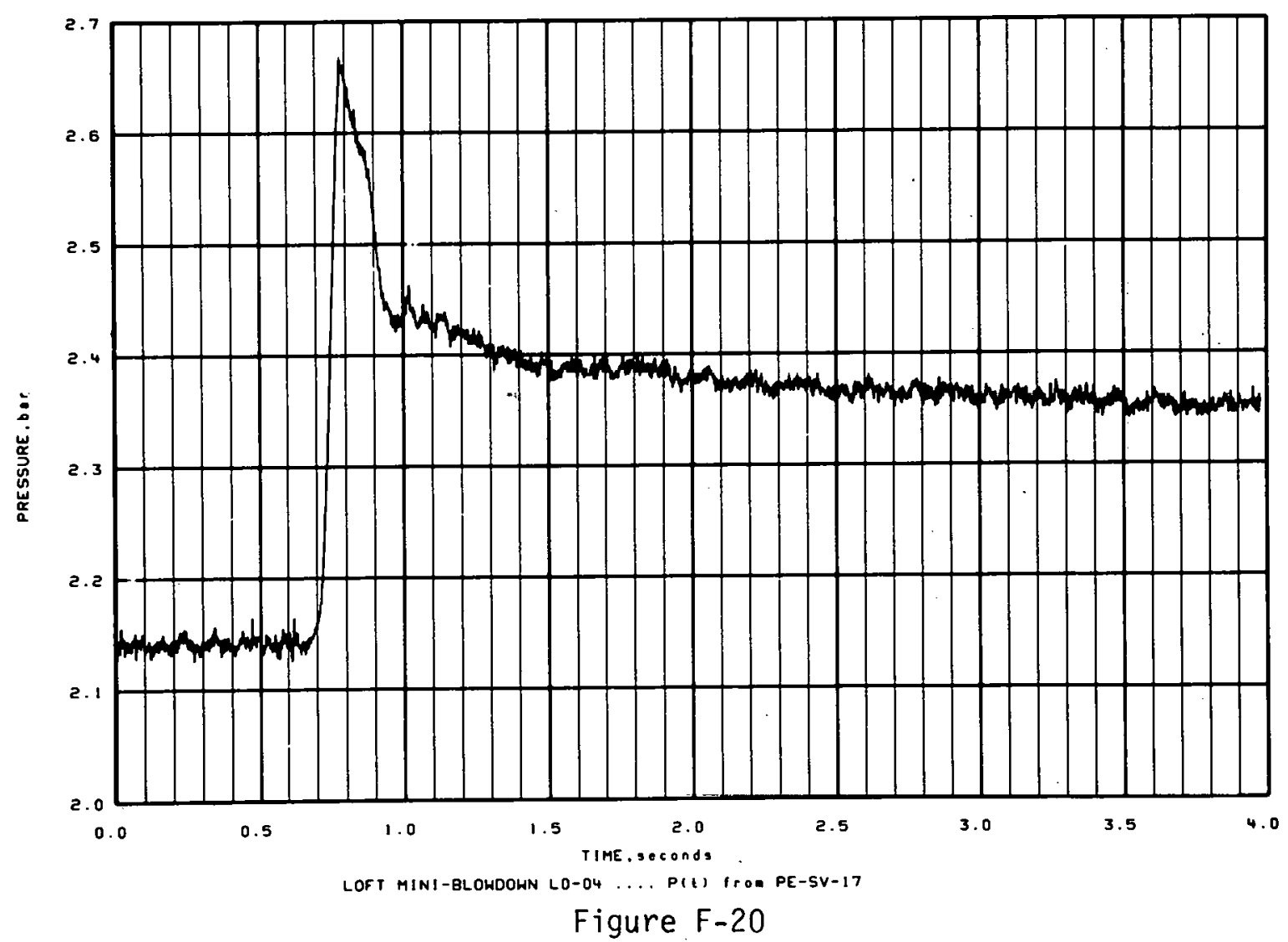



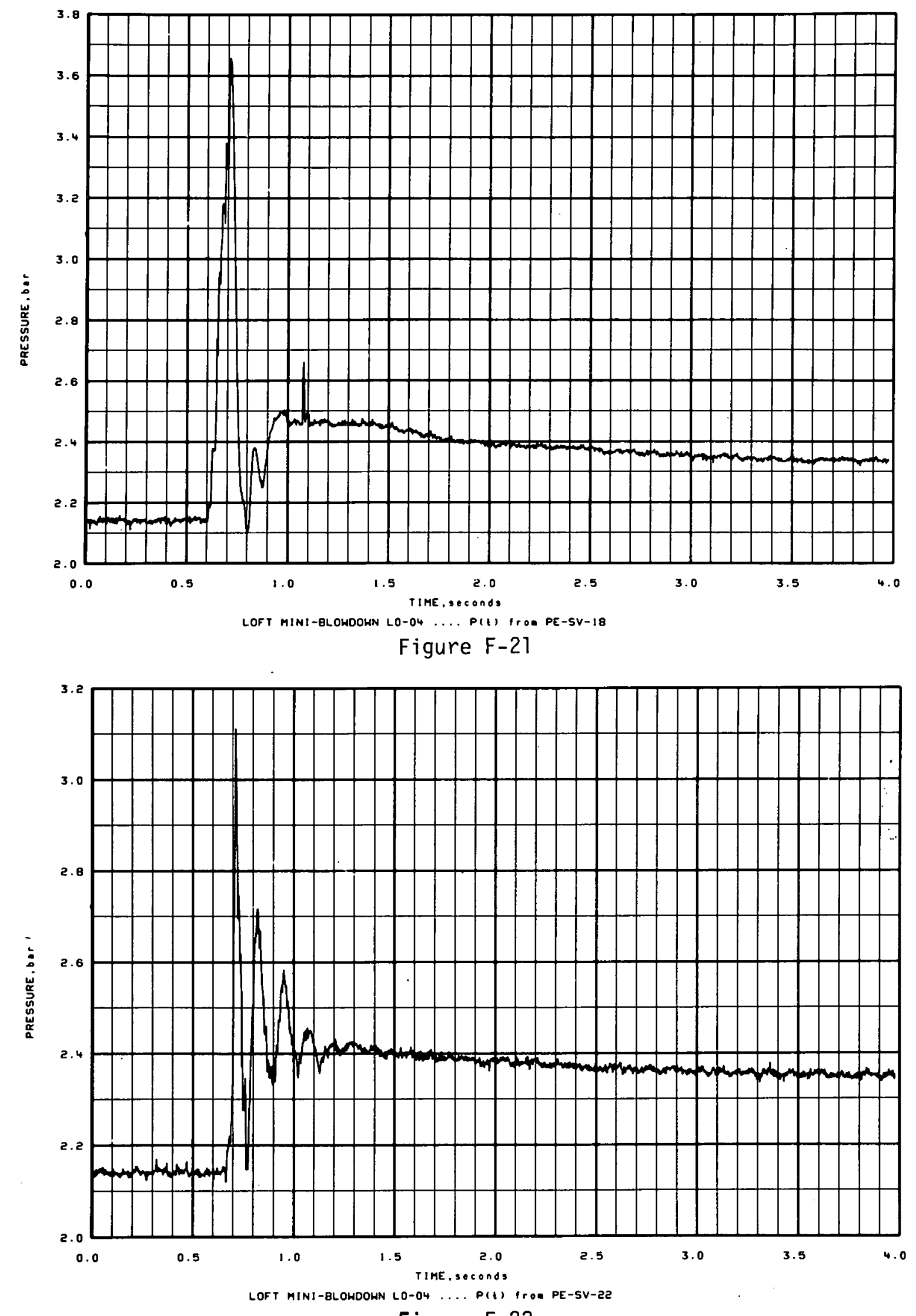

Figure F-22 


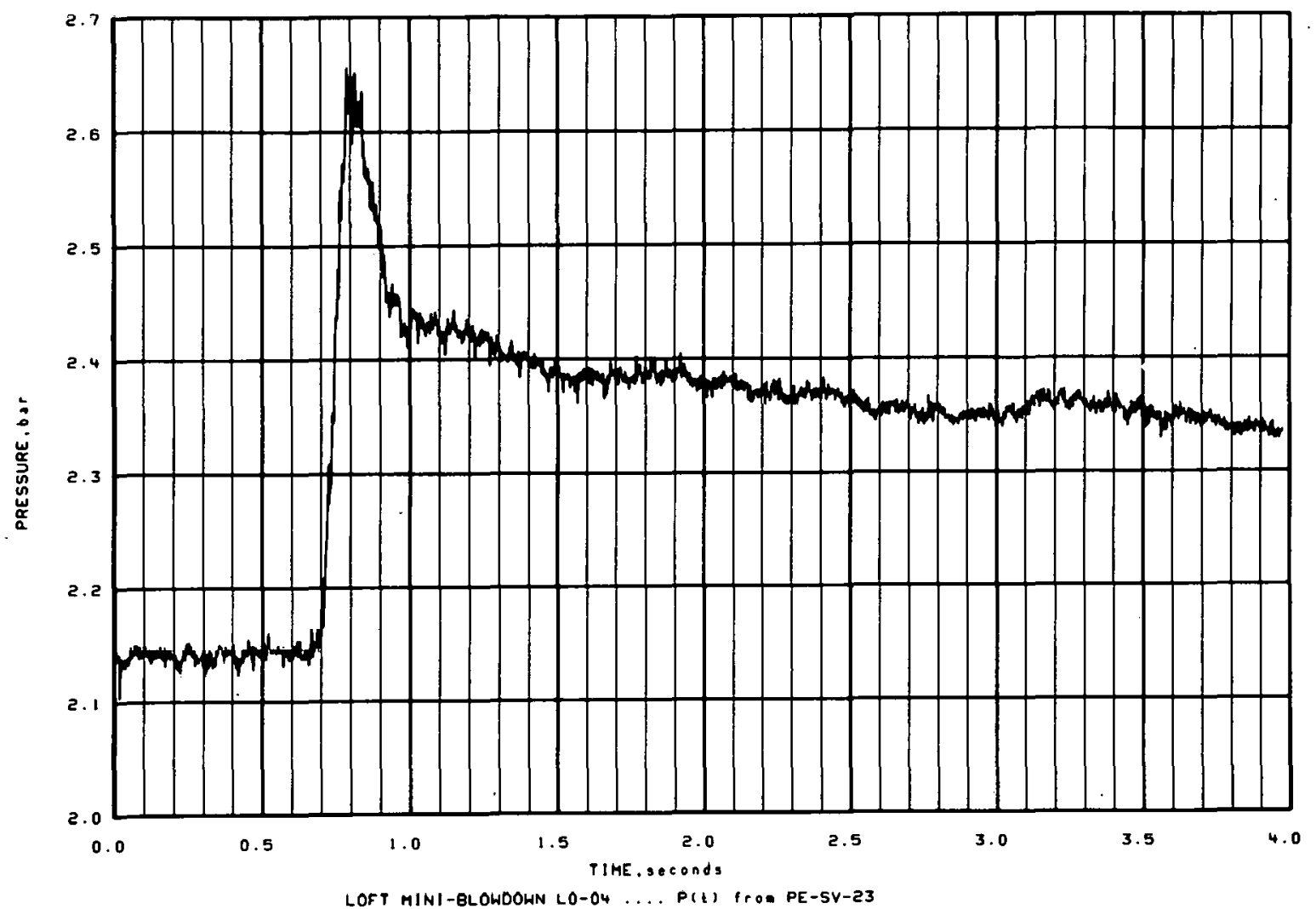

Figure F-23

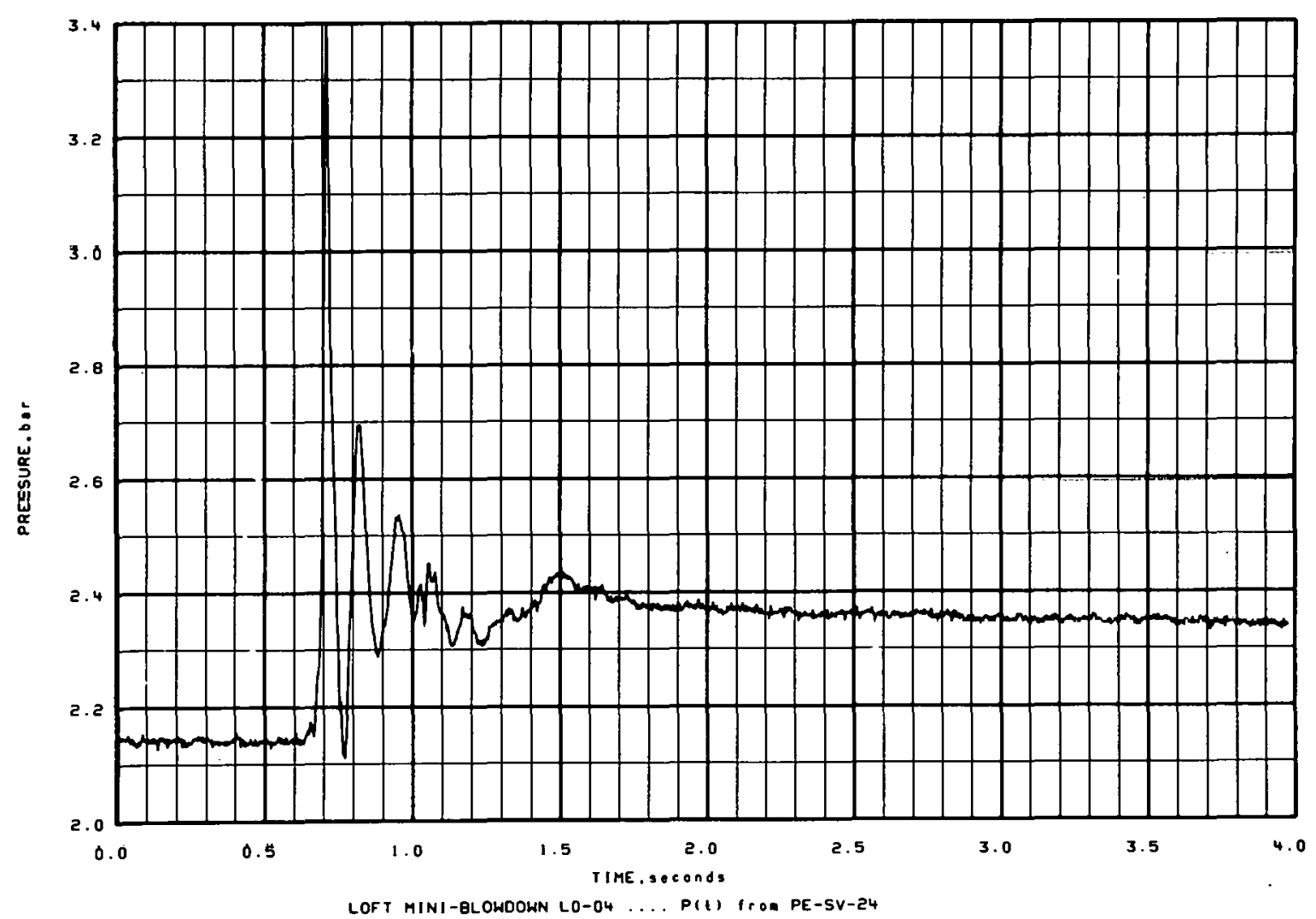

Figure F-24 


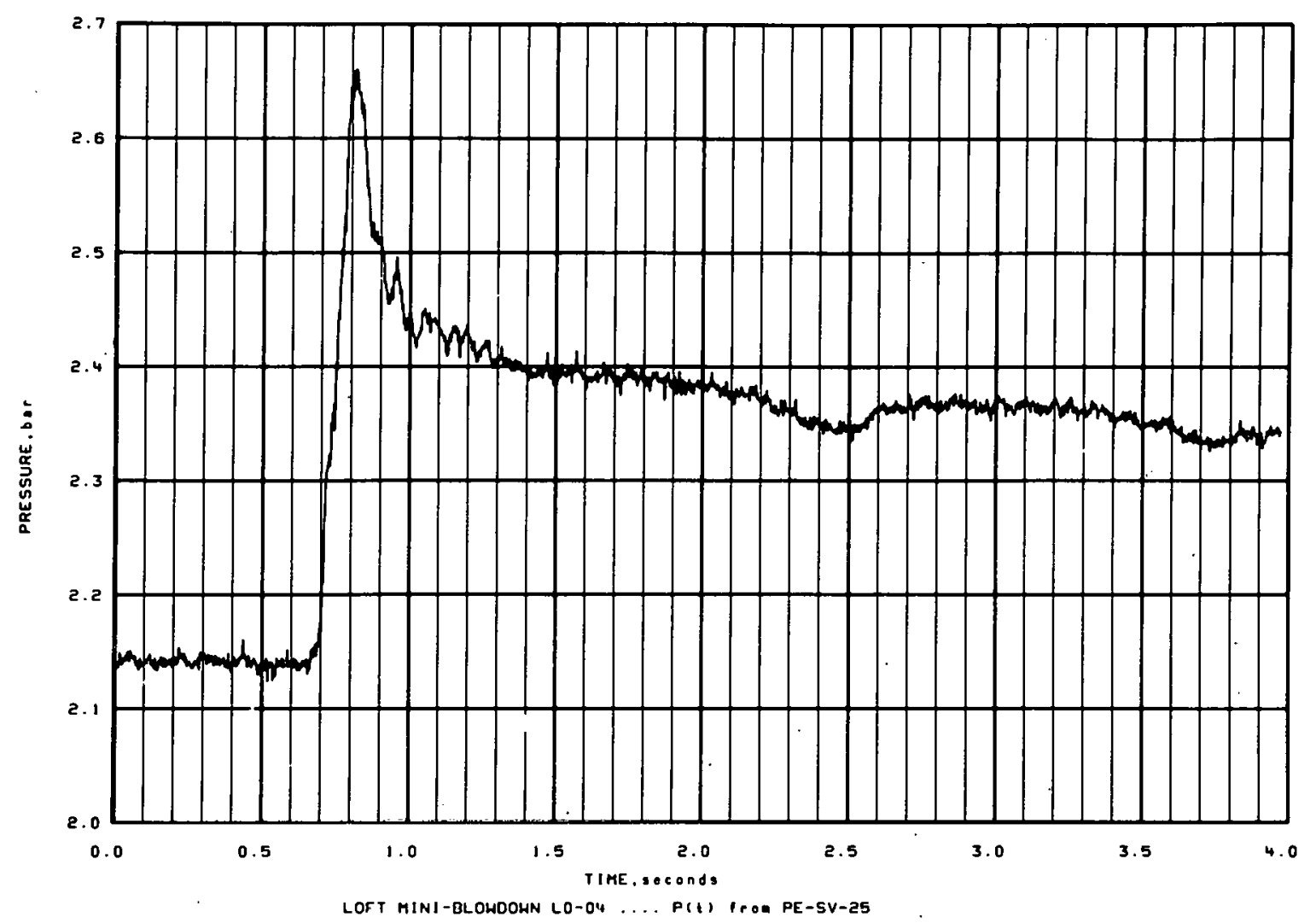

Figure F-25

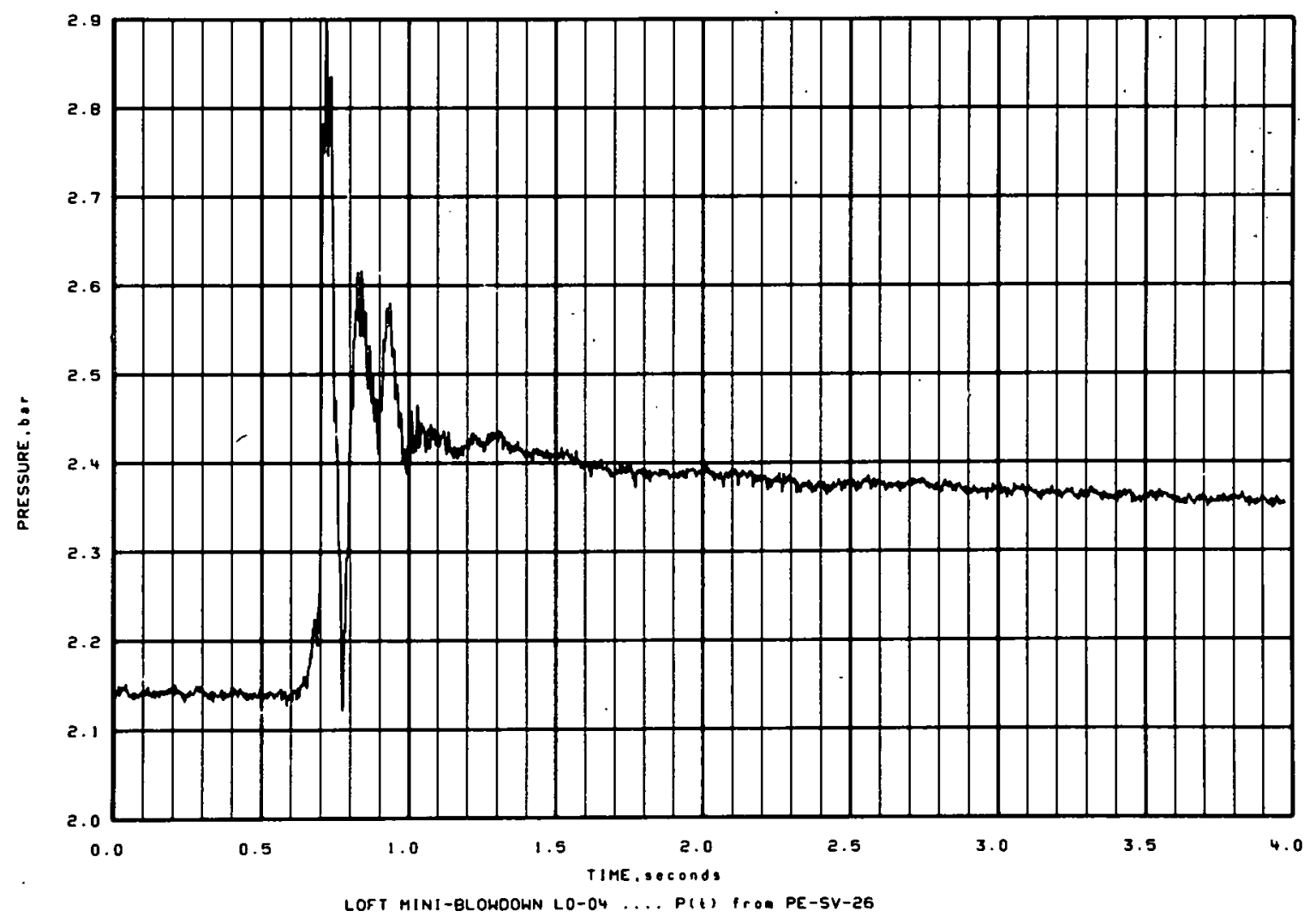

Figure F-26 


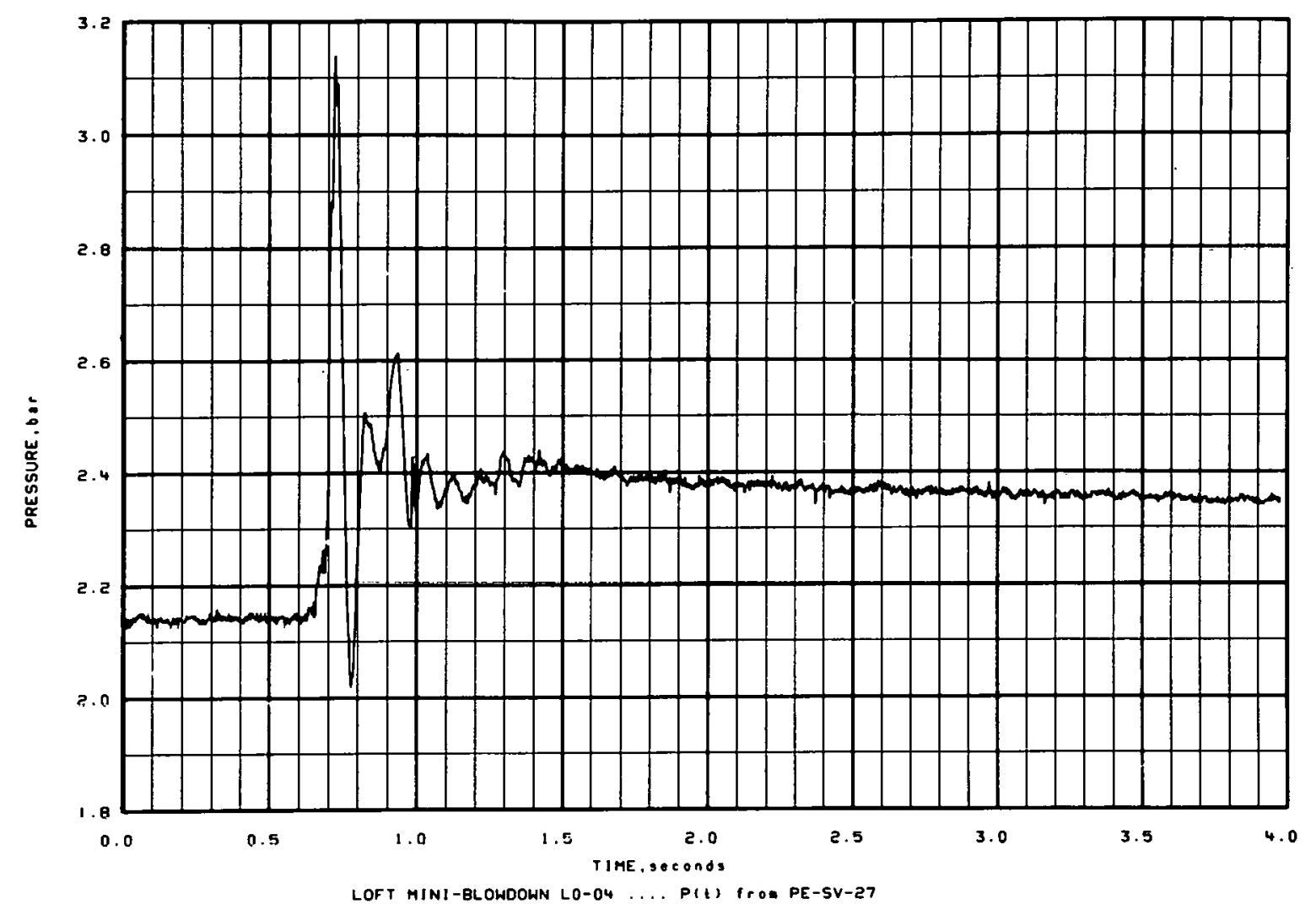

Figure F-27

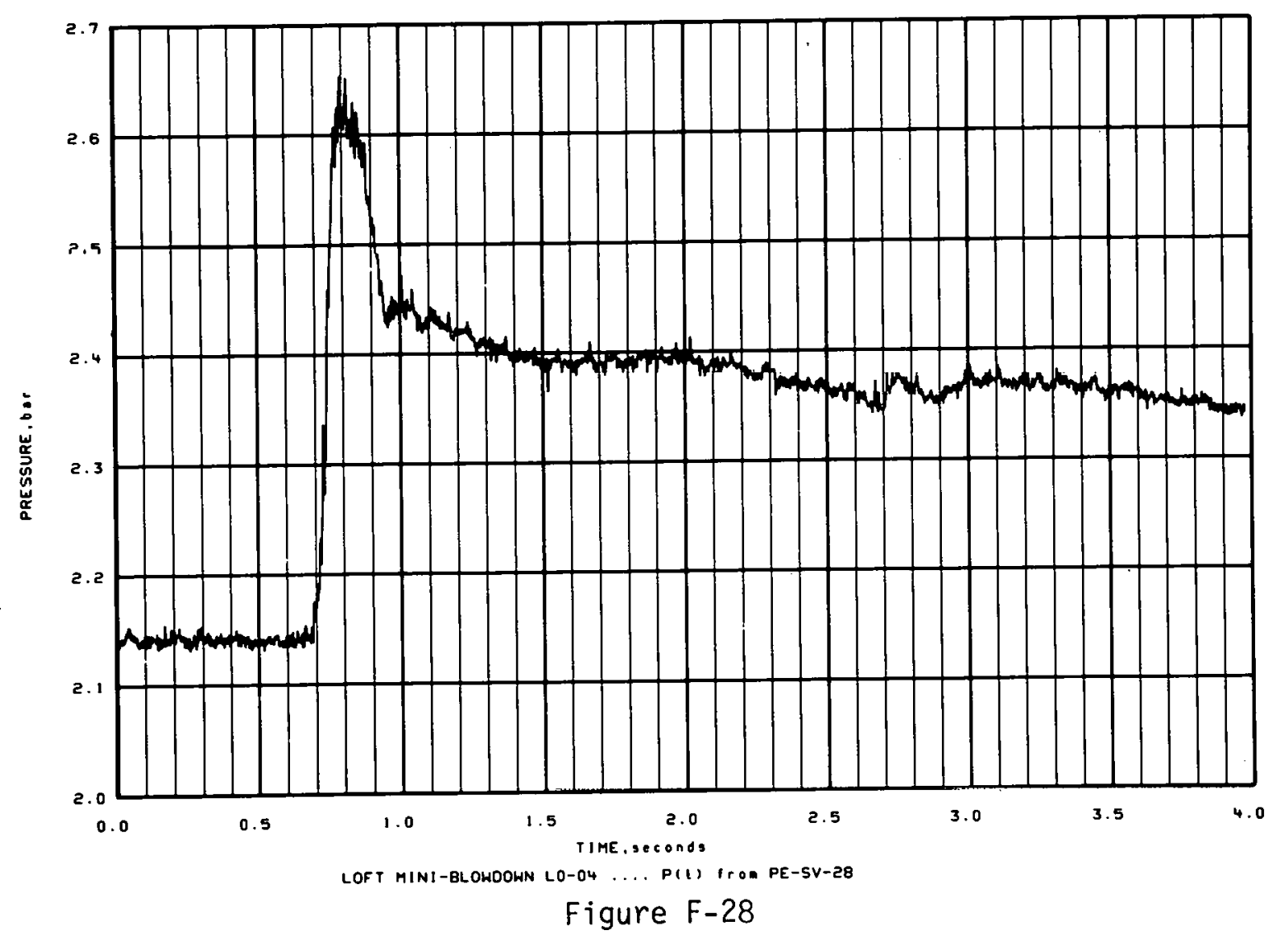




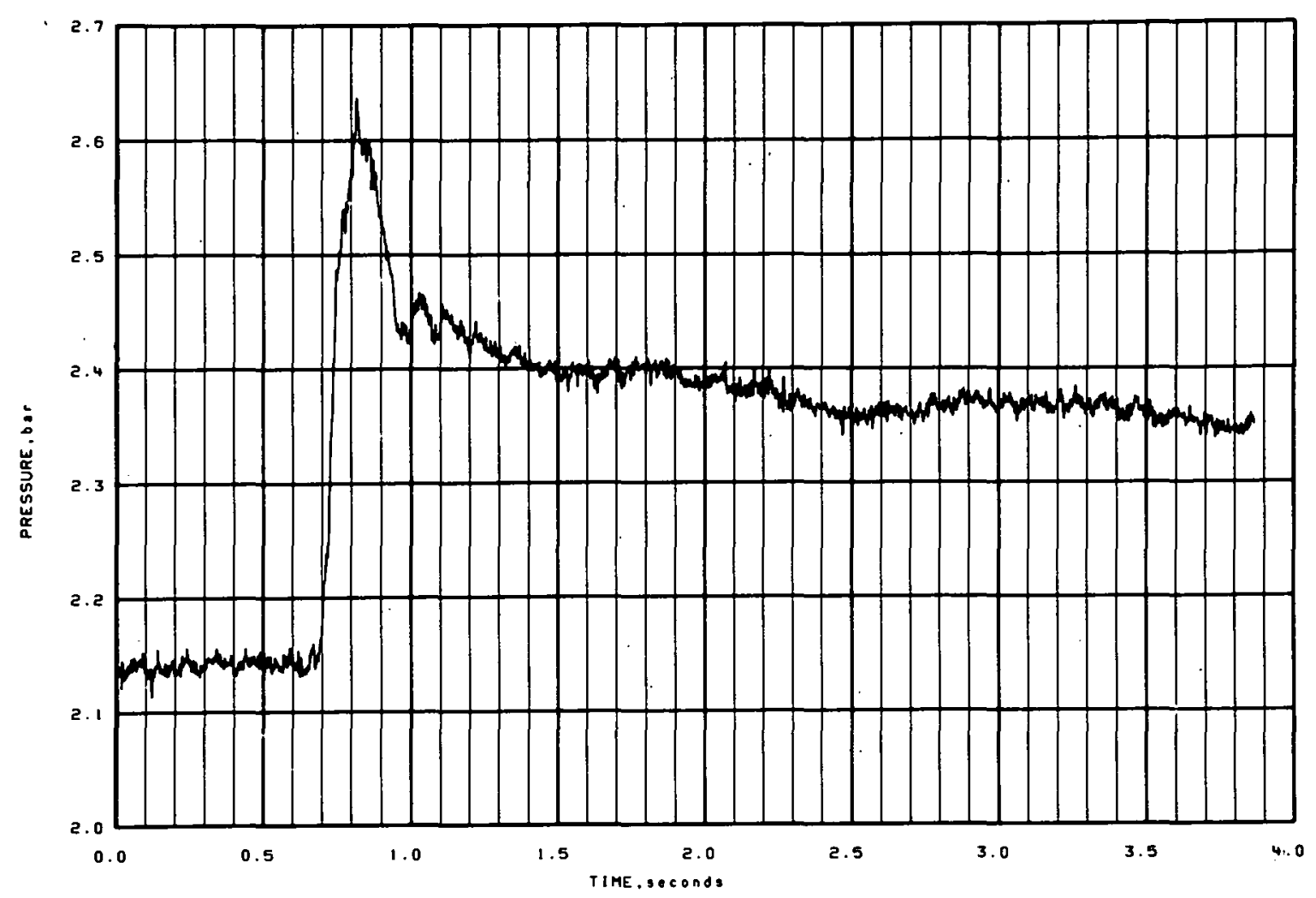

LOFT MINI-BLOWDOHN L0-04 ... P(t) IrOA PE-5V-29

Figure F-29

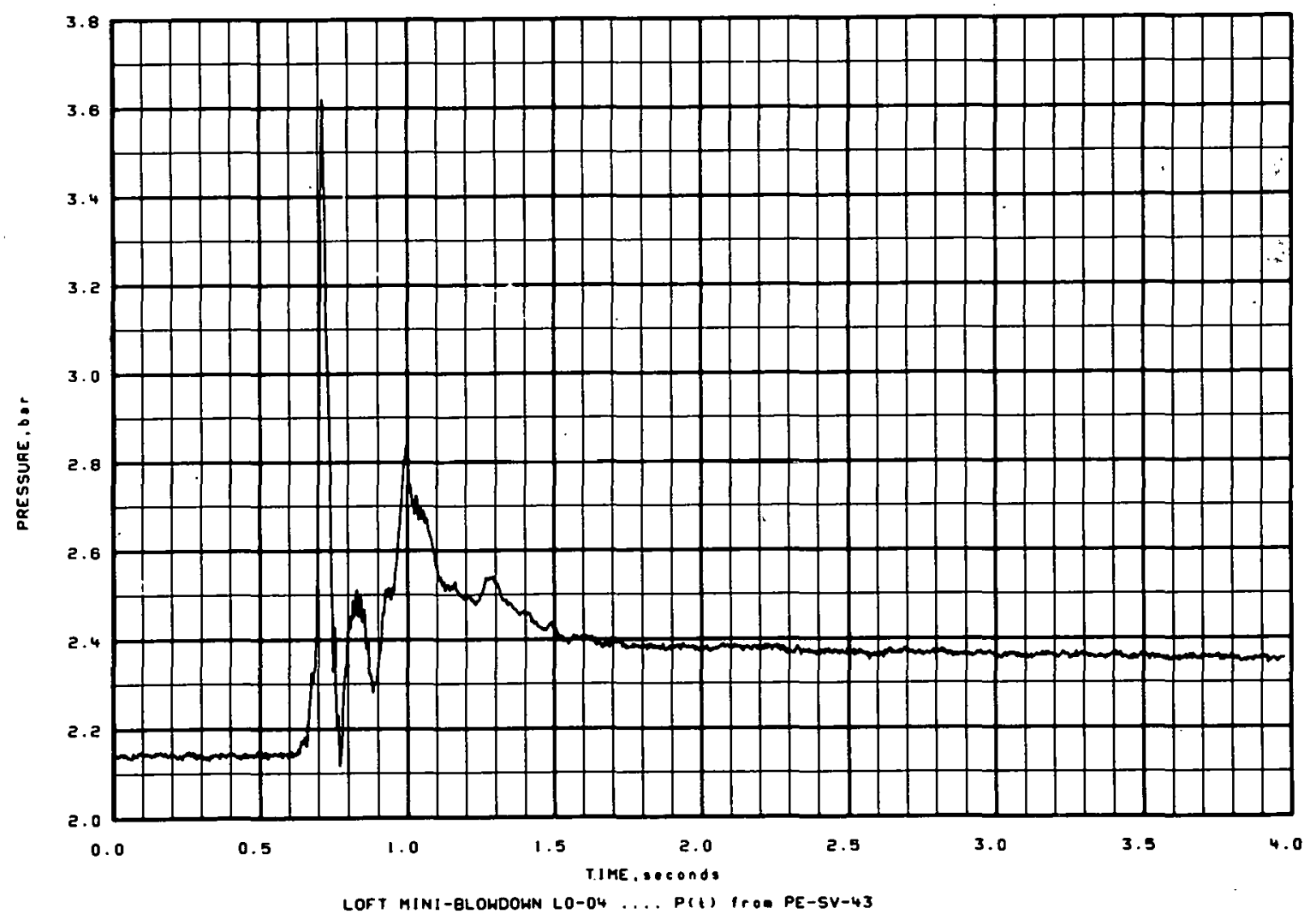

Figure F-30 


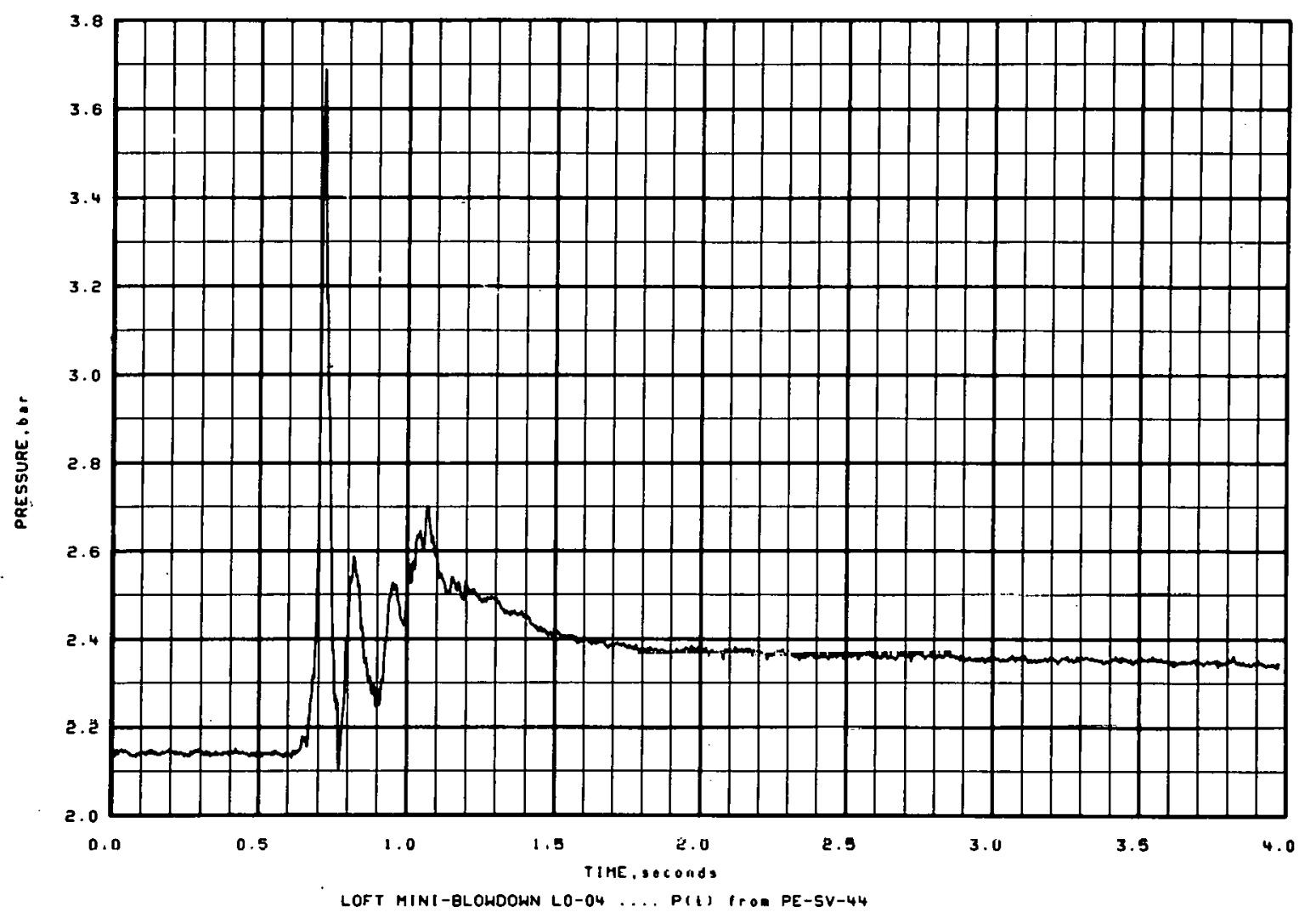

Figure F-31

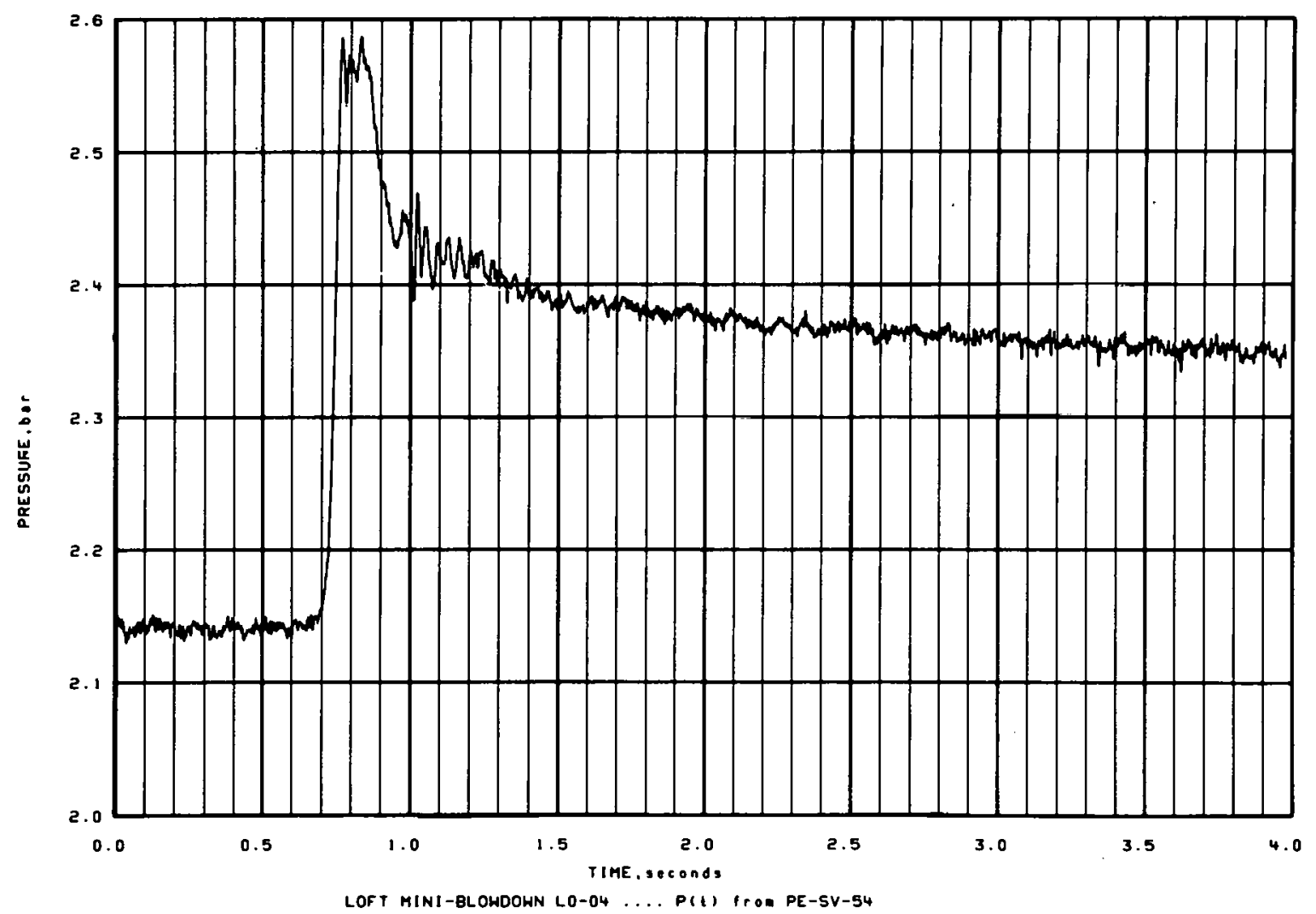

Figure F-32 


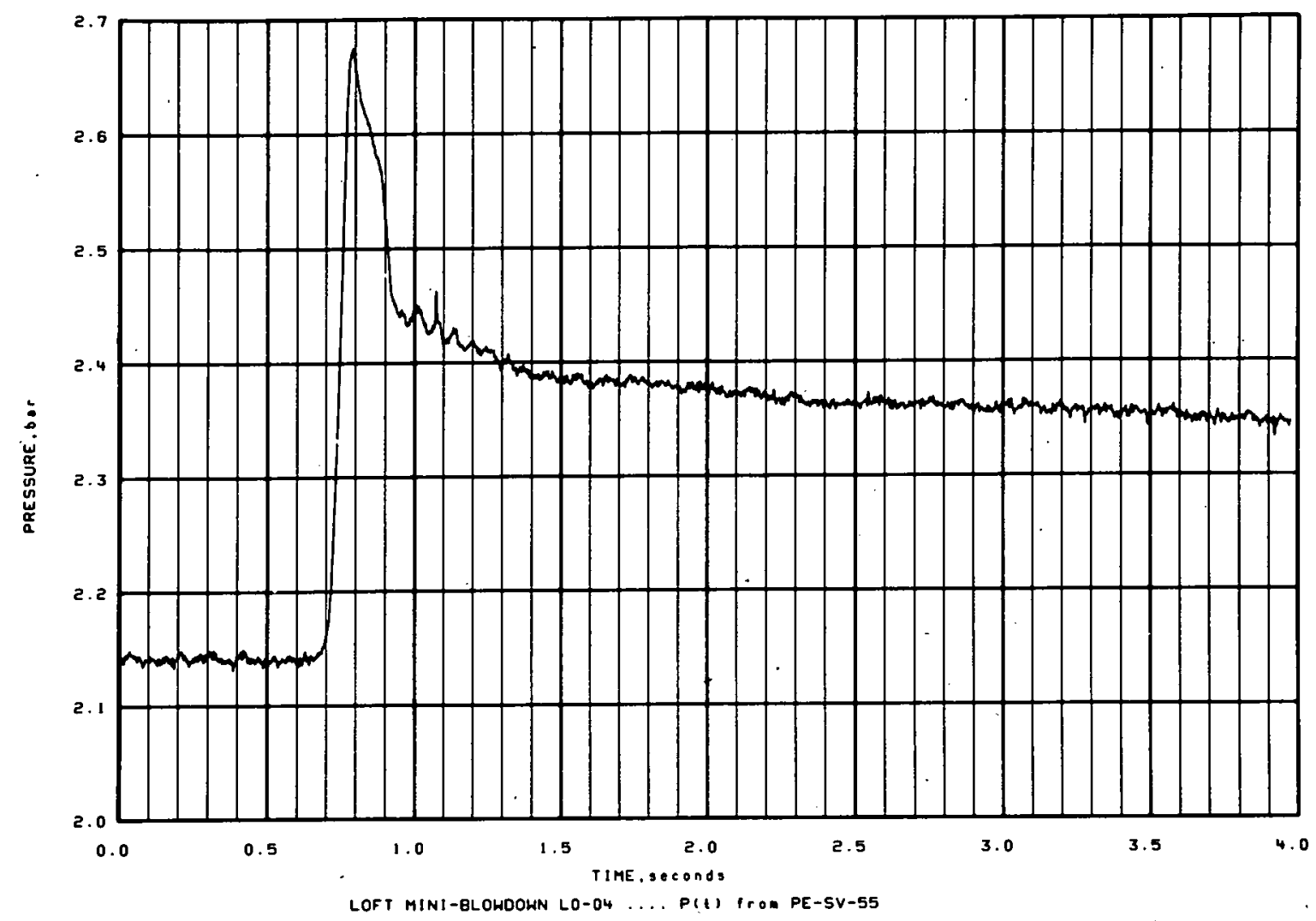

Figure F-33

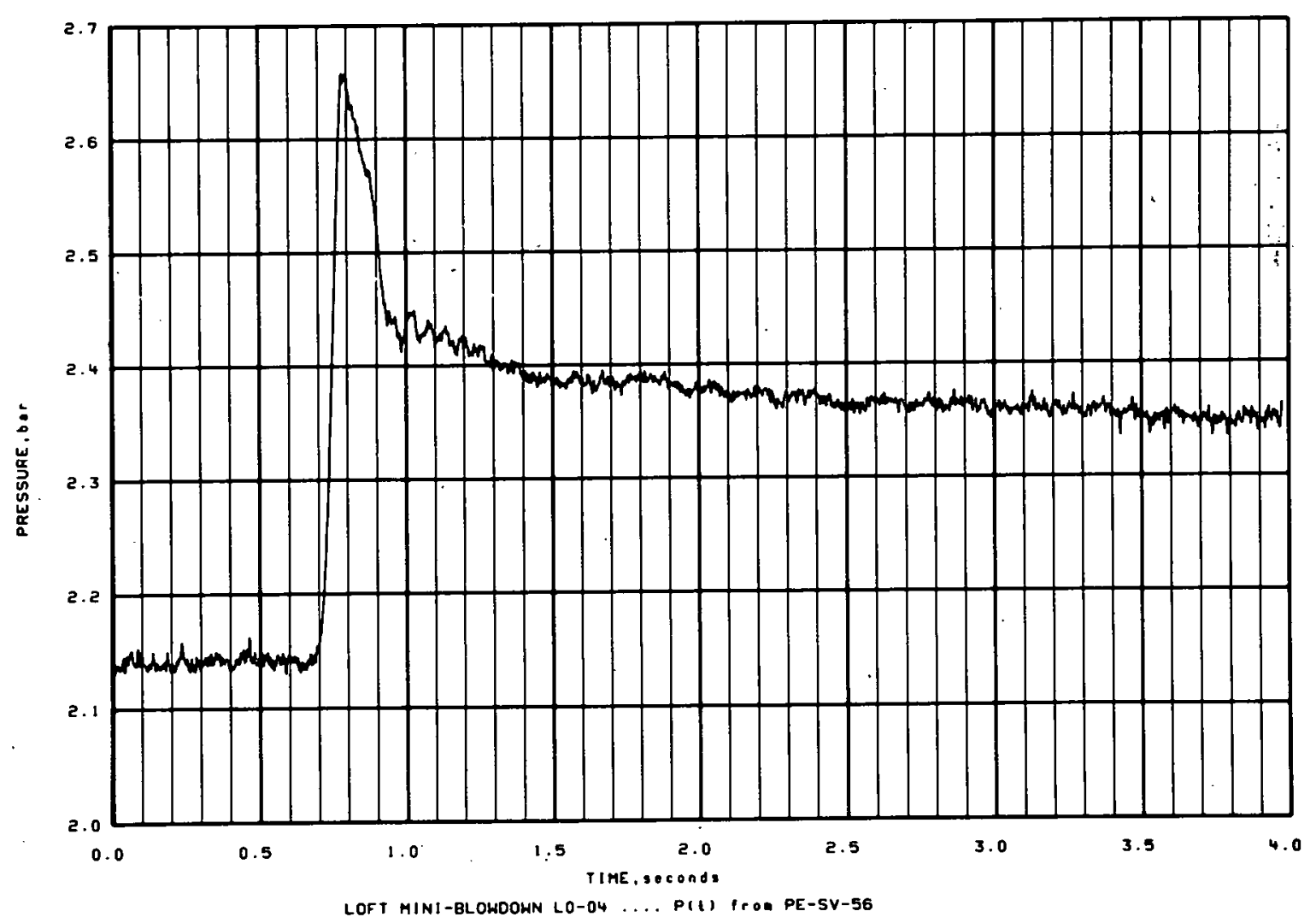

Figuré F-34 


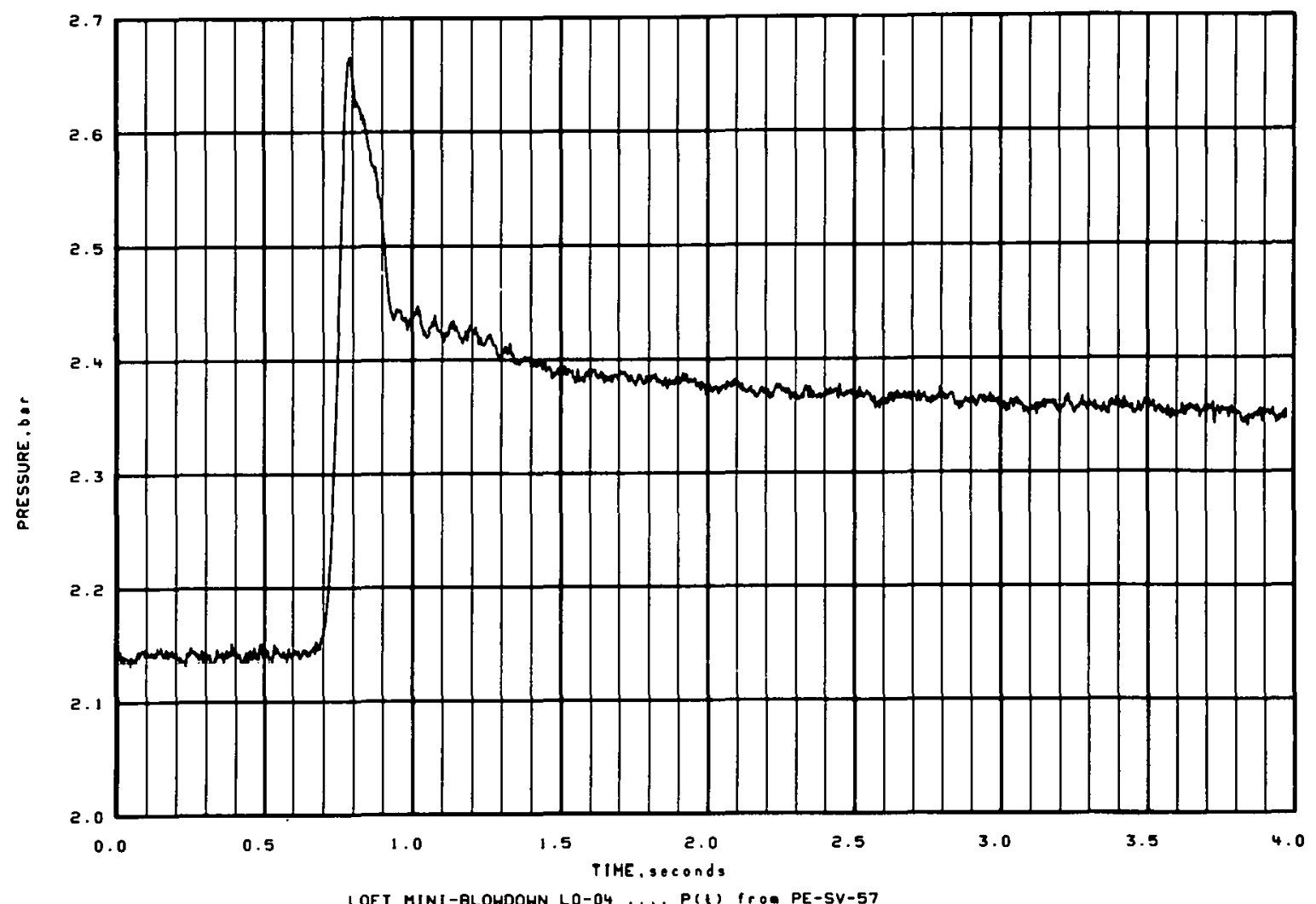

Fiqure F-35

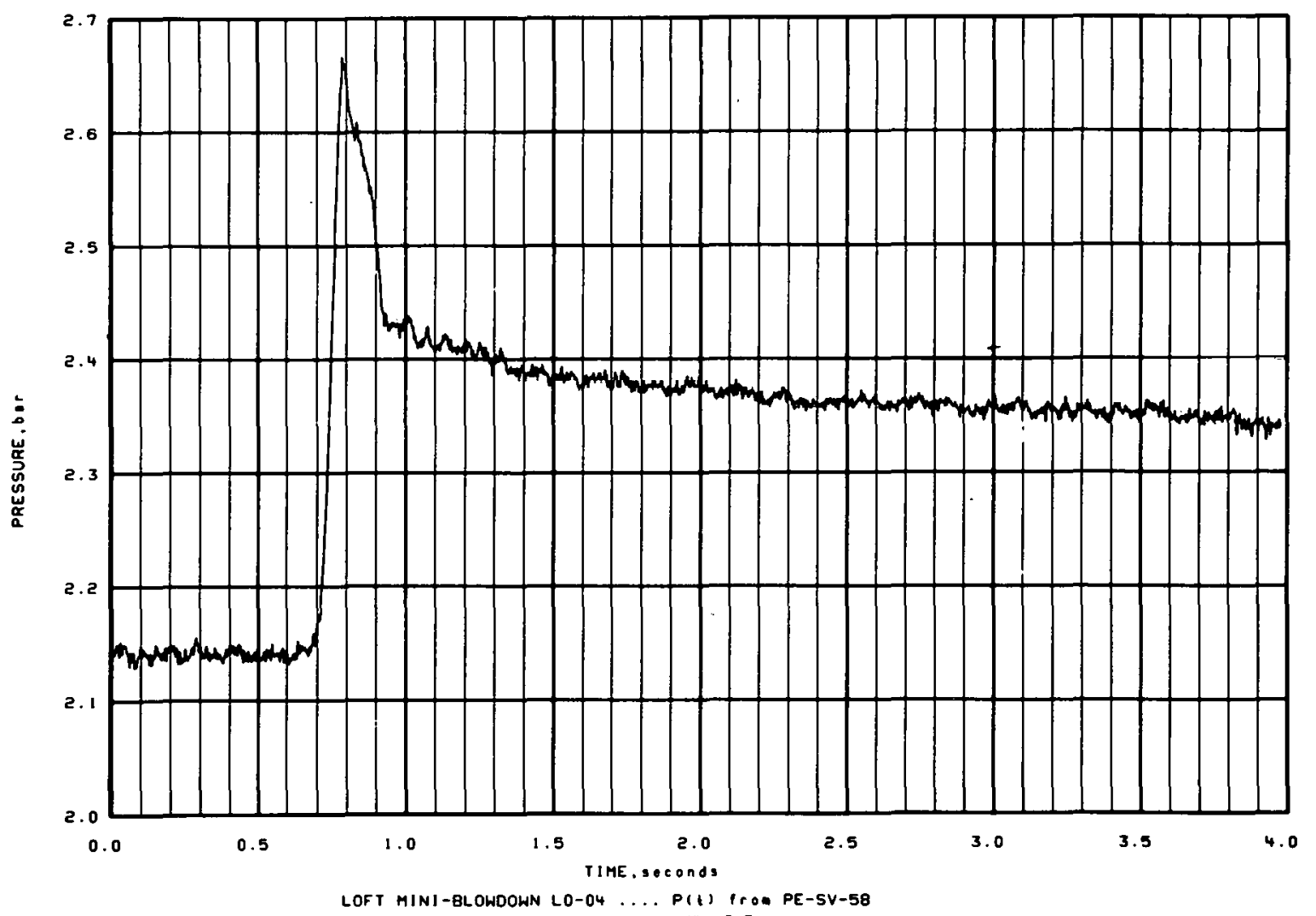

Figure F-36 


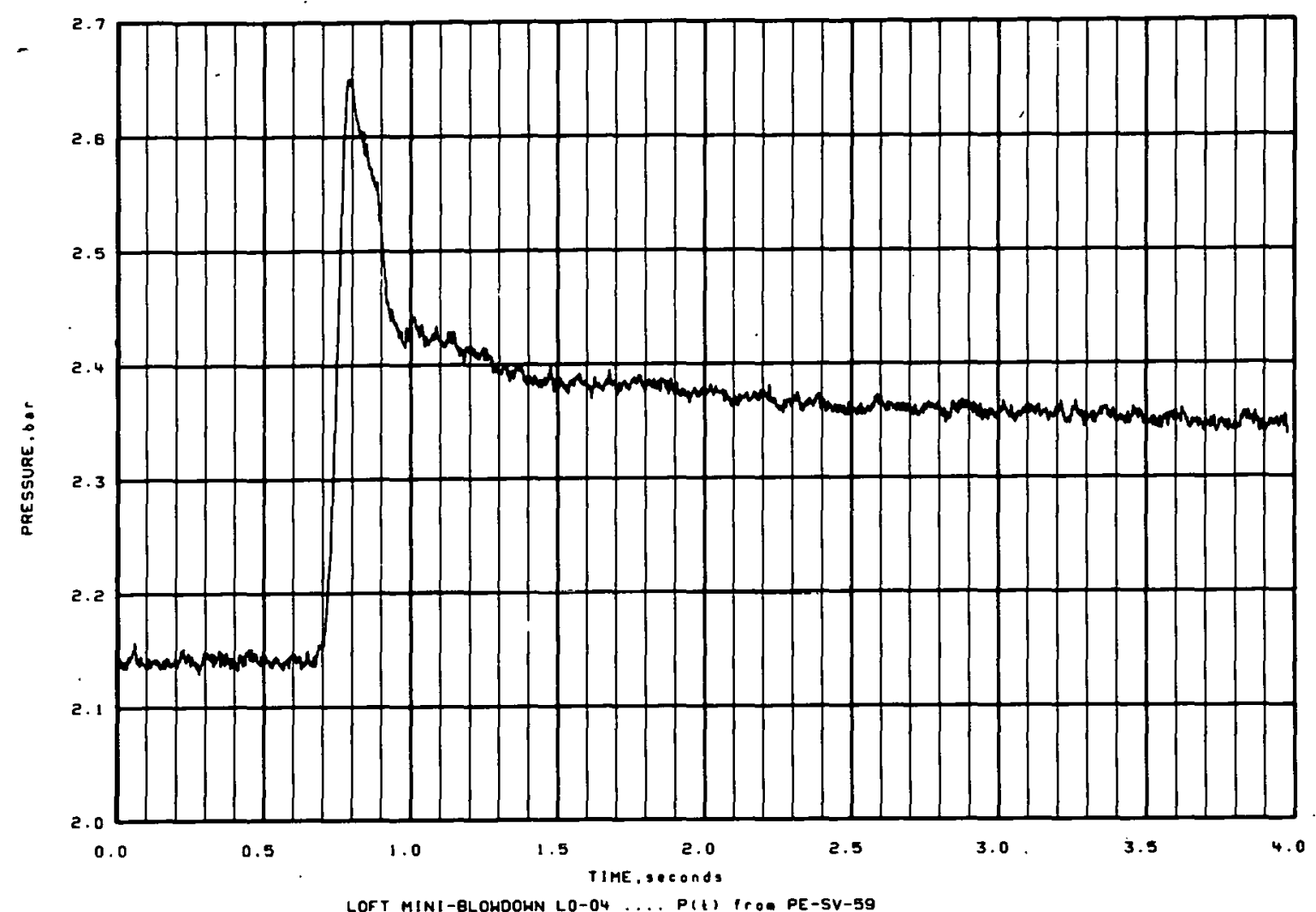

Figure $\mathrm{F}-37$

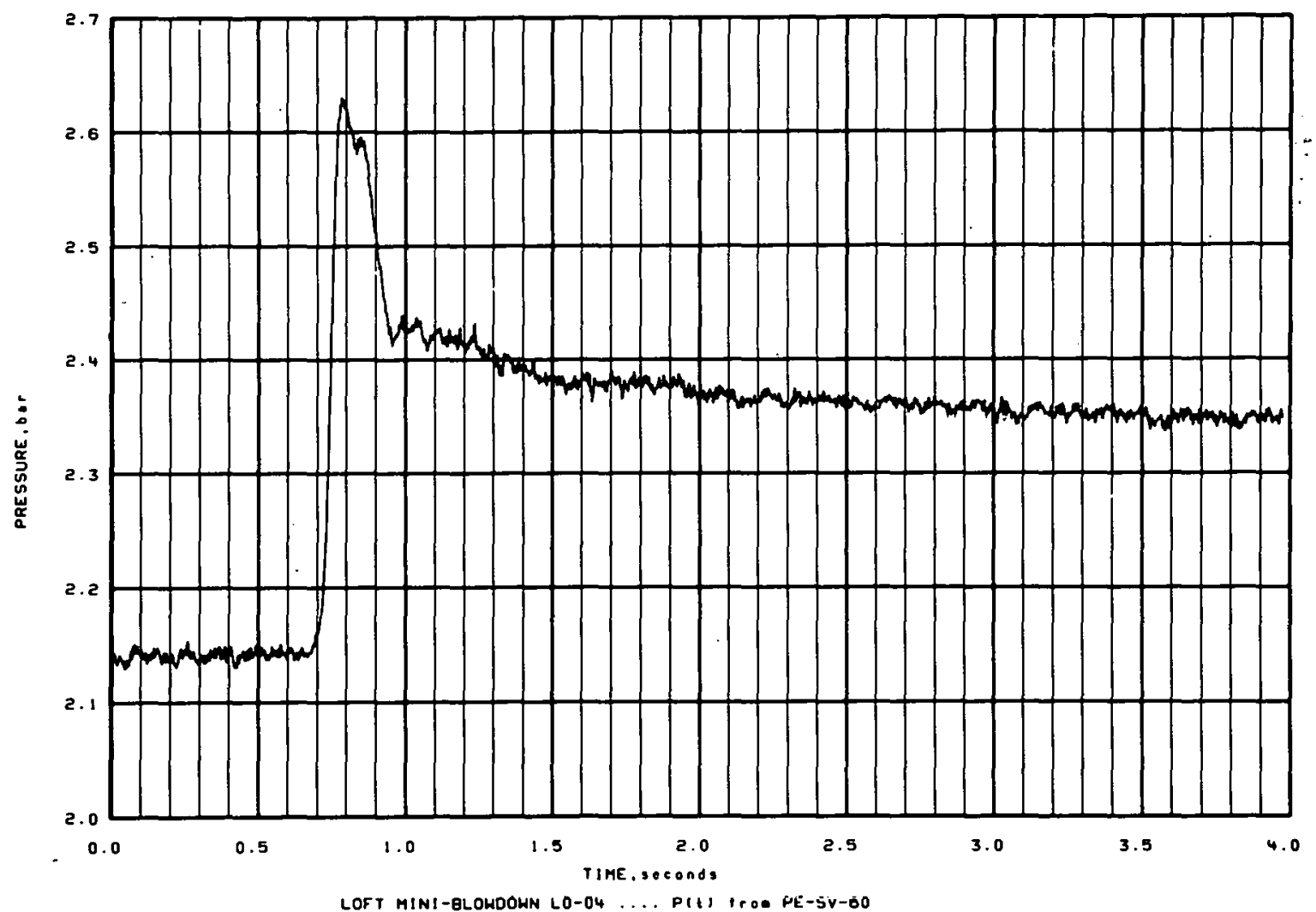

Figure F-38 


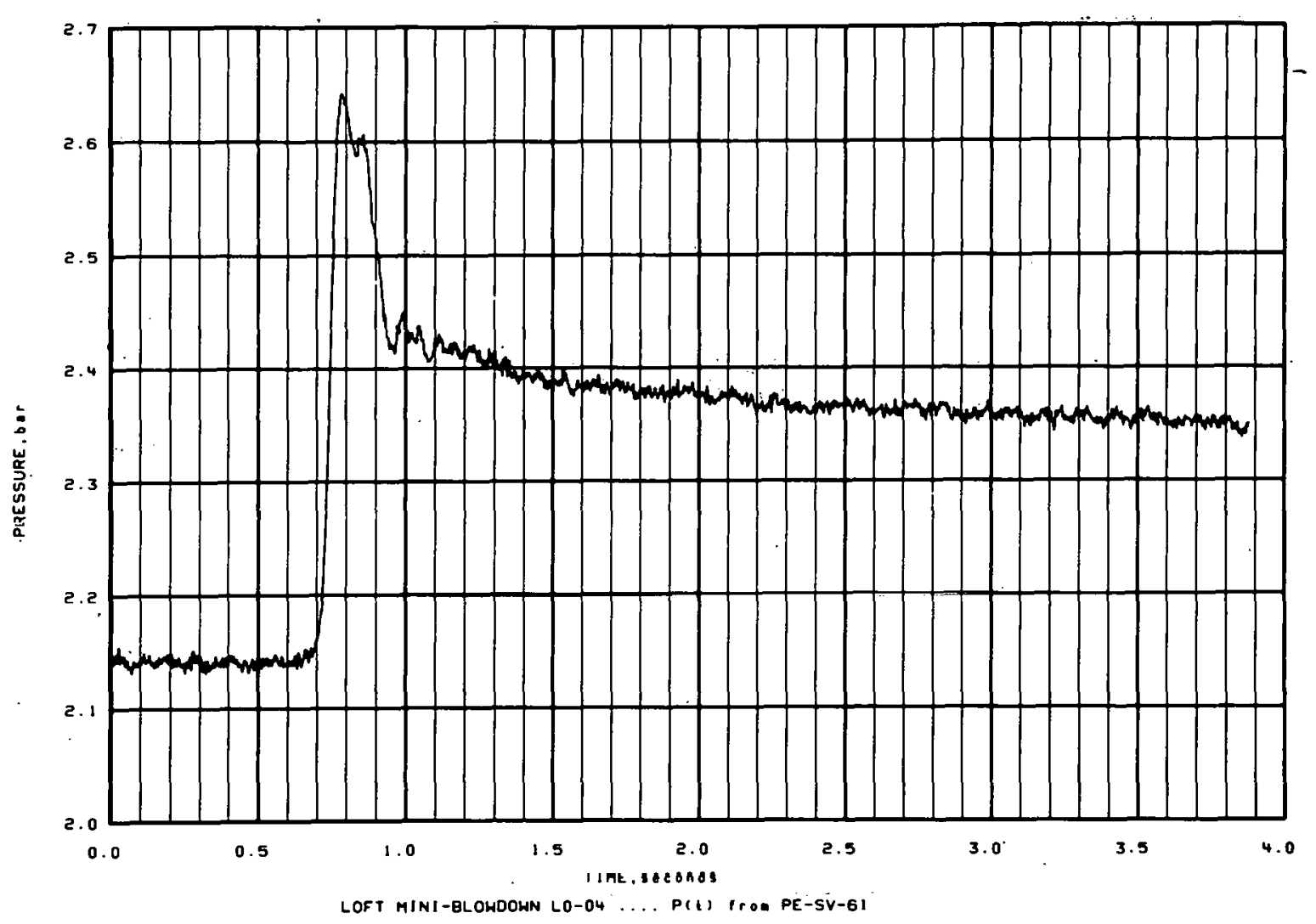

Figure F-39 


\section{APPENDIX G}

MINI-BLOWDOWN LO-05 EXPERIMENTAL DATA 
THIS PAGE

\section{WAS INTENTIONALLY LEFT BLANK}


Both QOBVs fully opened with approximately a 7-msec difference in the start times. The fluid temperature was $250.4 \pm 1.5^{\circ} \mathrm{C}$ in Q0BV -1 and $251.2 \pm 1.5^{\circ} \mathrm{C}$ in QOBV -15 . The suppression tank initial conditions were $2.16 \pm 0.08 \mathrm{bar}, 27.5 \pm 1.5^{\circ} \mathrm{C}$ in the gas volume, and $26.6 \pm 1.5^{\circ} \mathrm{C}$ in the pool. The vents were submerged $56.4 \pm 2.5 \mathrm{~cm}$. The internal vent submergence was nearly the same at $56.2 \pm 3.2 \mathrm{~cm}$.

The experimental data are defined in Table G-I. The opening characteristics of the QOBVS are shown in terms of percent sleeve travel versus time. The flow area of the valve begins to open at a sleeve position of $17 \%$ of full travel and is fully open at a sleeve position of $66 \%$ of full travel. The differential pressure between the header and the tank gas volume is measured with a very sensitive device primarily to provide information on vent preclearing. The data for this measurement is driven to saturation in the early part of the transient. 
TABLE G-I

EXPERIMENT L0-05 DATA SUMMARY

\begin{tabular}{|c|c|c|c|c|c|}
\hline $\begin{array}{c}\text { Mea surement } \\
\text { or } \\
\text { Calculation } \\
\end{array}$ & $\begin{array}{c}\text { Pre-Transient } \\
\text { Data Channel } \\
\text { Variancc } \\
\left(10^{-4} \text { bar } 2\right) \\
\end{array}$ & Figure Number & Measurement & $\begin{array}{c}\text { Pre-Transient } \\
\text { Data Channel } \\
\text { Variance } \\
\left(10^{-4} \text { bar } 2\right) \\
\end{array}$ & Figure Number \\
\hline QOBV-1 opening & $3 \quad-$ & $G-1, G-2$ & PE-SV-22 & 0.42976 & G-22 \\
\hline QOBV-15 opening & - & $G-3, G-4$ & $P E-S V-23$ & 0.49773 & $G-23$ \\
\hline $\begin{array}{l}\text { Combined QOBV } \\
\text { opening }\end{array}$ & $:$ & $G-5, G-6$ & PE-SV-24 & 0.20659 & $G-24$ \\
\hline Vertical load & . & G-7 & PE-SV-25 & 0.14579 & G-25 \\
\hline PDE-SV-09 & $: \quad-$ & G-8. & $P E-S V-26$ & .0 .11395 & G-26 \\
\hline PE-SV-01 & $0.32271^{\circ}$ & G-9 & $P E-S V-27$ & 0.25934 & $G-27$ \\
\hline PE-SV-02 & 0.34261 & G-10 & $P E-S V-28$ & 0.27074 & $G-28$ \\
\hline PE-SV-03 & 0.32637 & G-11 & PE-SV-29 & 0.29426 & $G-29$ \\
\hline PE-SV-04 & 0.42203 & G-12 & PE-SV- 43 & 0.18049 & $G-30$ \\
\hline PE-SV-10 & 0.26395 & G-13 & PE-SV-44 & 0.24097 & $G-31$ \\
\hline$P E-S V-I I$ & 2.2938 & $G=14$ & $P E-S V-54$ & 0.20480 & $G-32$ \\
\hline PE-SV-12 & 0.35220 & G- 15 & PE-SV-55 & 0.09356 & $G-33$ \\
\hline PE-SV-13 & 0.20437 & G-16 & PE-SV-56 & 0.17141 & $G-34$ \\
\hline PE-SV-14 & 0.29424 & G-17 & PE-SV-57 & 0.11228 & $G-35$ \\
\hline$P \Gamma-S V-15$ & 0.25740 & G-18 & PE-SV-58 & 0.18298 & $G-36$ \\
\hline PE-SV-16 & 0.20339 & G-19 & PE-SV-59 & 0.21524 & G-37 \\
\hline PE-SV-17 & 0.39486 & $G-20$ & PE-SV-60 & 0.22945 & $G-38$ \\
\hline$P E-S V-18$ & 0.44286 & $G-21$ & $P E-S V-61$ & 0.26931 & G-39 \\
\hline
\end{tabular}



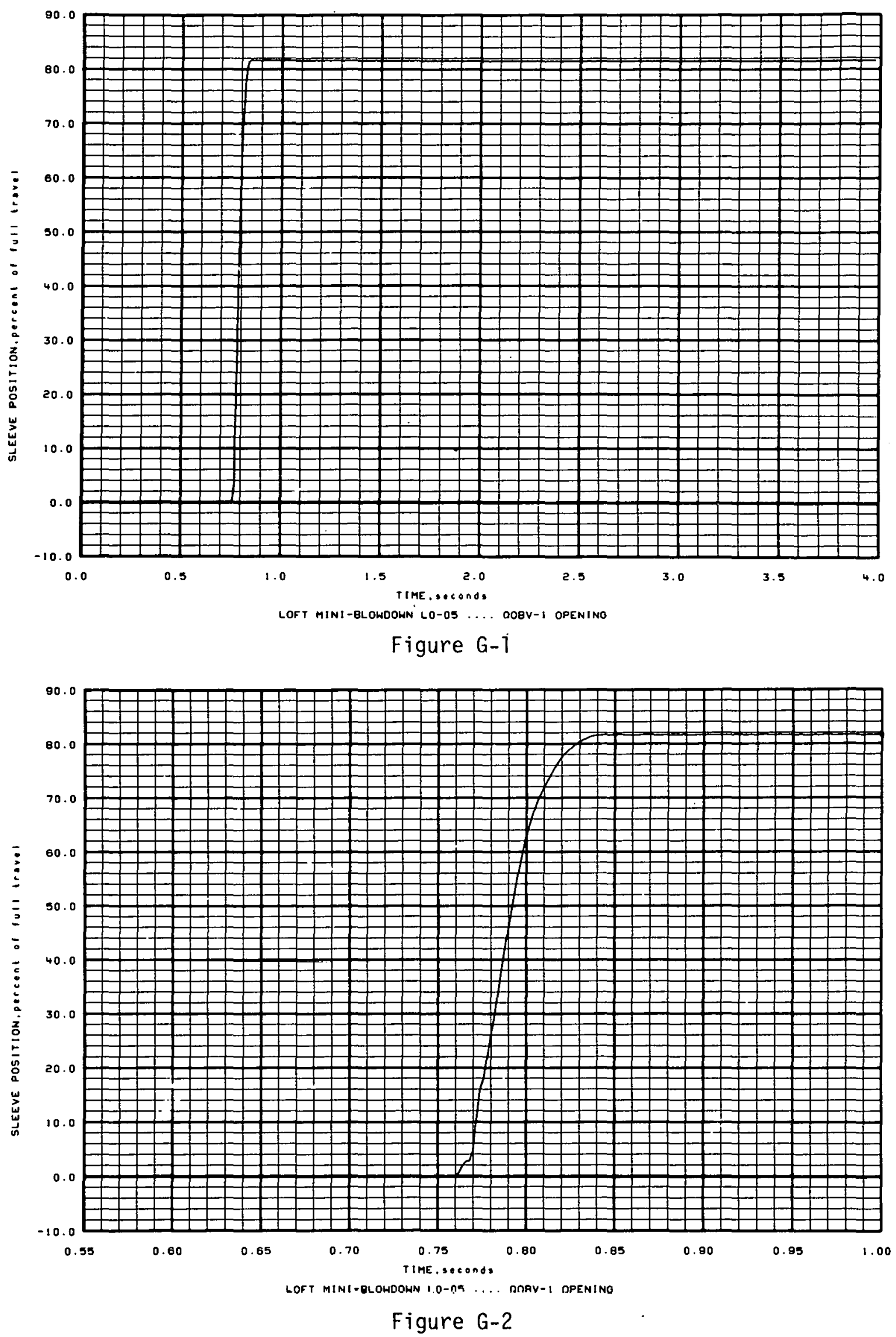


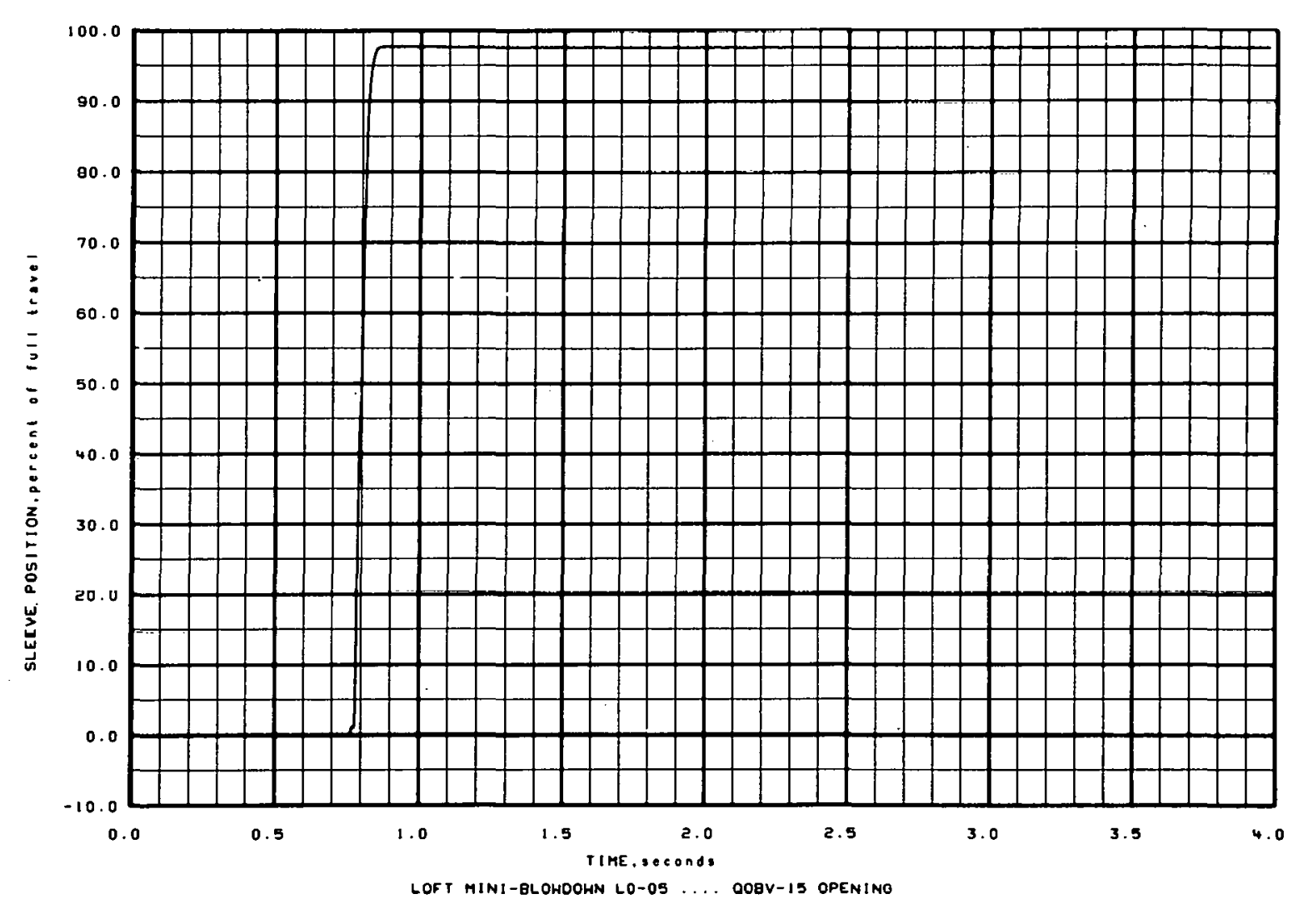

Figure G-3

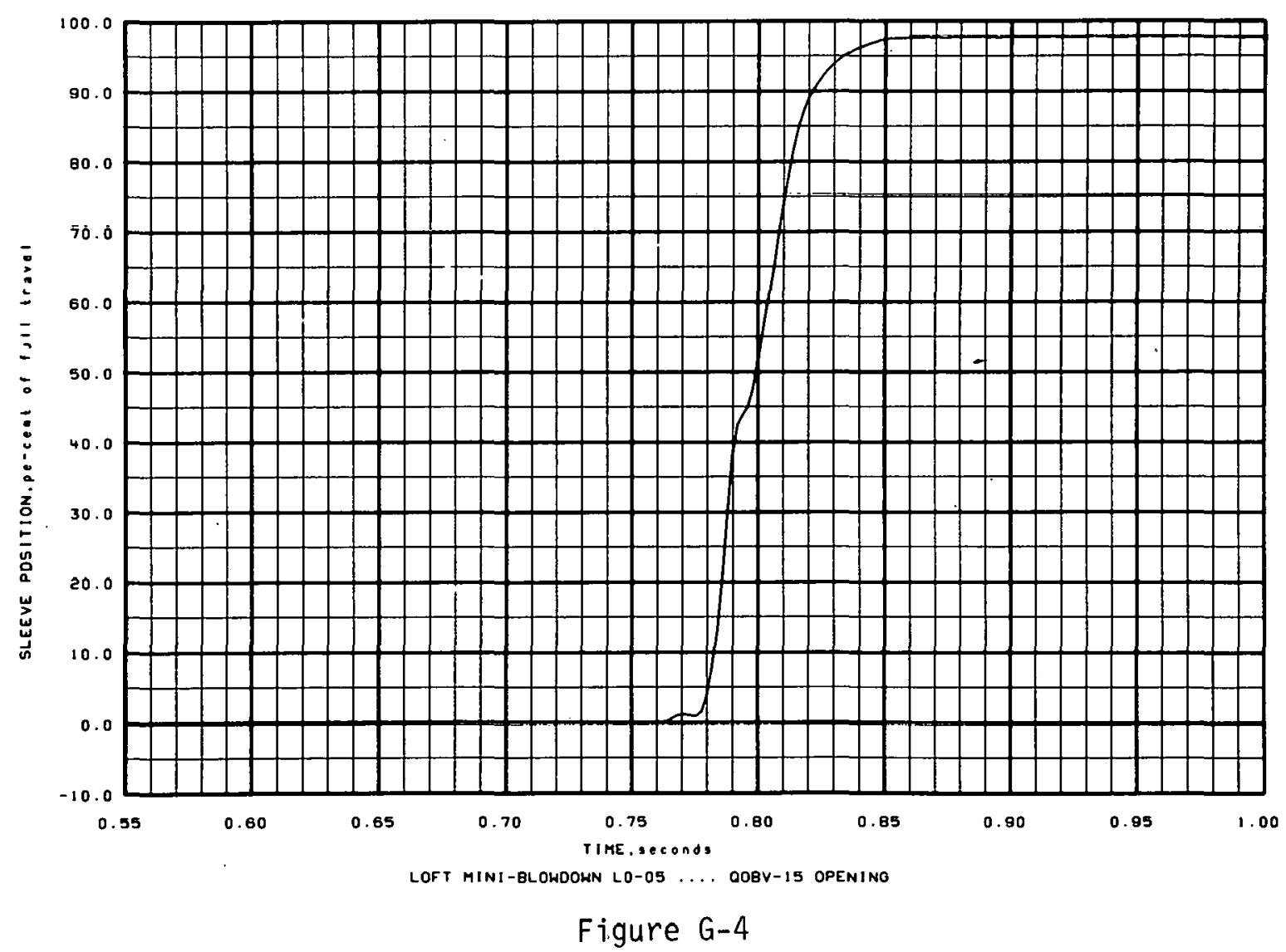



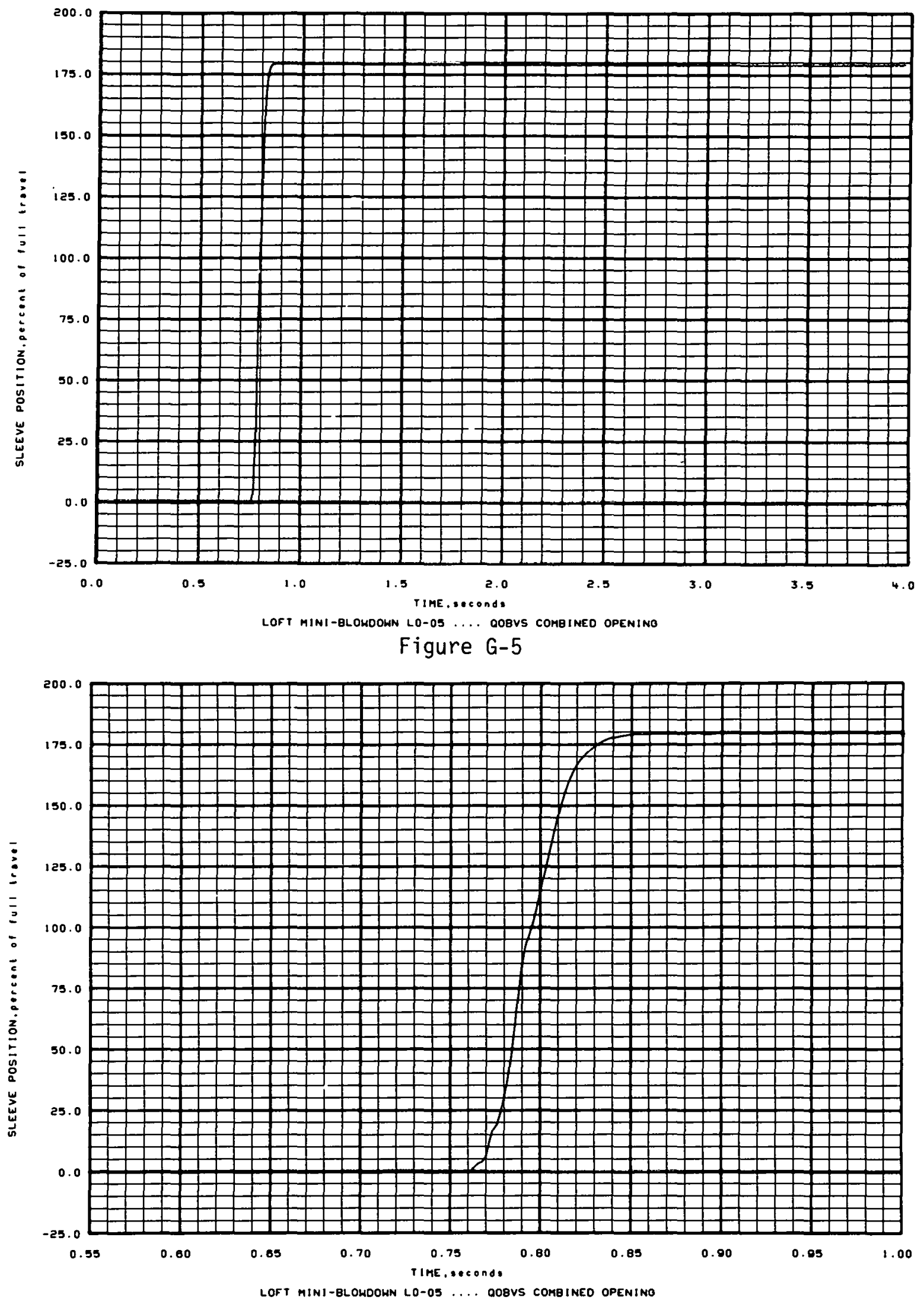

Figure G-6 

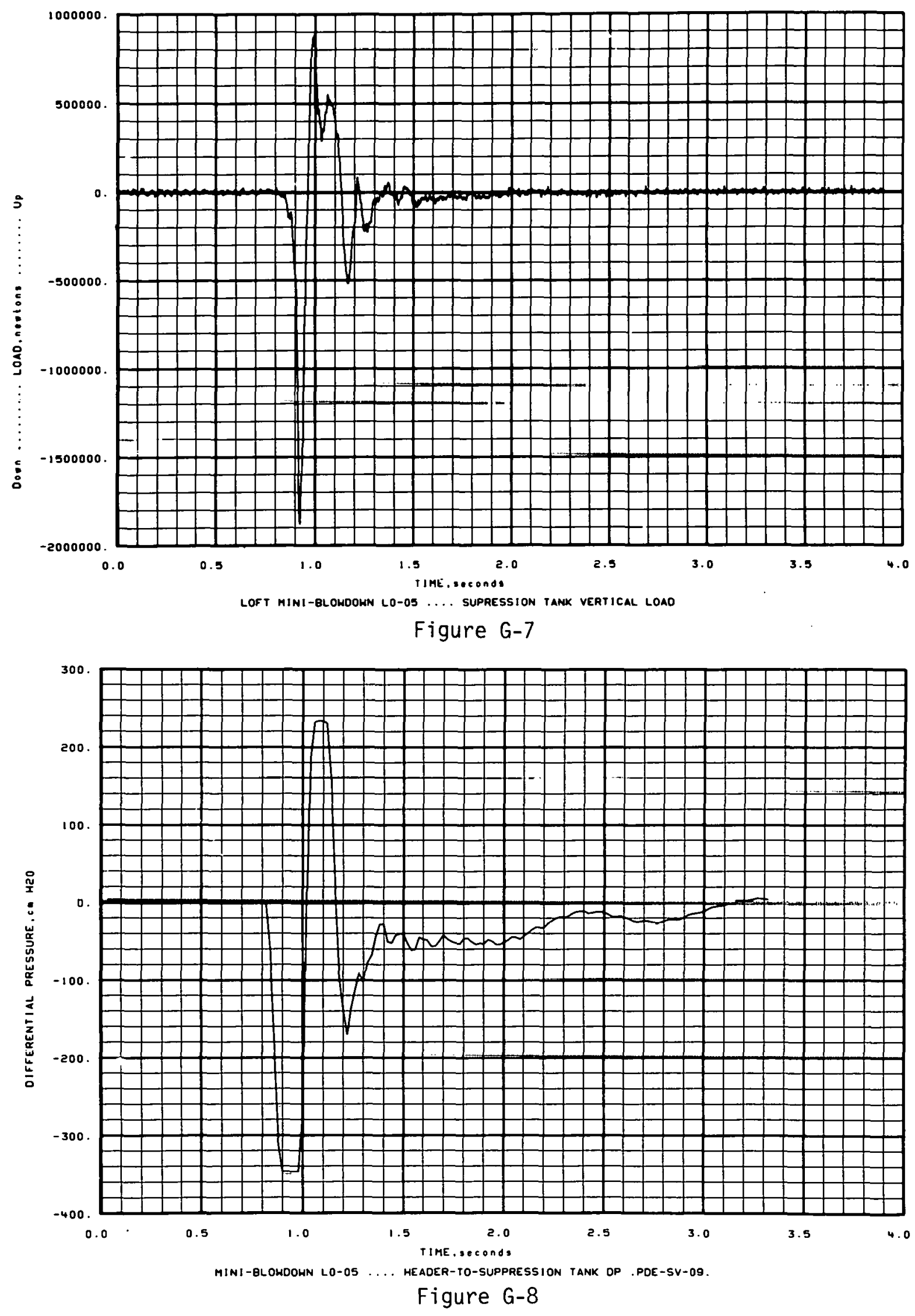

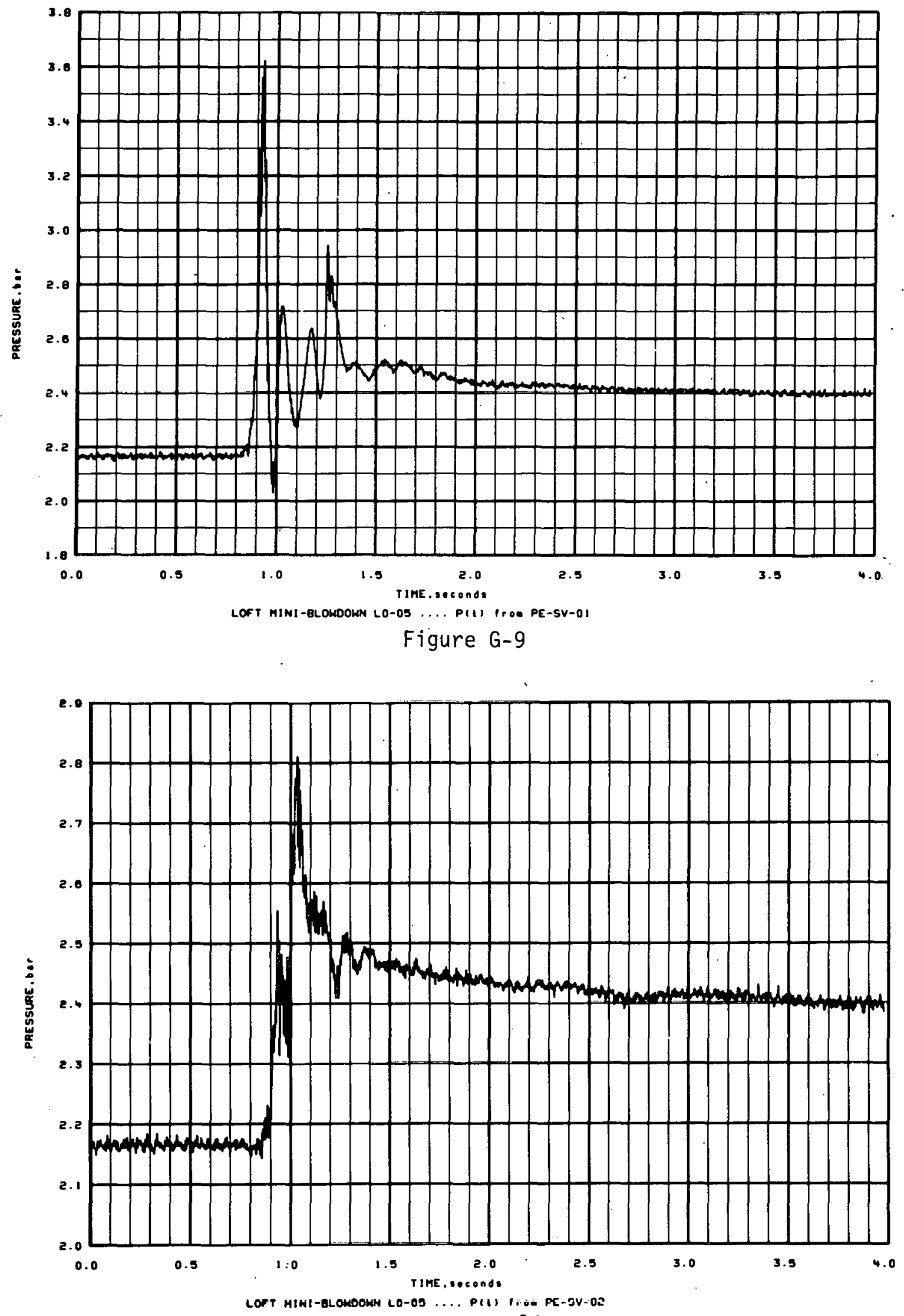

Figure G-10 


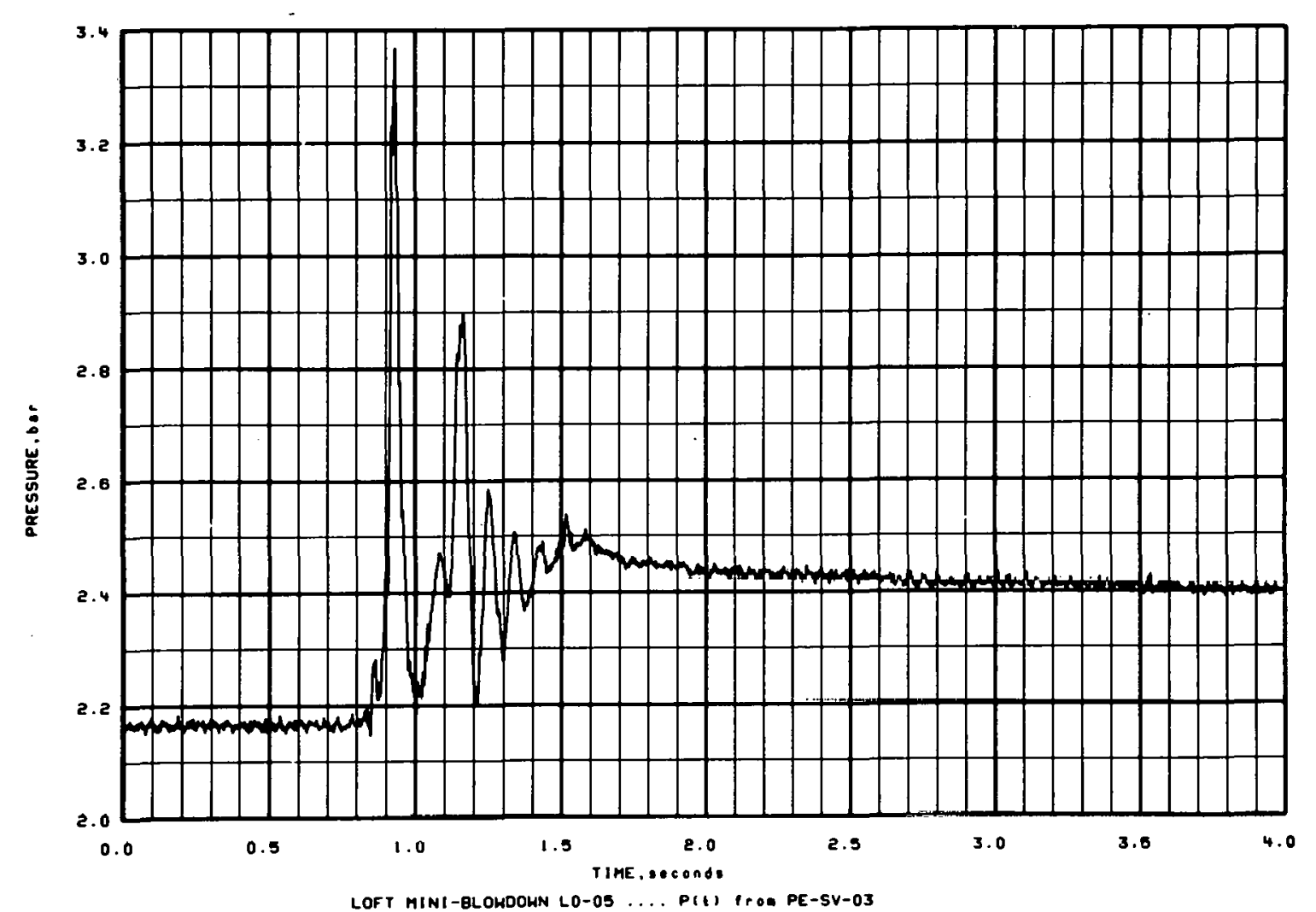

Figure G-11

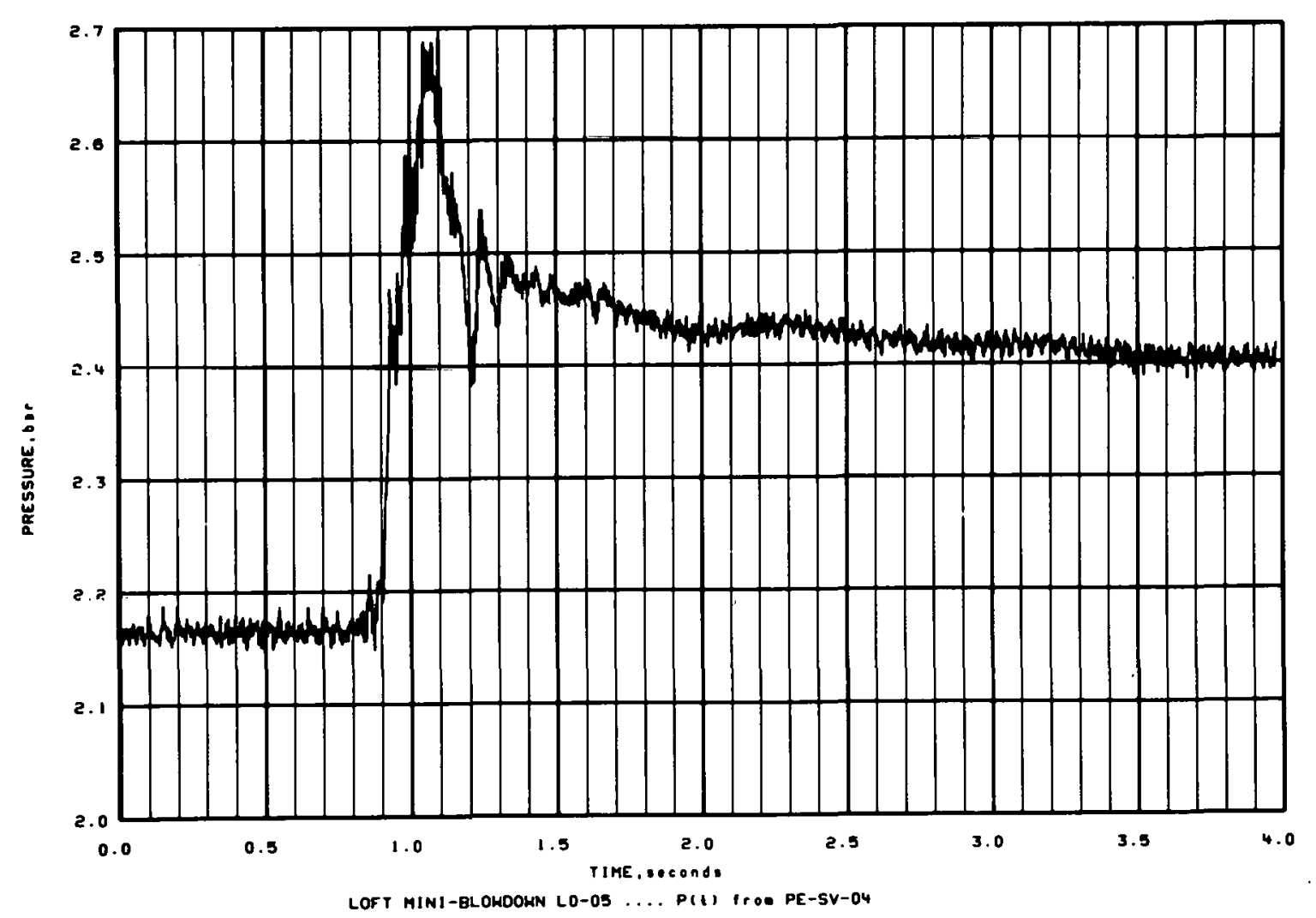

Figure G-12 


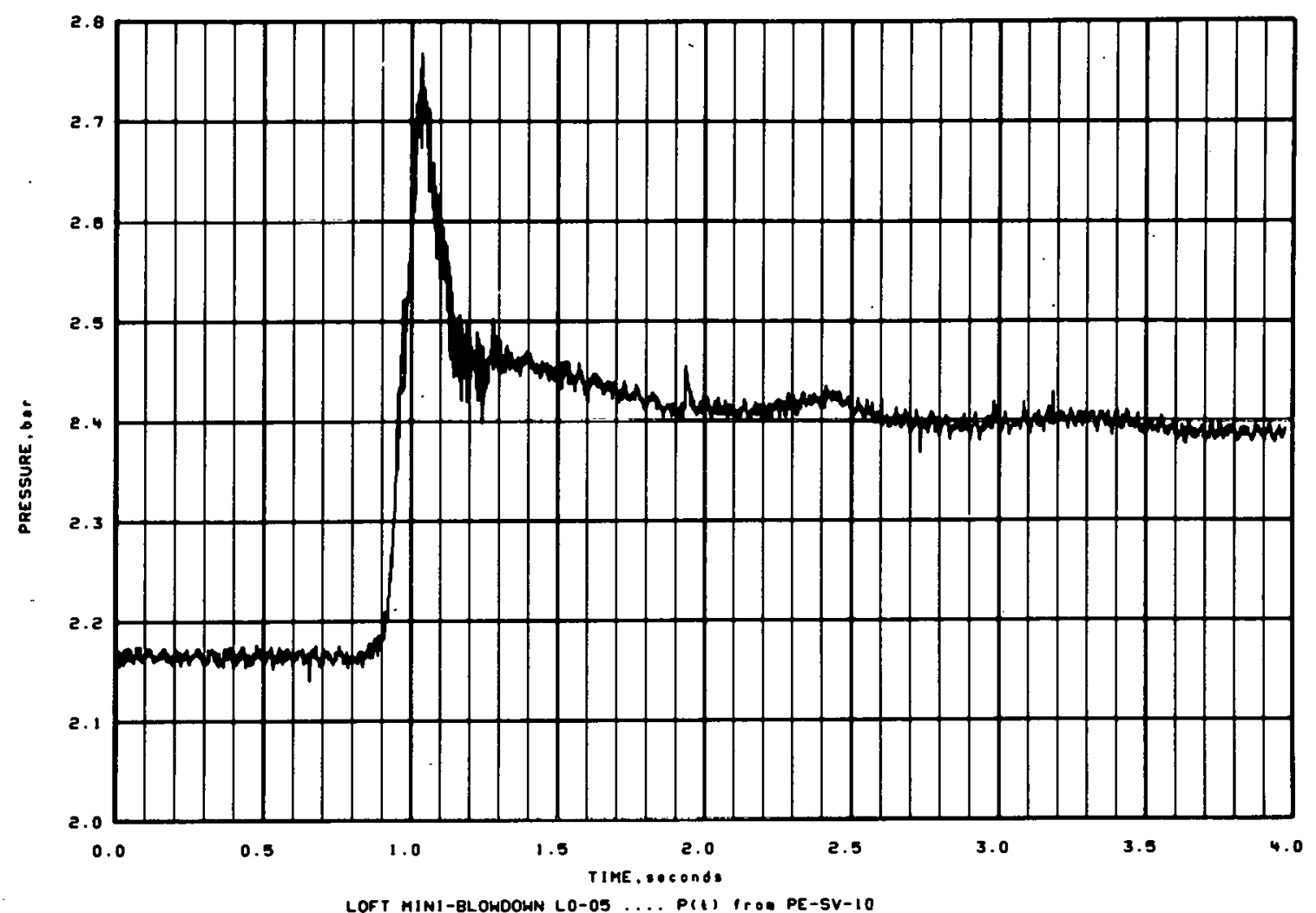

Figure G-13

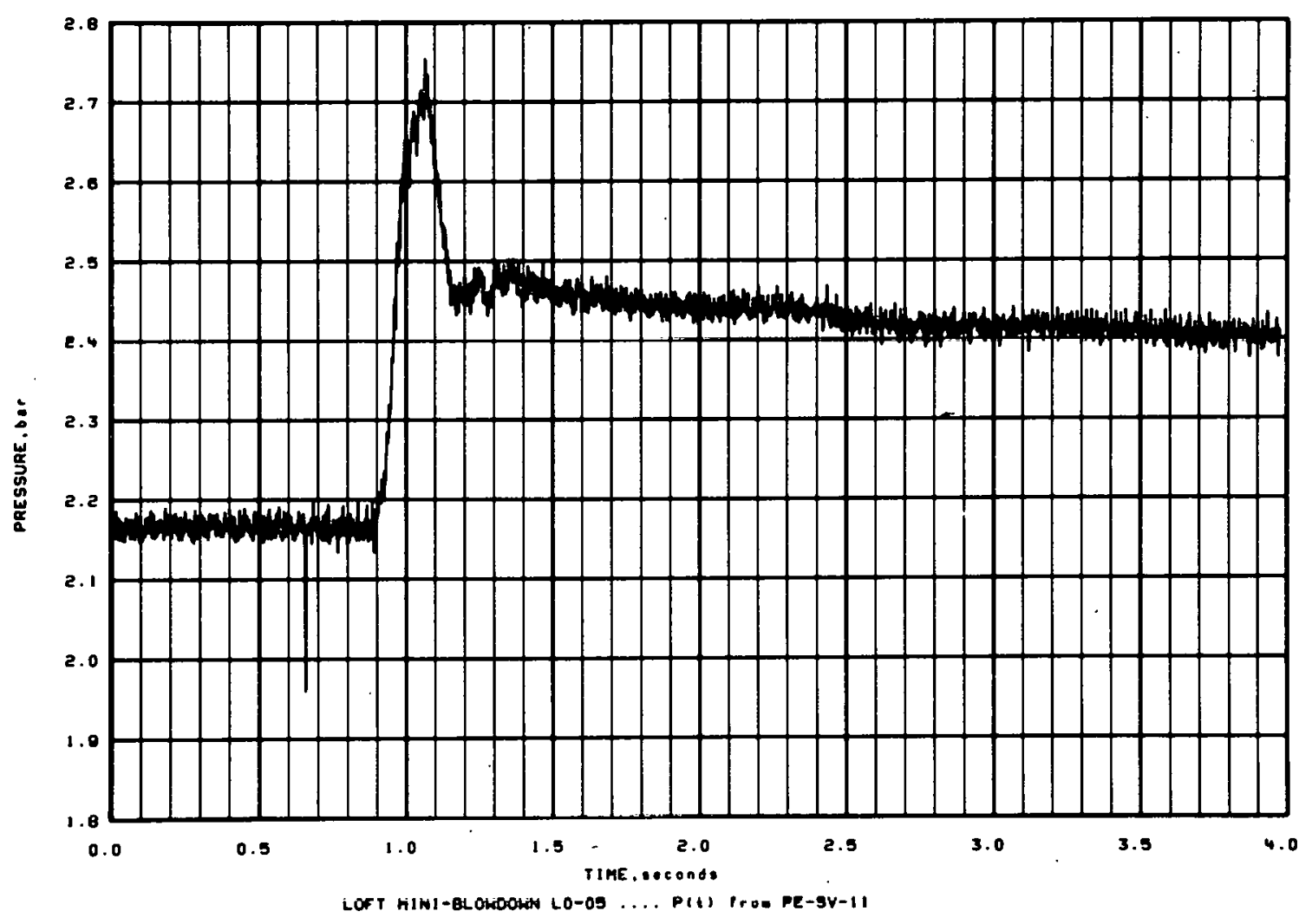

Figure G-14 


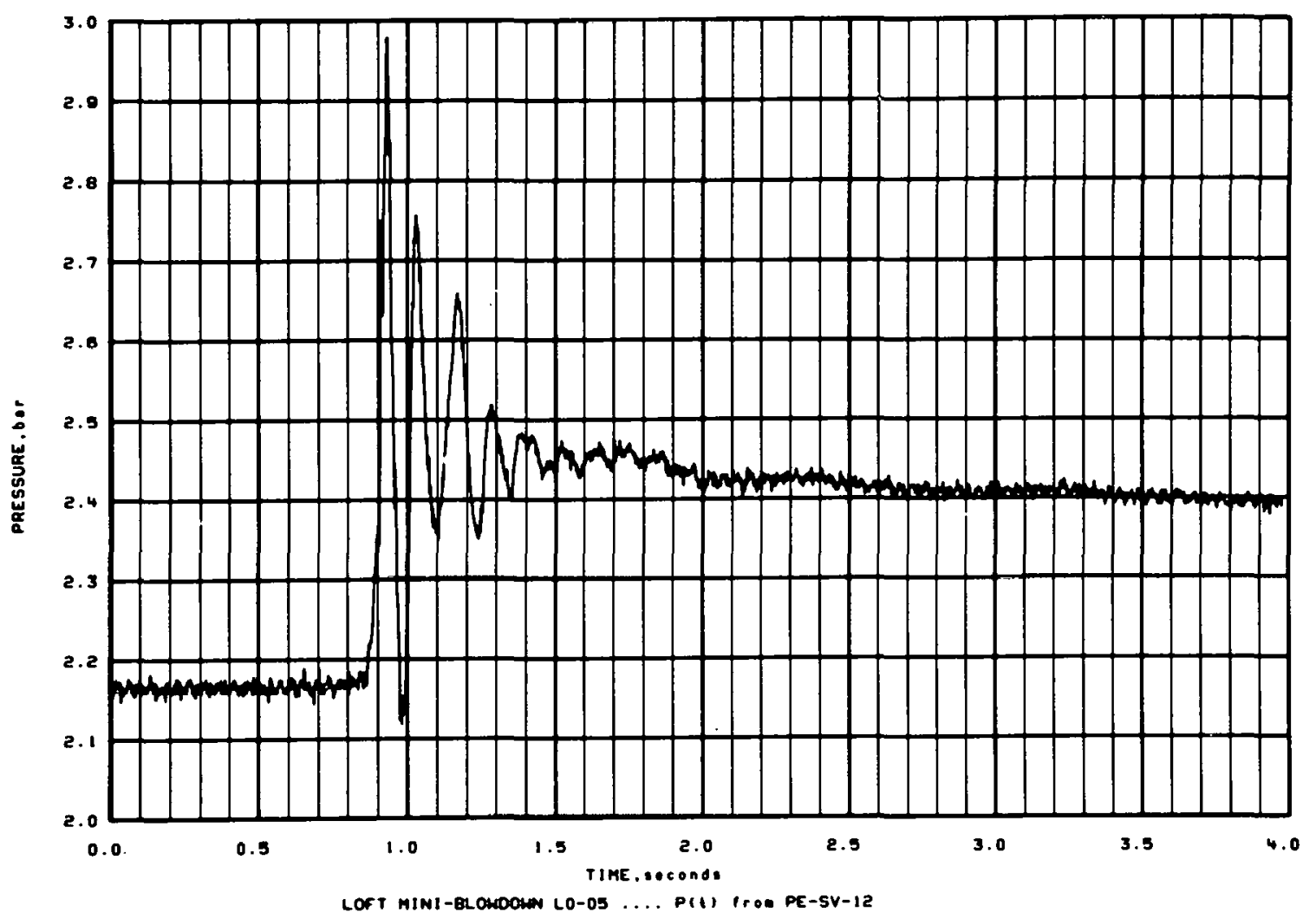

Figure G-15

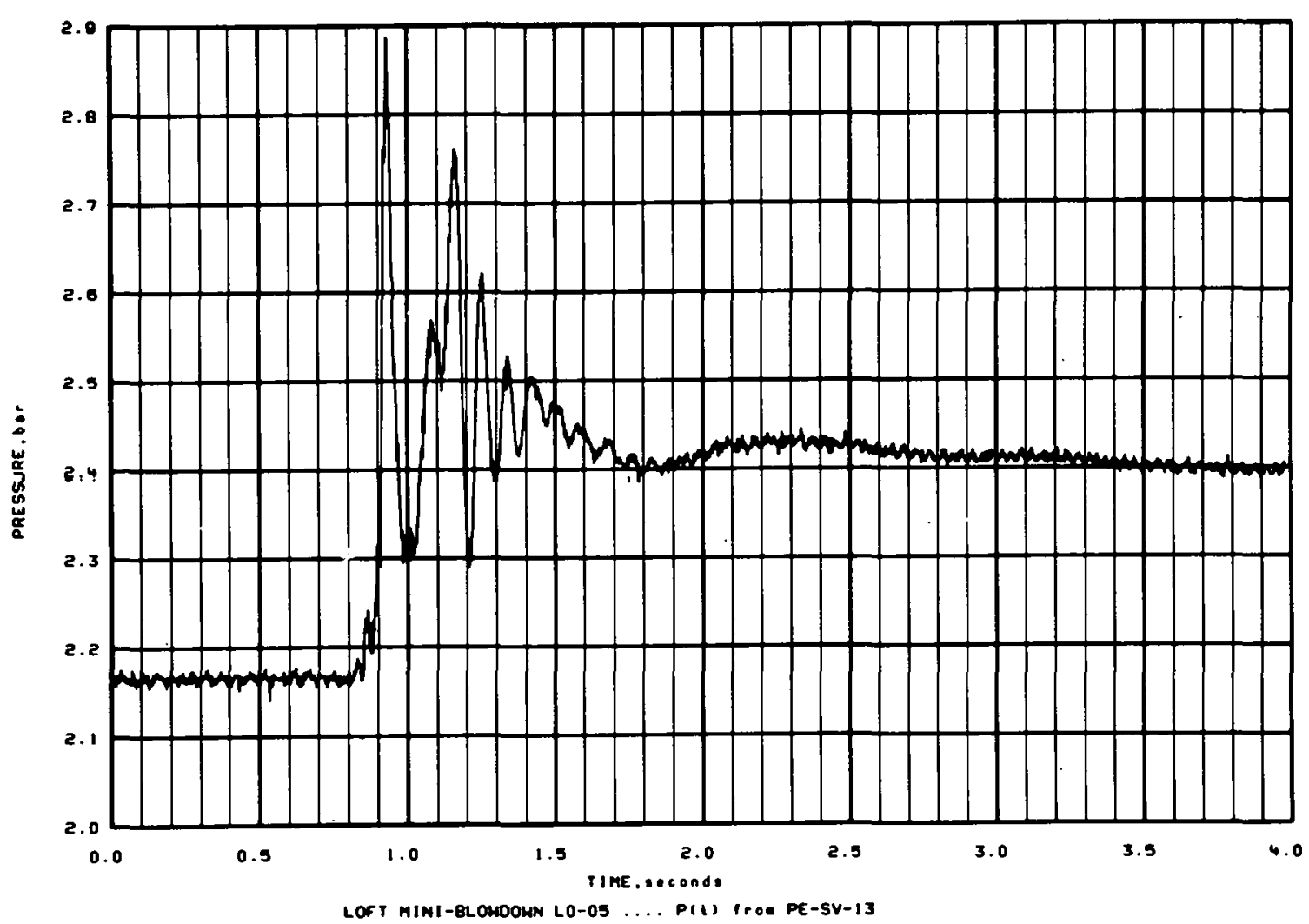

Figure G-16 

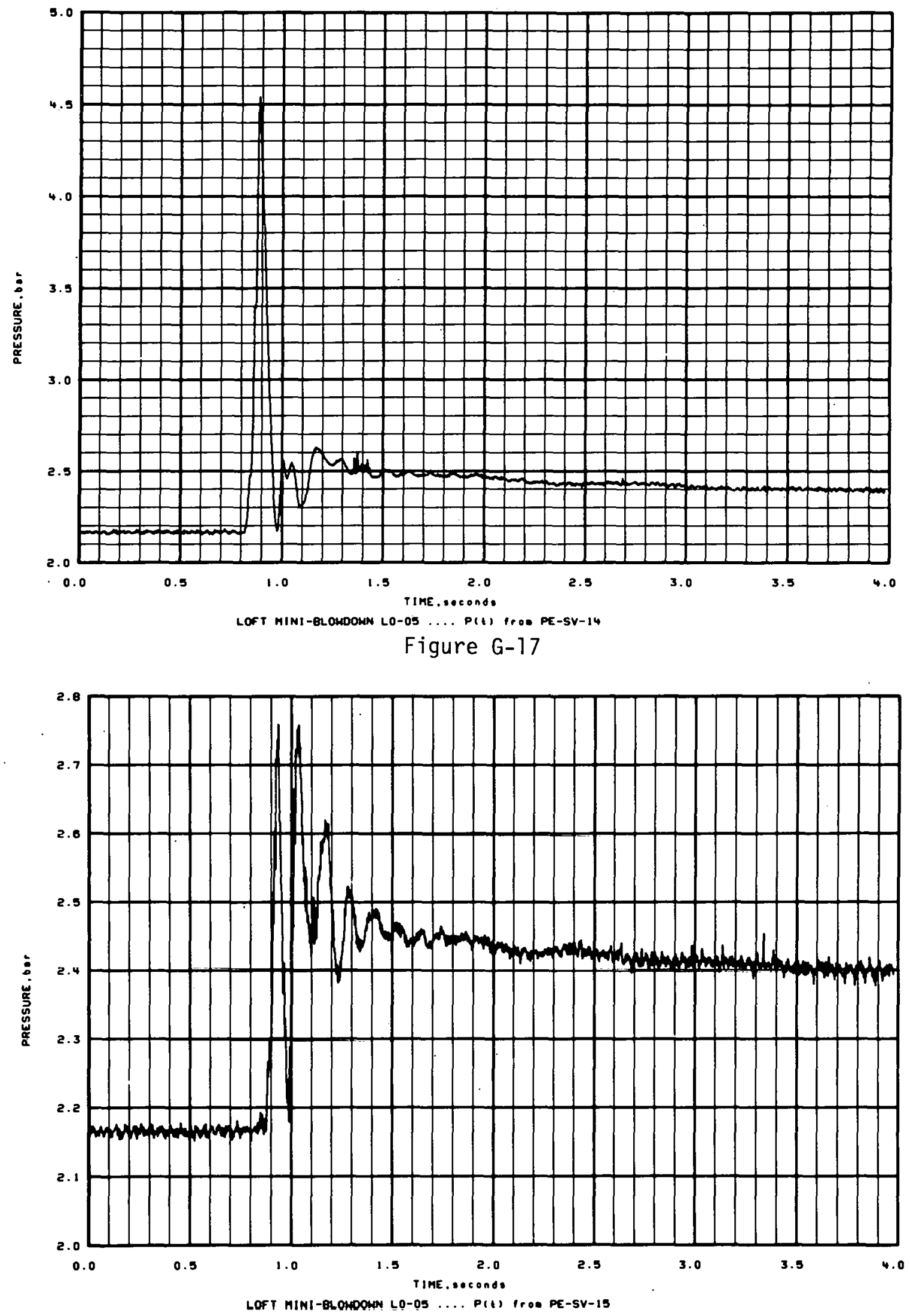

Figure G-18 


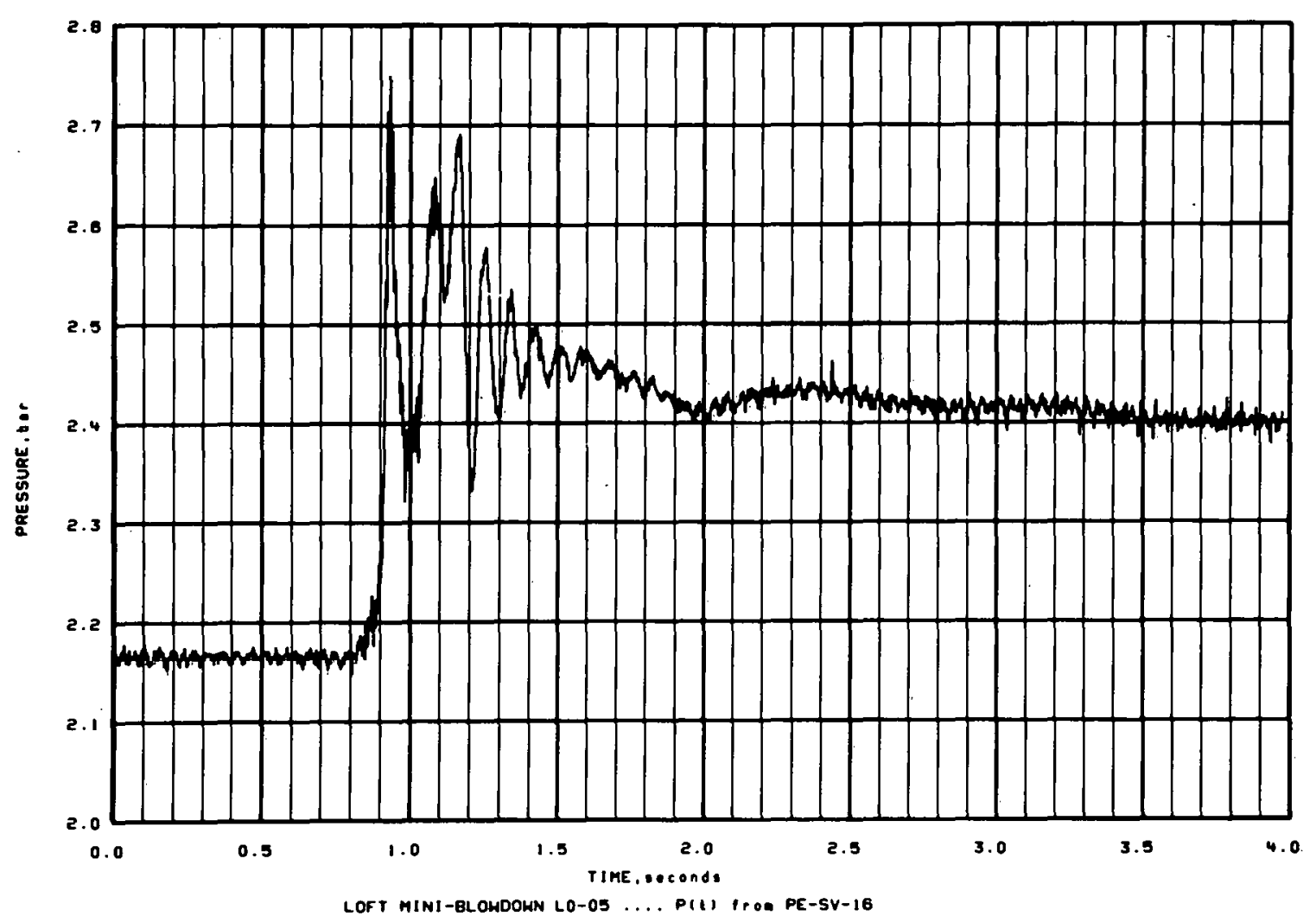

Figure G-19

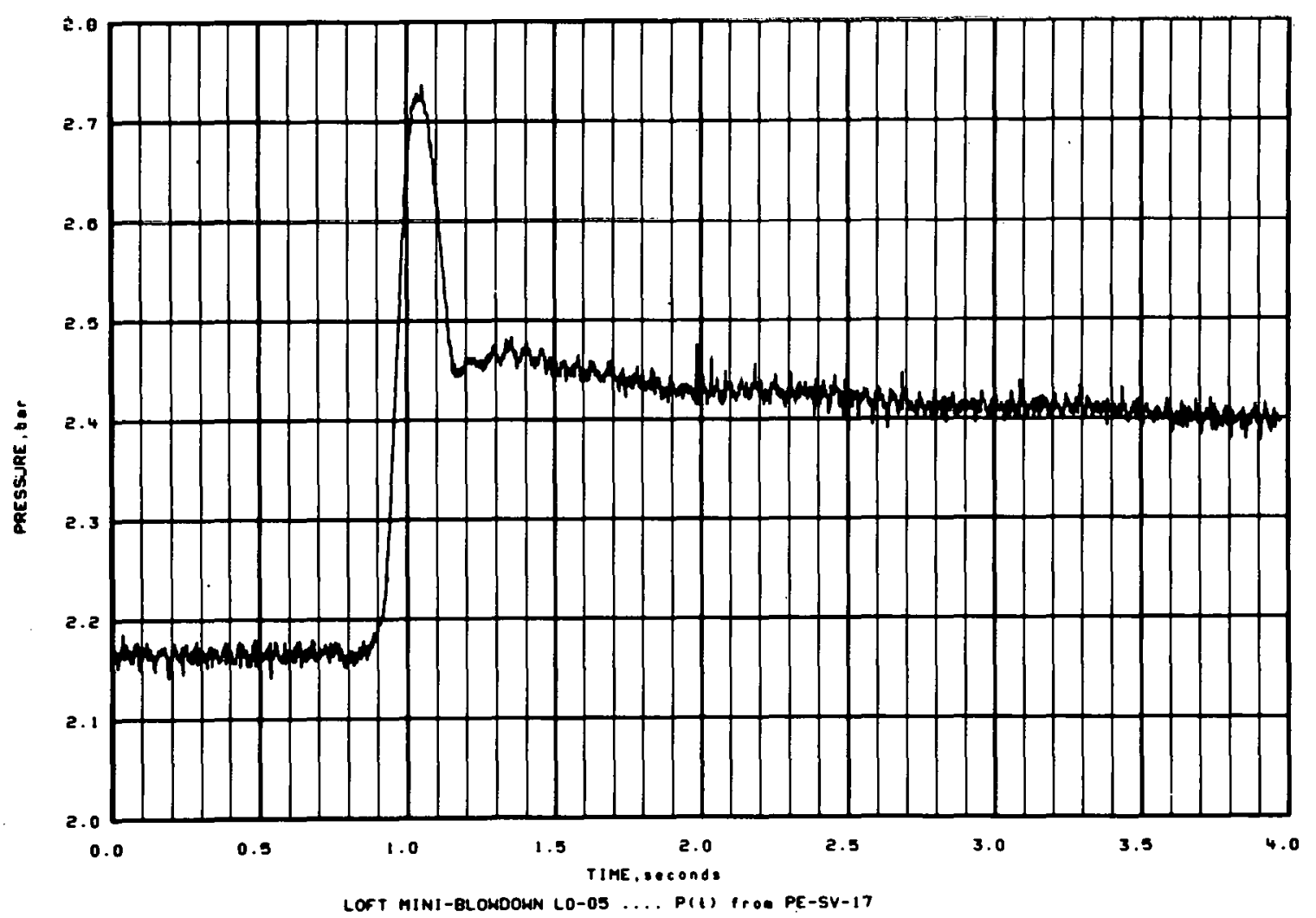

Figure G-20 


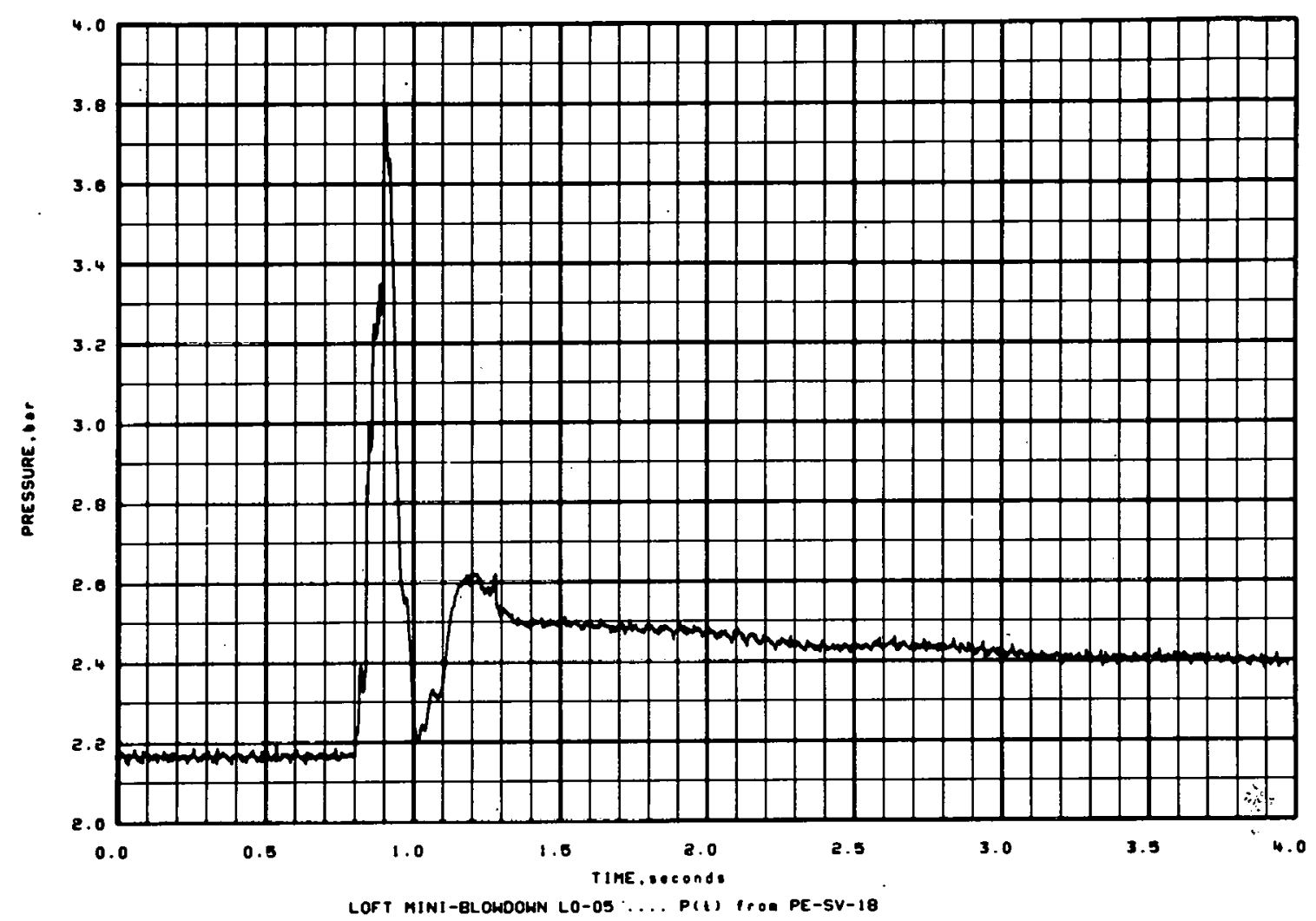

Figure G-21

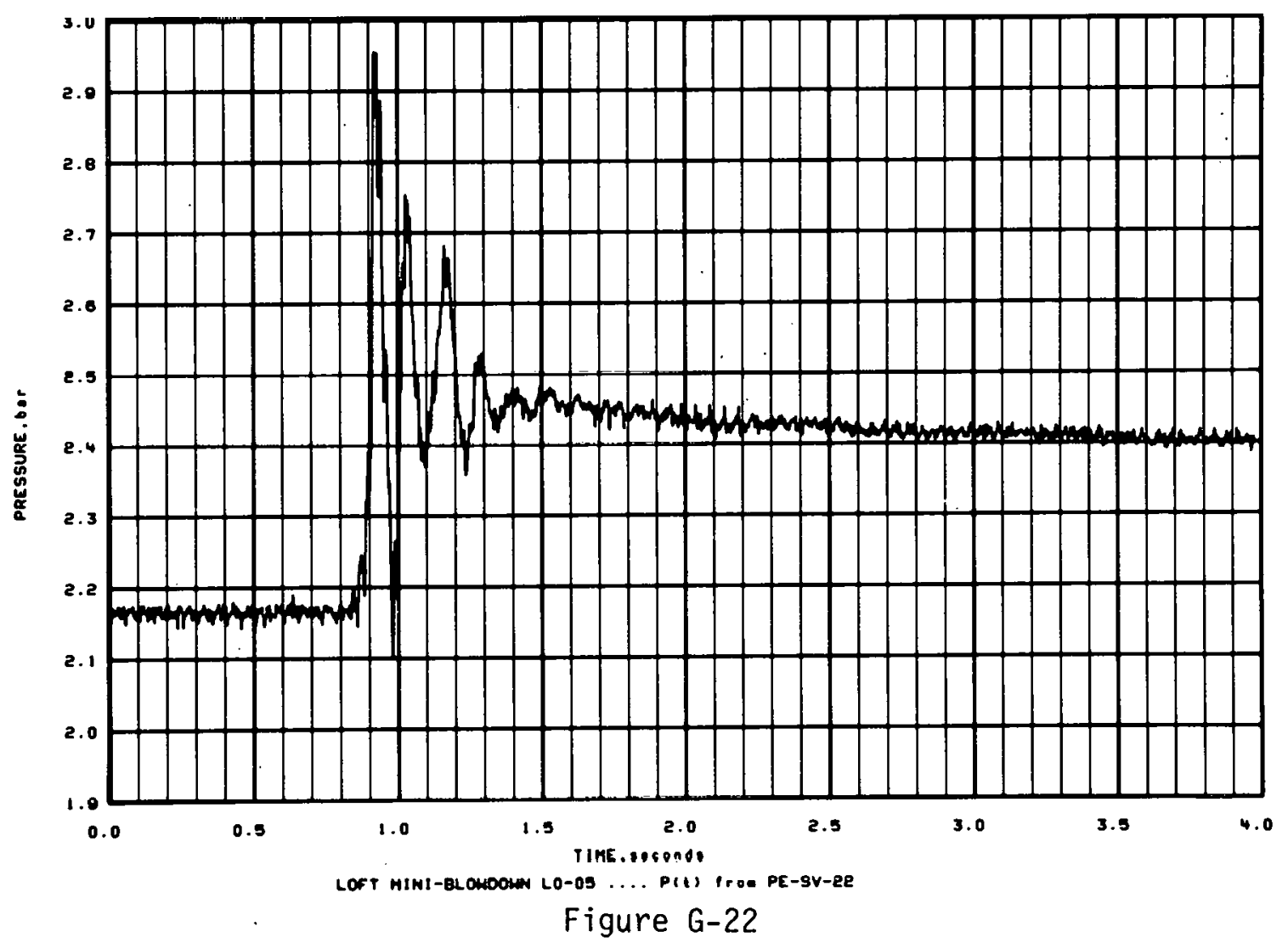




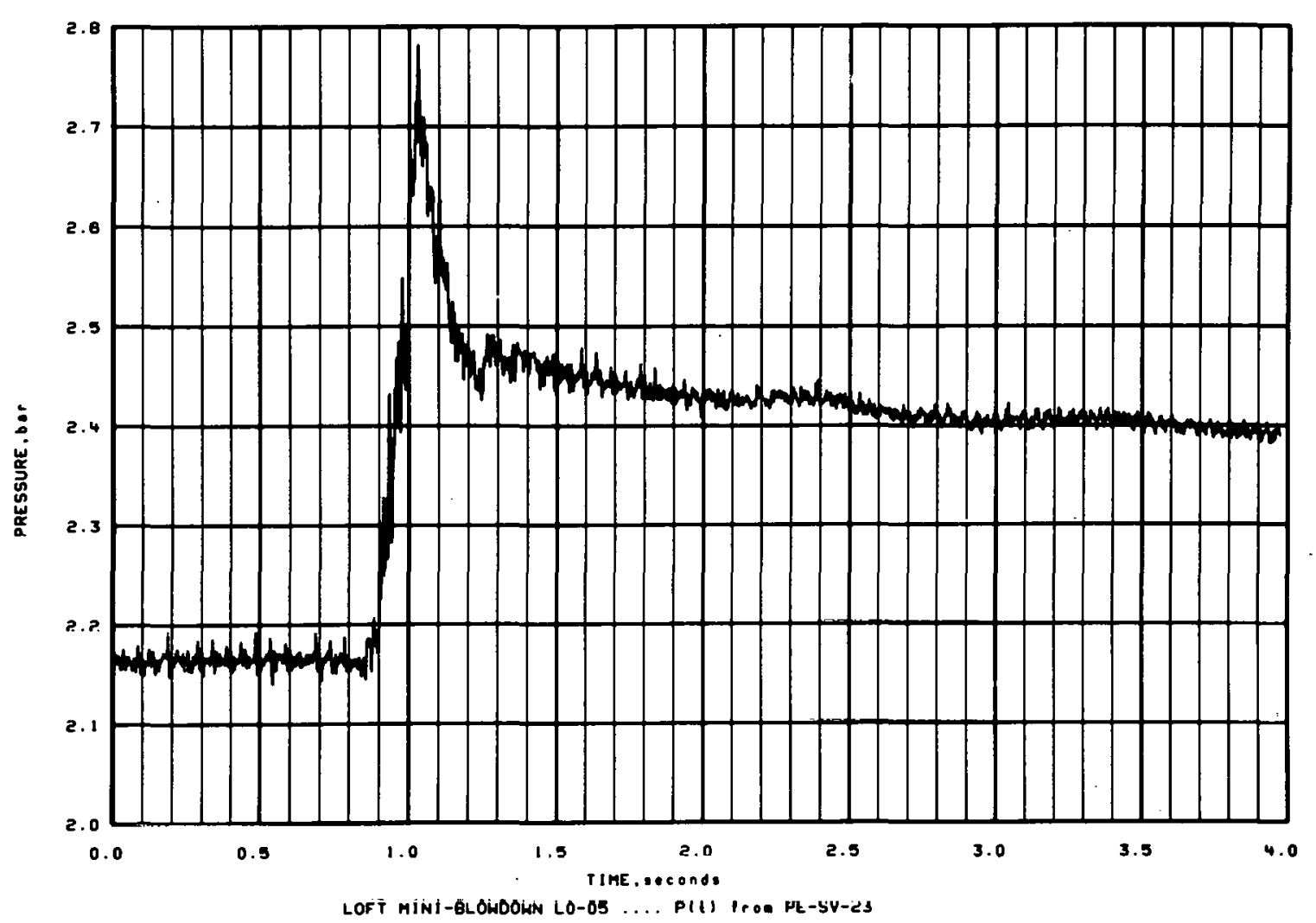

Figure G-23

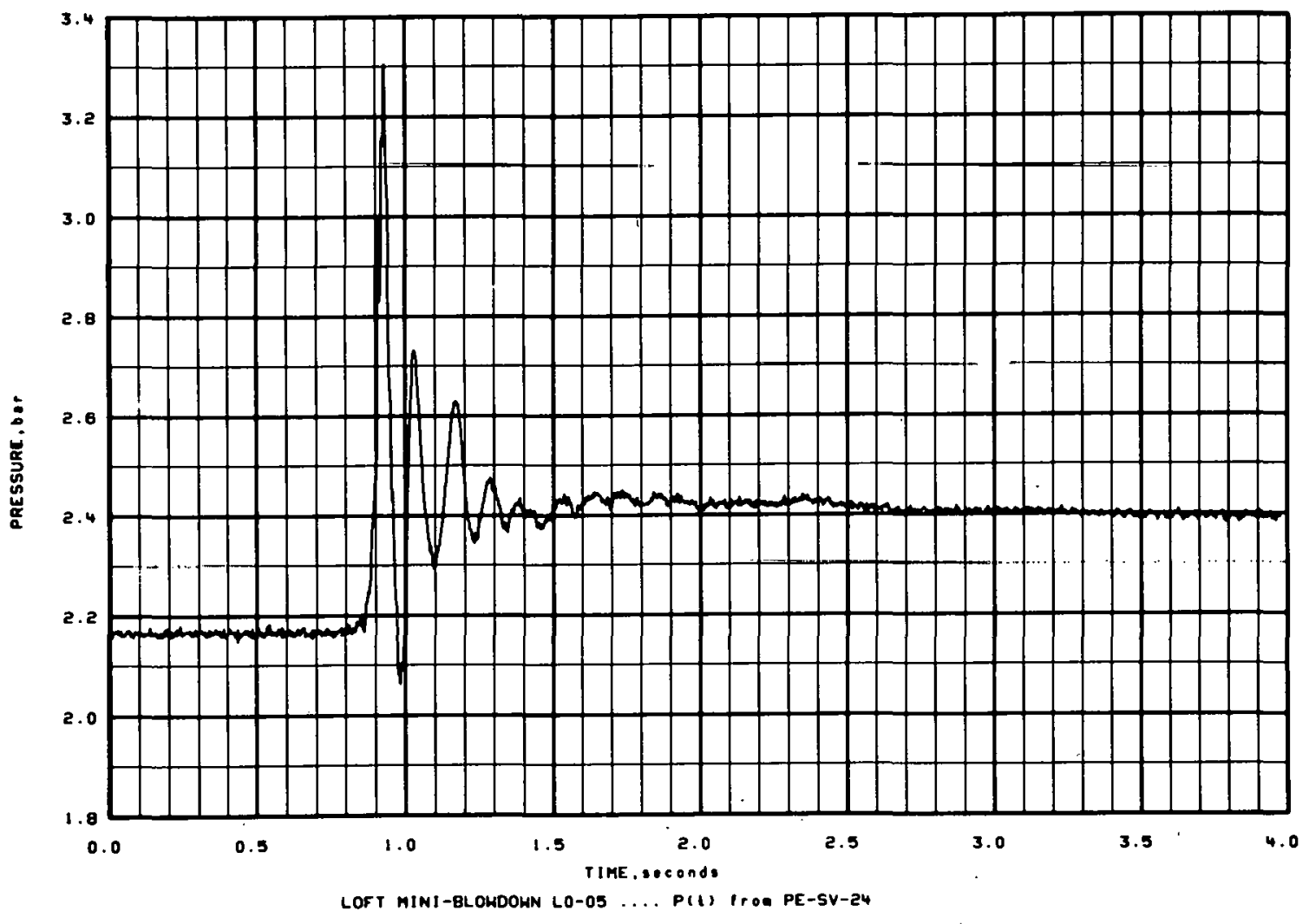

Figure G-24 


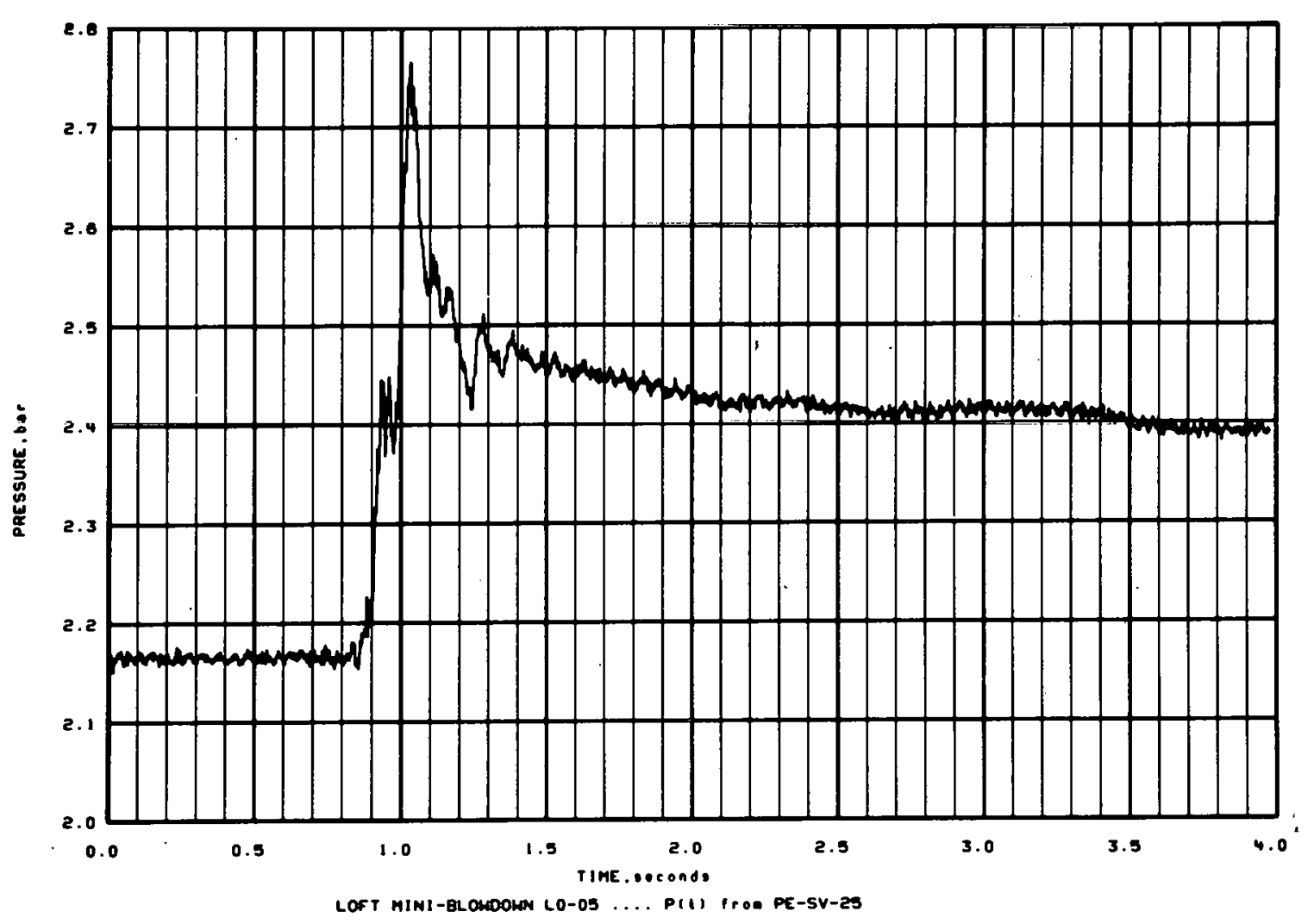

Figure G-25

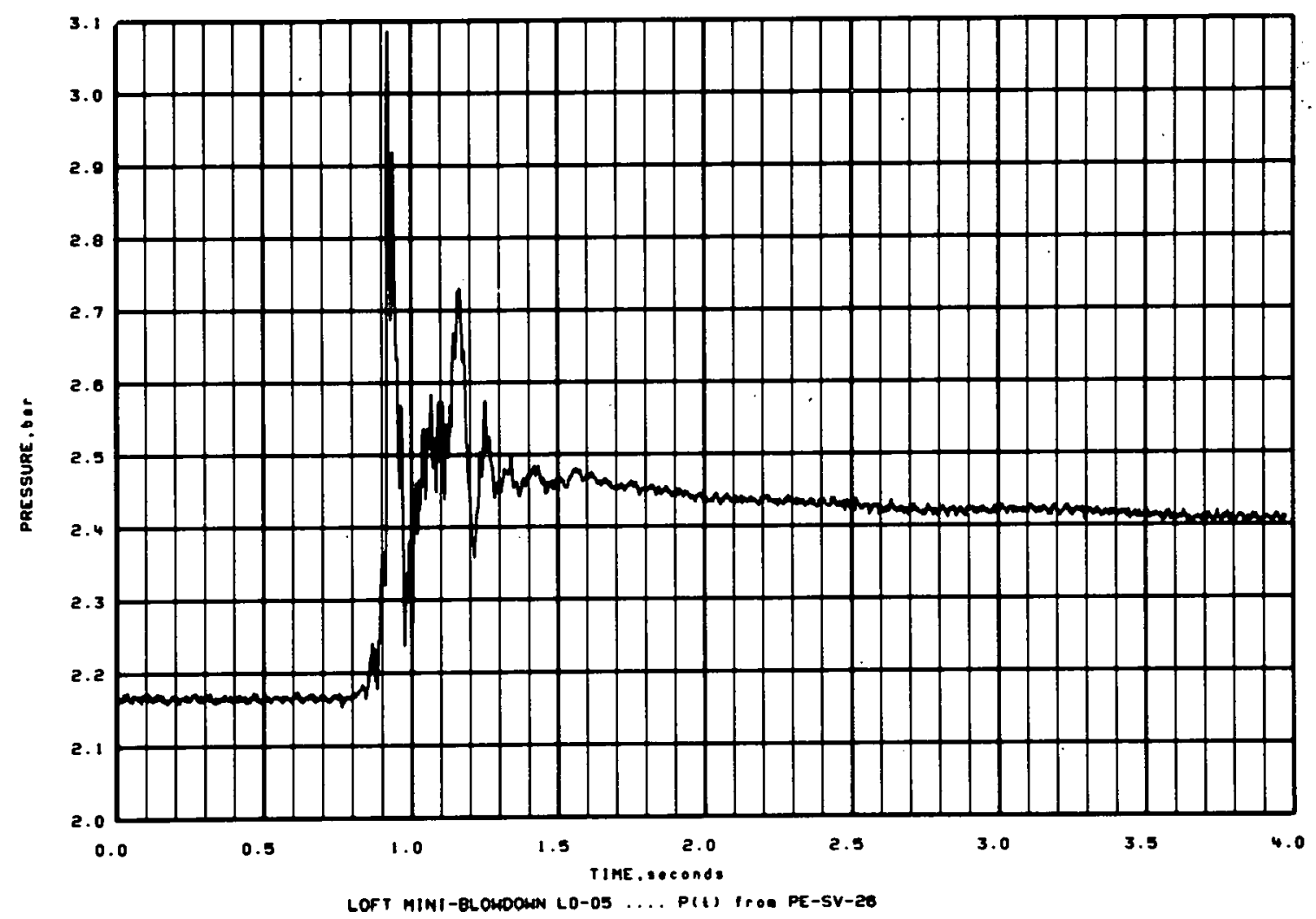

Figure G-26 


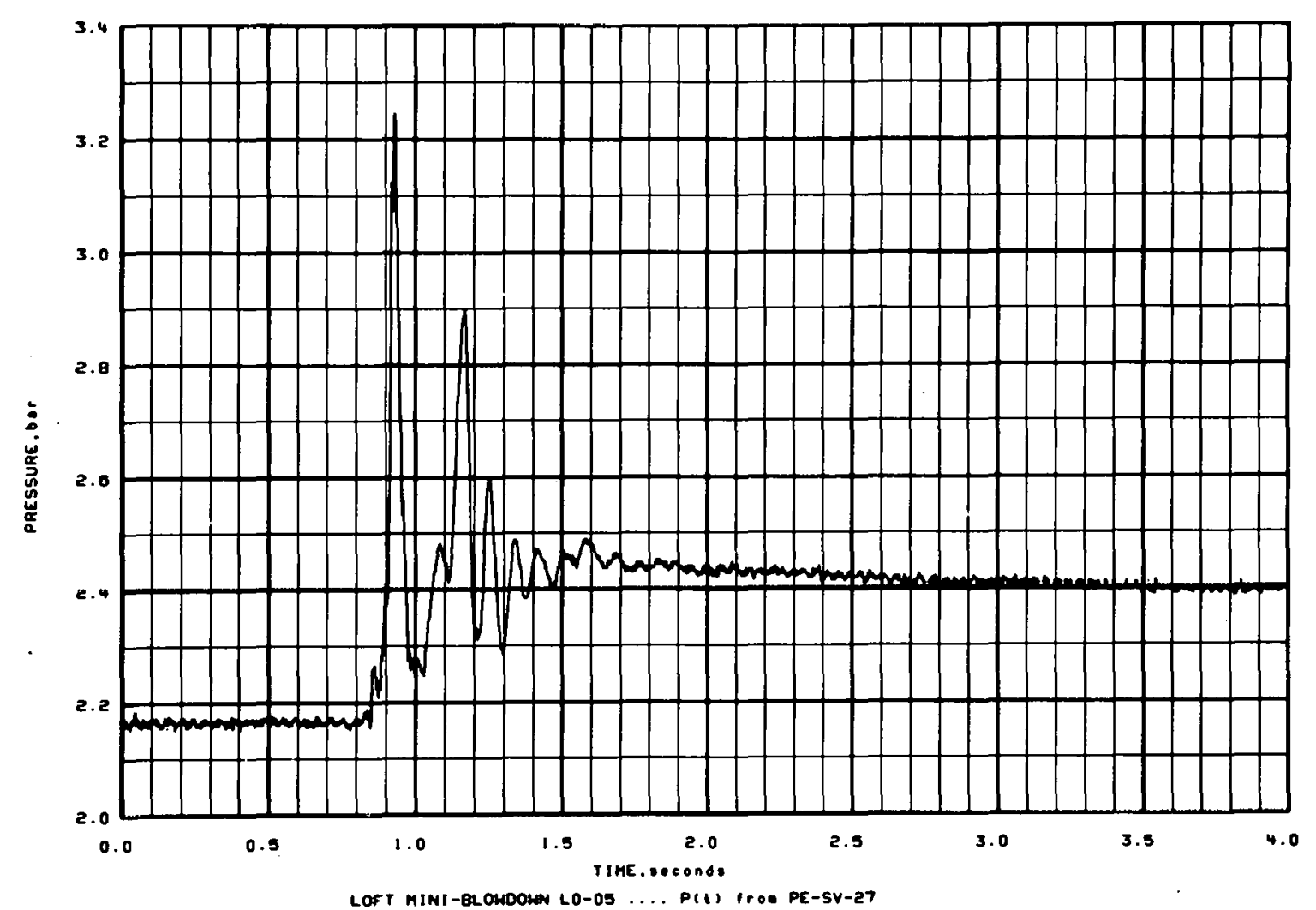

Figure G-27

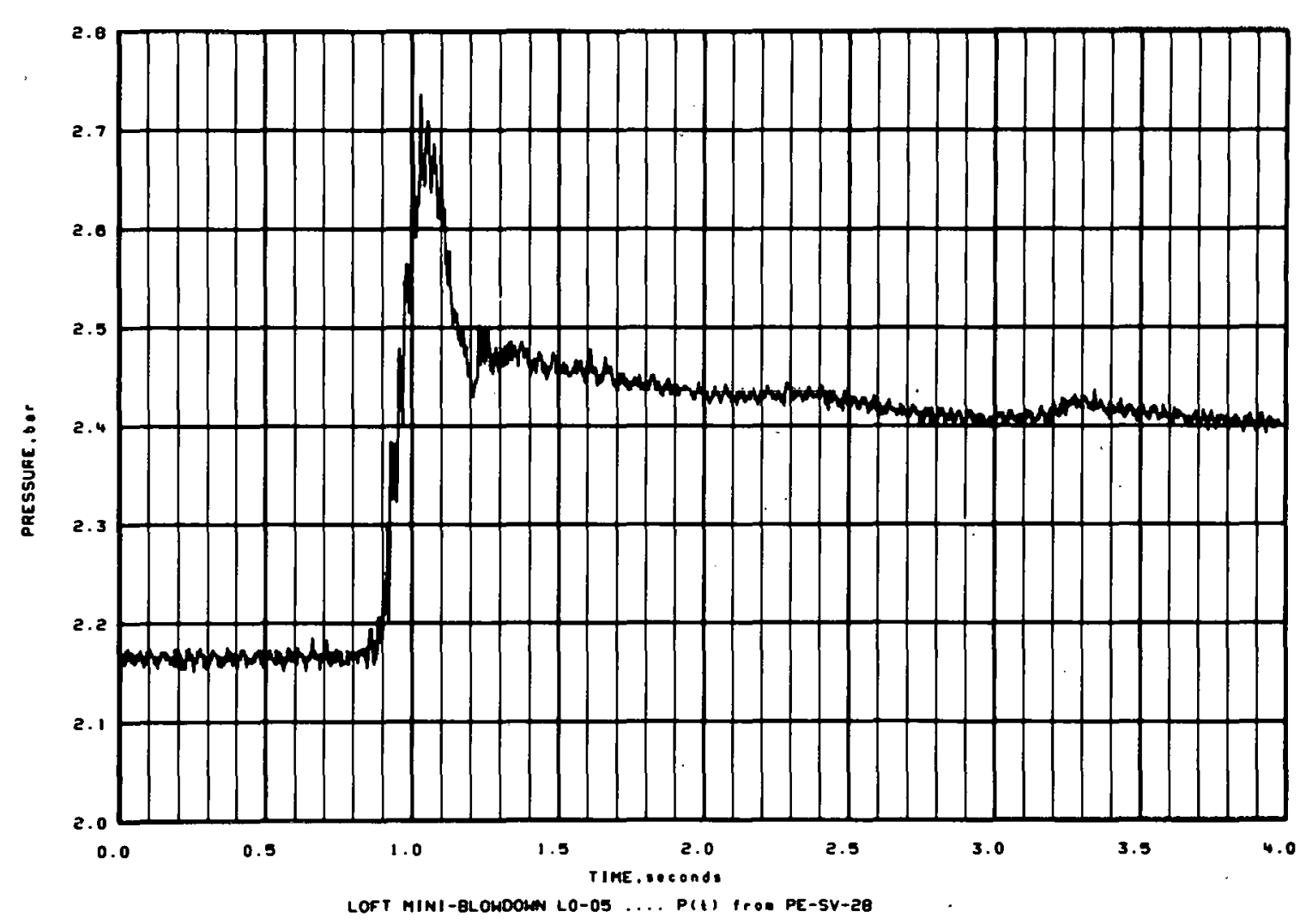

Figure G-28 

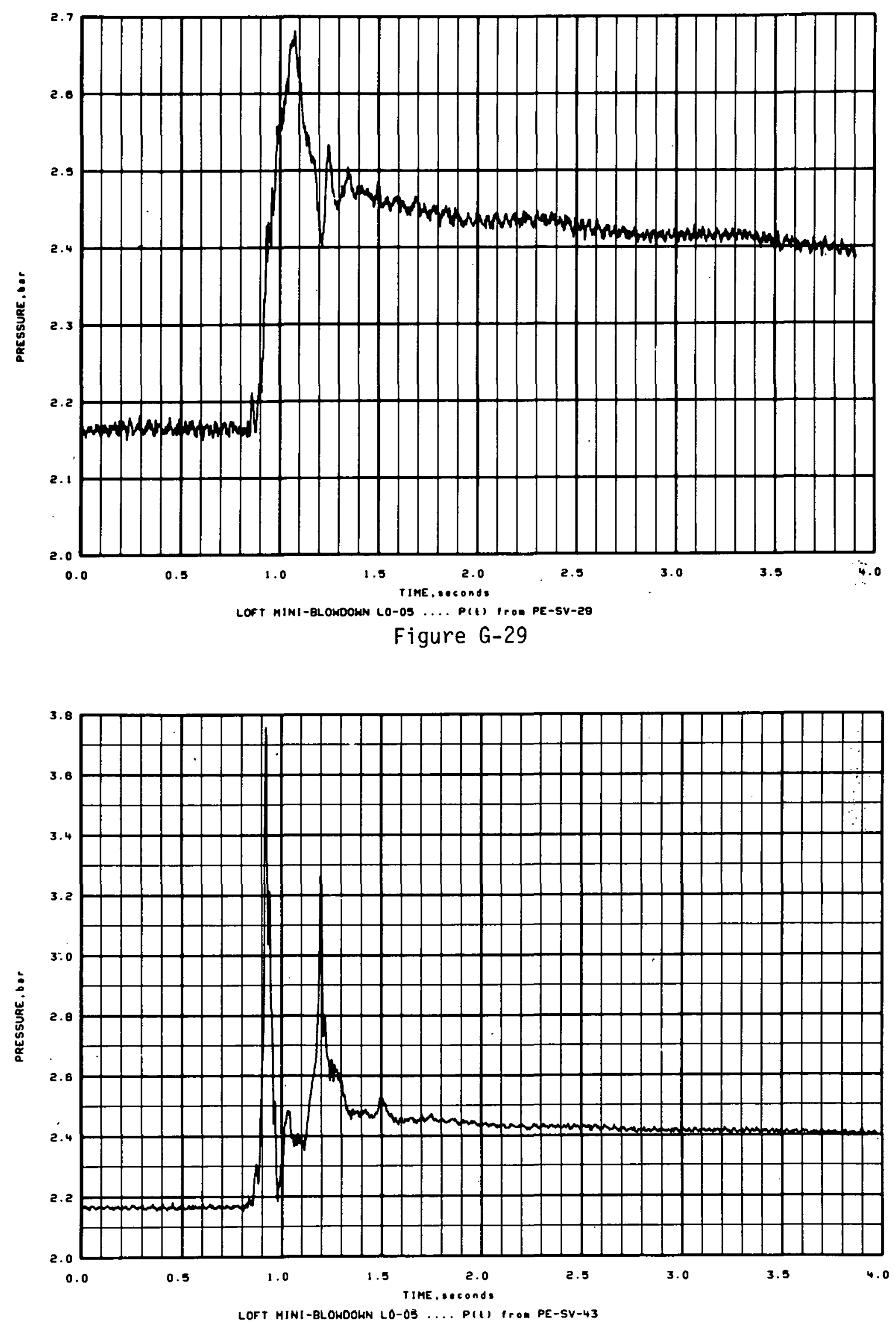

Figure G-30 

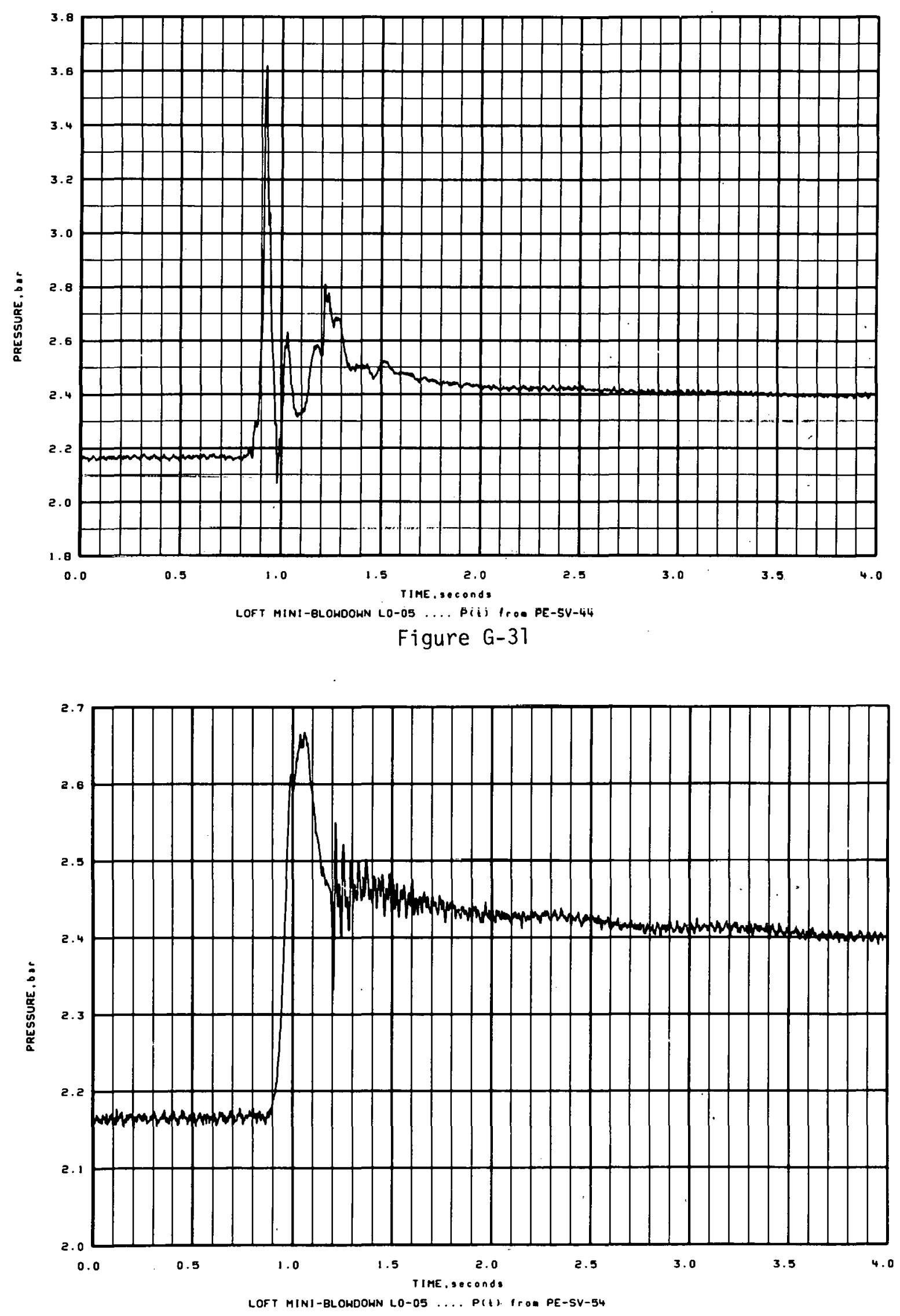

Figure G-32 


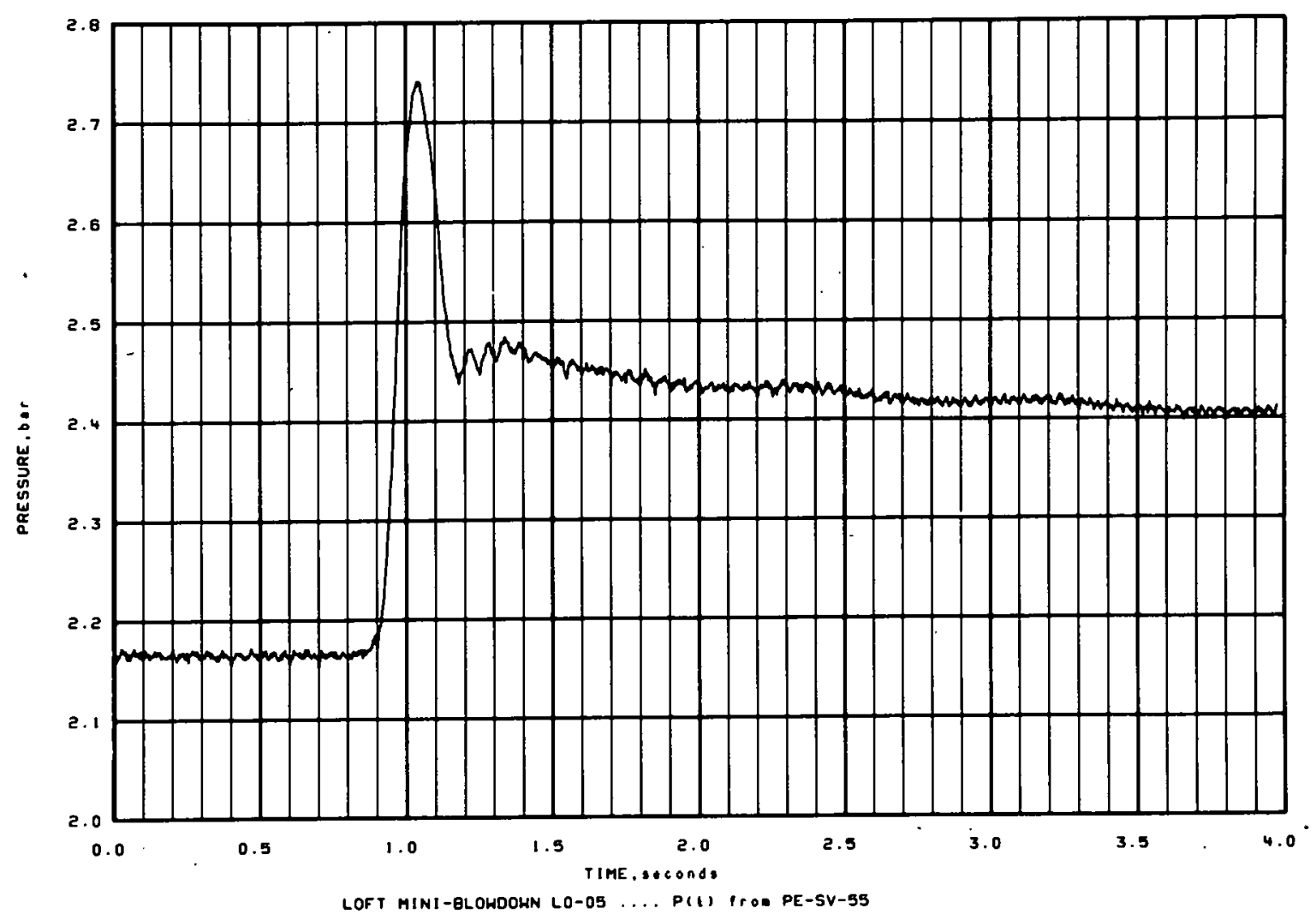

Figure G-33

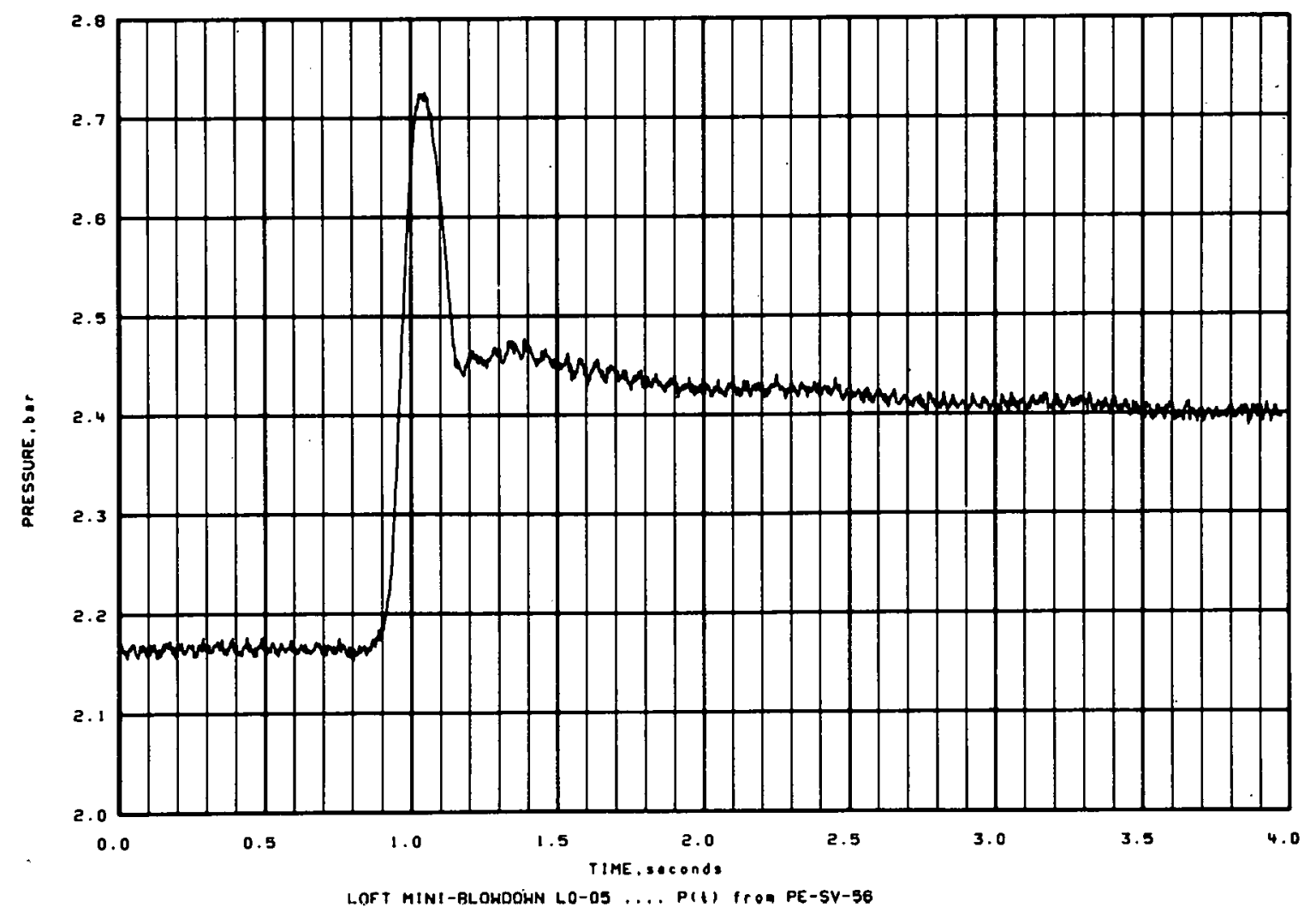

Figure G-34 


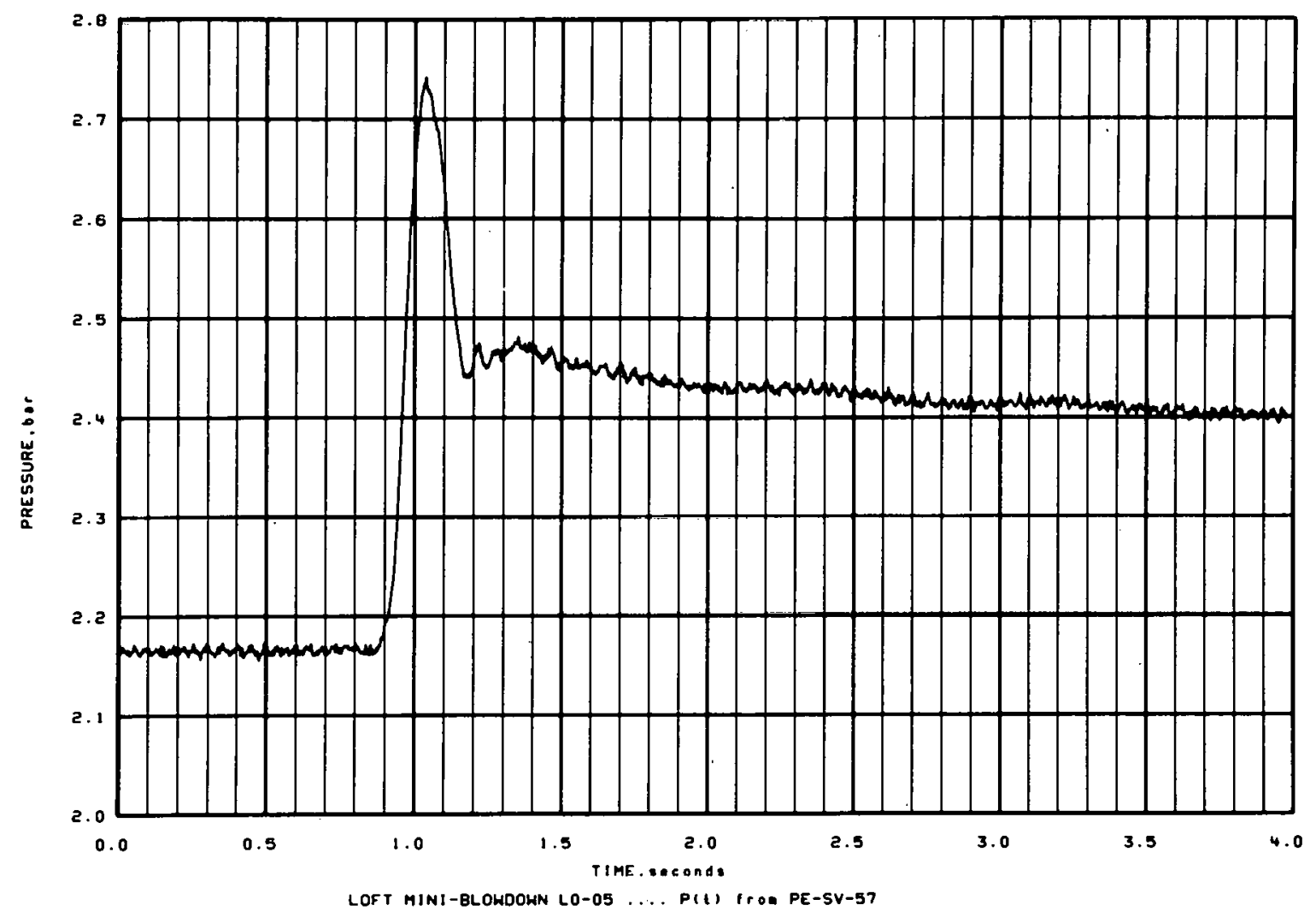

Figure G-35

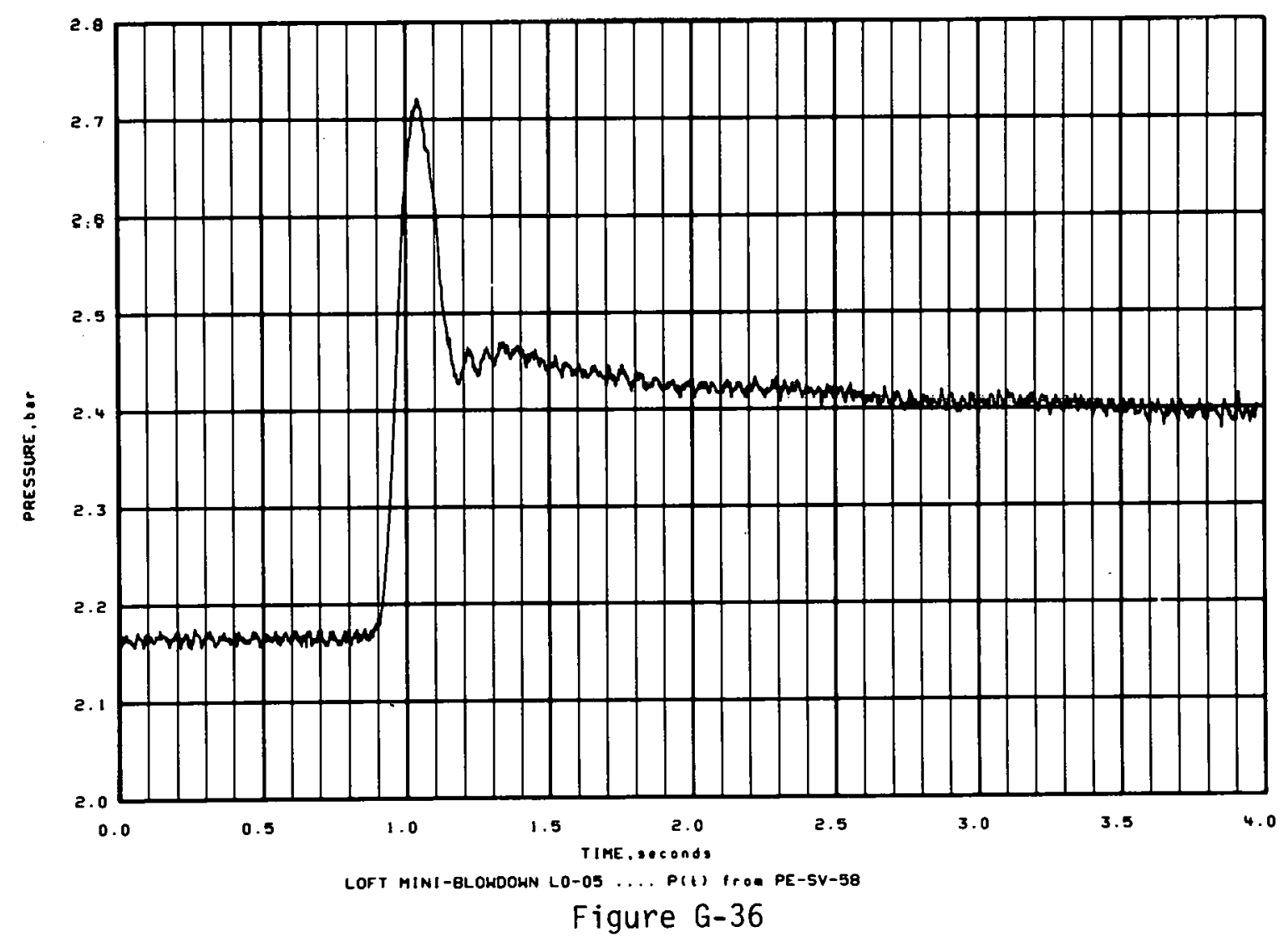




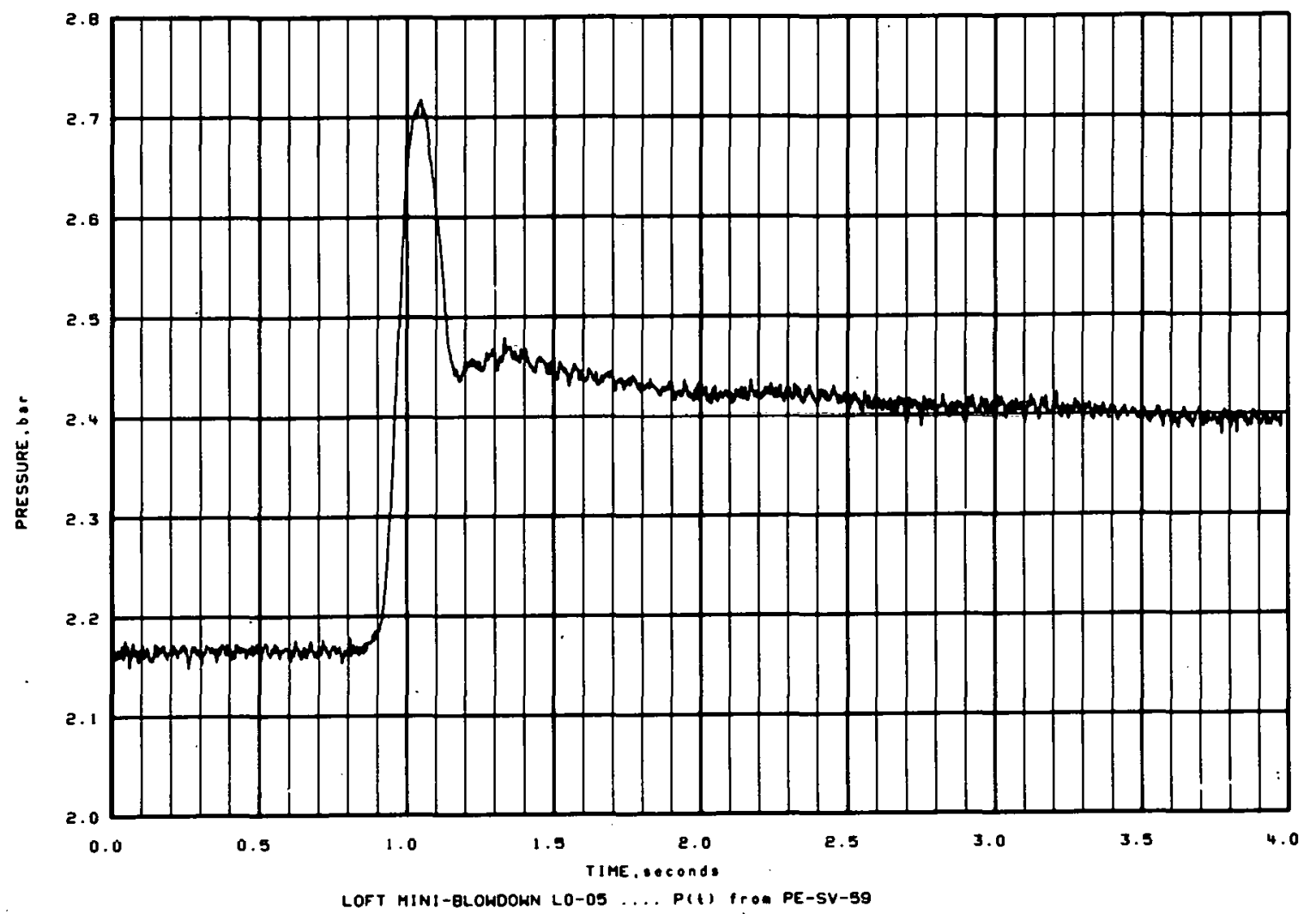

Figure G-37

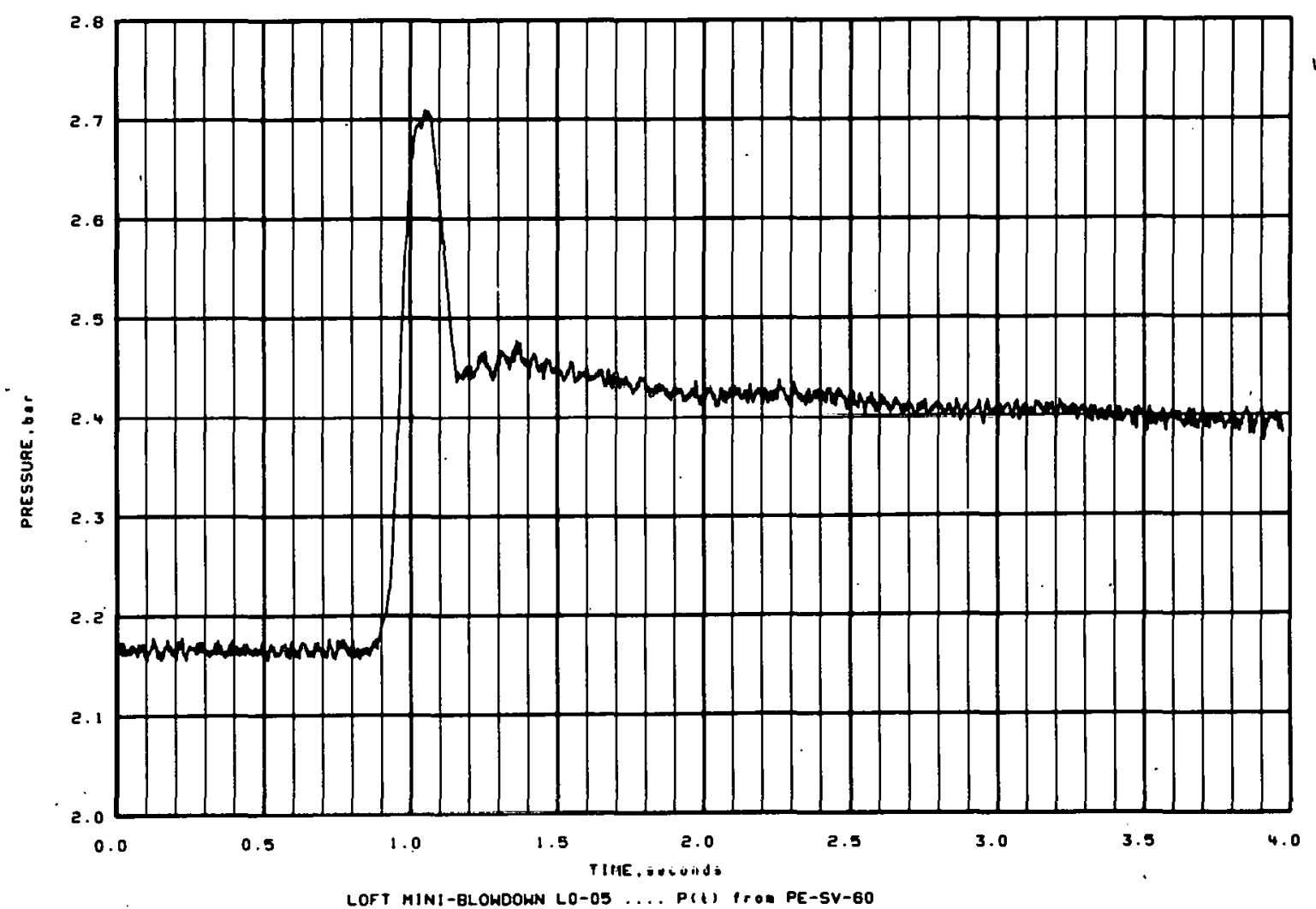

Figure G-38 


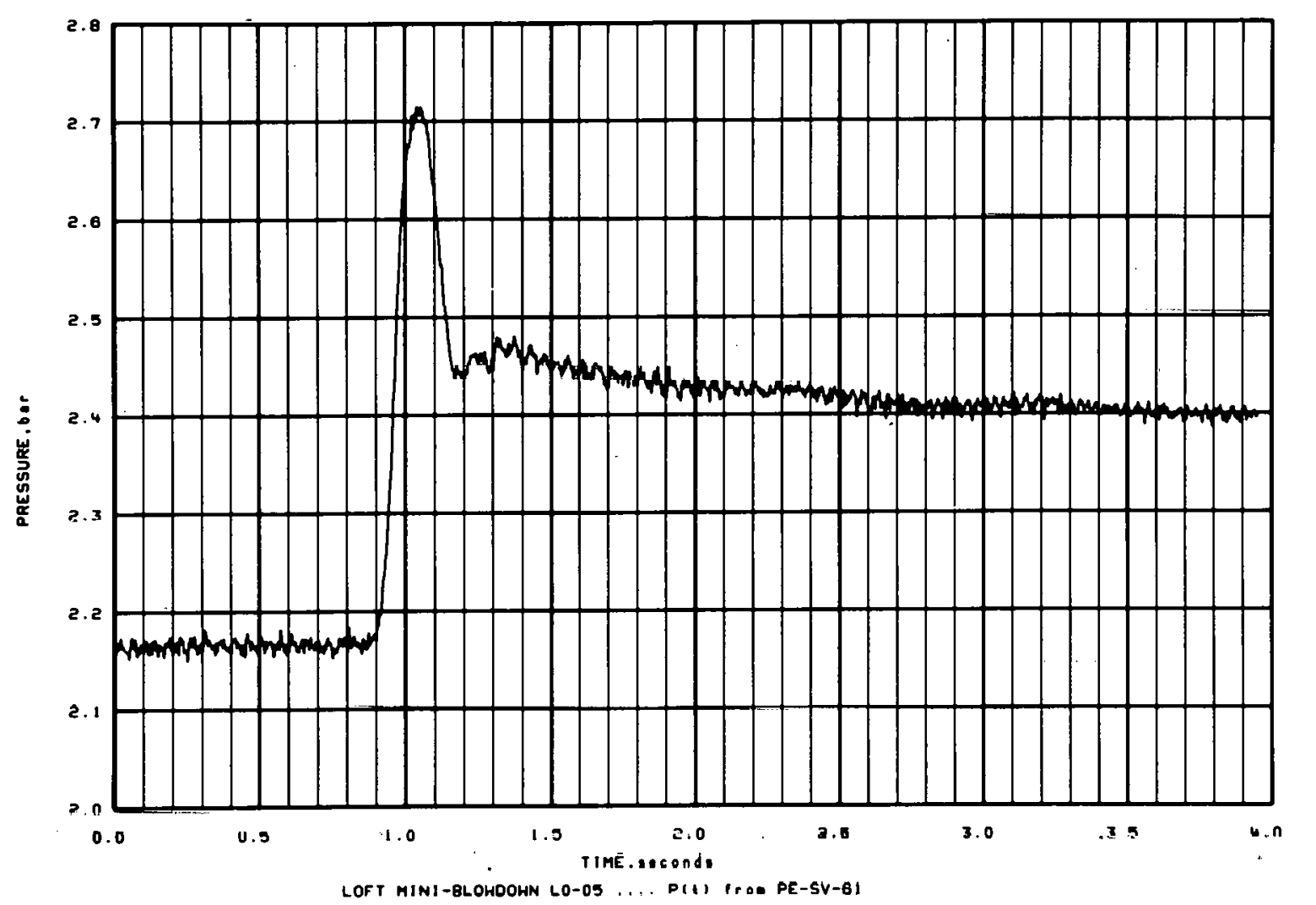

Figure G-39 


\section{APPENDIX H}

MINI-BLOWDOWN LO-08 EXPERIMENTAL DATA 
THIS PAGE

\section{WAS INTENTIONALLY LEFT BLANK}




\section{APPENDIX H}

MINI-BLOWDOWN LO-08 EXPERIMENTAL DATA

Only one QOBV was intended to be opened in this experiment. QOBV-1 fully opened. The fluid temperature in the valve was $232.5 \pm 1.5^{\circ} \mathrm{C}$. The suppression tank initial conditions were $2.34 \pm 0.08$ bar, $31.7 \pm 1.5^{\circ} \mathrm{C}$ in the gas volume, and $28.1 \pm 1.5^{\circ} \mathrm{C}$ in the pool. The vents were submerged $39.1 \pm 2.5 \mathrm{~cm}$. The internal vent submergence was $40.1 \pm 3.2 \mathrm{~cm}$.

The experimental data are defined in Table H-I. The opening characteristics of the QOBVs are shown in terms of percent sleeve travel versus time. The flow area of the valve begins to open at a sleeve position of $17 \%$ of full travel and is fully open to a sleeve position of $66 \%$ of full travel. The differential pressure between the header and the tank gas volume is measured with a very sensitive device primarily to provide information on vent preclearing. The data channel for this measurement is driven to saturation in the early part of the transient. 
TABLE H-I

EXPERIMENT L0-08 DATA SUMMARY

\begin{tabular}{|c|c|c|c|c|c|}
\hline $\begin{array}{c}\text { Measurement } \\
\text { or } \\
\text { Calculation }\end{array}$ & $\begin{array}{c}\text { Pre-Transient } \\
\text { Data Channel } \\
\text { Variance } \\
\left(10^{-4} \text { bar }^{2}\right) \\
\end{array}$ & Figure Number & Measurement & $\begin{array}{c}\text { Pre-Transient } \\
\text { Data Channel } \\
\text { Varjance } \\
\left(10^{-4} \text { bar }^{2}\right) \\
\end{array}$ & Figure Number \\
\hline gOBV-T upening & $=$ & $H-1, H-2$ & PE-SV-22 & 0.31386 & H- 18 \\
\hline Vertical load & - & $\mathrm{H}-3$ & $P E-S V=23$ & 0.23767 & $H-19$ \\
\hline PDE-SV-09 & - & $H-4$ & PE-SV-24 & 0.15026 & $\mathrm{H}-20$ \\
\hline PE-SV-01 & 0.33072 & $H-5$ & PE-SV-25 & 0.15507 & H..21 \\
\hline PE-SV-02 & 0.25070 & $H-6$ & PE-SV-26 & 0.10897 & $H-22$ \\
\hline PE-SV-03 & 0.35919 & $\mathrm{H}-7$ & PE-SV-27 & 0.23381 & $\mathrm{H}-23$ \\
\hline PE-SV-04 & 0.38100 & $H-8$ & PE-SV-28 & 0.19473 & $\mathrm{H}-24$ \\
\hline PE-SV-10 & 0.31511 & $H-9$ & PE-SV-29 & 0.22225 & $H-25$ \\
\hline$P E-S V=11$ & 1.0062 & $H-10$ & $P E-S V-43$ & 0.10626 & $\mathrm{H}-26$ \\
\hline PE-SV-12 & 0.30467 & $\mathrm{H}-11$ & PE-SV-44 & 0.13161 & $\mathrm{H}-27$ \\
\hline PE-SV-13 & 0.19741 & $\mathrm{H}-12$ & PE-SV-54 & 0.10617 & $H=28$ \\
\hline PE-SV-14 & 0.26596 & $H-13$ & $P E-S V-55$ & 0.05865 & $H-29$ \\
\hline PE-SV-15 & 0.25261 & $H-14$ & $P E=S V-56$ & 0.13895 & $H-30$ \\
\hline PE-SV-16 & 0.22827 & $\mathrm{H}-15$ & PE-SV-57 & 0.07749 & $\mathrm{H}-31$ \\
\hline PE-SV-17 & 0.26314 & $\mathrm{H}-16$ & PE-SV-58 & 0.16622 & $\mathrm{H}-32$ \\
\hline \multirow[t]{3}{*}{$\mu \mathrm{E}-\mathrm{SV}-18$} & 0.25399 & $\mathrm{H}-11$ & $P[-S V-59$ & 0.10445 & $\mathrm{H}-33$ \\
\hline & & & $P E-S V-60$ & 0.16377 & $\mathrm{H}-34$ \\
\hline & & & PE-SV-6I & 0.11440 & $\mathrm{H}-35$ \\
\hline
\end{tabular}



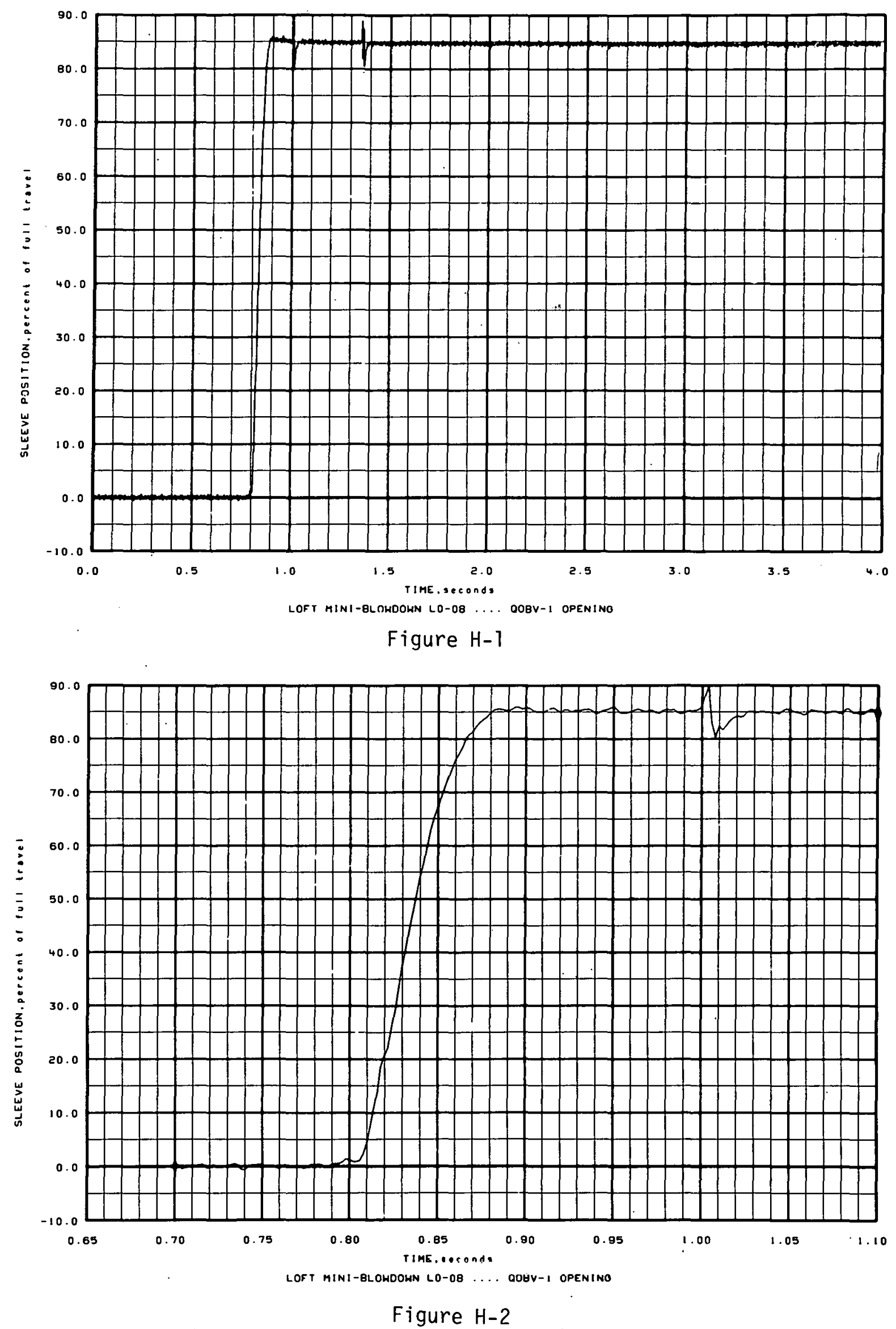

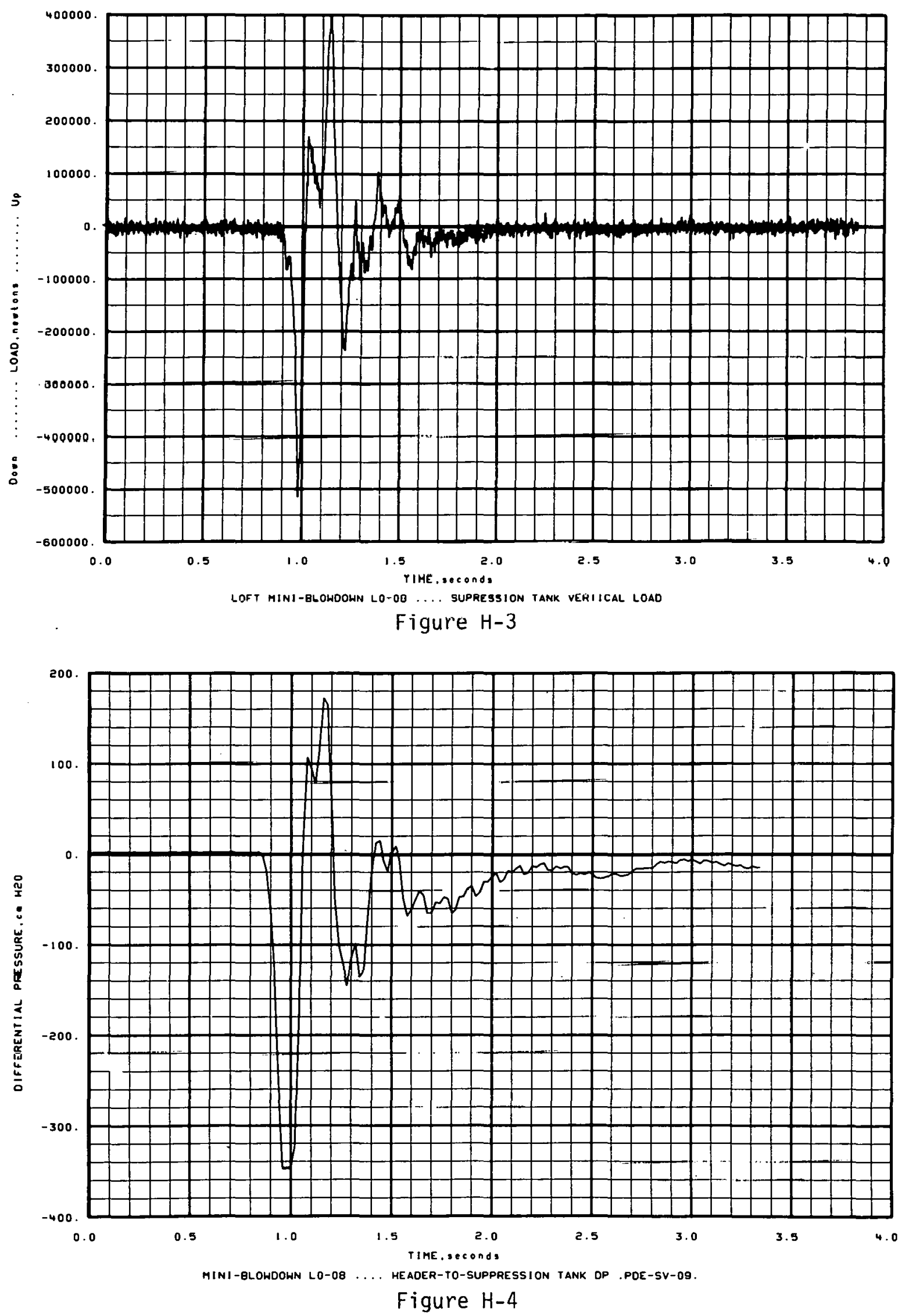


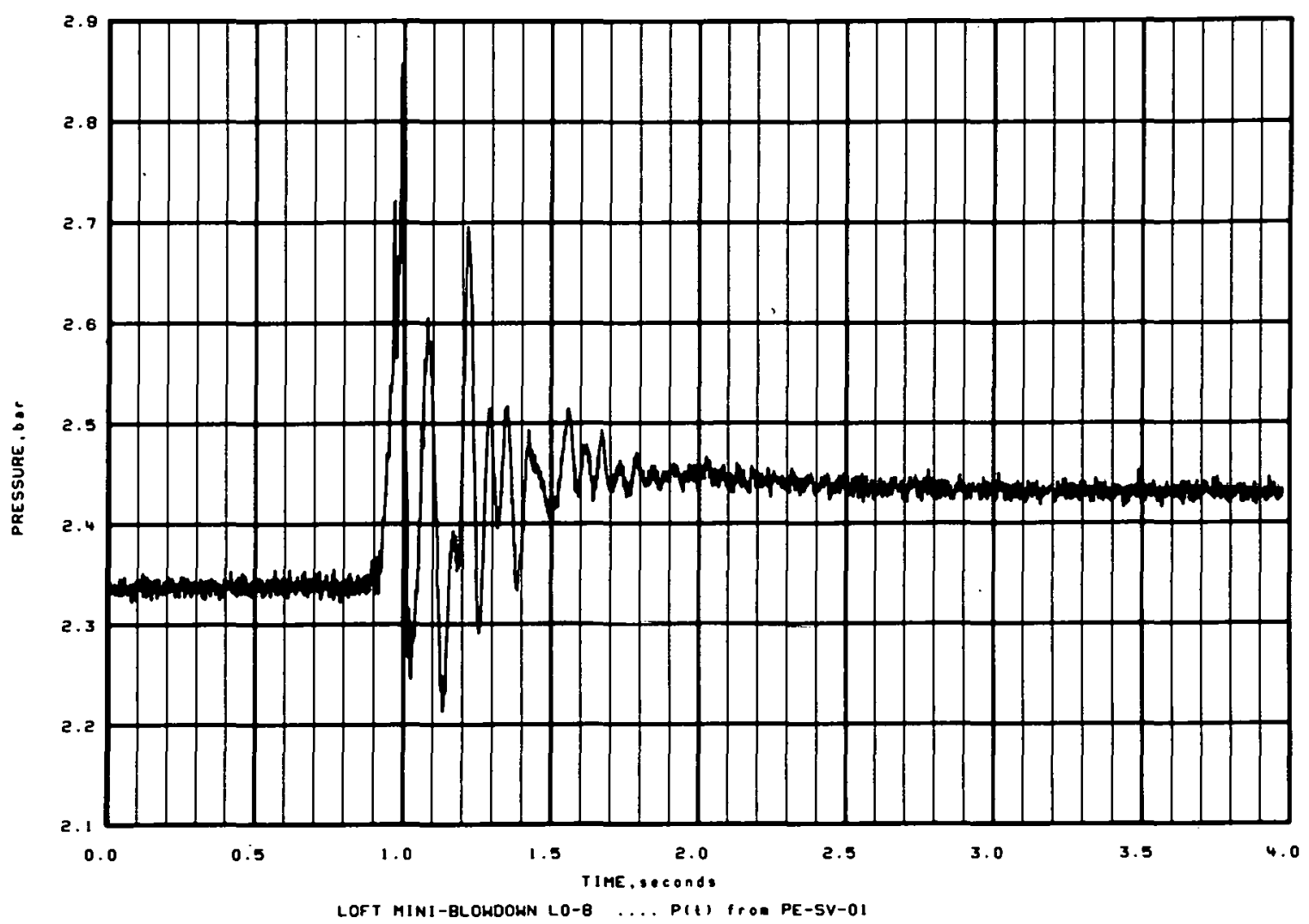

Figure $\mathrm{H}-5$

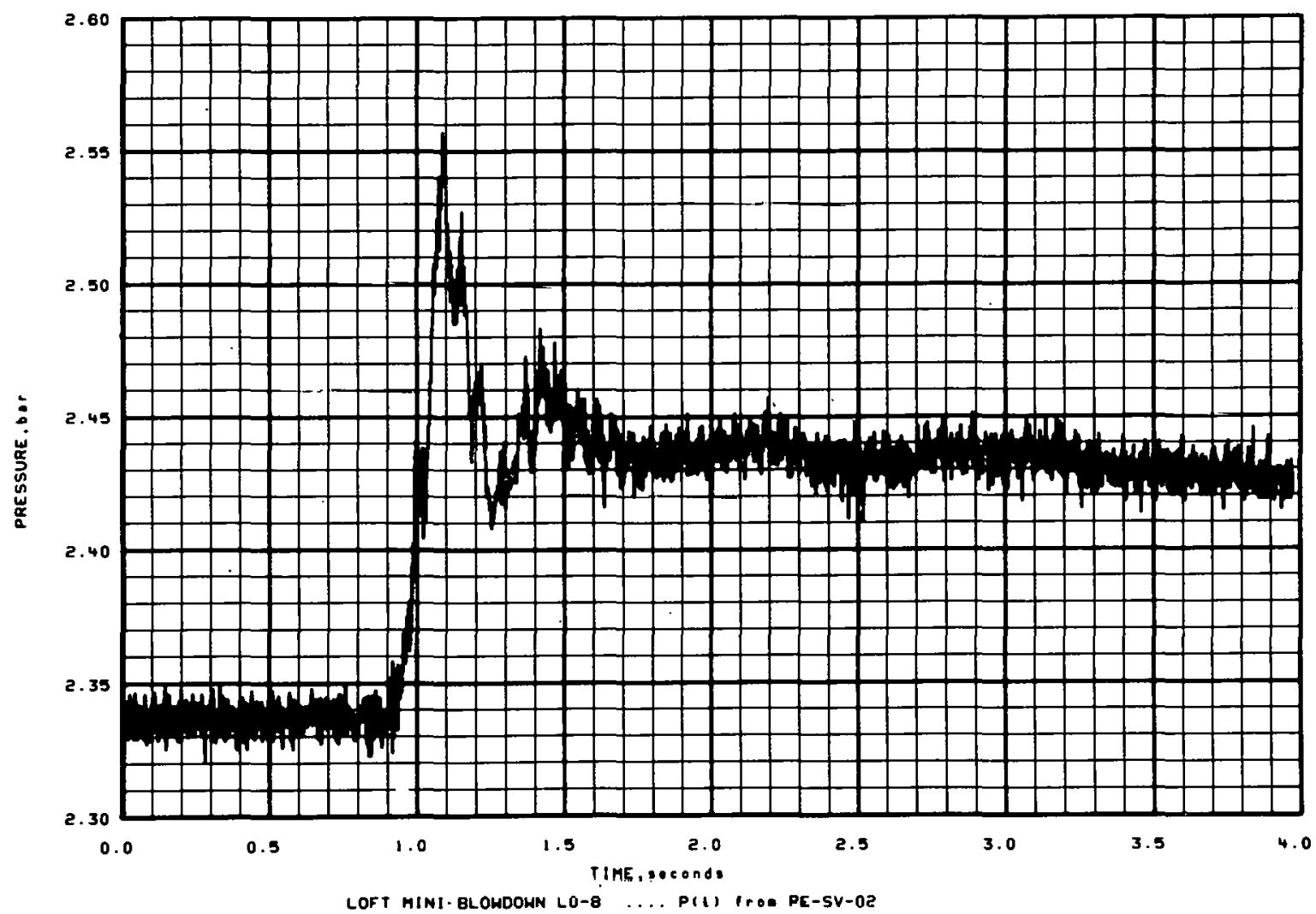

Figure $H-6$ 


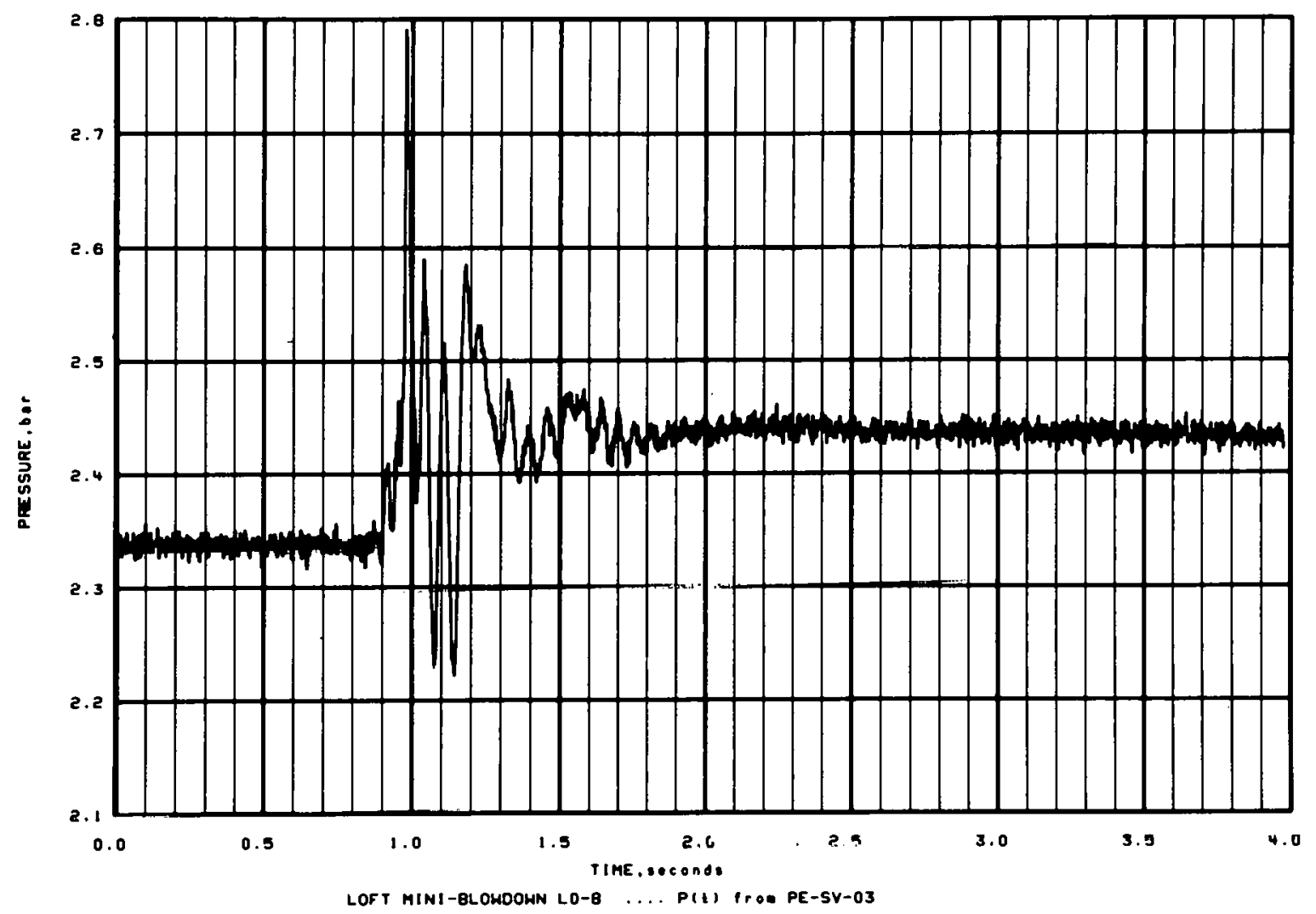

Figure $\mathrm{H}-7$

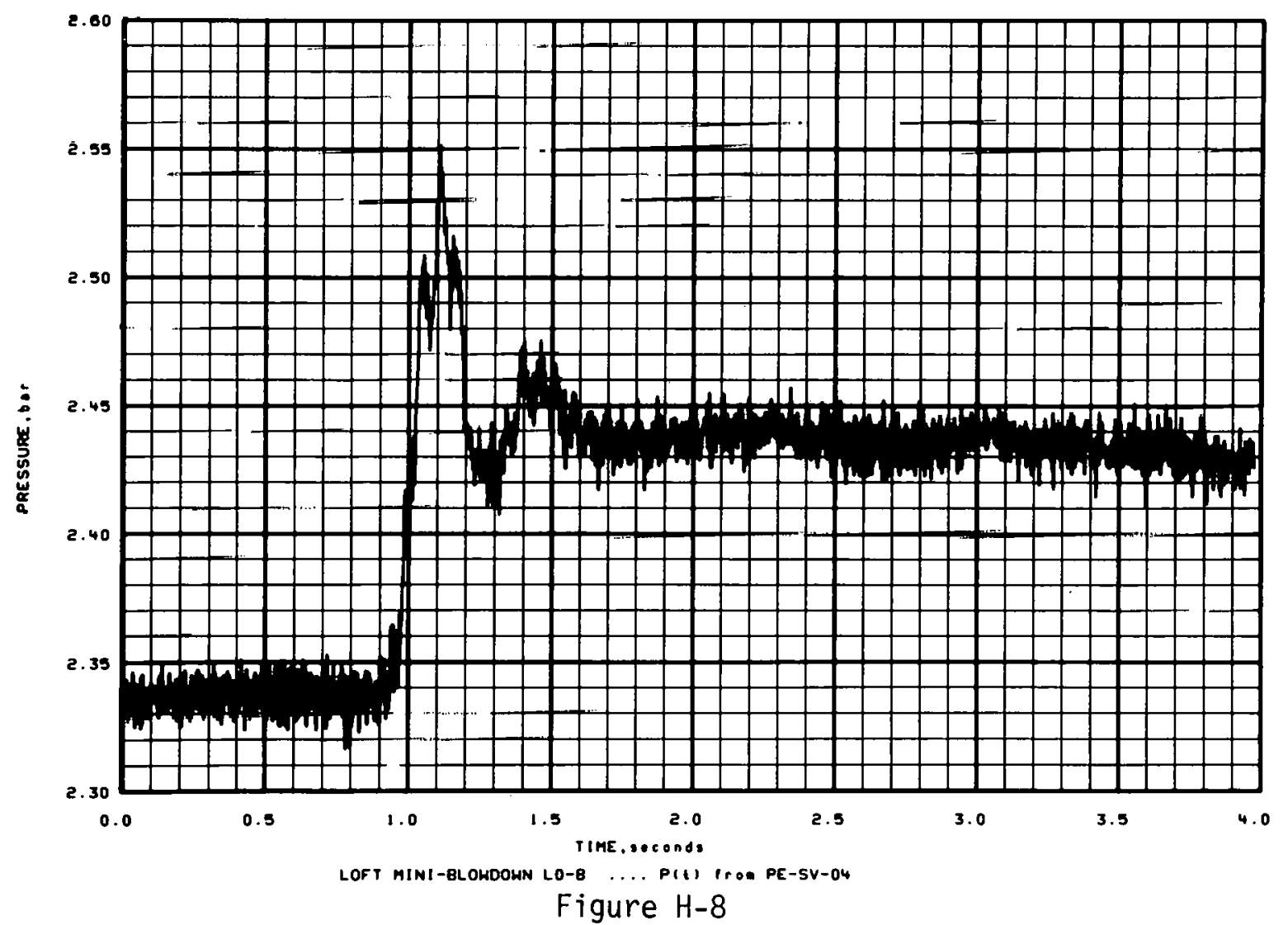



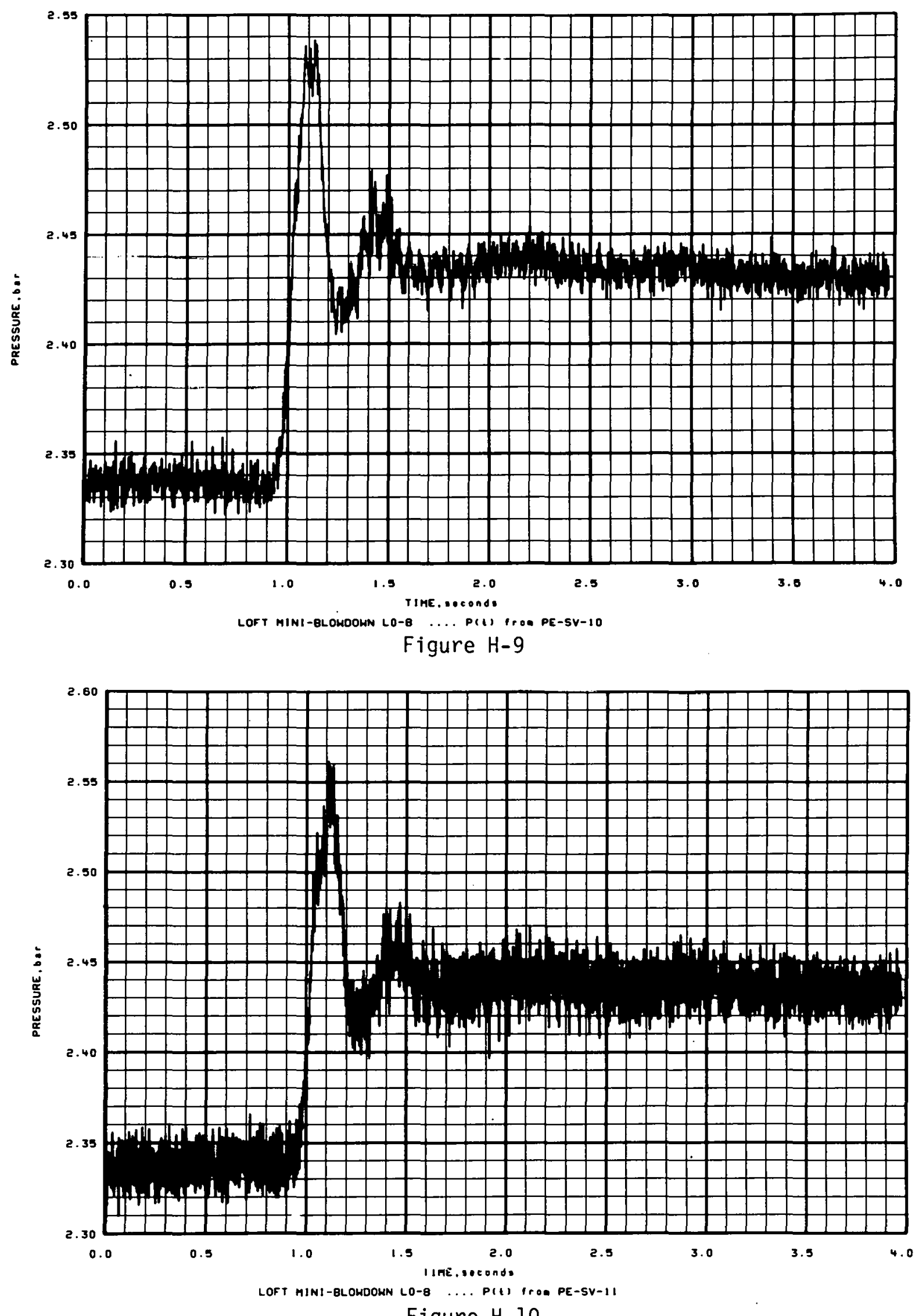

Figure $\mathrm{H}-10$ 


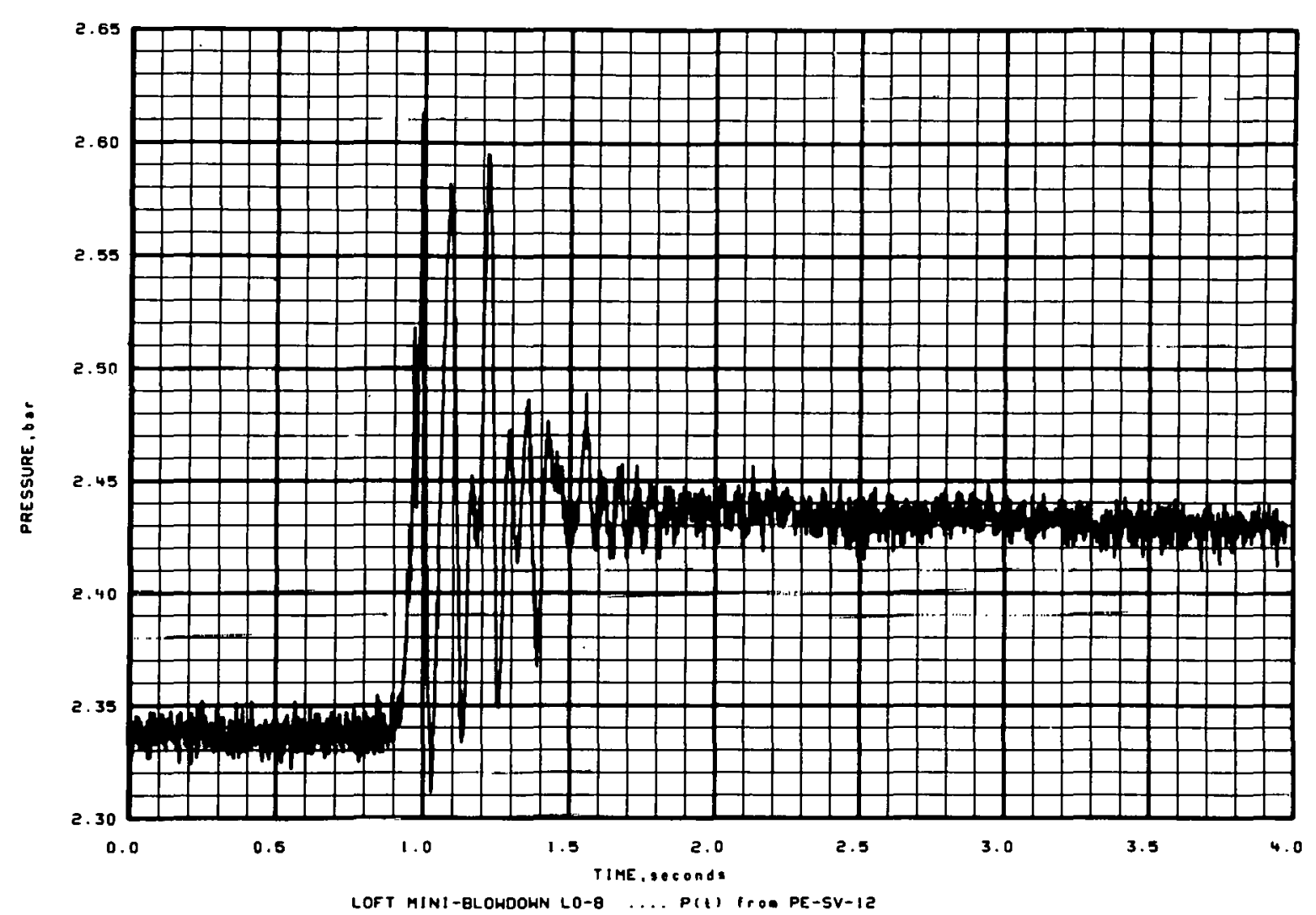

Figure $\mathrm{H}-11$

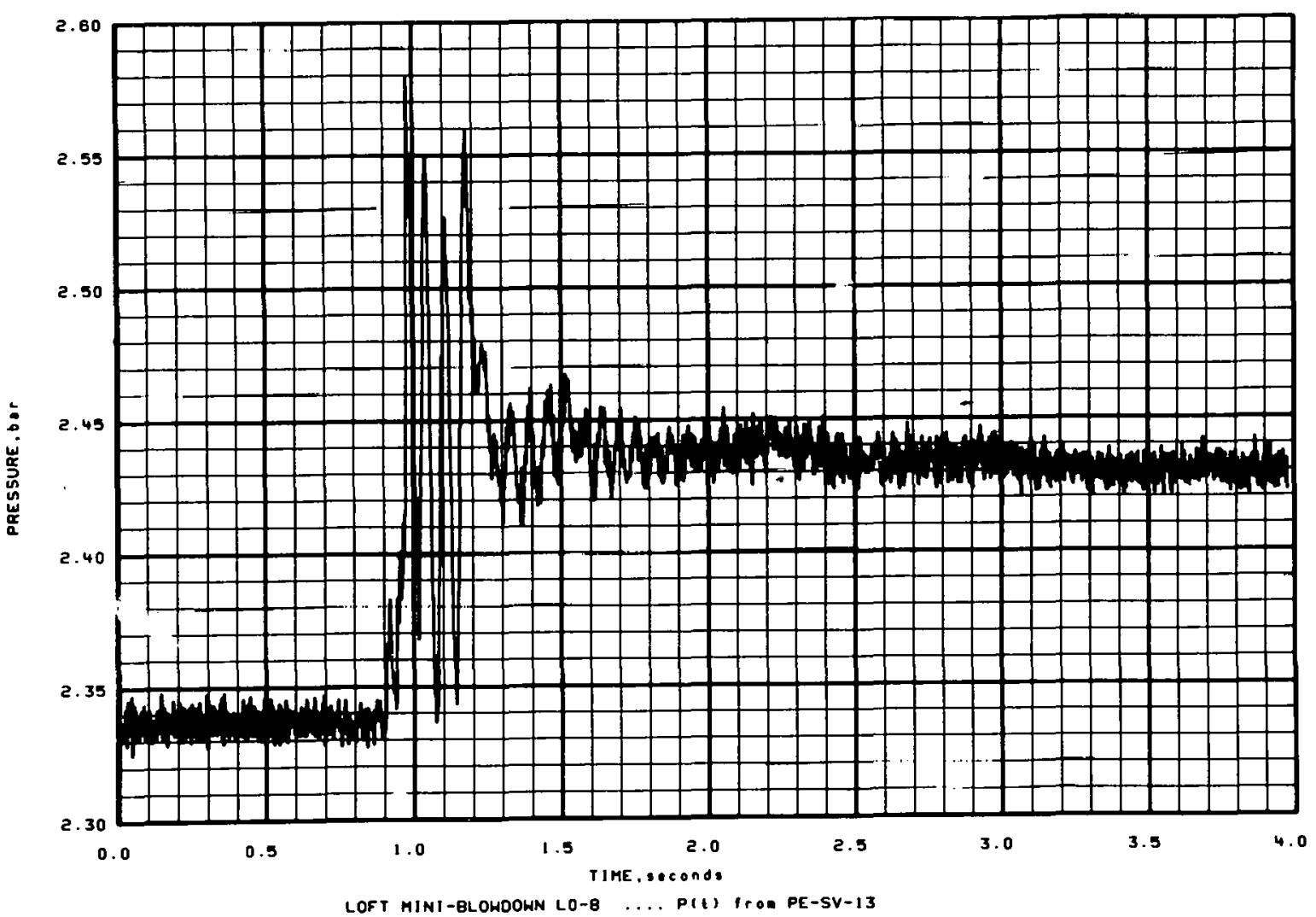

Figure $\mathrm{H}-12$ 


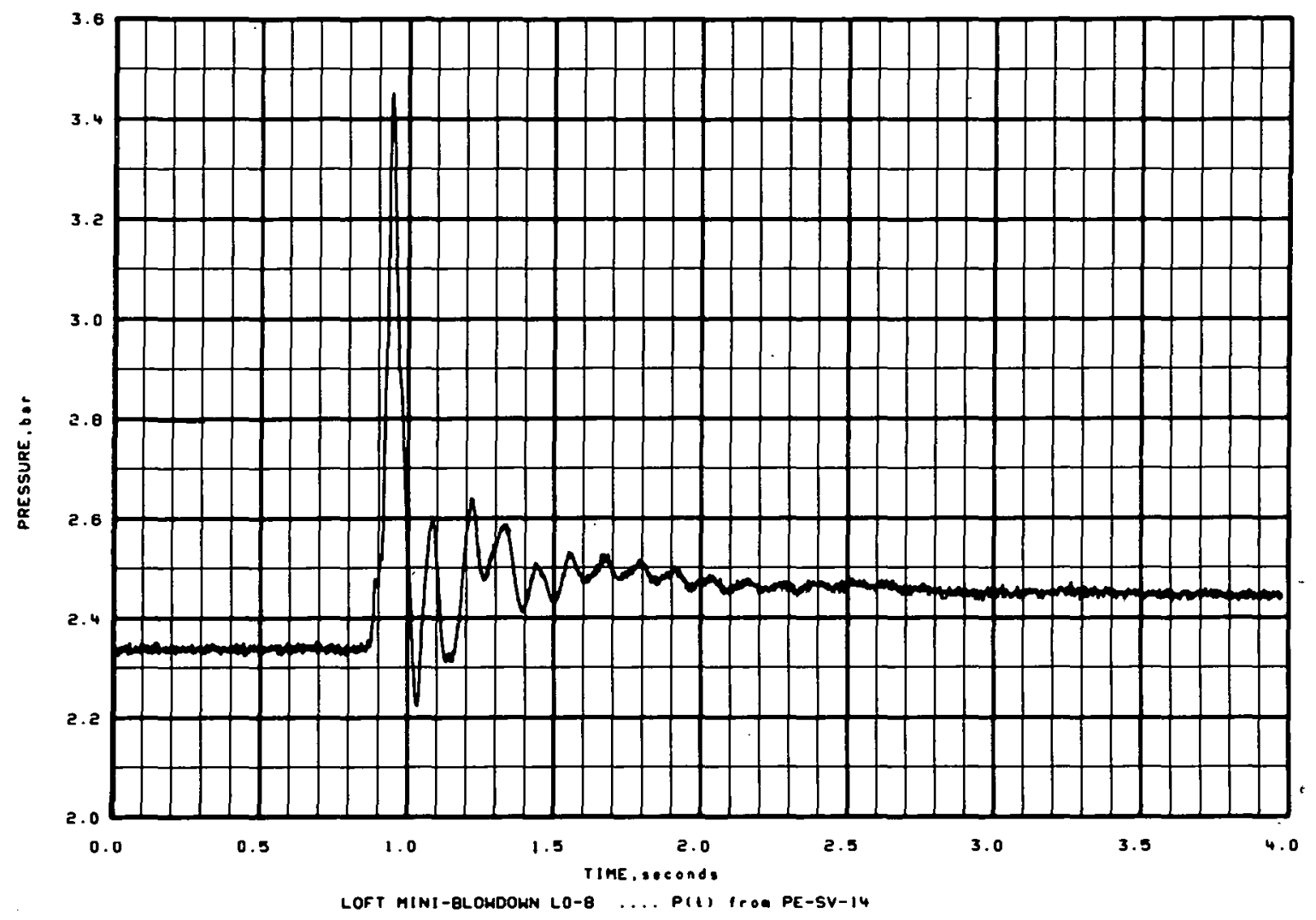

Figure $\mathrm{H}-13$

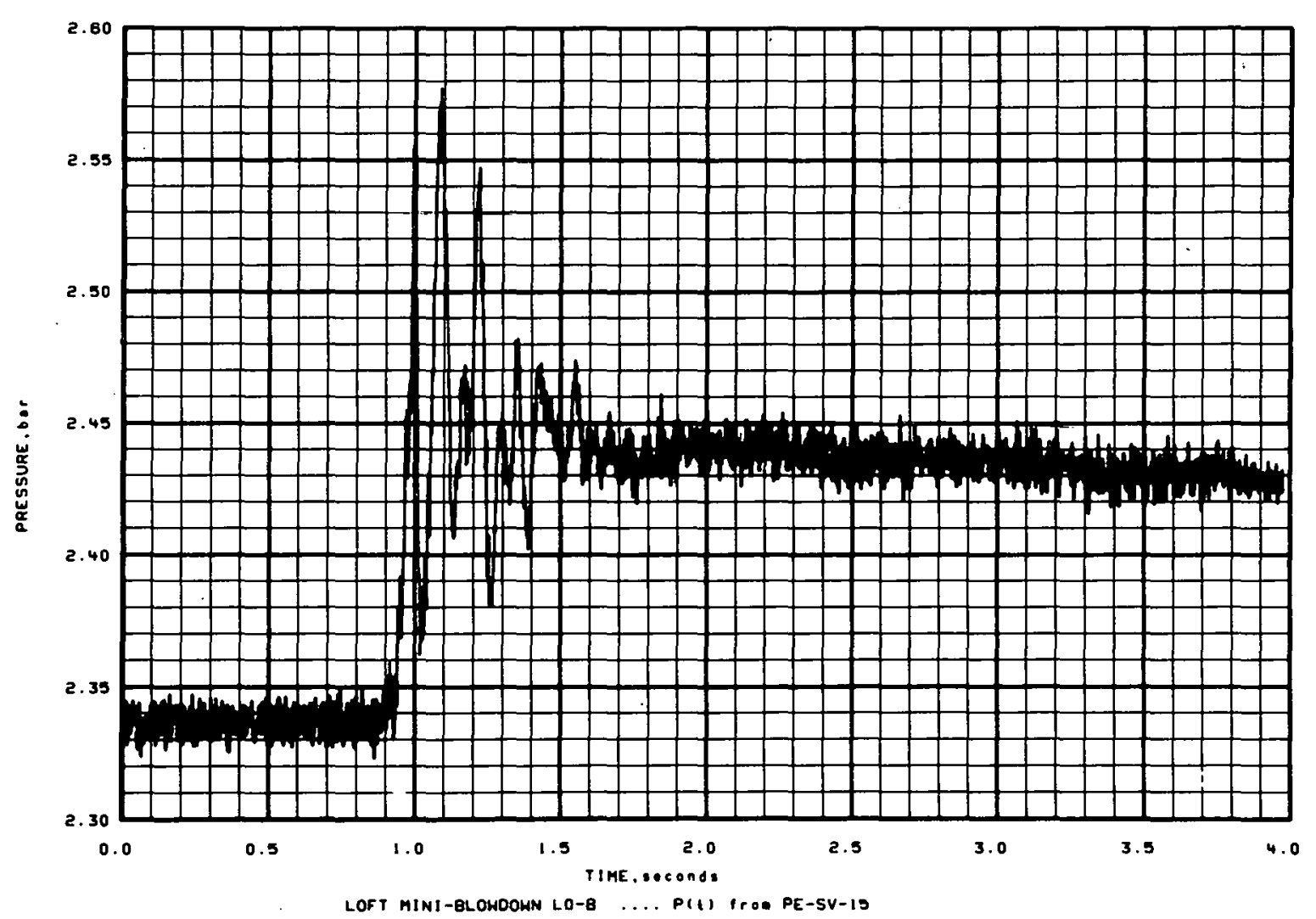

Figure $\mathrm{H}-14$ 

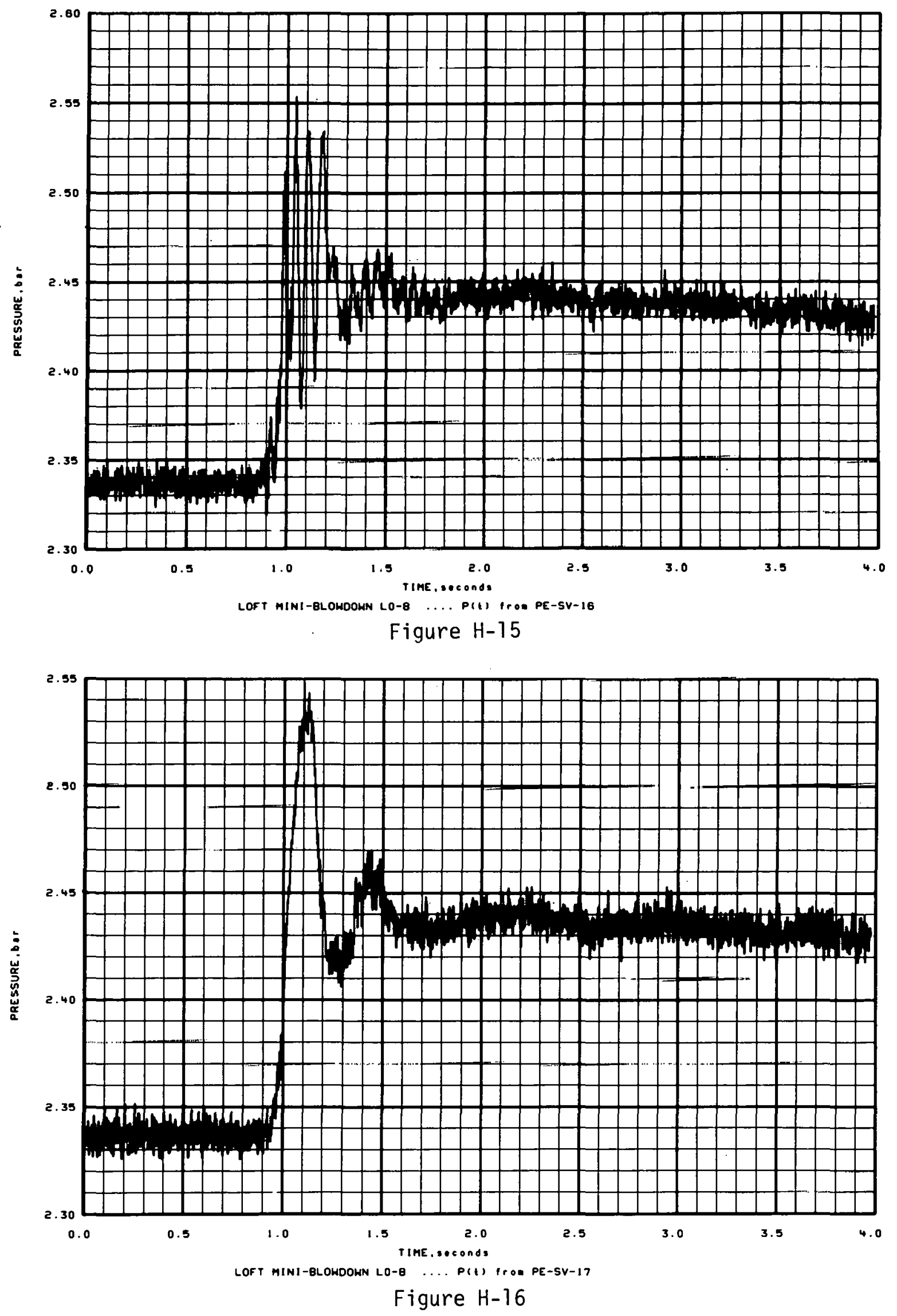

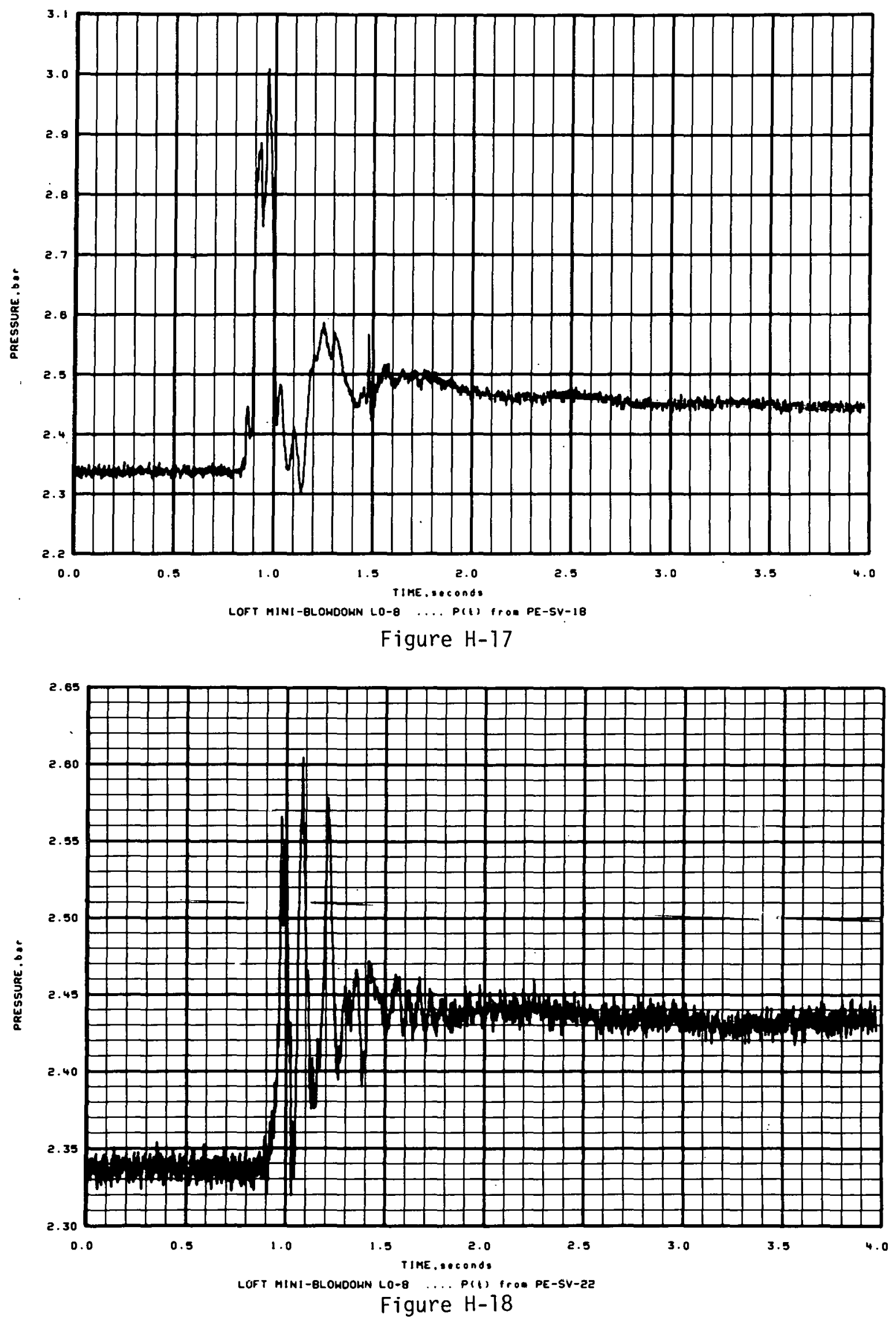


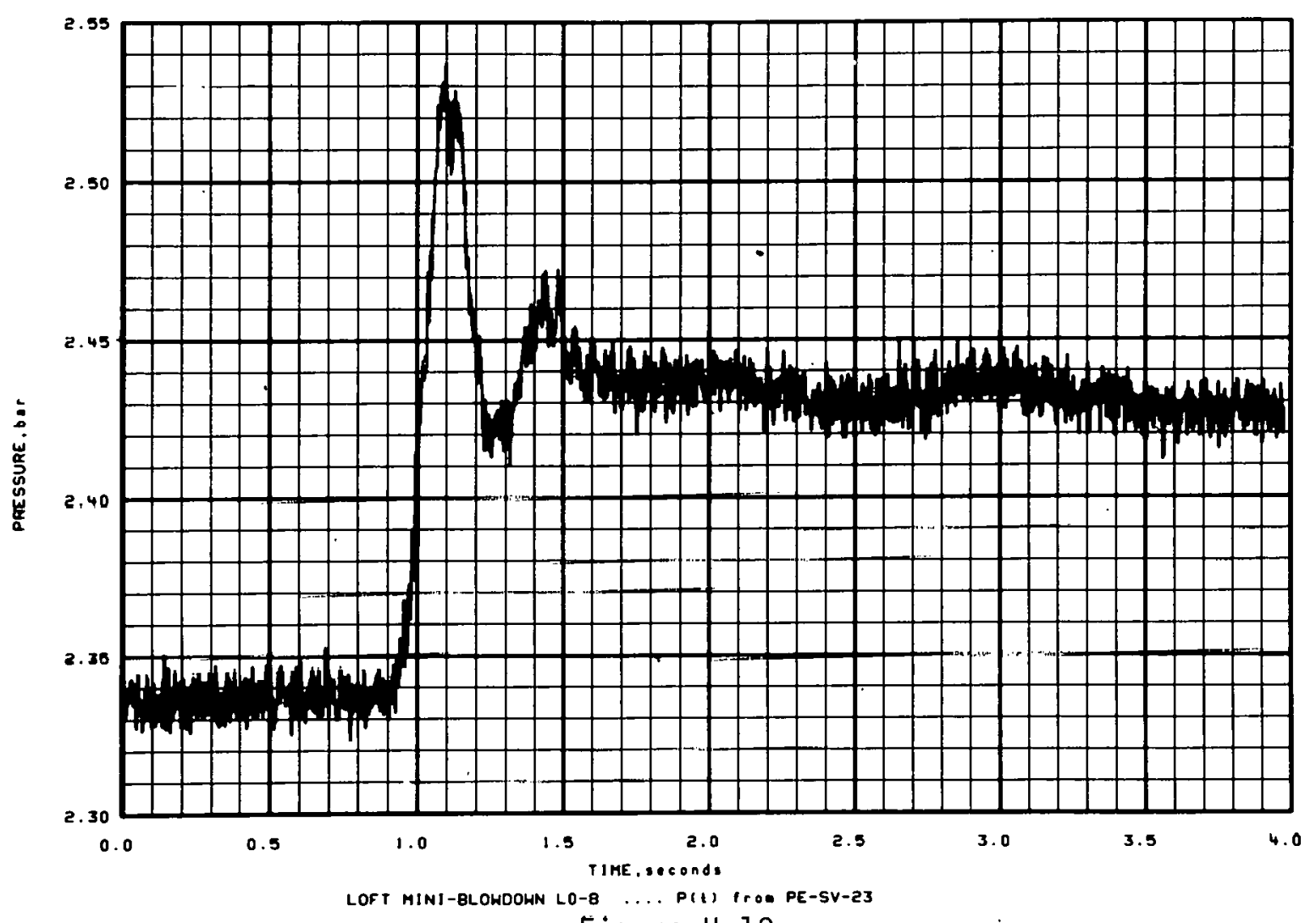

Figure H-19

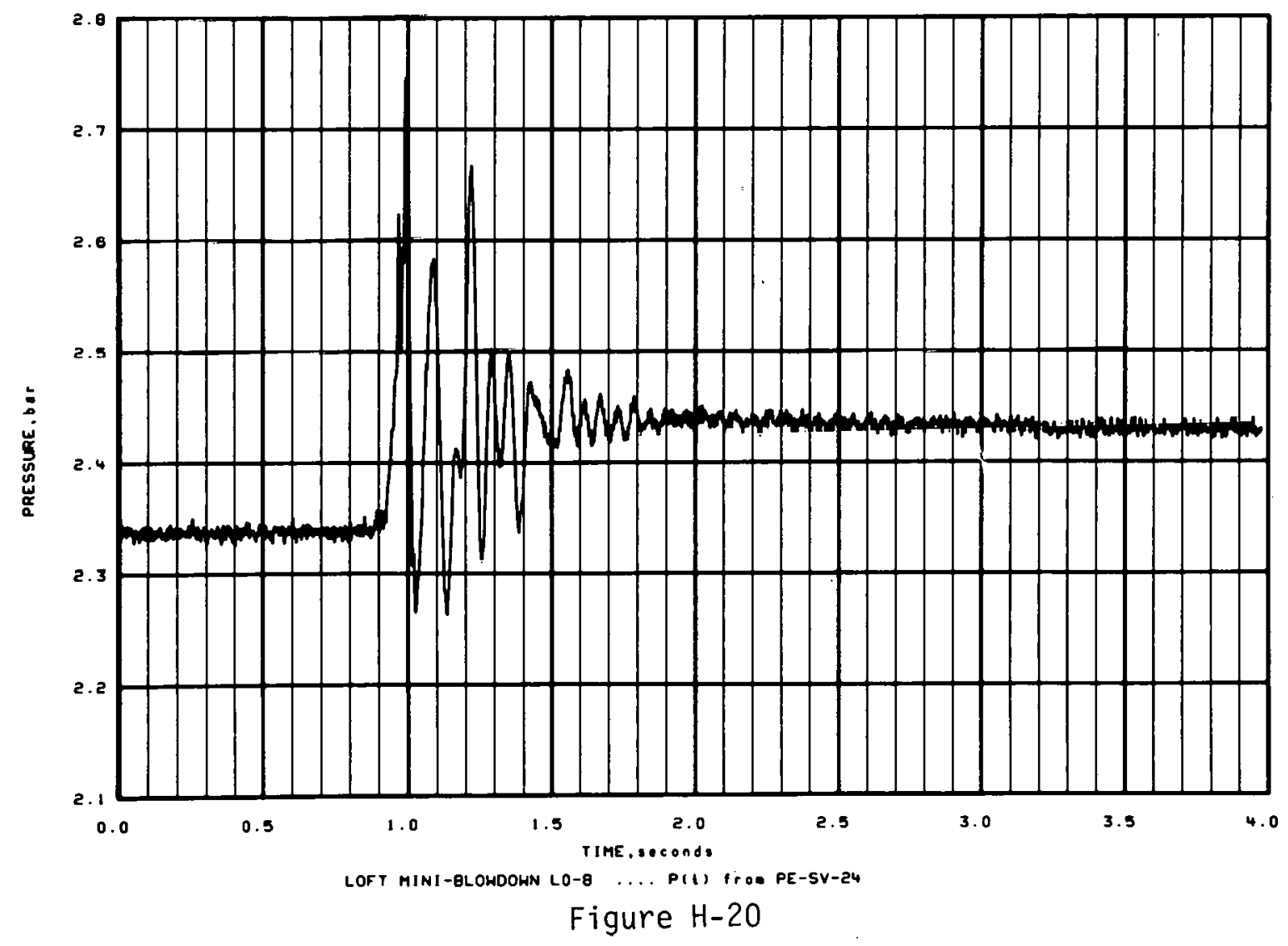



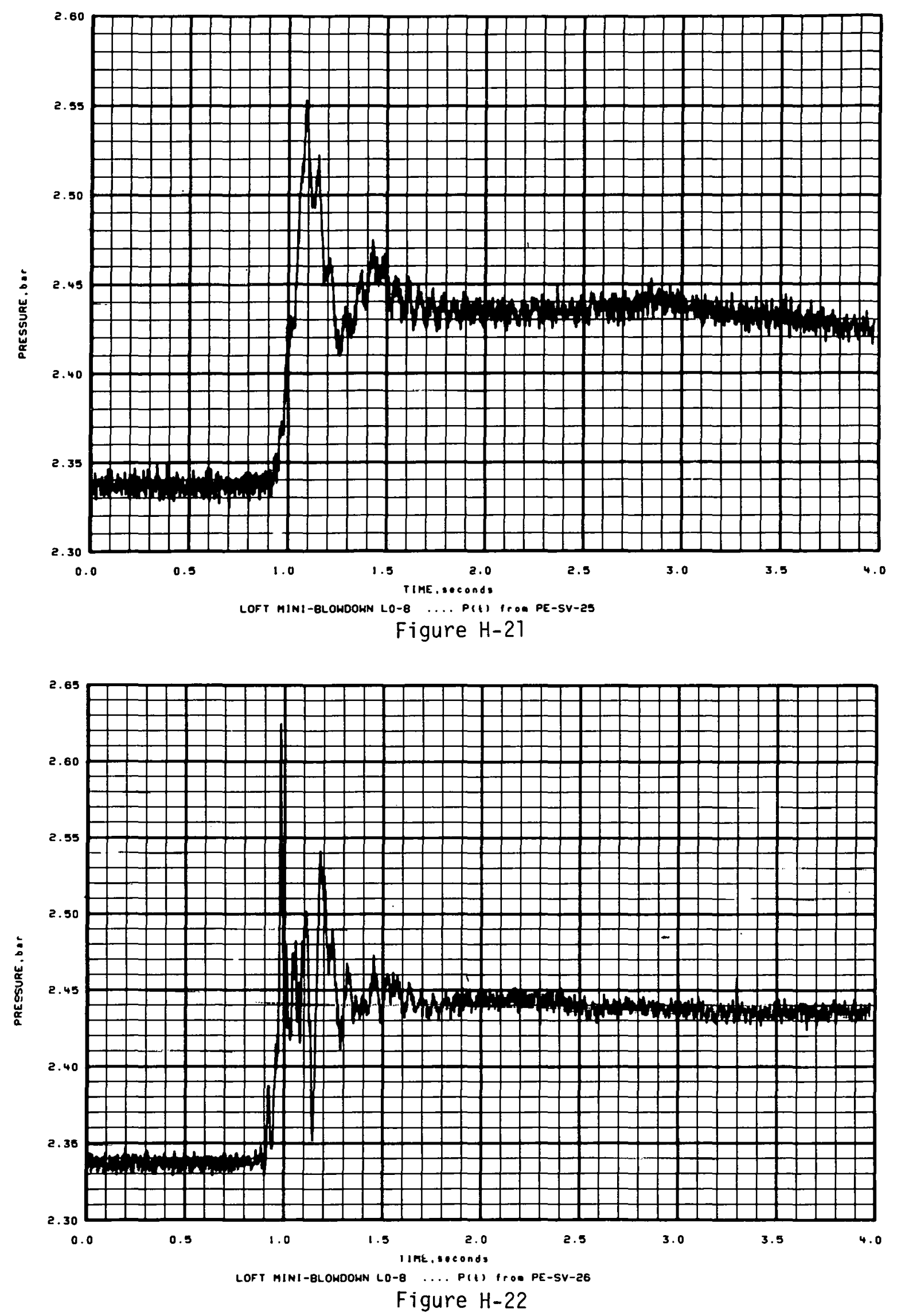

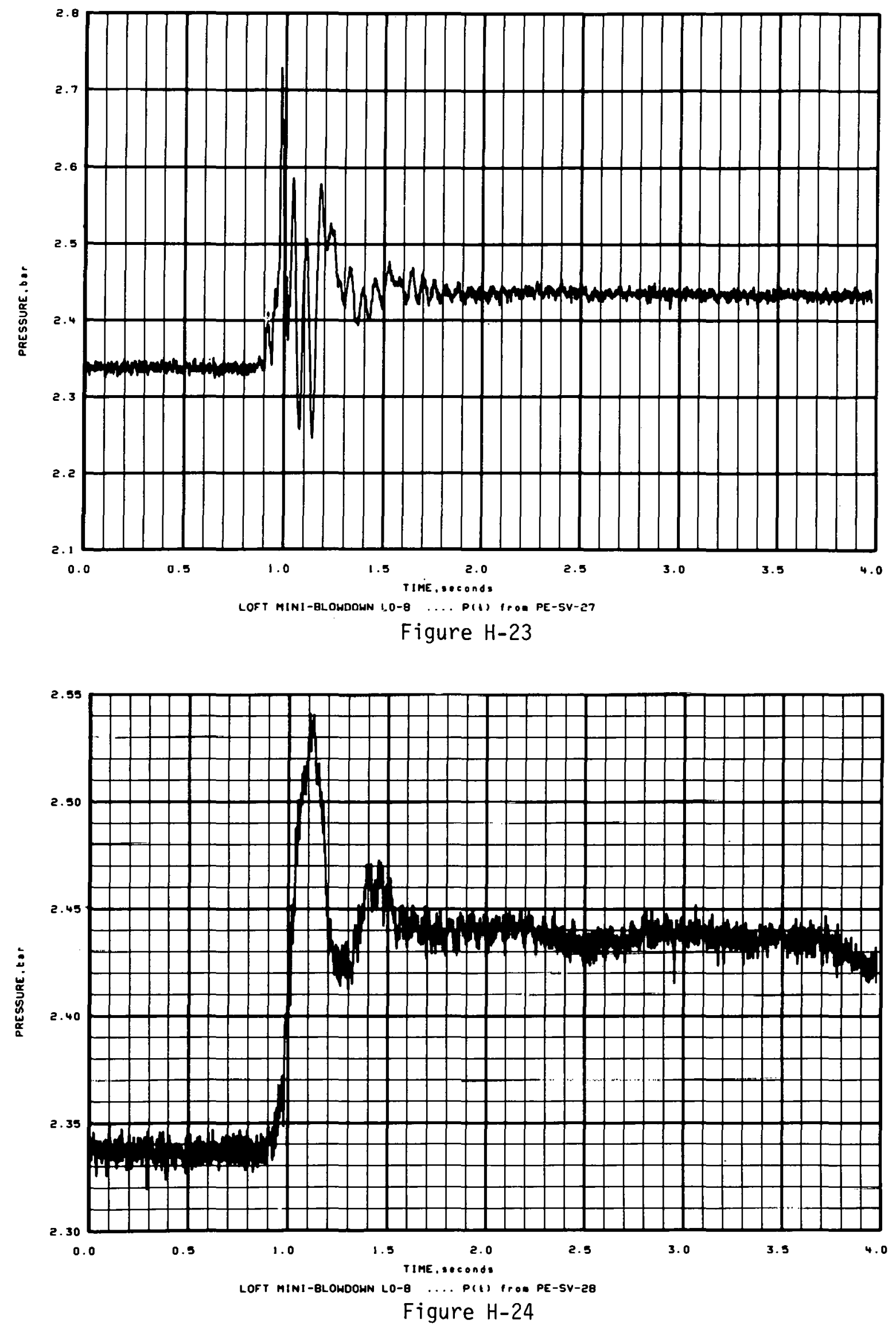

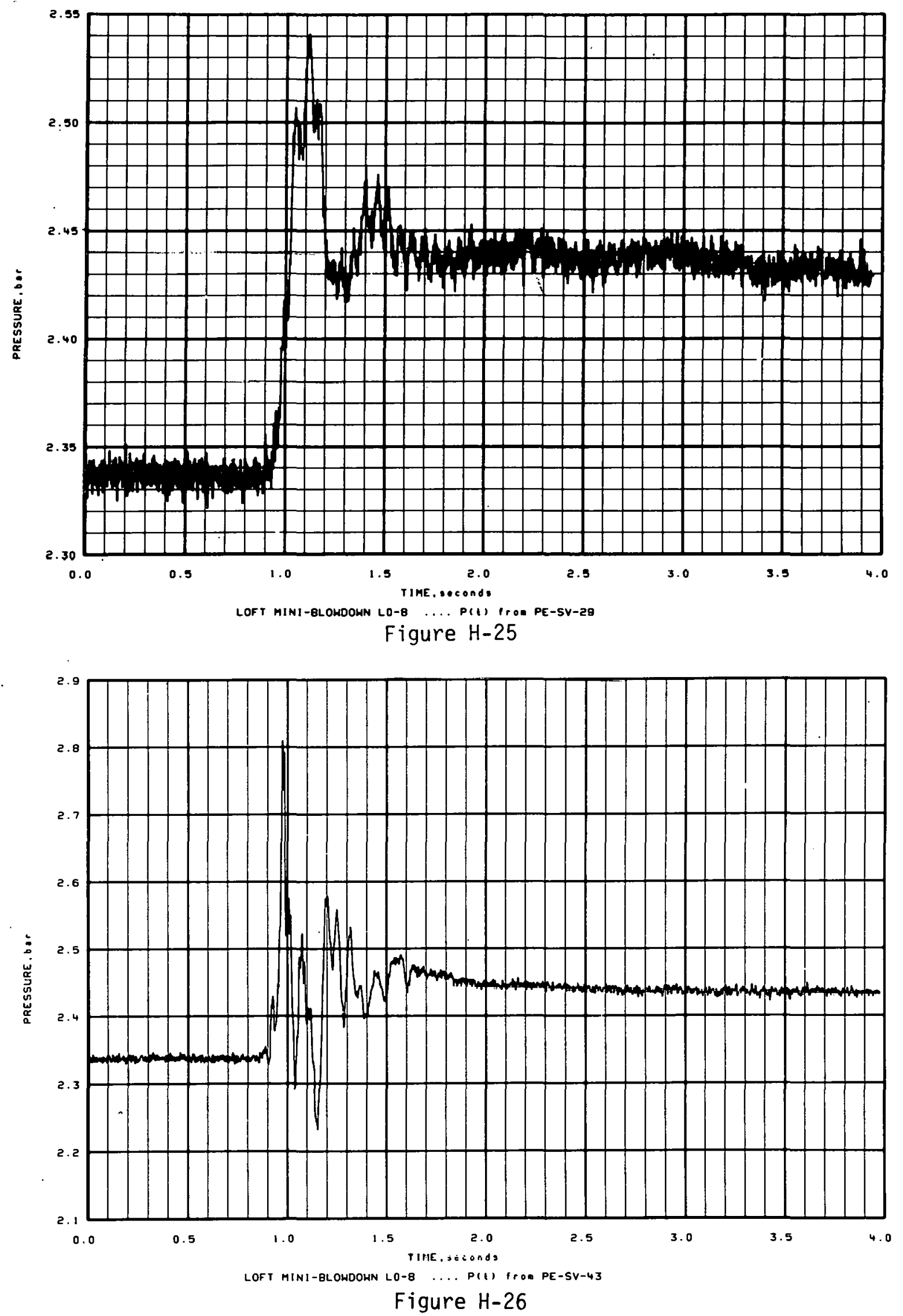


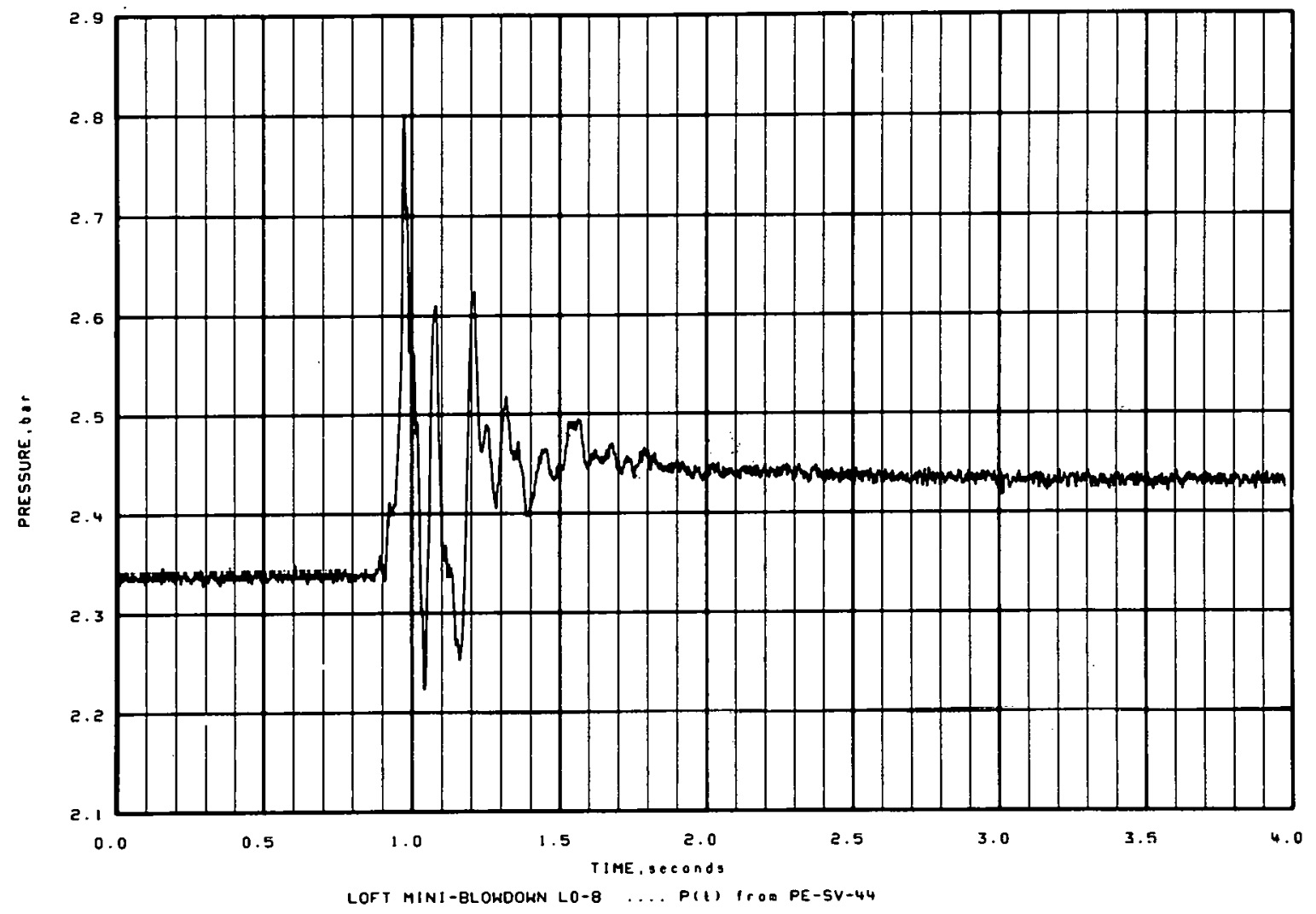

Figure $\mathrm{H}-27$

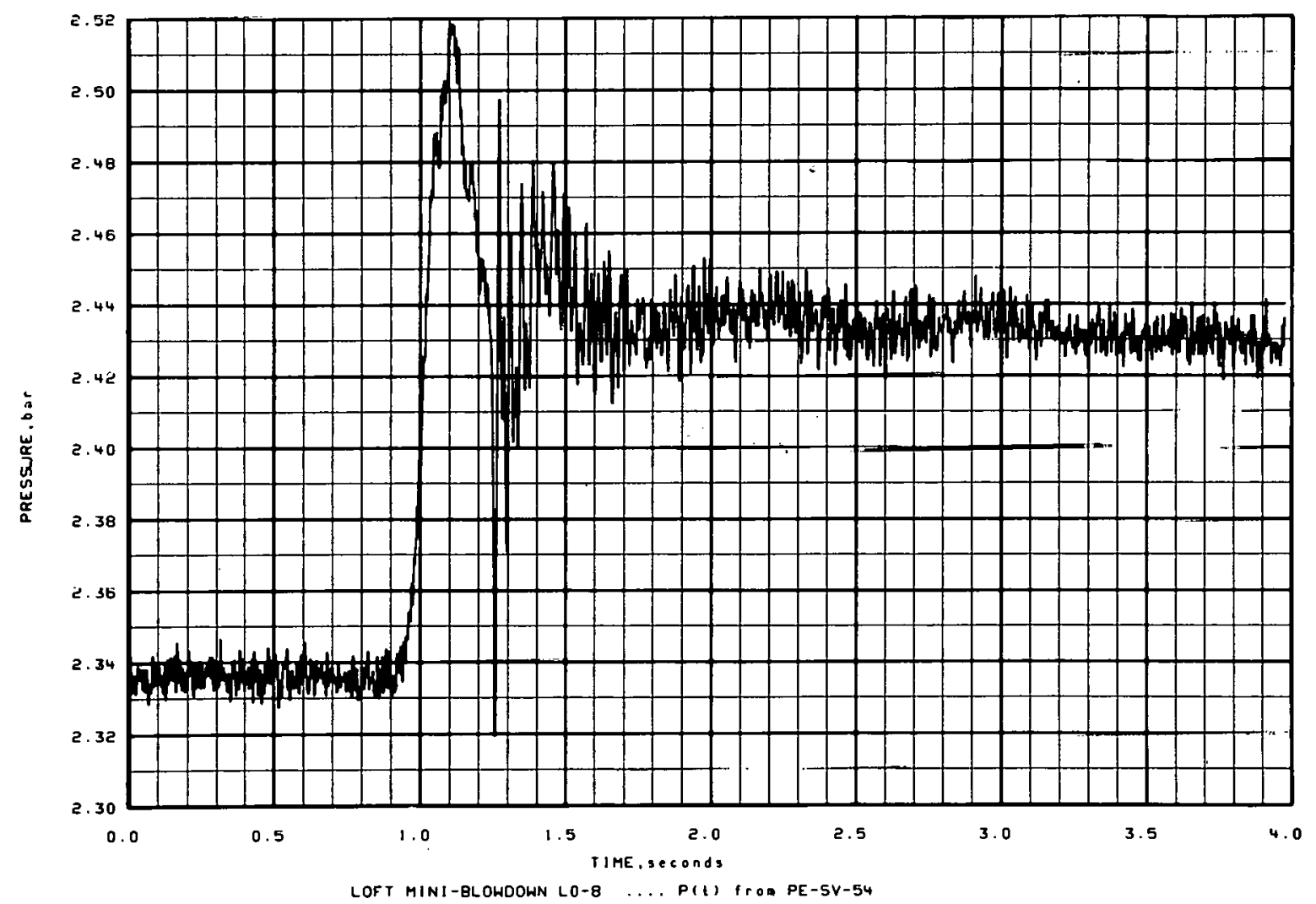

Figure $H-28$ 

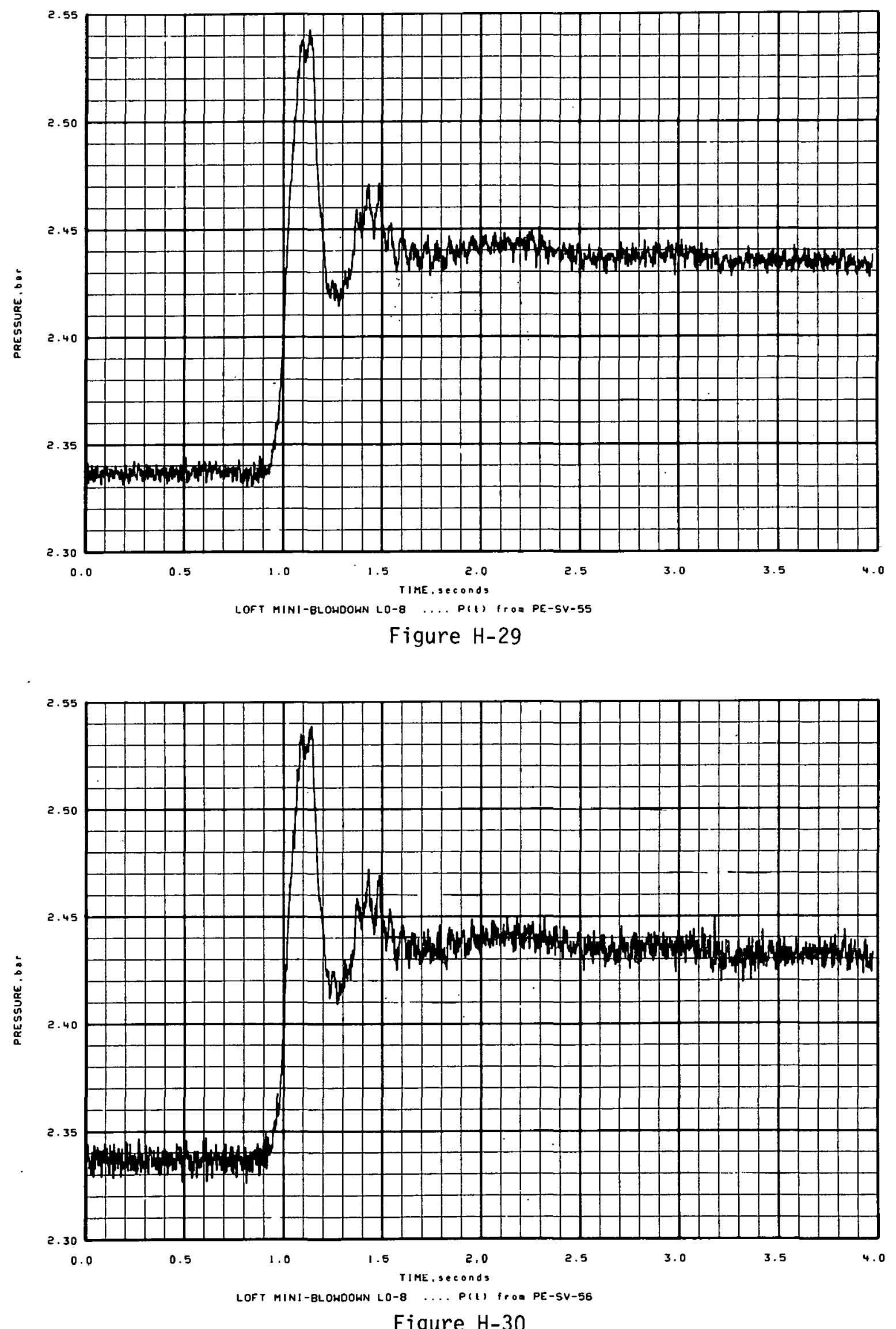


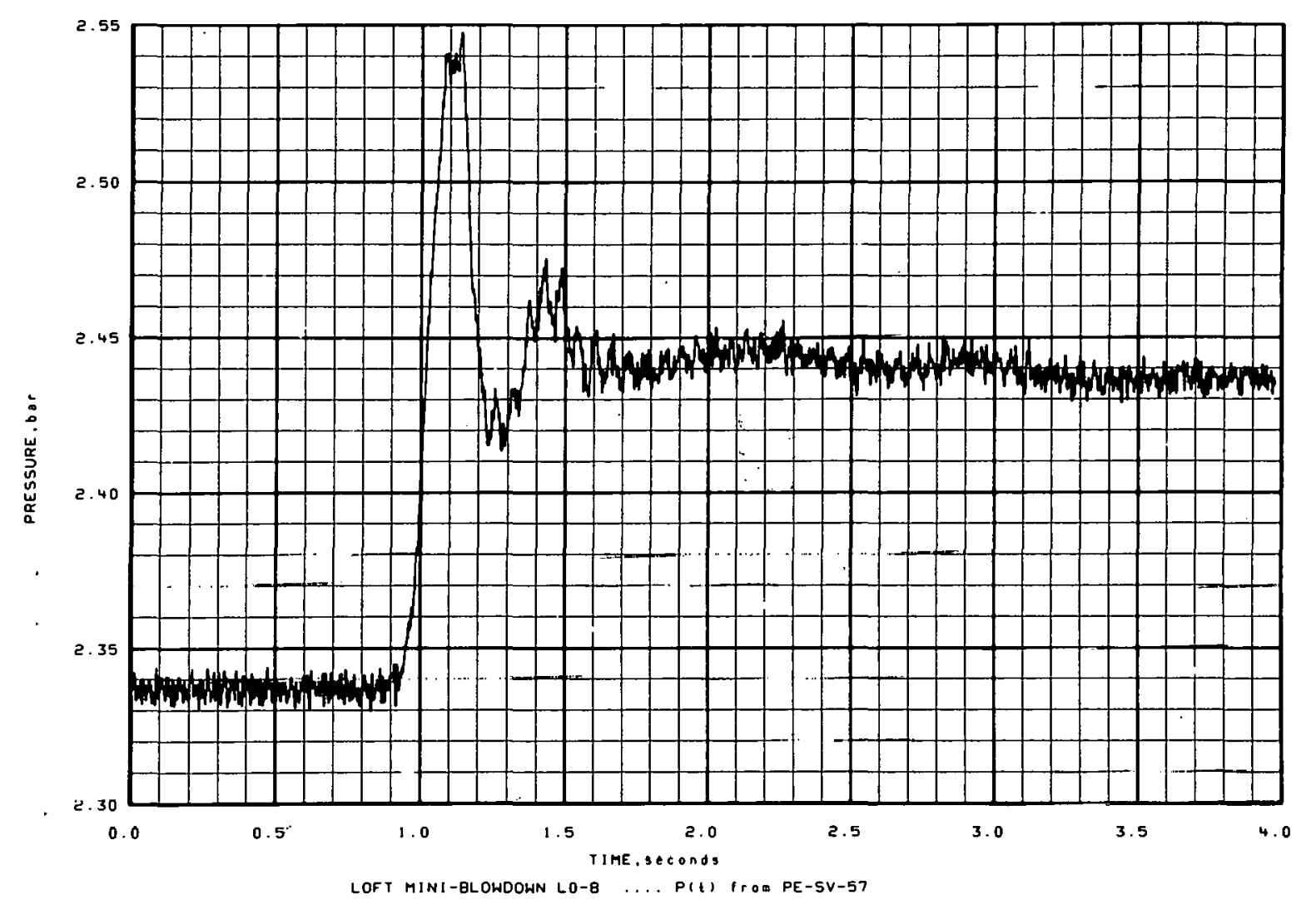

Figure $\mathrm{H}-31$

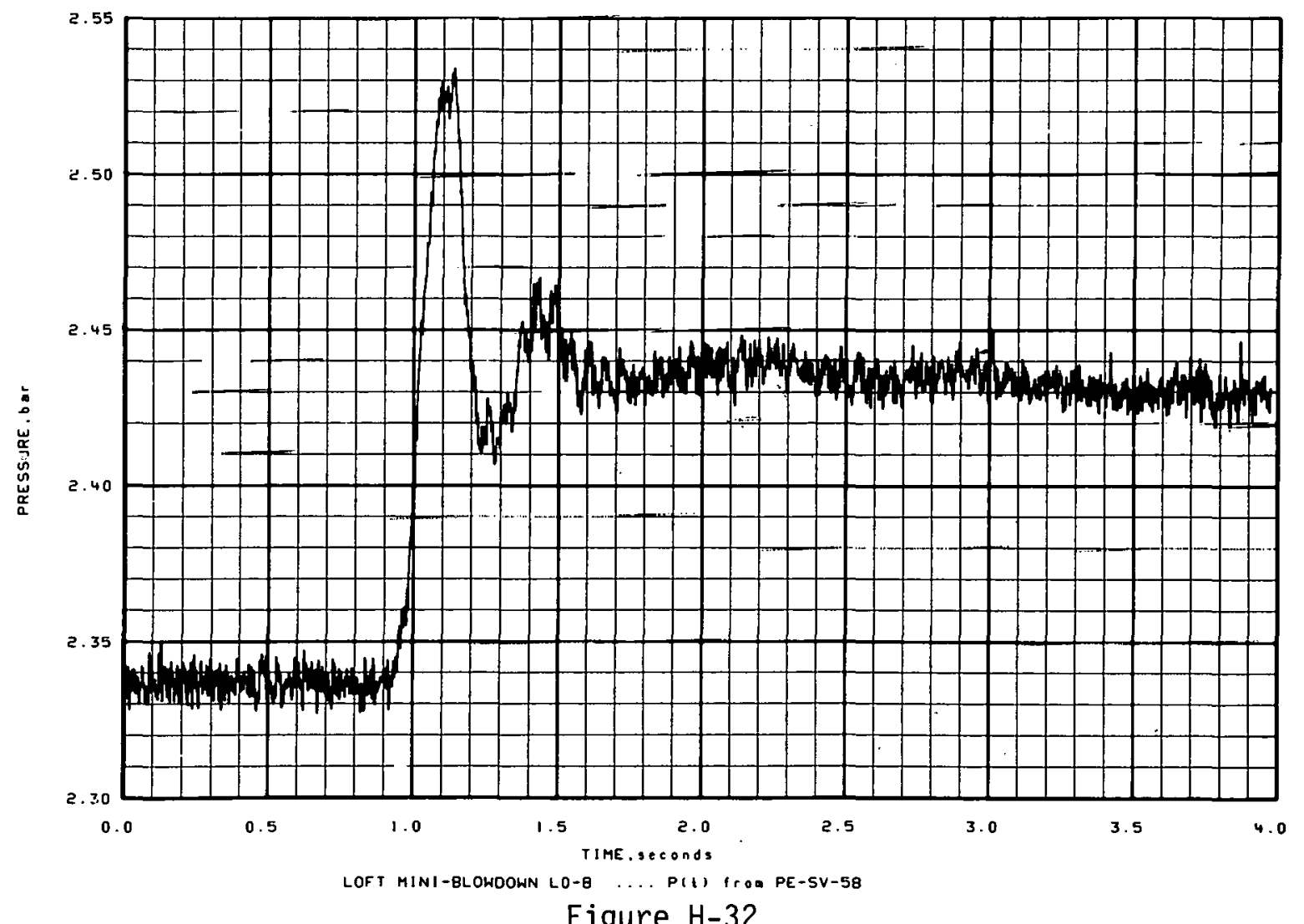

Figure $\mathrm{H}-32$ 

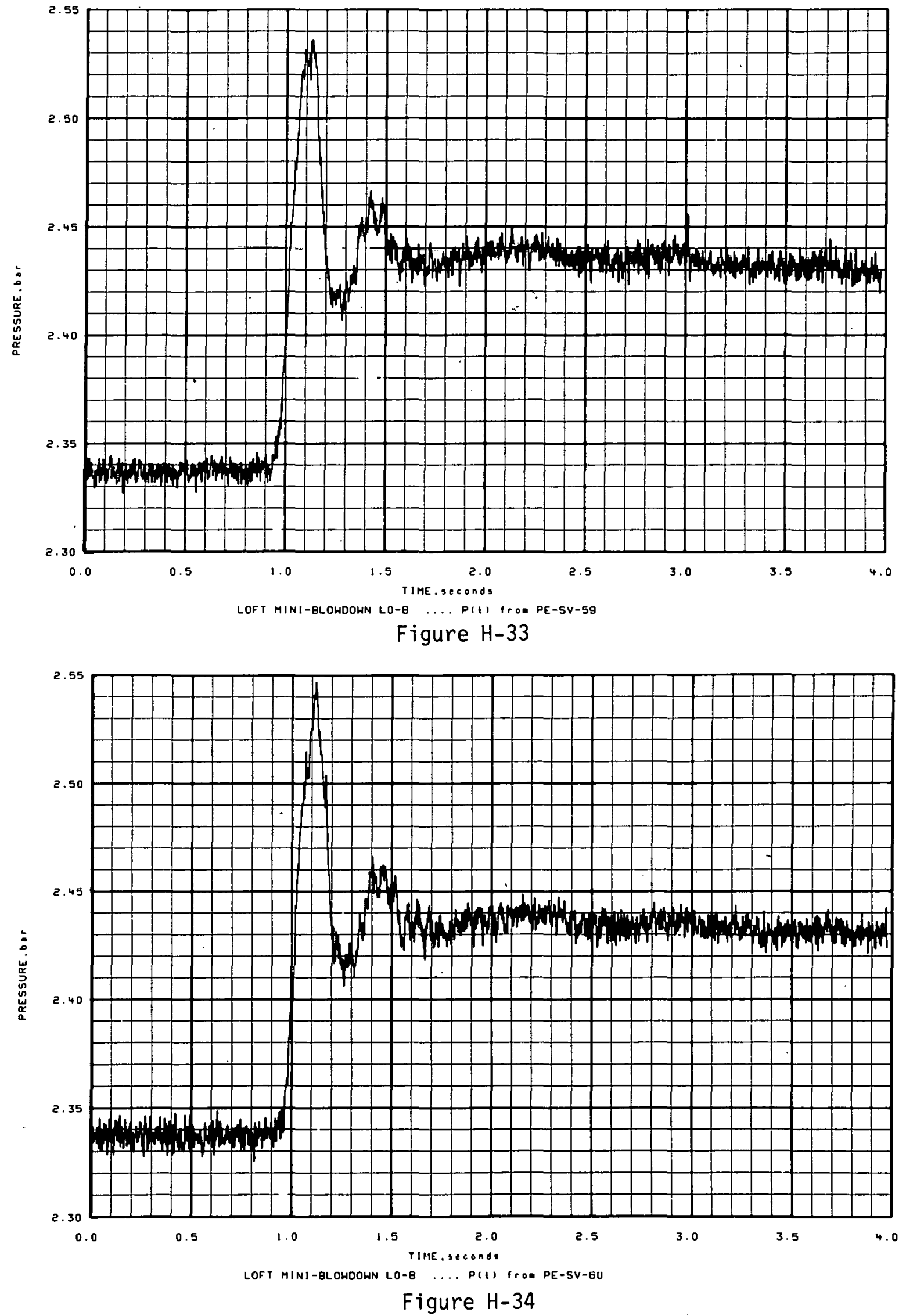


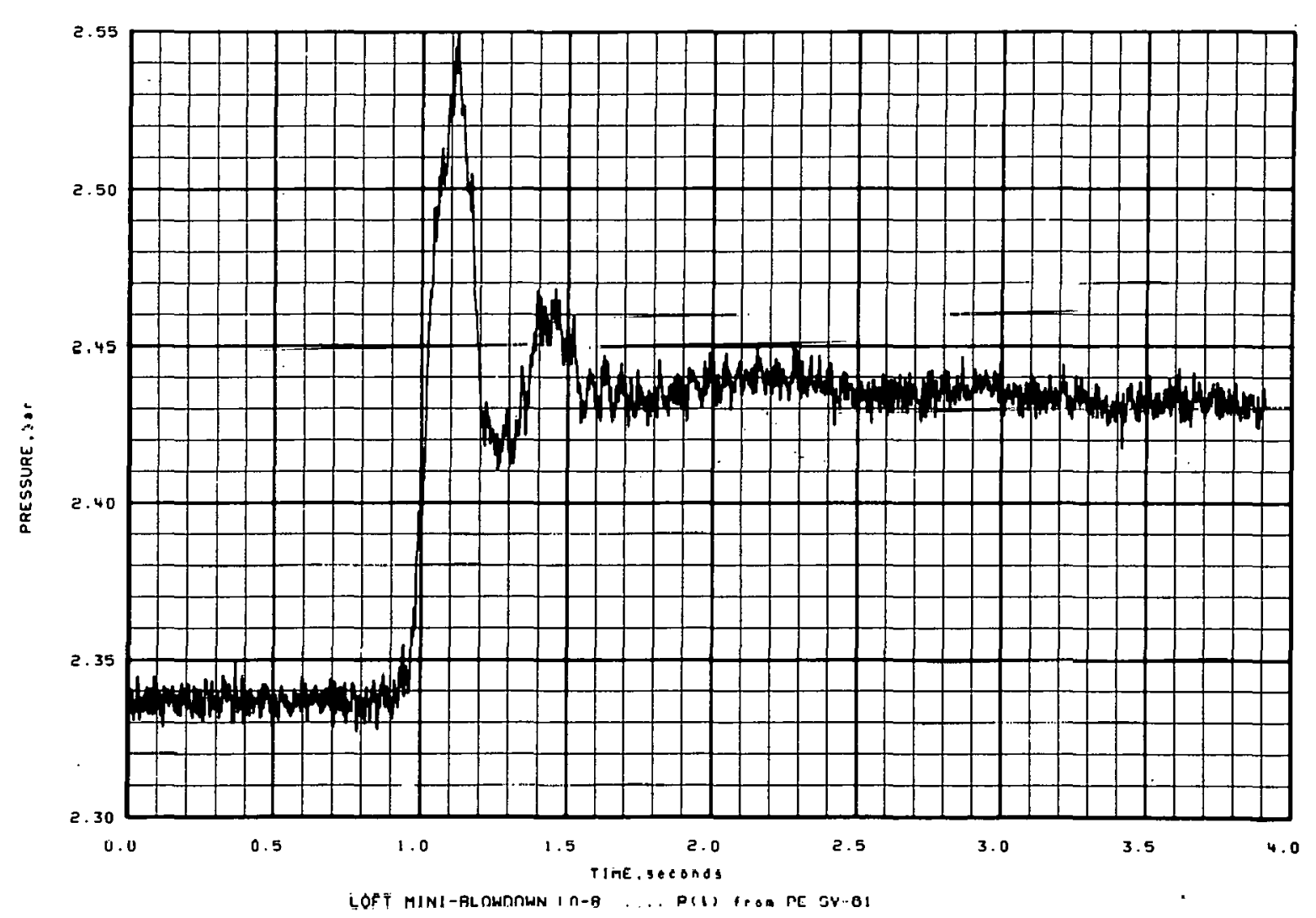

Figure $\mathrm{H}-35$ 


\section{APPENDIX I}

MINI-BLOWDOWN LO-09 EXPERIMENTAL DATA 


\section{THIS PAGE}

WAS INTENTIONALLY

LEFT BLANK 


\section{MINI-BLOWDOWN LO-09 EXPERIMENTAL DATA}

Both QOBVs were to open in this experiment; however, only QOBV-15 opened and did open fully. The fluid temperature in the valve was $237.6 \pm 1.5^{\circ} \mathrm{C}$. The suppression tank initial conditions were $2.34 \pm 0.08 \mathrm{bar}$, and $33.6 \pm 1.5^{\circ} \mathrm{C}$ in the gas volume and pool. The vents were submerged $27.9 \pm 2.5 \mathrm{~cm}$. The internal vent submergence was $21.9 \pm 3.2 \mathrm{~cm}$.

The experimental data are defined in Table I-I. The opening characteristics of the QOBVS are shown in terms of percent sleeve travel. versus time. The flow area of the valve begins to open at a sleeve position of $17 \%$ of full travel and is fully open at a sleeve position of $66 \%$ of full travel. The differential pressure between the header and and the tank gas volume is measured with a very sensitive device primarily to provide information on vent preclearing. The data channel for this measurement is driven to saturation in the early part of the transient. 
TABLE I-I

EXPERIMENT L0-09 DATA SUMMARY

\begin{tabular}{|c|c|c|c|c|c|}
\hline $\begin{array}{c}\text { Measurement } \\
\text { or } \\
\text { Calculatinn }\end{array}$ & $\begin{array}{c}\text { Pre-Transient } \\
\text { Data Channel } \\
\text { Varjance } \\
\left(10^{-4} \text { bar } 2\right) \\
\end{array}$ & Figure Number & Measurement & $\begin{array}{c}\text { Pre-Transient } \\
\text { Data Channel } \\
\text { Variance } \\
\left(10^{-4} \text { bar }^{2}\right)\end{array}$ & Figure Number \\
\hline QOBV-1 opening & - & $I-1, I-2$ & PE-SV-22 & 0.07337 & $\mathrm{I}-22$ \\
\hline QOBV $=15$ opening & - & $I-3, I-1$ & PE-SV-23 & 0.07266 & $I-23$ \\
\hline $\begin{array}{l}\text { Combined QOBV } \\
\text { opening }\end{array}$ & - & $I-5, T-6$ & PE-SV-24 & 0.04182 & $I-24$ \\
\hline Vertical load & - & $I-7$ & PE-SV-25 & 0.03699 & $\mathrm{I}-25$ \\
\hline PDE-SV-09 & - & $\mathrm{I}-8$ & PE-SV-26 & 0.01731 & I-26 \\
\hline PE-SV-01 & 0.07966 & I-9 & $P E-S V-27$ & 0.03365 & I -27 \\
\hline PE-SV-02 & 0.08707 & $I-10$ & $P E-S V-28$ & 0.04973 & $I-28$ \\
\hline PE-SV-03 & 0.11171 & $I-11$ & PE-SV-29 & 0.04356 & $I-29$ \\
\hline PE-SV-04 & 0.18758 & $\mathrm{I}-12$ & PE-SV-43 & 0.04360 & $I-30$ \\
\hline PE-SV-10 & 0.12265 & $\bar{I}-13$ & PE-SV-44 & 0.04835 & {$[-31$} \\
\hline PE-SV-11 & 4.0794 & $\mathrm{I}-14$ & PE-SV-54 & 0.03205 & $I-32$ \\
\hline$P E-S V-12$ & 0.13871 & $1-15$ & PE-SV-55 & 0.02054 & $1-33$ \\
\hline PE-SV-13 & 0.05826 & $I-16$ & PE-SV-56 & \multicolumn{2}{|c|}{ measurement deleted } \\
\hline$P E-S V-14$ & 0.06295 & $1-17$ & PE-SV-57 & 0.01963 & I -34 \\
\hline$P E-S V-15$ & 0.07625 & I 18 & PE-SV-58 & 0.05844 & I -35 \\
\hline PE-SV-16 & 0.10790 & $I-19$ & PE-SV- 59 & 0.04818 & $I-36$ \\
\hline PE-SV-17 & 0.07351 & $I-20$ & PE-SV-60 & 0.03789 & I- -37 \\
\hline PE-SV-18 & 0.05434 & $I-2]$ & PE-SV-61 & 0.03489 & I-38 \\
\hline
\end{tabular}



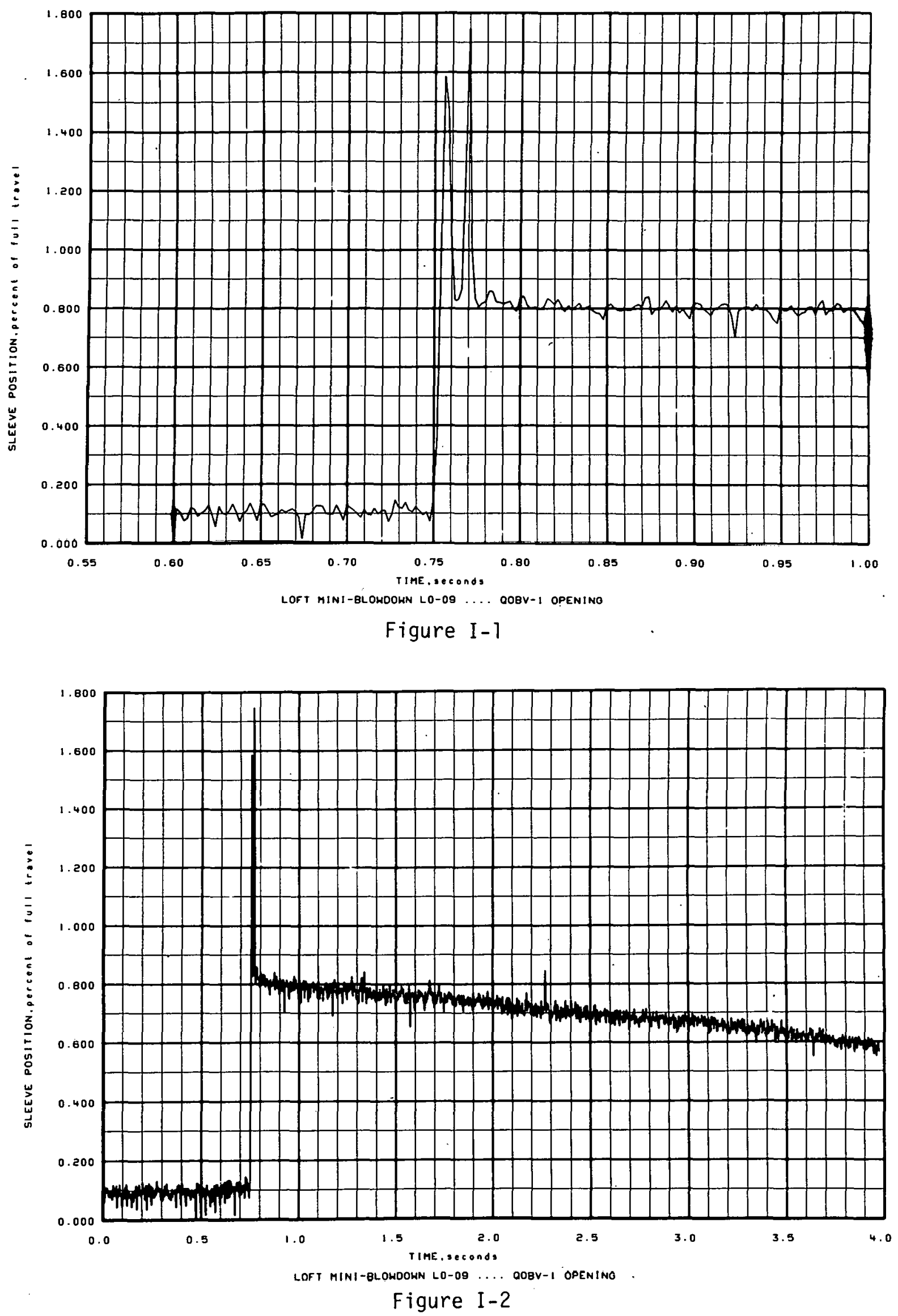

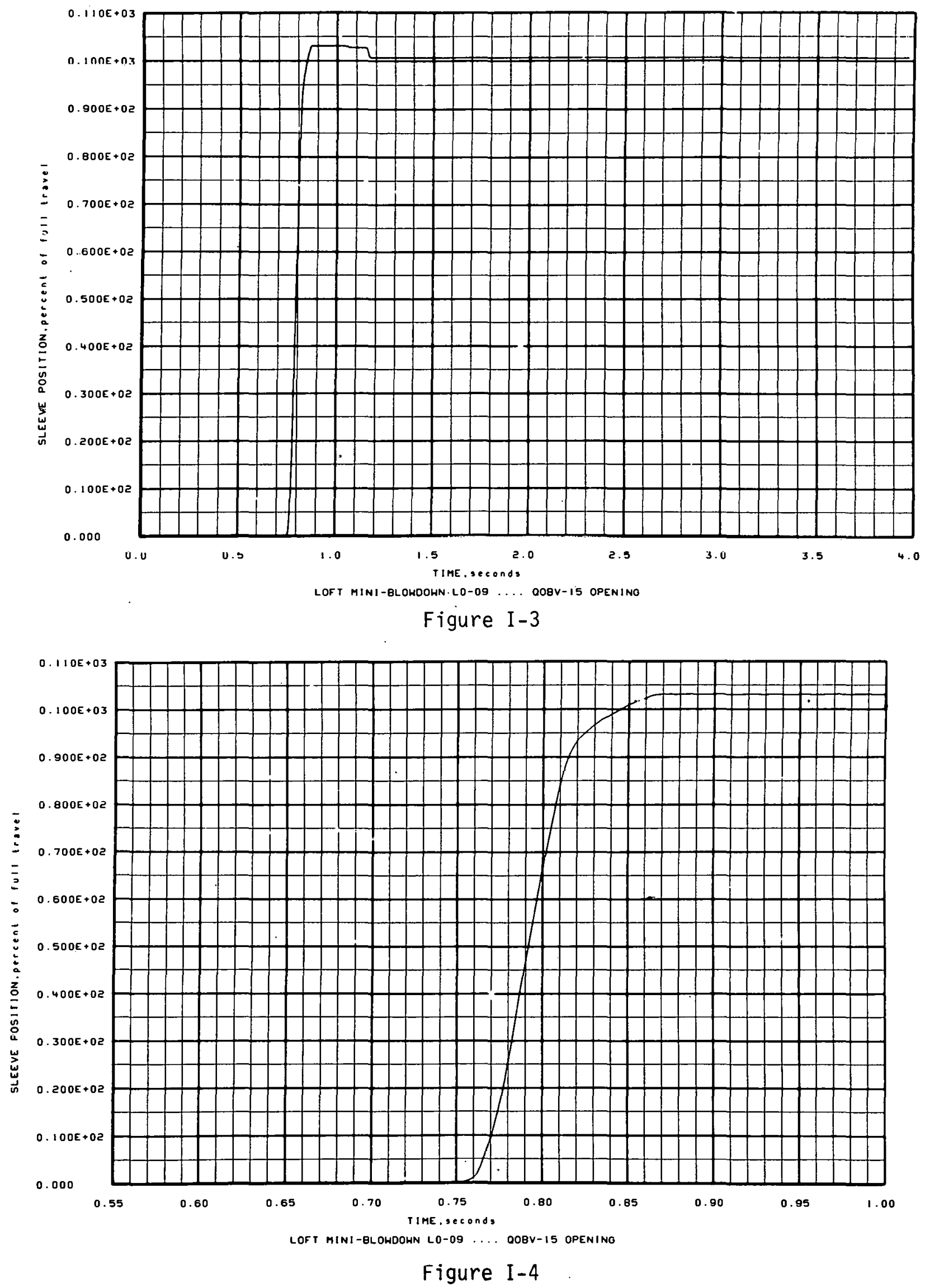


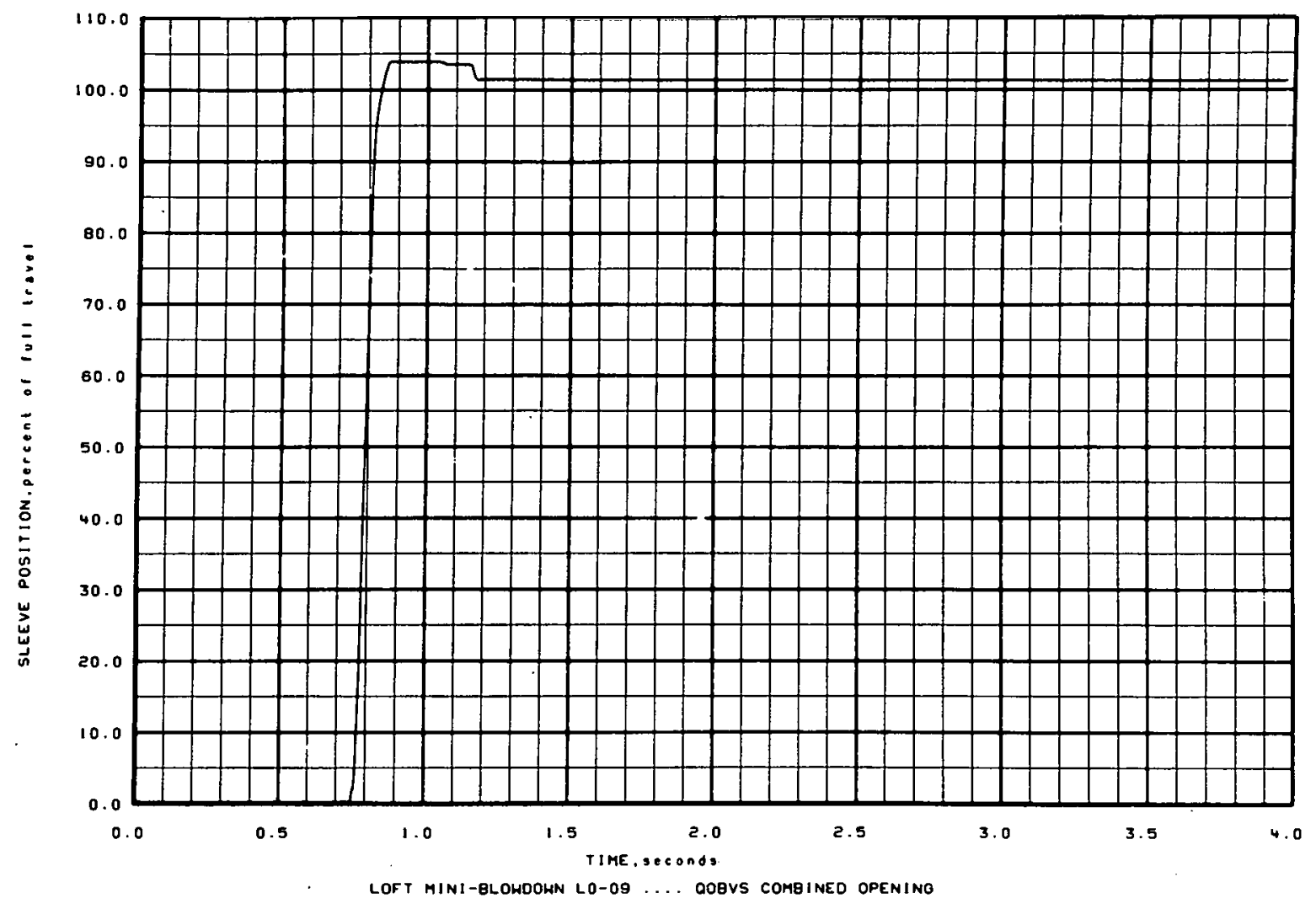

Figure I-5

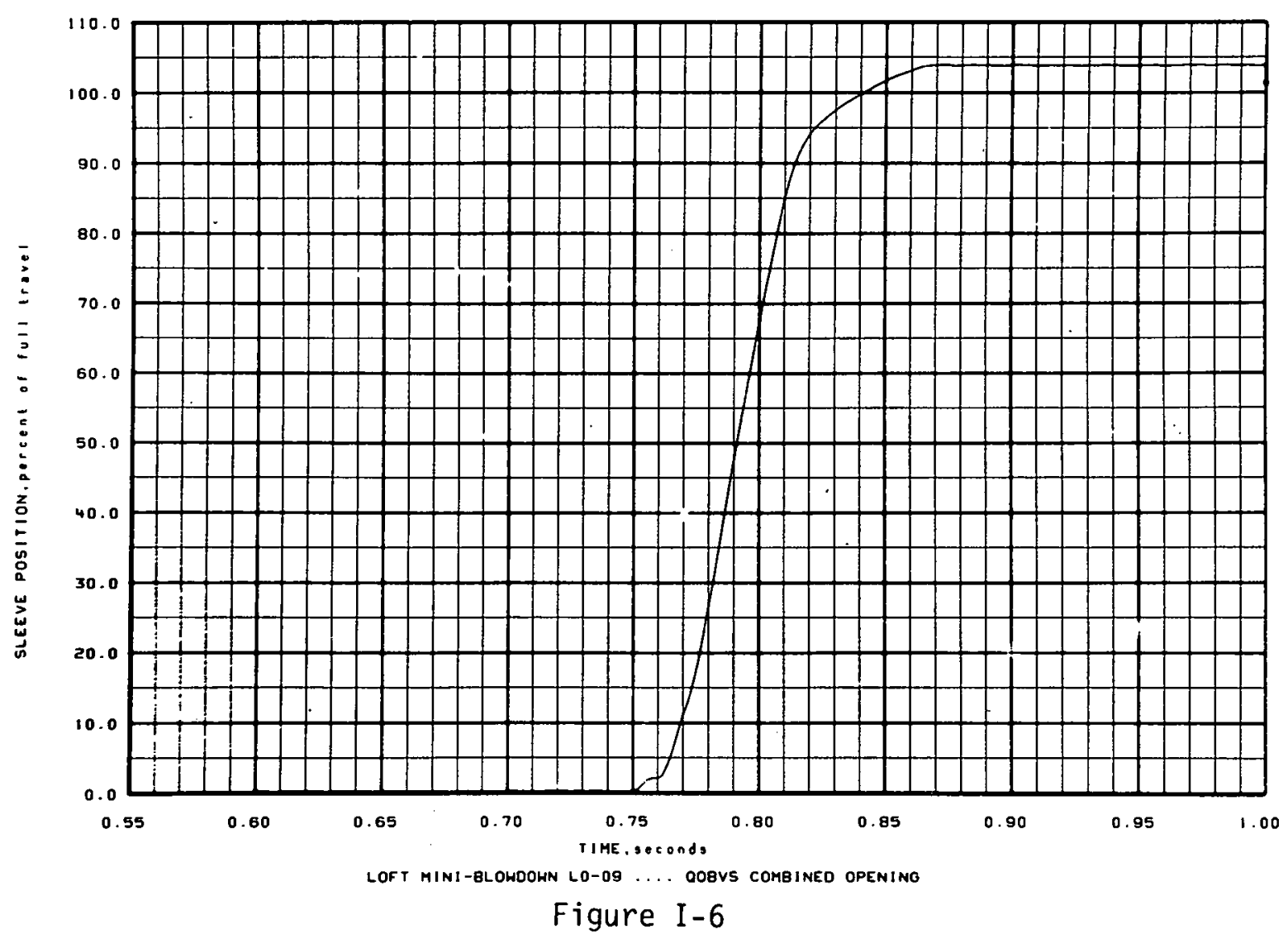




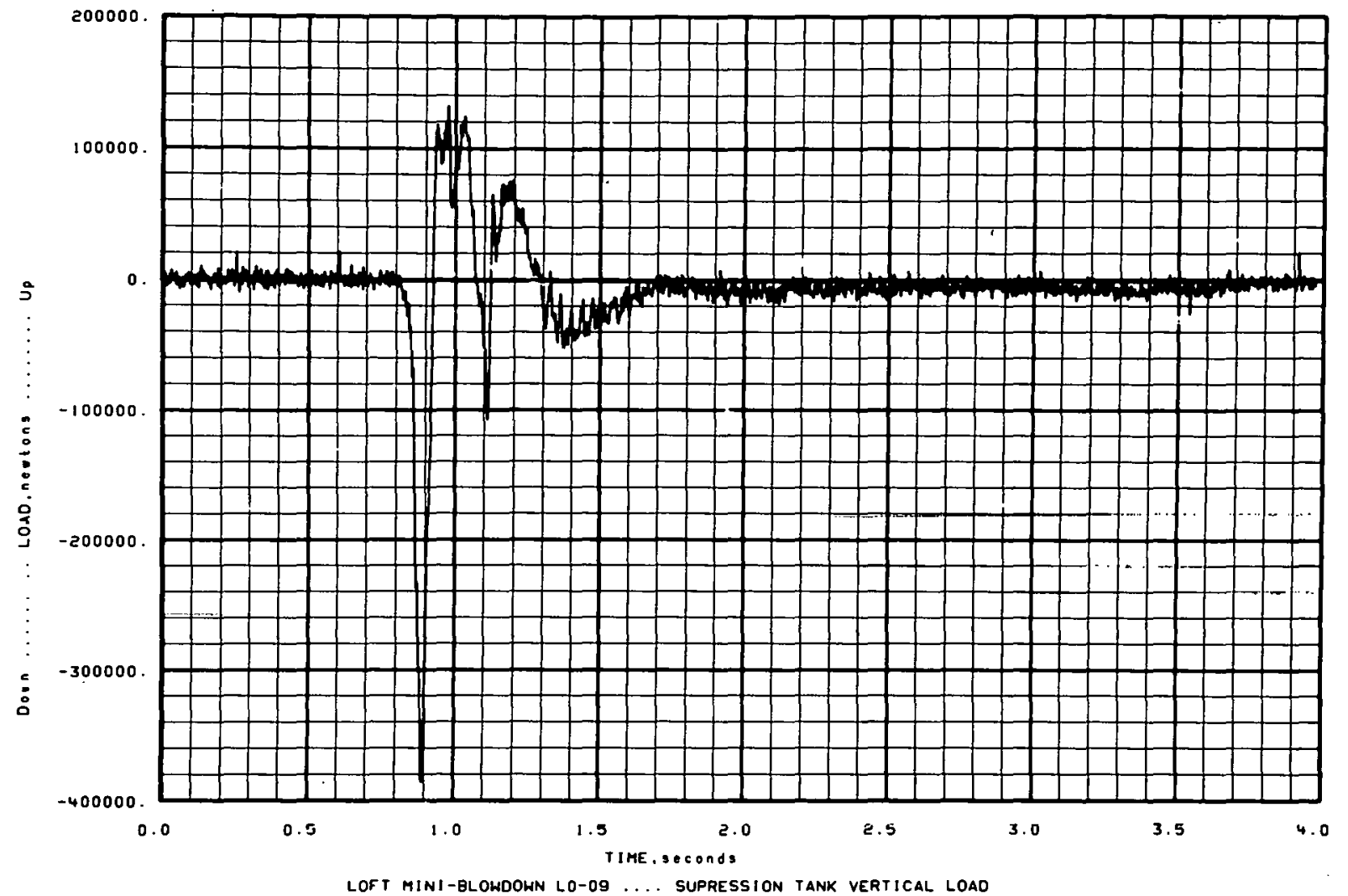

Figure I-7

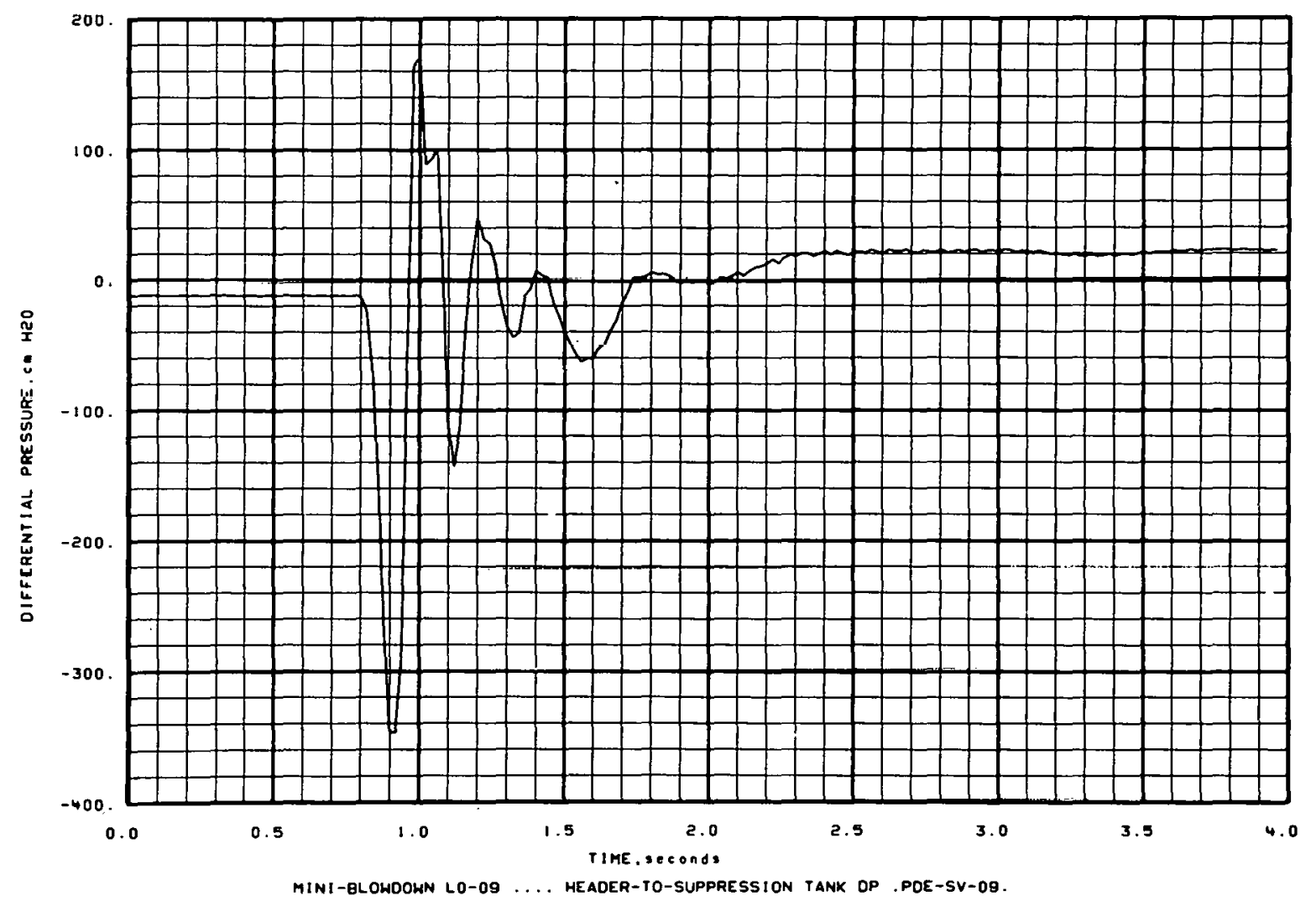

Figure I-8 

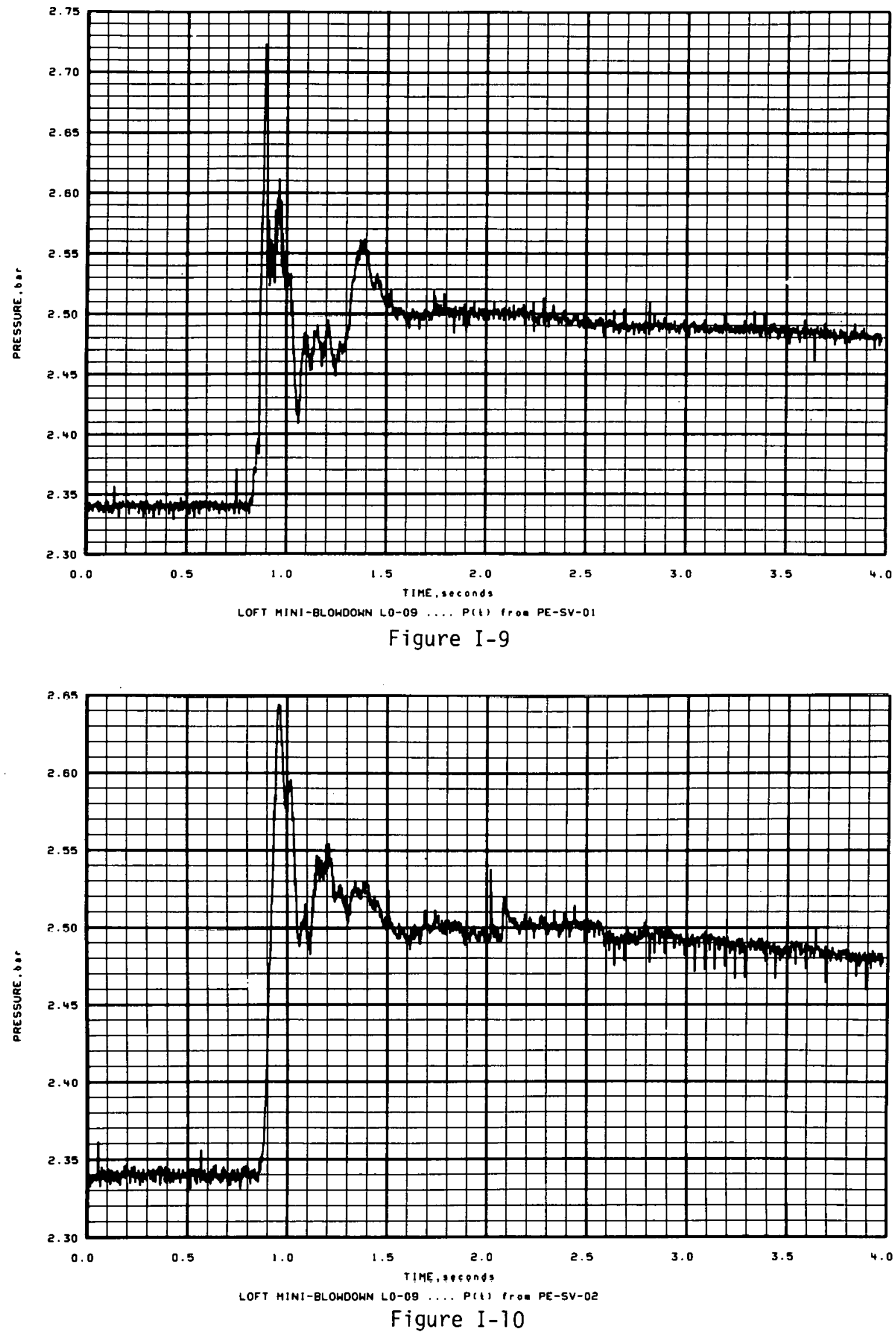

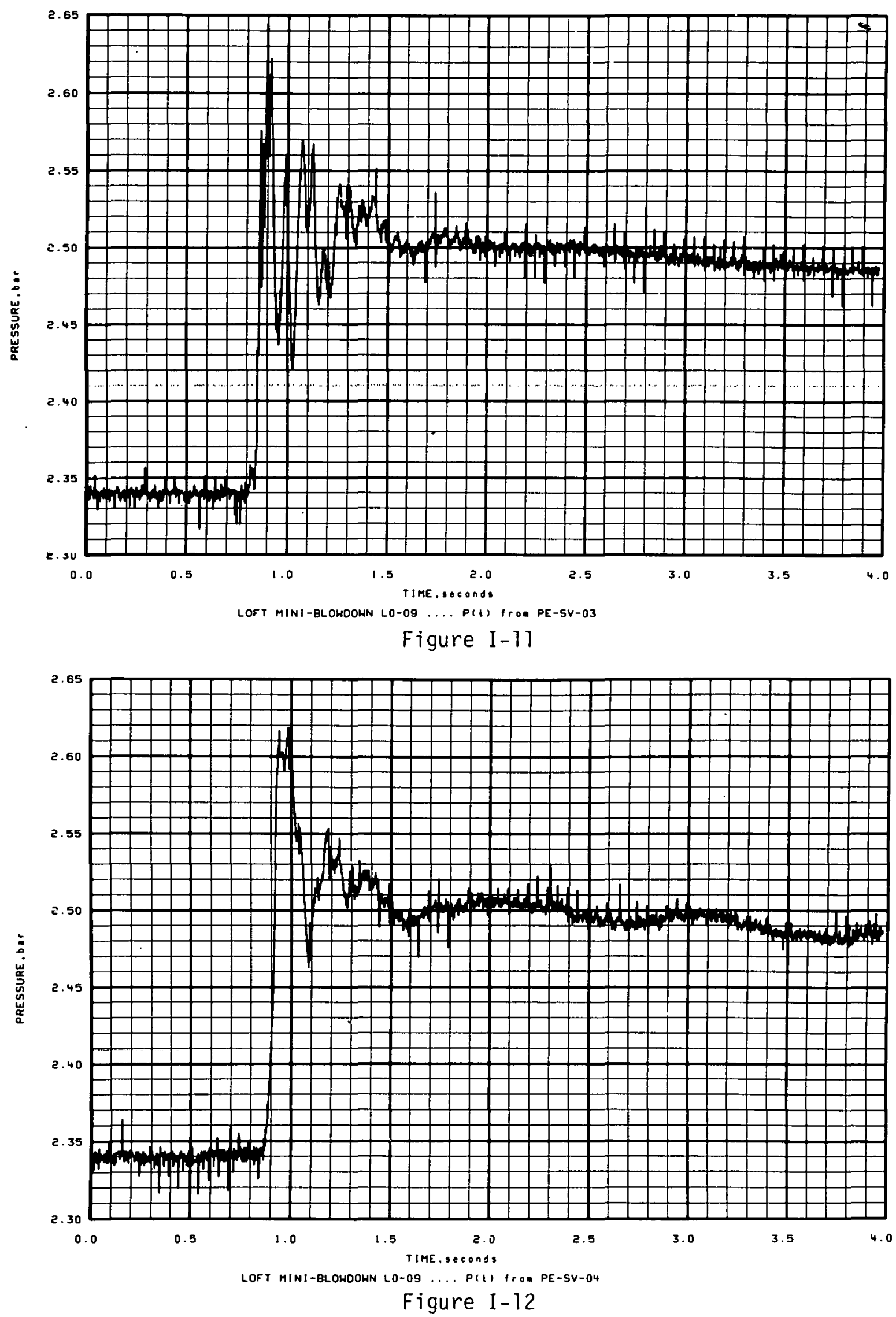

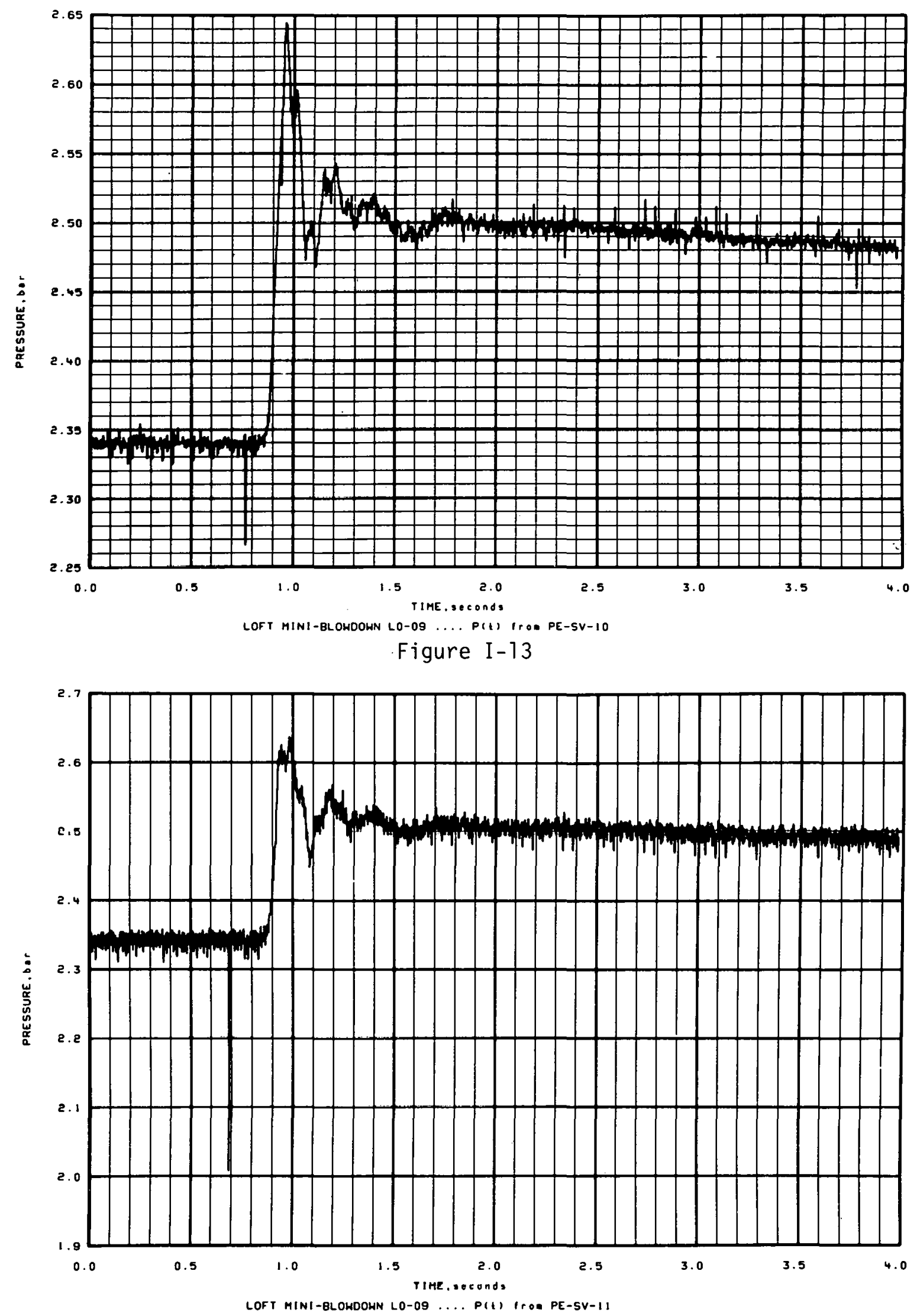

Figure I-14 

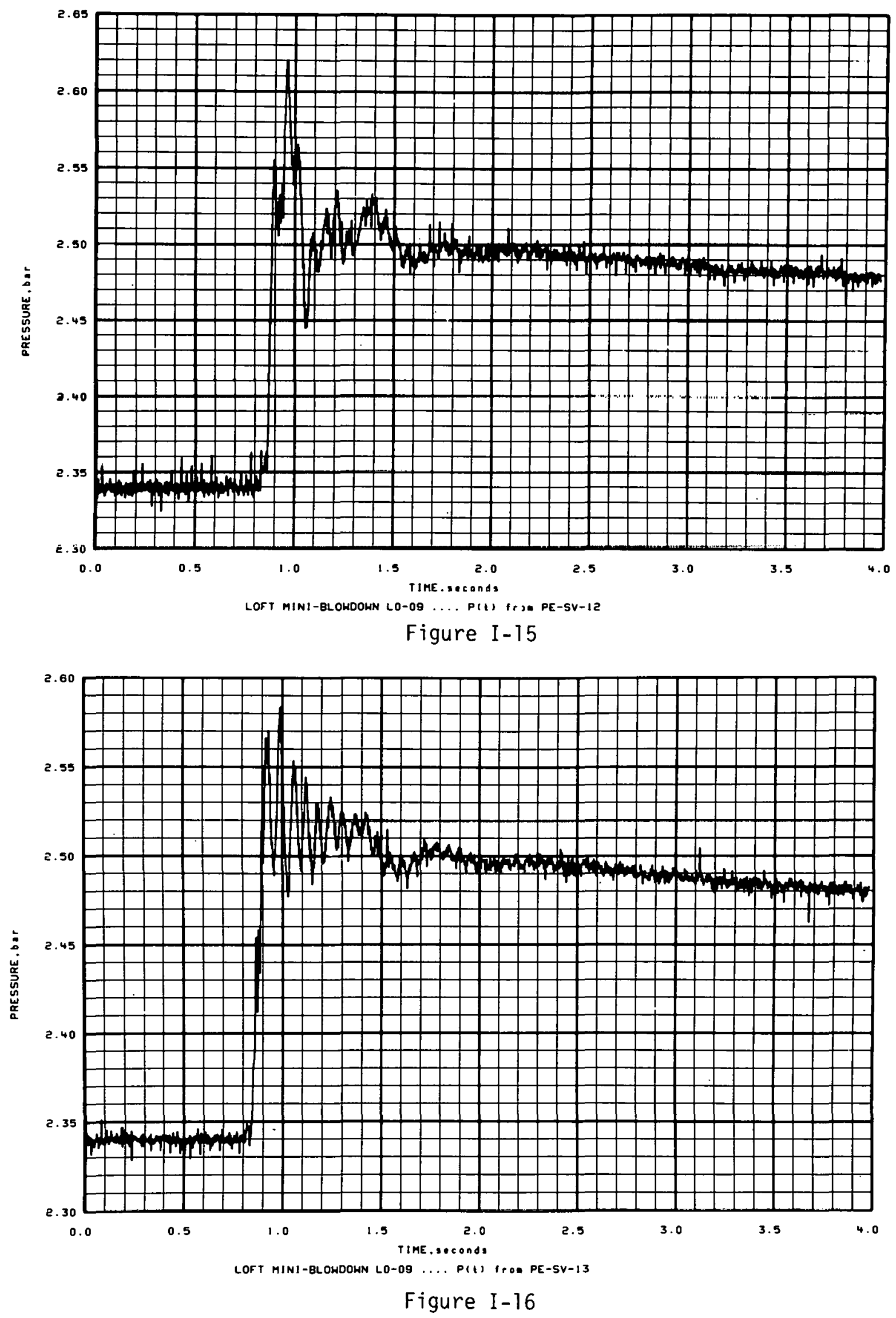

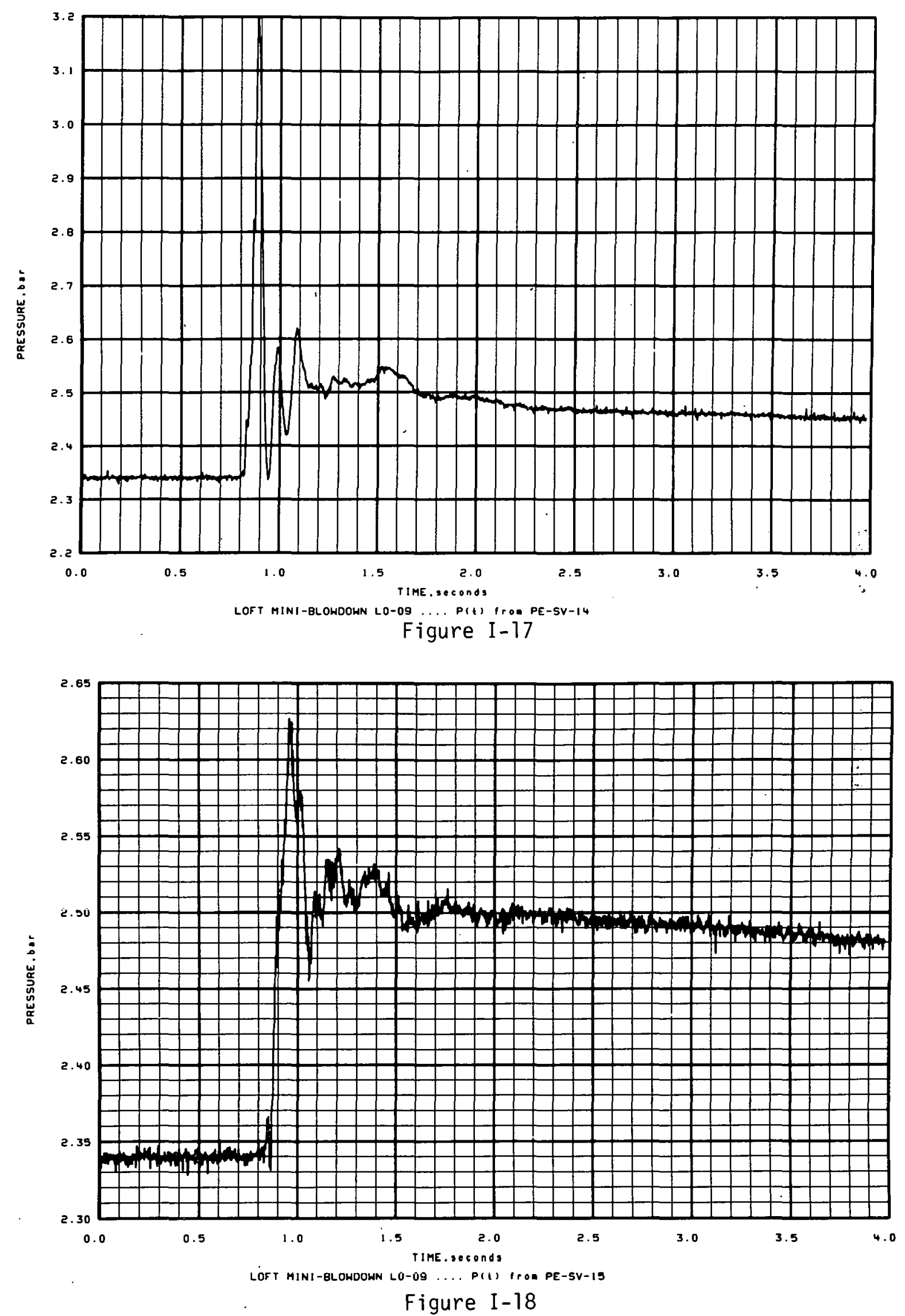

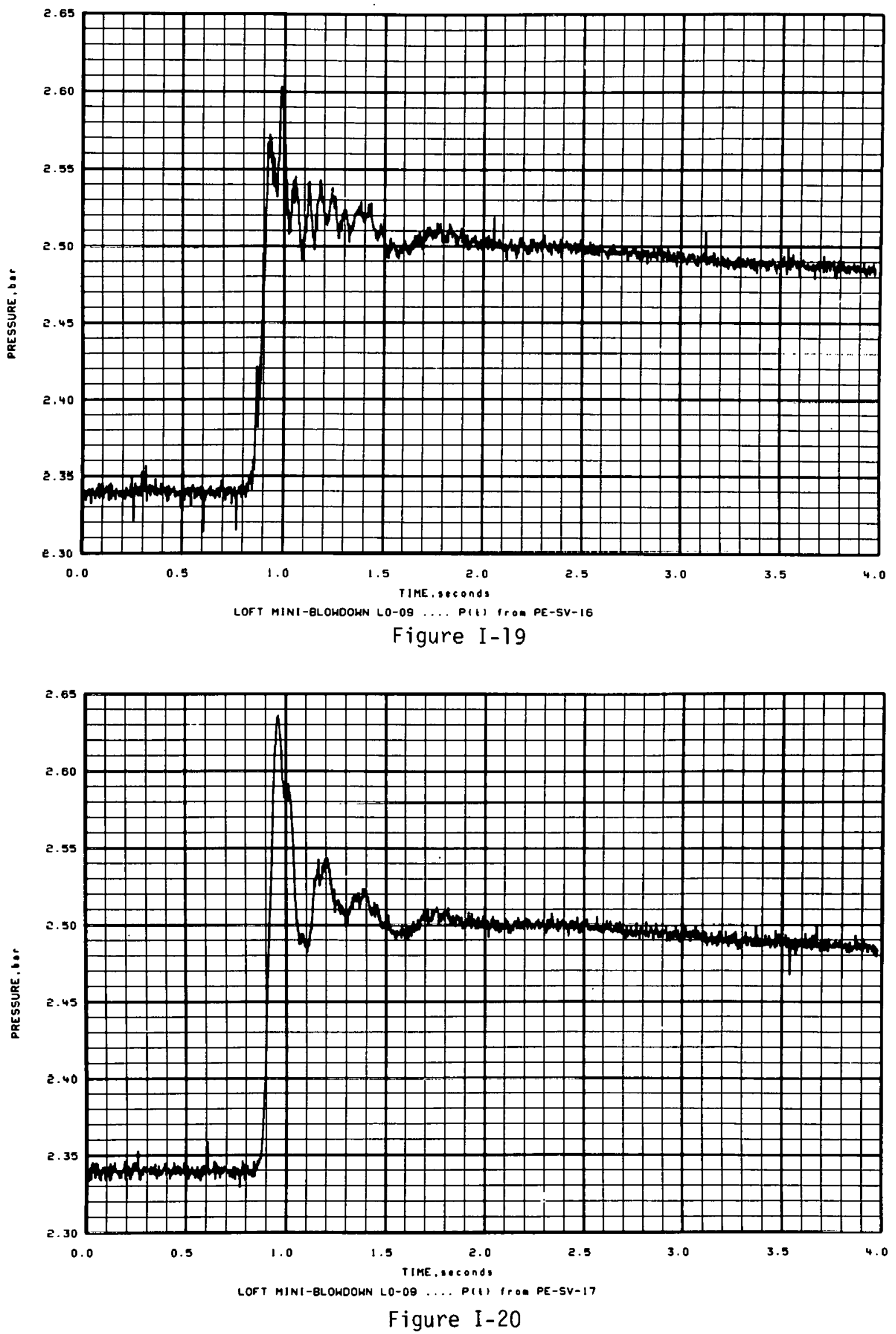


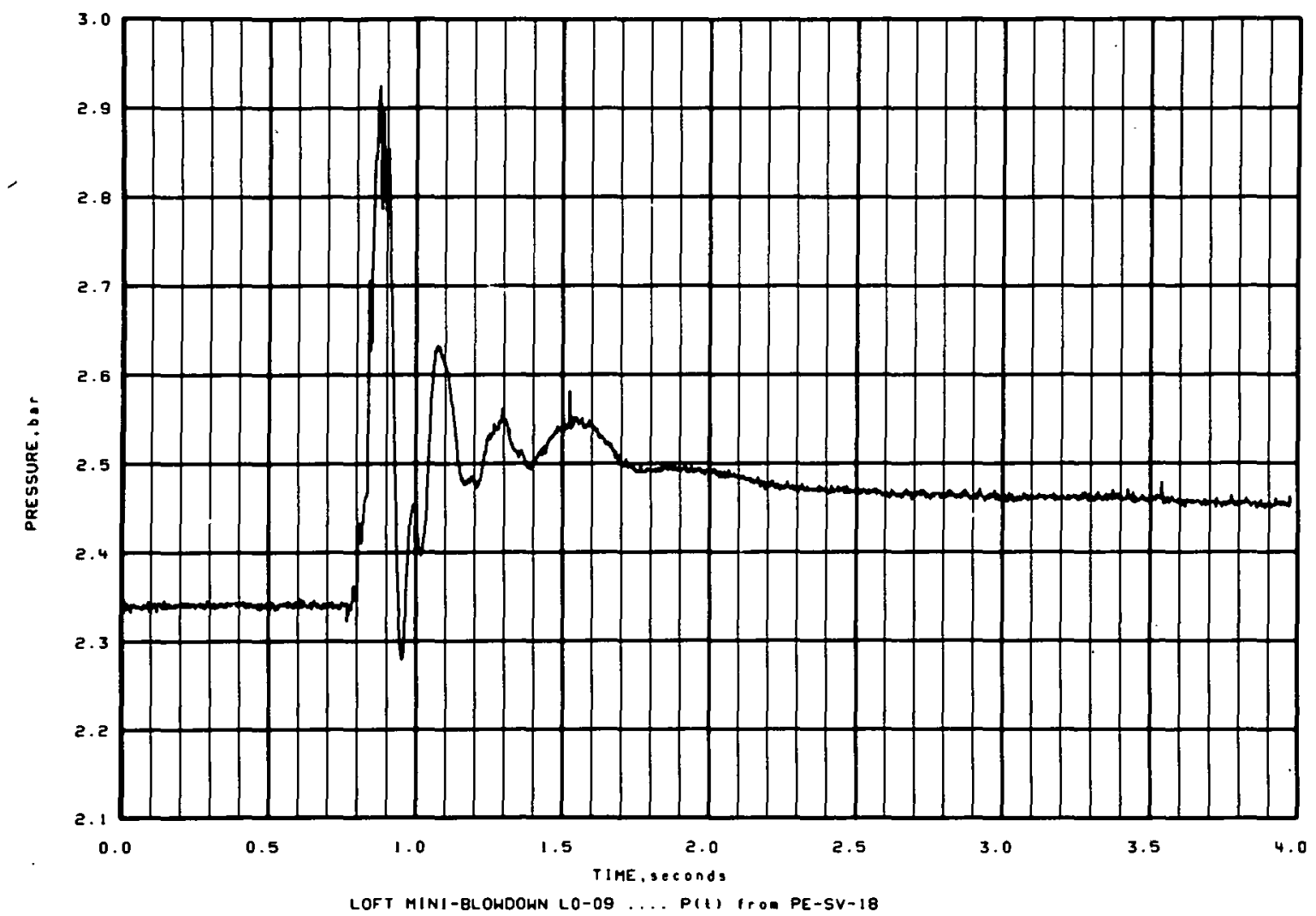

Figure I-21

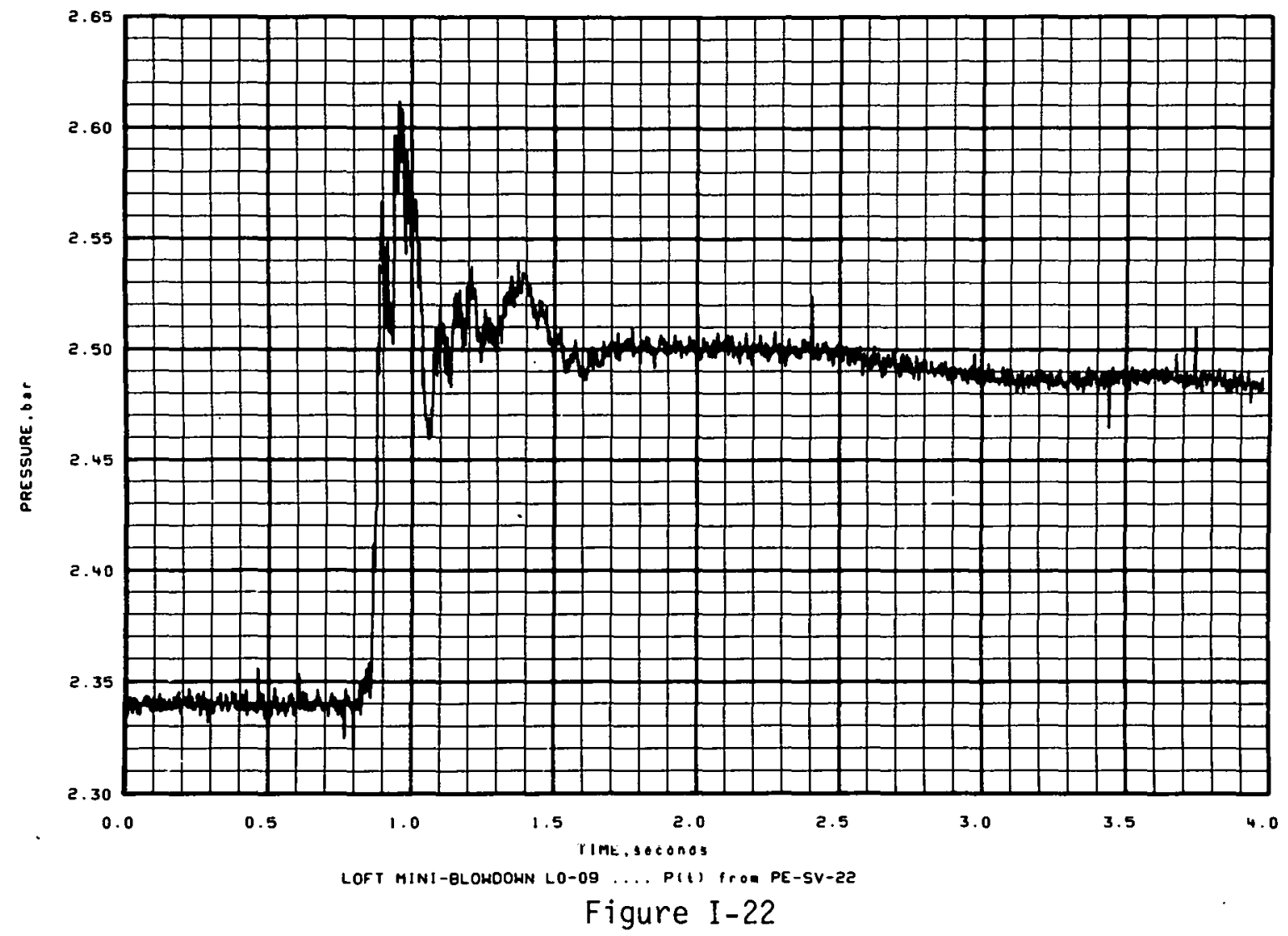



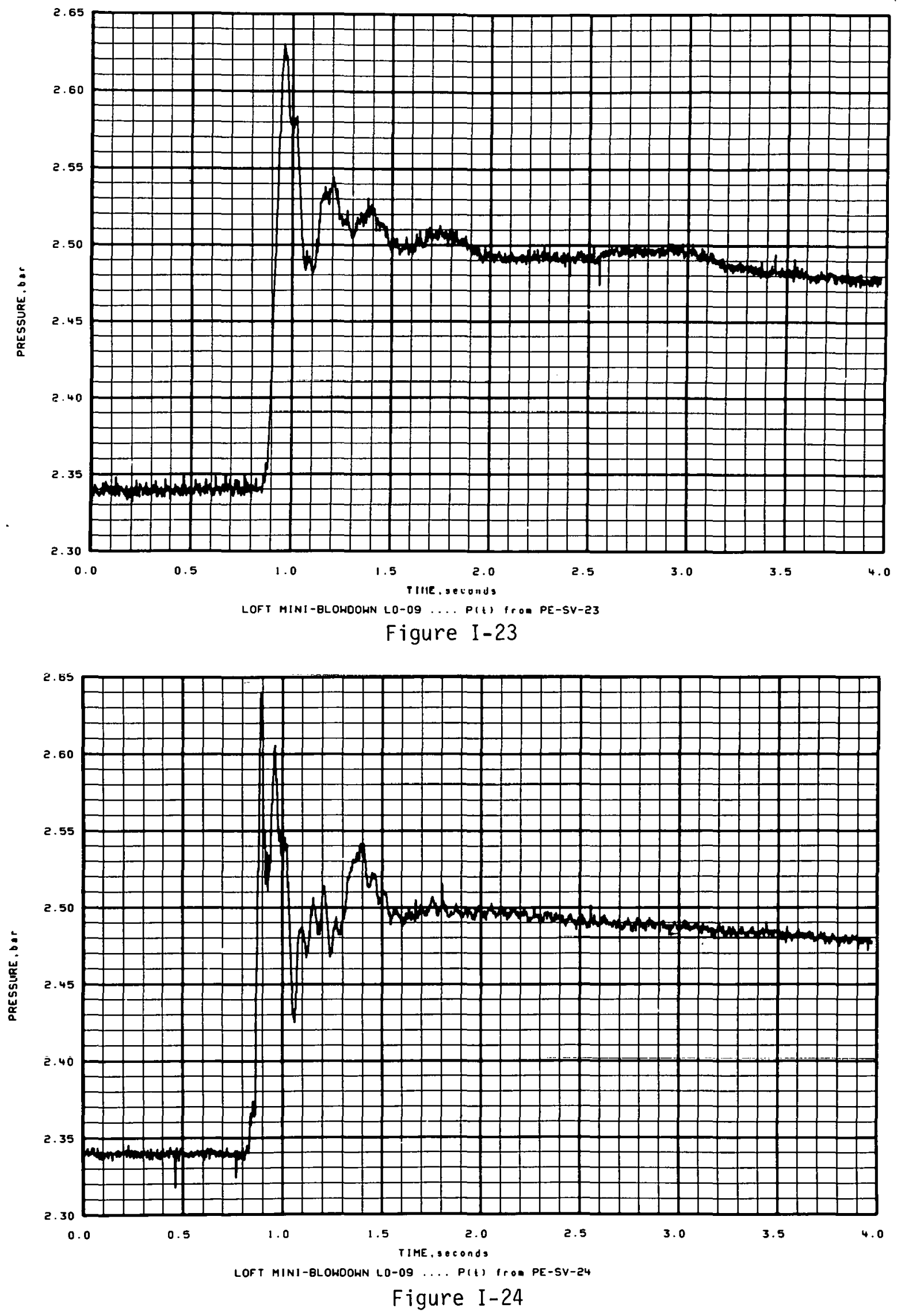

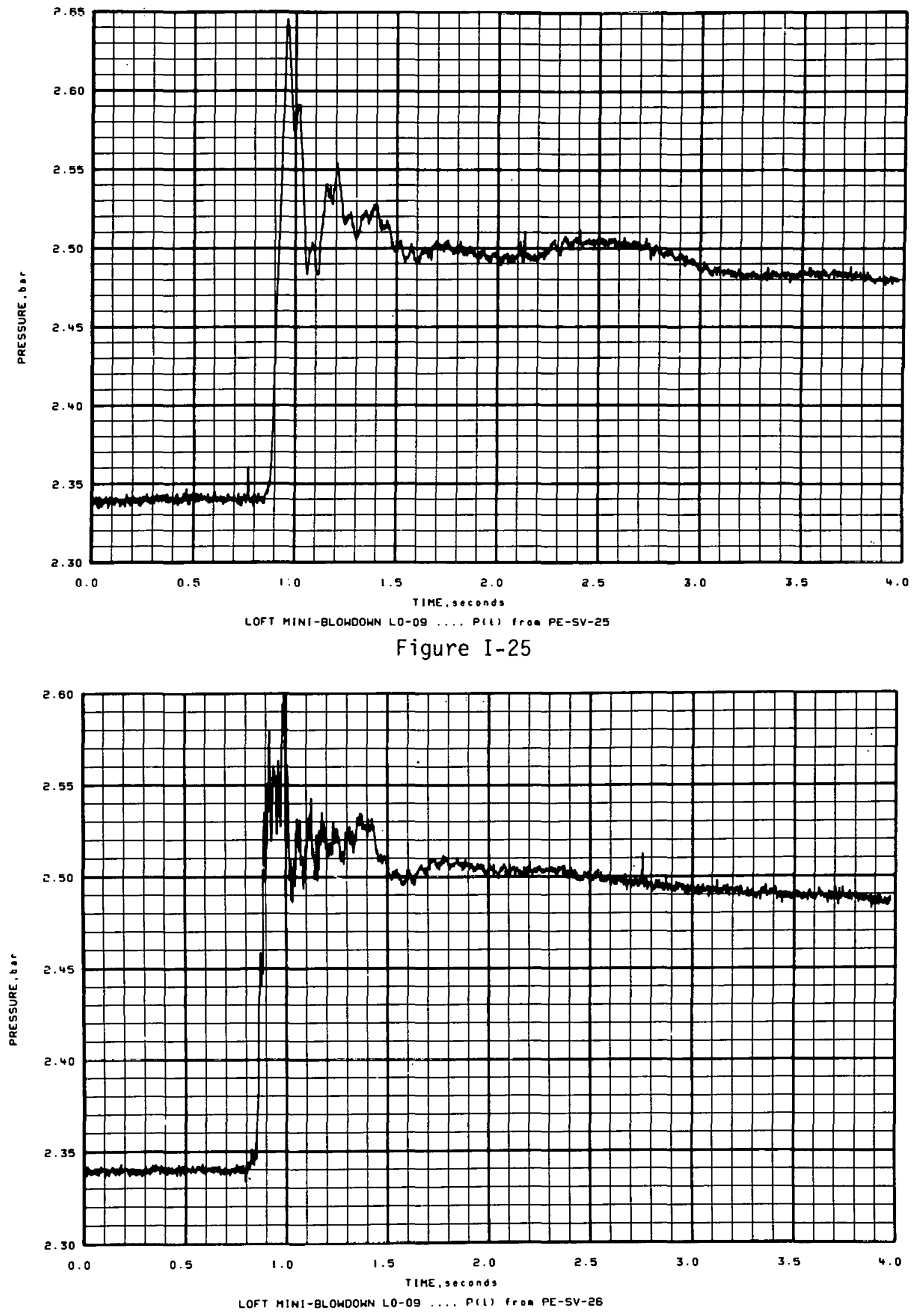

Figure I-26 

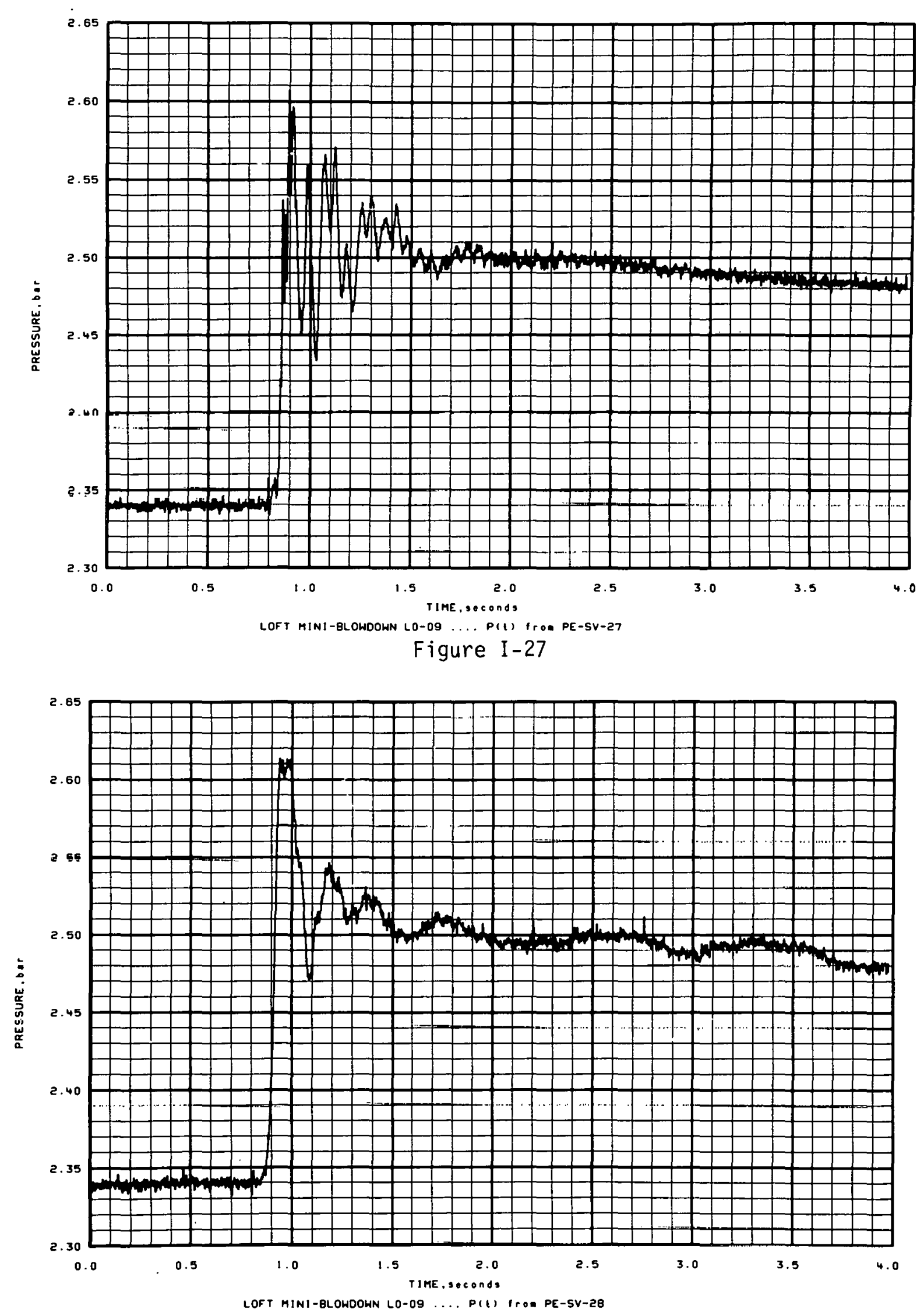

Figure I-28 


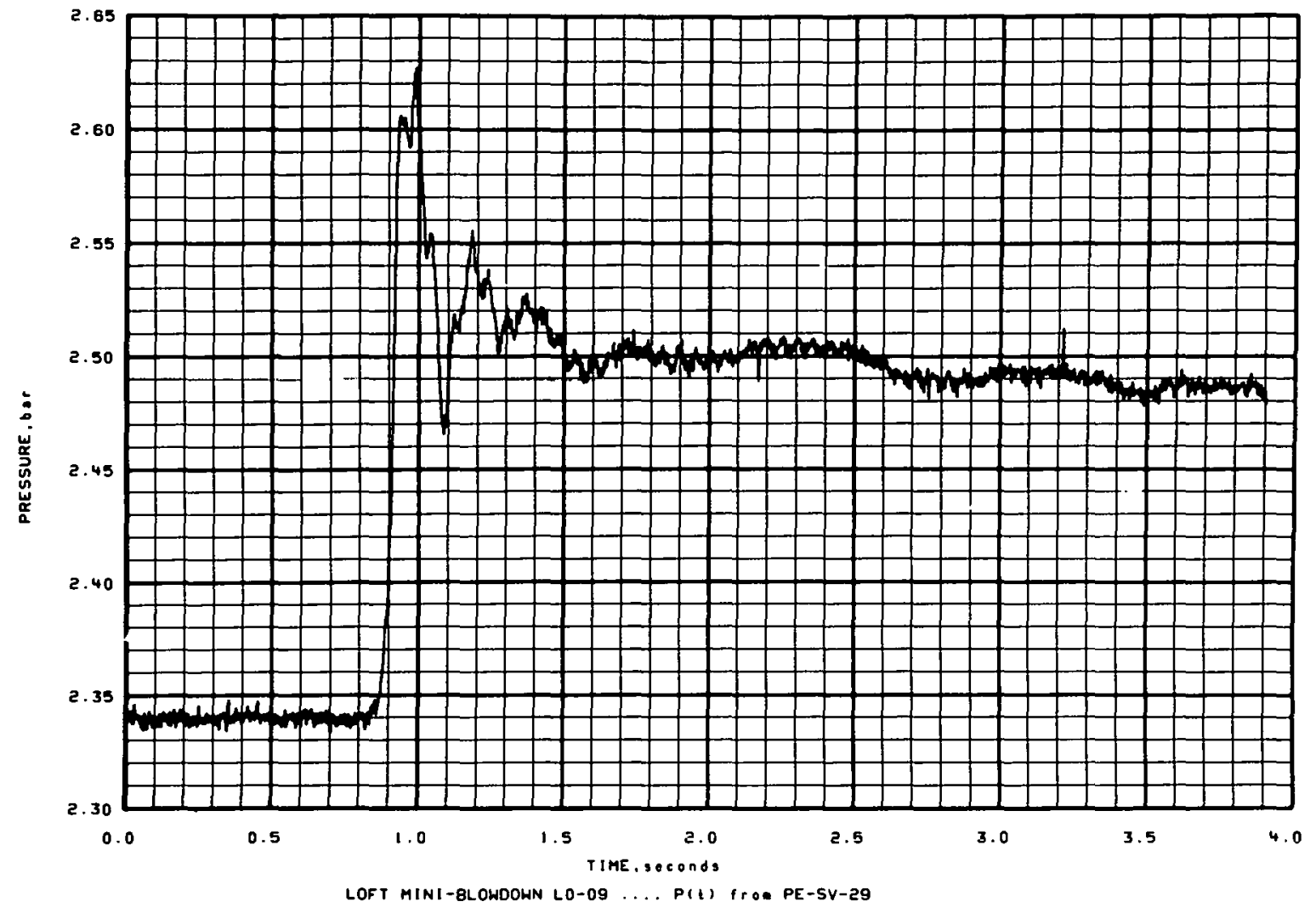

Figure I-29

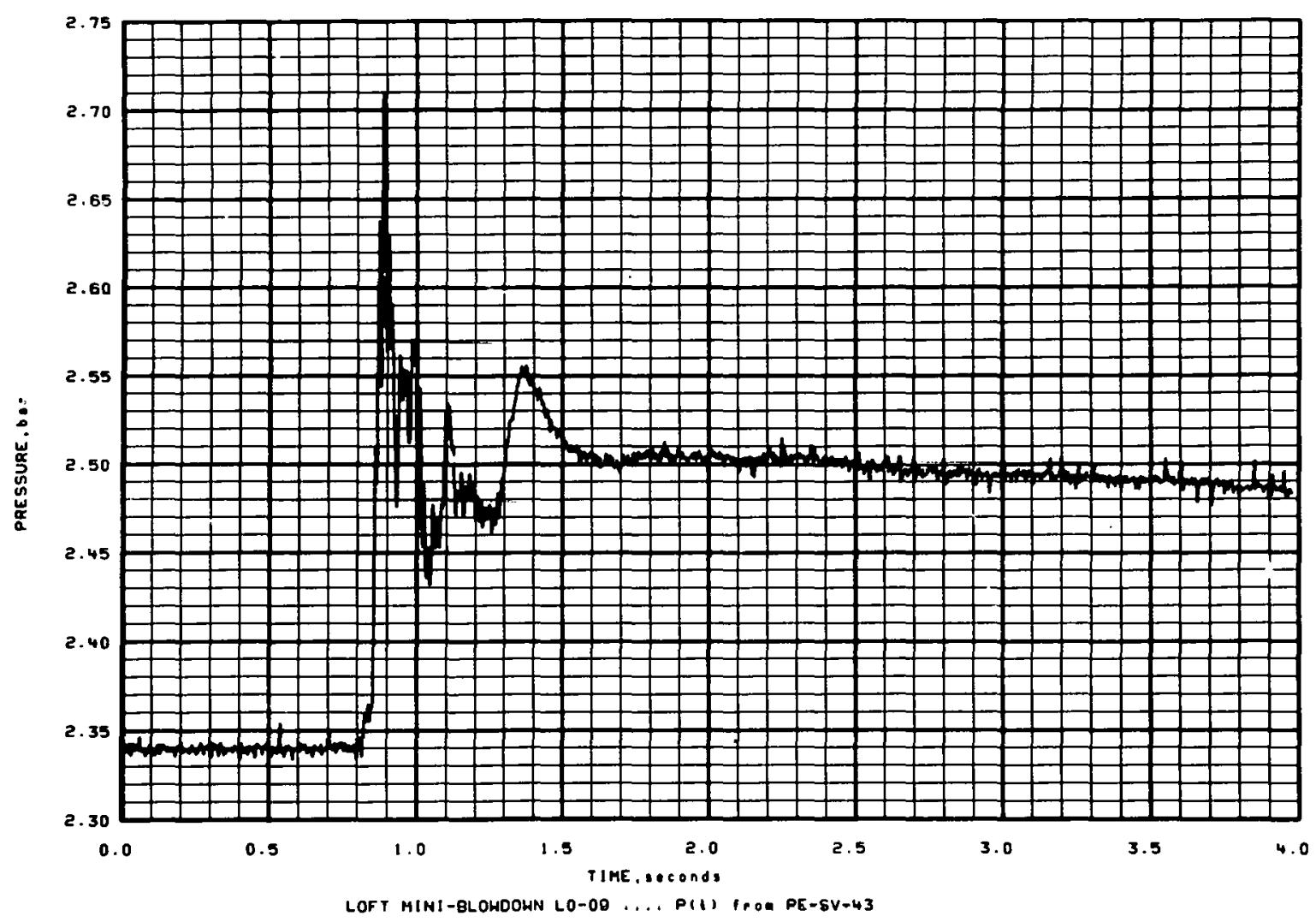

Figure I-30 


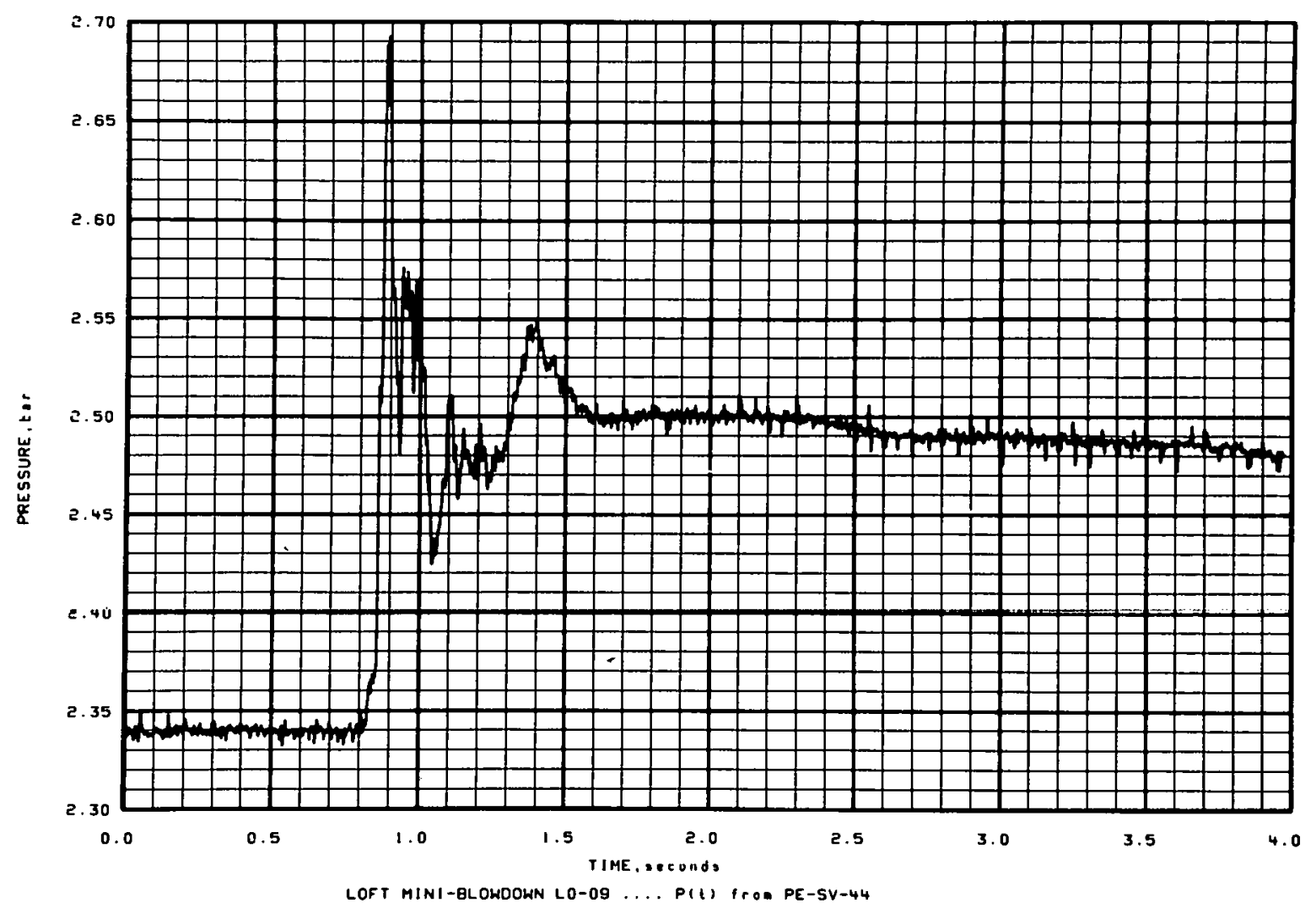

Figure I-31

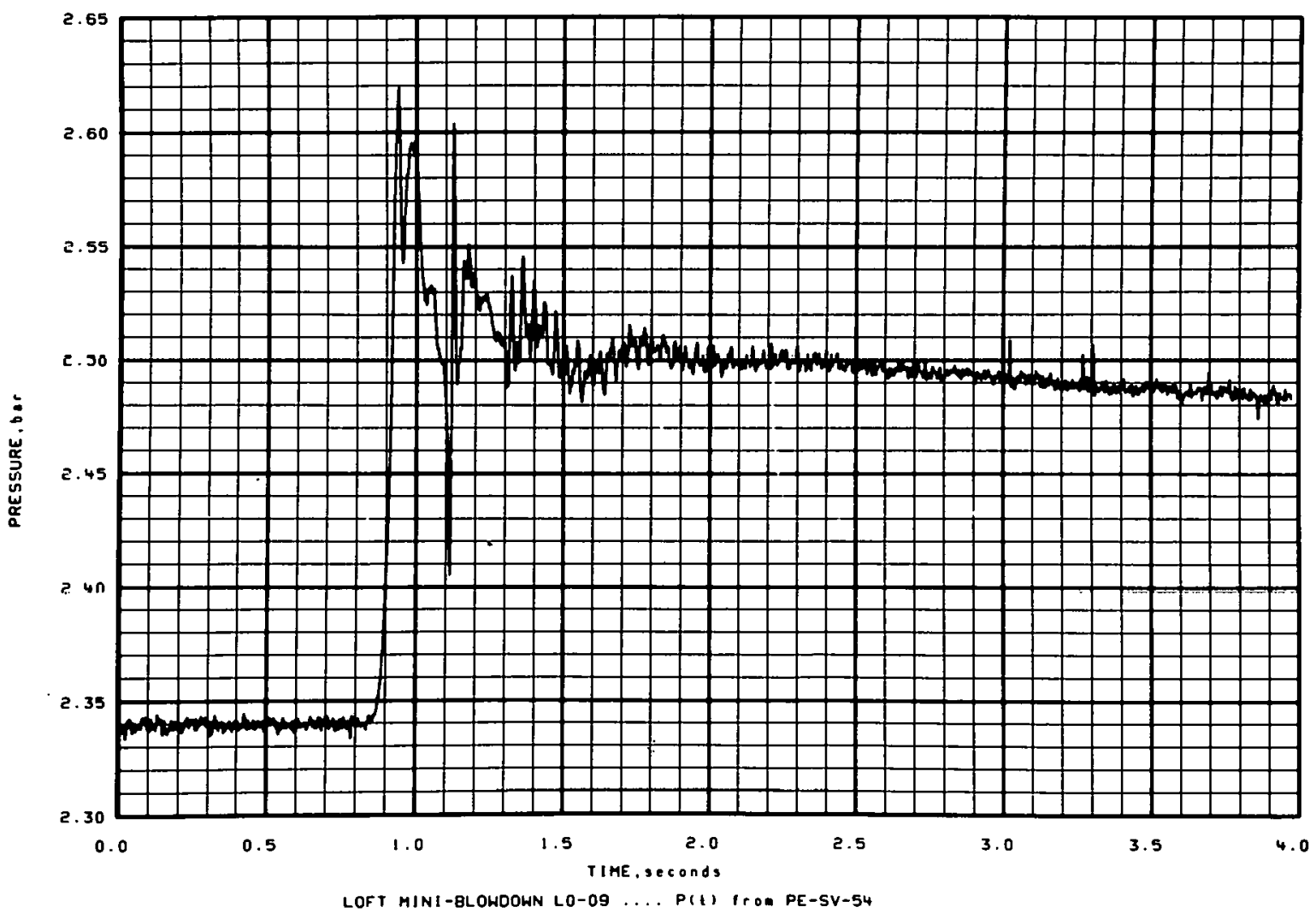

Figure I-32 

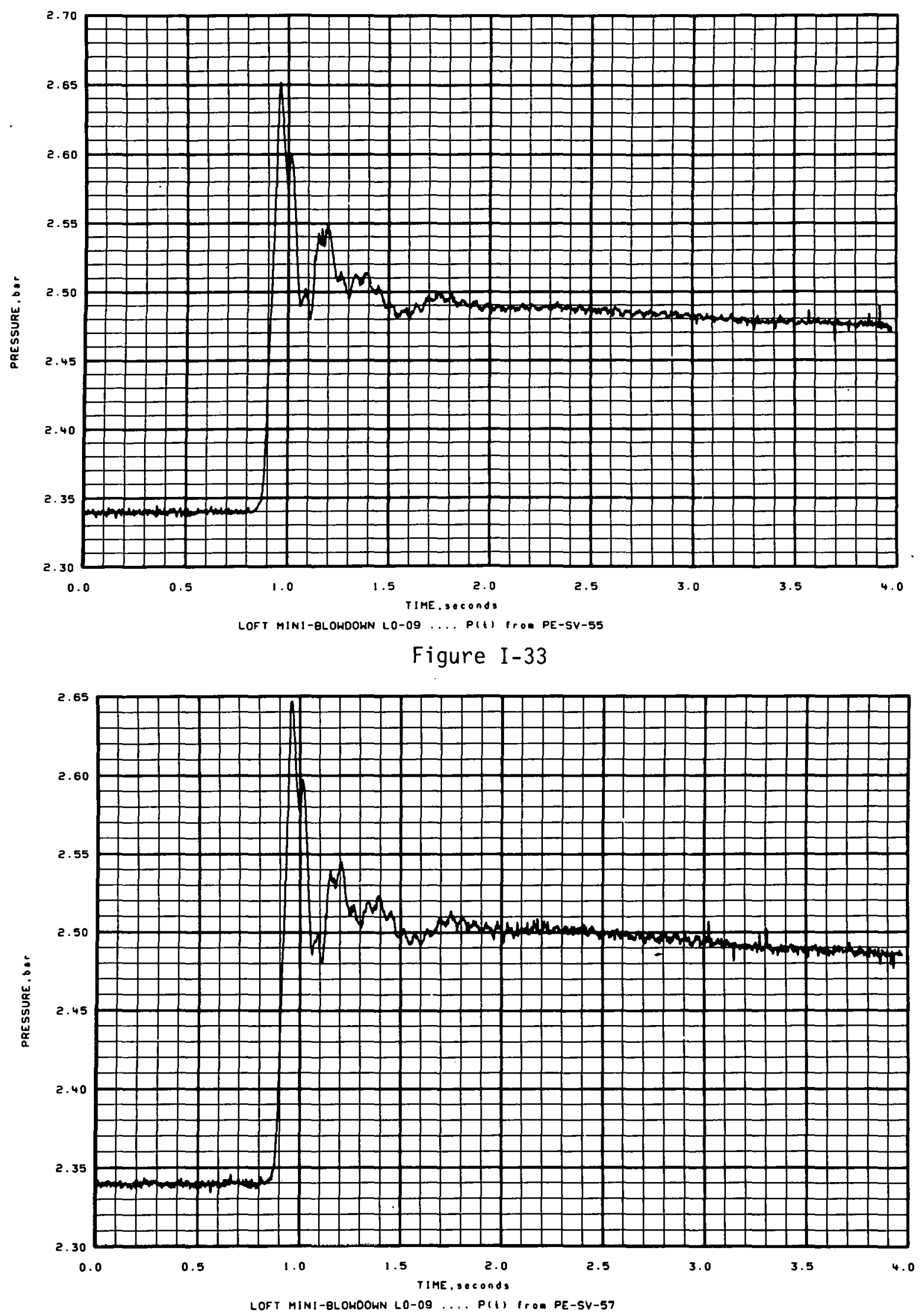

Figure I-34 


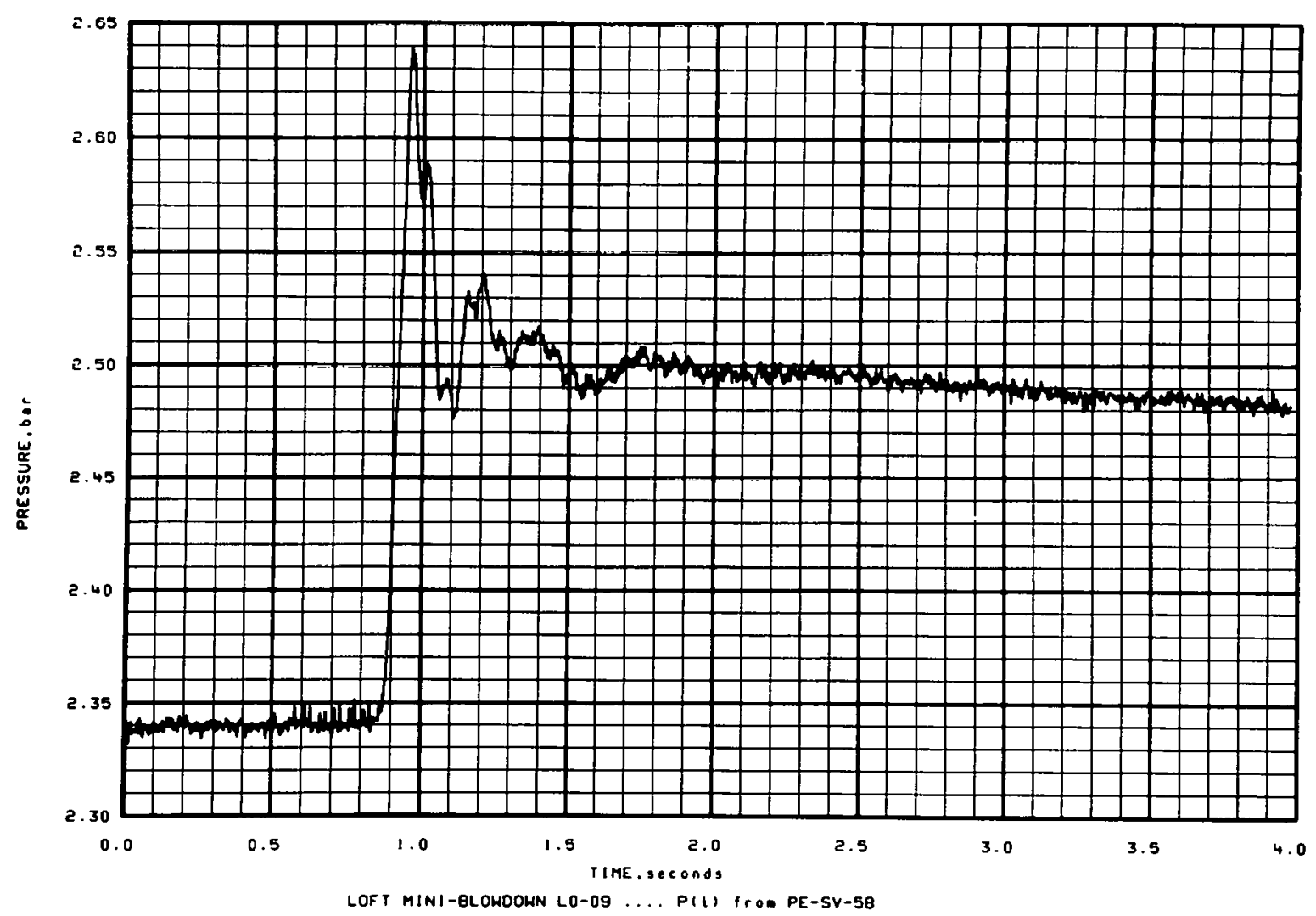

Figure I-35

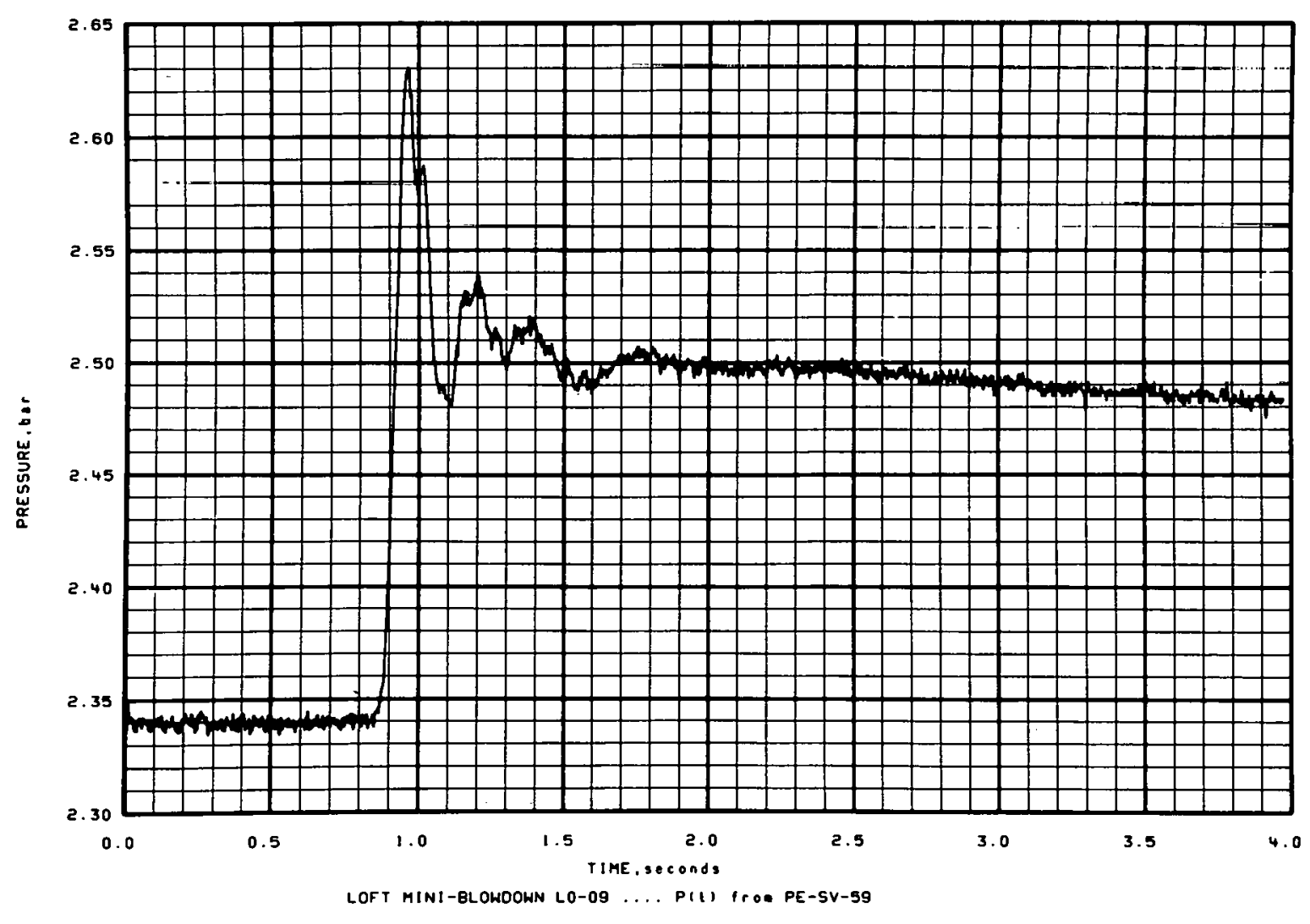

Figure I-36 


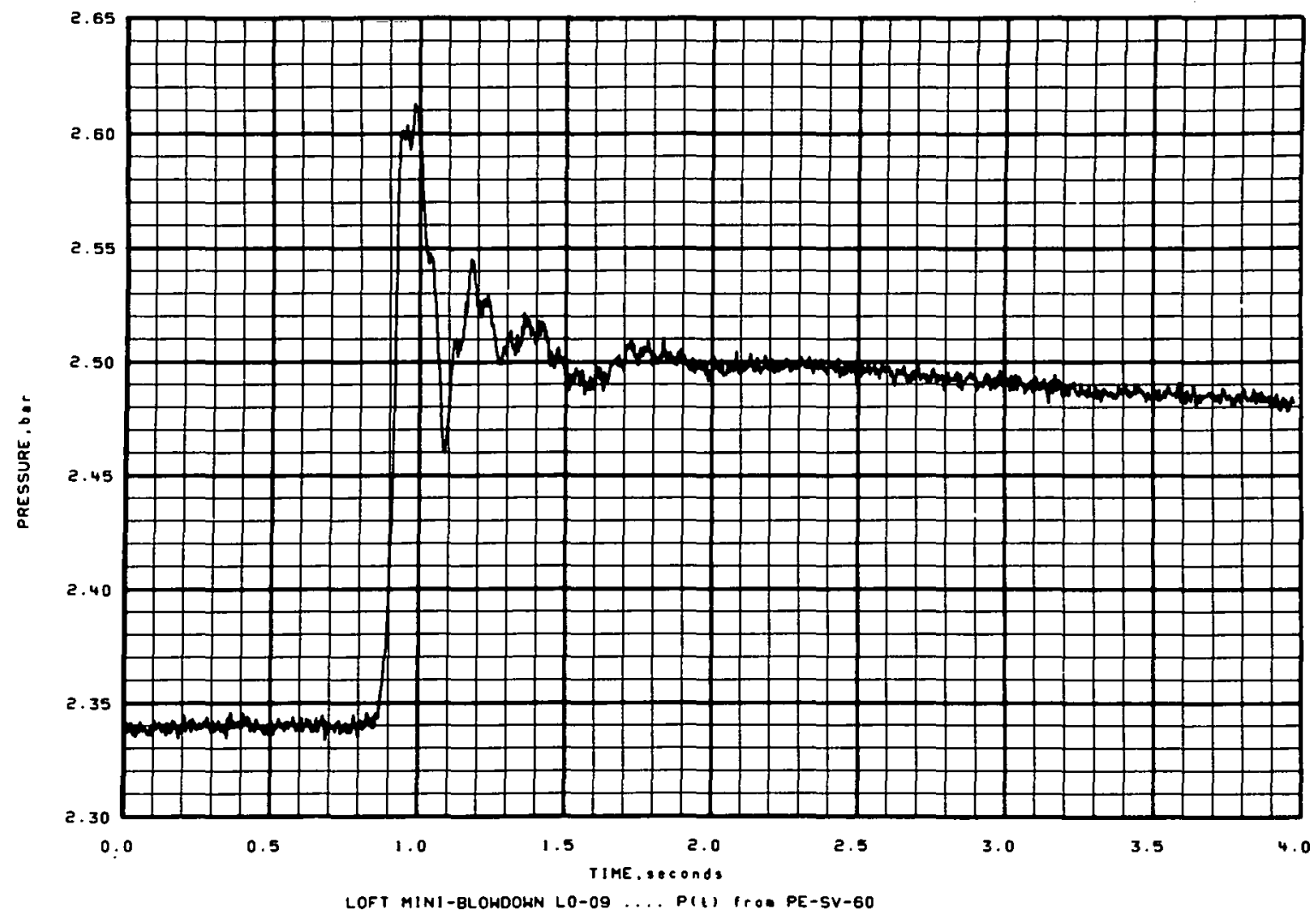

Figure I-37

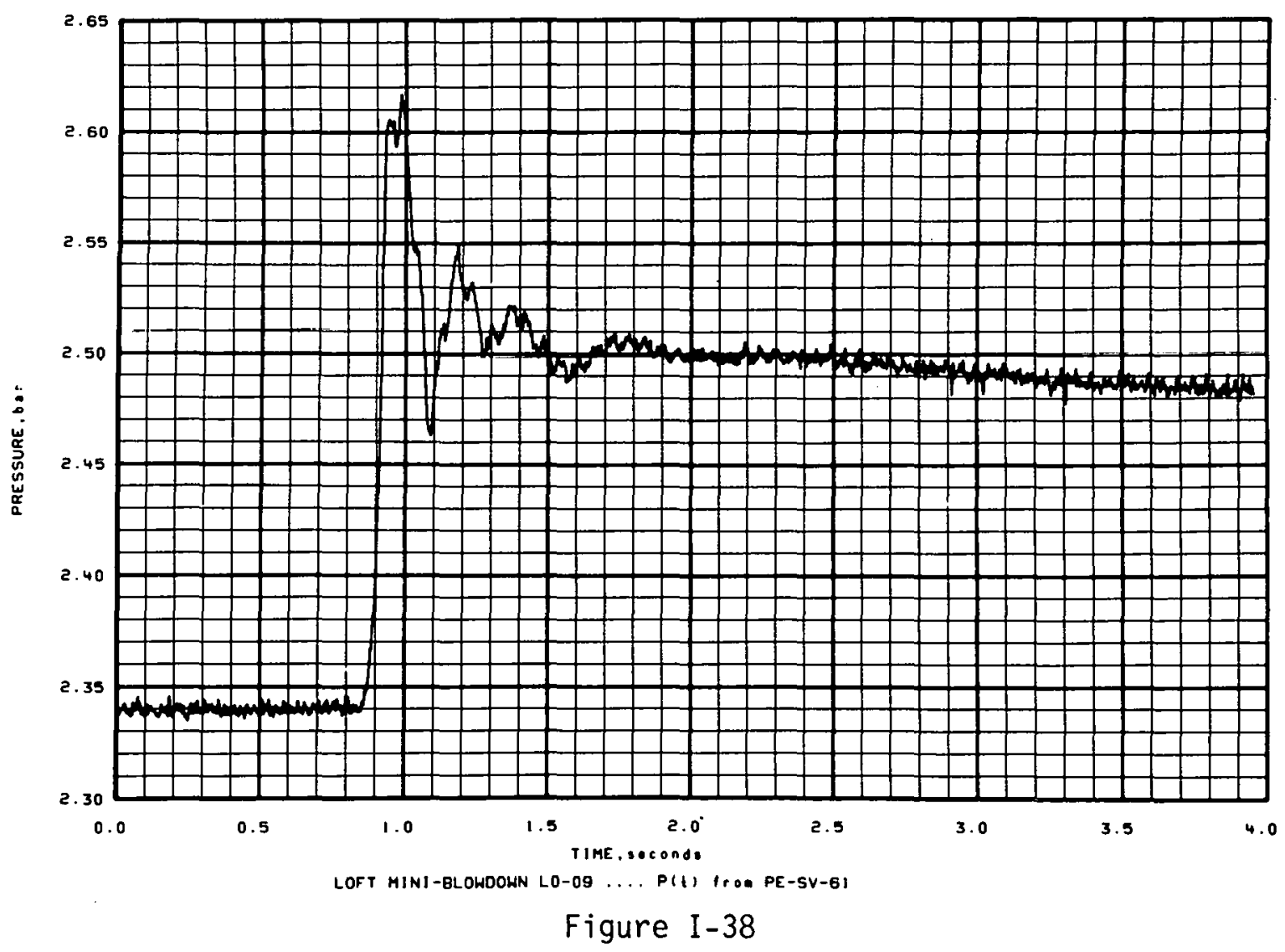




\section{THIS PAGE \\ WAS INTENTIONALLY \\ LEFT BLANK}


APPENDIX J

MINI-BLOWDOWN LO-10 EXPERIMENTAL DATA 


\section{THIS PAGE}

\section{WAS INTENTIONALLY}

LEFT BLANK 
Both QOBVs fully opened in this experiment with start times within $4 \mathrm{msec}$ of each other. The fluid temperature was $250.7 \pm 1.5^{\circ} \mathrm{C}$ in QOBV-1 and $244.9 \pm 1.5^{\circ} \mathrm{C}$ in QOBV-15. The suppression tank conditions were $2.38 \pm 0.08 \mathrm{bar}, 33.2 \pm 1.5^{\circ} \mathrm{C}$ in the gas volume, and $33.9 \pm 1.5^{\circ} \mathrm{C}$ in the pool. The vents were submerged $27.9 \pm 2.5 \mathrm{~cm}$. The internal vent submergence was the same as the external vent submergence.

The experimental data are defined in Table J-I. The opening characteristics of the QOBVs are shown in terms of percent sleeve travel versus time. The flow area of the valve begins to open at a sleeve position of $17 \%$ of full travel and is fully open at a sleeve position of $66 \%$ of full travel. The differential pressure between the header and the tank gas volume is measured with a very sensitive device primarily to provide information on vent preclearing. The data channel for this measurement is driven to saturation in the early part of the transient. 
TABLE J-I

EXPERIMENT L0-10 DATA SUMMARY

\begin{tabular}{|c|c|c|c|c|c|}
\hline $\begin{array}{l}\text { Measurement } \\
\text { or } \\
\text { Calculation }\end{array}$ & $\begin{array}{l}\text { Pre-Transient } \\
\text { Data Channe1 } \\
\text { Variance } \\
\left(10^{-4} \text { bar }^{2}\right) \\
\end{array}$ & Figure Number & Measurement & $\begin{array}{c}\text { Pre-Transient } \\
\text { Data Channel } \\
\text { Variance } \\
\left(10^{-4} \text { bar }\right) \\
\end{array}$ & Figure Number \\
\hline QOBV-1 opening & - & $\mathrm{J}-1, \mathrm{~J}-2$ & PE-SV-22 & 0.07664 & $\mathrm{~J}-22$ \\
\hline QOBV-15 opening & - & $J-3, J-4$ & PE-SV-23 & 0.10206 & $J-23$ \\
\hline $\begin{array}{l}\text { Combined QOBV } \\
\text { opening }\end{array}$ & - & $J-5, J-6$ & PE-SV-24 & 0.07348 & $J-24$ \\
\hline Vertical load & - & $3-7$ & PE-SV-25 & 0.10011 & $J-25$ \\
\hline PDE-SV-09 & - & $\mathrm{J}-8$ & $P, E-S V-26$ & 0.05908 & $J-26$ \\
\hline PE-SV-01 & 0.06842 & $J-9$ & $P E-S V-27$ & 0.10686 & $\mathrm{~J}-27$ \\
\hline PE-SV-02 & 0.06807 & $\mathrm{~J}-10$ & $P E-S V-28$ & 0.08586 & $\mathrm{~J}-28$ \\
\hline$P E-5 V-03$ & 0.06192 & $J-11$ & PE-SV-29 & 0.07840 & $\mathrm{~J}-29$ \\
\hline PE-SV-04 & 0.06958 & $J-12$ & PE-SV-43 & 0.03447 & $\mathrm{~J}-30$ \\
\hline PE-SV-10 & 0.08650 & $J-13$ & PE-SV-44 & 0.03392 & $J=31$ \\
\hline PE-SV-11 & 0.82880 & $J-14$ & PE-SV-54 & 0.04761 & $\mathrm{~J}-32$ \\
\hline$P[-2 V-15$ & 0.07621 & $3-15$ & PE-.SV-55 & 0.02308 & $\mathrm{~J}-33$ \\
\hline$P E-5 V-13$ & .0 .05048 & $J-16$ & $P E-S V-50$ & \multicolumn{2}{|c|}{ measurement deleted } \\
\hline PE-SV-14 & 0.06146 & $\mathrm{~J}-17$ & PE-SV-57 & 0.03260 & $\mathrm{~J}-34$ \\
\hline PE-SV-15 & 0.06646 & $J-18$ & $P E-S V-58$ & 0.05076 & $J-35$ \\
\hline PE-SV-16 & 0.05912 & $\mathrm{~J}-19$ & PE-SV-59 & 0.05462 & $J-36$ \\
\hline PE-SV-17 & 0.07027 & $J-20$ & PE-SV-60 & 0.05282 & $\mathrm{~J}-37$ \\
\hline PE-SV-18 & 0.07027 & $J-21$ & PE-SV-61 & 0.07023 & $\mathrm{~J}-38$ \\
\hline
\end{tabular}




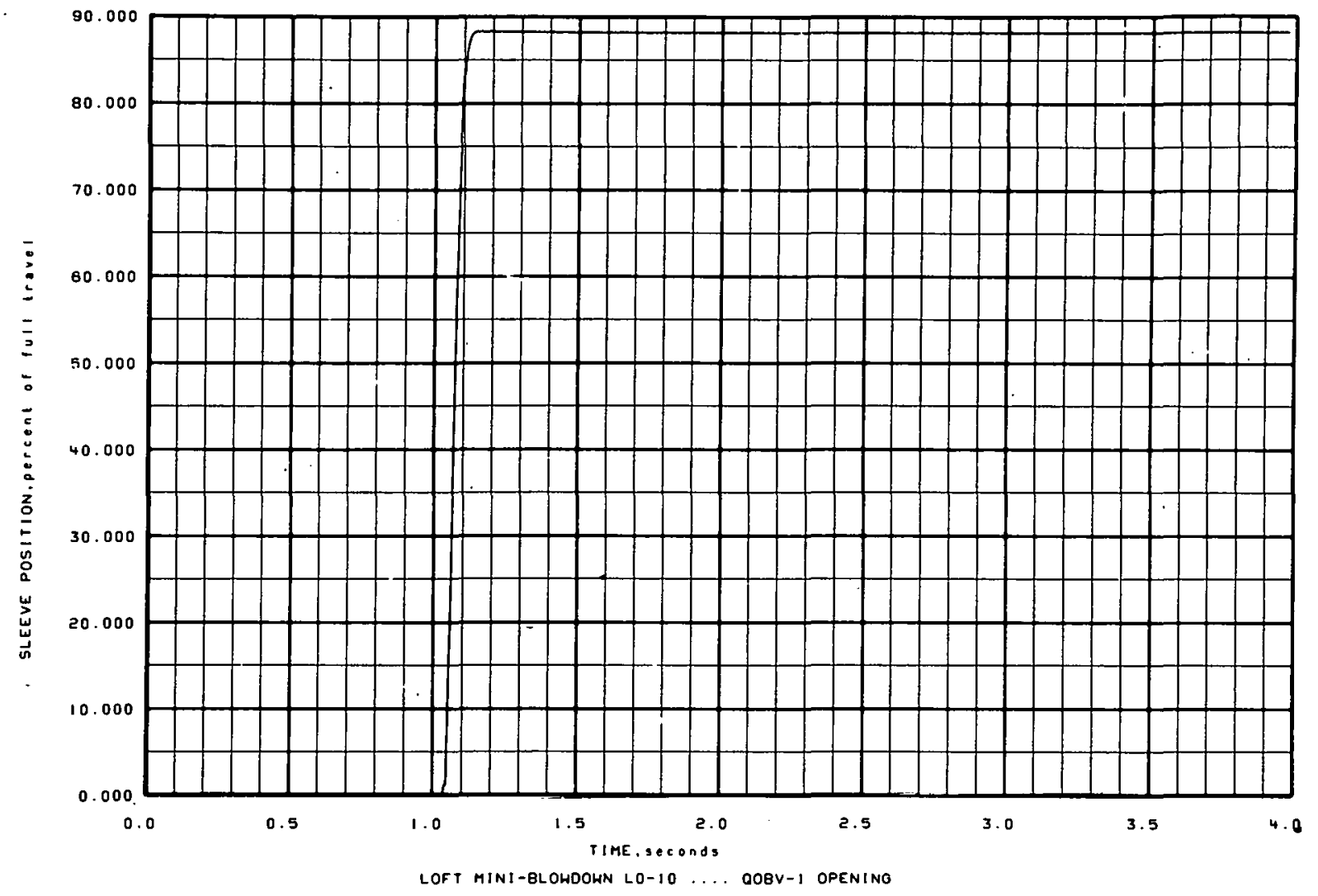

Figure J-l

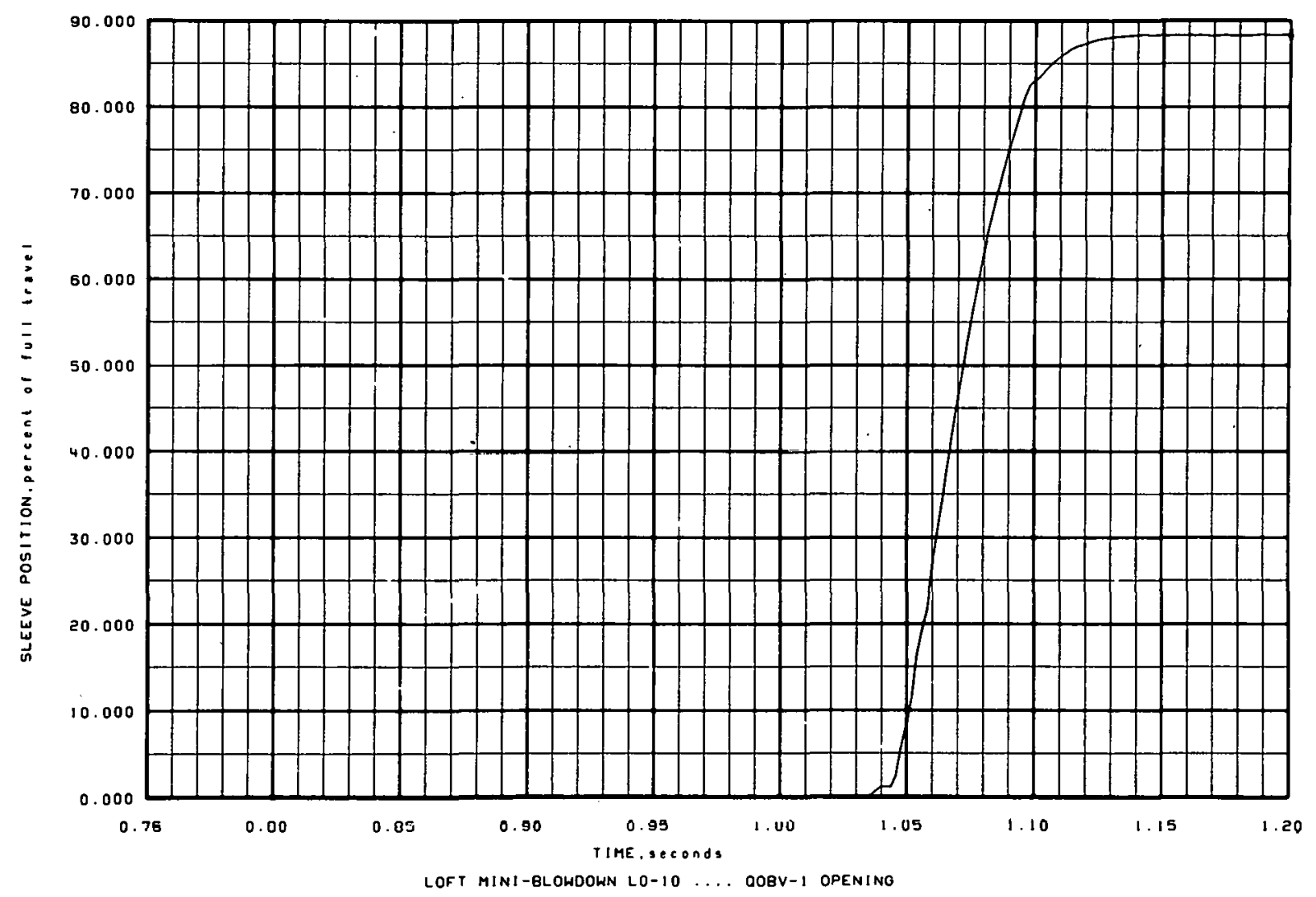

Figure $\mathrm{J}-2$ 

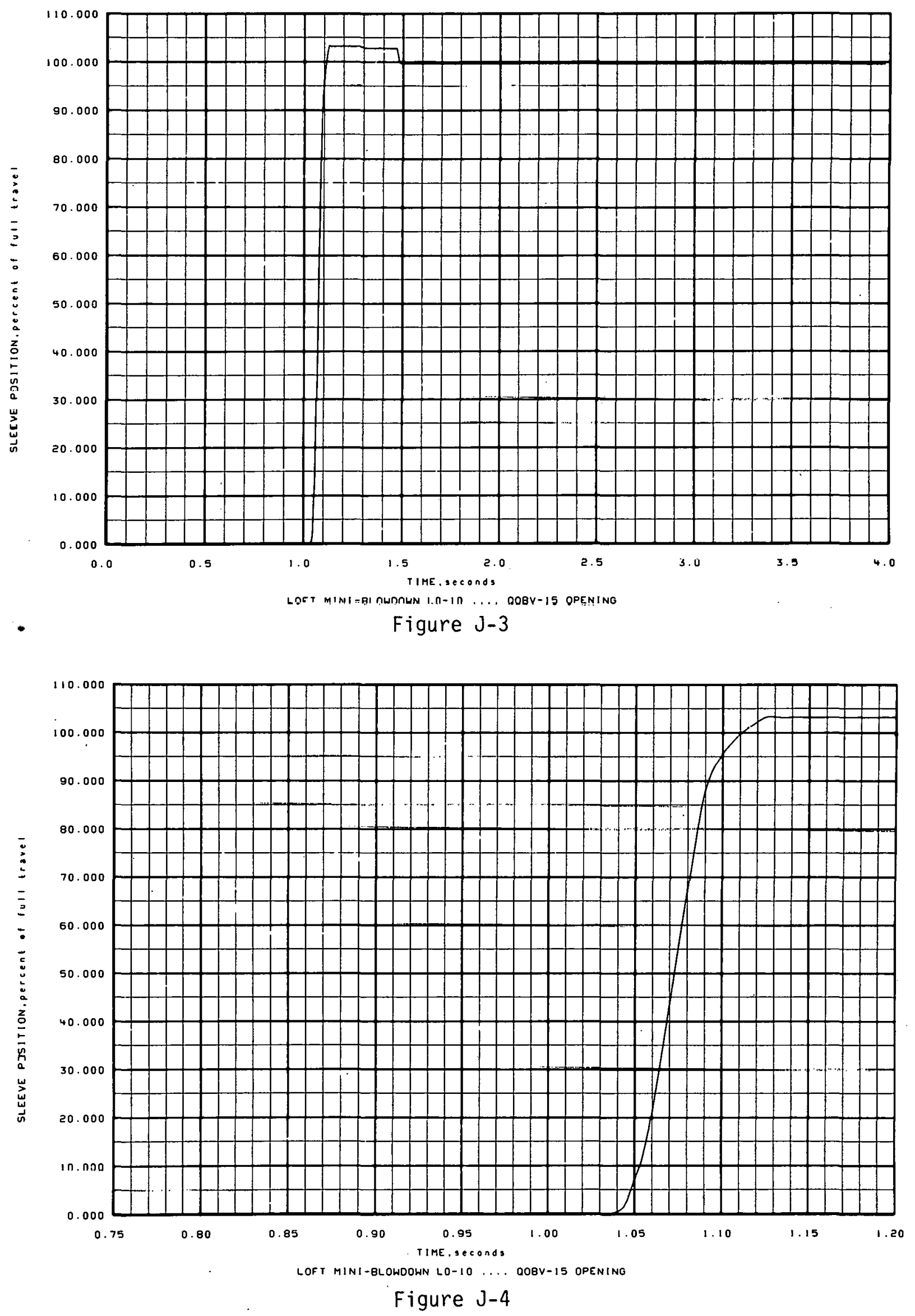

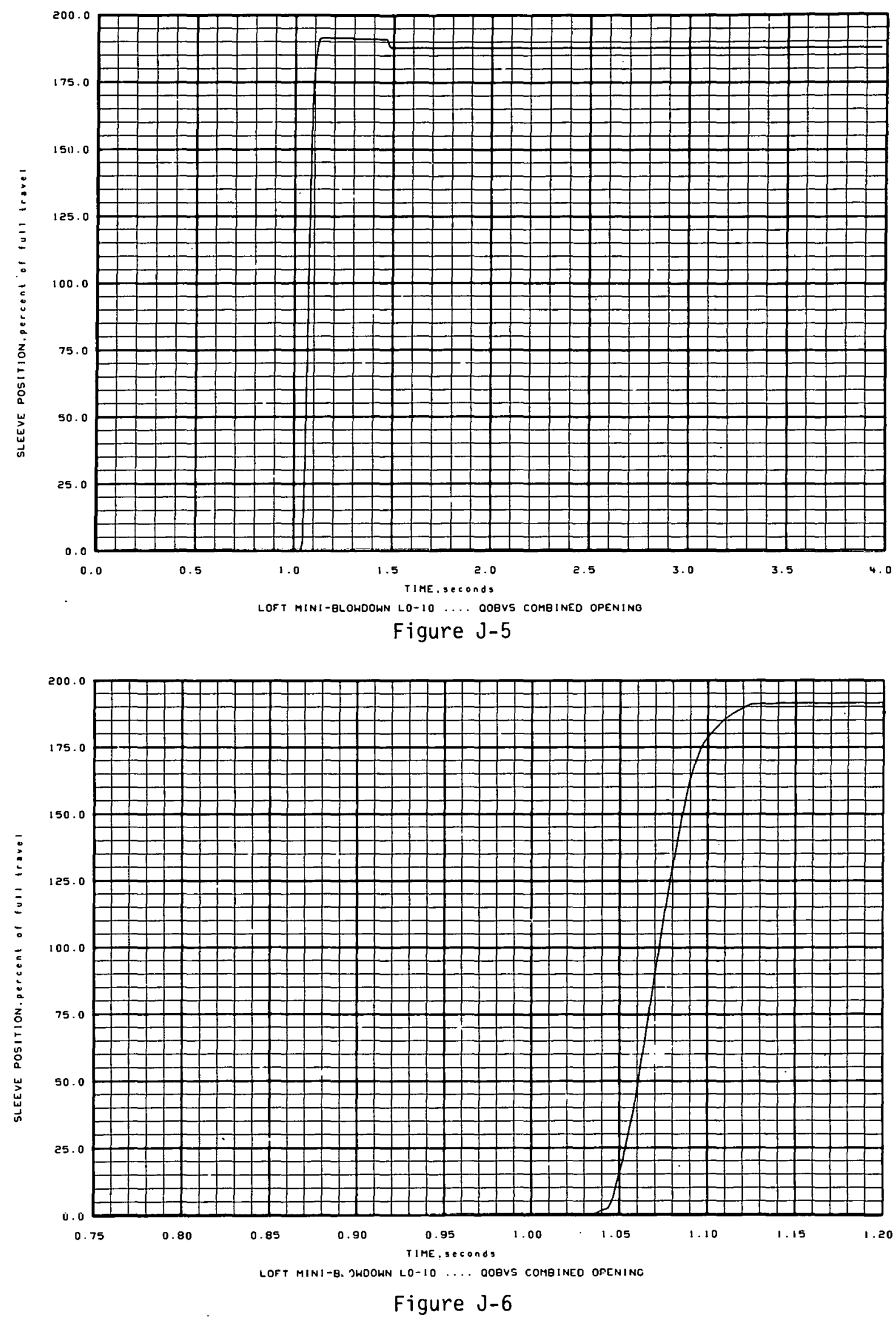


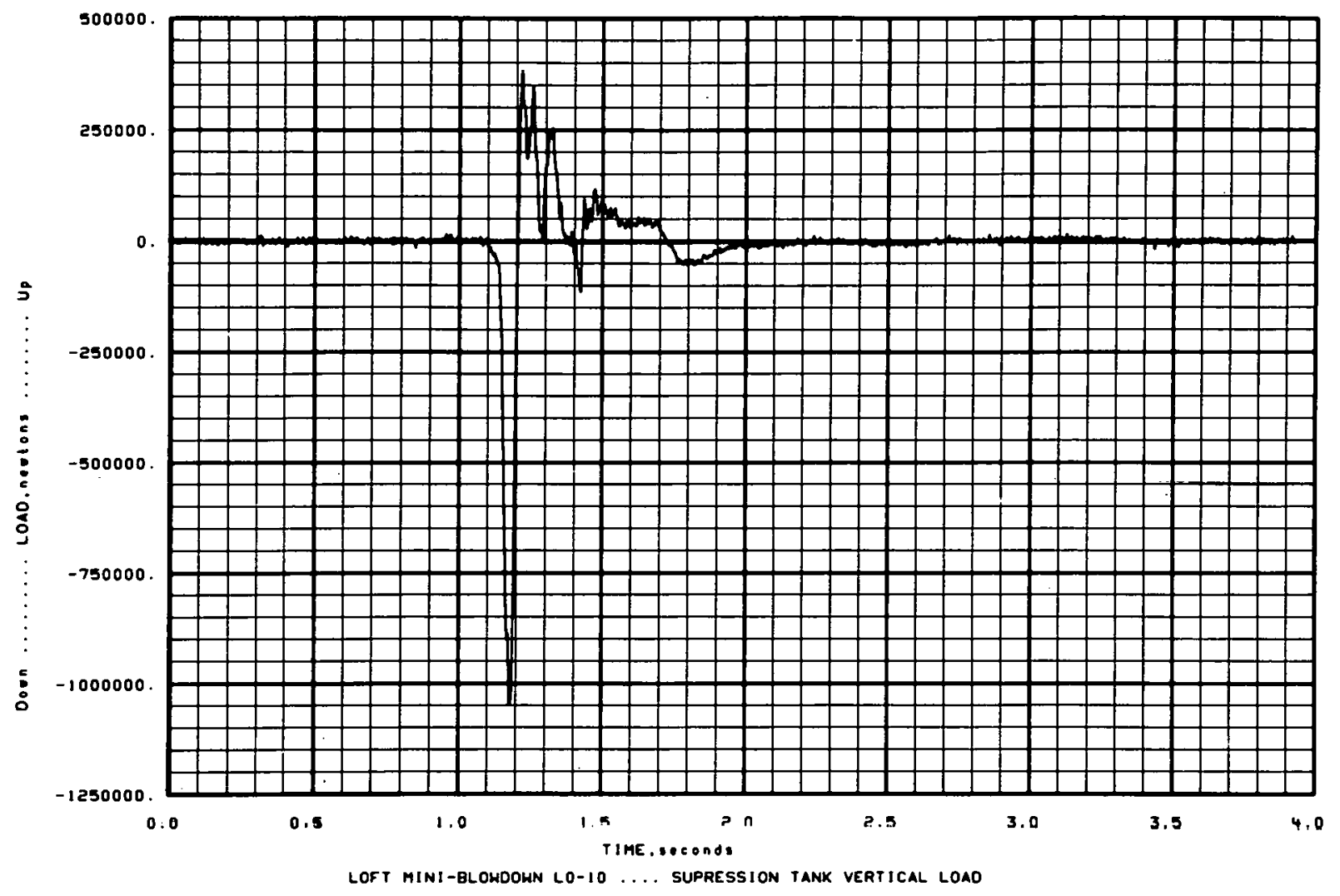

Figure J-7

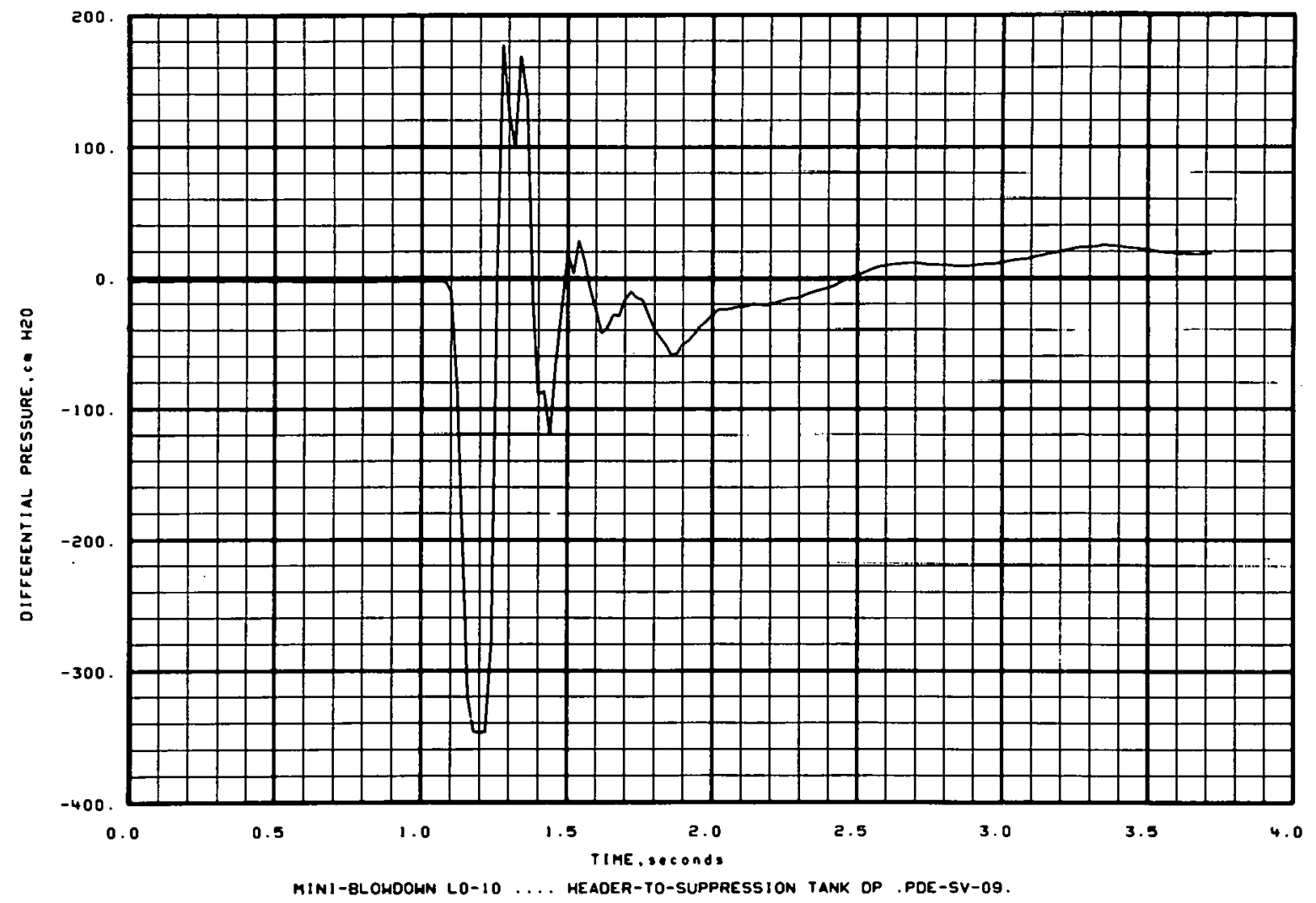

Figure J-8 


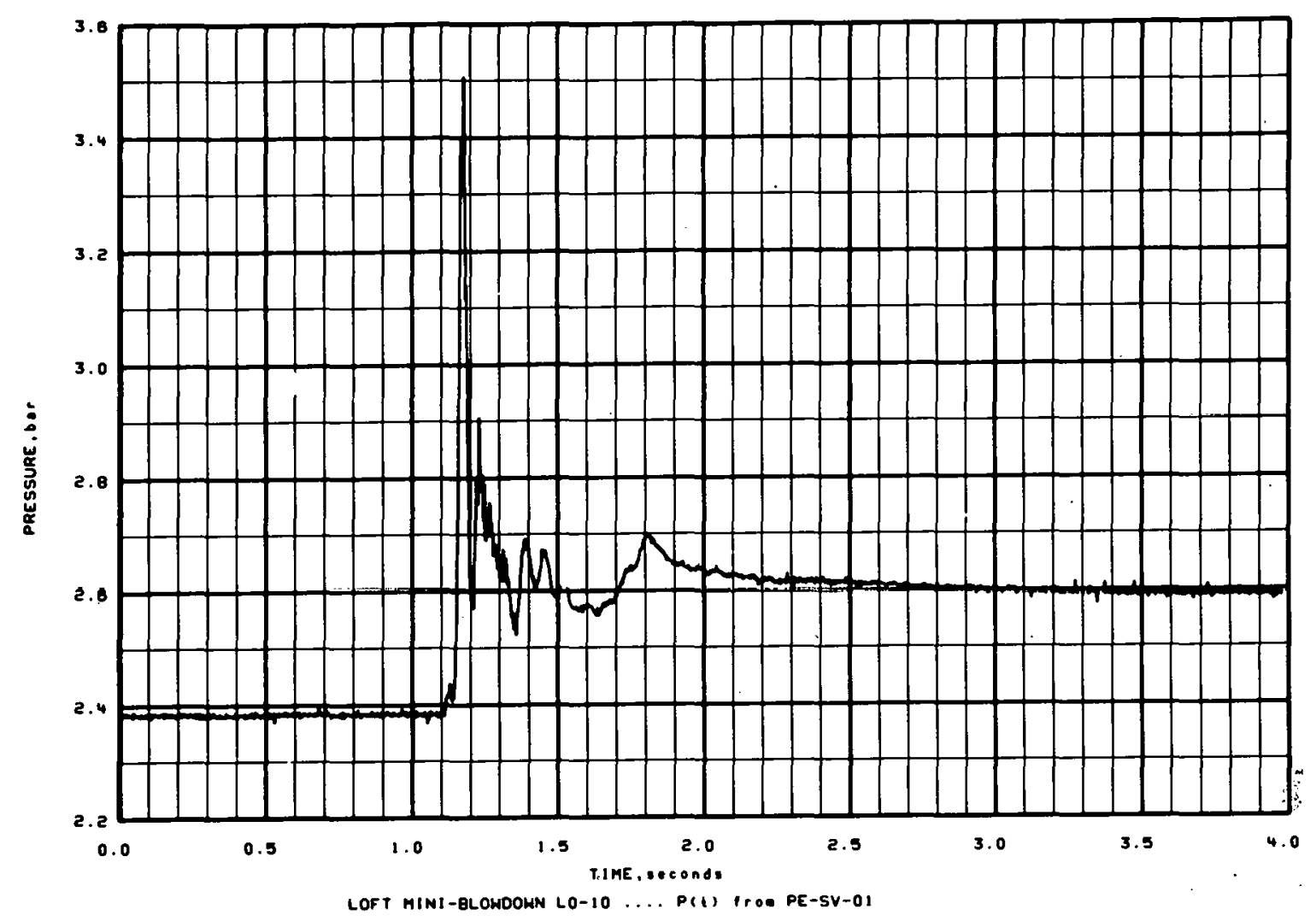

Figure J-9

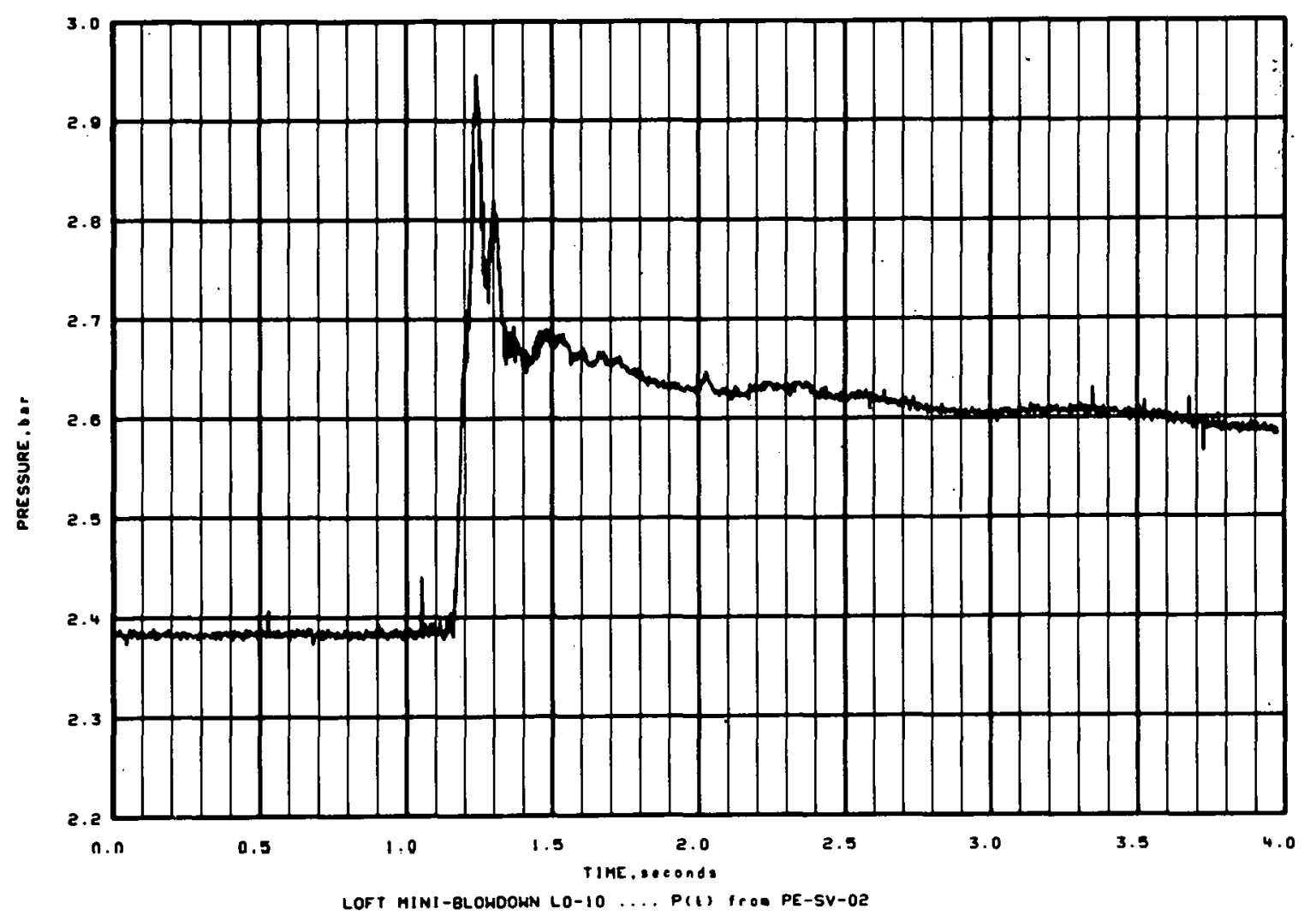

Figure J-10 


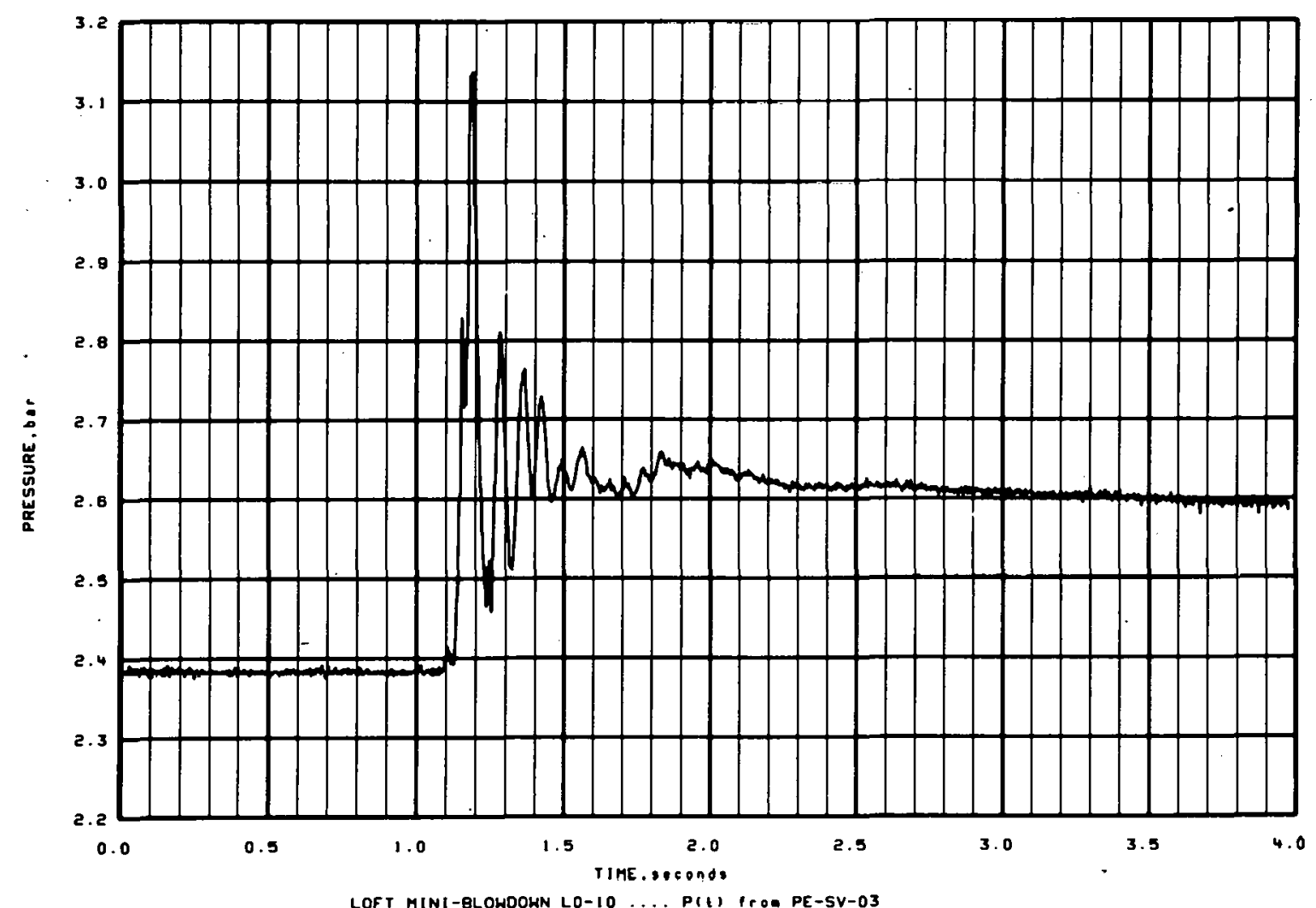

Figure J-11

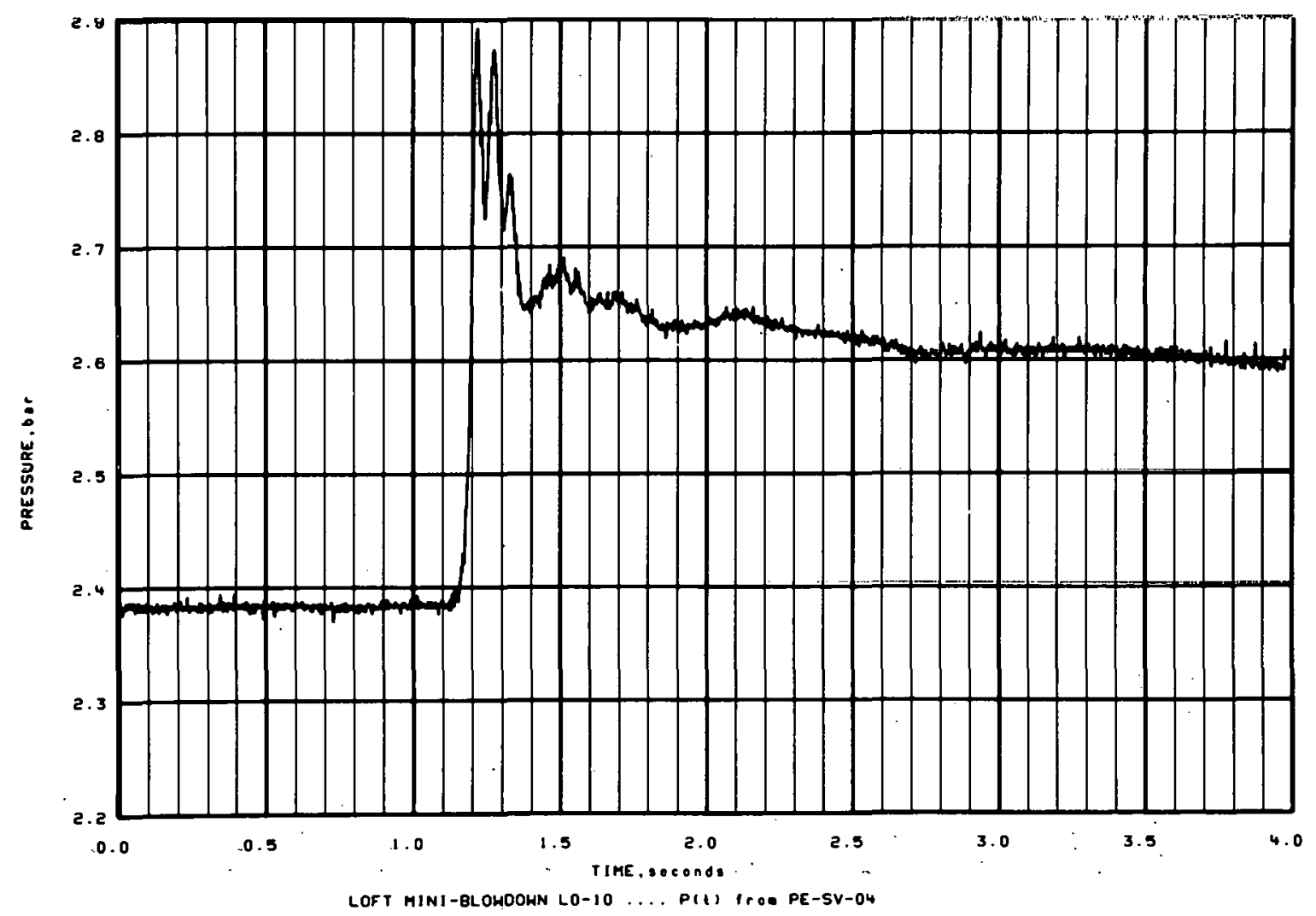

Figure J-12 

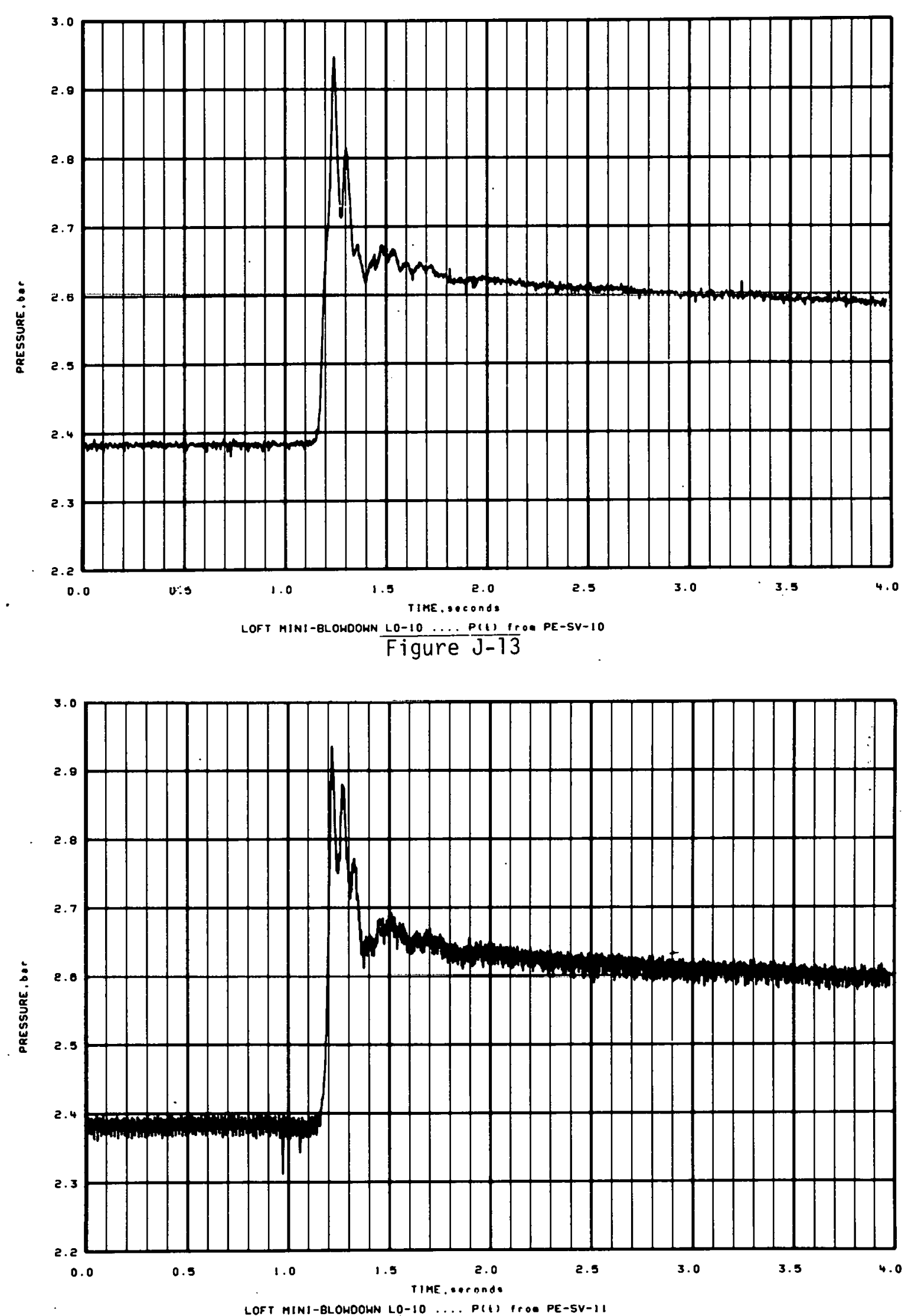

Figure J-14 


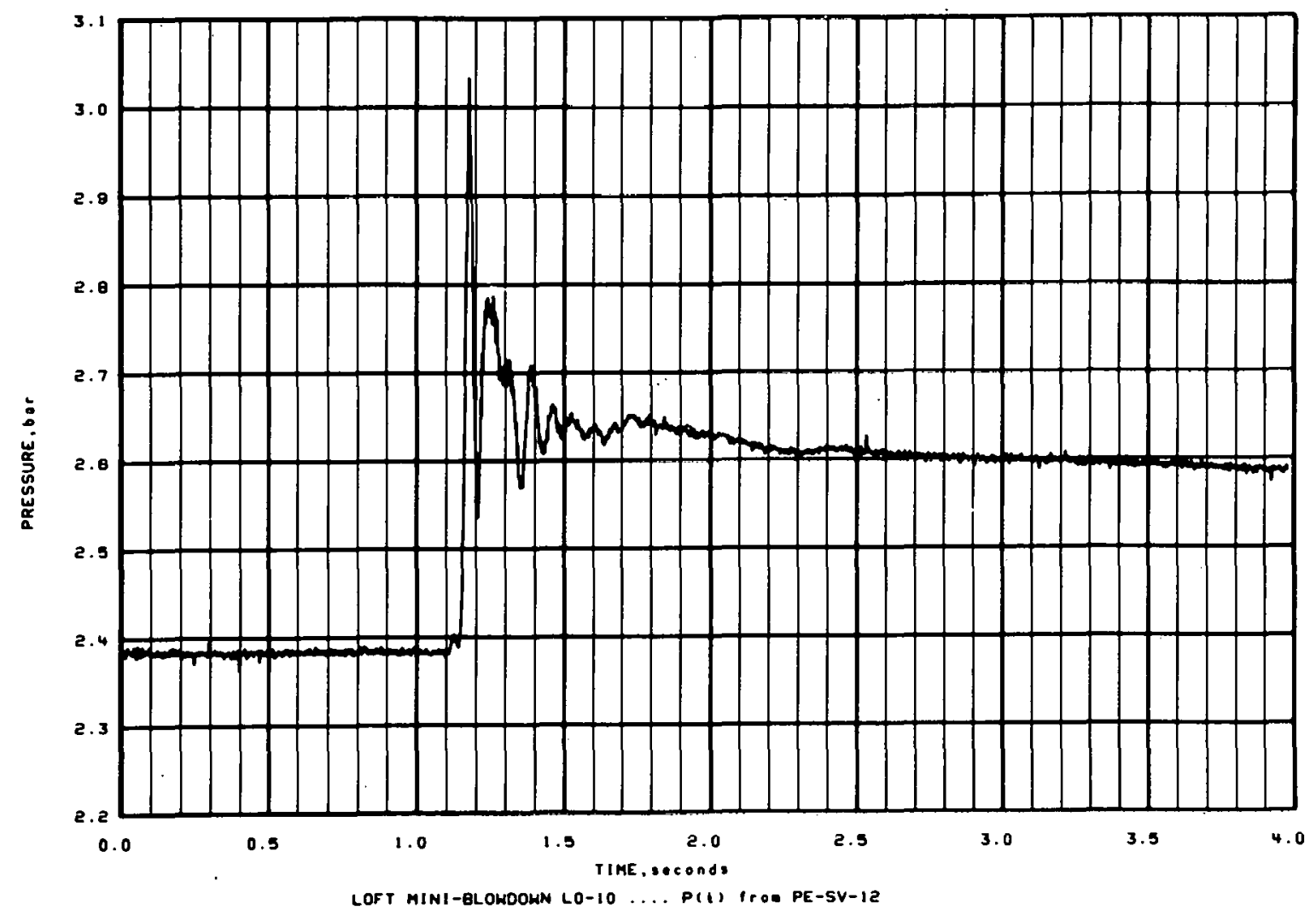

Figure J-15

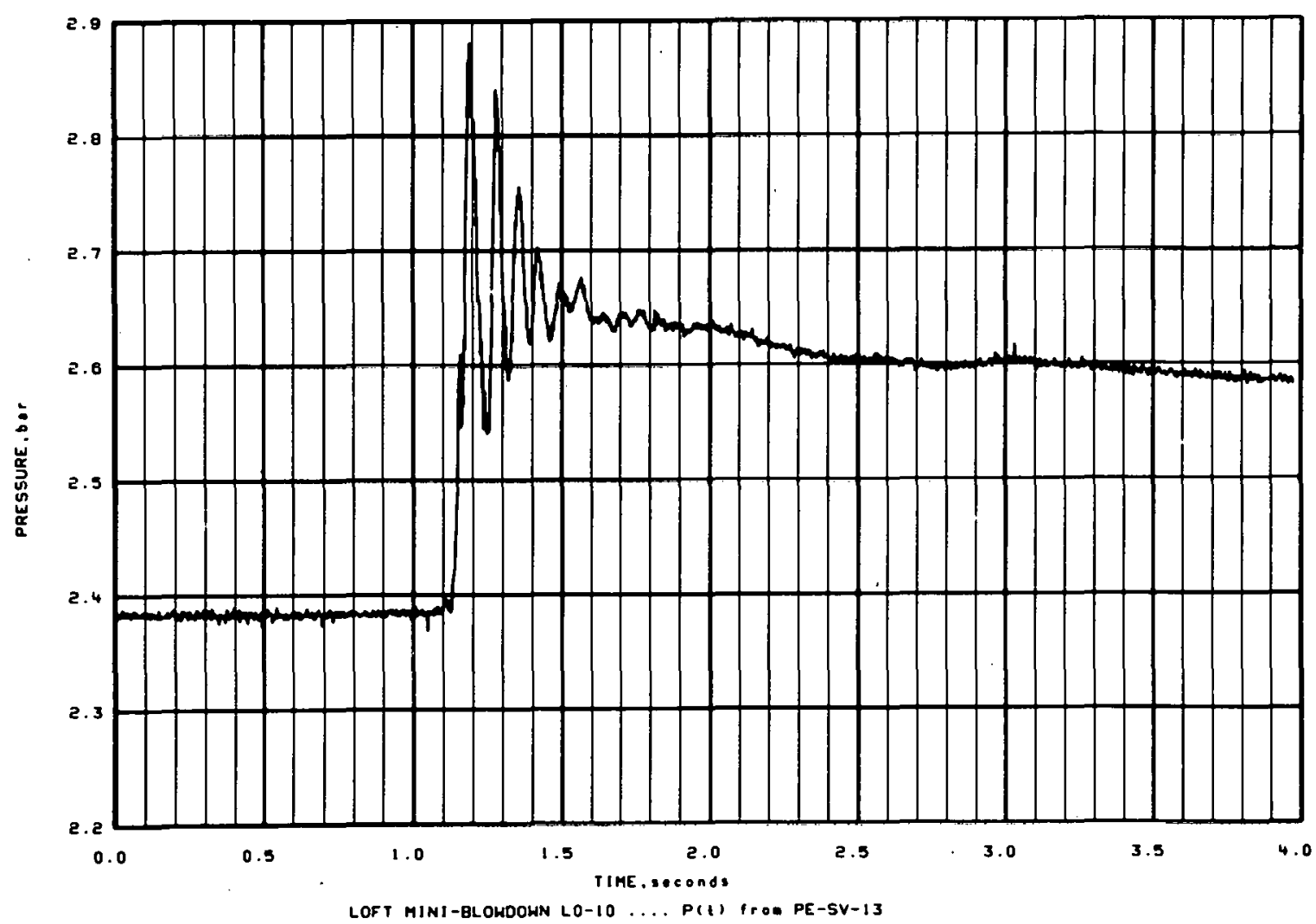

Figure J-16 

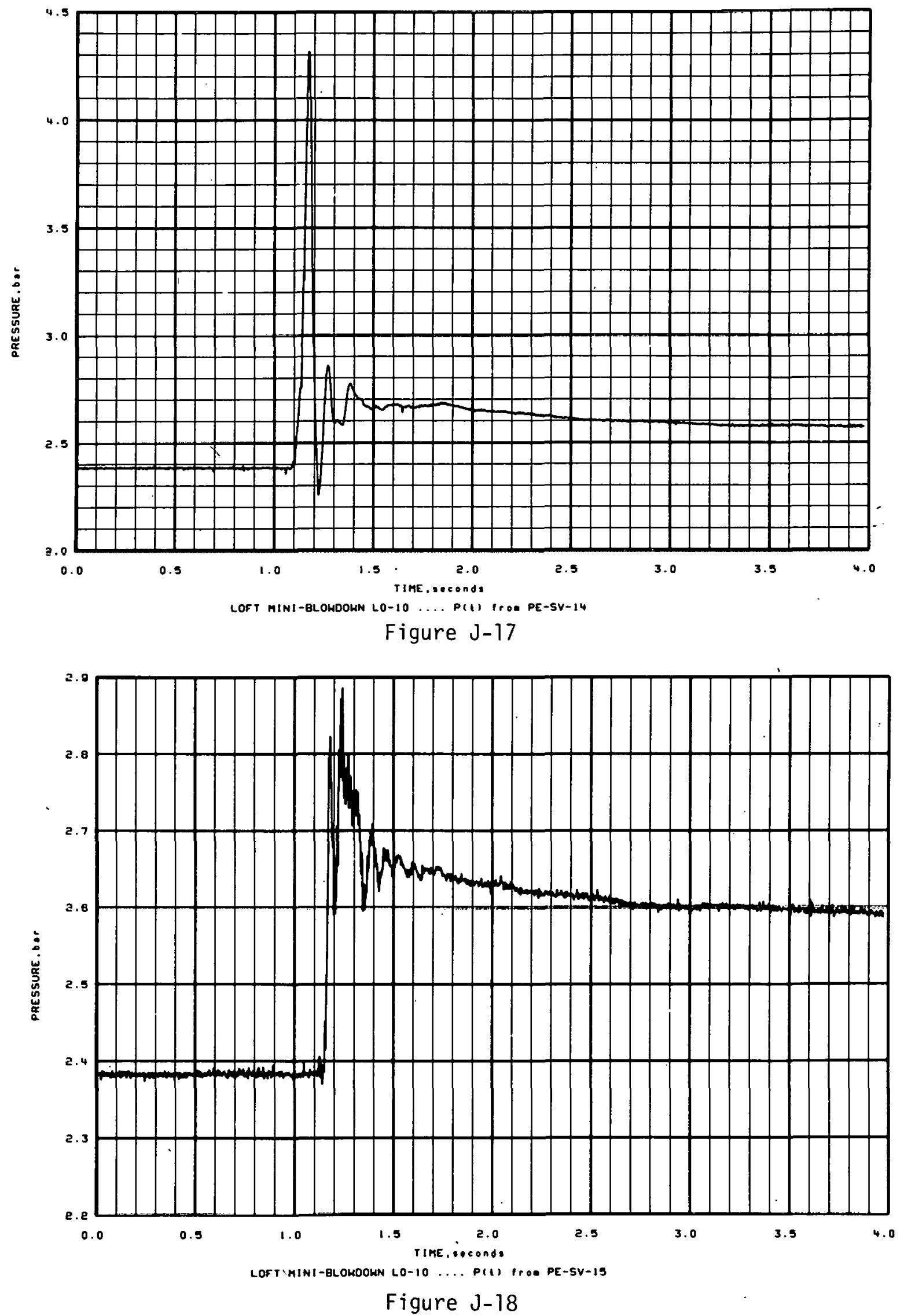


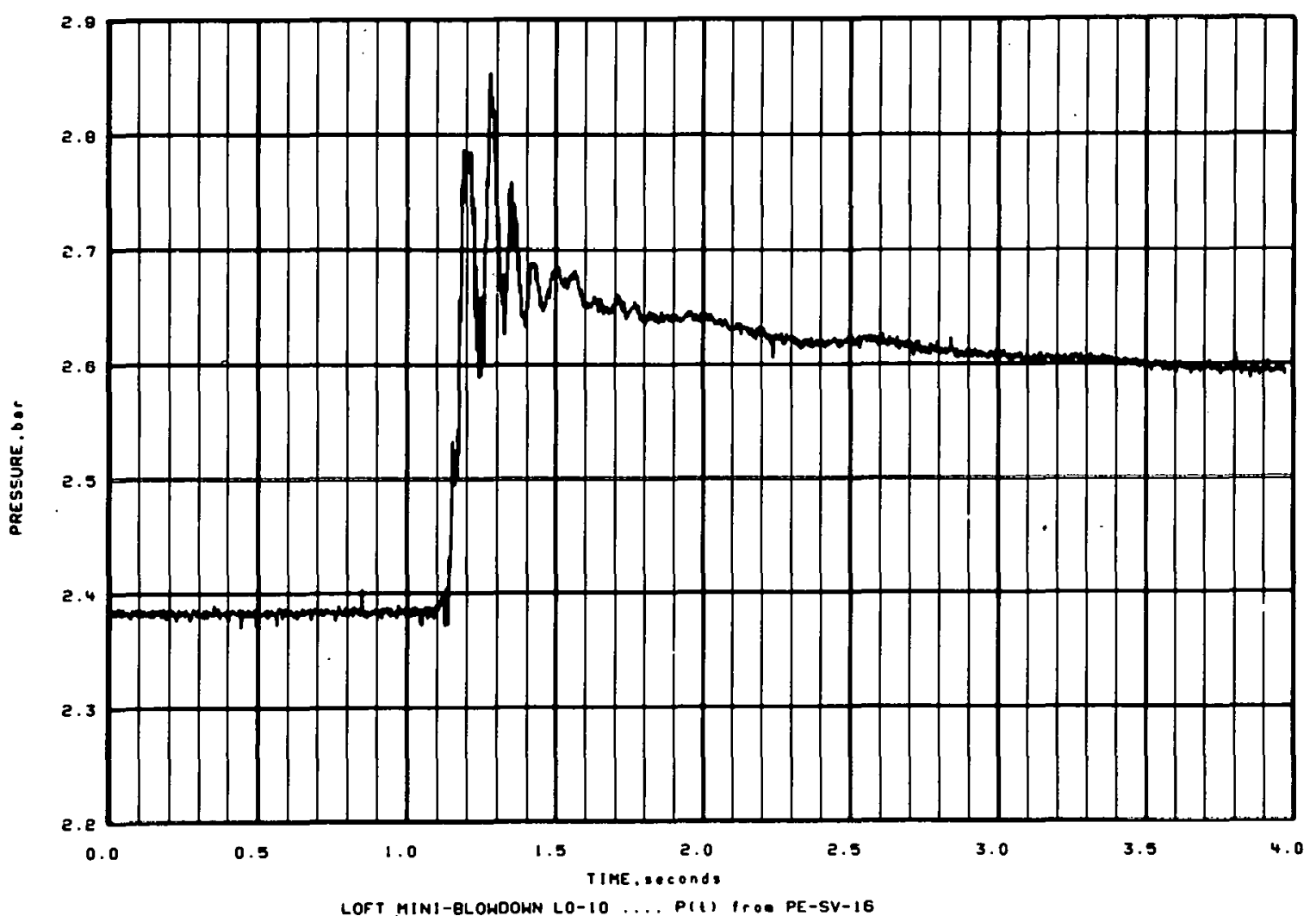

Figure J-19

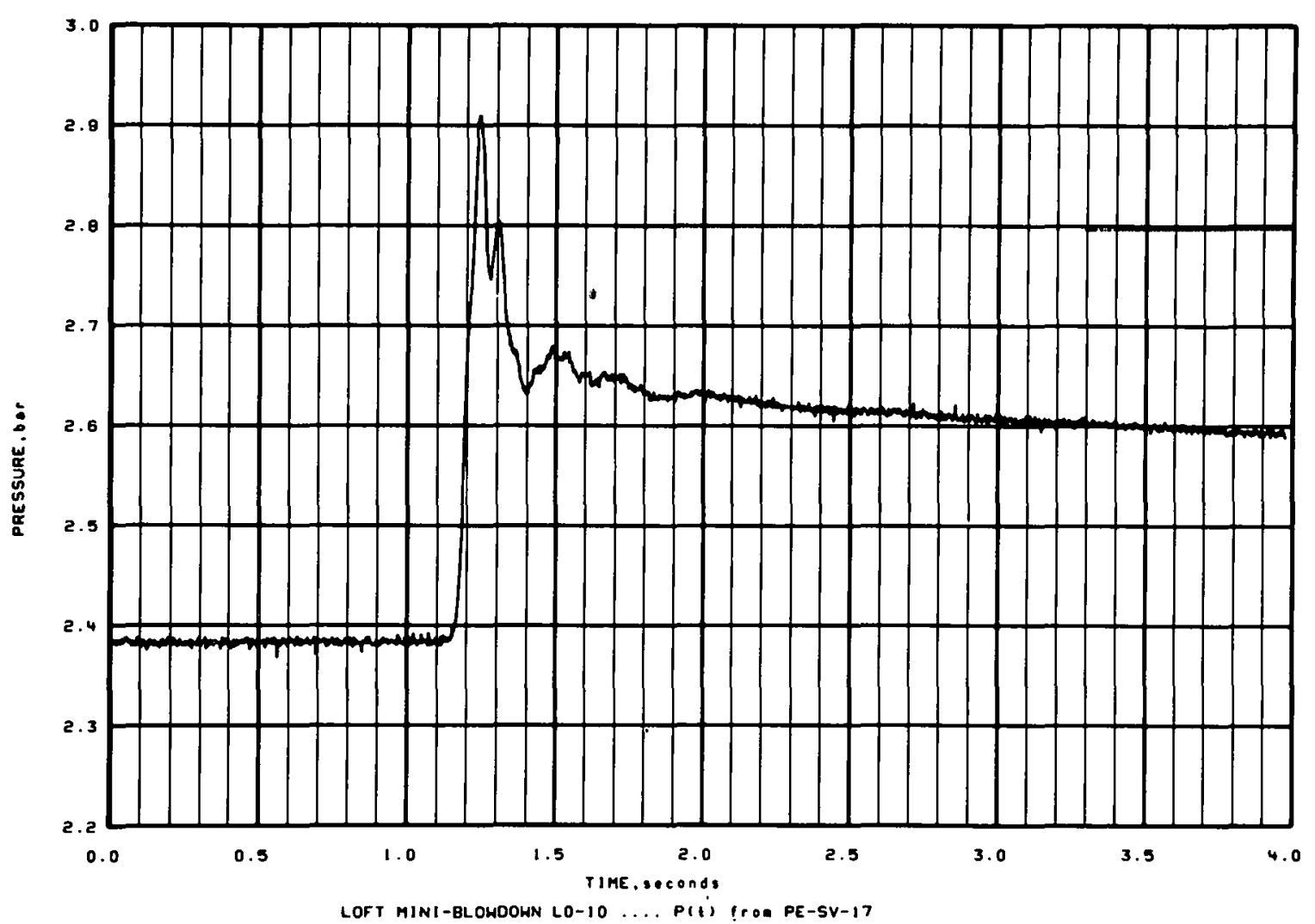

Figure J-20 


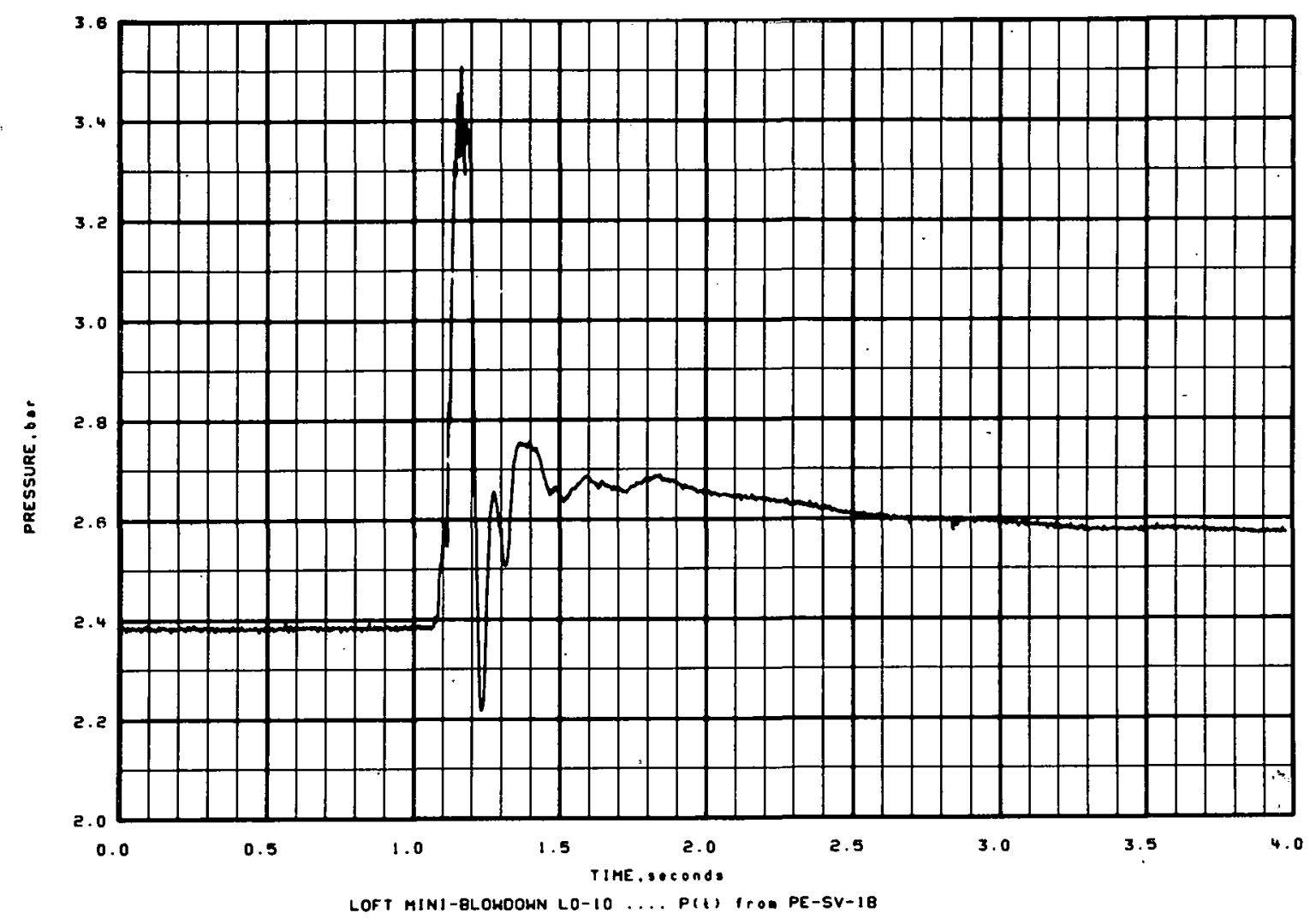

Figure J-21

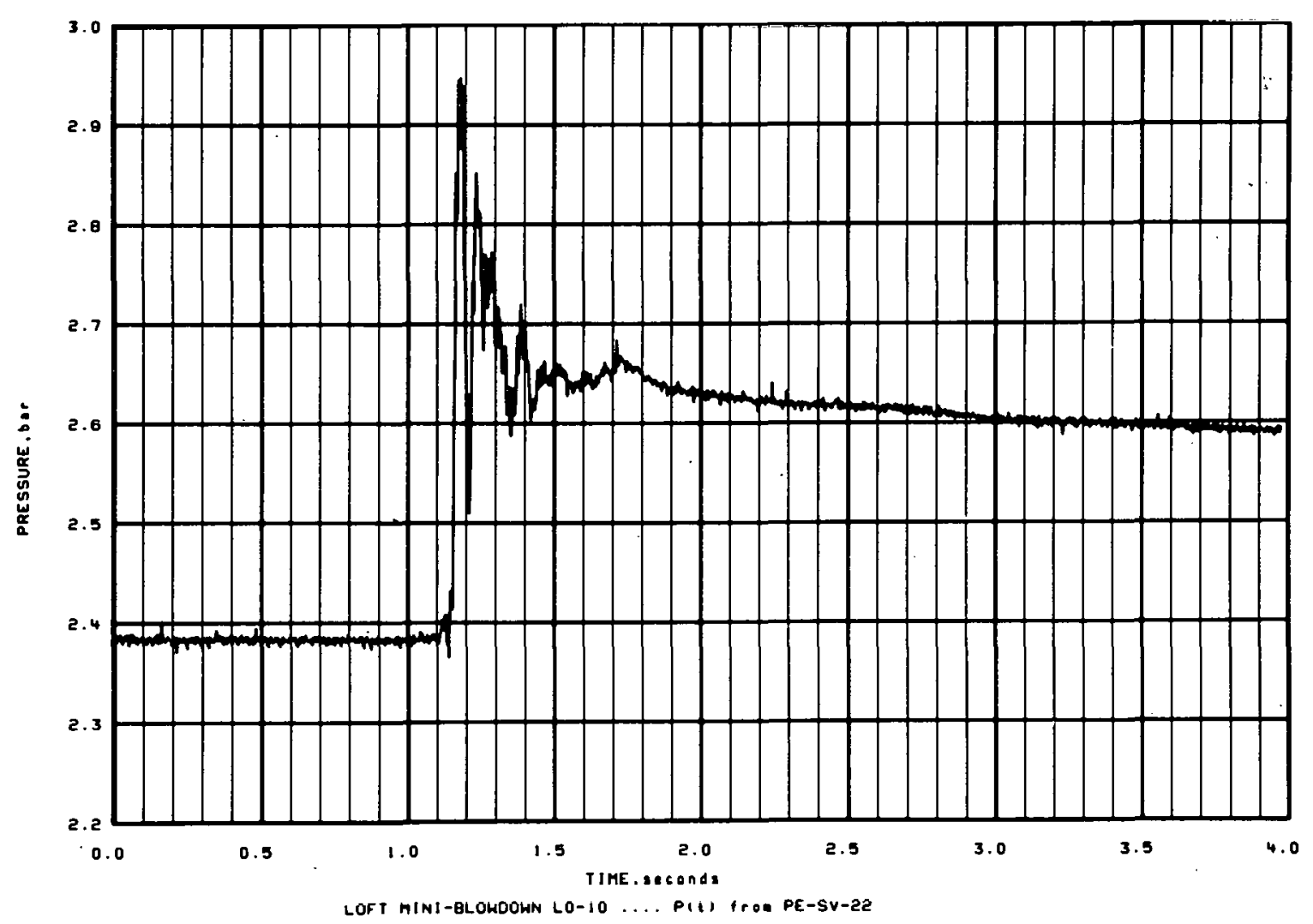

Figure J-22 


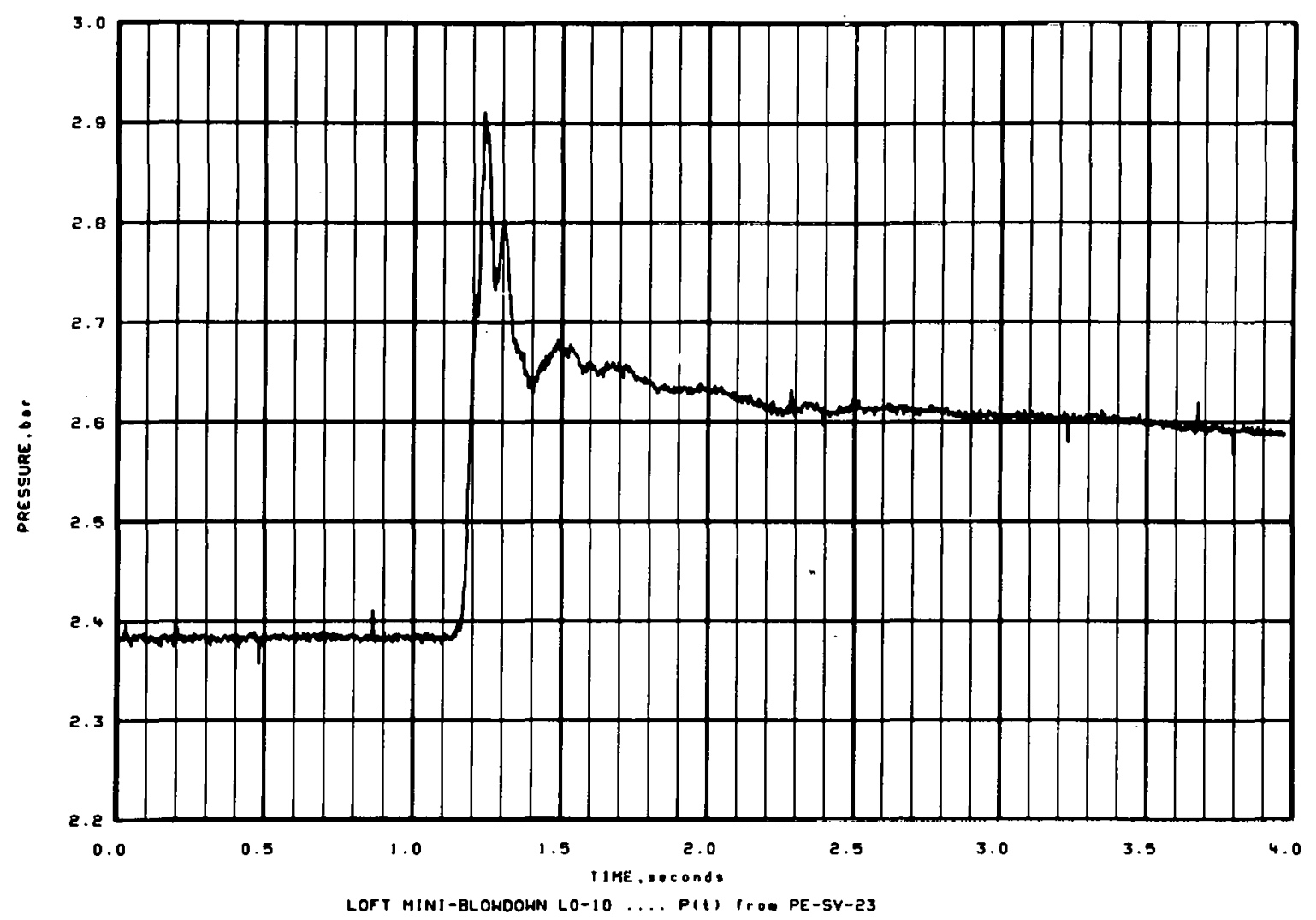

Figure J-23

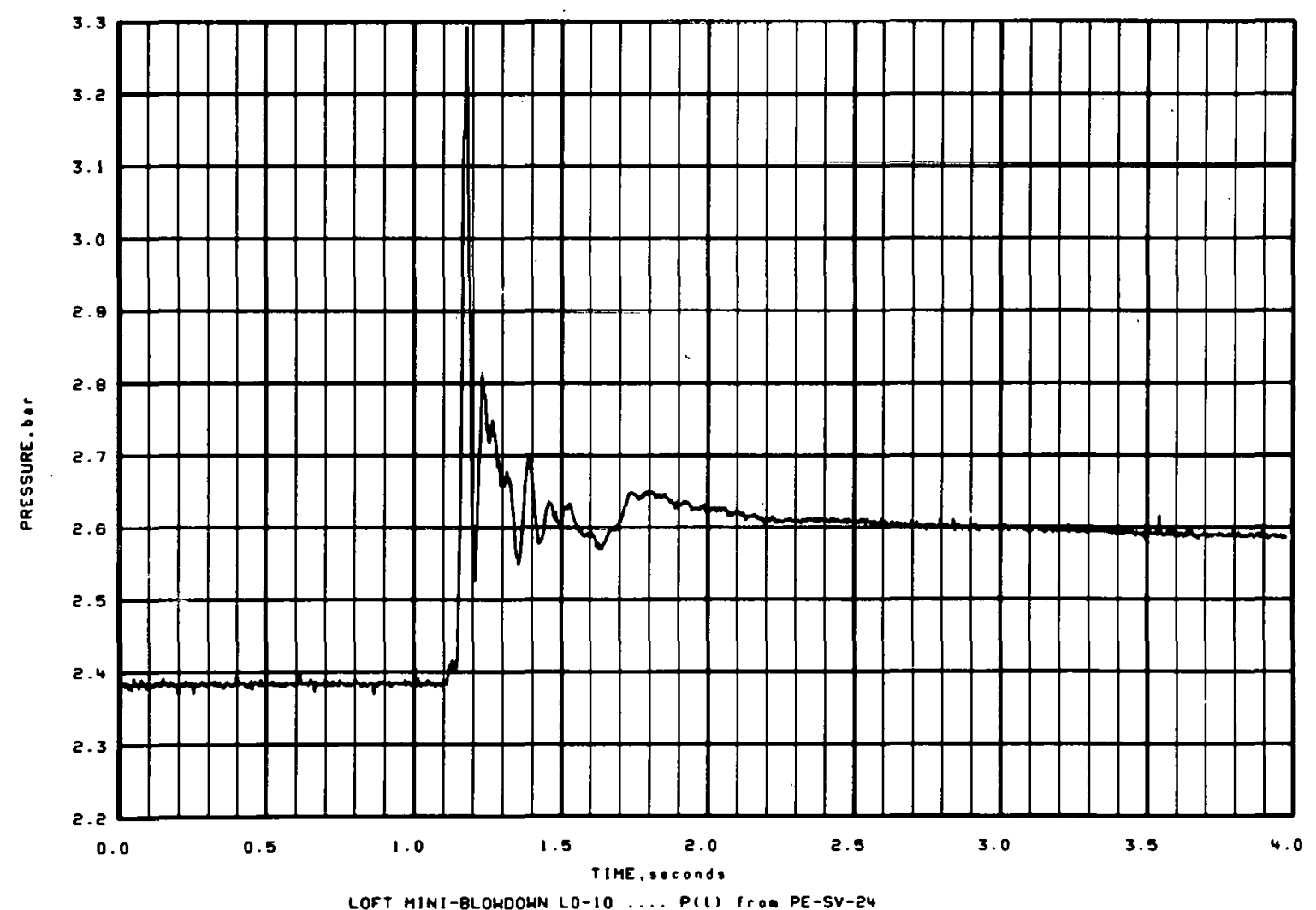

Figure J-24 

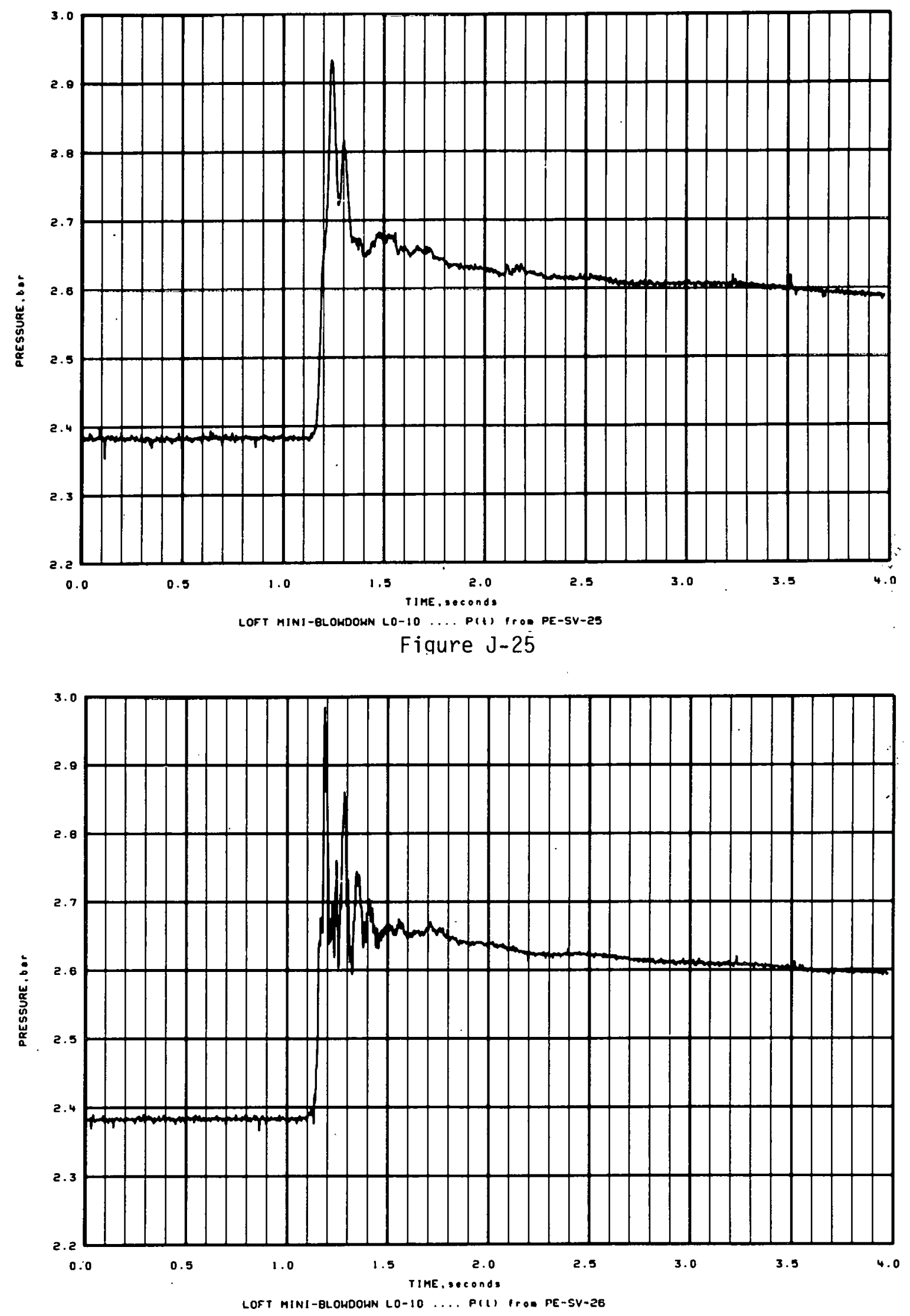

Figure J-26 


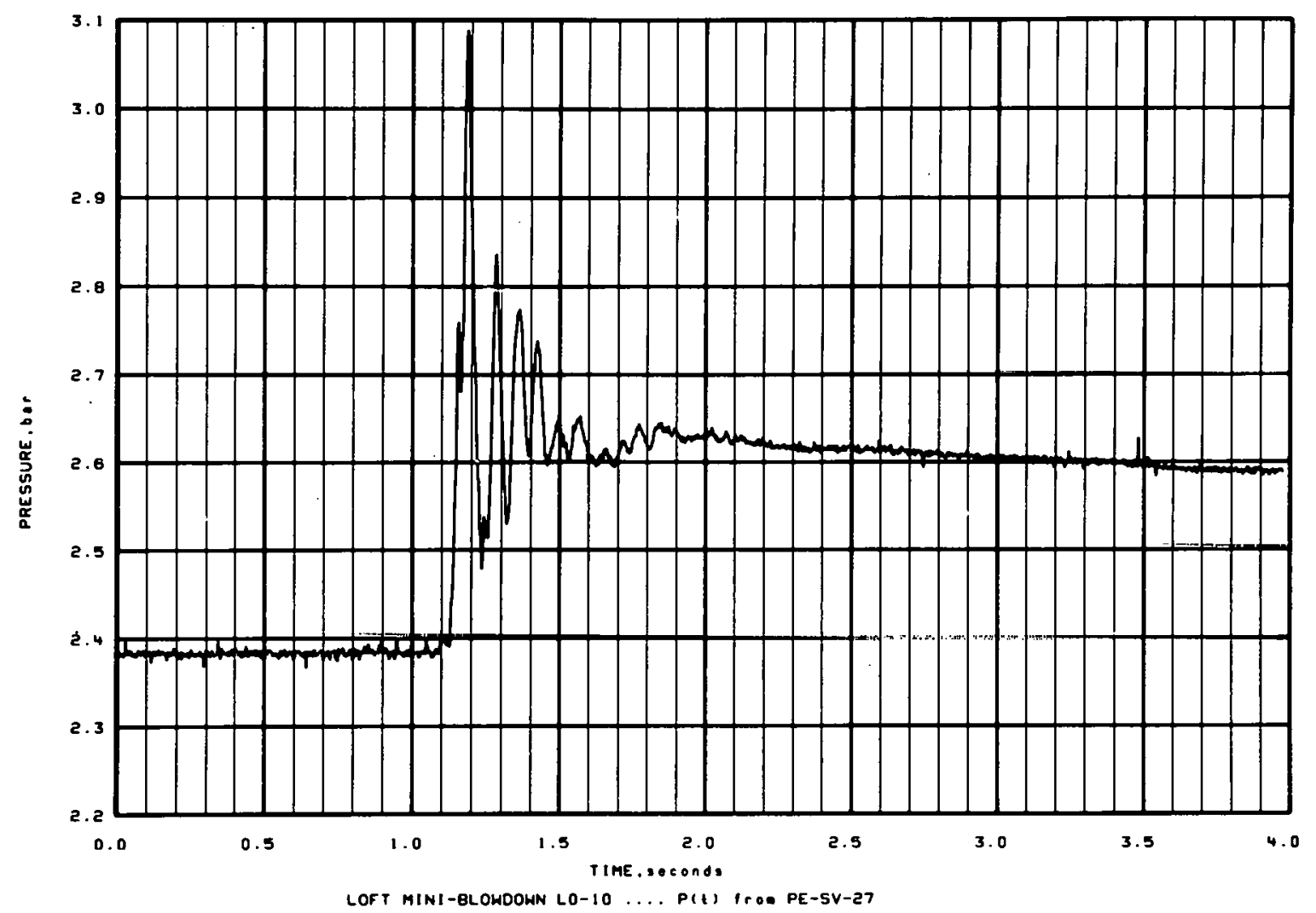

Figure J-27

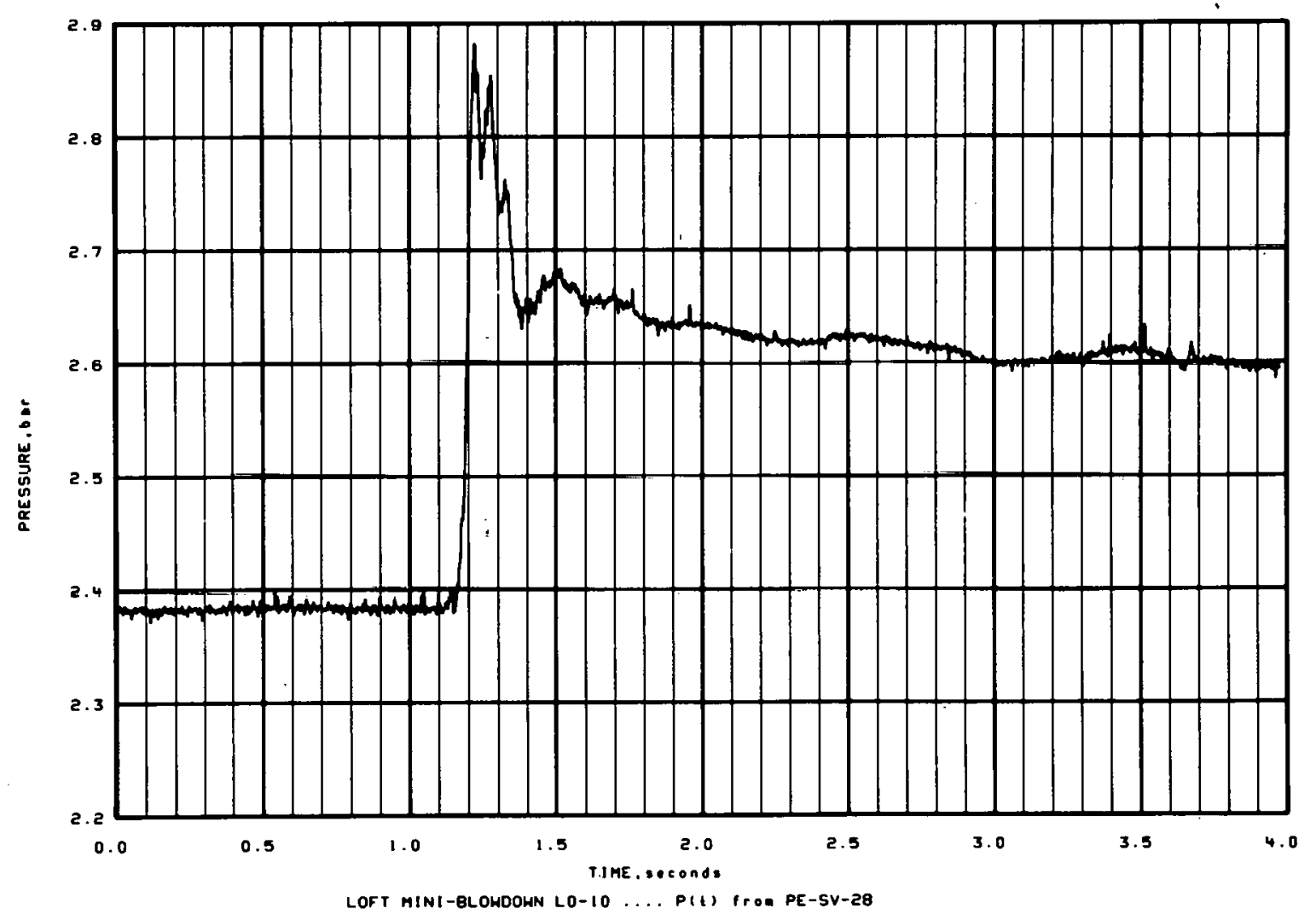

Figure J-28 


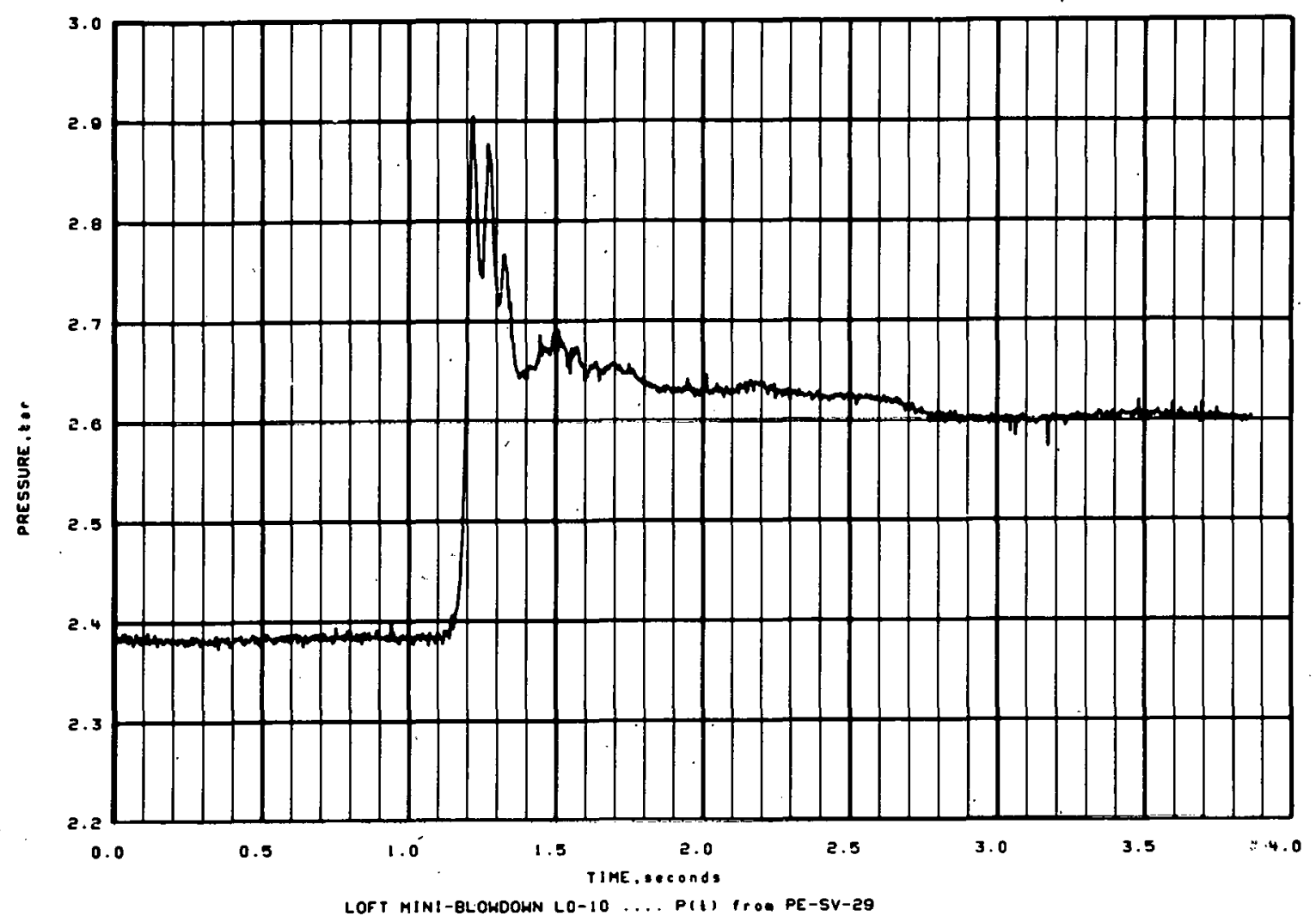

Figure J-29

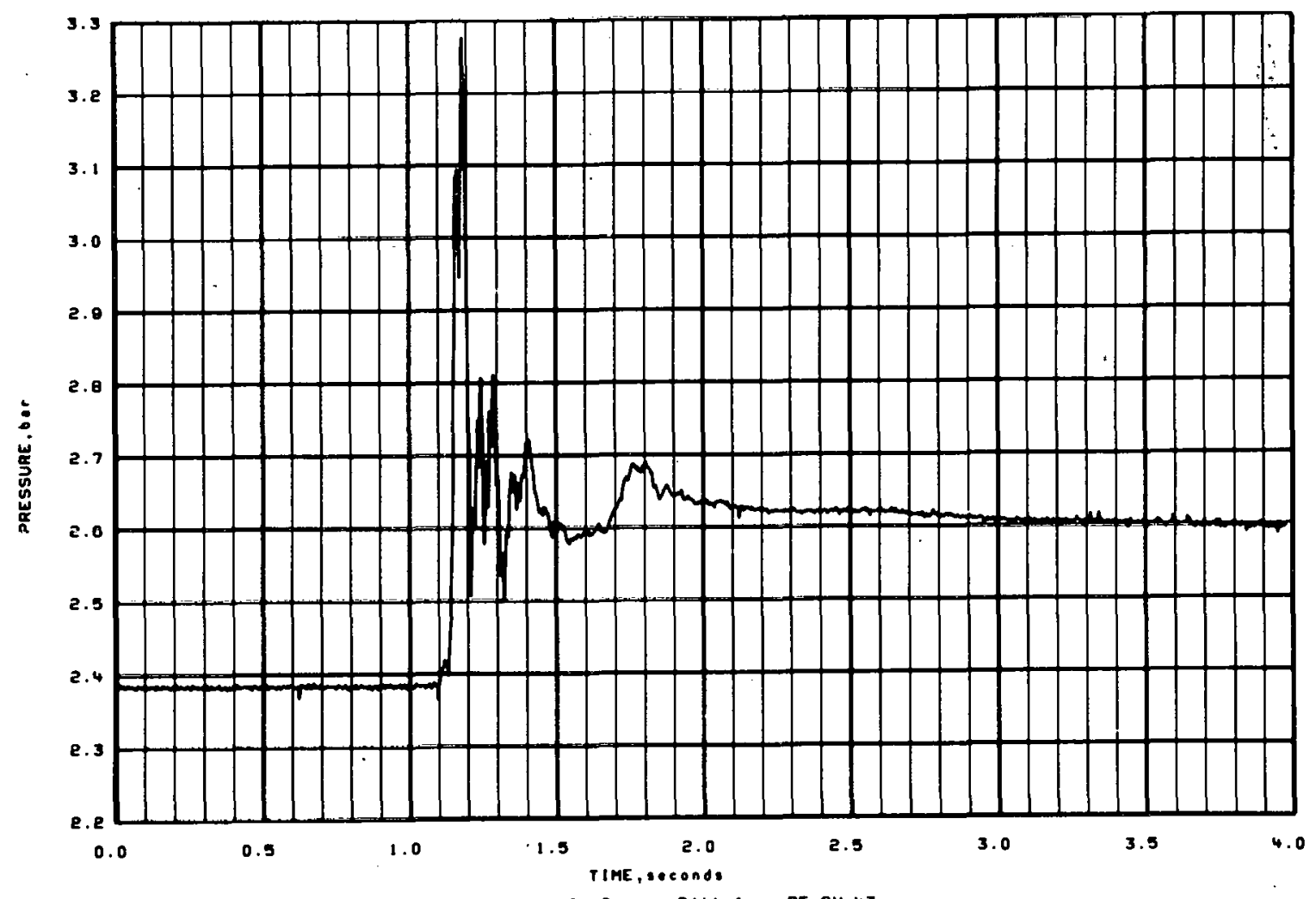

LOFT MINI-BLOHDOWN LO-10 ... P(1) IROA PE-SV-43

Figure J-30 


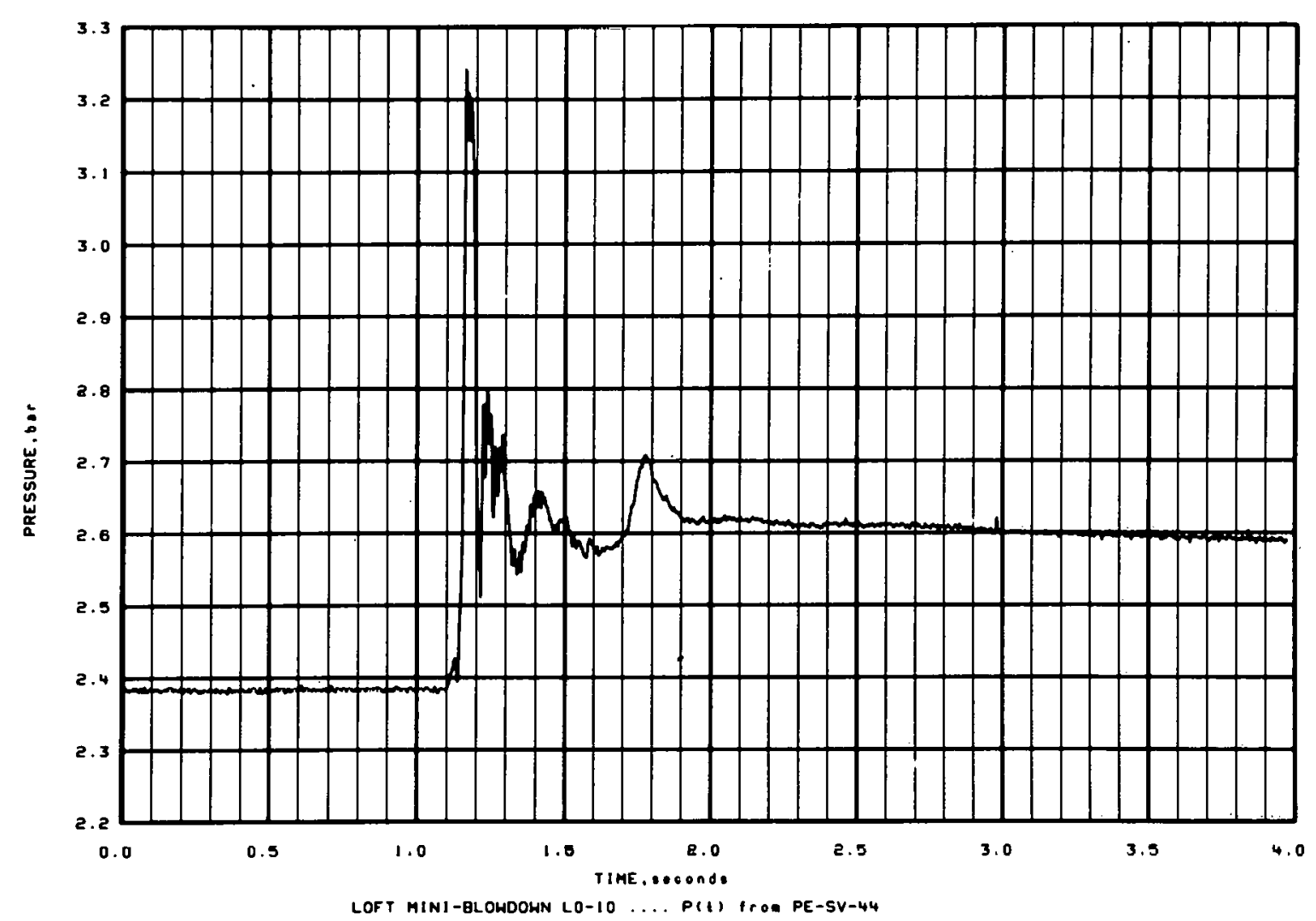

Figure J-31

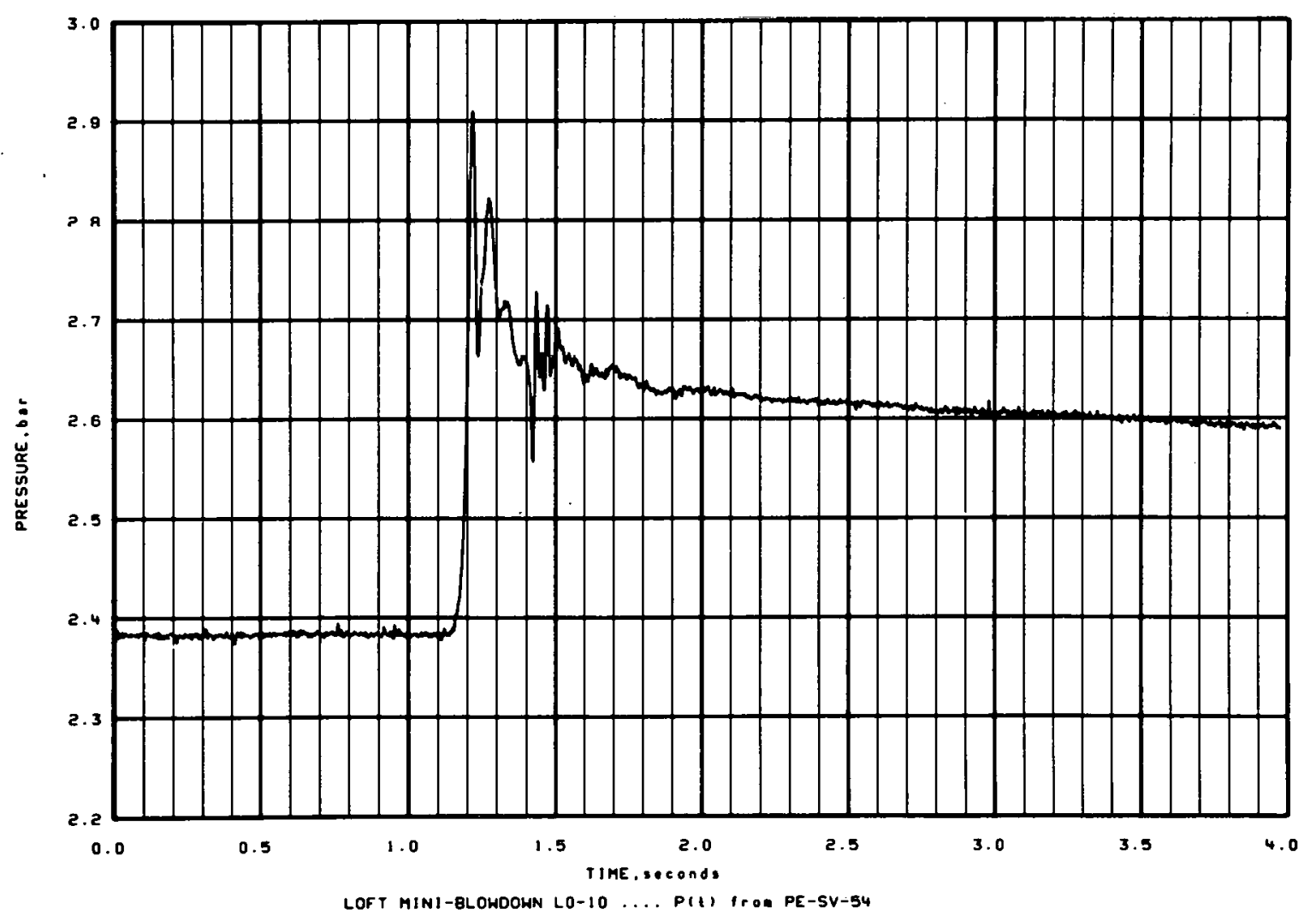

Figure J-32 


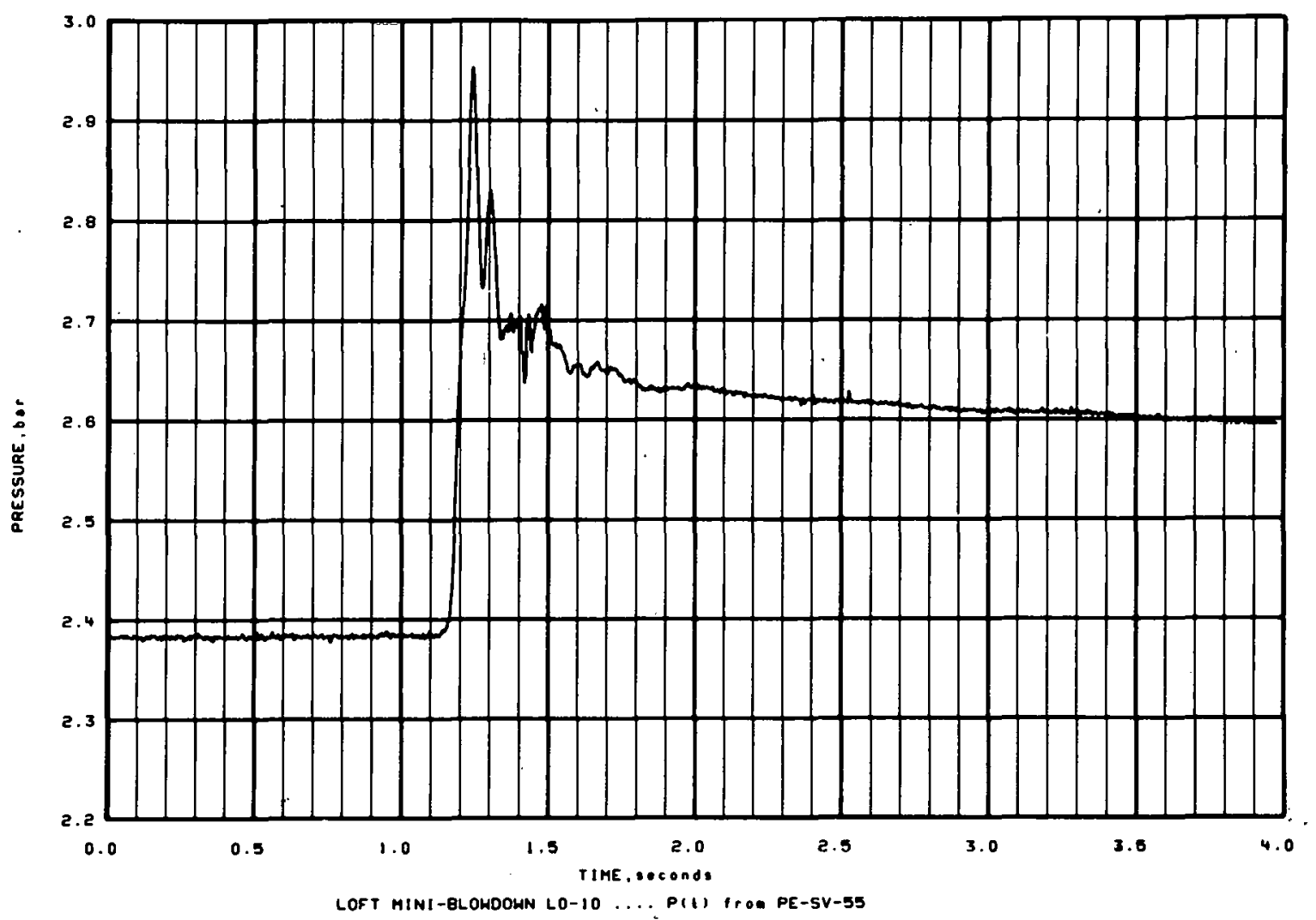

Figure J-33

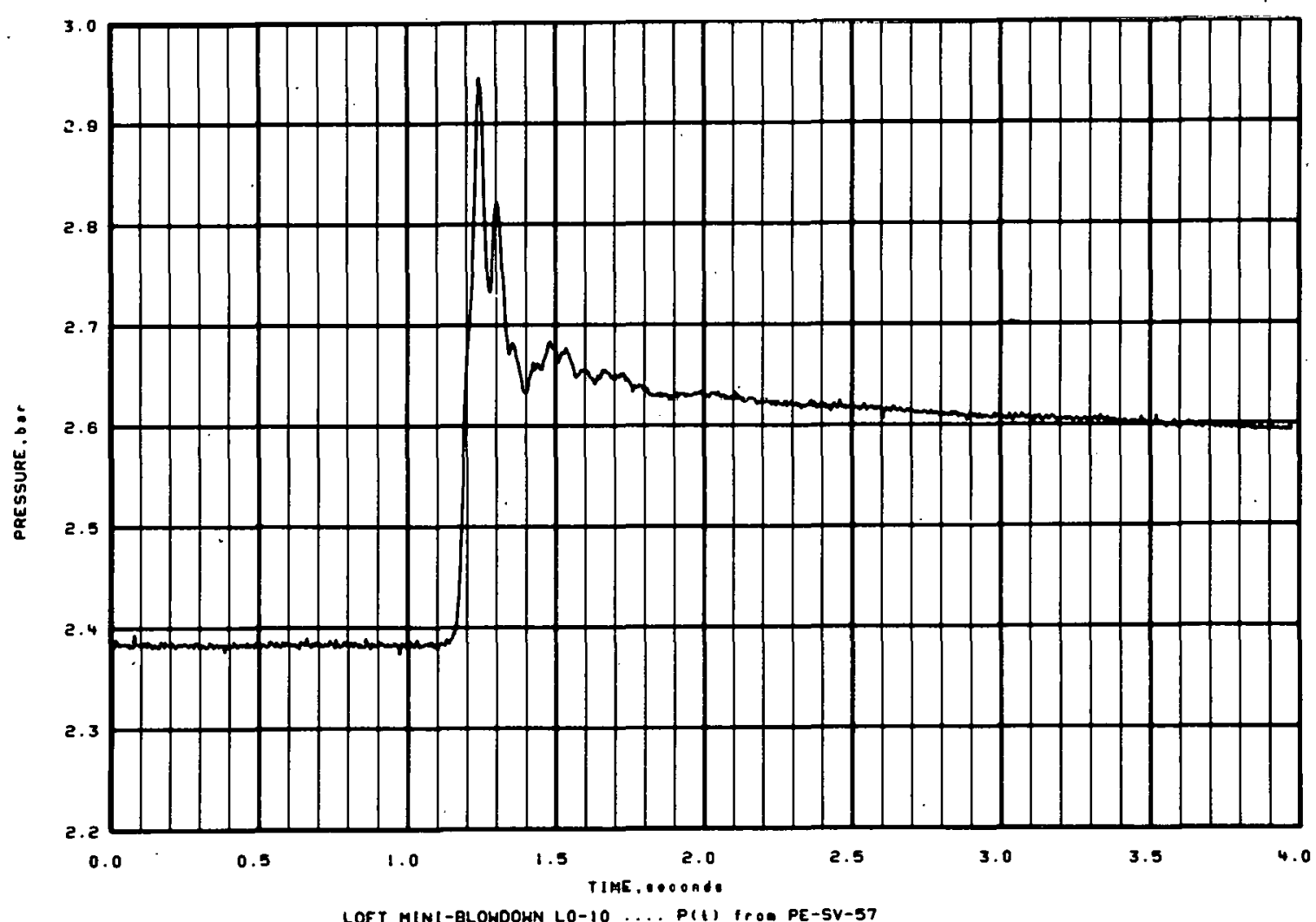

Figure J-34 

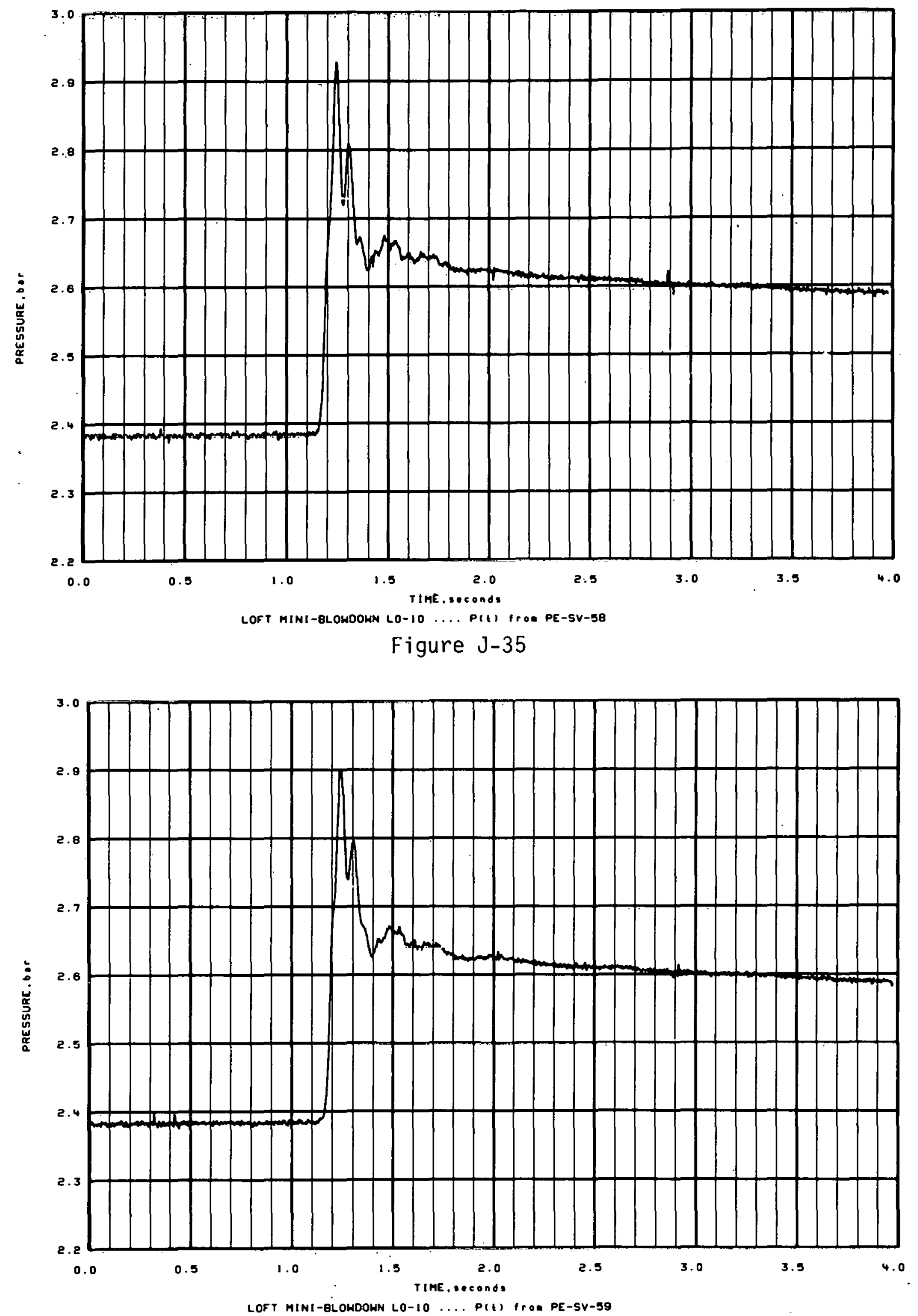

Figure J-36 


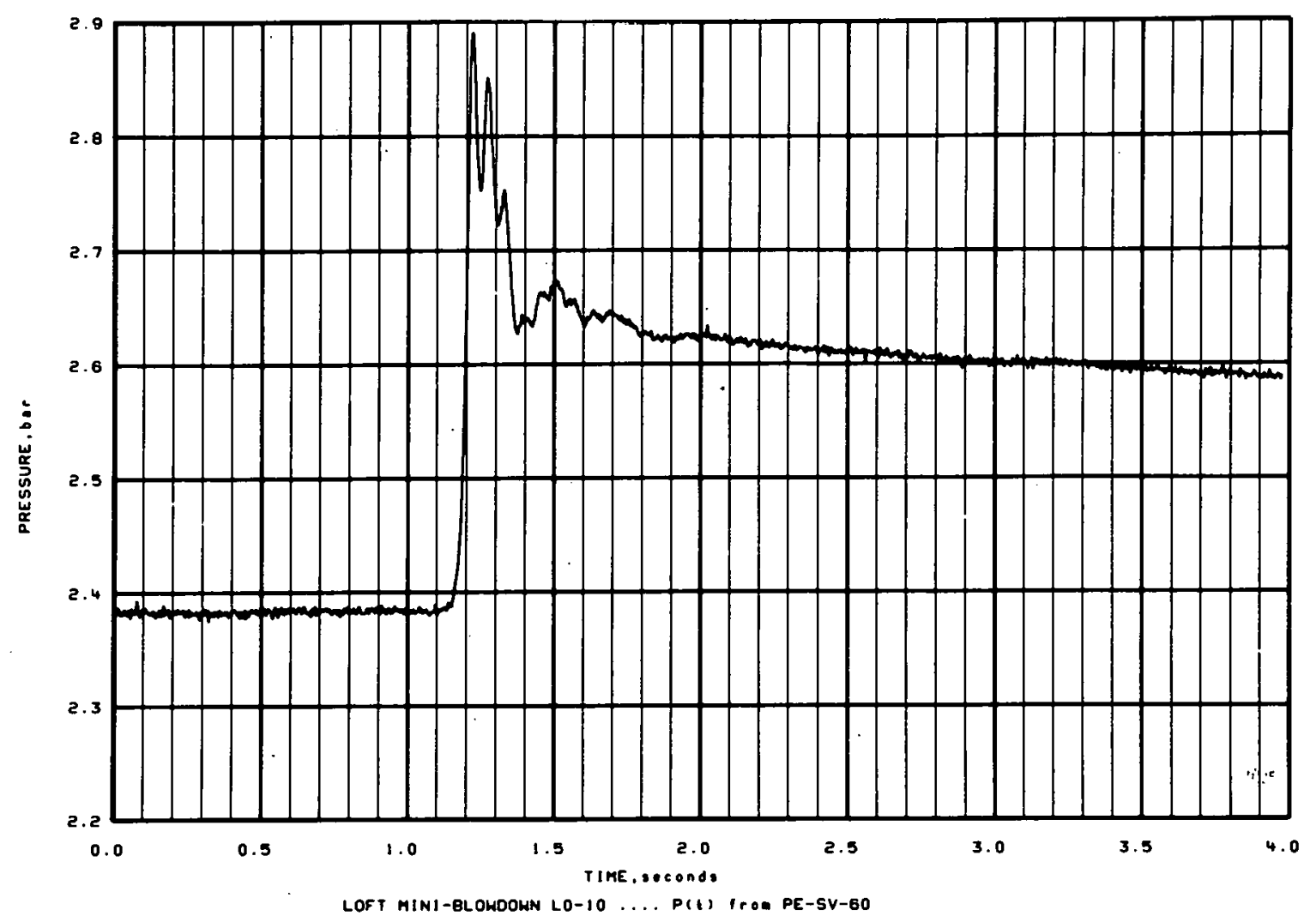

Figure J-37

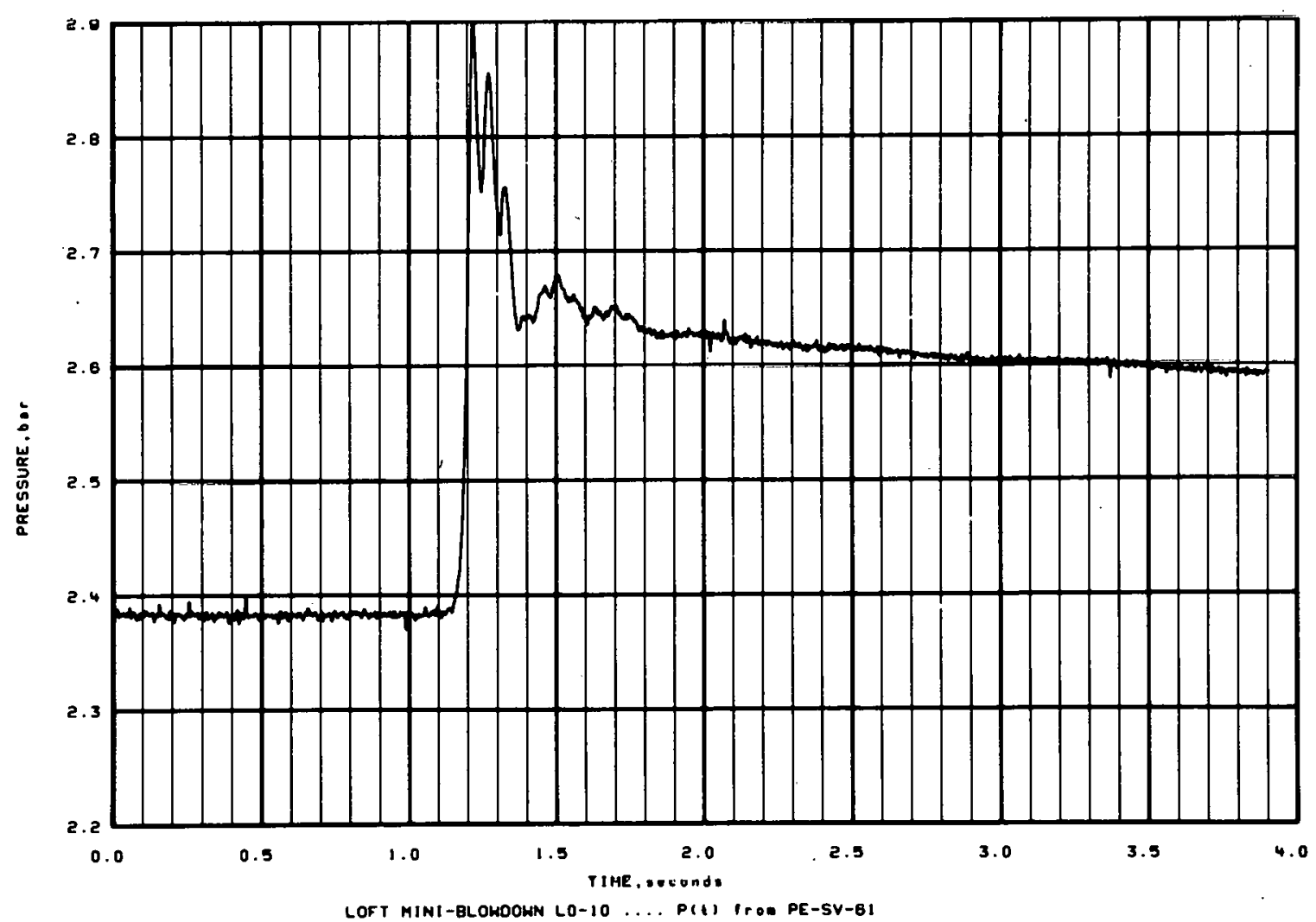

Figure J-38 


\section{THIS PAGE}

\section{WAS INTENTIONALLY}

LEFT BLANK 
APPENDIX K

LOCE L1-01 EXPERIMENTAL DATA 


\section{THIS PAGE}

\section{WAS INTENTIONALLY}

LEFT BLANK 
APPENDIX $K$

\section{LOCE L1-01 EXPERIMENTAL DATA}

Both QOBVs fully opened in this experiment. The fluid temperature was $256.6 \pm 1.5^{\circ} \mathrm{C}$ in QOBV-1 and $241.4 \pm 1.5^{\circ} \mathrm{C}$ in QOBV-15. The suppression tank initial conditions were $2.36 \pm 0.08$ bar, $29.4 \pm 1.5^{\circ} \mathrm{C}$ in the gas volume, and $30.8 \pm 1.5^{\circ} \mathrm{C}$ in the pool. The vents were submerged $24.7 \pm 2.5 \mathrm{~cm}$. The internal vent submergence was $21.8 \pm 3.2 \mathrm{~cm}$.

The experimental data are defined in Table K-I. The opening characterisitics of the QOBVs are shown in terms of percent sleeve travel versus time. The flow area of the valve begins to open at a sleeve position of $17 \%$ of full travel and is fully open at a sleeve position of $66 \%$ of full travel. The differential pressure between the header and the tank gas volume is measured with a very sensitive device primarily to provide information on vent preclearing. The data channel for this measurement is driven to saturation in the early part of the transient. 
TABLE K-I

EXPERIMENT L1-01 DATA SUMMARY

\begin{tabular}{|c|c|c|c|c|c|}
\hline $\begin{array}{c}\text { Measurement } \\
\text { or } \\
\text { calrulatinn }\end{array}$ & $\begin{array}{c}\text { Pre-Transient } \\
\text { Data Channel } \\
\text { Variance } \\
\left(1 n^{-4} \text { har }^{2}\right) \\
\end{array}$ & Figure Number & Measurement & $\begin{array}{c}\text { Pre-Transient } \\
\text { Data Channel } \\
\text { Variance } \\
\left(10^{-4} \text { bar }{ }^{2}\right) \\
\end{array}$ & Figure Number \\
\hline QOBV-1 opening & $=$ & $k=1, k=2$ & $P F-S ., V-? ?$ & ก. nisifis? & $k-22$ \\
\hline QOBV-15 opening & - & $K-3, K-4$ & PE SV 23 & 0.06605 & $k=23$ \\
\hline $\begin{array}{l}\text { Combined QOBV } \\
\text { opening }\end{array}$ & - & $k-5, k-6$ & $P E-S V-24$ & 0.03868 & $k-24$ \\
\hline Vertical load & - & $k-7$ & $P E-S V-25$ & 0.04636 & $k-25$ \\
\hline PDE-SV-09 & - & $K-8$ & PE-SV-26 & 0.02948 & $K-26$ \\
\hline PE-SV-01 & 0.10300 & K-9 & PE-SV-27 & 0.05841 & $k-27$ \\
\hline PE-SV-02 & 0.10311 & $k-10$ & PE-SV-28 & 0.06134 & $k-28$ \\
\hline PE-SV-03 & 0.13418 & $k-11$ & PE-SV-29 & 0.07639 & $k-29$ \\
\hline PE-SV-04 & 0.13905 & $K-12$ & $P E-S V-43$ & 0.05393 & $k-30$ \\
\hline PE-SV-10 & 0.08816 & $k-13$ & $P E-S V-44$ & .0 .04584 & $k-31$ \\
\hline$P E=S V=11$ & 0.73659 & $k-14$ & $P E-S V-51$ & 0.04718 & $K=32$ \\
\hline PE-SV-12 & 0.06883 & $K-15$ & $P E-S V-55$ & 0.02043 & $k-33$ \\
\hline$P E-S V-13$ & 0.05084 & $\mathrm{~K}-16$ & $P E-S V-56$ & \multicolumn{2}{|c|}{ measurement deleted } \\
\hline PE-SV-14 & 0.07219 & $k-17$ & PE-SV-57 & 0.02568 & $k-34$ \\
\hline PE-SV-15 & 0.05489 & $K-18$ & PE-SV-58 & 0.03330 & $k-35$ \\
\hline PE-SV-16 & 0.04748 & $k-19$ & $P E-5 V-59$ & 0.04016 & $k-36$ \\
\hline PE-SV-17 & 0.06256 & $K-20$ & $P E-S V-60$ & 0.03684 & $K-37$ \\
\hline PE-SV-18 & 0.04430 & $K-21$ & PE-SV-6I & 0.12369 & $K-38$ \\
\hline
\end{tabular}



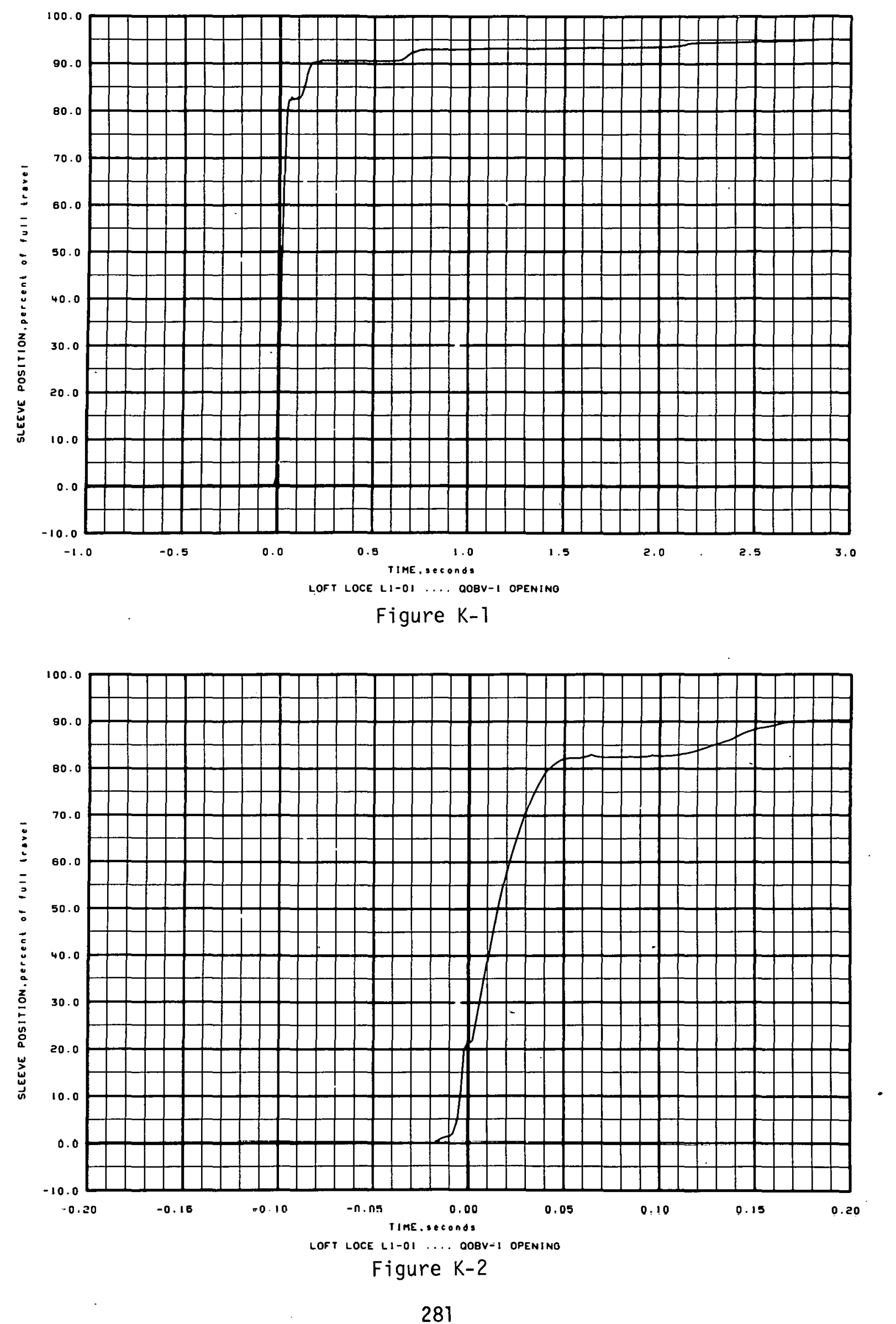

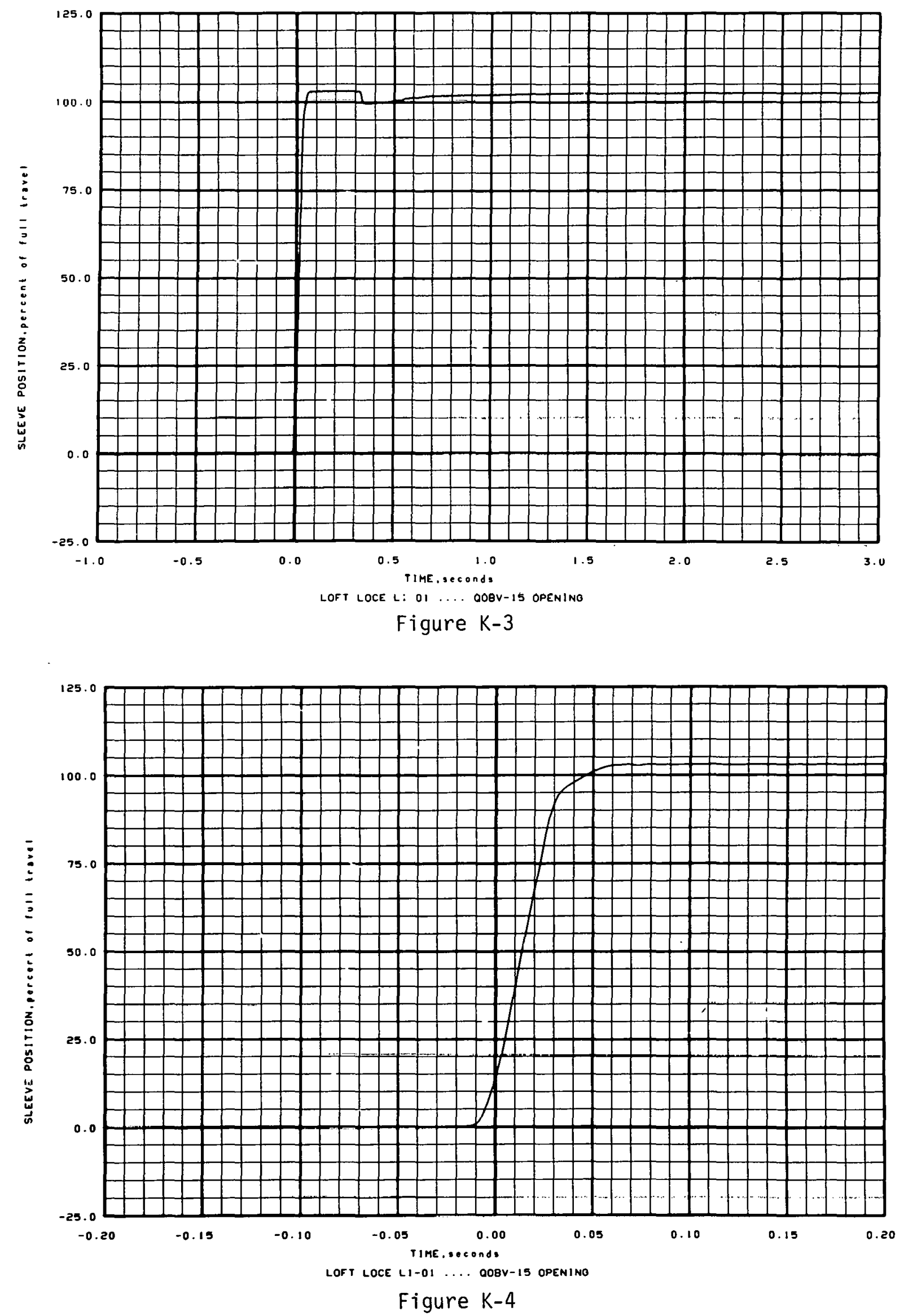

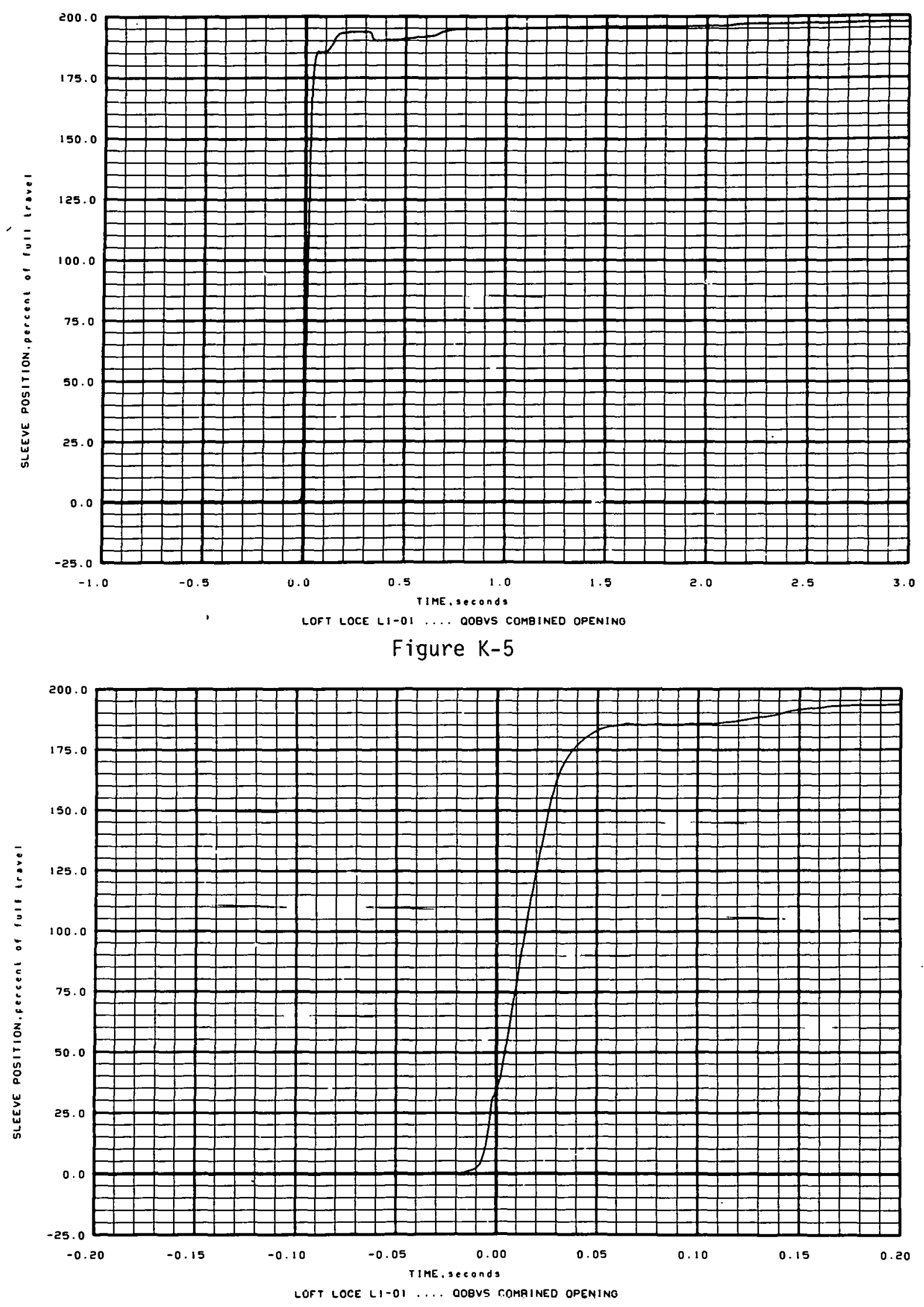

Figure K-6 

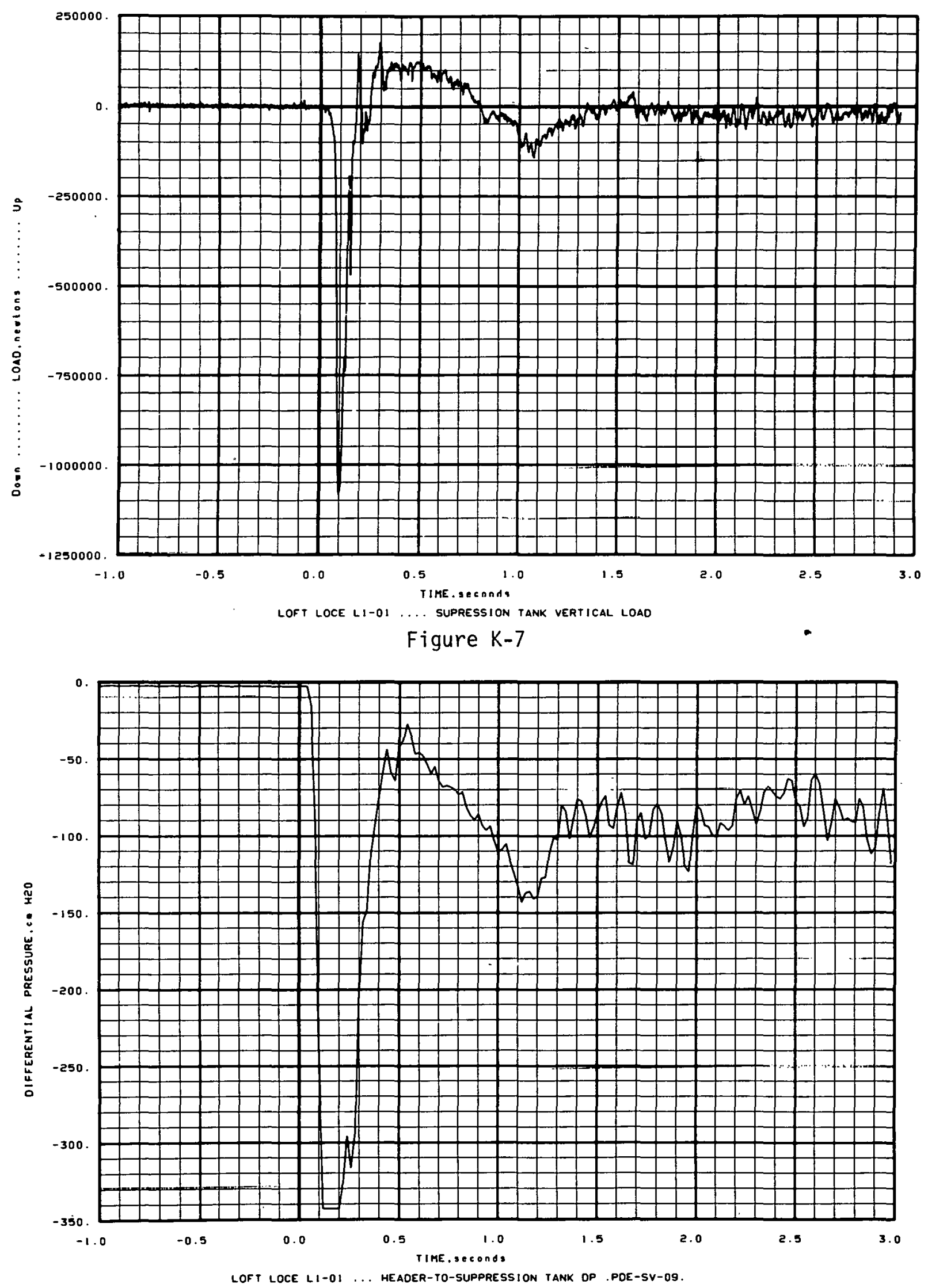

Figure K-8 


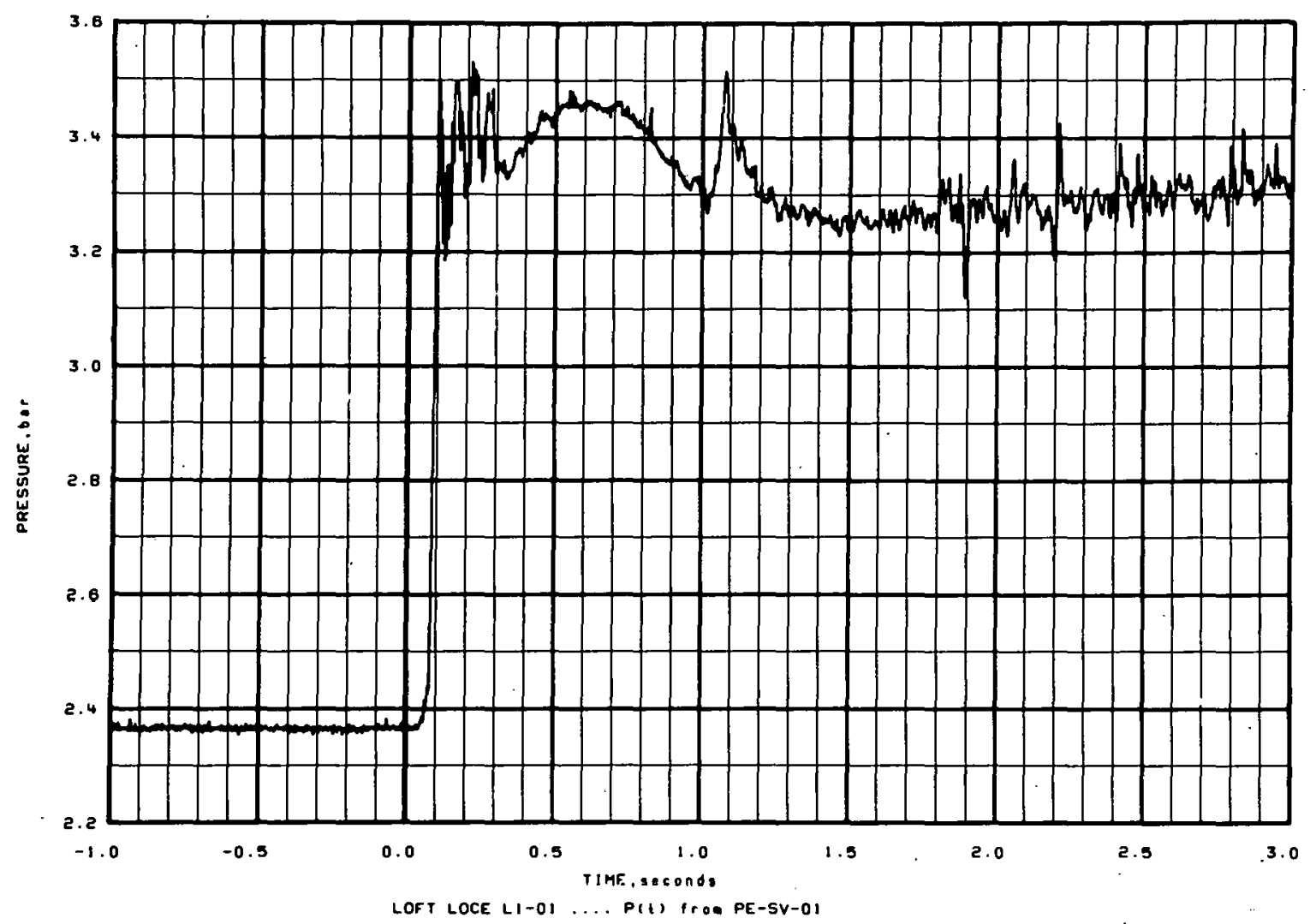

Figure K-9

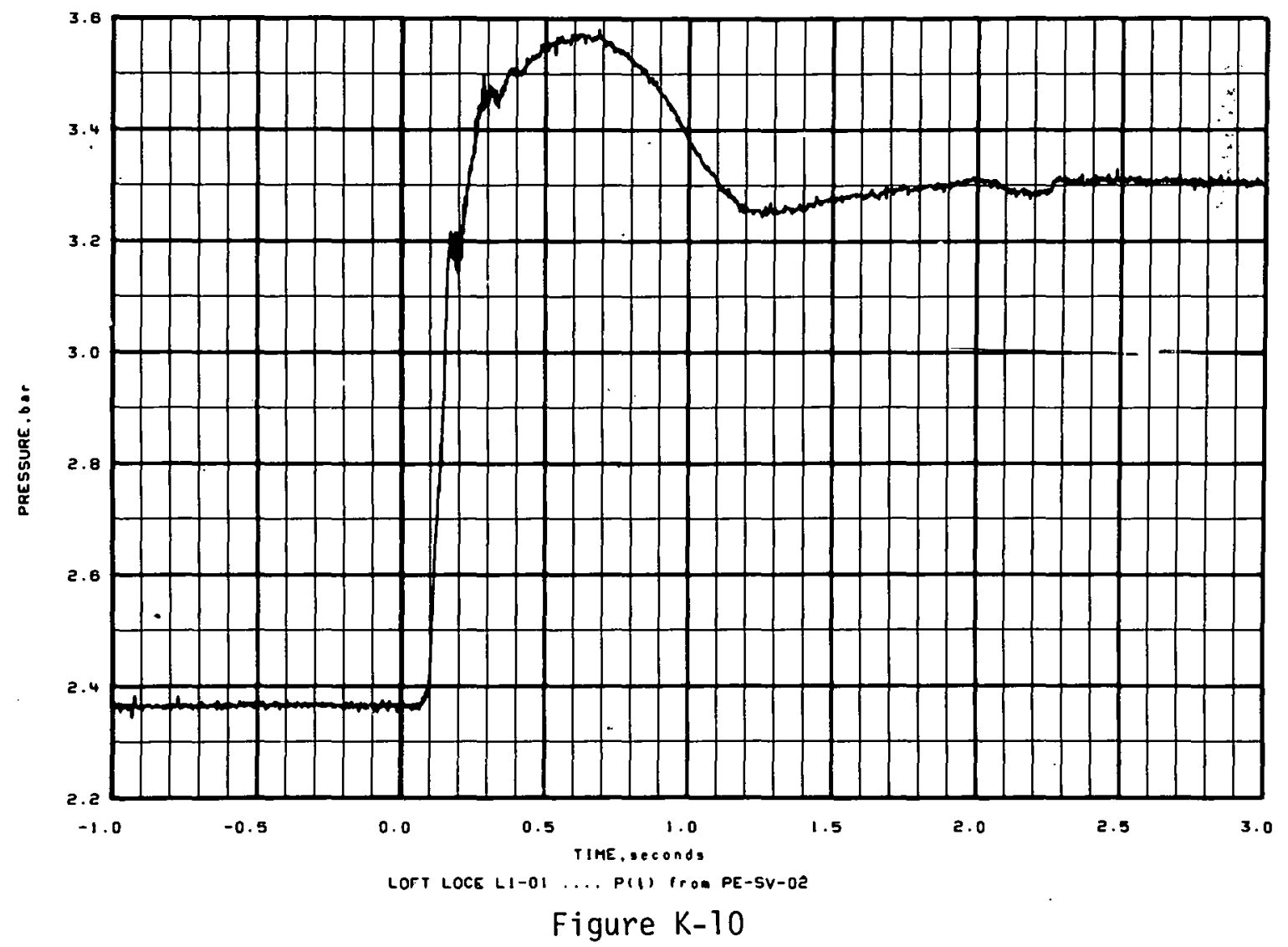



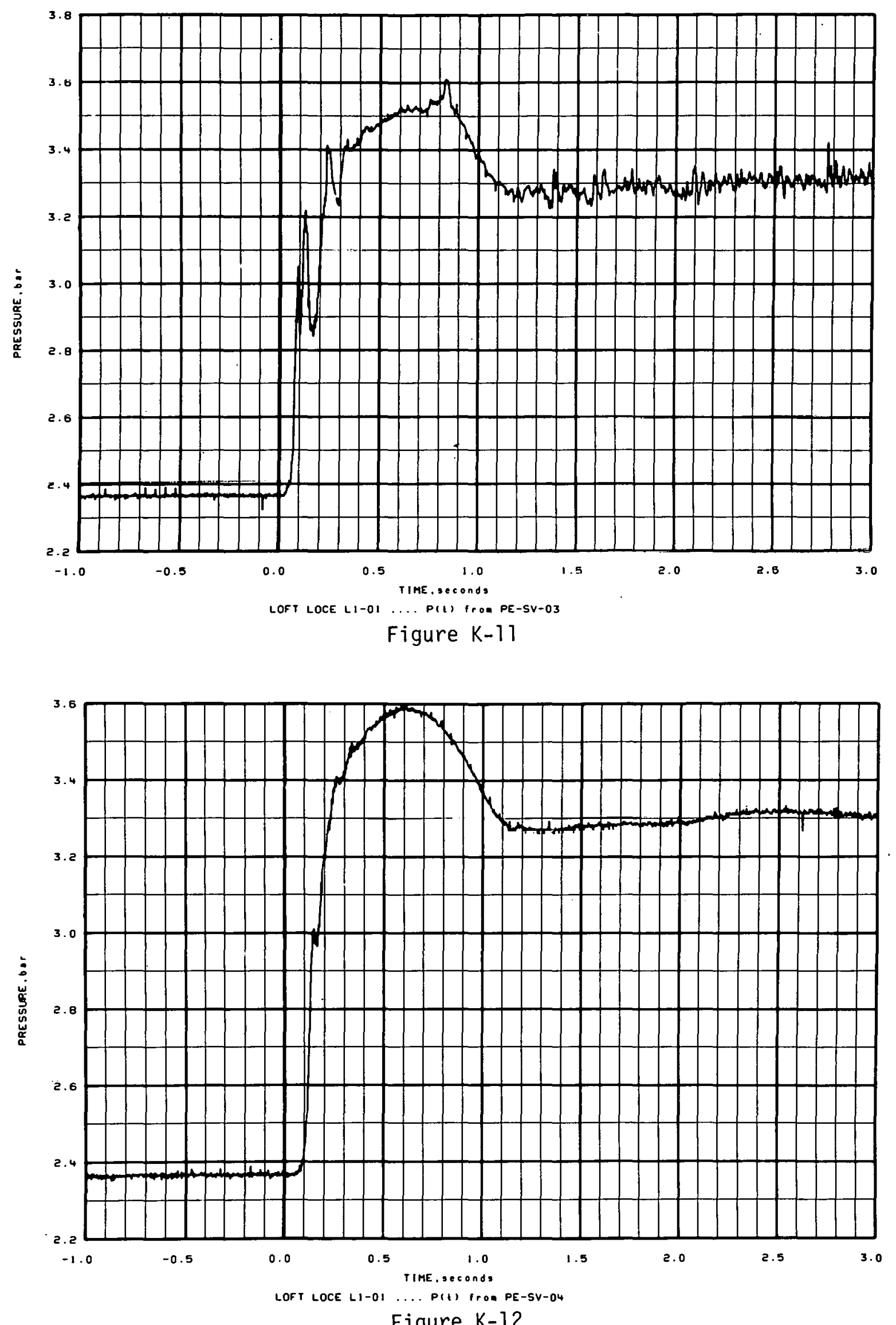

Figure $\mathrm{K}-12$ 


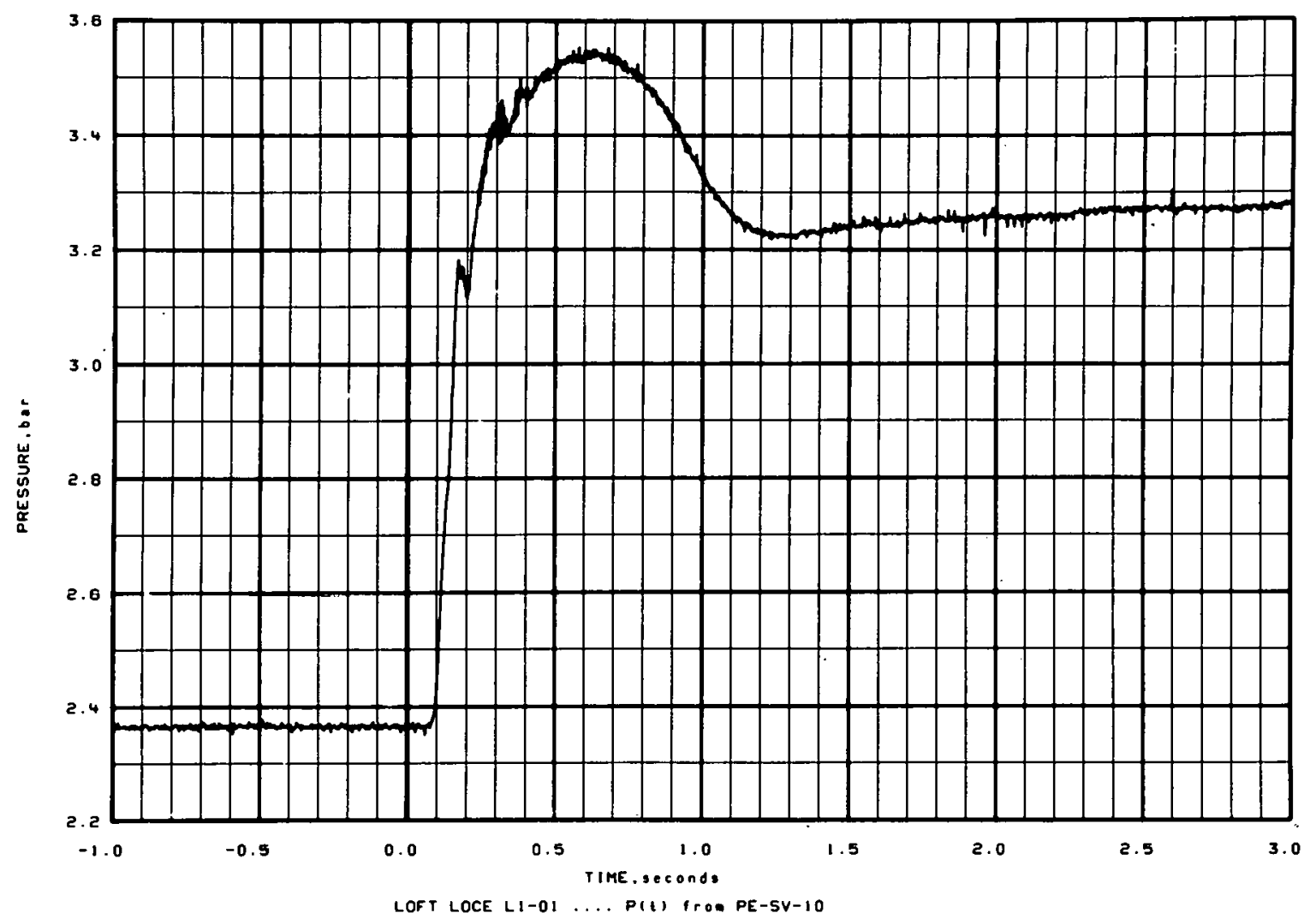

Figure $k-13$

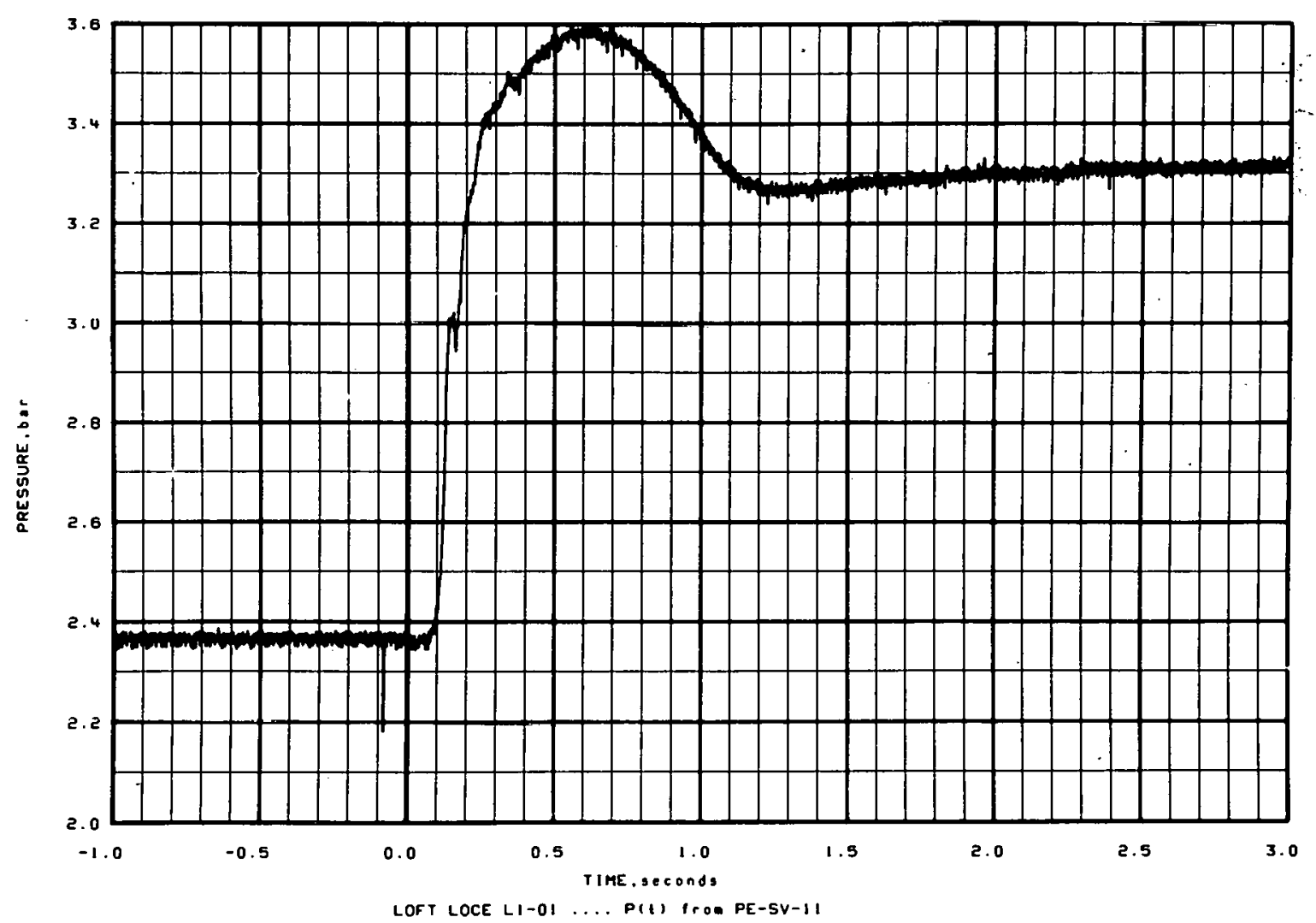

Figure $\mathrm{K}-14$ 


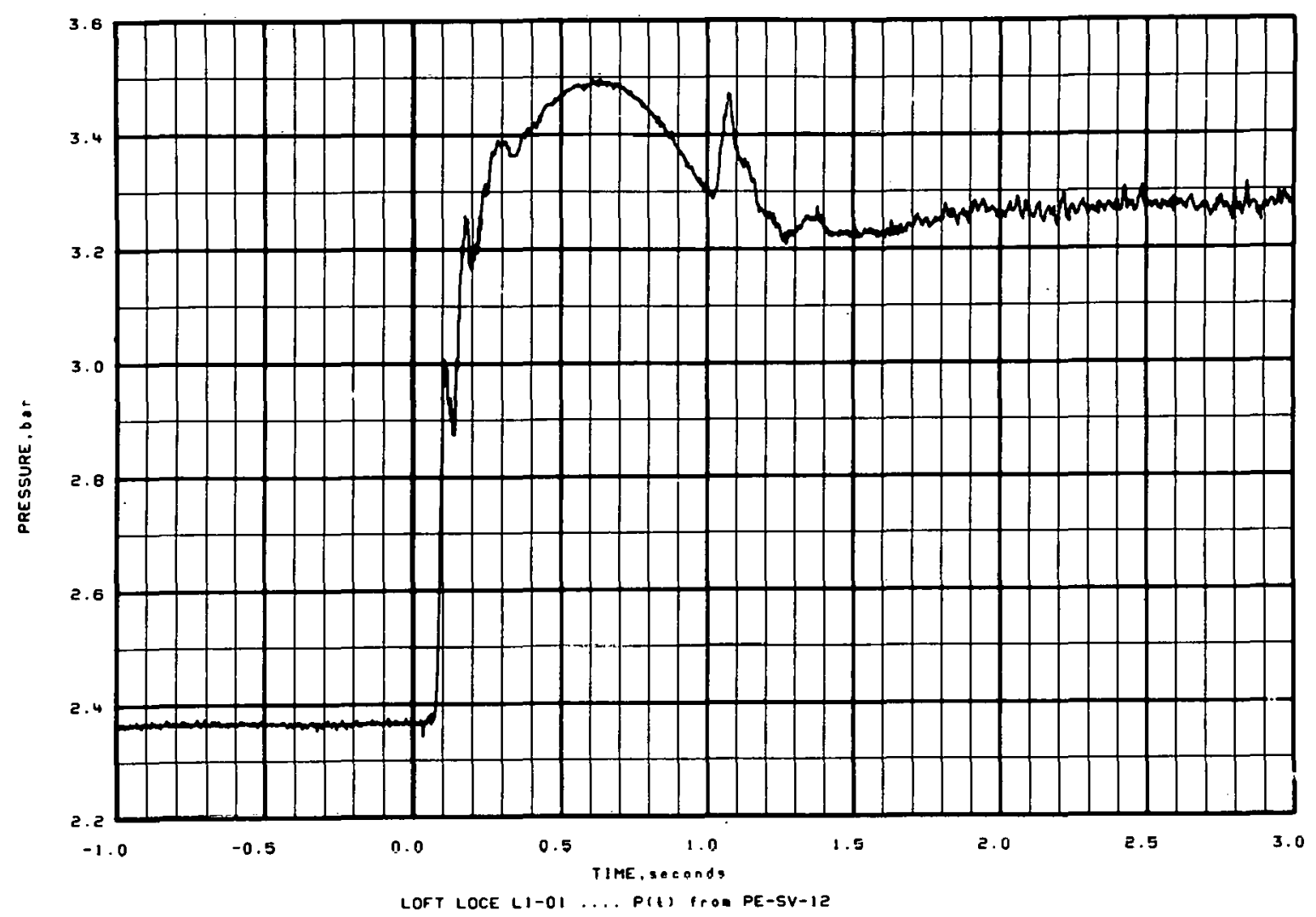

Figure K-15

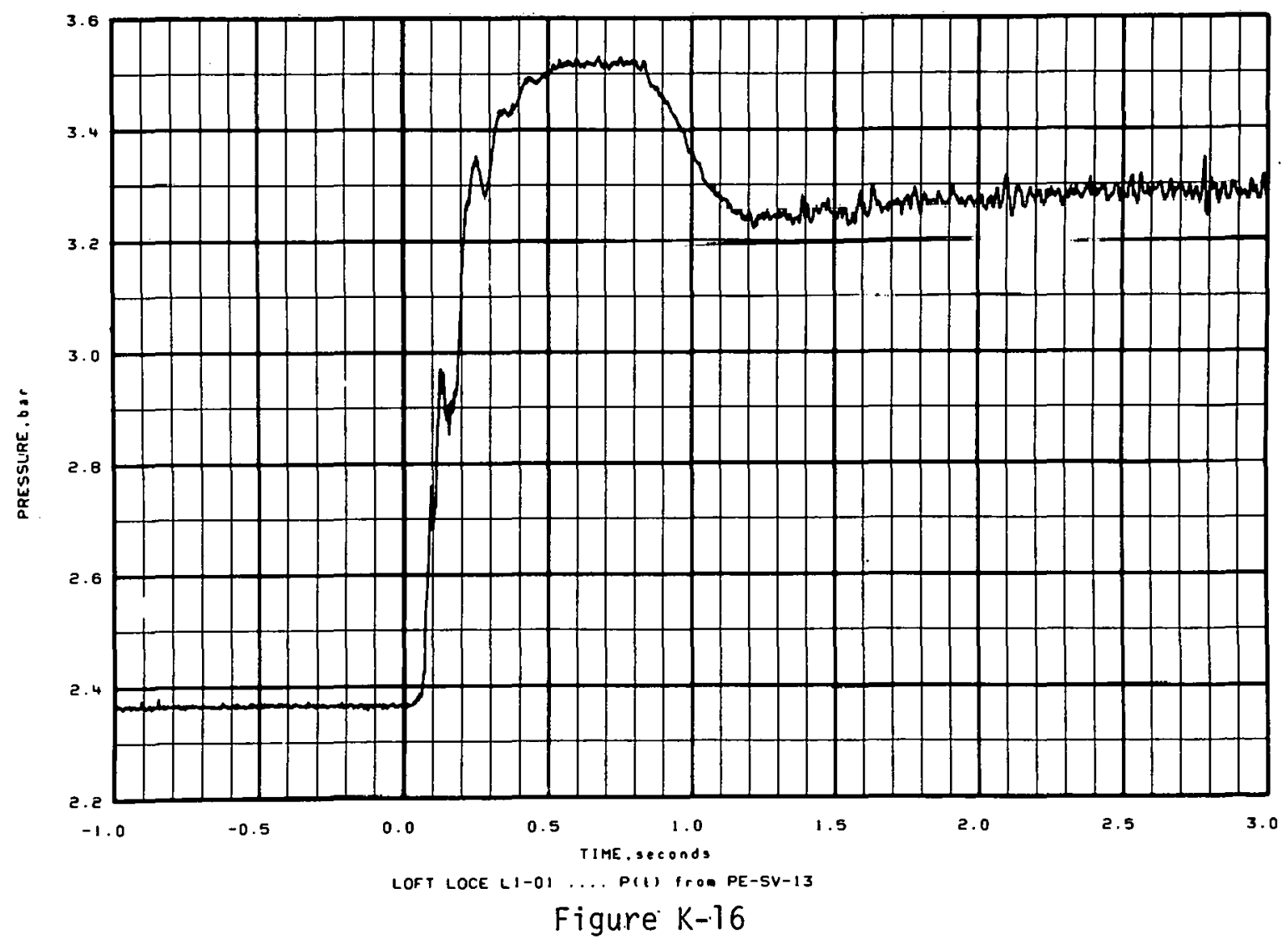



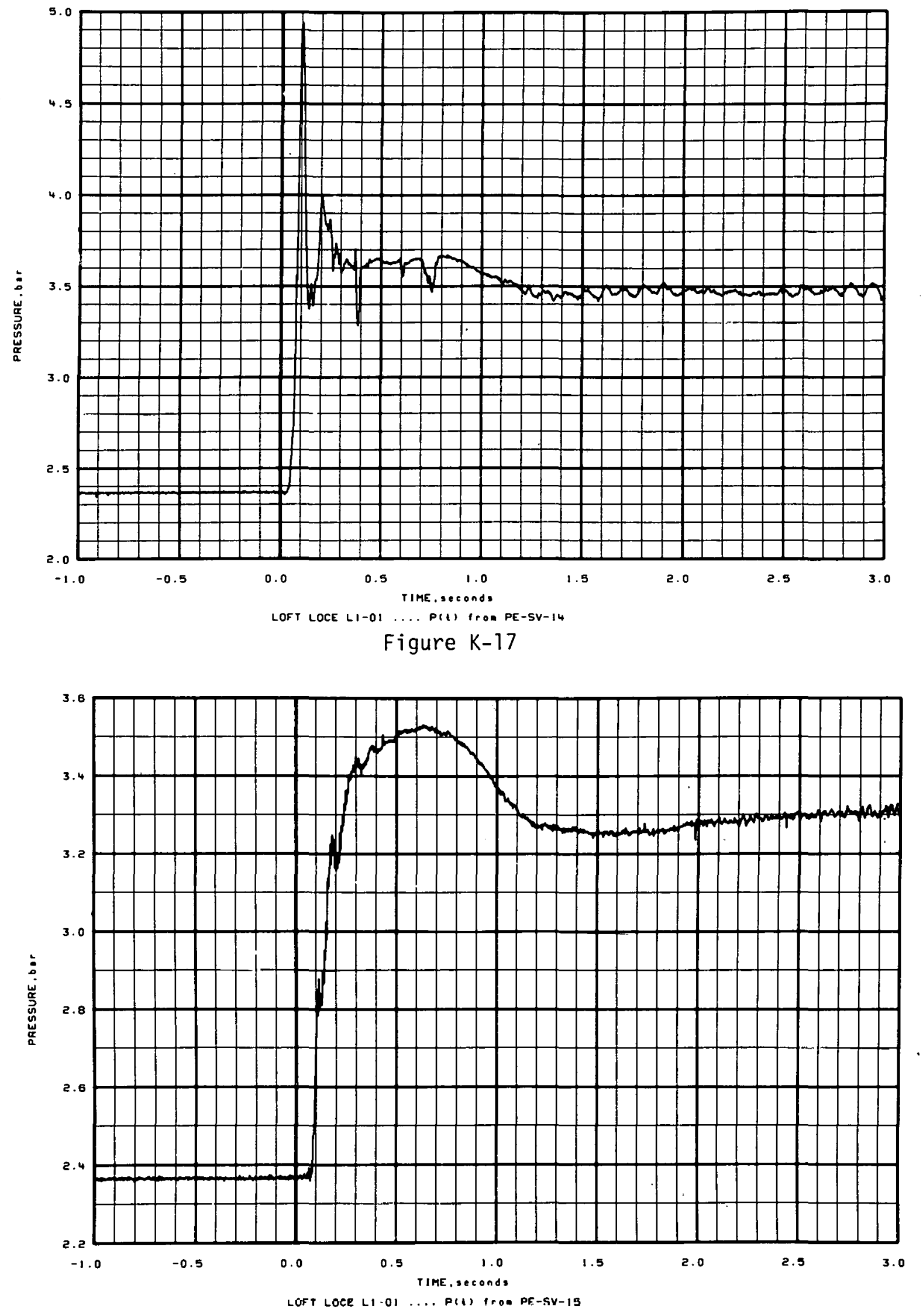

Figure K-18 


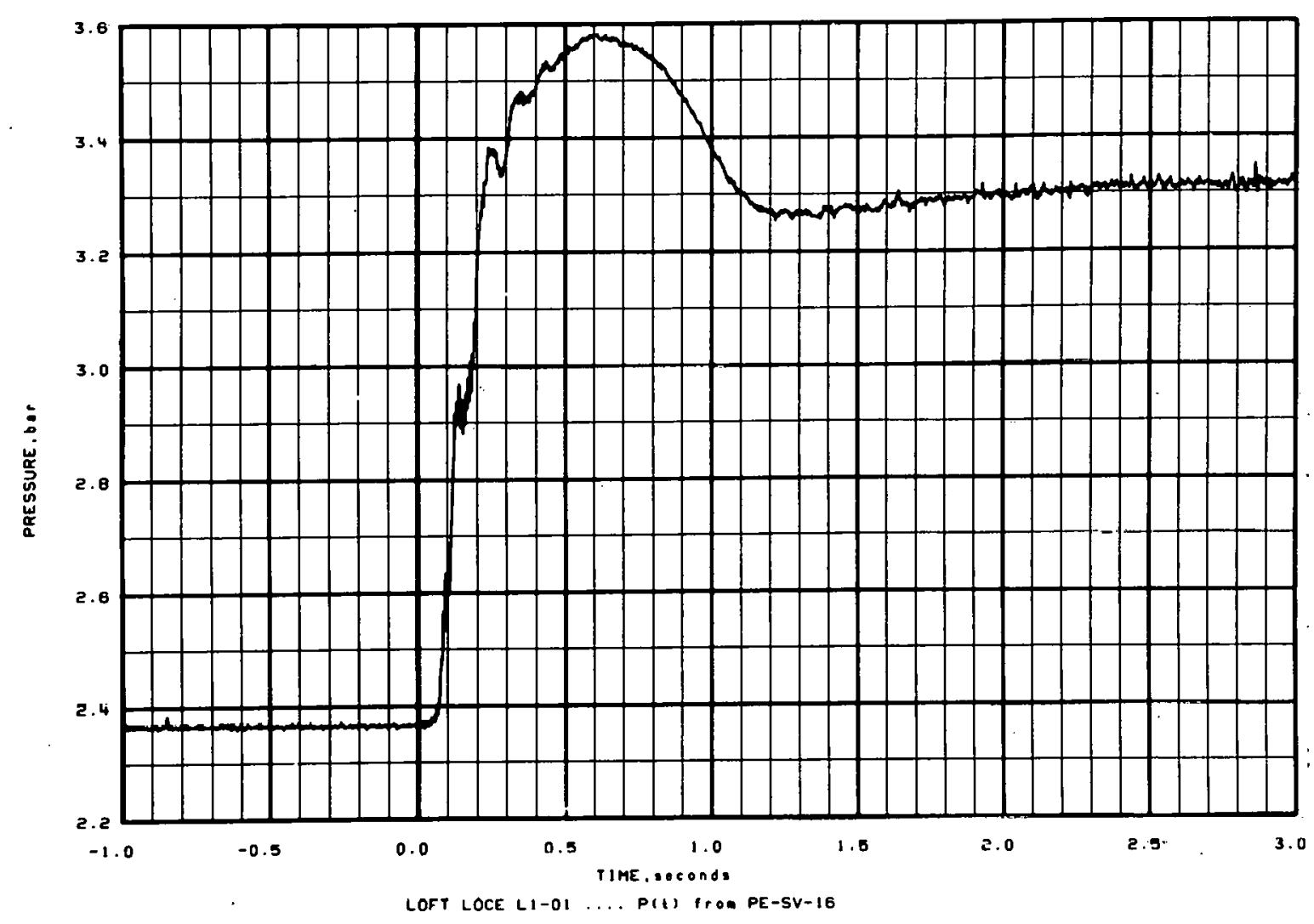

Figure K-19

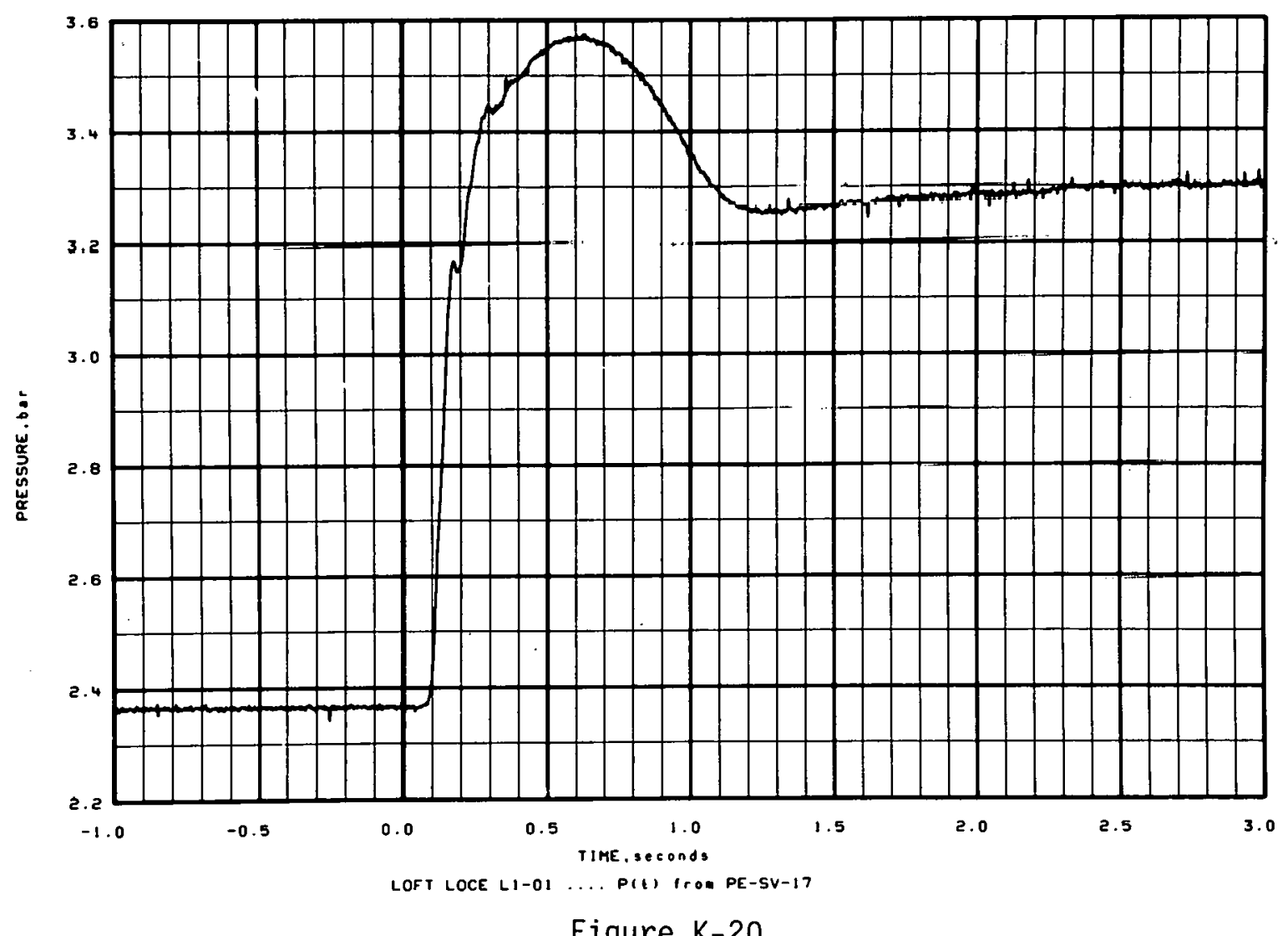



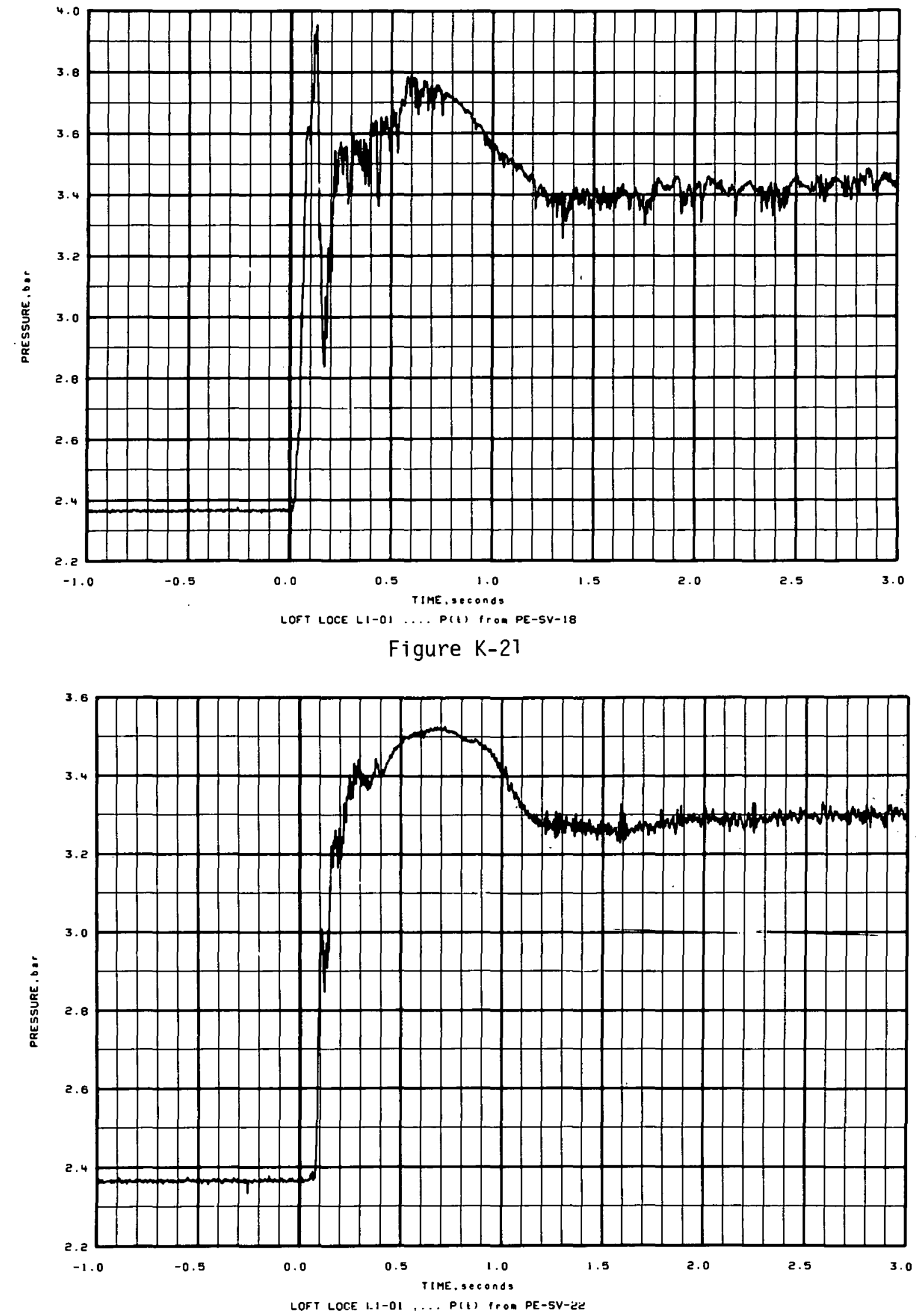

Figure K-22 


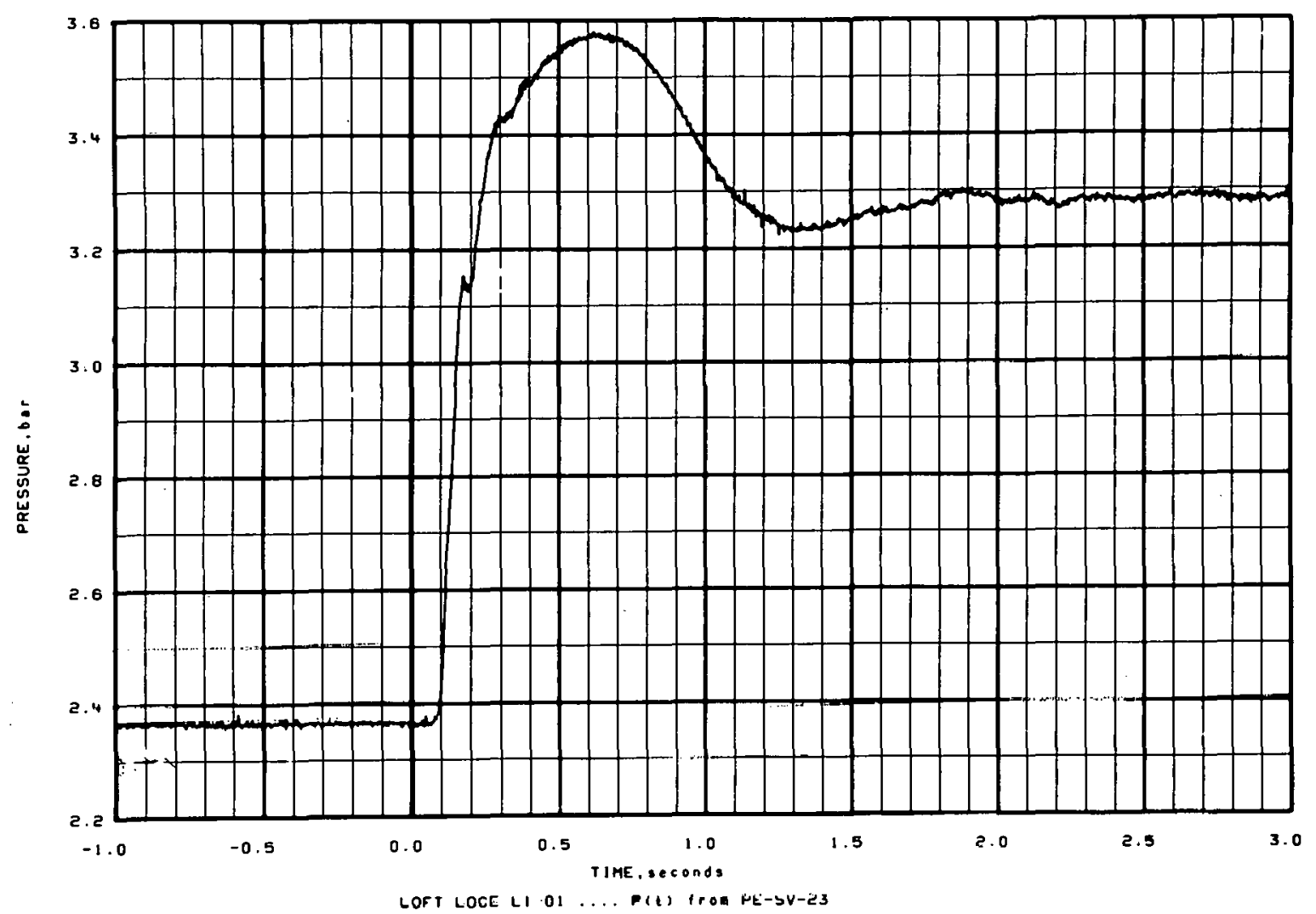

Figure K-23

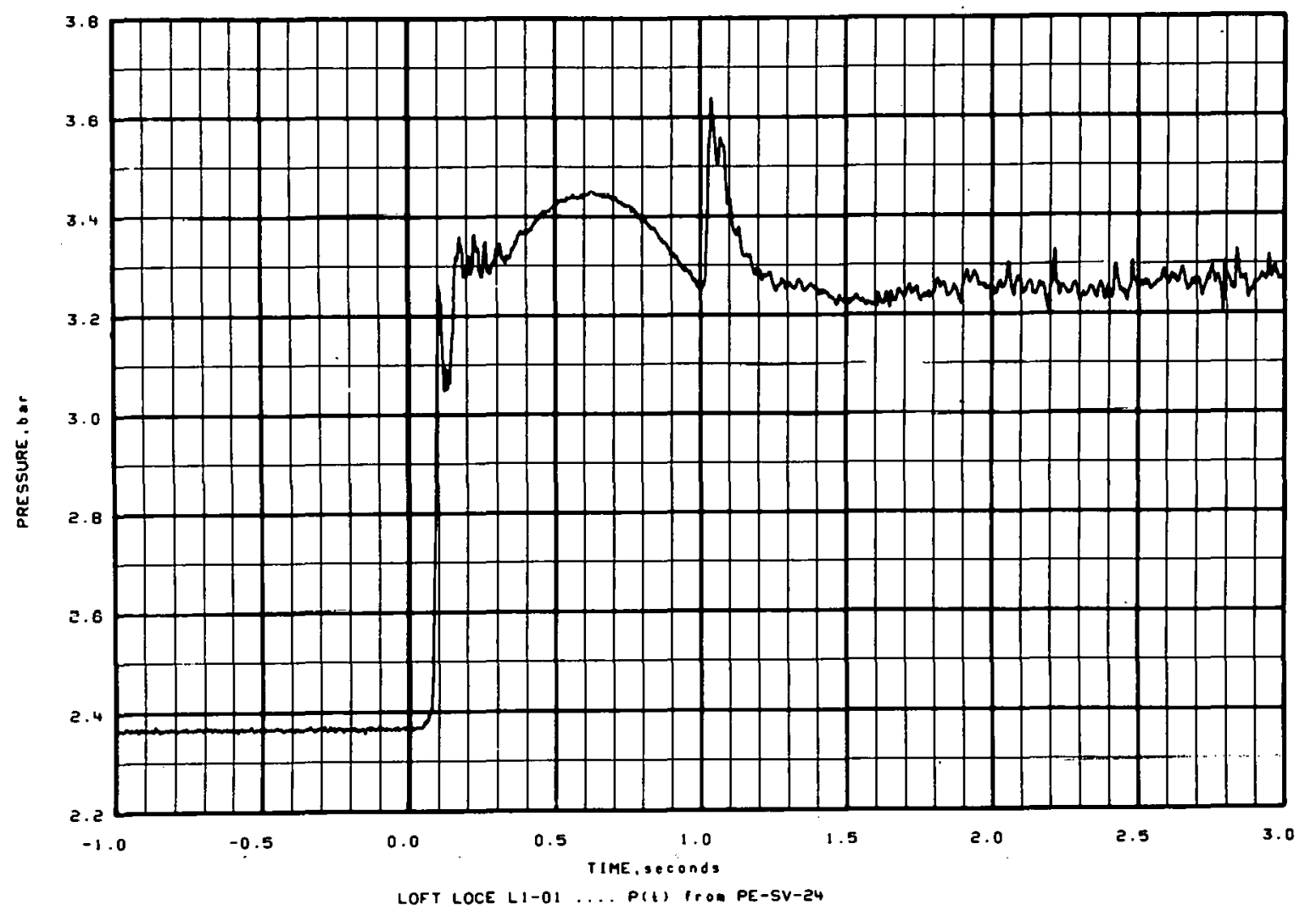

Figure K-24 

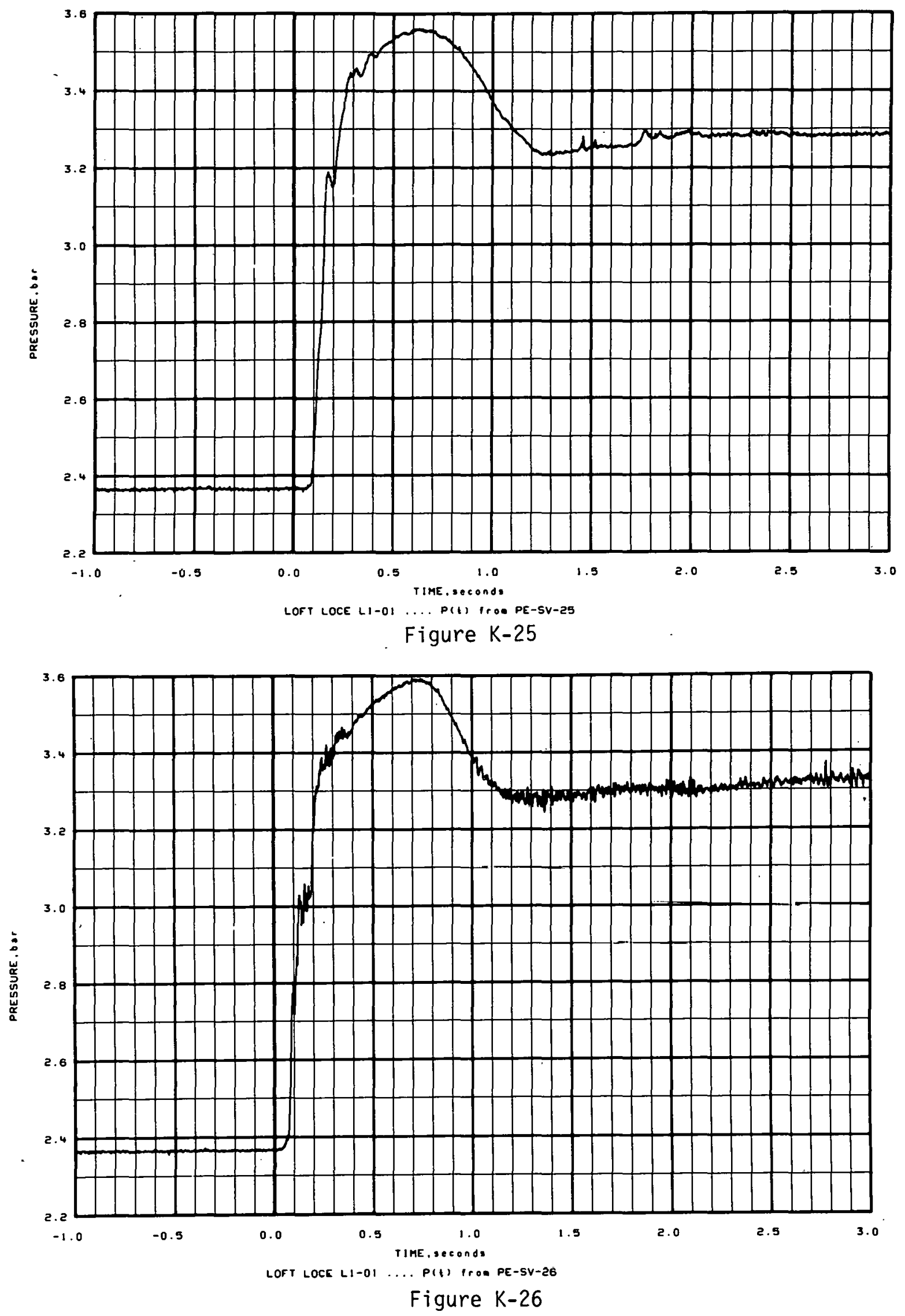


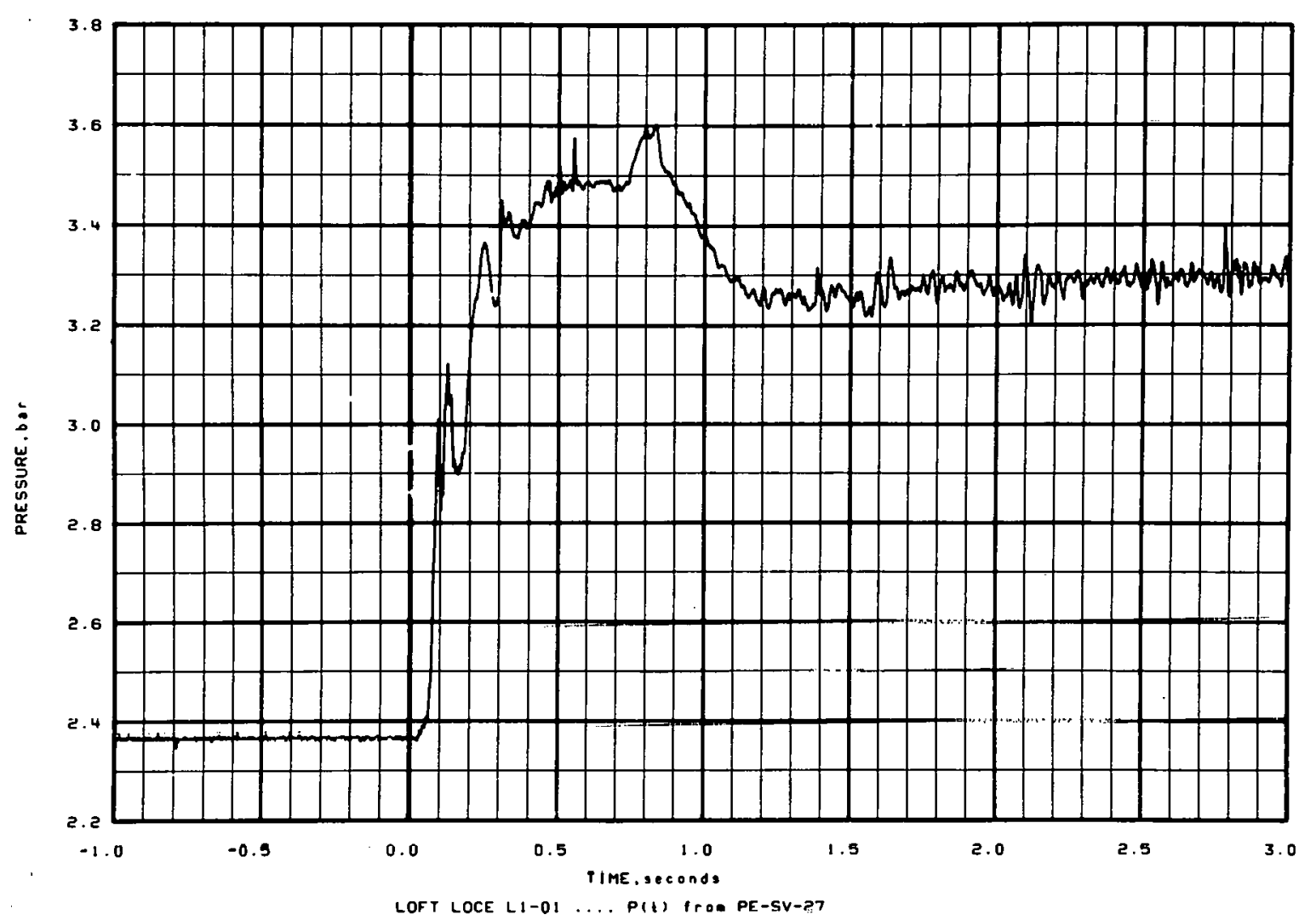

Figure K-27

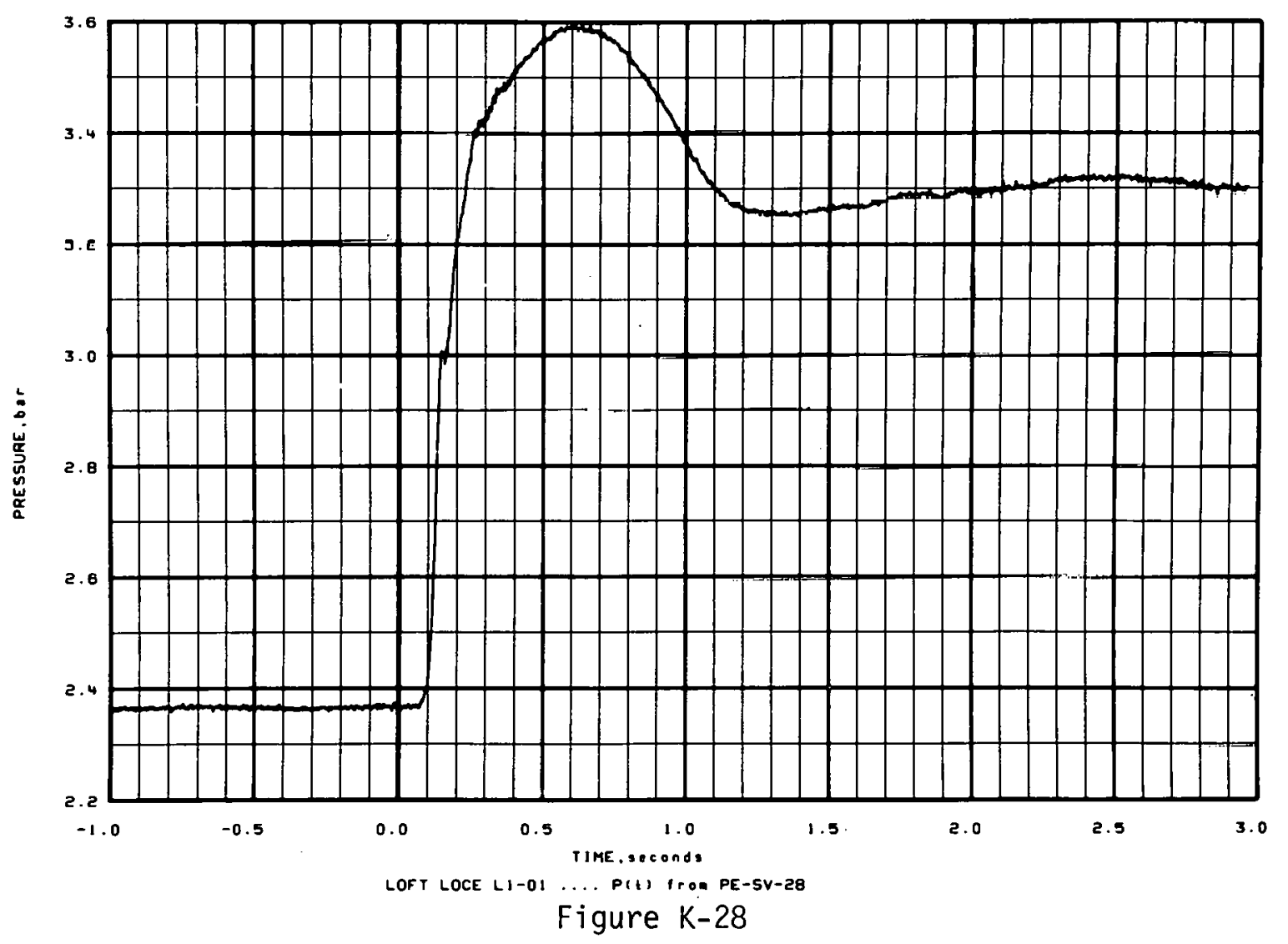



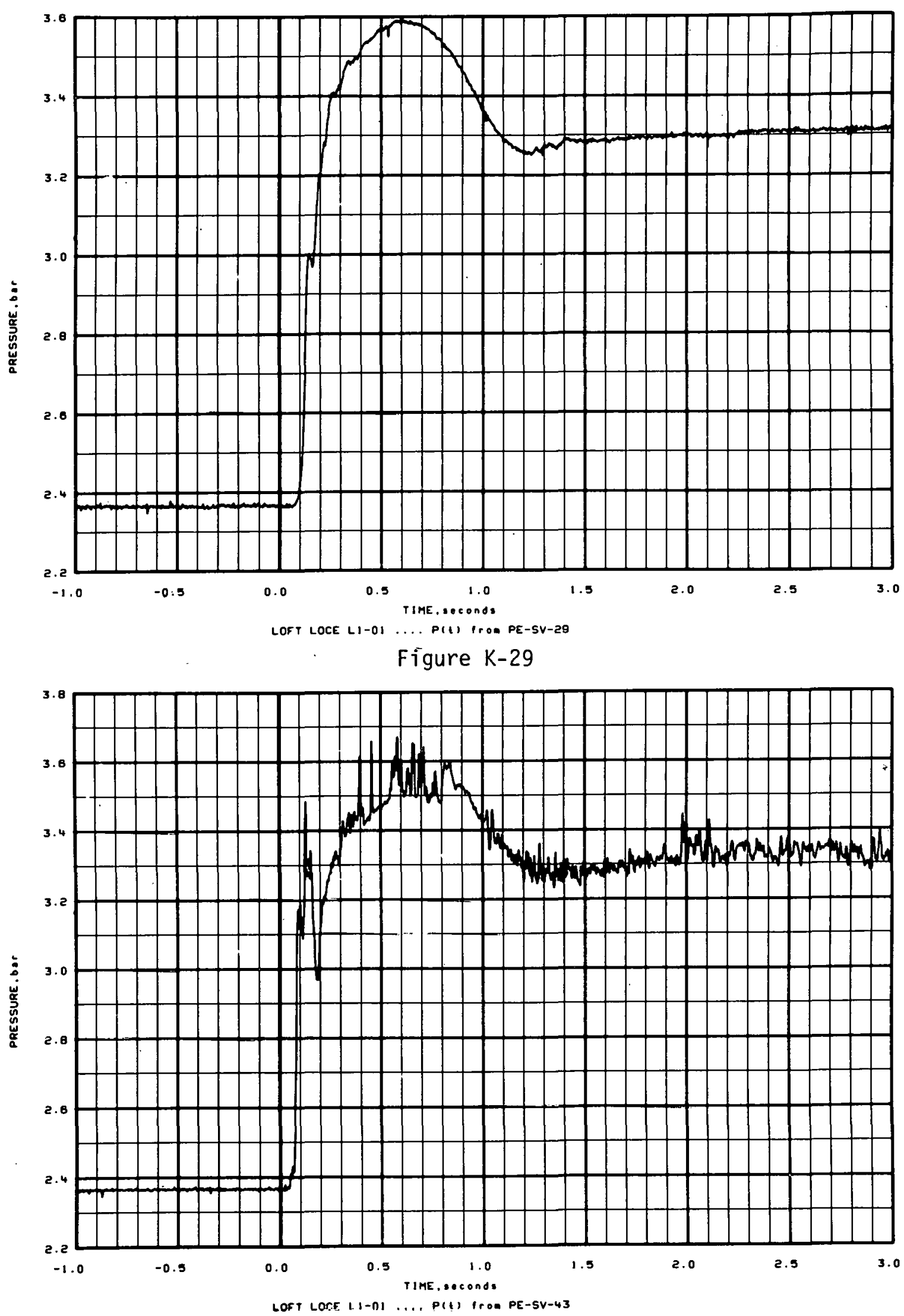

Figure K-30 

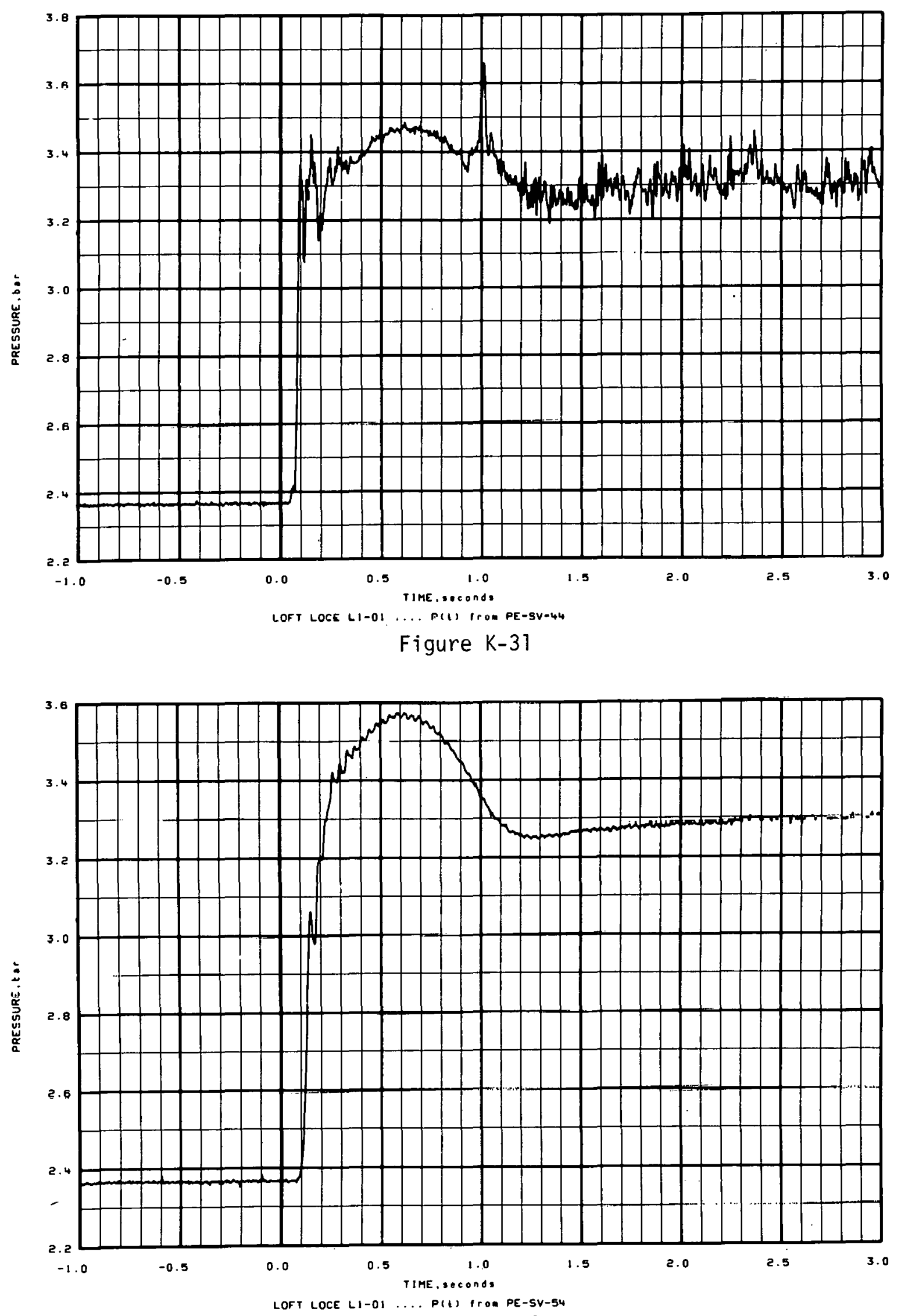

Figure K-32 

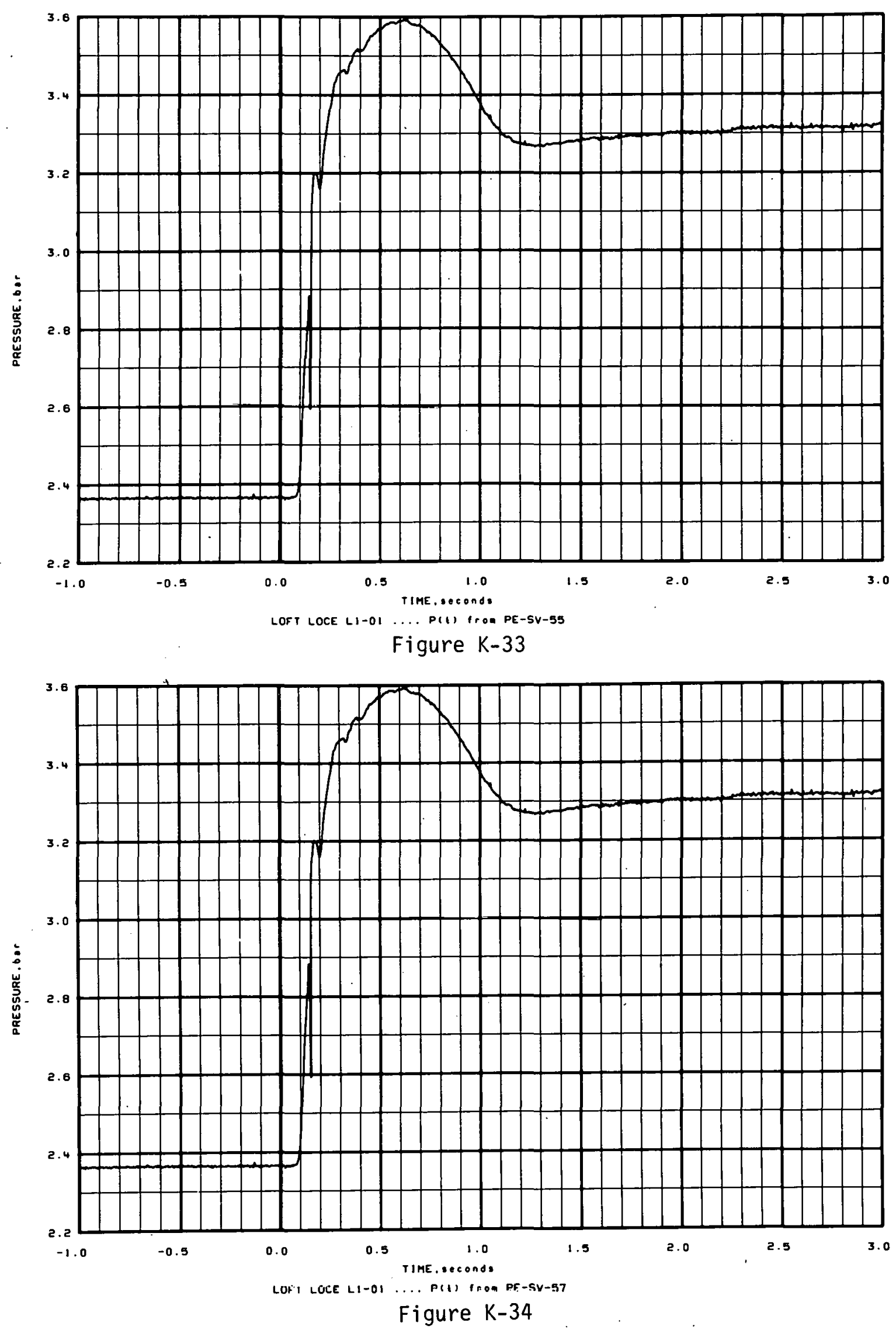

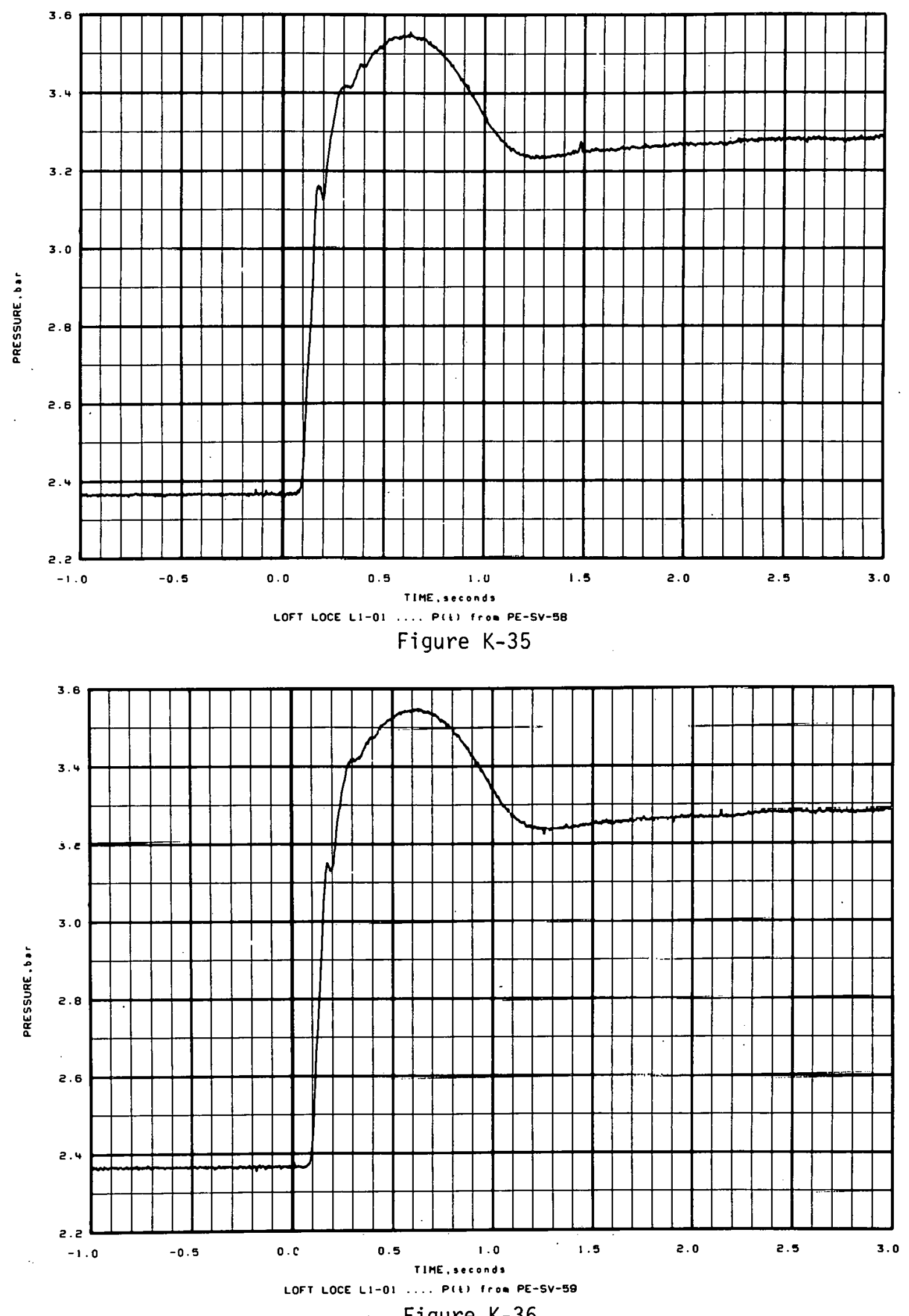

Figure K-36 


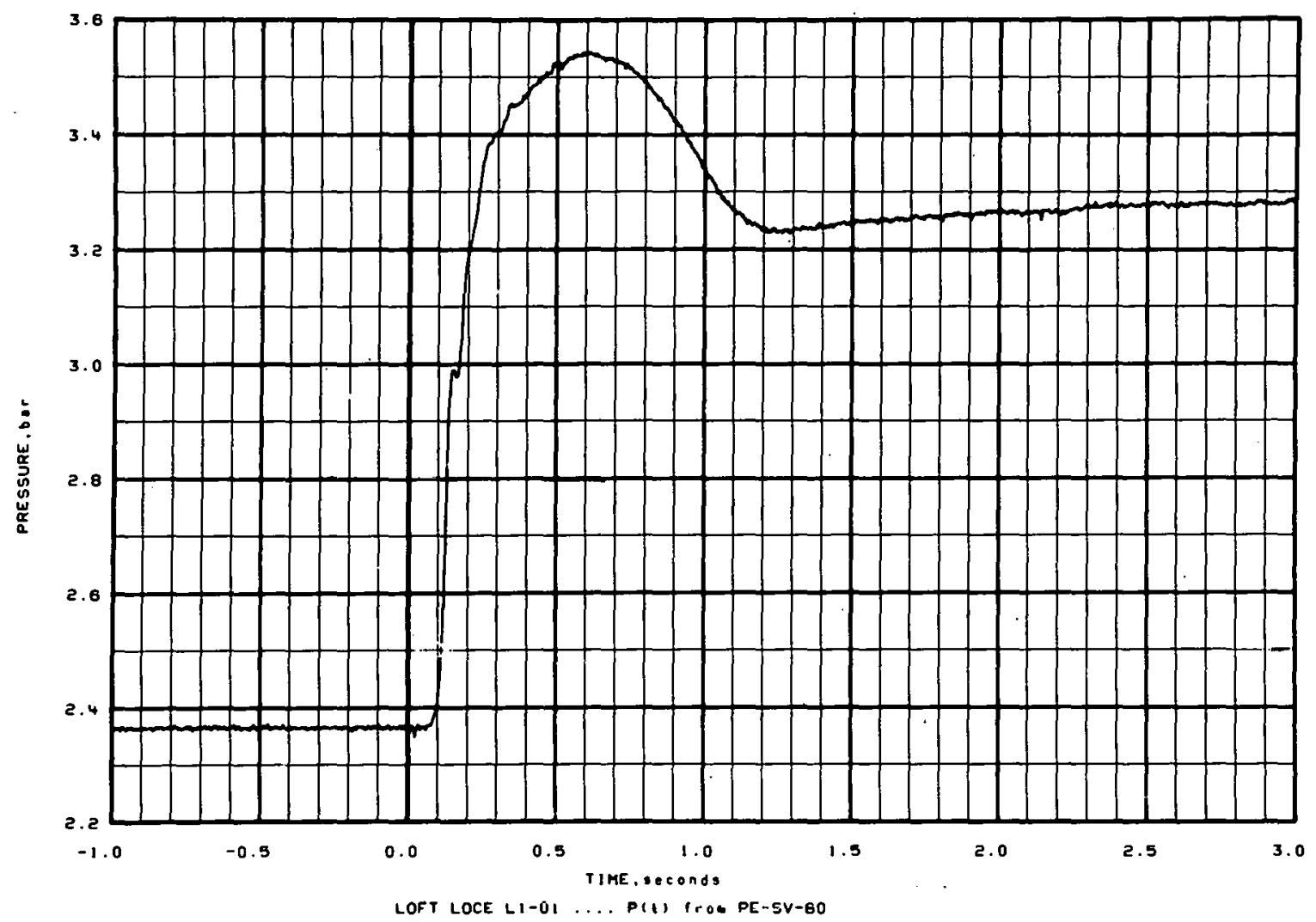

Figure K-37

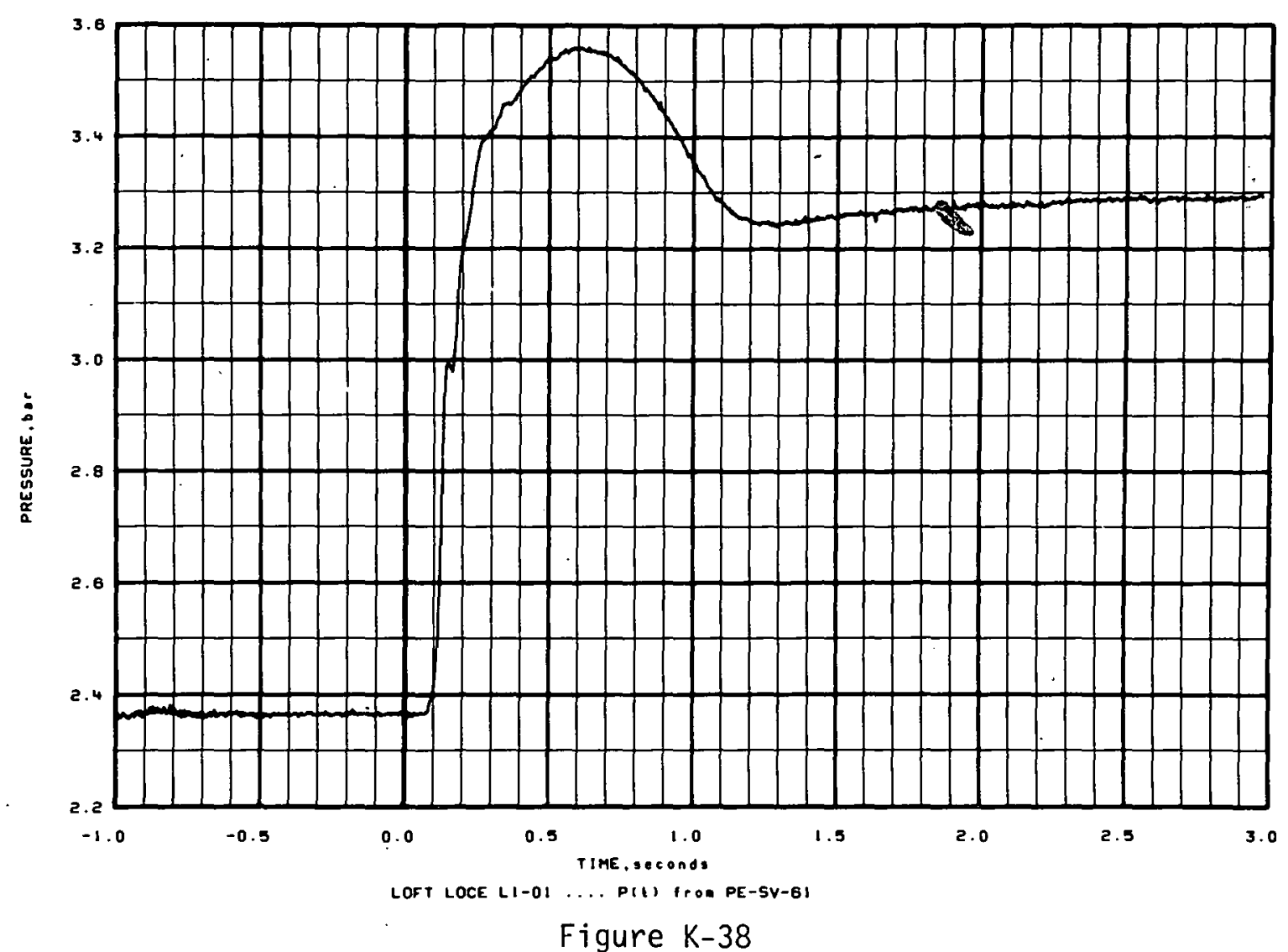




\section{THIS PAGE}

WAS INTENTIONALLY

LEFT BLANK 
APPENDIX L

LOCE L1-02 EXPERIMENTAL DATA 


\section{THIS PAGE}

\section{WAS INTENTIONALLY}

LEFT BLANK 


\section{APPENDIX L \\ LOCE LI-02 EXPERIMENTAL DATA}

Both QOBVs fully opened in this experiment. The fluid temperature was $246.7 \pm 1.5^{\circ} \mathrm{C}$ in QOBV- 7 and $253.3 \pm 1.5^{\circ} \mathrm{C}$ in QOBV-15. The suppression tank initial conditions were $1.74 \pm 0.08 \mathrm{bar}, 68.9 \pm 1.5^{\circ} \mathrm{C}$ in the gas volume, and $75.6 \pm 1.5^{\circ} \mathrm{C}$ in the pool. The vents were submerged $43.6 \pm 2.5 \mathrm{~cm}$. The internal vent submergence was $13.6 \pm 3.2 \mathrm{~cm}$.

The experimental data are defined in Table L-I. The opening characteristics of the QOBVS are shown in terms of percent sleeve travel versus time. The flow area of the valve begins to open at a sleeve position of $17 \%$ of full travel and is fully open at a sleeve position of $66 \%$ of full travel. The differential pressure between the header and the tank gas volume is measured with a very sensitive device primarily to provide information on vent preclearing. The data channel for this measurement is driven to saturation in the early part of the transtent. 
TABLE L-I

EXPERIMENT LT-02 DATA SUMMARY

\begin{tabular}{|c|c|c|c|c|c|}
\hline $\begin{array}{c}\text { Measurement } \\
\text { or } \\
\text { Calculation }\end{array}$ & $\begin{array}{c}\text { Pre-Transient } \\
\text { Data Channel } \\
\text { Variance } \\
\left(10^{-4} \text { bar }^{2}\right) \\
\end{array}$ & Figure Number & Measurement & $\begin{array}{c}\text { Pre-Transient } \\
\text { Data Channel } \\
\text { Variance } \\
\left(10^{-4} \text { bar }^{2}\right) \\
\end{array}$ & Figure Number \\
\hline QOBV-1 opening & - & $L-1, L-2$ & PE-SV-22 & 0.16176 & $L-22$ \\
\hline QOBV - 15 opening & $=$ & $L-3, L--4$ & PE-SV-23 & 0.16027 & $\mathrm{~L}-23$ \\
\hline $\begin{array}{l}\text { Combined QOBV } \\
\text { opening }\end{array}$ & - & $L=5, I-6$ & $P E-S V-24$ & 0.11748 & $L-24$ \\
\hline Vertical load & - & $\mathrm{L}-7$ & PE-SV-25 & 0.11313 & $L-25$ \\
\hline PDE-SV-09 & - & $L-8$ & PE-SV-26 & 0.06488 & $L-26$ \\
\hline PE-SV-01 & 0.18528 & $L-9$ & PE-SV-27 & 0.13657 & $\mathrm{~L}-27$ \\
\hline PE-SV-02 & 0.18865 & $L-10$ & PE-SV-28 & 0.11040 & $L-28$ \\
\hline PE-SV-03 & 0.18680 & $L-71$ & PE-SV-29 & 0.13673 & $L-29$ \\
\hline PE-SV-04 & 0.18536 & $L-12$ & PE-SV-43 & 0.09353 & $L=30$ \\
\hline$P E-S V-10$ & 0.13946 & L-13 & PE-SV-44 & 0.10625 & L. -3. \\
\hline PE-SV-11 & 1.32824 & $L-14$ & $P[-S V-54$ & 0.08271 & $L-32$ \\
\hline PE $-5 V-12$ & 0.17752 & $L-15$ & PE-SV-55 & \multicolumn{2}{|c|}{ measurement failed } \\
\hline$P E-S V-13$ & 0.12185 & $L-16$ & PE-SV-56 & \\
\hline$P E-S V-14$ & 0.17543 & L- 17 & PE-SV-57 & 0.07907 & $L-33$ \\
\hline PE-SV-15 & 0.16861 & L. -18 & PE-SV-58 & 0.13837 & $L-34$ \\
\hline P.E-SV-16 & 0.12531 & $L-19$ & PE-SV-59 & 0.13737 & $L-35$ \\
\hline PE-SV-17 & 0.14715 & $\mathrm{~L}-20$ & PE-SV-60 & 0.14627 & $L-36$ \\
\hline PE-SV- 18 & 0.16660 & $L-21$ & $P E-S V=61$ & 0.11678 & L-3] \\
\hline
\end{tabular}




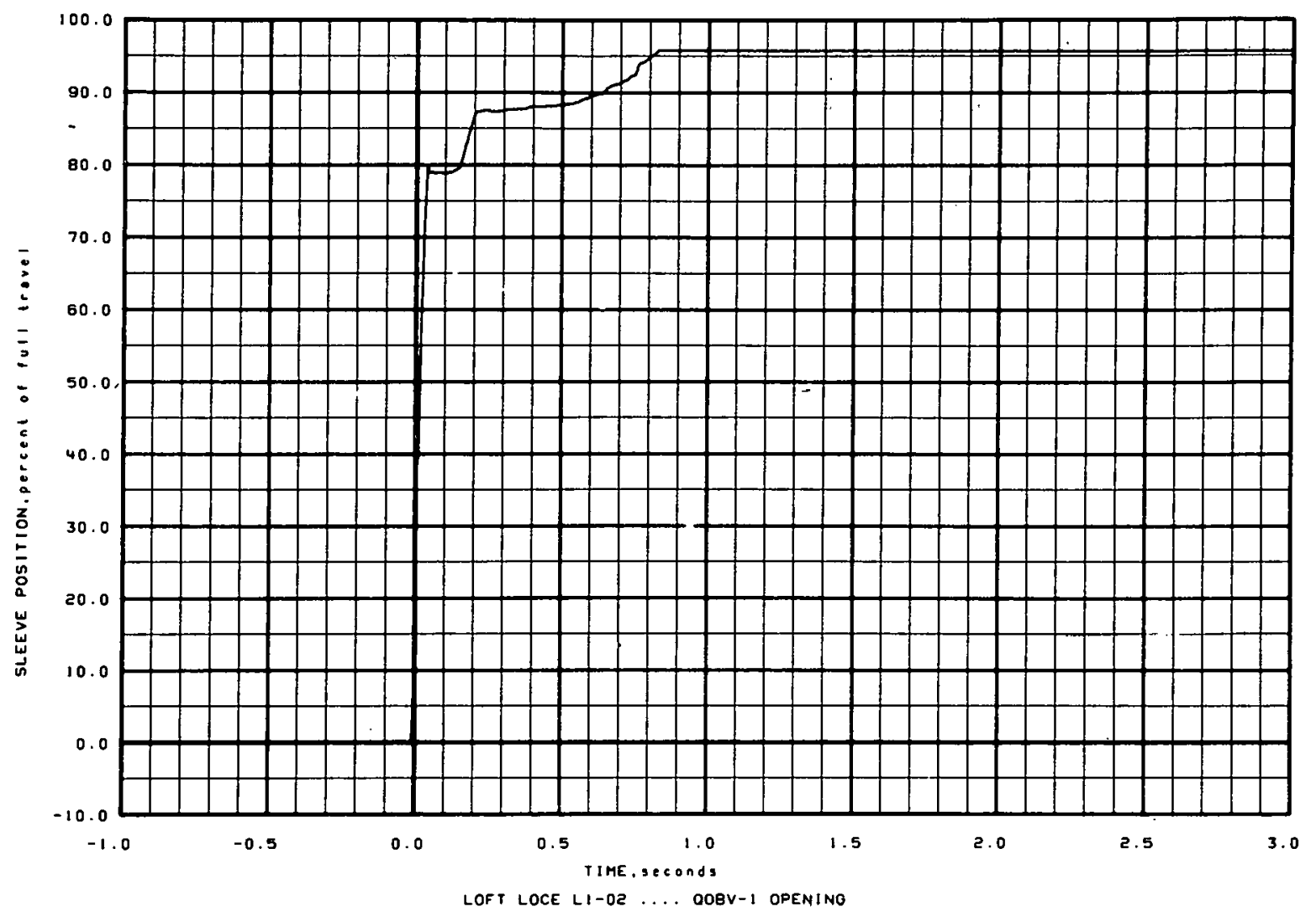

Figure L-1

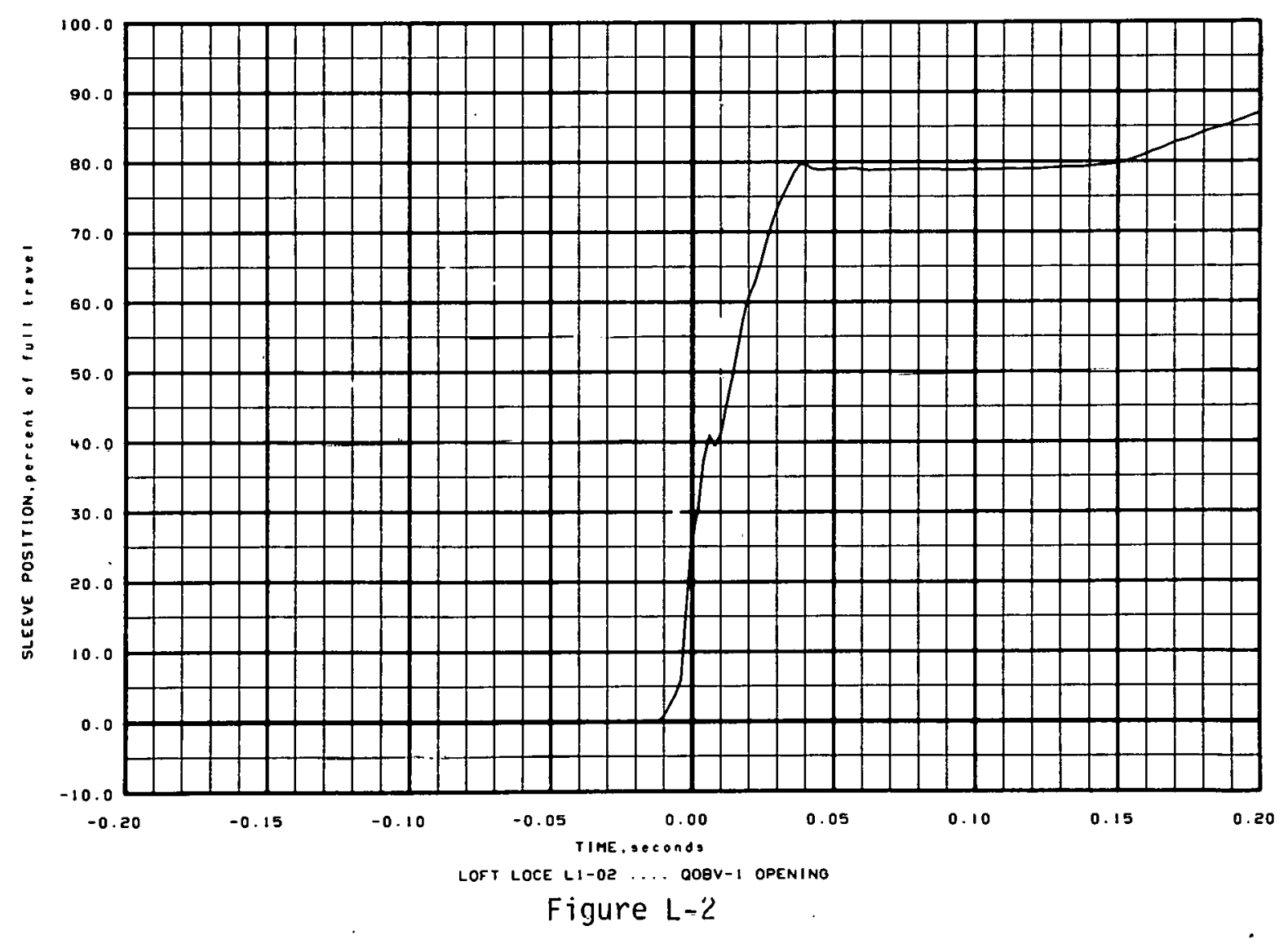



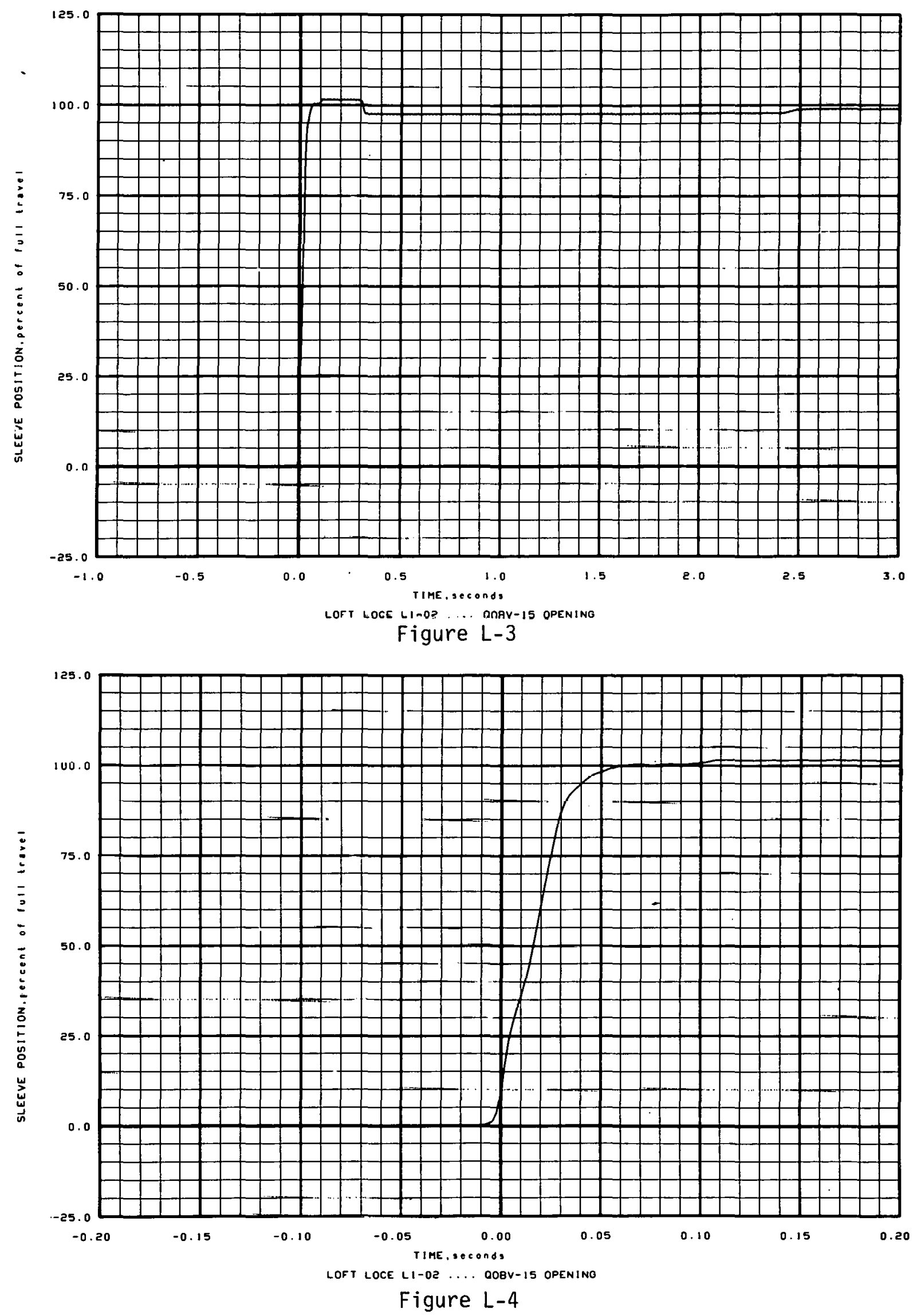

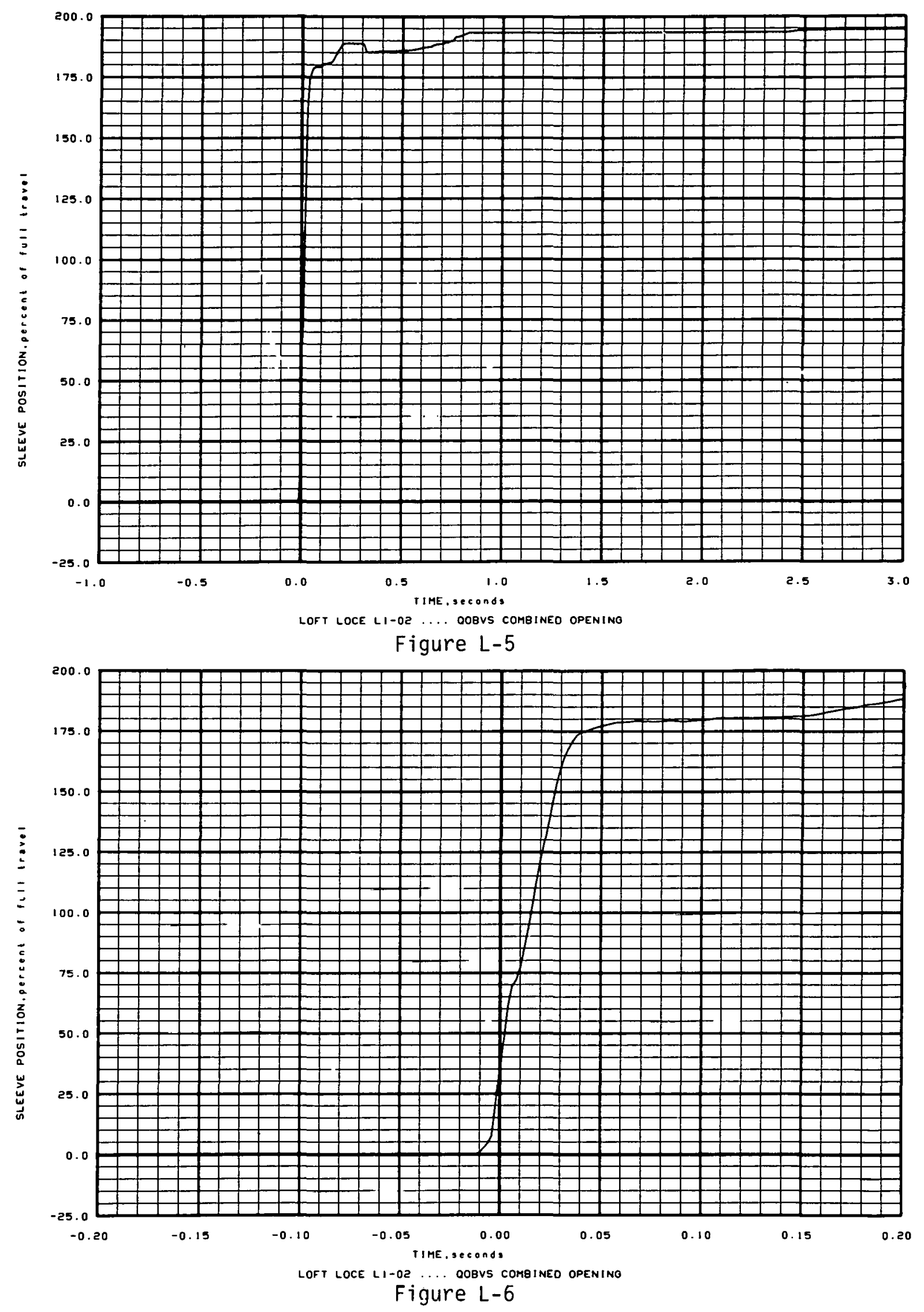


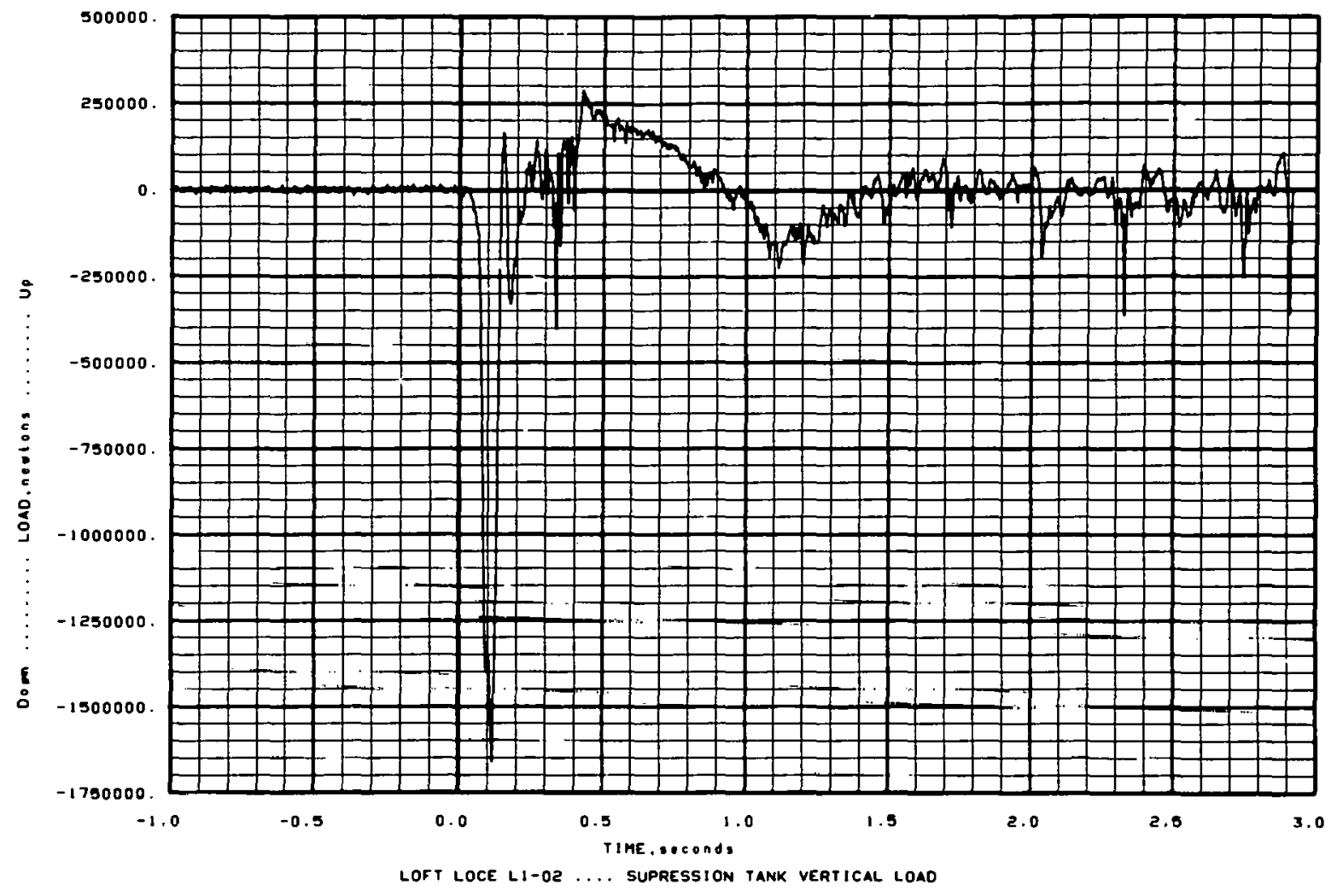

Figure L-7

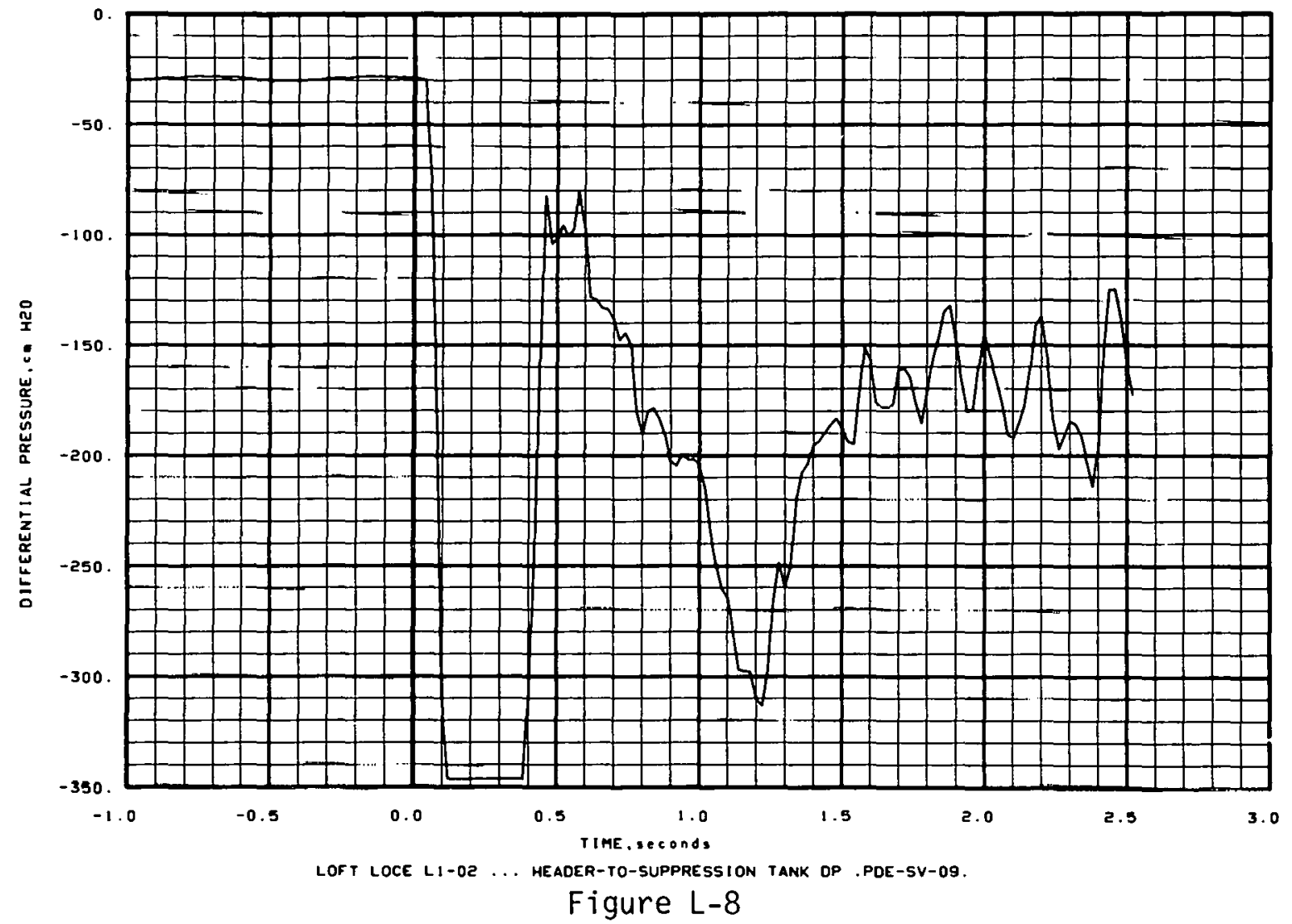




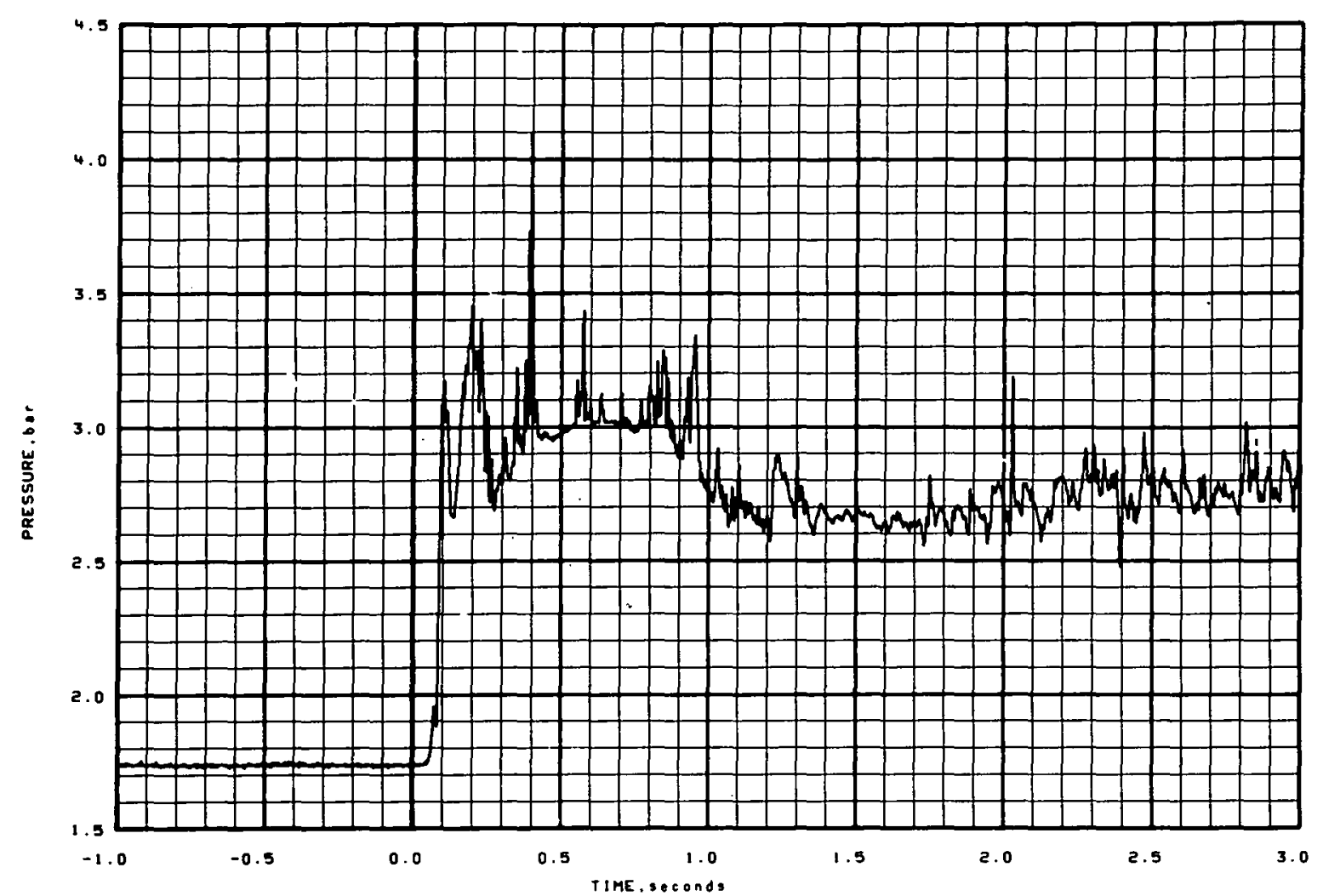

LOFT LOCE LI-02 ... PIt tro. PE-Sv-uI

Figure L-9

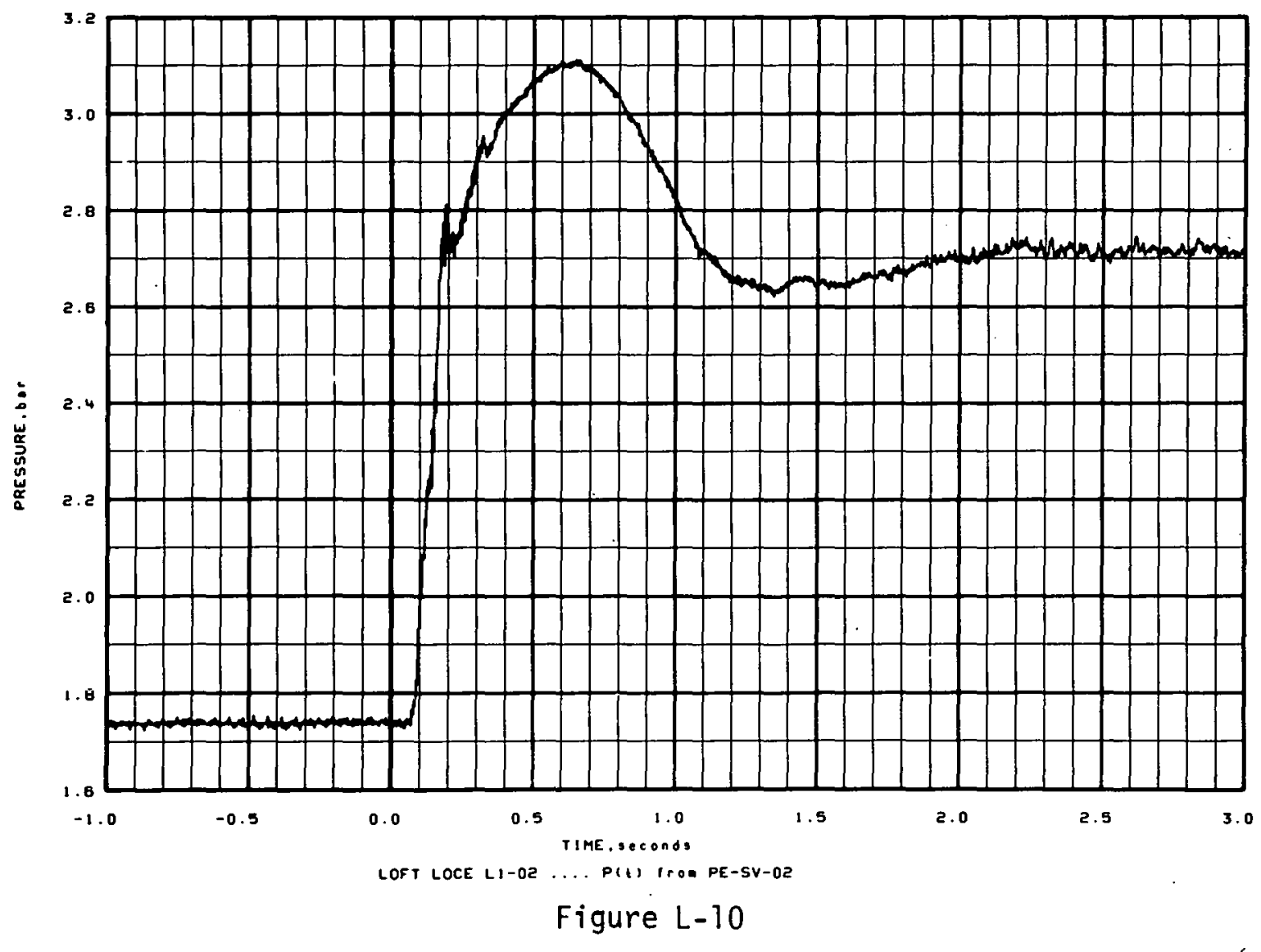




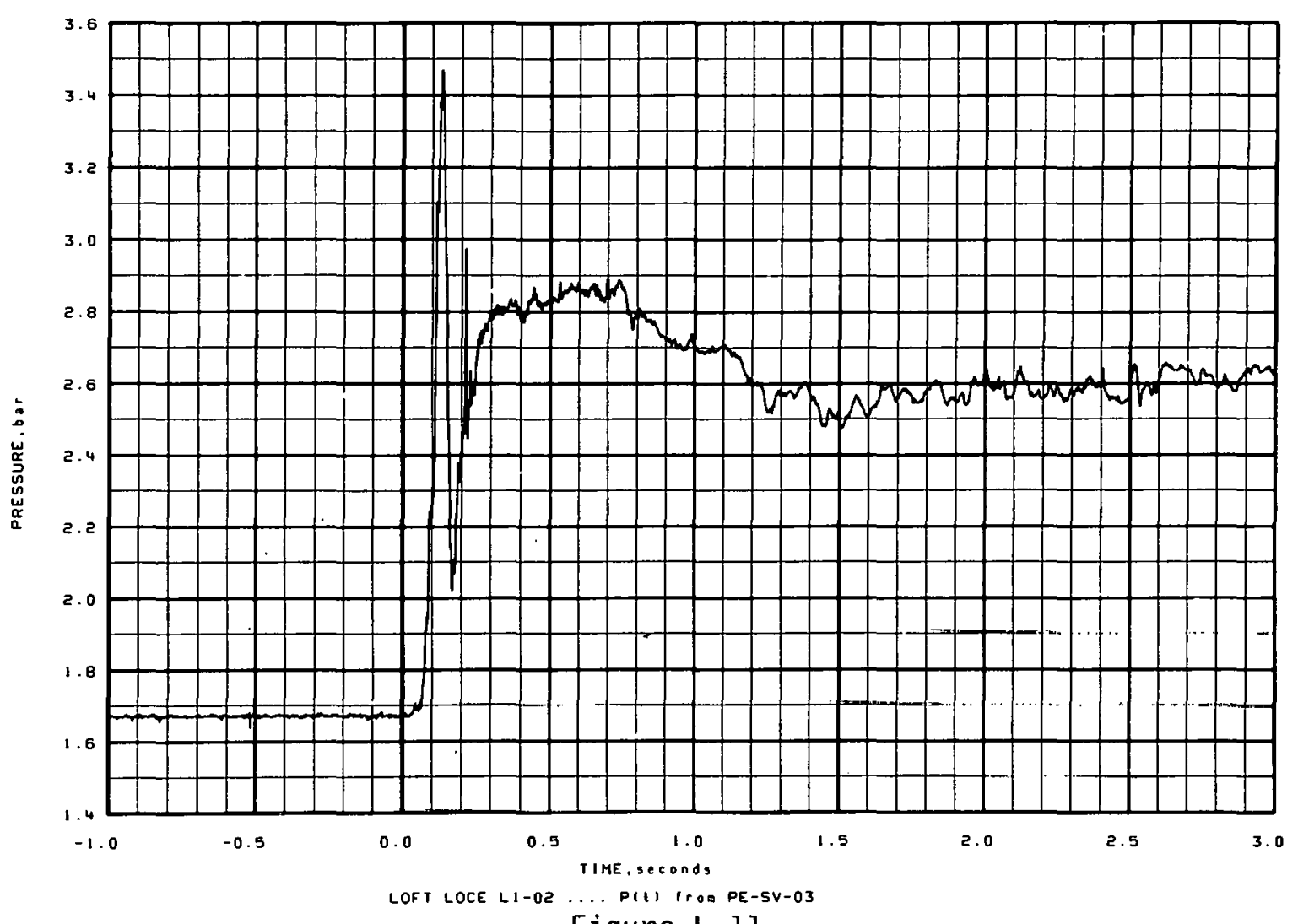

Figure $L-]]$

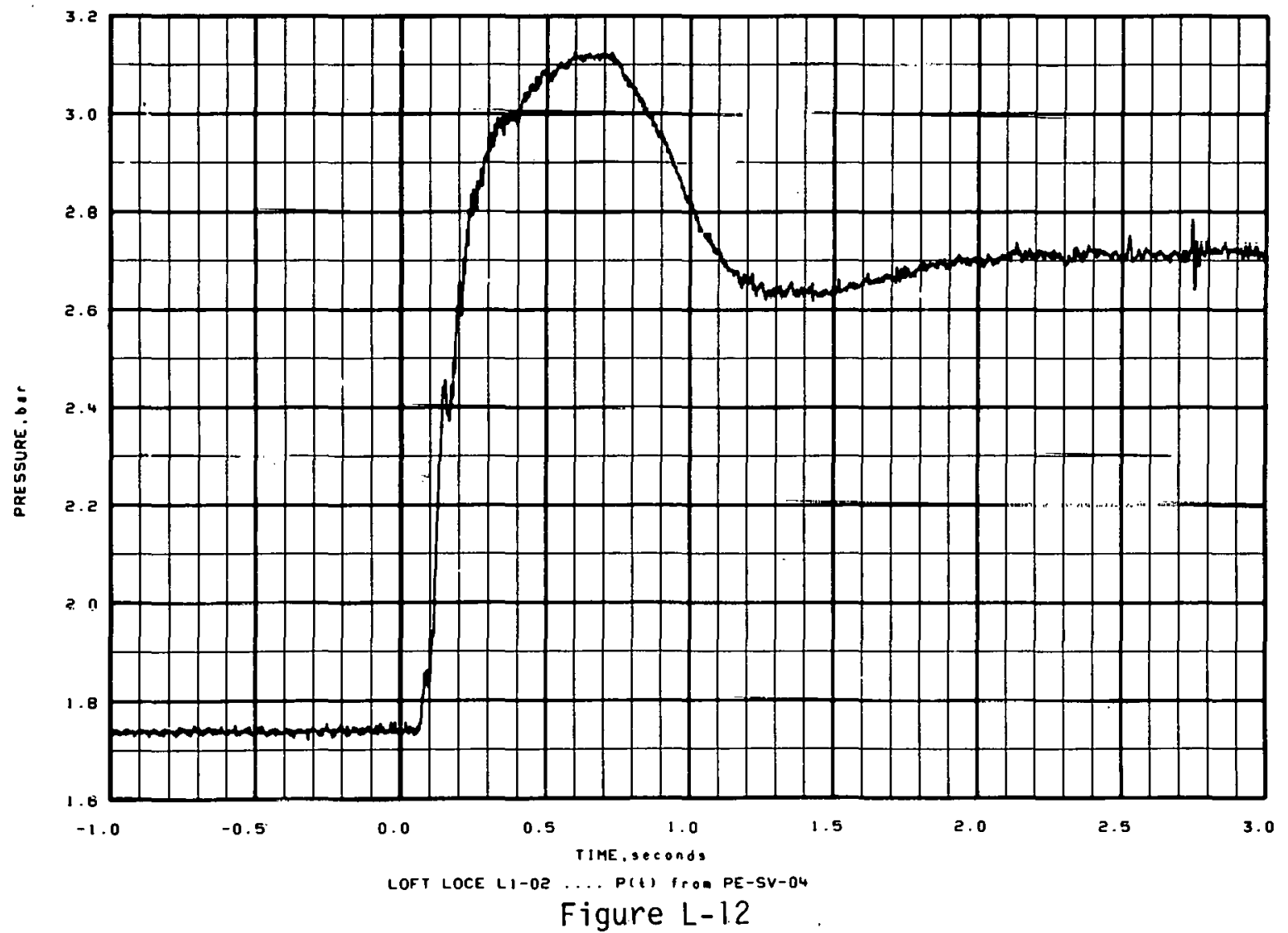




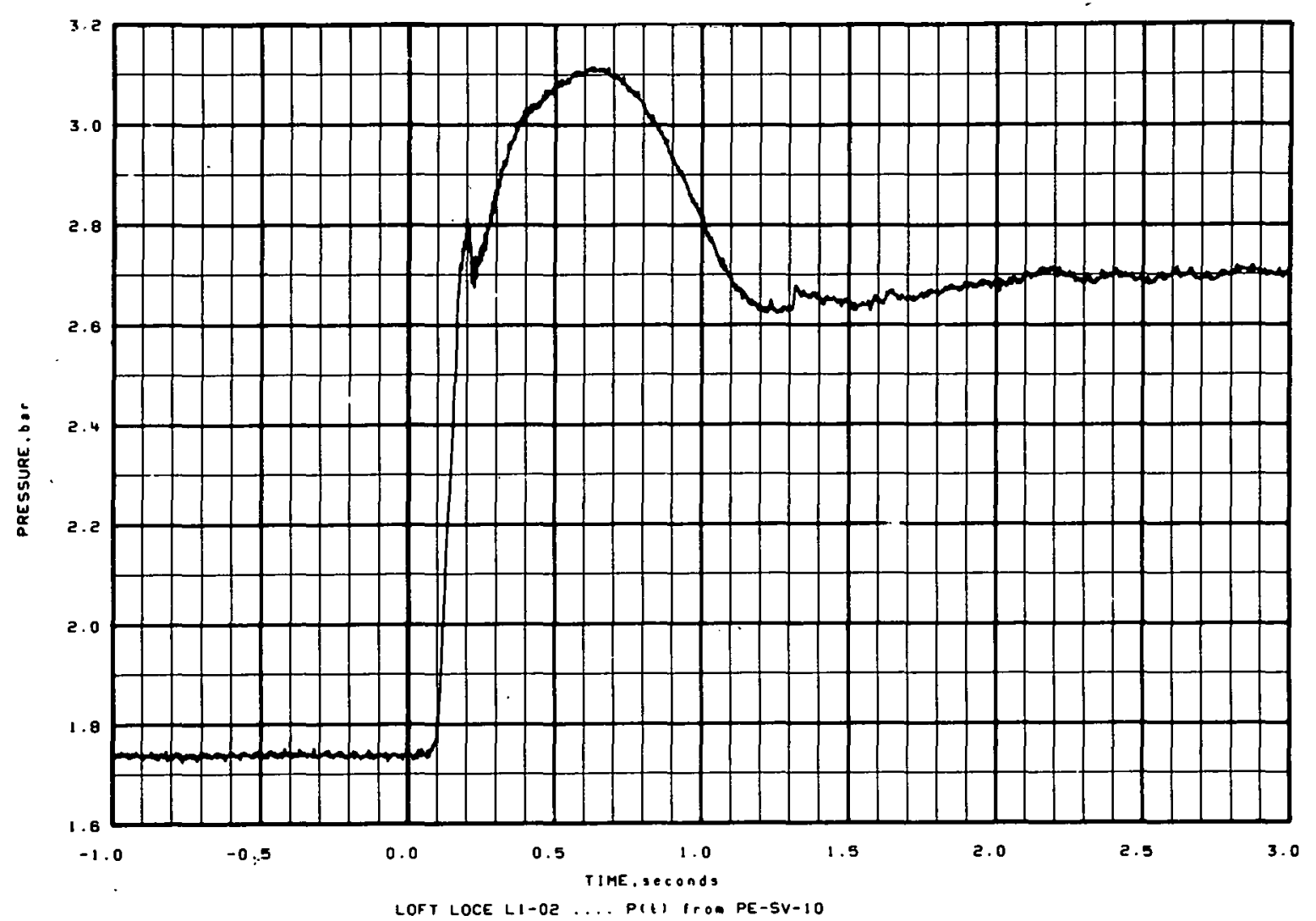

Figure L-13

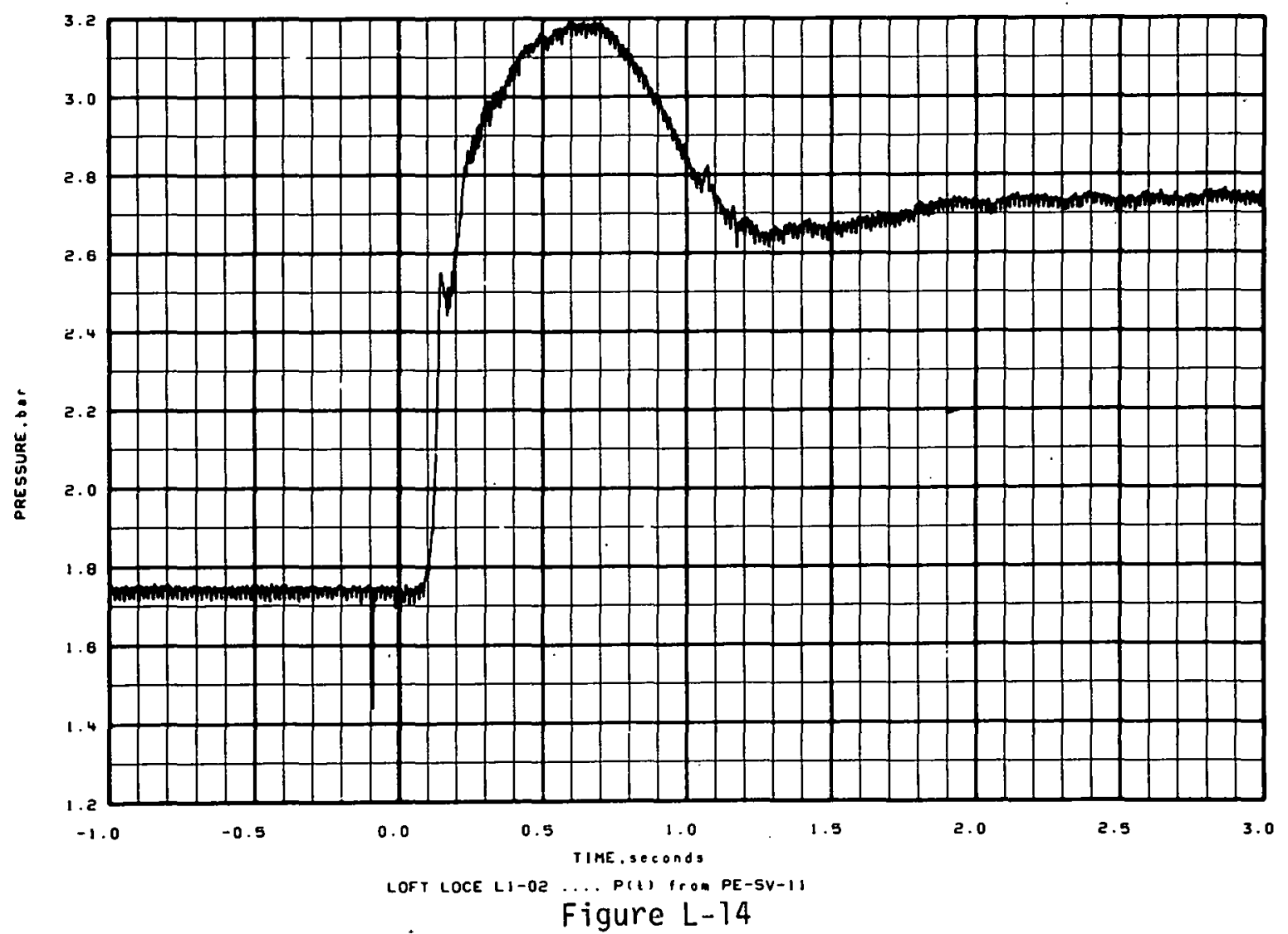



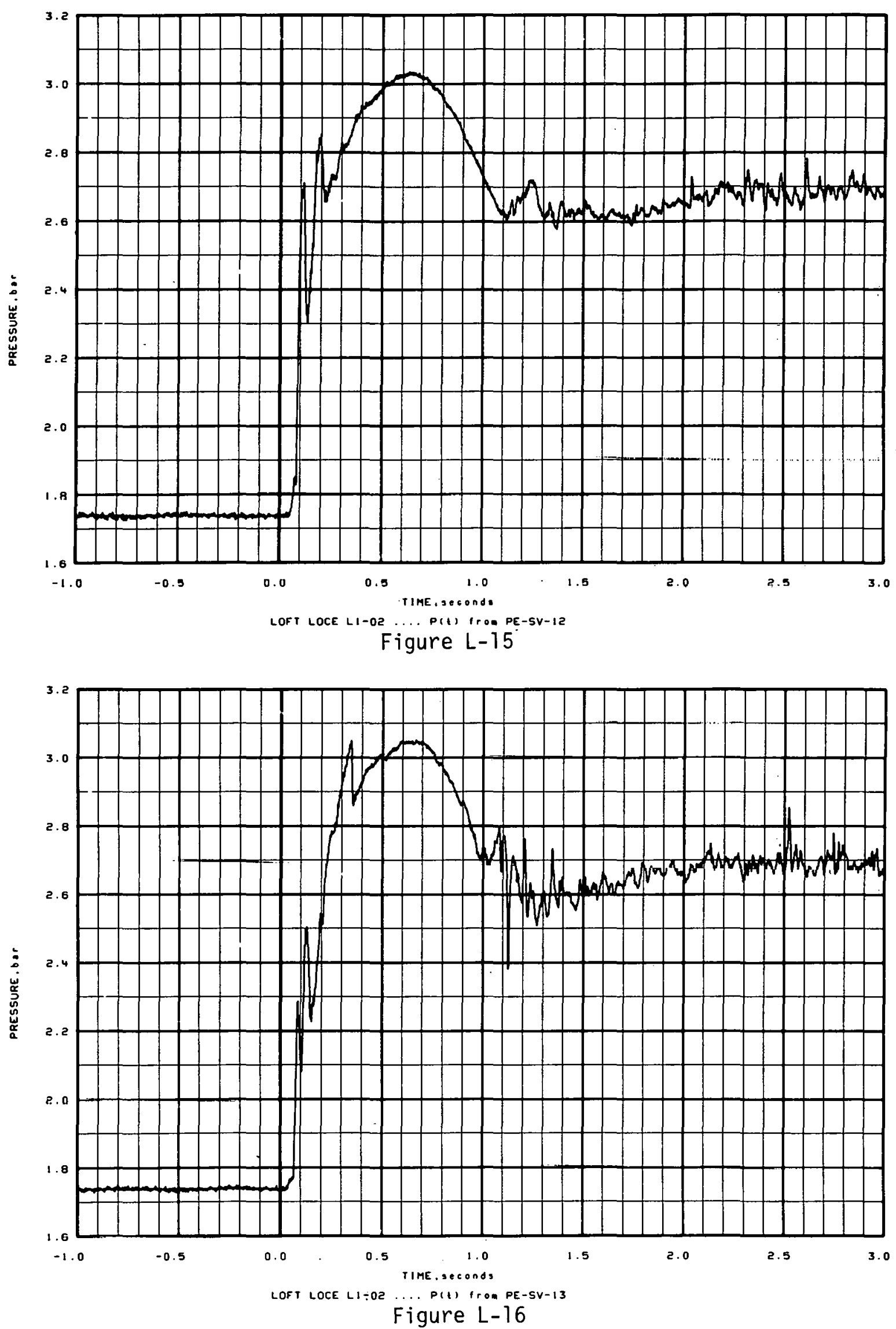

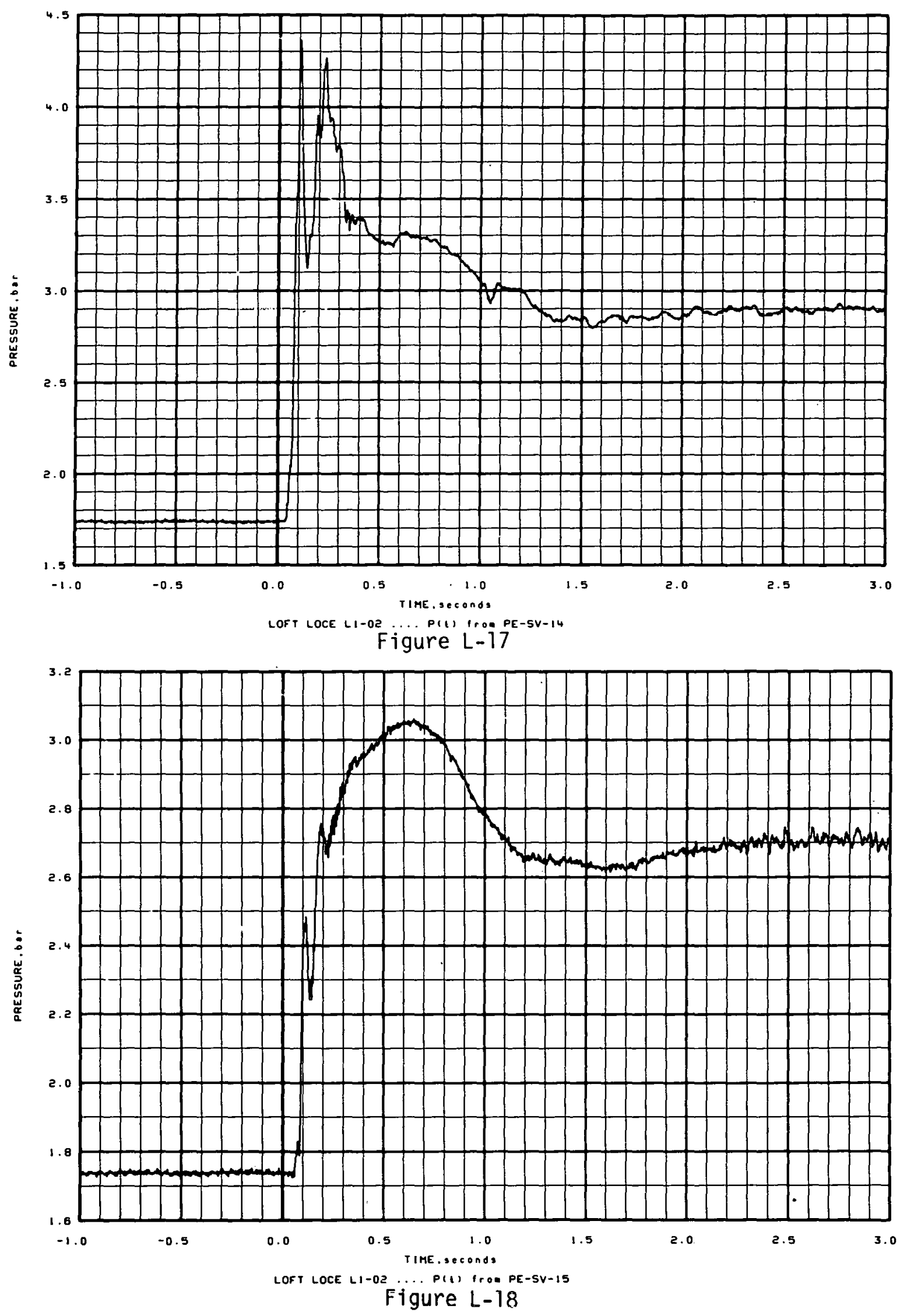


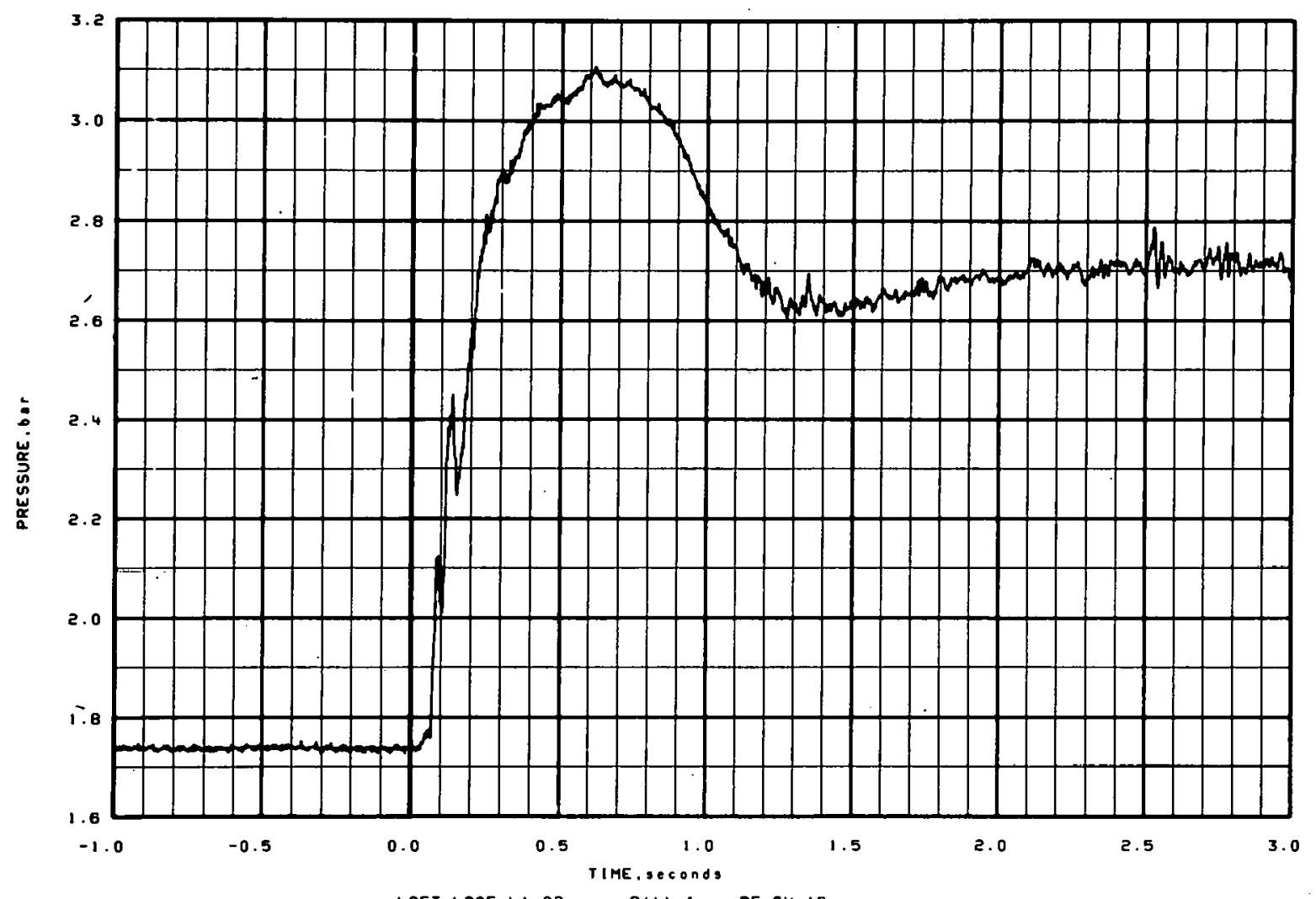

LOFT LOCE L1-02 .... P(t) H POA PE-SV-16

Figure $L-19$

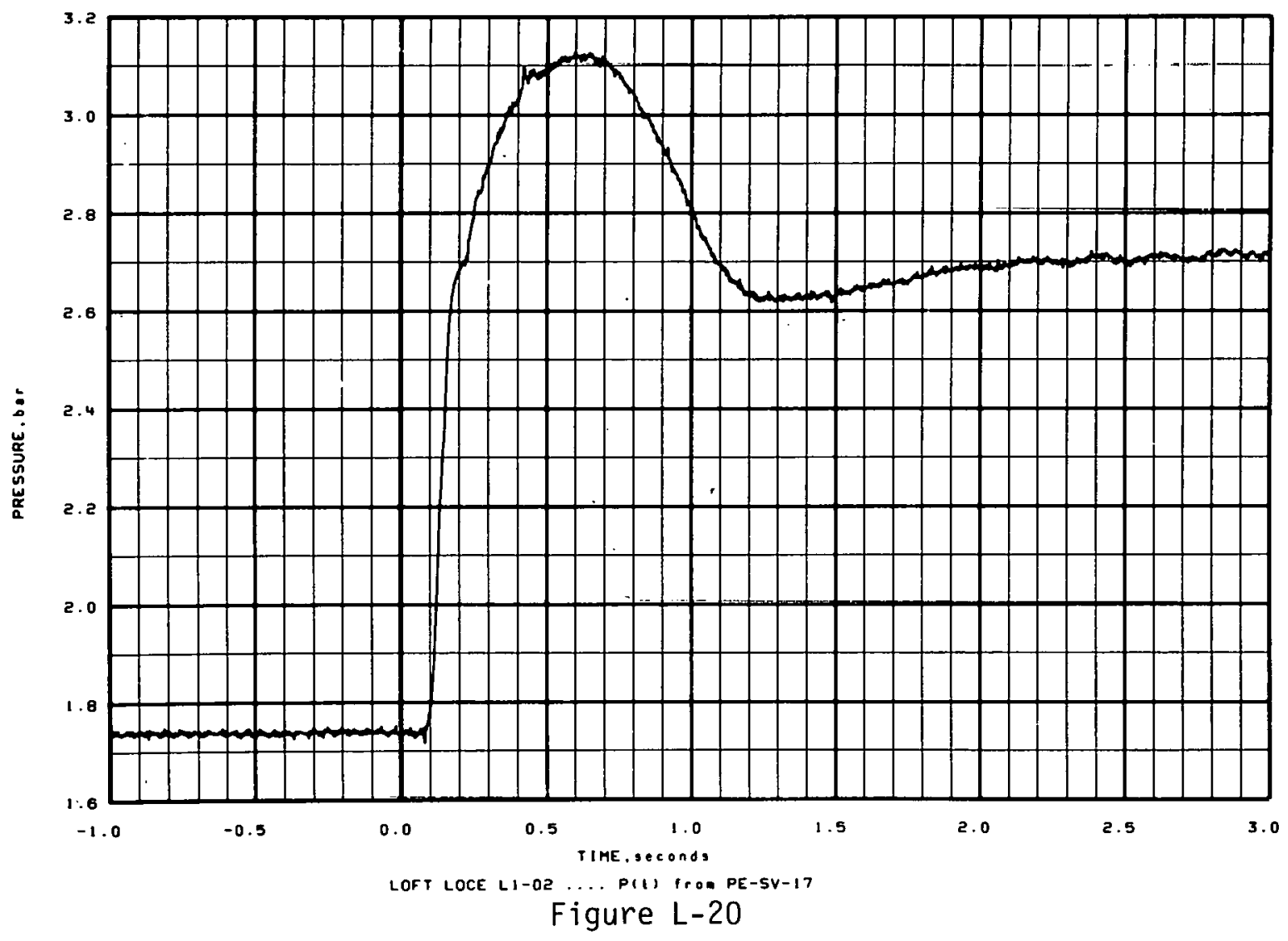



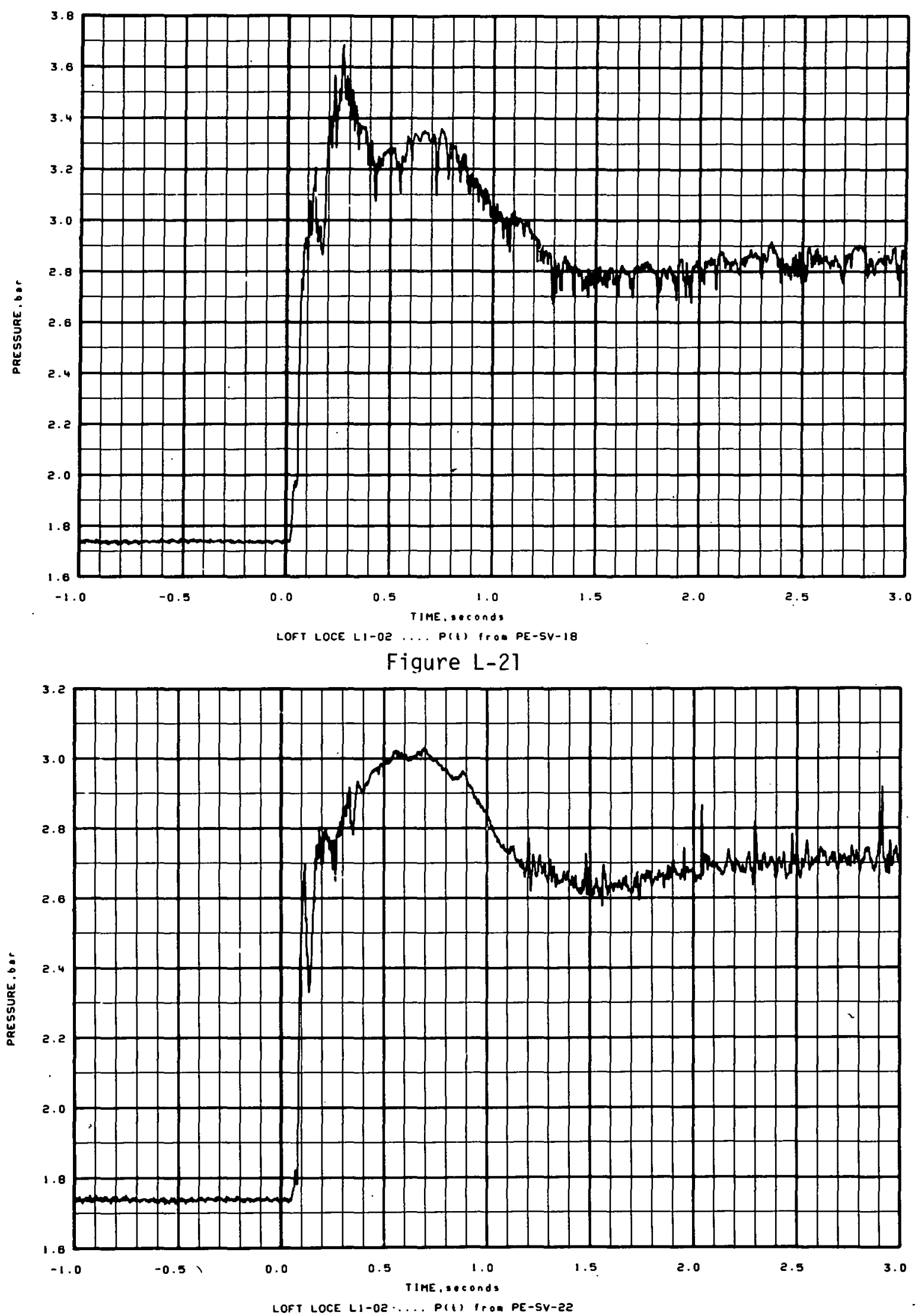

Figure L-22 

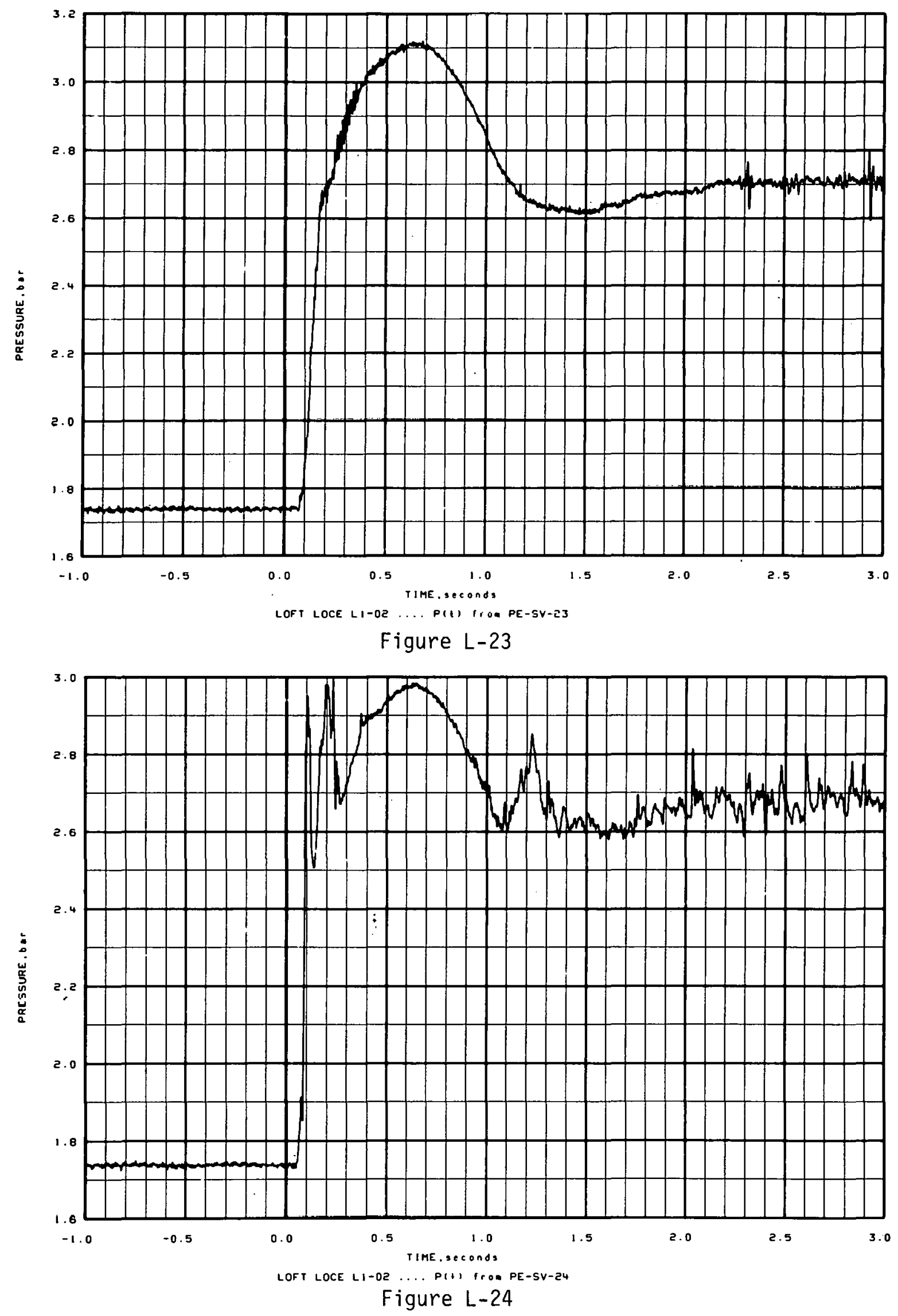

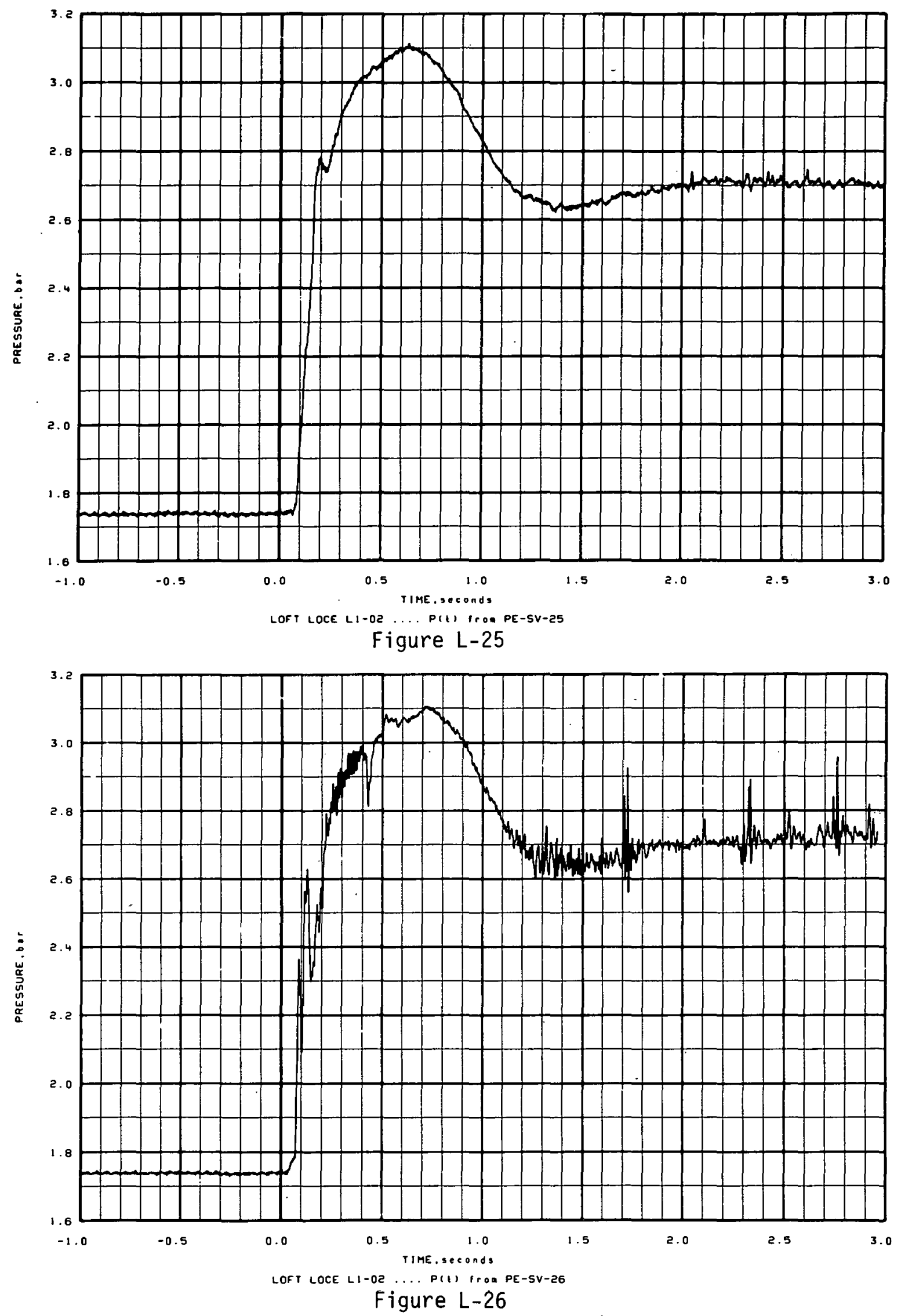


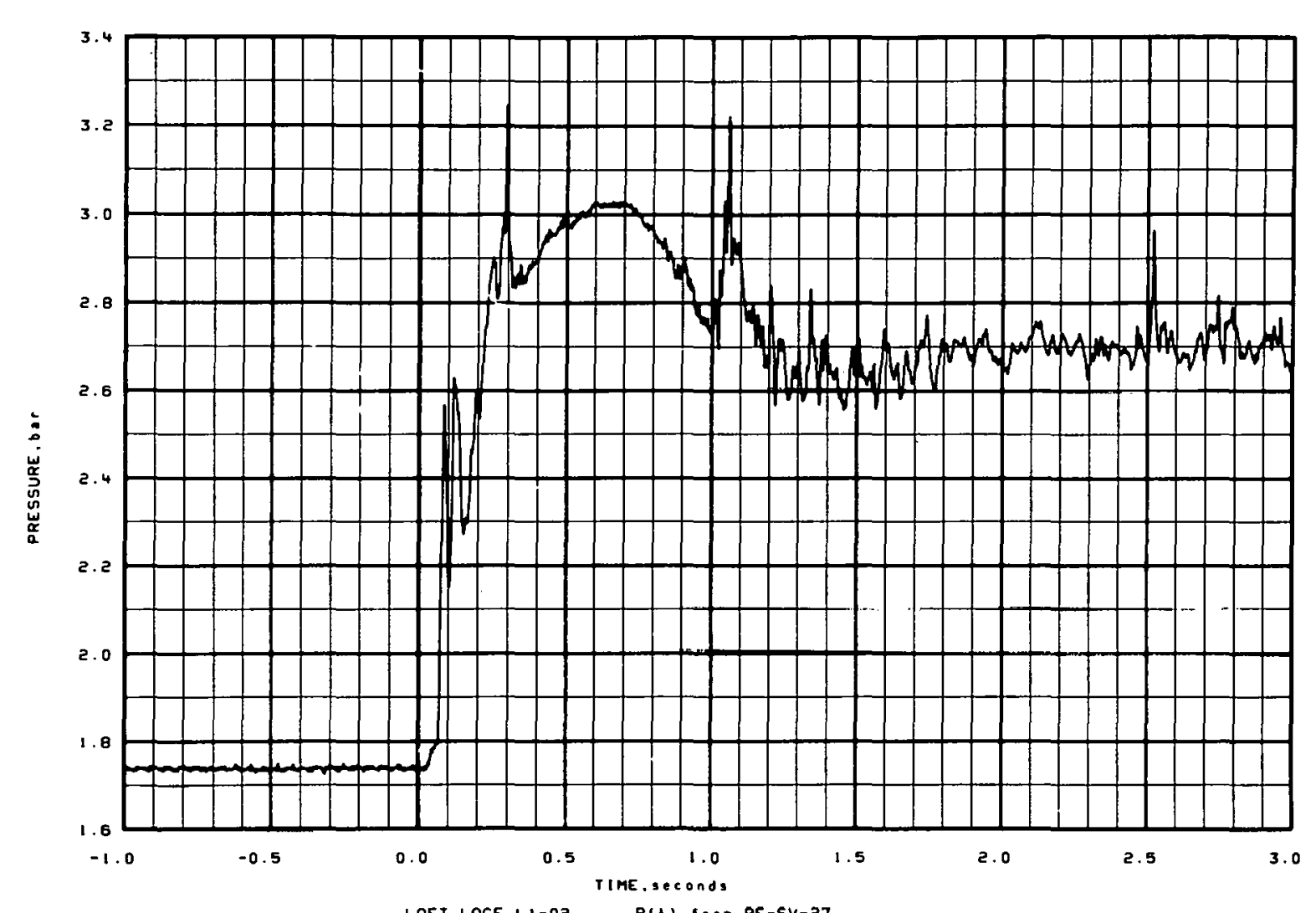

LOFT LOCE LI-02 ... PAI, irOA PE-SV-27

Figure $\mathrm{L}-27$

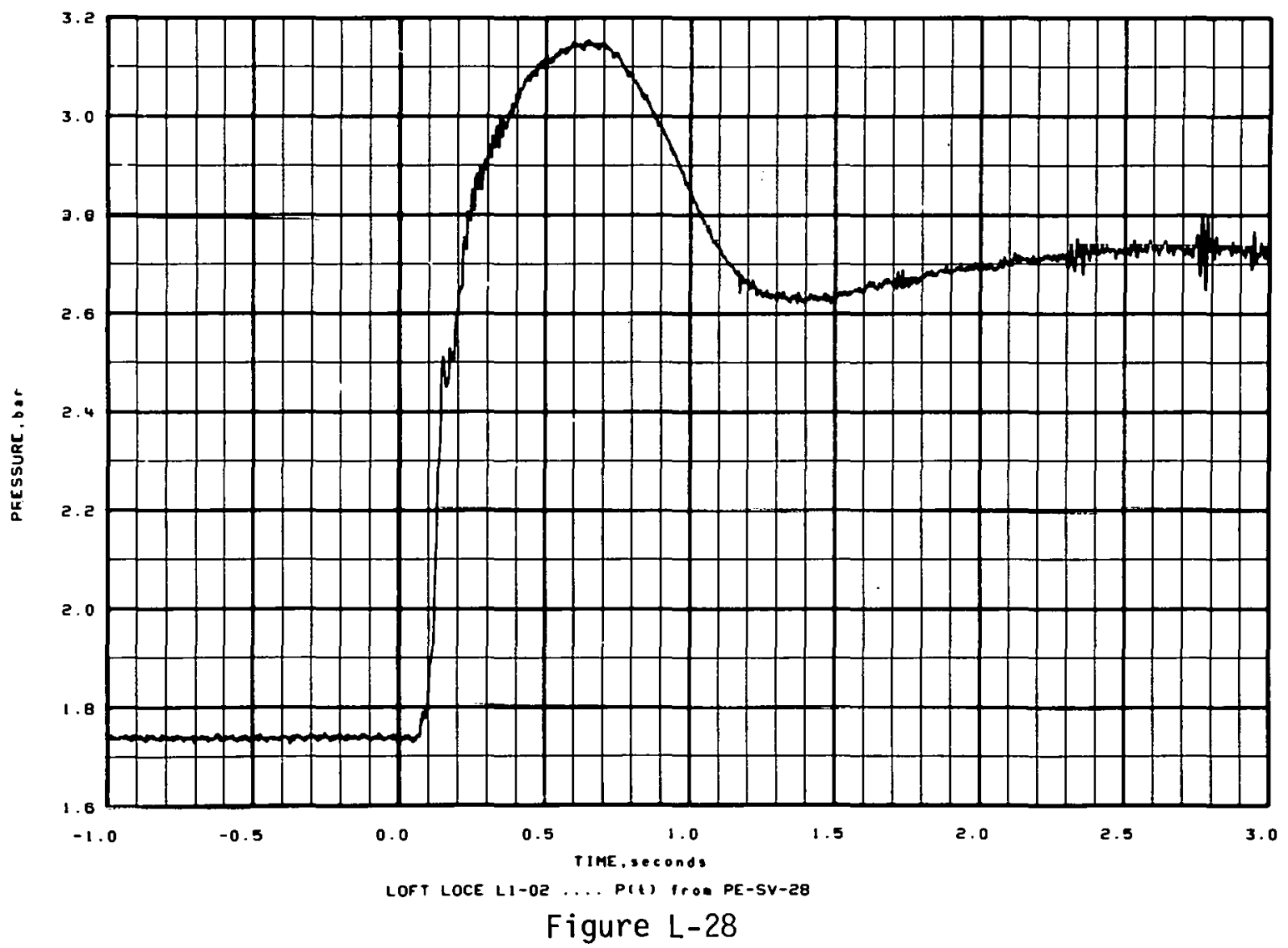



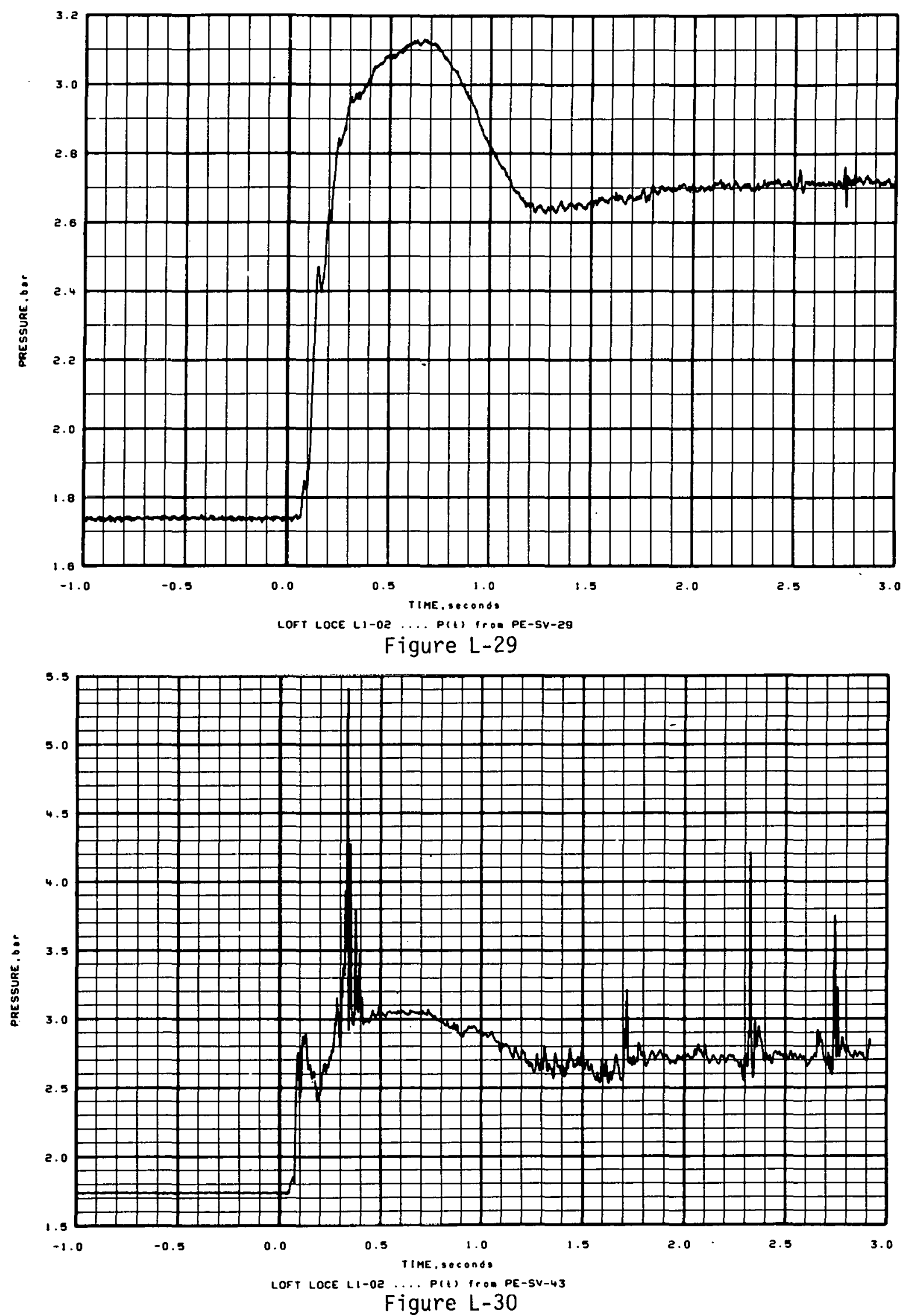

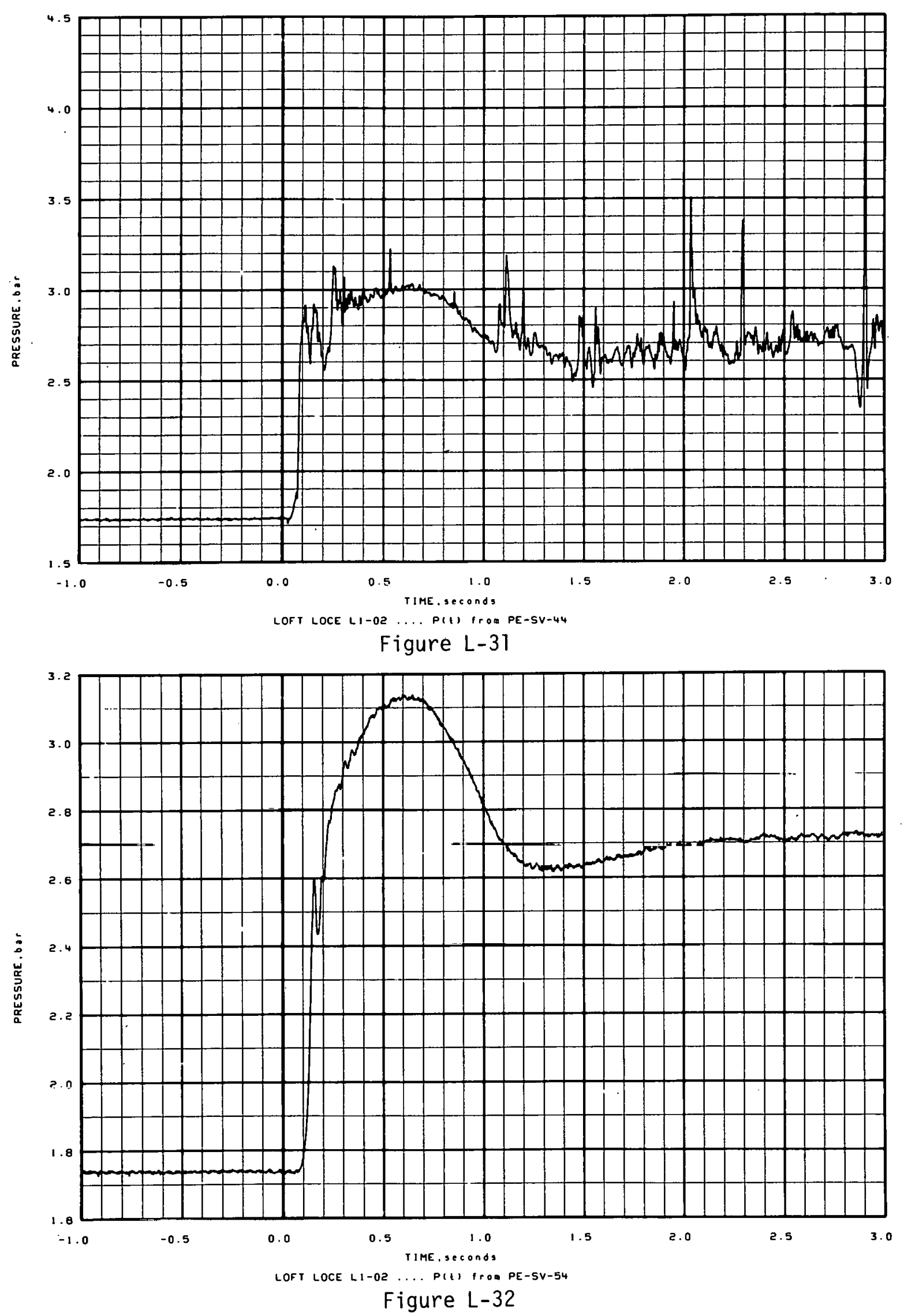


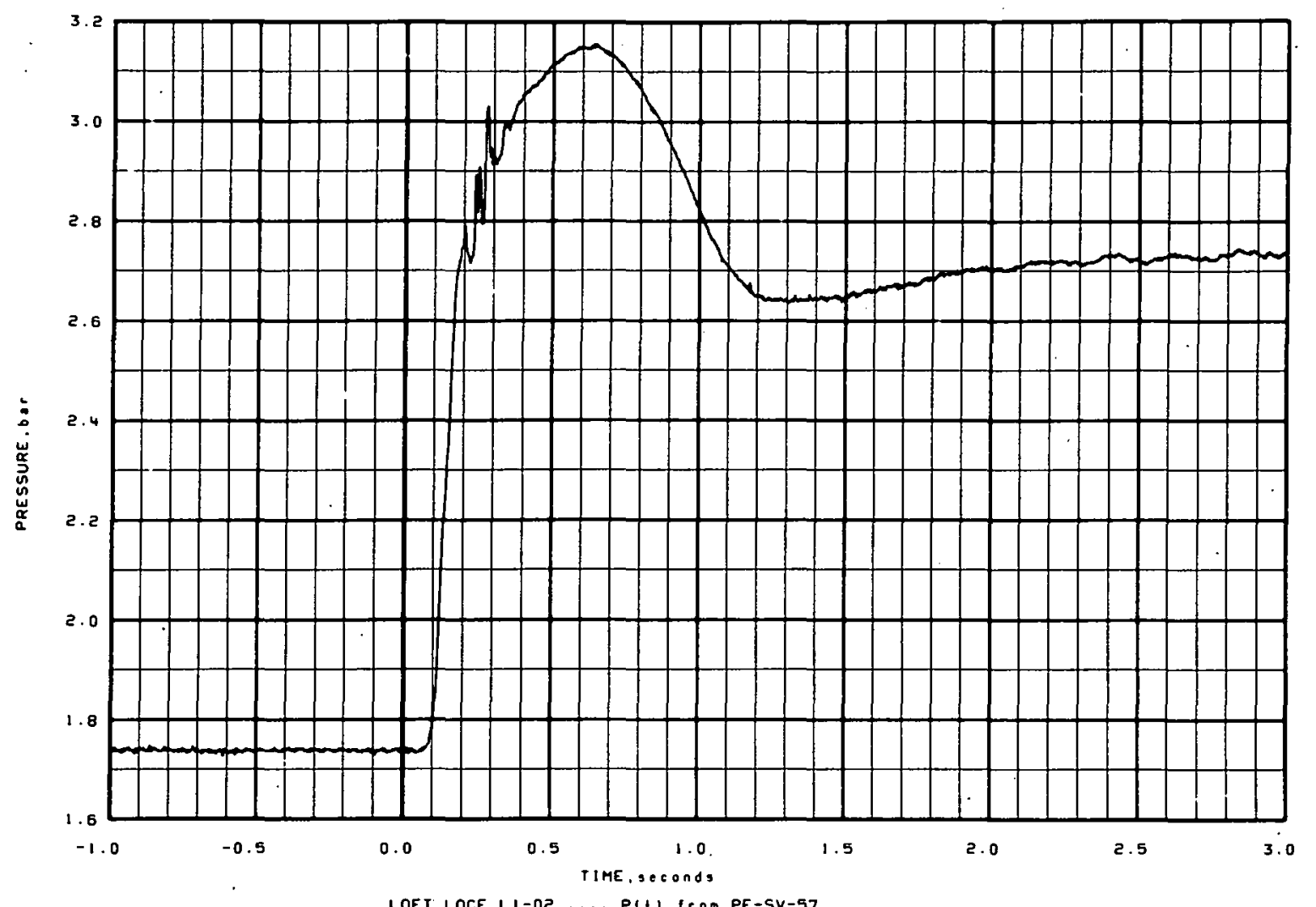

Figure L-33

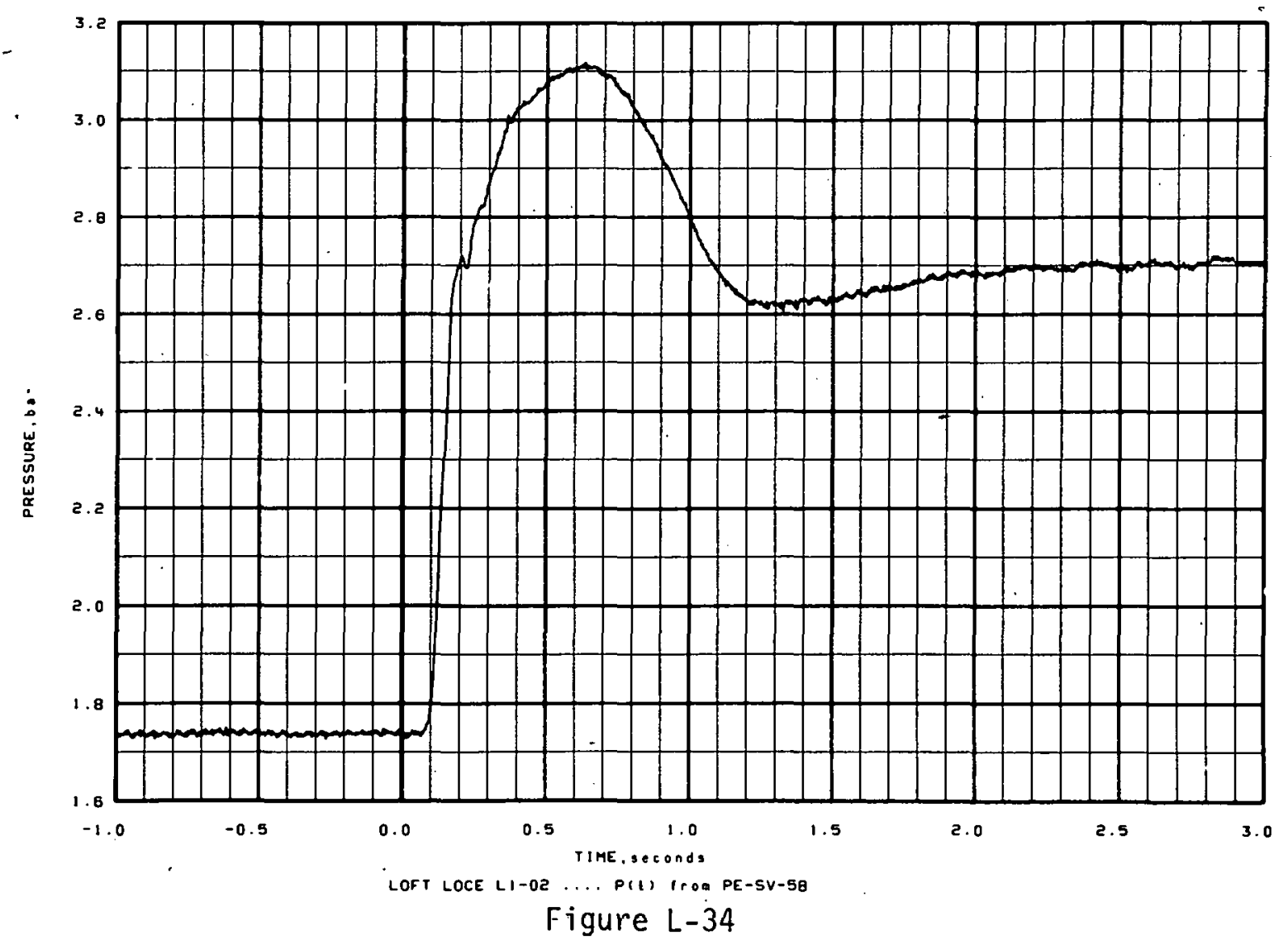



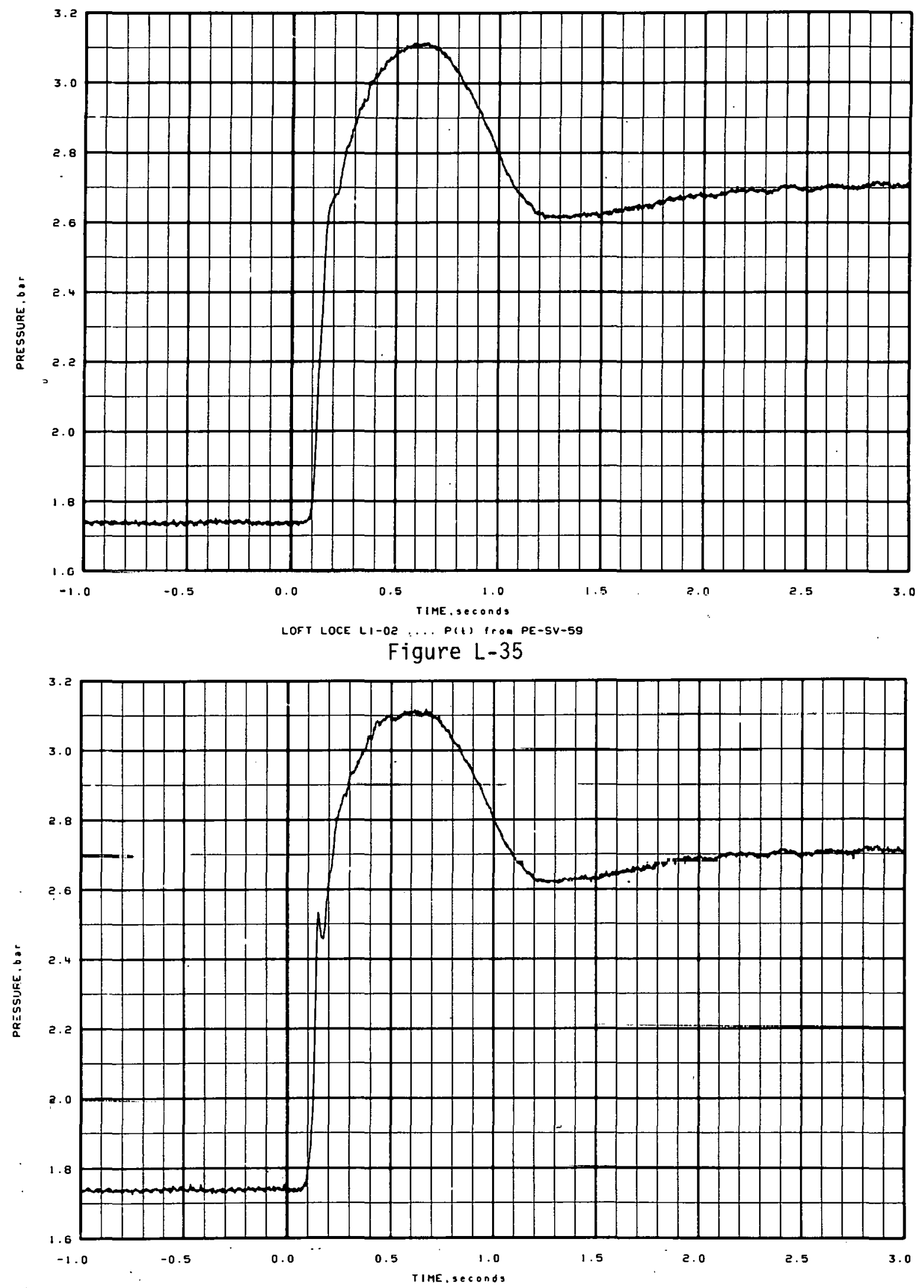

LOFT LOCE LI-02 ... P(I) IROA PE-SV-60

Figüre L-36. 


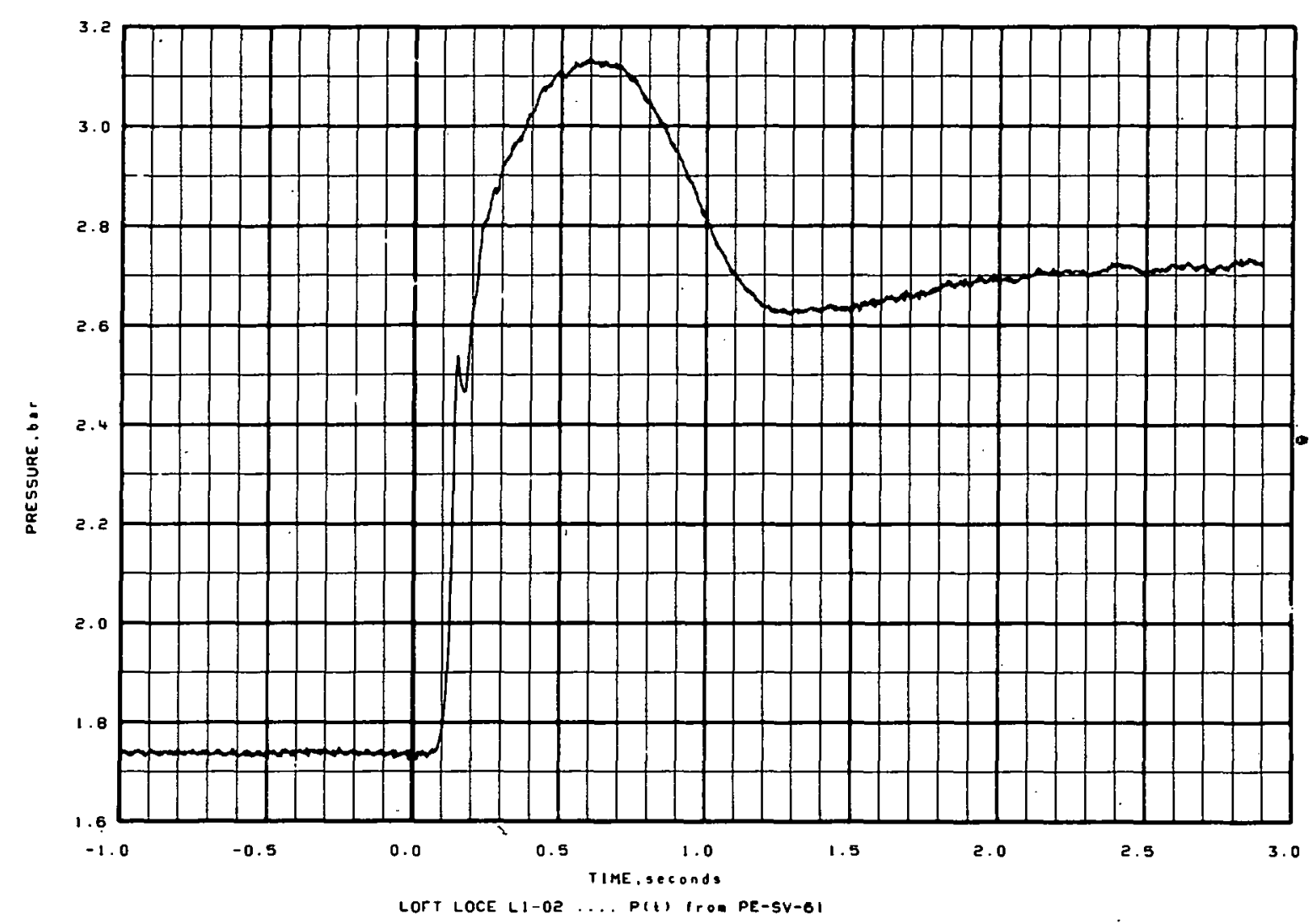

Figure L-37 


\section{THIS PAGE}

\section{WAS INTENTIONALLY \\ LEFT BLAN}




\section{APPENDIX $M$}

\section{LOCE L1-03 EXPERIMENTAL DATA}


THIS PAGE

WAS INTENTIONALLY

LEFT BLANK 
Both QOBVs fully opened in this experiment. The fluid temperature was $250.1 \pm 1.5^{\circ} \mathrm{C}$ in QOBV-1 and $257.2 \pm 1.5^{\circ} \mathrm{C}$ in QOBV-15. The suppression tank initial conditions were $1.67 \pm 0.08$ bar, $82.8 \pm 1.5^{\circ} \mathrm{C}$ in the gas volume, and $86.7 \pm 1.5^{\circ} \mathrm{C}$ in the pool. The vents were submerged $43.0 \pm 2.5 \mathrm{~cm}$. The internal vent submergence was $27.3 \pm 3.2 \mathrm{~cm}$.

The experimental data are defined in Table M-I. The opening characteristics of the QOBVs are shown in terms of percent sleeve travel versus time. The flow area of the valve begins to open at a sleeve position of $17 \%$ of full travel and is fully open at a sleeve position of $66 \%$ of full travel. The differential pressure between the header and the tank gas volume is measured with a very sensitive device primarily to provide information on vent preclearing. The data channel for this measurement is driven to saturation in the early part of the transient. 
TABLE M-I

EXPERIMENT LI-D3 DATA SUMMARY

\begin{tabular}{|c|c|c|c|c|c|}
\hline $\begin{array}{c}\text { Measurement } \\
\text { or } \\
\text { Calculation }\end{array}$ & $\begin{array}{c}\text { Pre-Transient } \\
\text { Data Channel } \\
\text { Variance } \\
\left(10^{-4} \text { bar } 2\right) \\
\end{array}$ & Figure Number & Measurement & $\begin{array}{c}\text { Pre-Transient } \\
\text { Data Channel } \\
\text { Varjance } \\
\left(10^{-4} \text { bar. }{ }^{2}\right) \\
\end{array}$ & Figure Number \\
\hline QUBV-1 opening & - & $M-1, M-2$ & PE-SV-22 & 0.07684 & $M-22$ \\
\hline QOBV 15 opening & - & $M-3, M-4$ & PE-SV-23 & 0.06390 & $M-23$ \\
\hline $\begin{array}{l}\text { Combined QOBV } \\
\text { opening }\end{array}$ & - & $M-5, M-6$ & PE-SV-24 & 0.04273 & $M-24$ \\
\hline Vertical load & - & $M-7$ & PE-SV-25 & 0.04363 & $M-25$ \\
\hline P:DE-SV-09 & - & $M-8$ & PE-SV-26 & 0.03105 & $M-26$ \\
\hline PE-SV-01 & 0.17188 & $M-9$ & PE-SV-27 & 0.05733 & $M-27$ \\
\hline PE-SV-02 & 0.06918 & $M-10$ & PE-SV-28 & 0.04952 & $M-28$ \\
\hline PE-SV-03 & 0.11 .087 & $M-11$ & PE-SV-29 & 0.05099 & $M-29$ \\
\hline PE-SV-04 & 0.11136 & $M-12$ & PE-SV-43 & 0.04360 & $M-30$ \\
\hline PE-SV-10 & 0.14065 & $M-13$ & PE-SV-11 & 0.05667 & $M-31$ \\
\hline PE-SV-11 & 0.48824 & $M-14$ & PE-SV-54 & 0.04491 & $M-32$ \\
\hline PE-SV-12 & $0: 107.31$ & $M=15$ & PE-SV-55 & 0.03439 & $M-33$ \\
\hline$P E-S V-13$ & 0.04732 & $M-16$ & $P E-S V=56$ & \multicolumn{2}{|c|}{ mcasurement dcleted } \\
\hline PE-SV-14 & 0.05928 & $M-17$ & PE-SV-57 & 0.03477 & $M-34$ \\
\hline PE-SV-15 & 0.07575 & $M-18$ & PE-SV-58 & 0.05830 & $M-35$ \\
\hline PE-SV-16 & 0.05833 & $M-19$ & PE-SV-59 & 0.04729 & $M-36$ \\
\hline PE-SV-17 & 0.06510 & $M-20$ & PE-SV-60 & 0.06196 & $M-37$ \\
\hline PE-SV-18 & 0.06407 & $M-21$ & PE-SV-61 & 0.04713 & $M-38$ \\
\hline
\end{tabular}



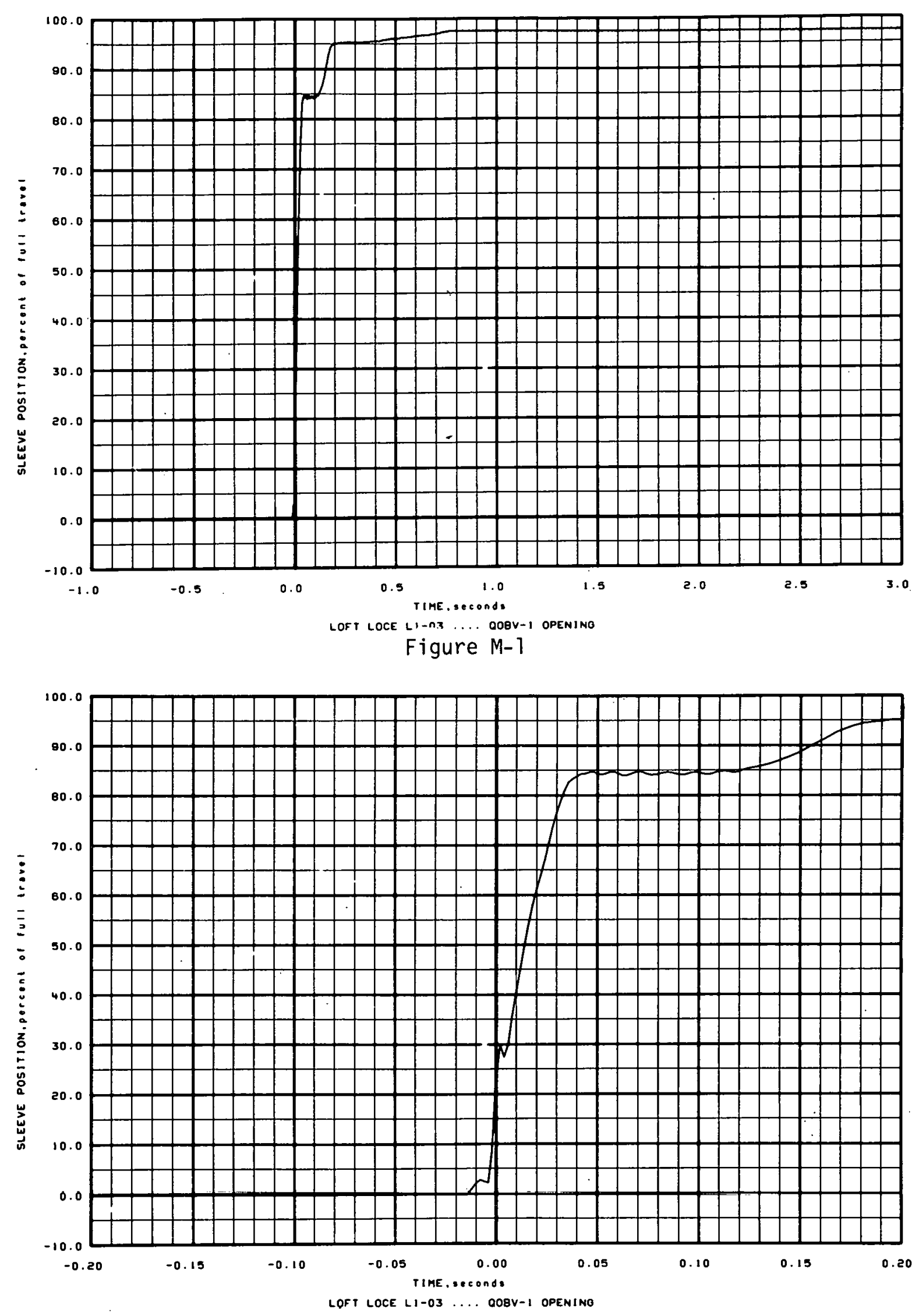

Figure M-2 

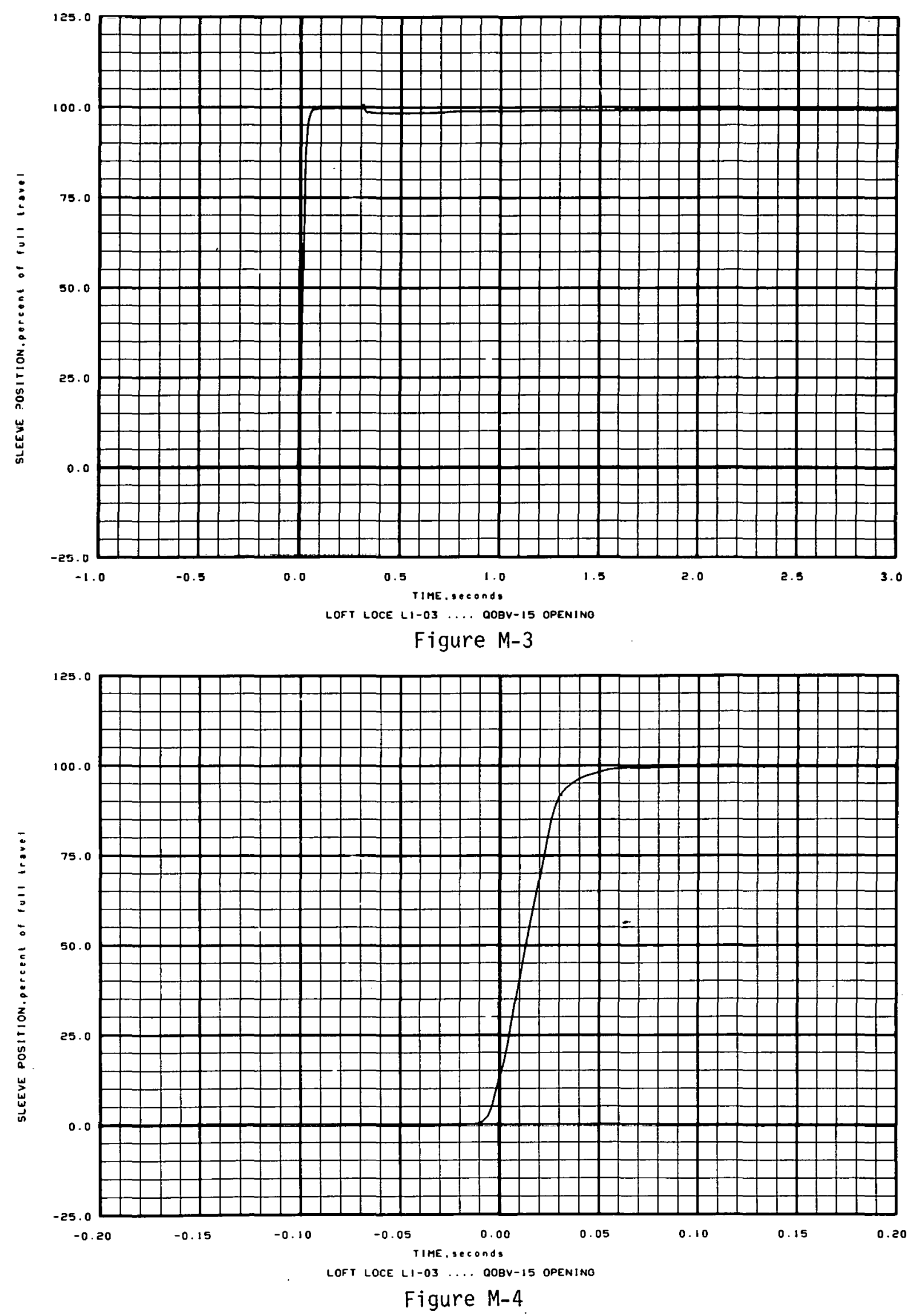

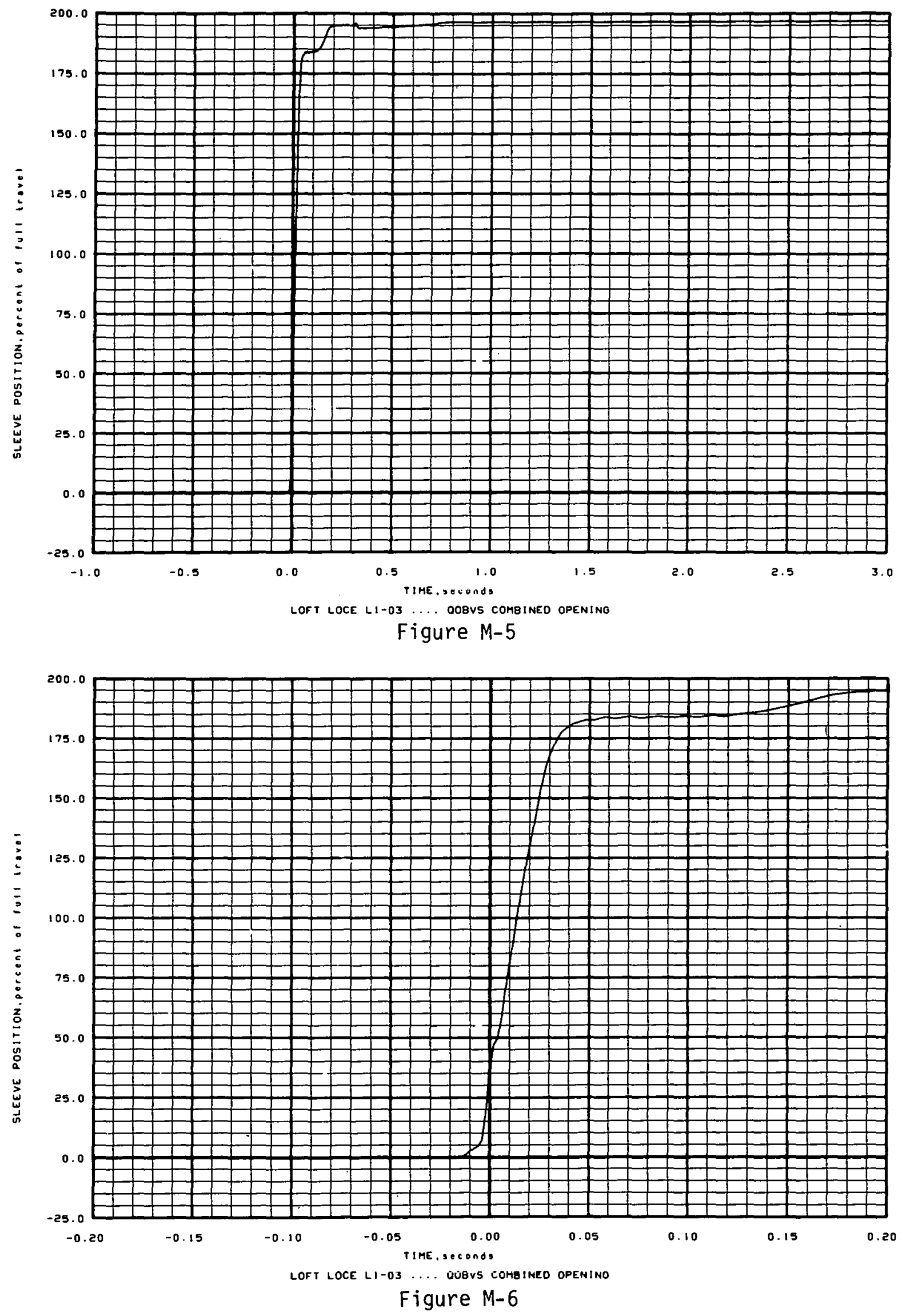

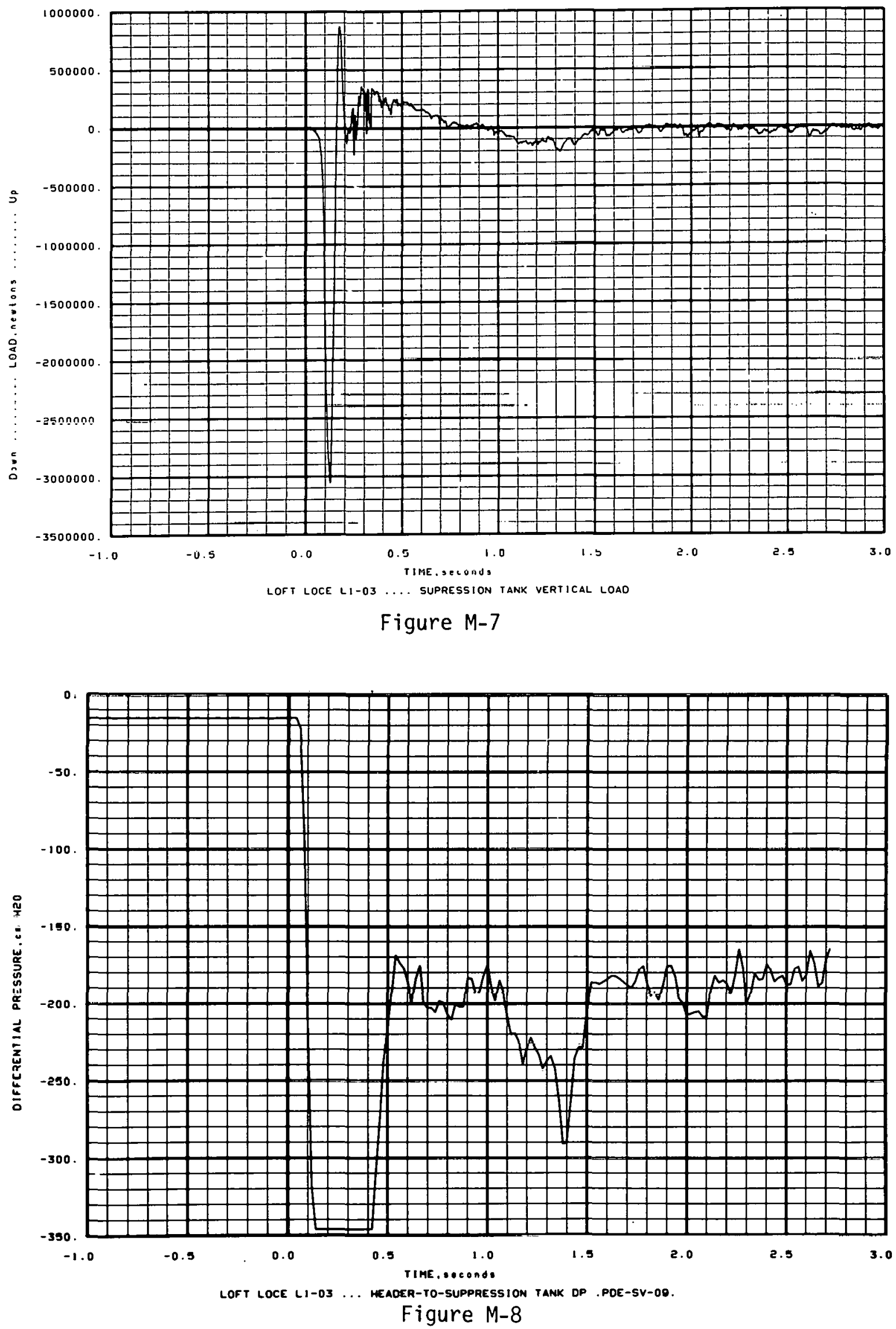

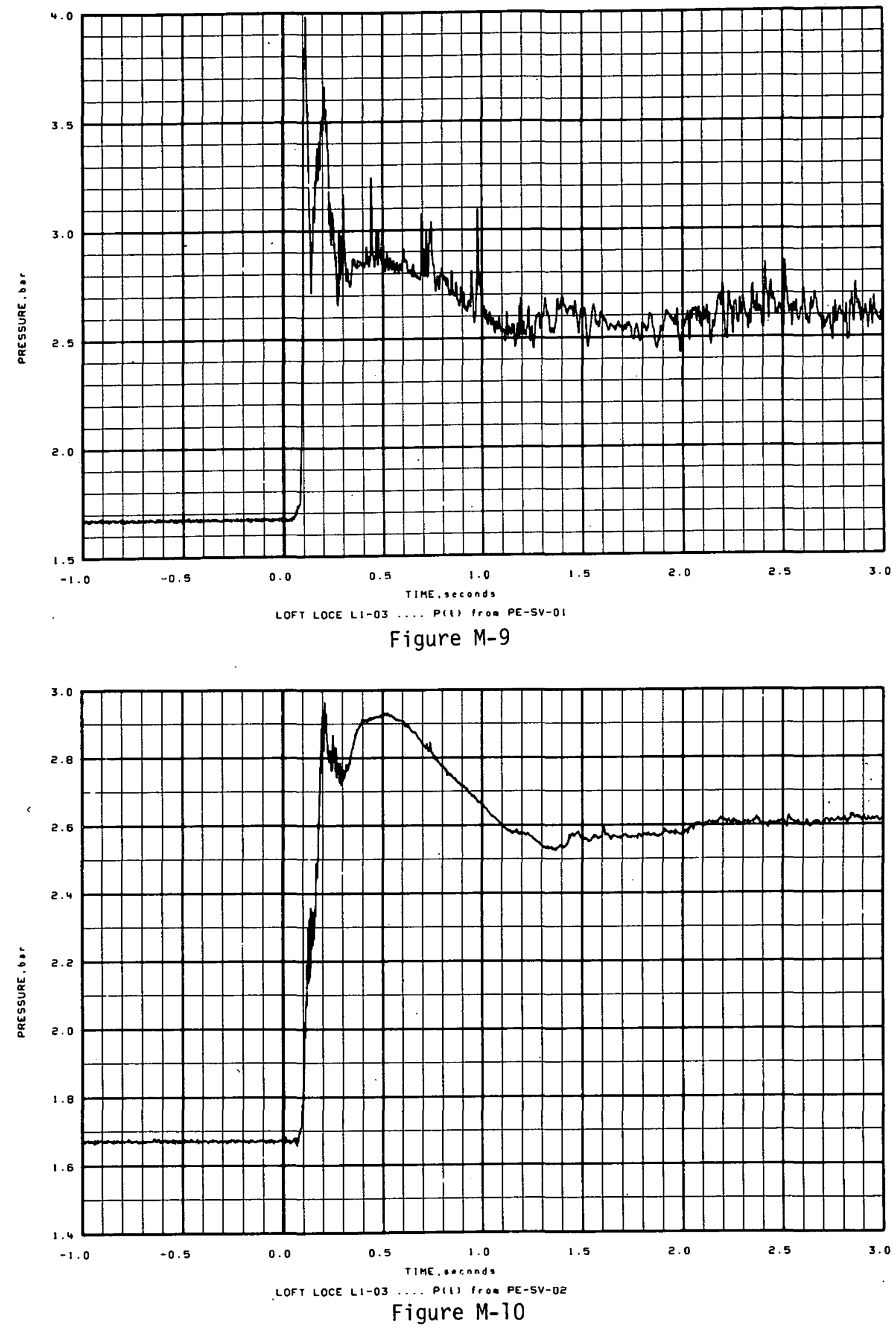


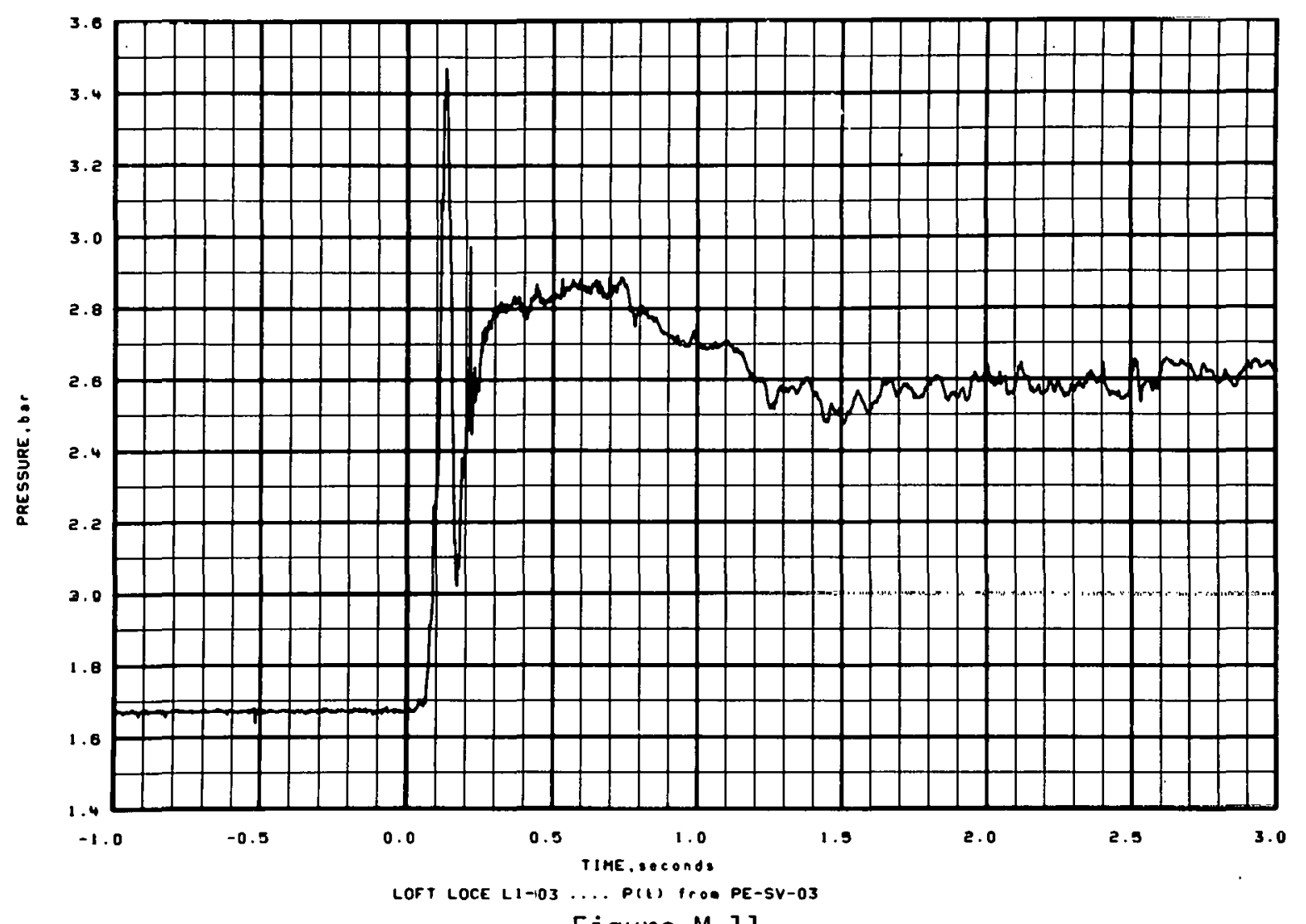

Figure M-11

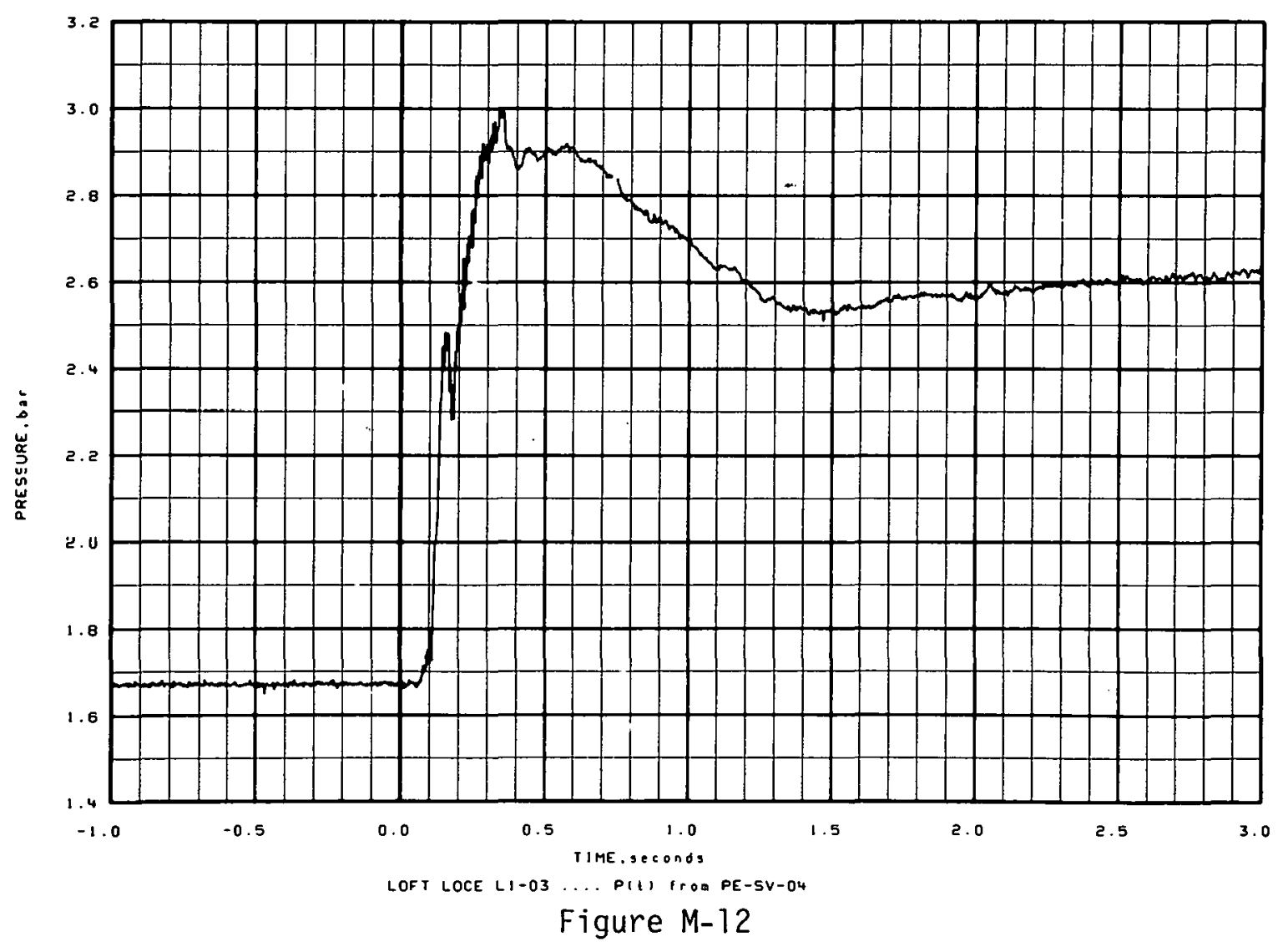




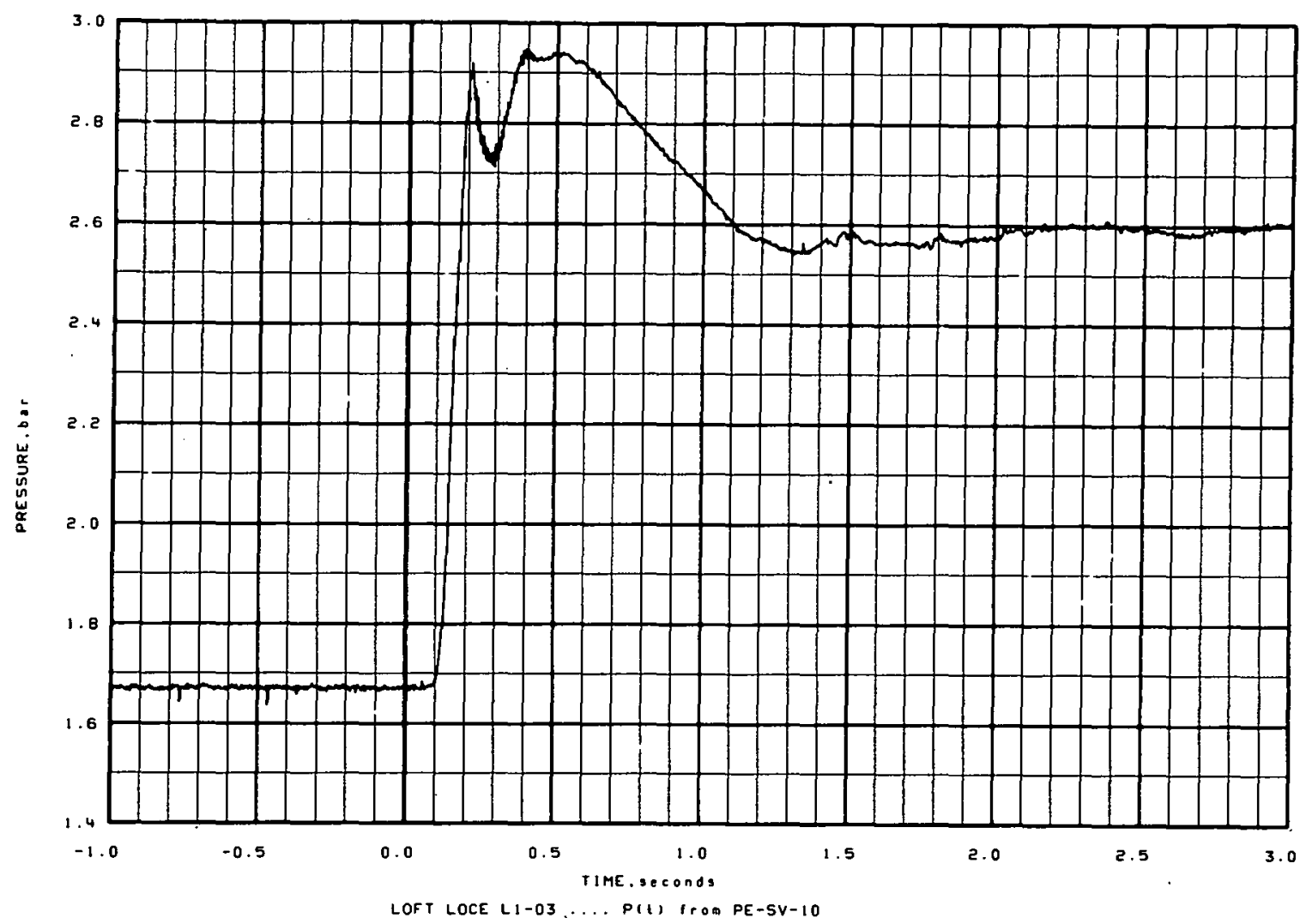

Figure $M-13$

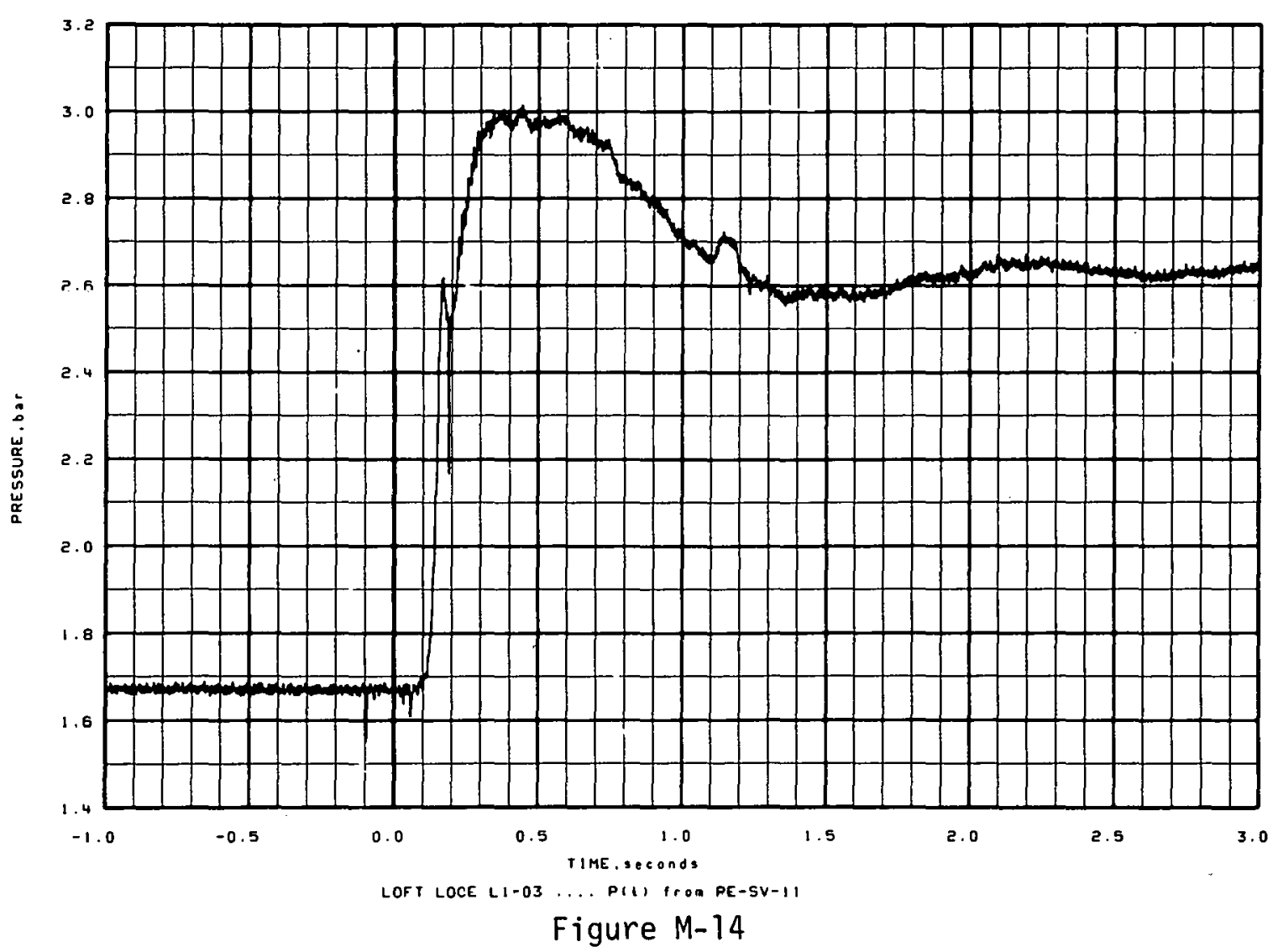



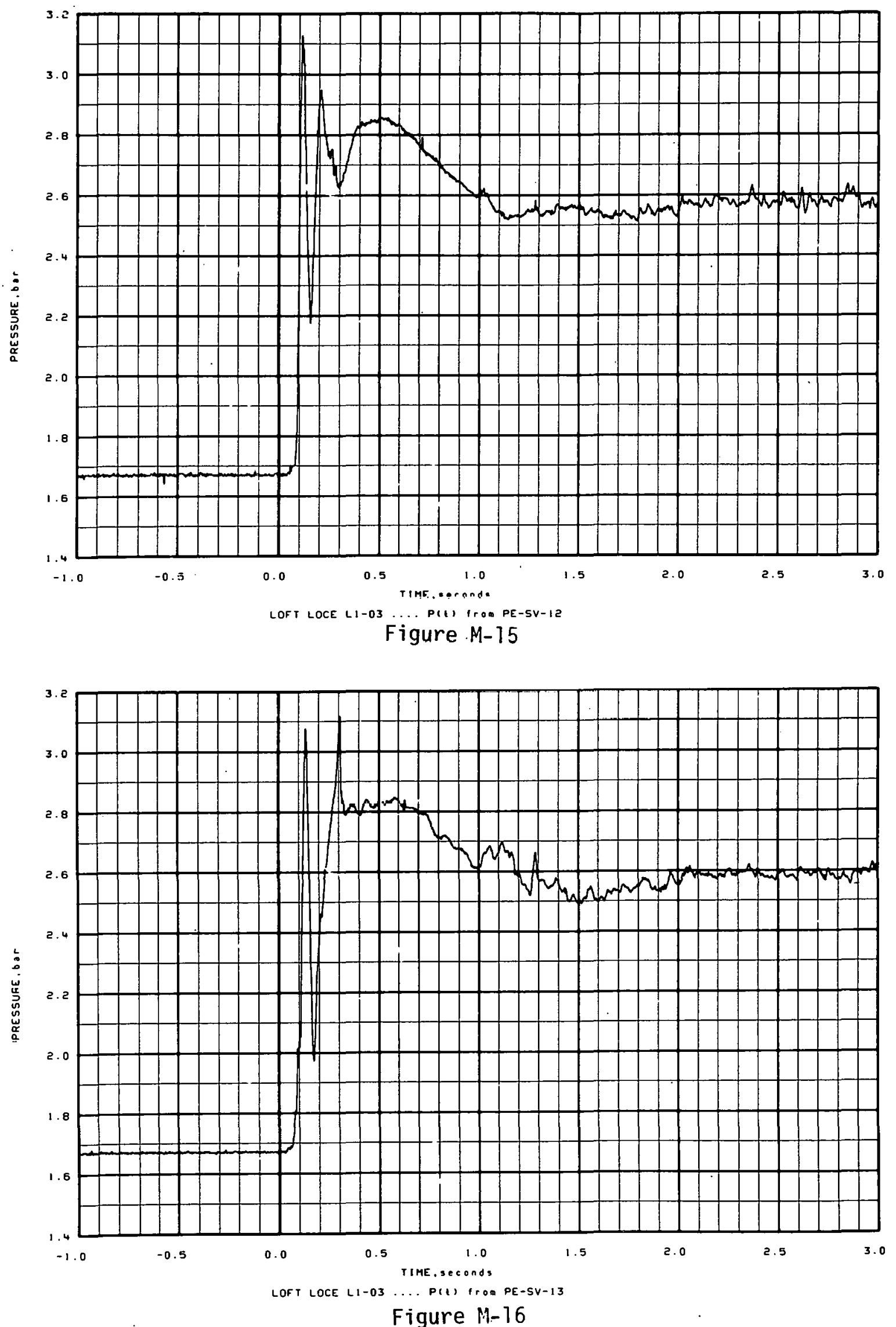

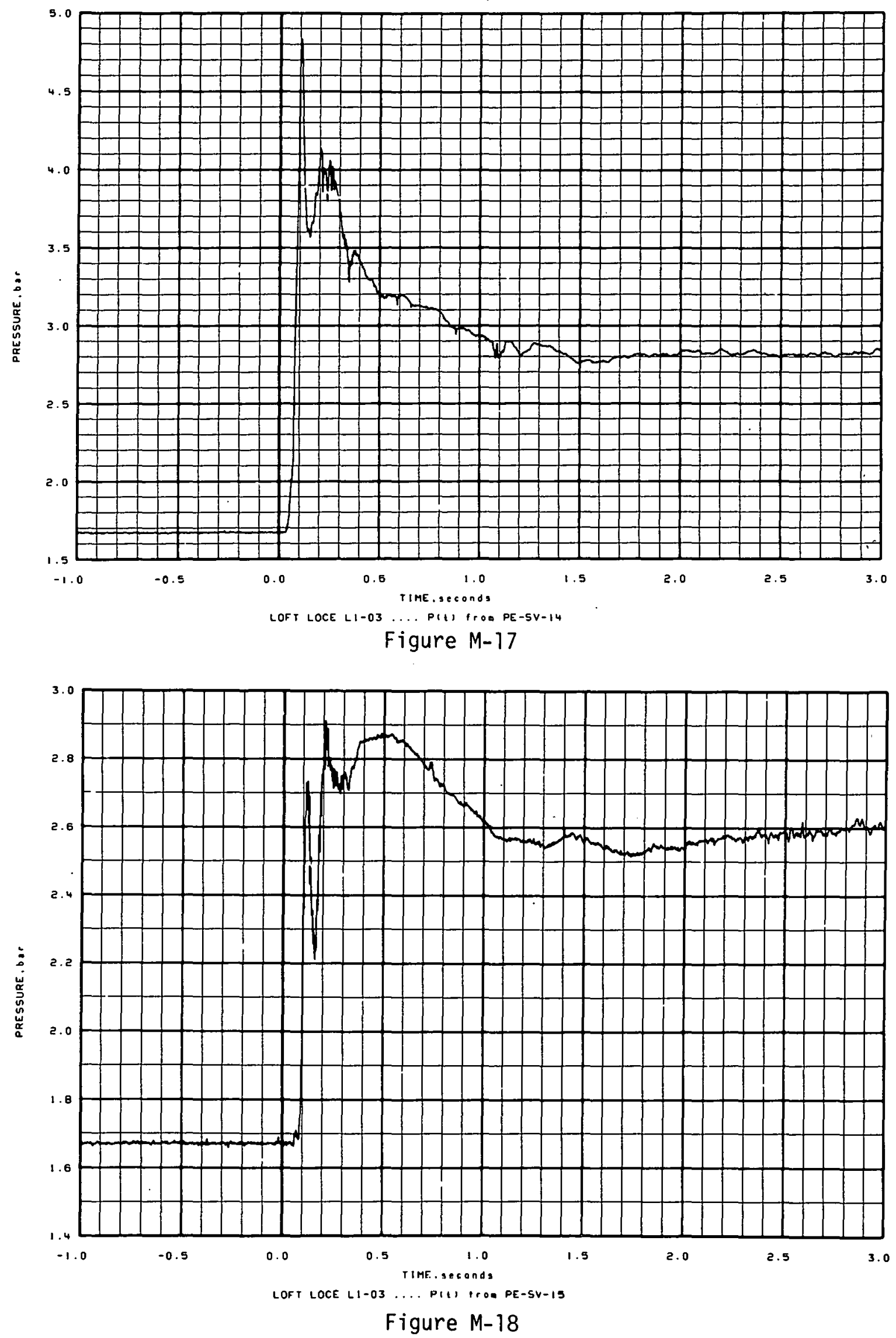

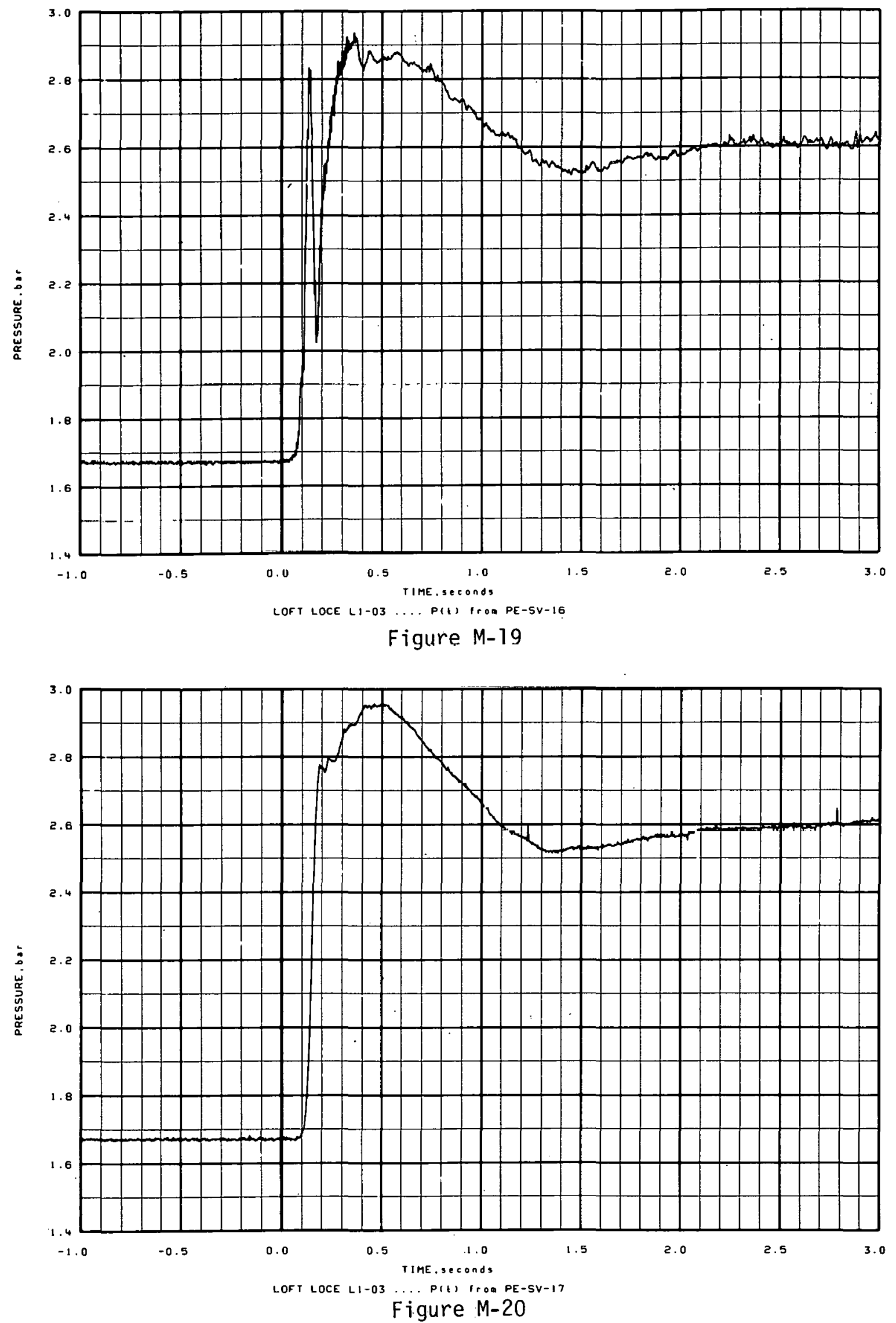

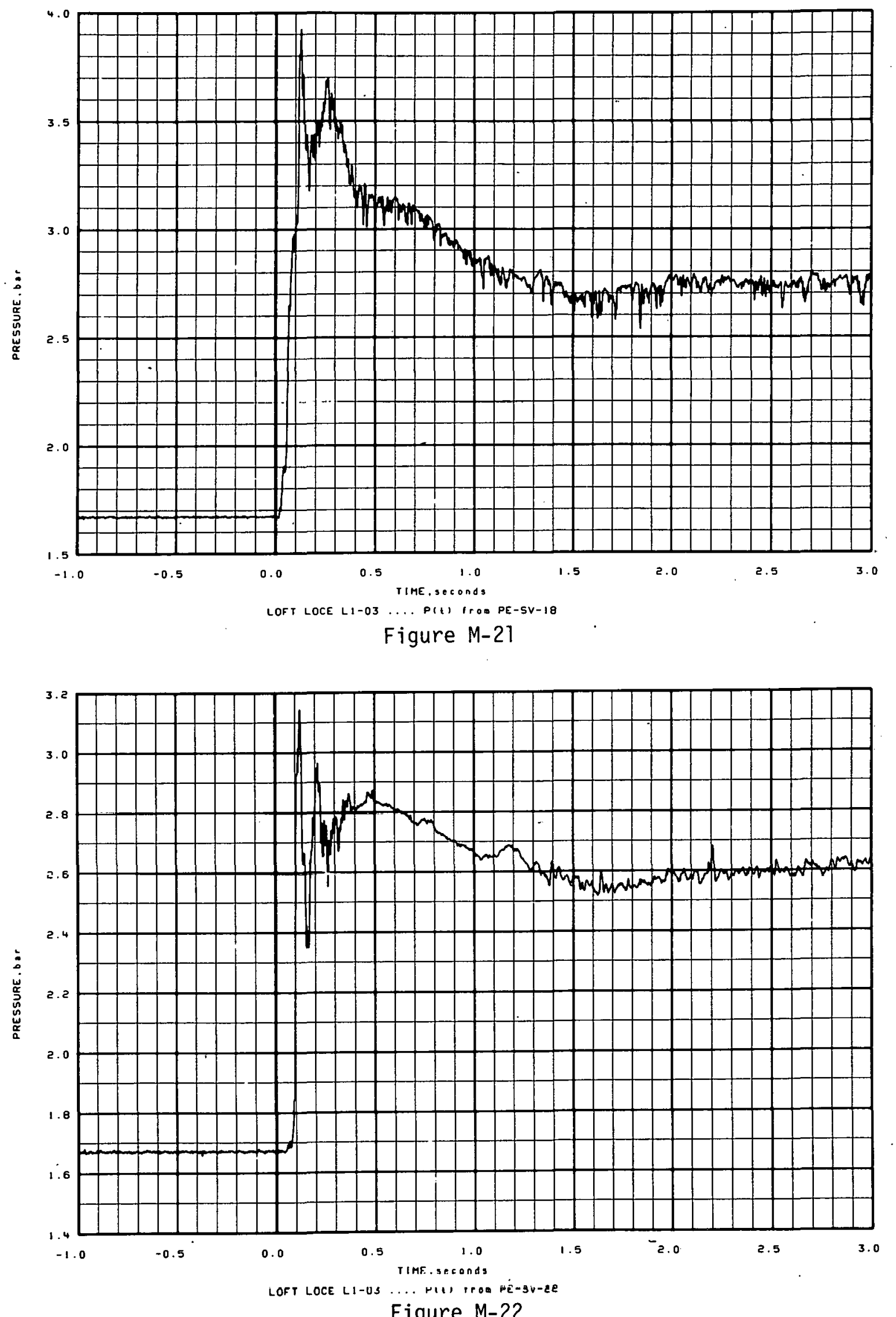

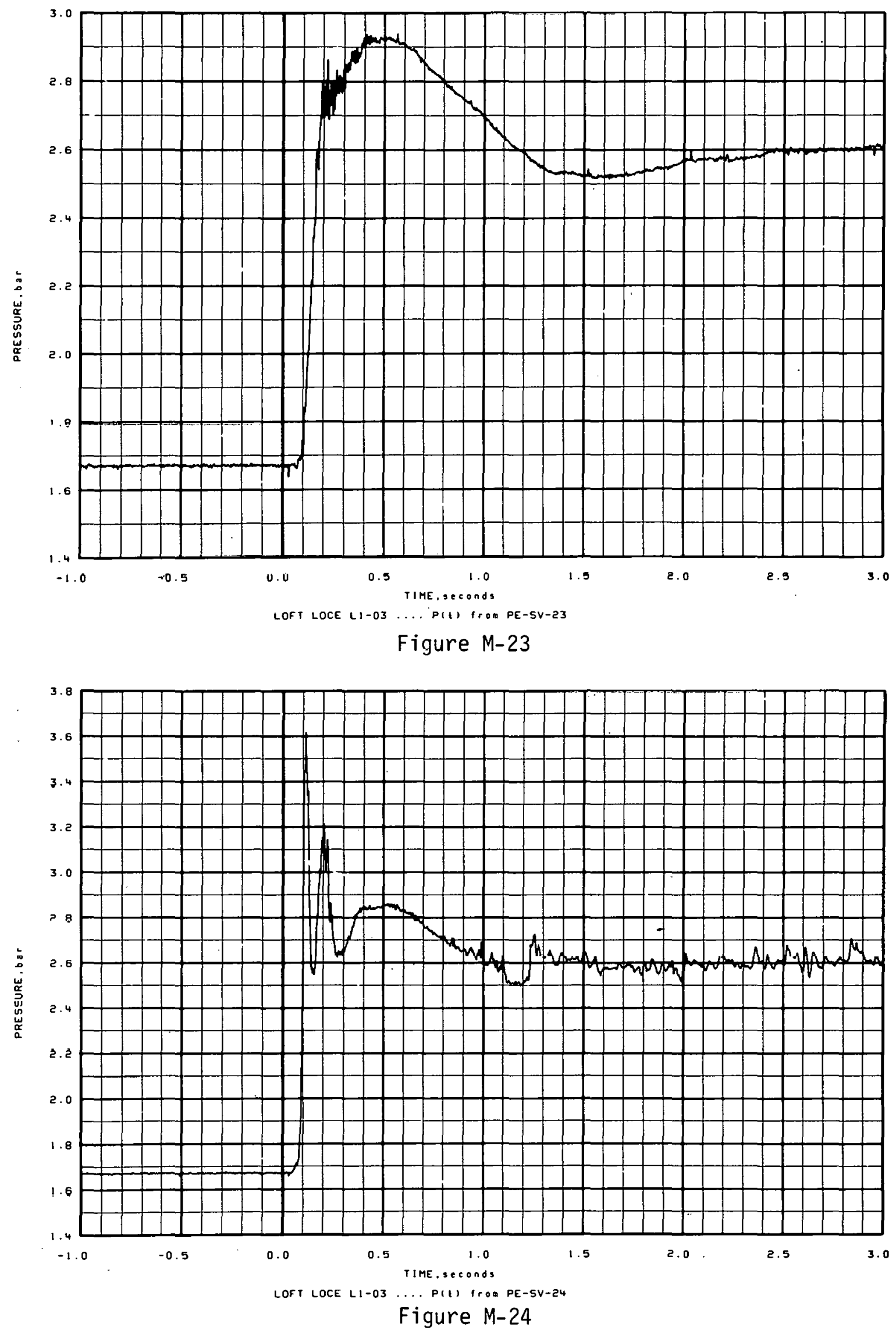

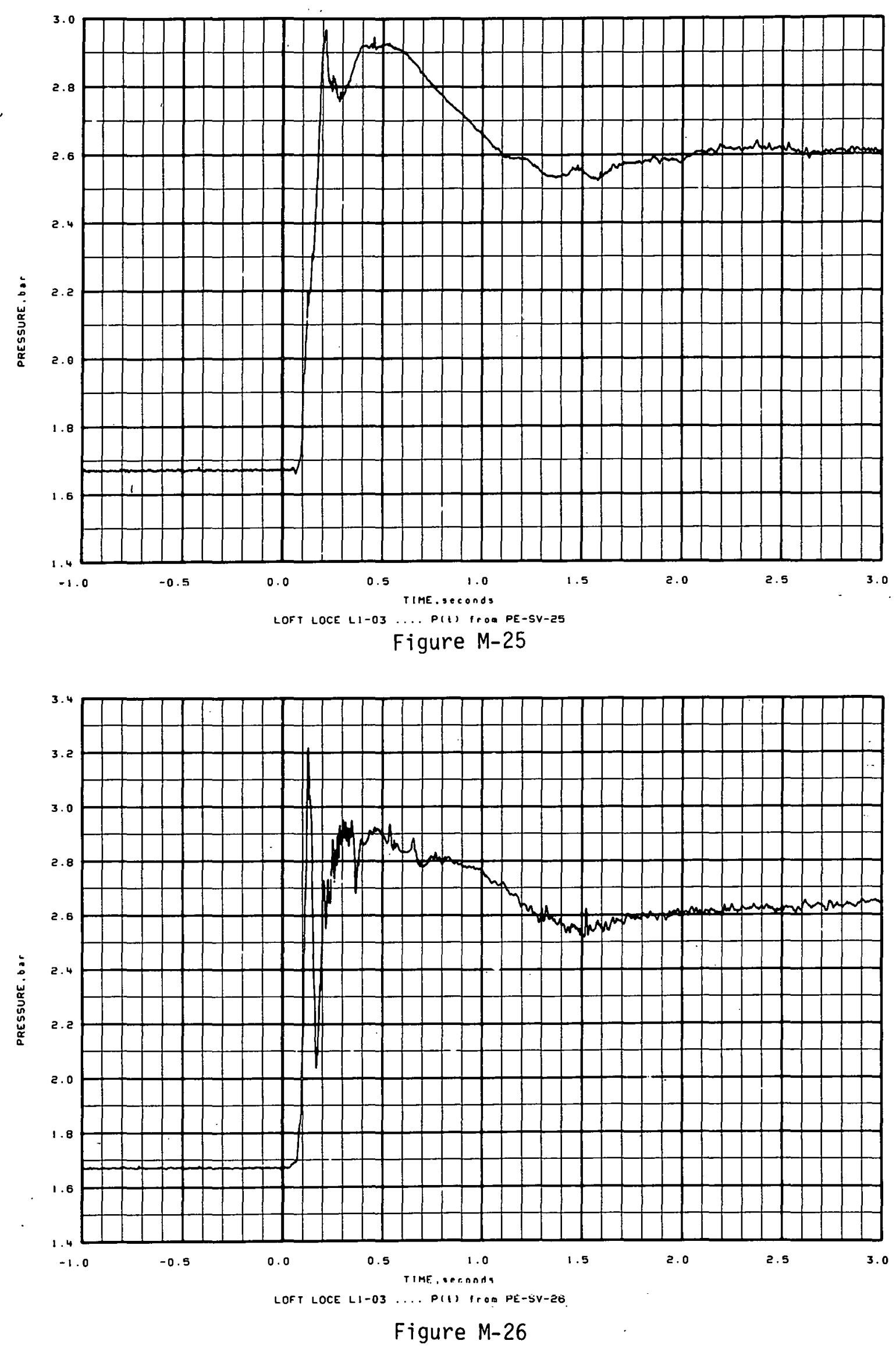

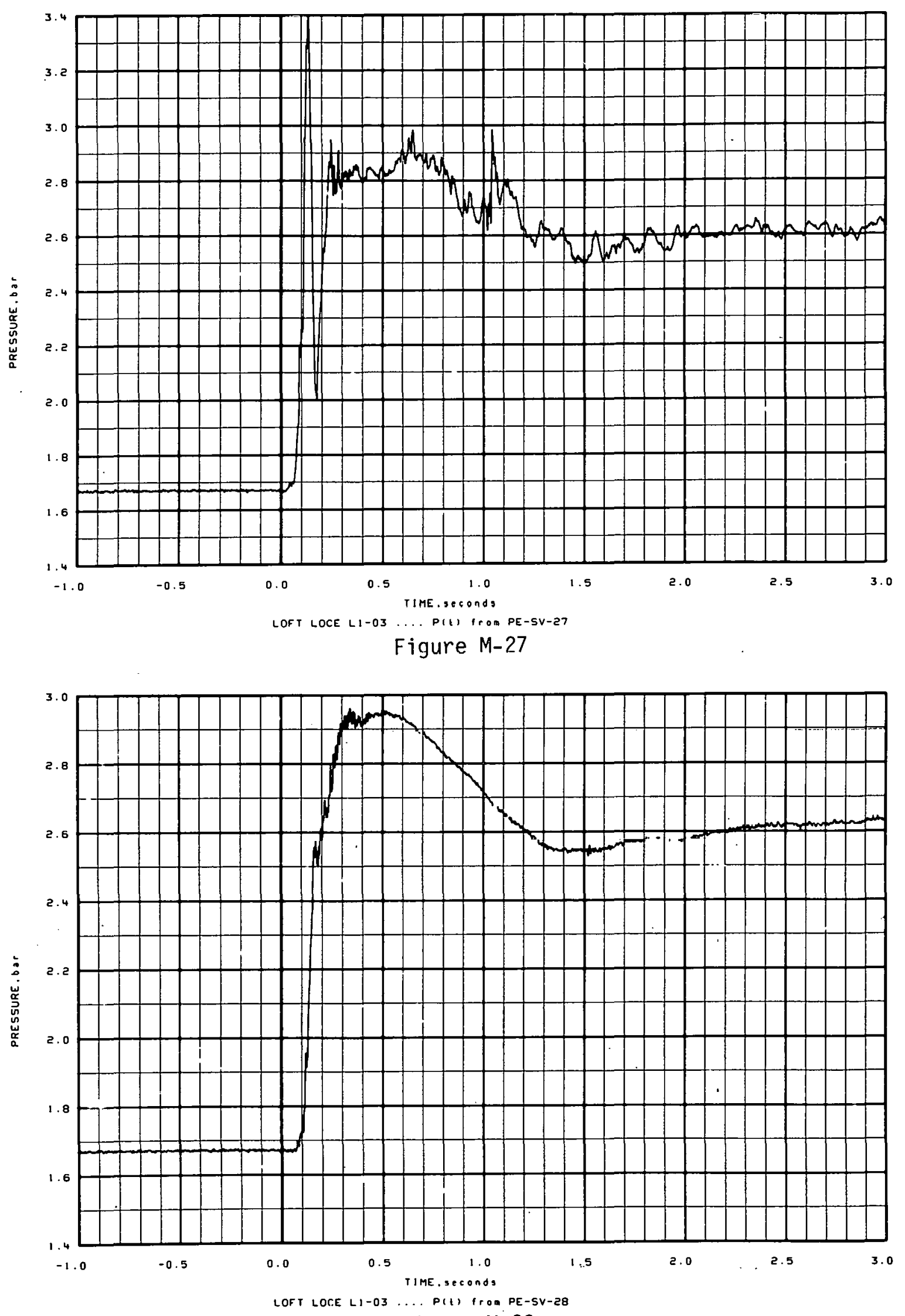

Figure M-28 

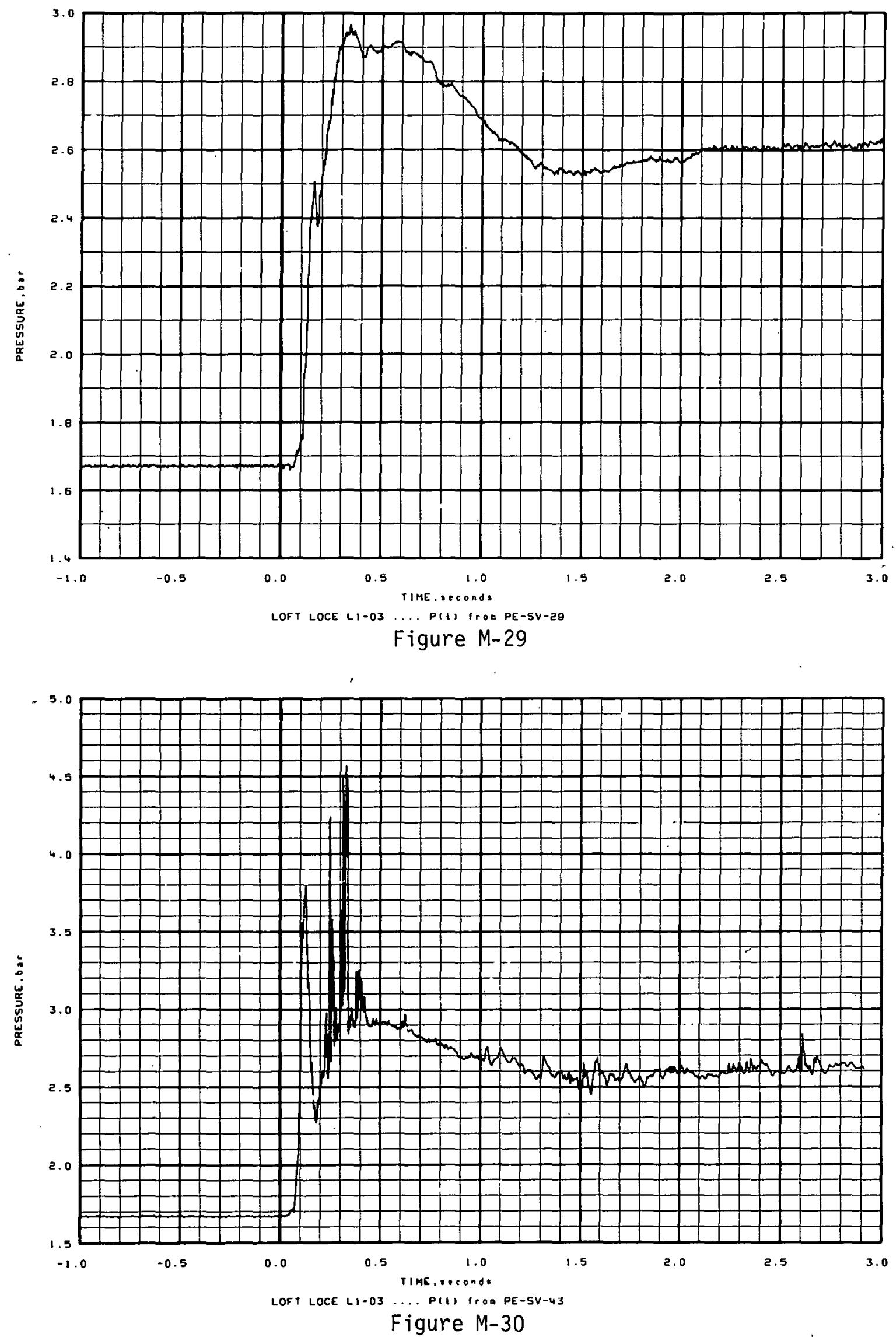

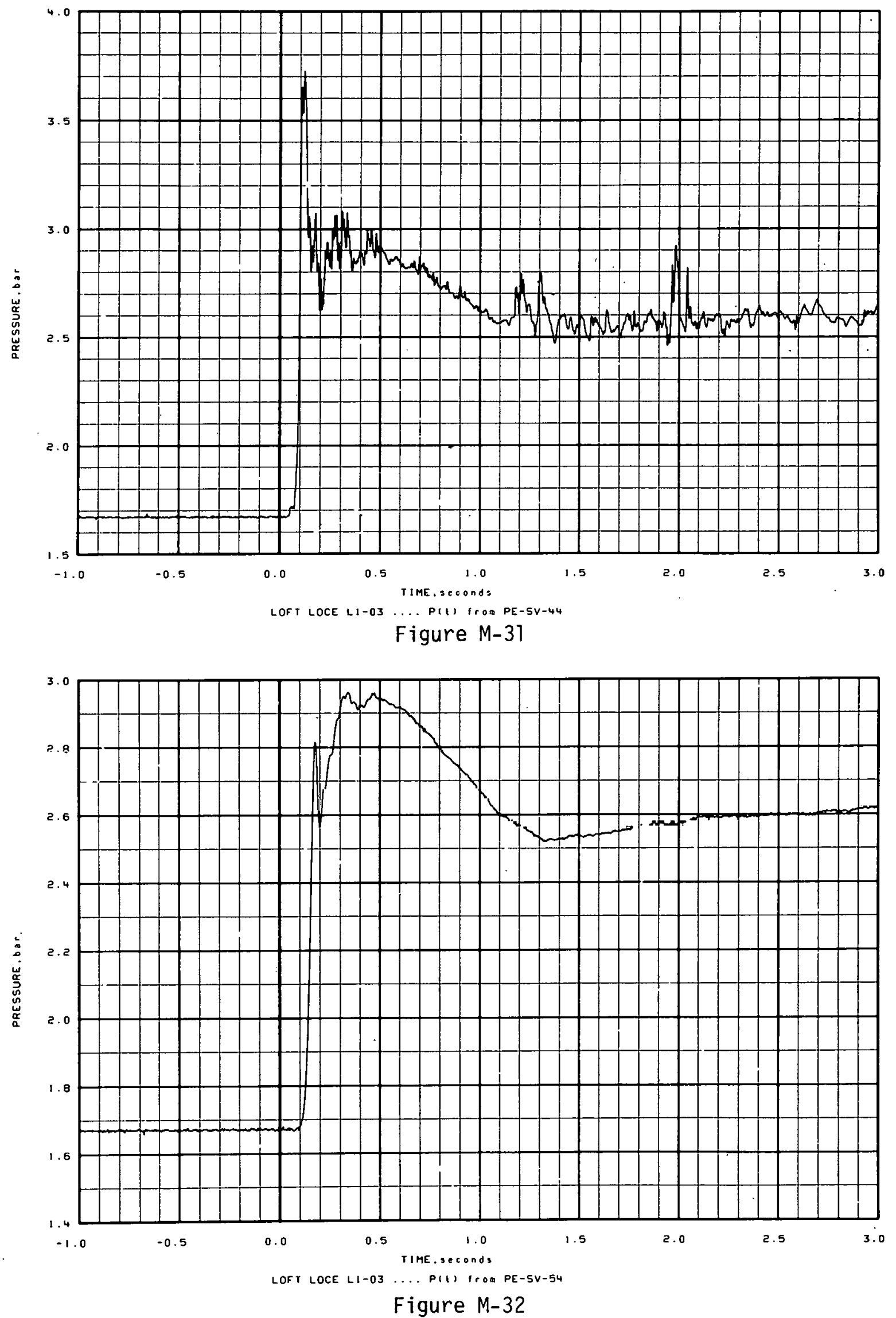

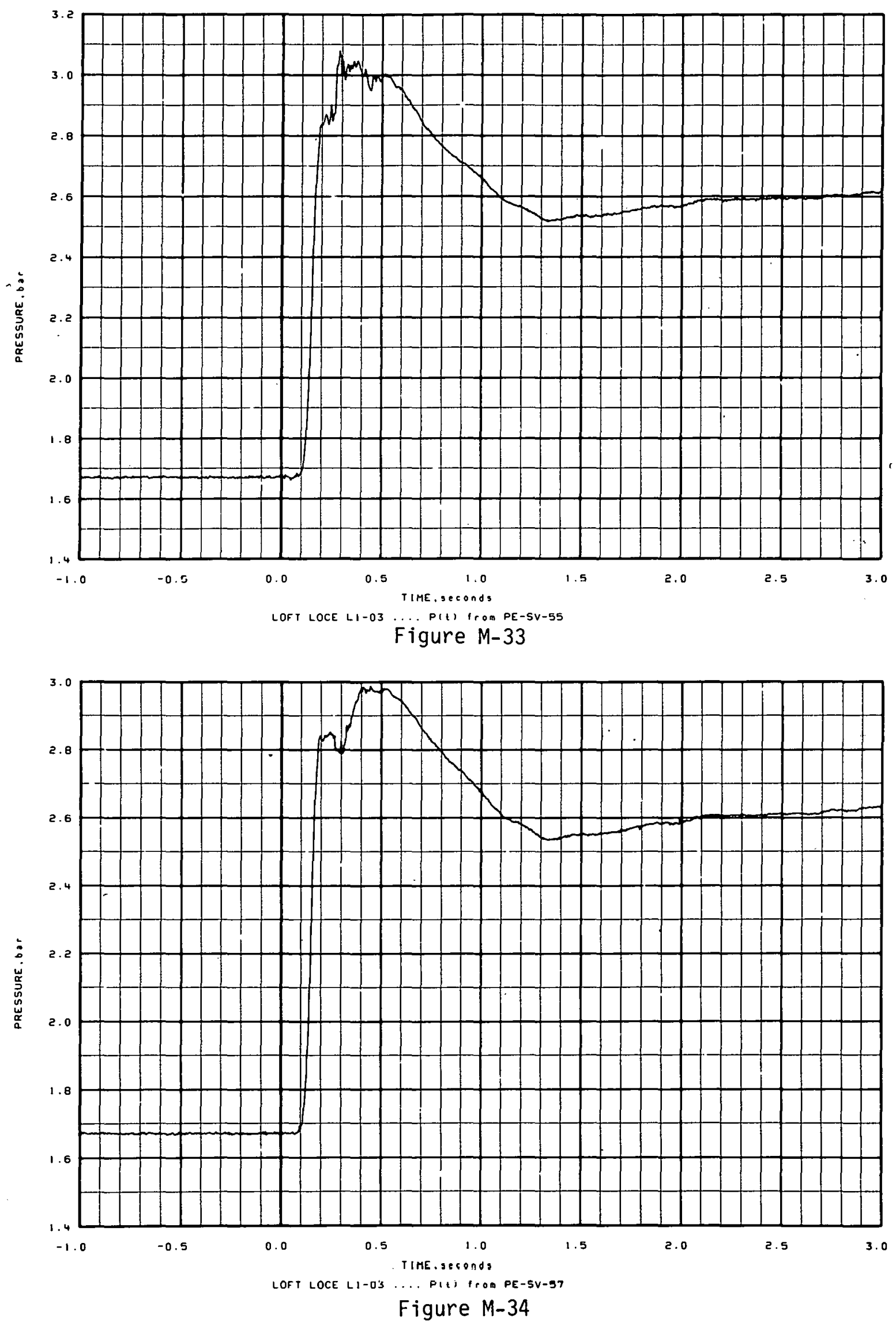

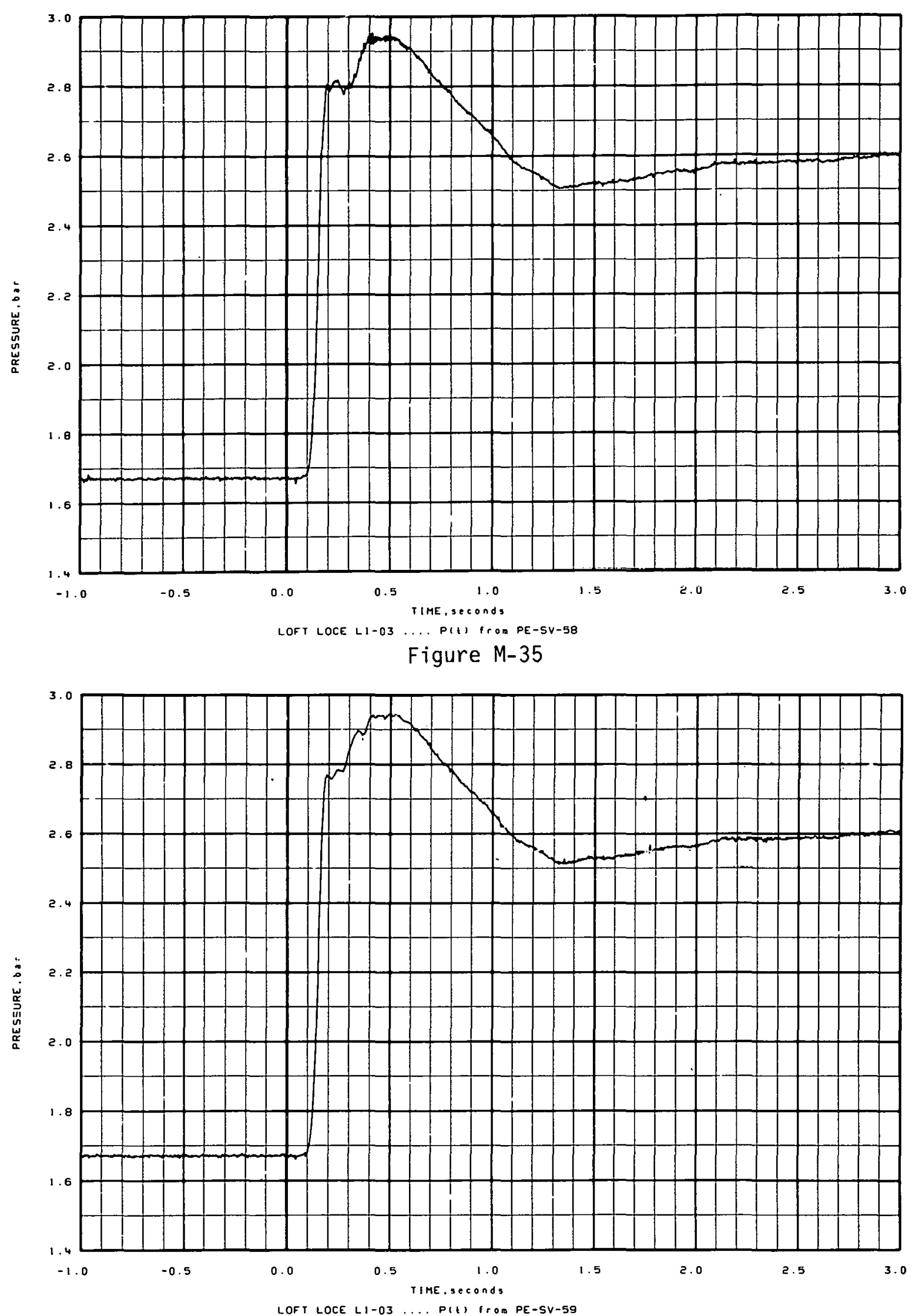

LOFT LOCE L1-03 .... PII 1 POO PE-SV-S

Figure M-36 


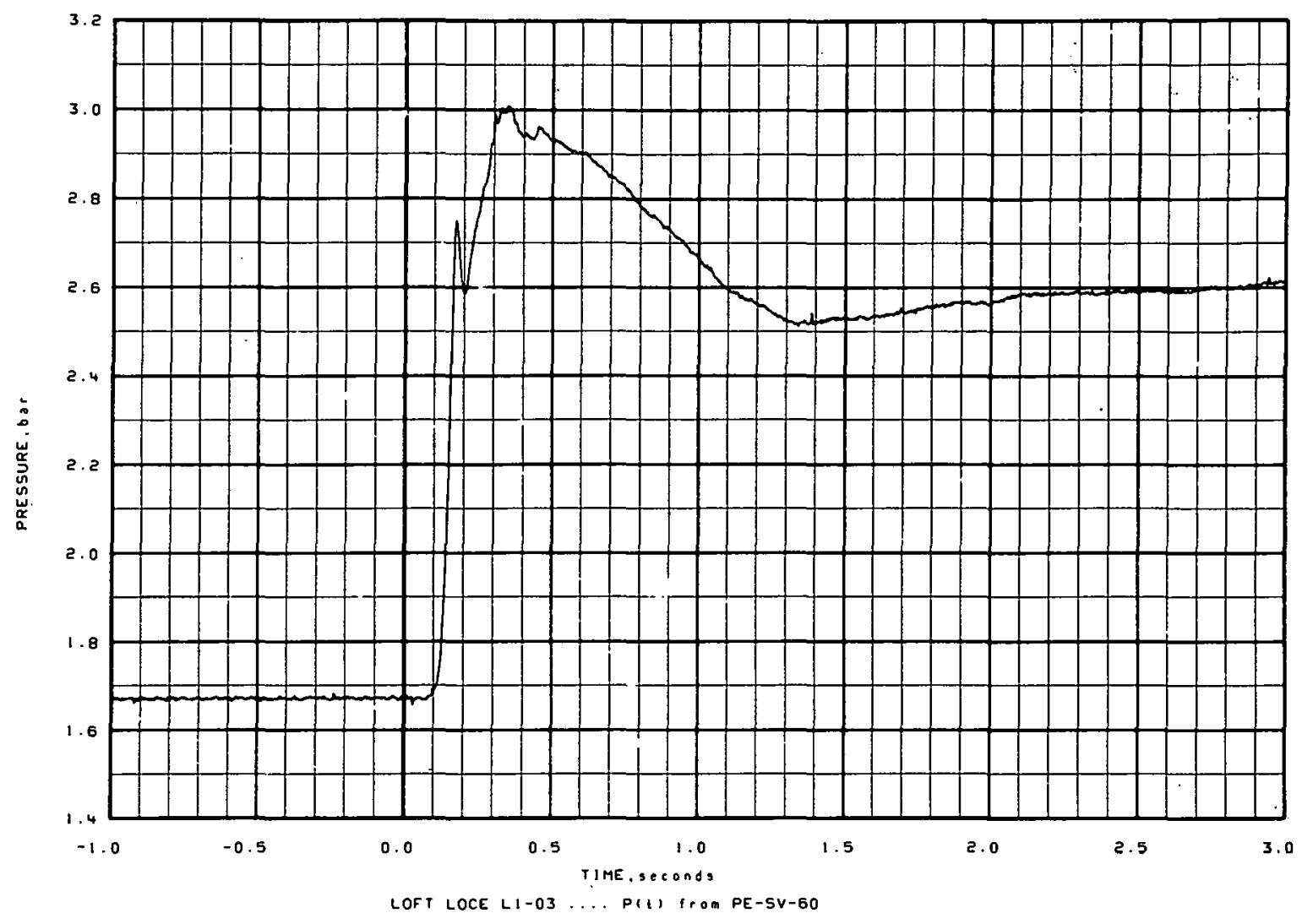

Figure M-37

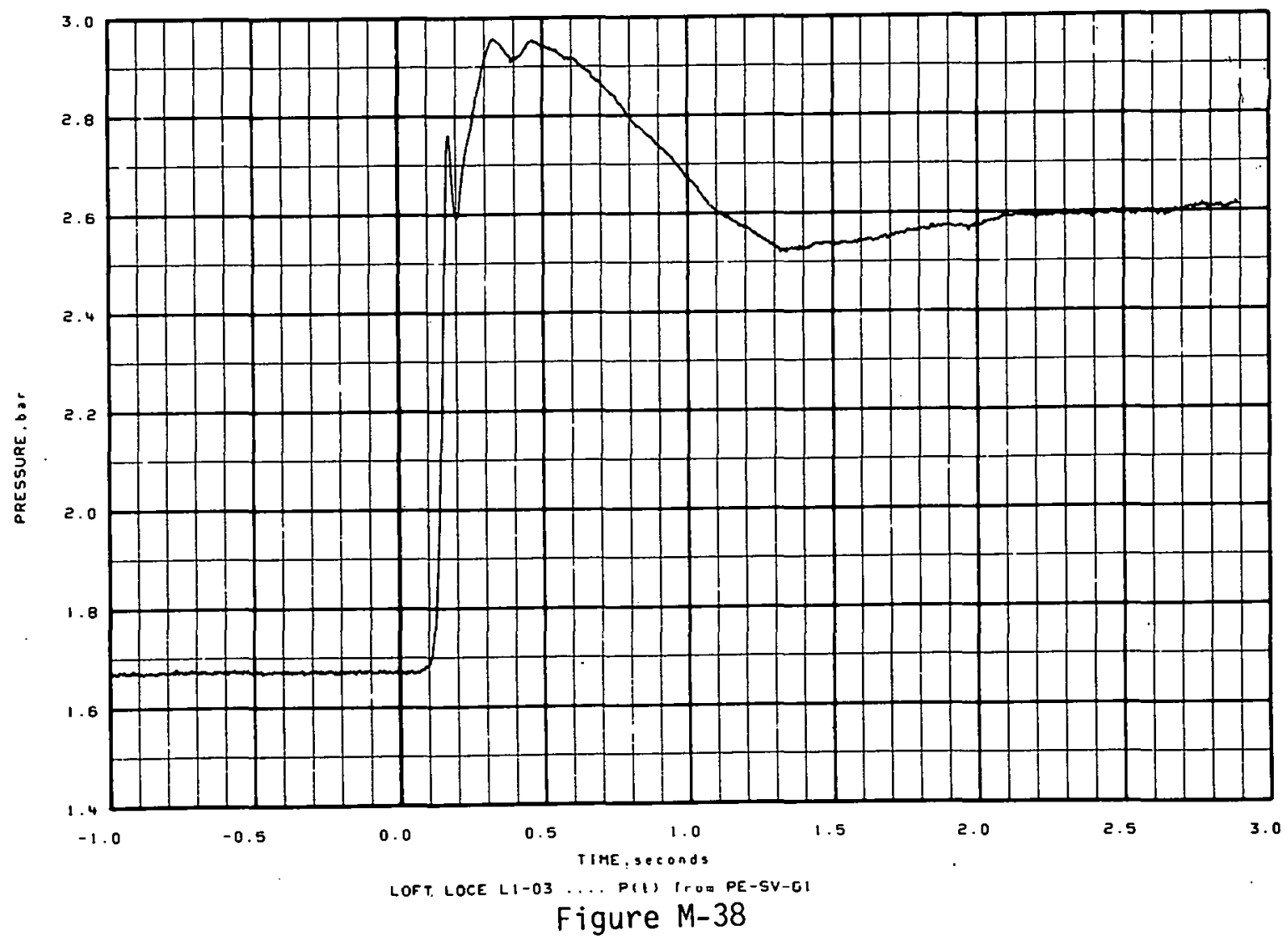


THIS PAGE

WAS INTENTIONALLY

LEFT BLANK 


\section{APPENDIX N}

LOCE LI-3A EXPERIMENTAL DATA 
THIS PAGE

\section{WAS INTENTIONALLY \\ LEFT BLANK}


Both QOBVs fully opened in this experiment. The fluid temperature was $245.3 \pm 1.5^{\circ} \mathrm{C}$ in QOBV-1 and $257.6 \pm 1.5^{\circ} \mathrm{C}$ in QOBV-15. The suppression tank initial conditions were $1.56 \pm 0.08 \mathrm{bar}, 81.7 \pm 1.5^{\circ} \mathrm{C}$ in the gas volume, and $85.3 \pm 1.5^{\circ} \mathrm{C}$ in the pool. The vents were submerged $30.1 \pm 2.5 \mathrm{~cm}$. The intcrnal vent submergence was $21.3 \pm 3.2 \mathrm{~cm}$.

The experimental data are defined in Table N-I. The opening characteristics of the QOBVs are shown in terms of percent sleeve travel versus time. The flow area of the valve begins to open at a sleeve position of $17 \%$ of full travel and is fully open at a sleeve position of $66 \%$ of full travel. The differential pressure between the header and the tank gas volume is measured with a very sensitive device primarily to provide information on vent preclearing. The data channel for this measurement is driven to saturation in the early part of the transient. 
TABLE N-I

EXPERIMENT L.7-3A DATA SUMMARY

\begin{tabular}{|c|c|c|c|c|c|}
\hline $\begin{array}{c}\text { Measurement } \\
\text { or } \\
\text { Calculation }\end{array}$ & $\begin{array}{c}\text { Pre-Transient } \\
\text { Data Channel } \\
\text { Variance } \\
\left(10^{-4} \text { bar }{ }^{2}\right) \\
\end{array}$ & Figure Number & Measurement & $\begin{array}{c}\text { Pre-Transient } \\
\text { Data Channel } \\
\text { Variance } \\
\left(10^{-4} \text { bar }^{2}\right) \\
\end{array}$ & Figure Number \\
\hline QOBV-1 opening & - & $\mathrm{N}-1, \mathrm{~N}-2$ & PE-SV-22 & 0.05558 & $\mathrm{~N}-2 ?$ \\
\hline QOBV-15 opening & - & $\mathrm{N}-3, \mathrm{~N}-4$ & $P E=5 V-23$ & $0.04 .3 n 9$ & $\mathrm{~N}=23$ \\
\hline $\begin{array}{l}\text { Combined QOBV } \\
\text { opcning }\end{array}$ & - & $N-5, N-6$ & $P E-S V-24$ & 0.02831 & $N-24$ \\
\hline Vertical load & - & $\mathrm{N}-7$ & PE-SV-25 & 0.02378 & $\mathrm{~N}-25$ \\
\hline PDE-SV-09 & - & $\mathrm{N}-8$ & PE-SV-26 & 0.02136 & $\mathrm{~N}-26$ \\
\hline PE-SV-01 & 0.05244 & $\mathrm{~N}-9$ & PE-SV-27 & 0.03806 & $\mathrm{~N}-27$ \\
\hline PE-SV-02 & 0.06278 & $\mathrm{~N}-10$ & PE-SV-28 & 0.03165 & $\mathrm{~N}-28$ \\
\hline PE-SV-03 & 0.06375 & $N-11$ & PE-SV-29 & 0.05249 & $\mathrm{~N}-29$ \\
\hline PE-SV-04 & 0.06169 & $\mathrm{~N}-12$ & PE-SV-43 & 0.02979 & $\mathrm{~N}-30$ \\
\hline PE-SV-10 & 0.05638 & $\mathrm{~N}-13$ & PE-SV-44 & 0.03967 & $N-31$ \\
\hline PE-SV-11 & 0.06262 & $N=74$ & $P E-S V-54$ & 0.10154 & $\mathrm{~N}-32$ \\
\hline PE-SV-12 & 0.05616 & $N-15$ & $P E-S V-55$ & 0.05169 & $\mathrm{~N}-33$ \\
\hline PE-SV-13 & 0.05325 & $\mathrm{~N}-16$ & PE-SV-56 & \multicolumn{2}{|c|}{ measurement deleted } \\
\hline PE-SV-14 & 0.06085 & $\mathrm{~N}-17$ & PE-SV-57 & 0.16961 & $\mathrm{~N}-34$ \\
\hline PE-SV-15 & 0.05814 & $N-18$ & $P E-S V-58$ & 0.19325 & $\mathrm{~N}-35$ \\
\hline PE-SV-16 & 0.04190 & $N-19$ & PF-SV-59 & 0.04029 & $\mathrm{~N}-36$ \\
\hline PE-SV-17 & 0.04181 & $\mathrm{~N}-20$ & PE-SV-60 & 0.12611 & $\mathrm{~N}-37$ \\
\hline PE-SV-18 & 0.05157 & $N-21$ & PE-SV-61 & 0.04804 & $\mathrm{~N}-38$ \\
\hline
\end{tabular}




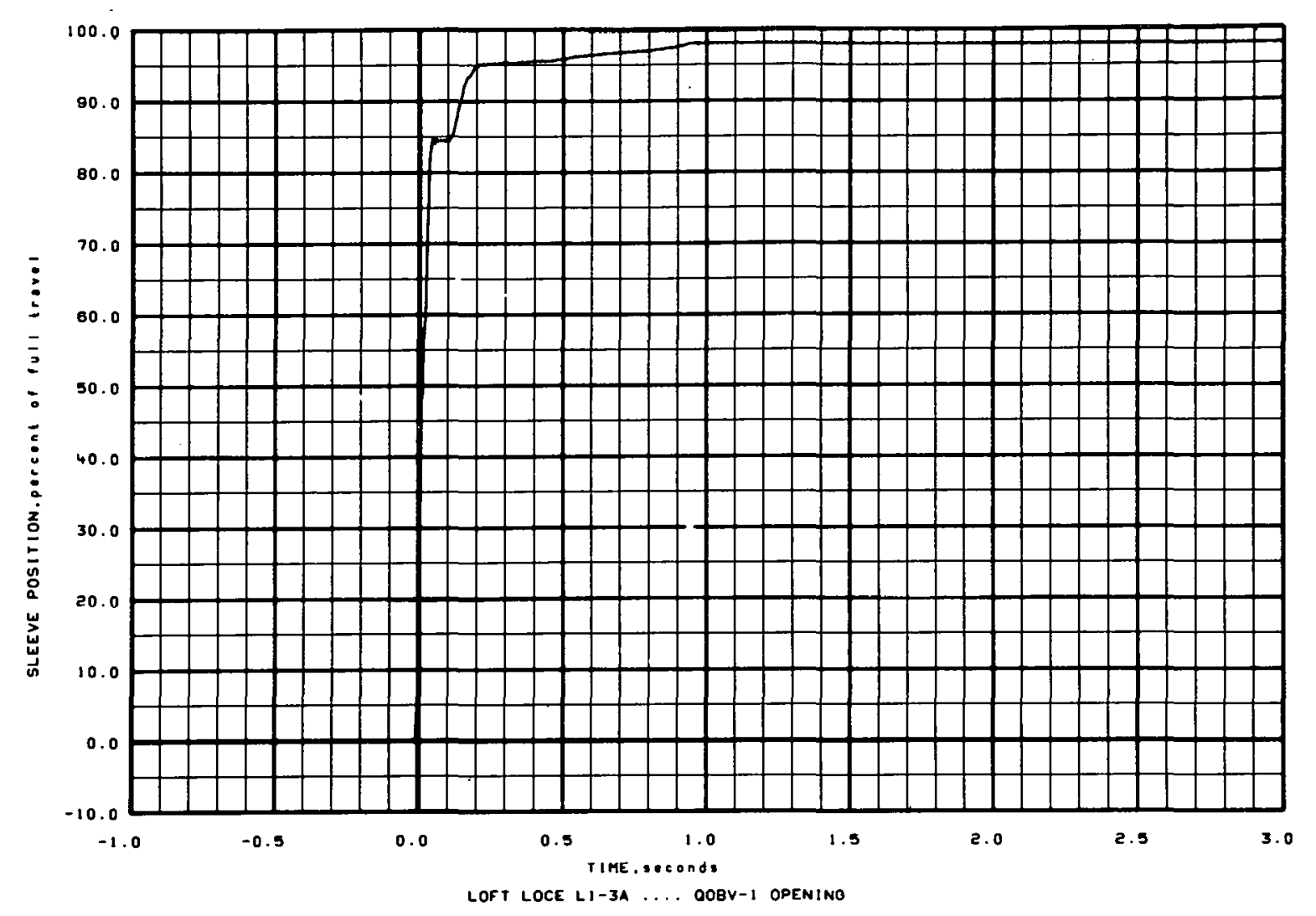

Figure $\mathrm{N}-1$

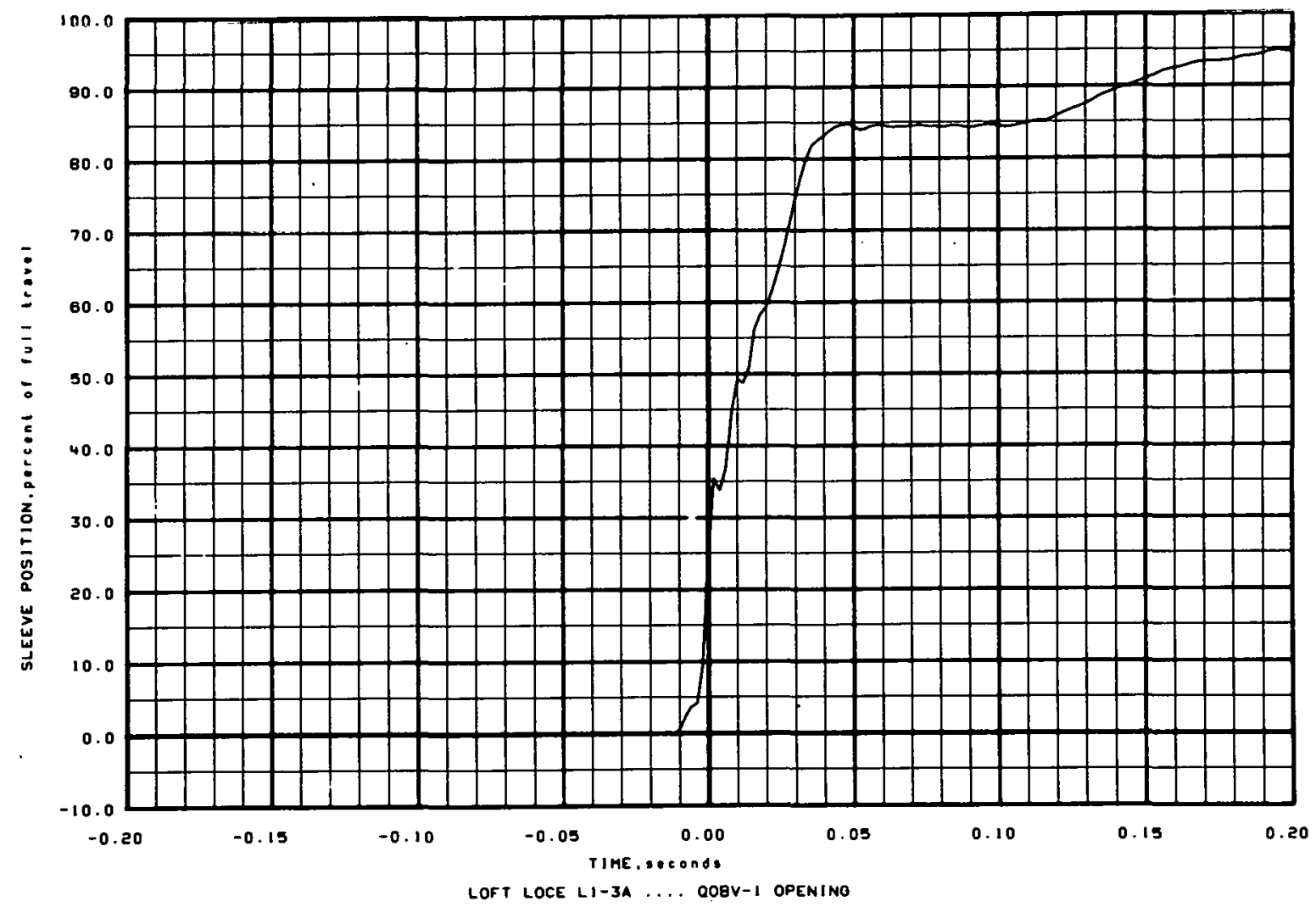

Figure N-2 


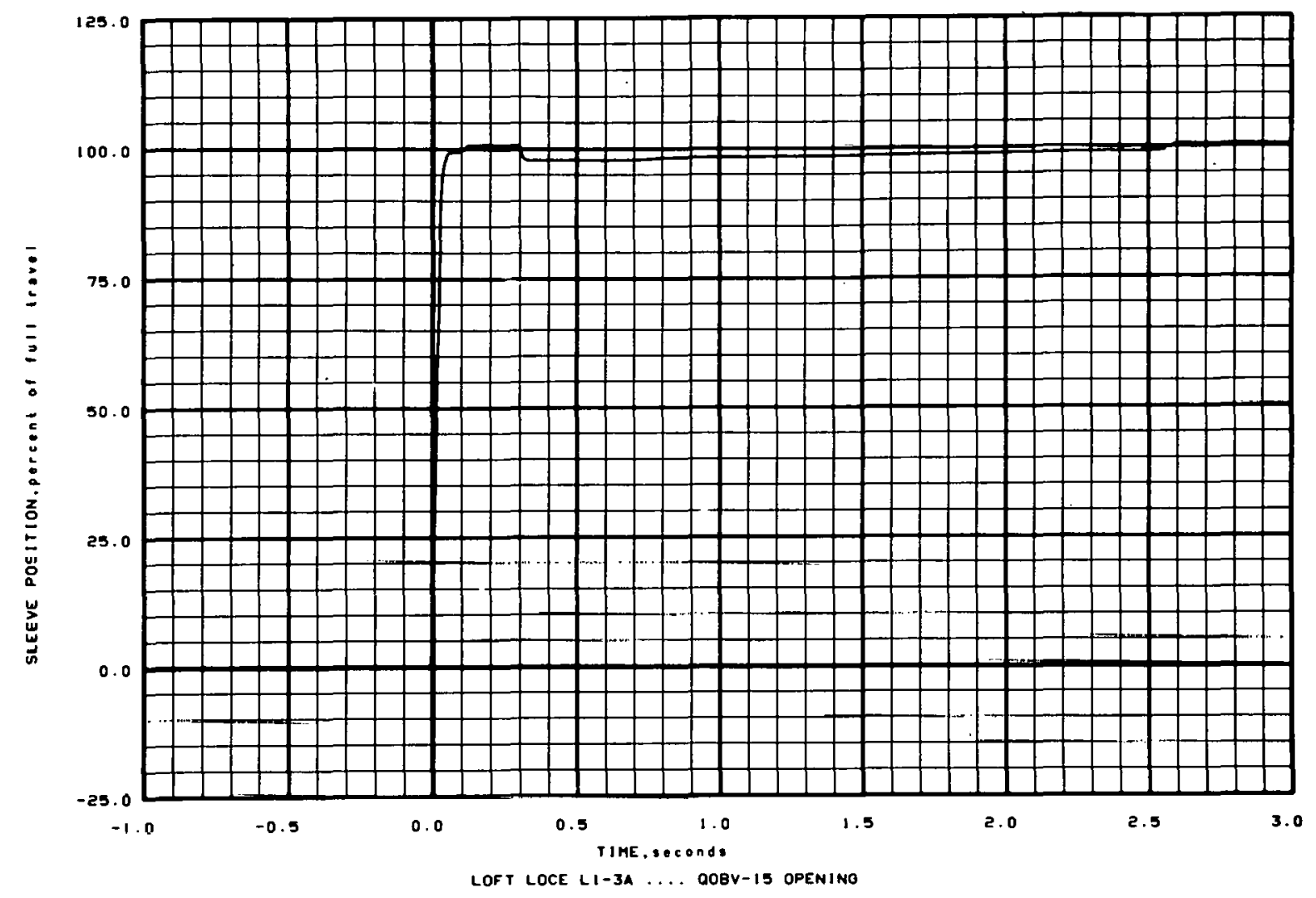

Figure $\mathrm{N}-3$

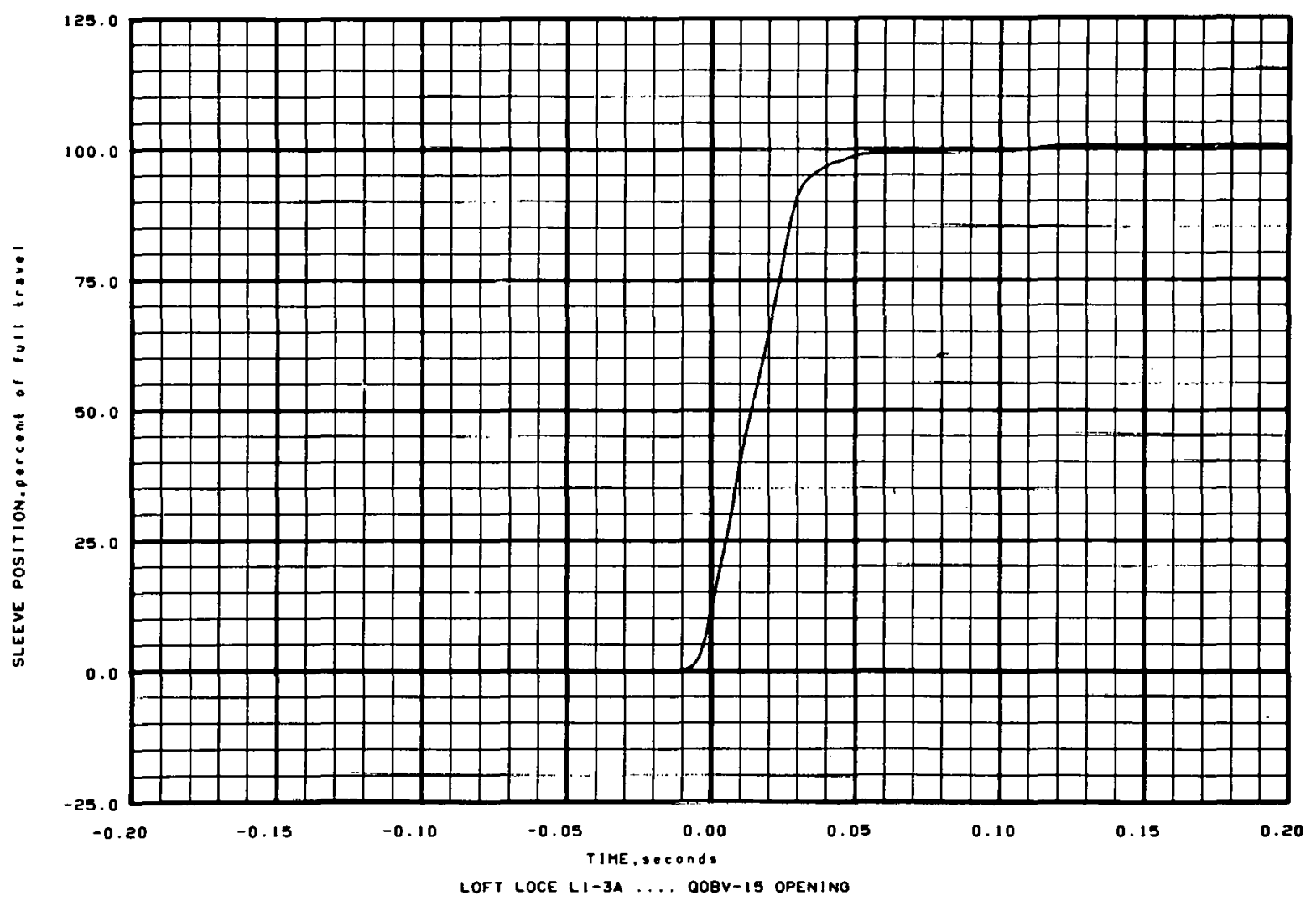

Figure N-4 


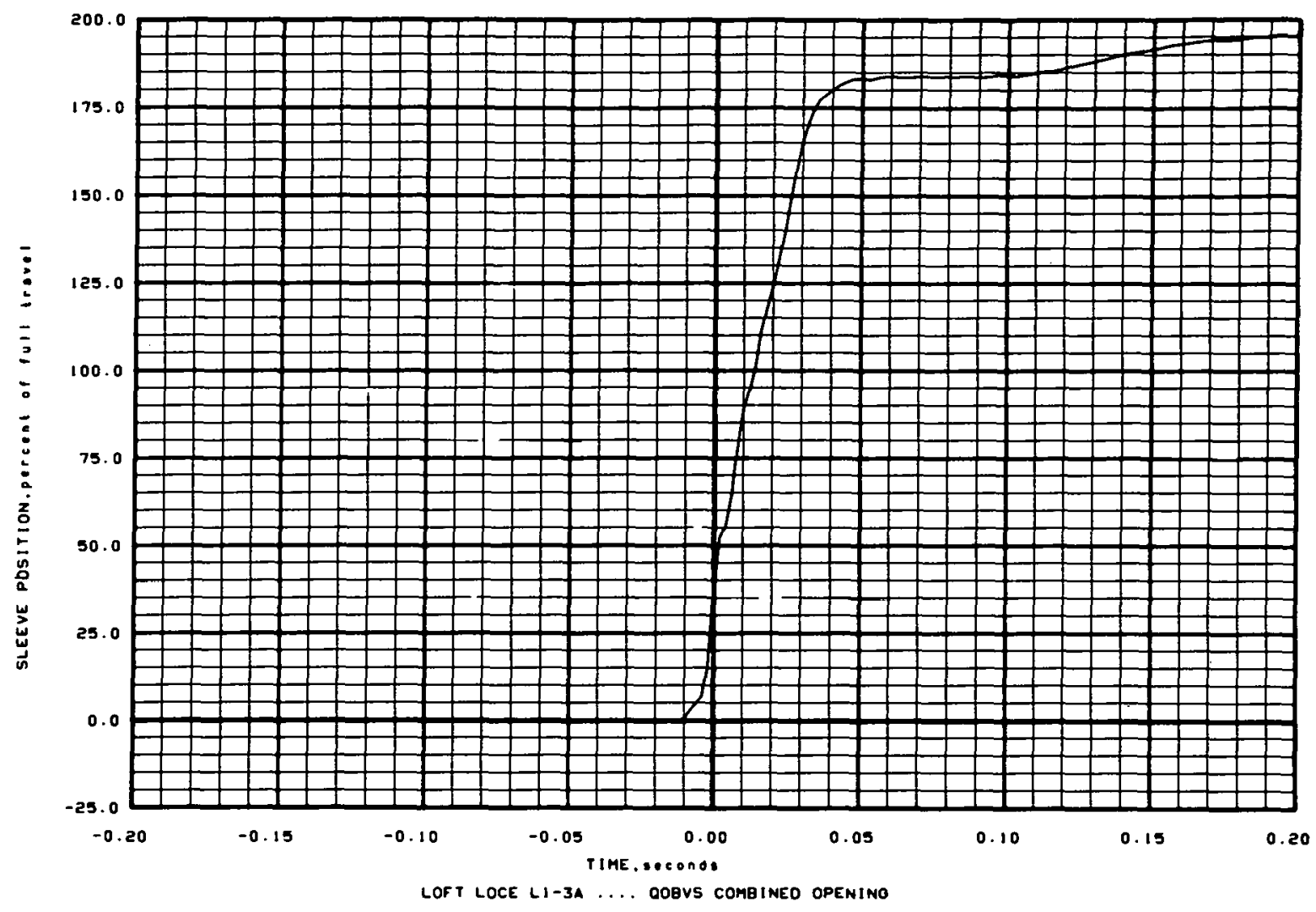

Figure N-5

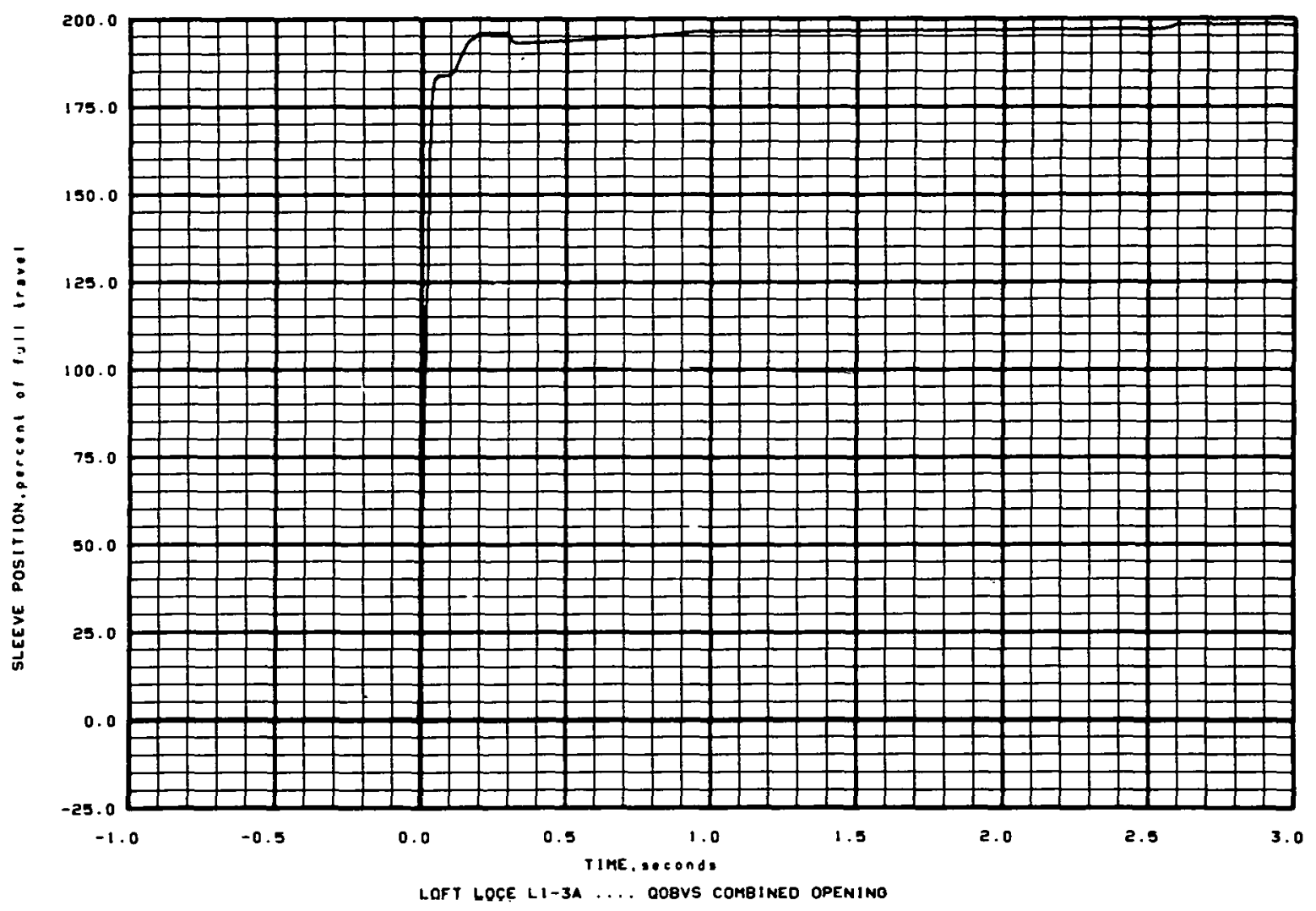

Figure N-6 


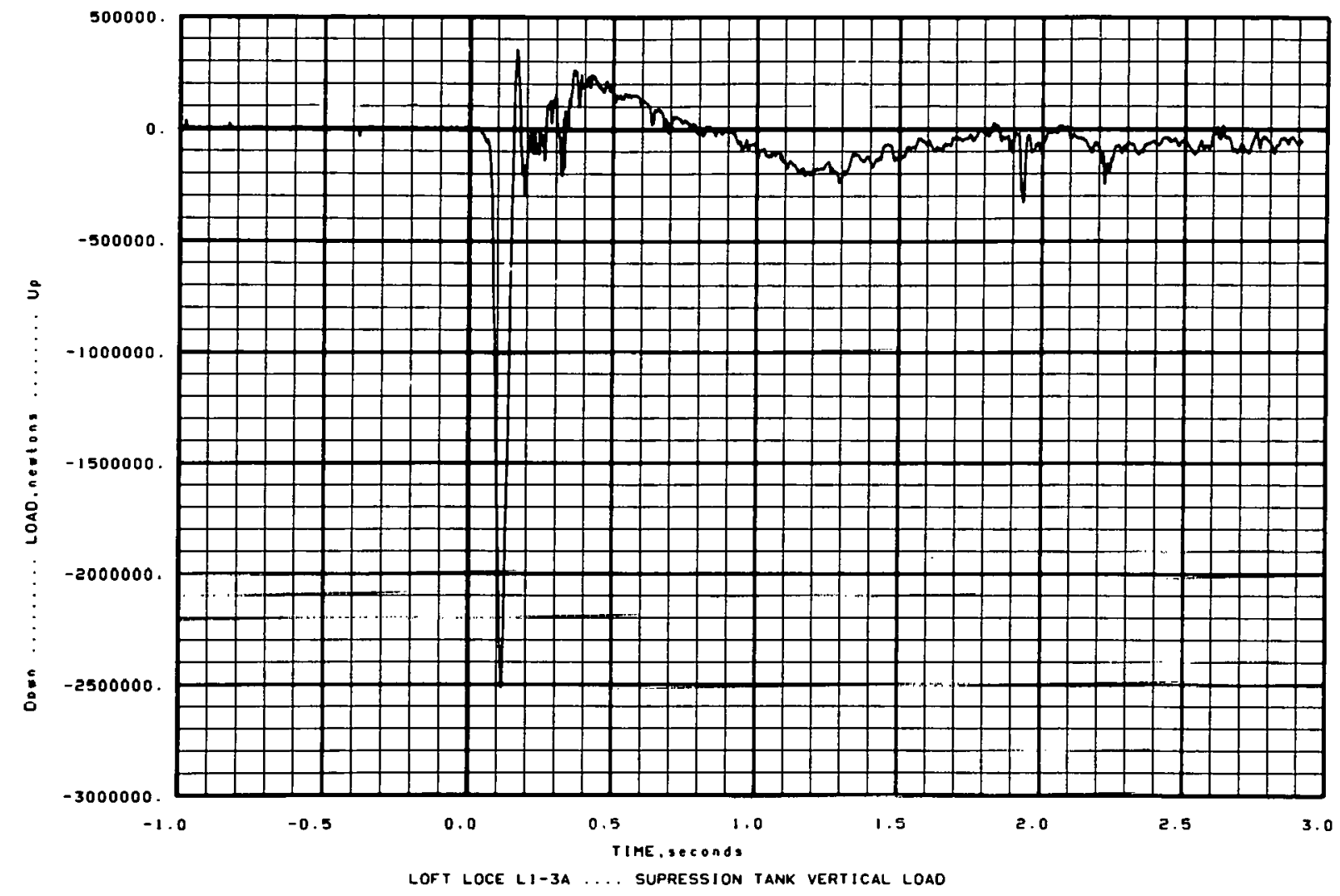

Figure N-7

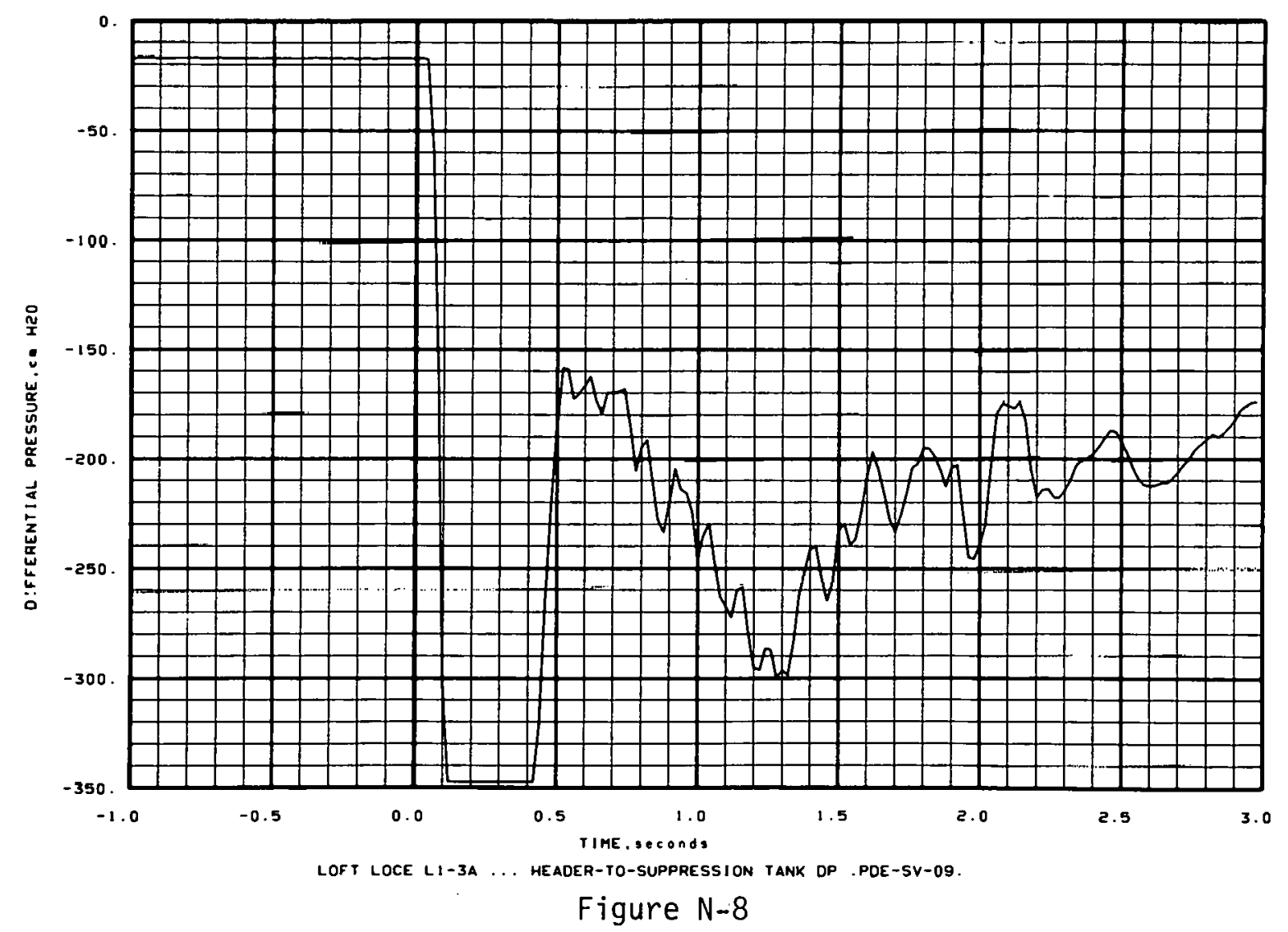




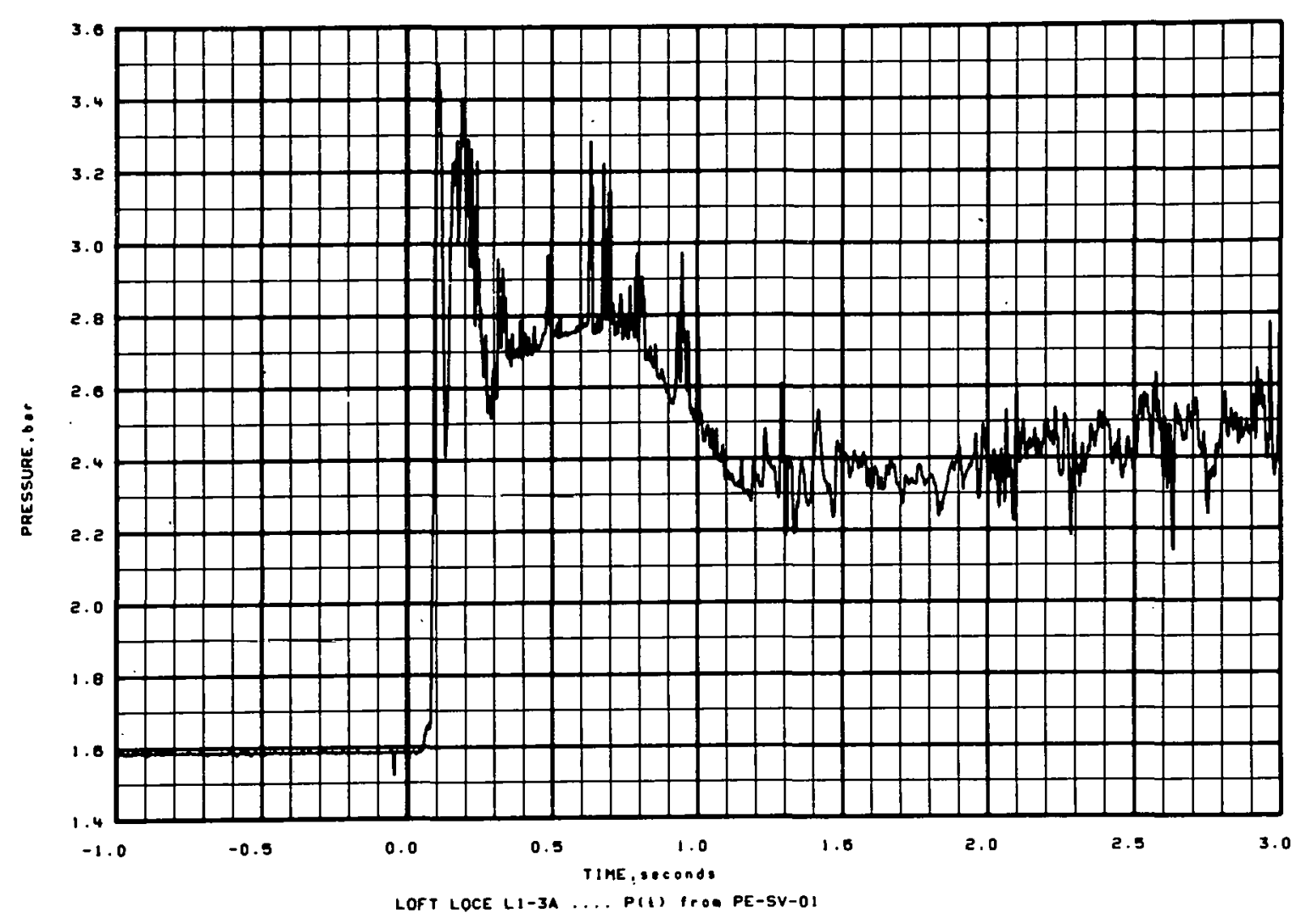

Figure N-9

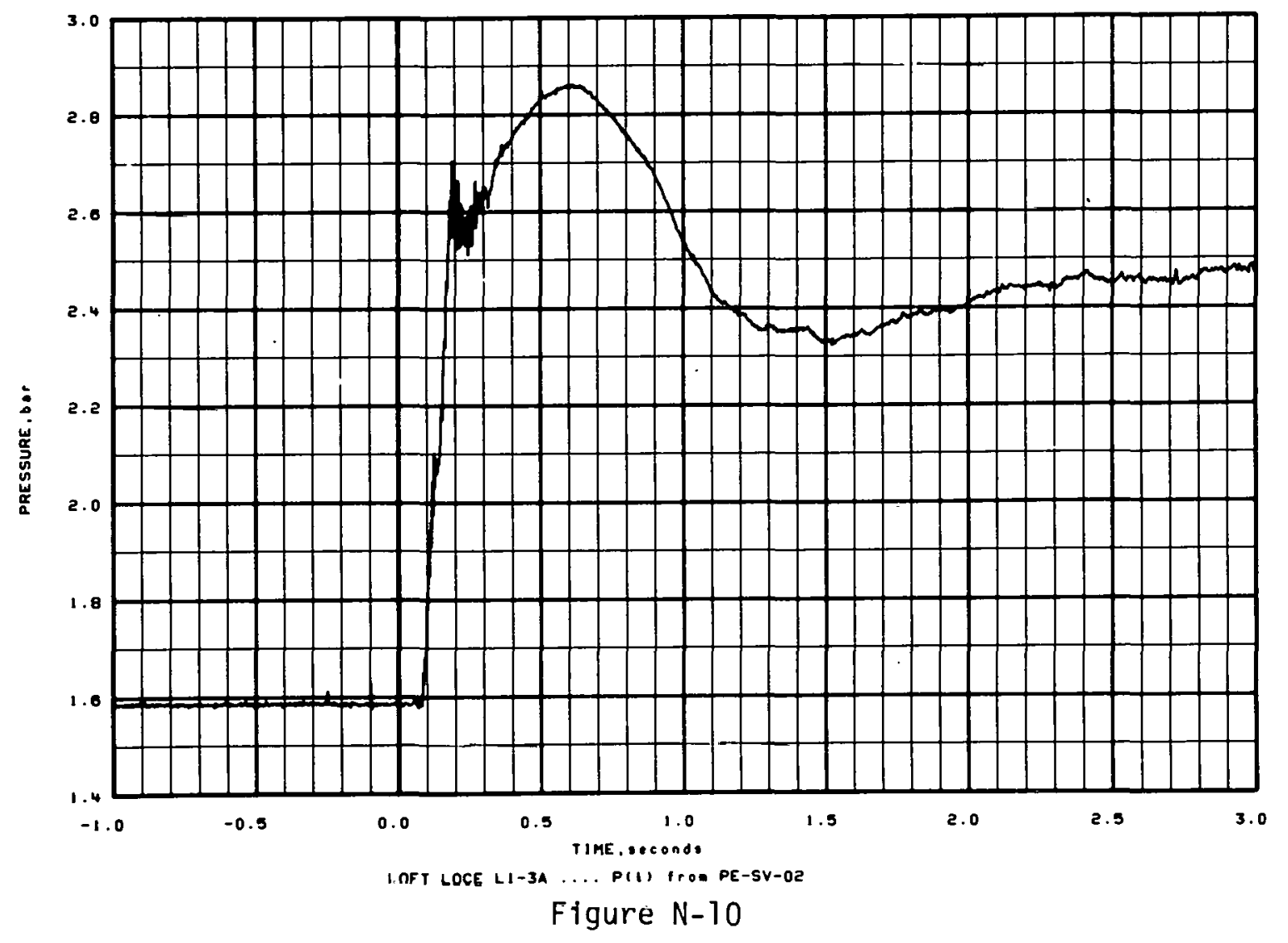




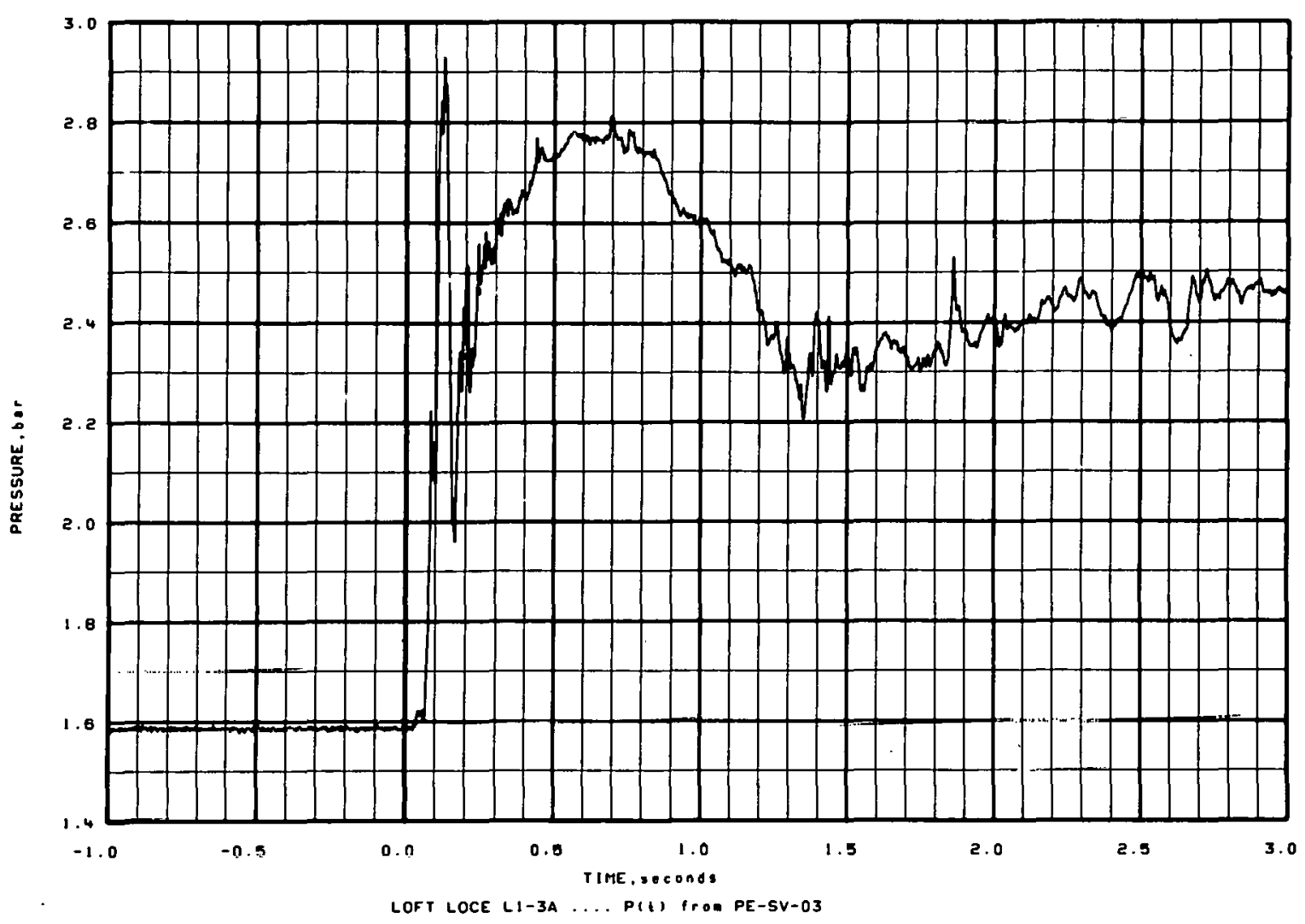

Figure $\mathrm{N}-11$

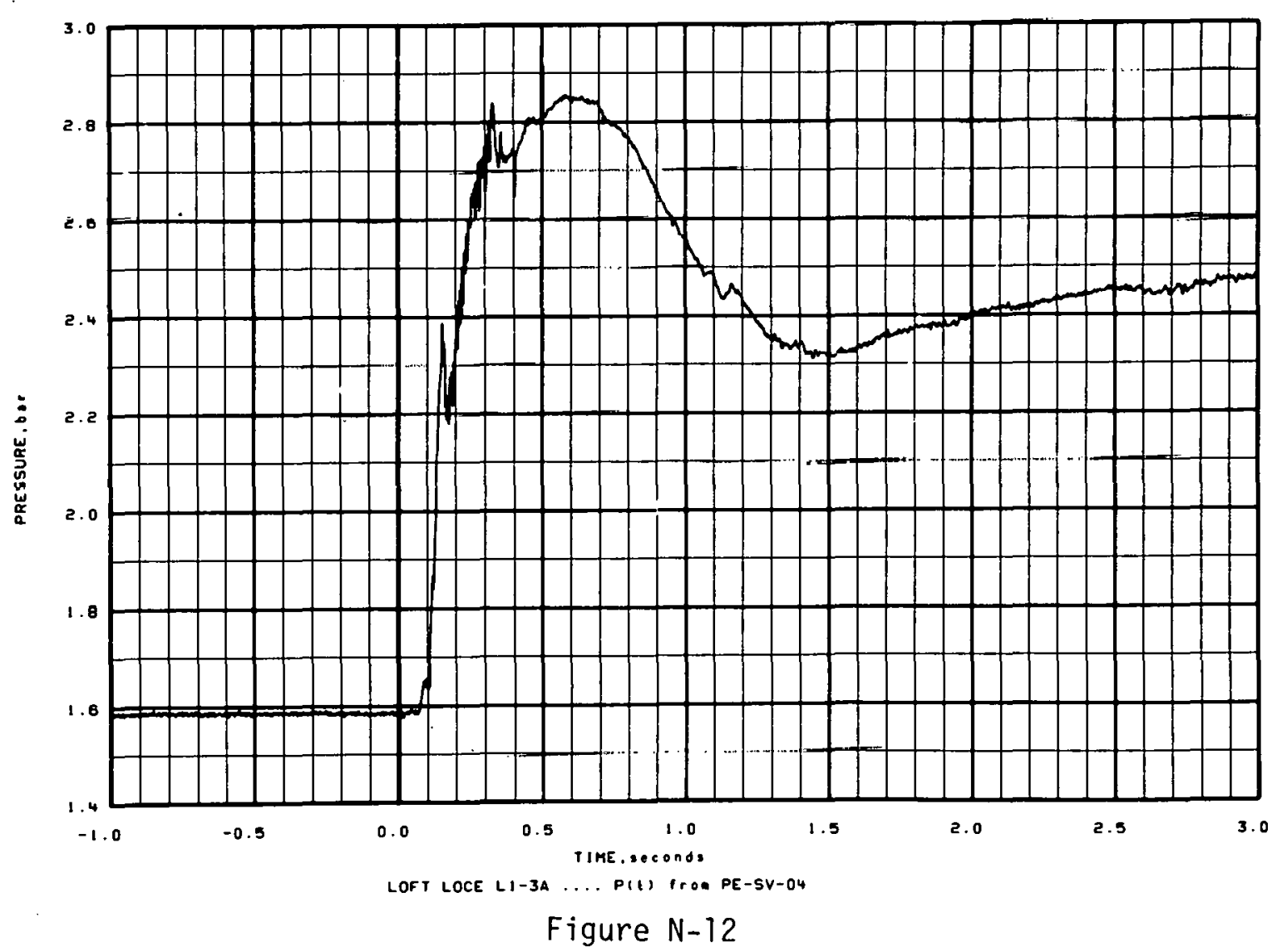




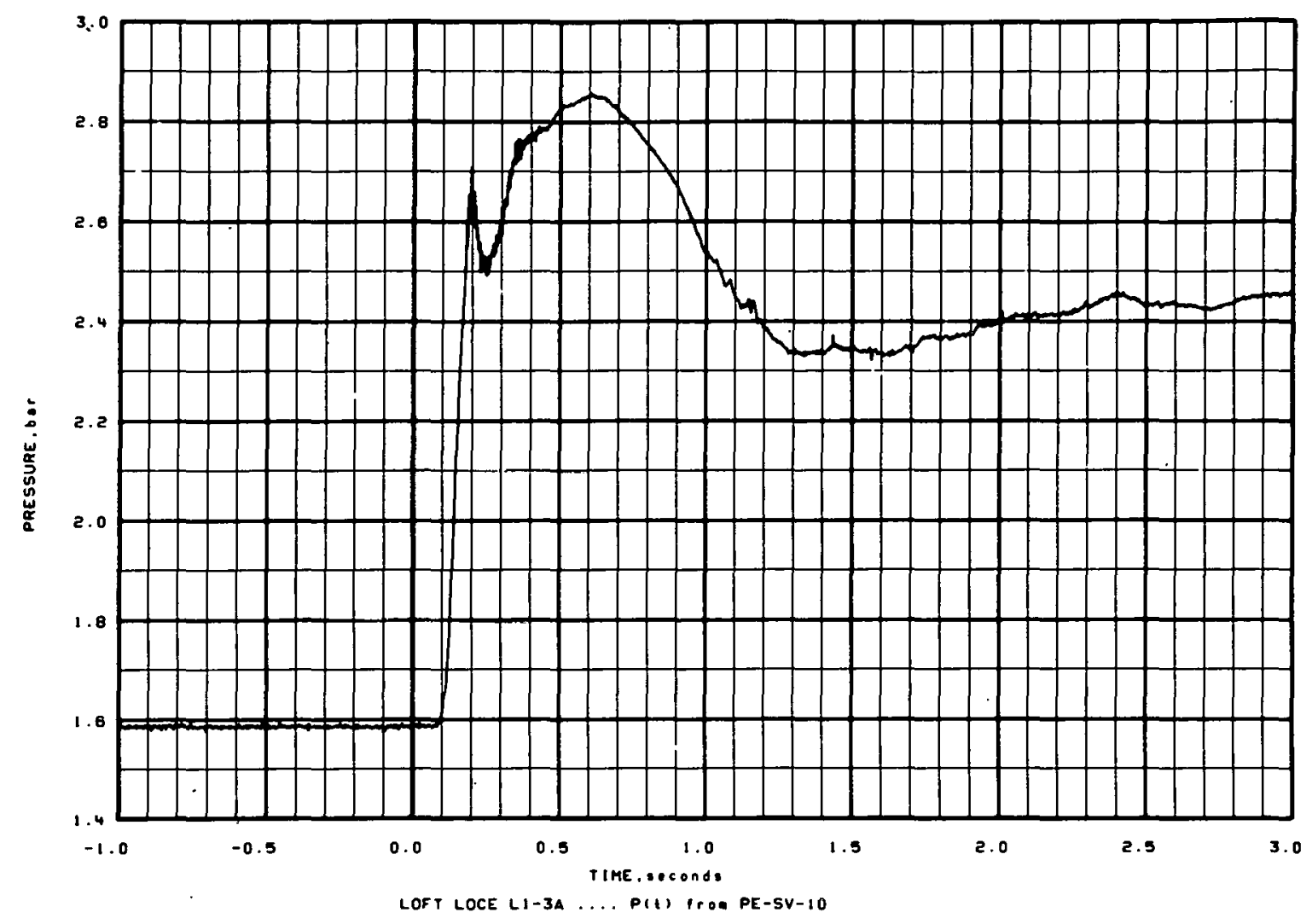

Figure $\mathrm{N}-13$

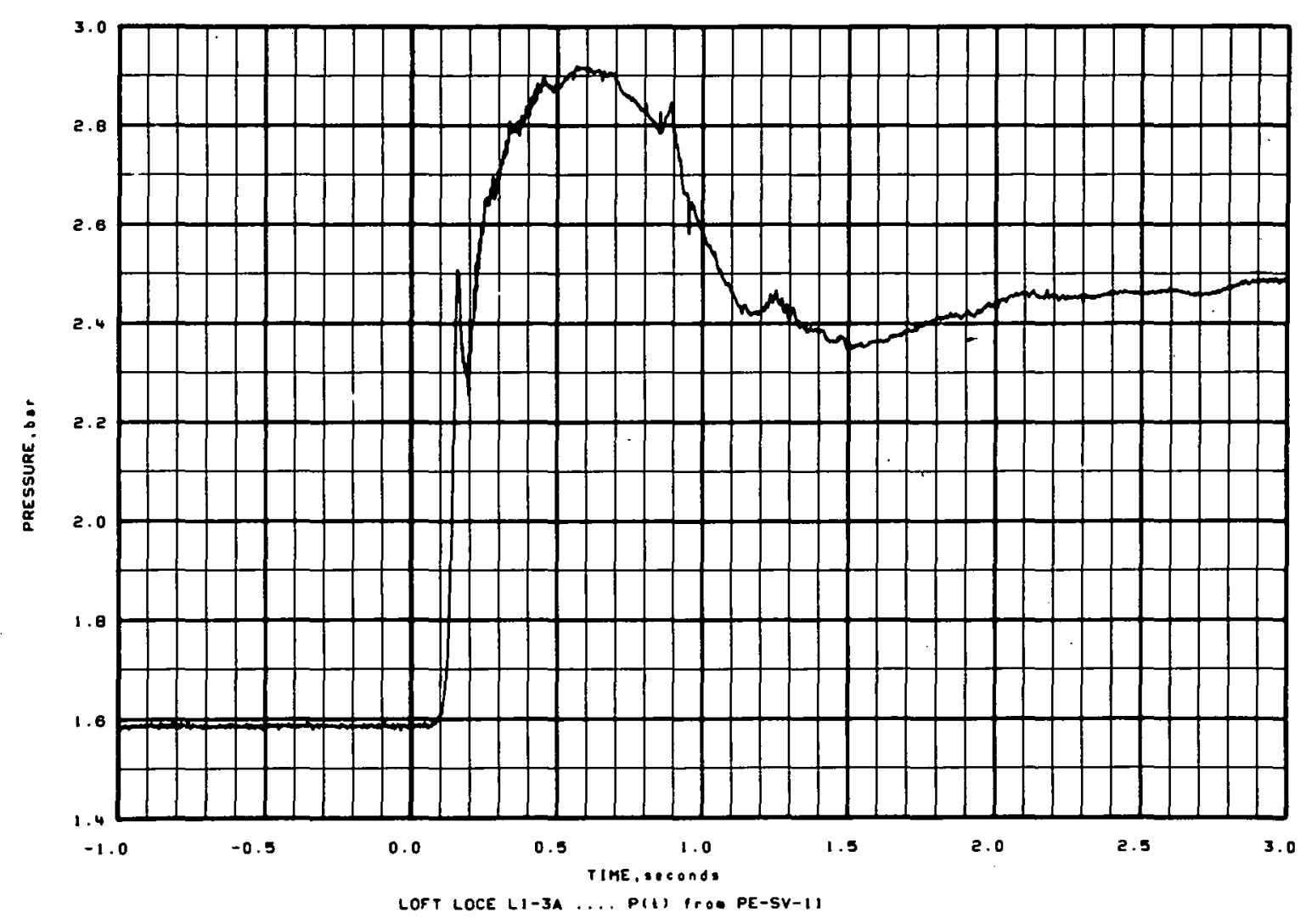

Figure $\mathrm{N}-14$ 


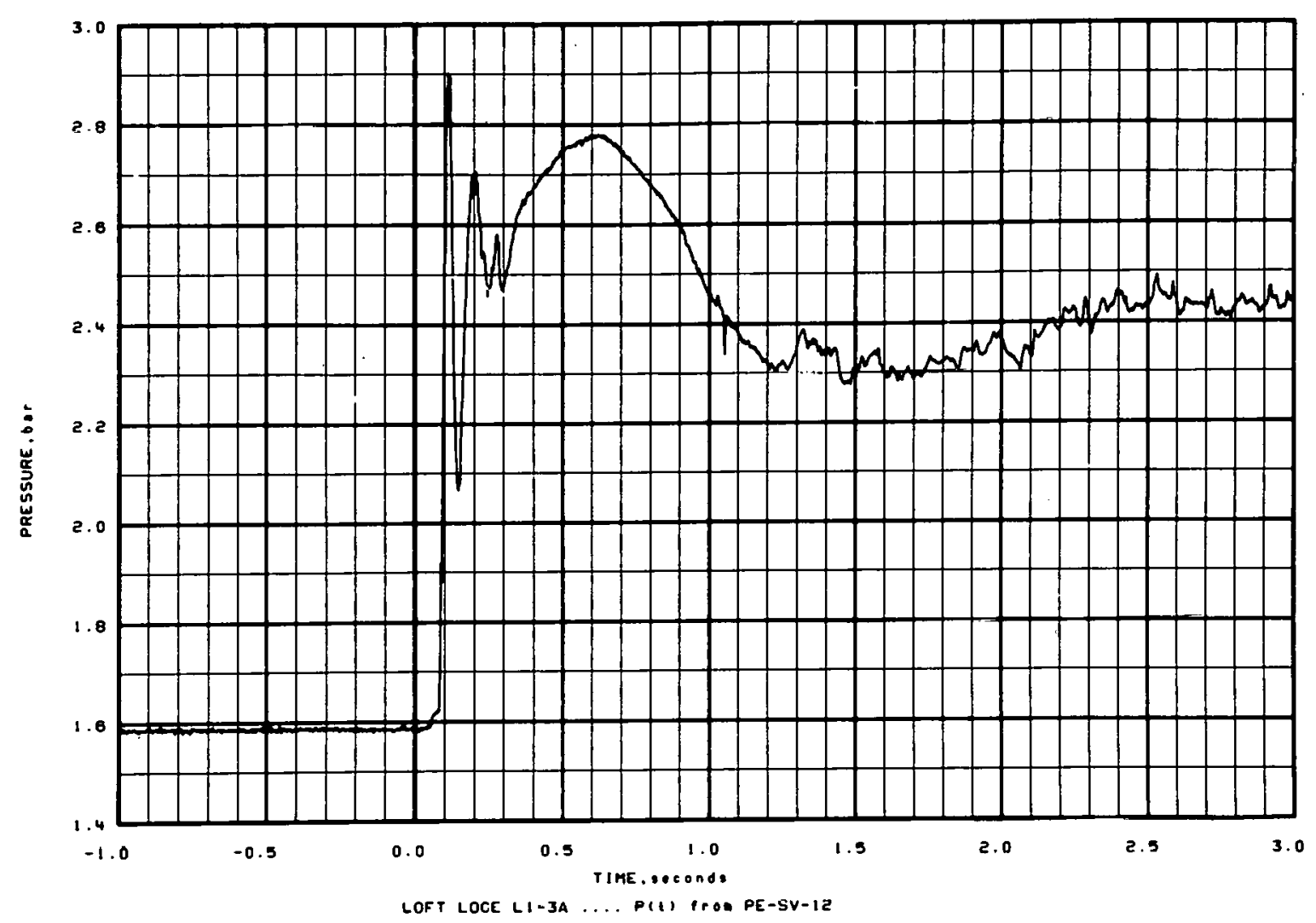

Figure N-15

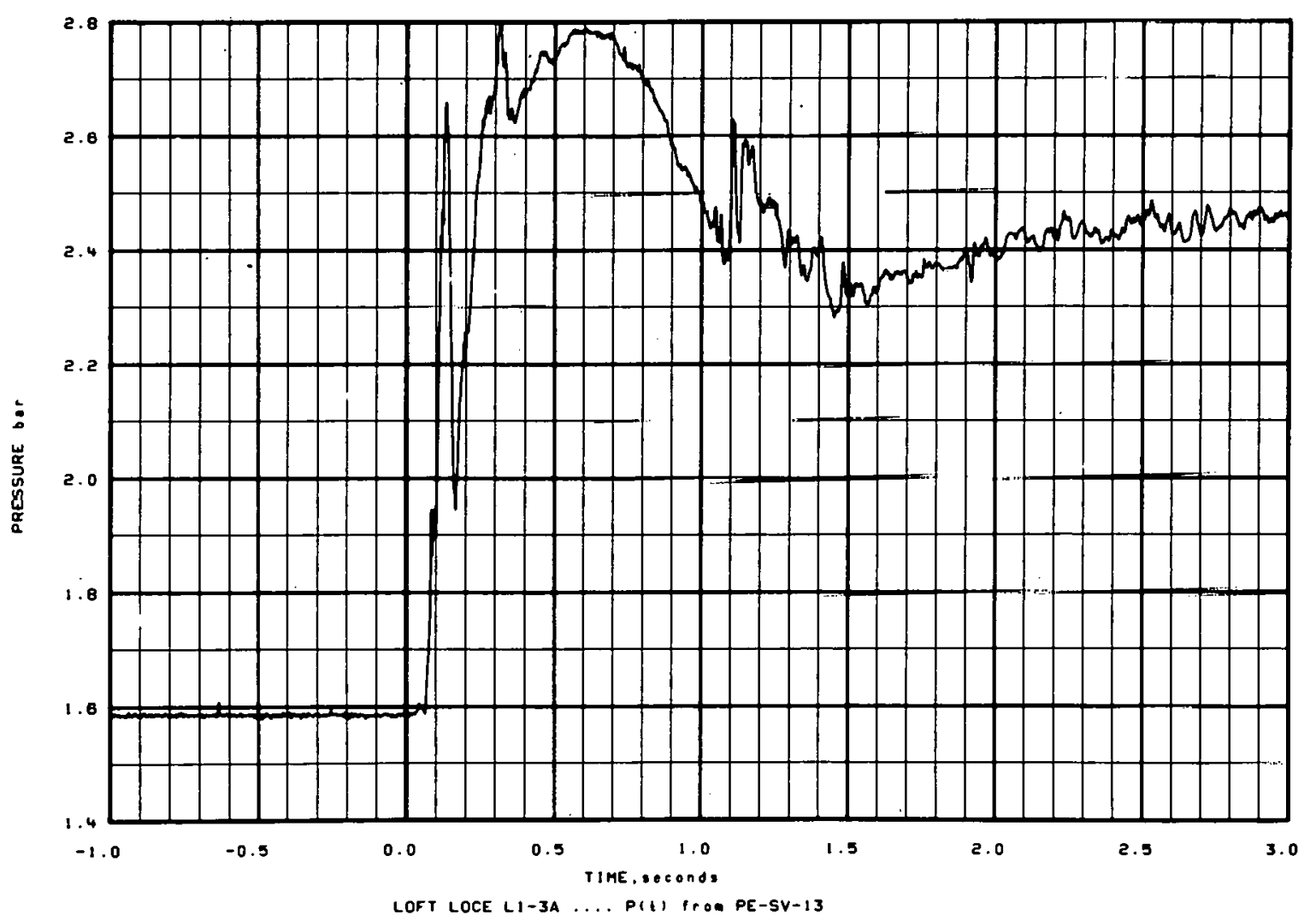

Figure N-16 


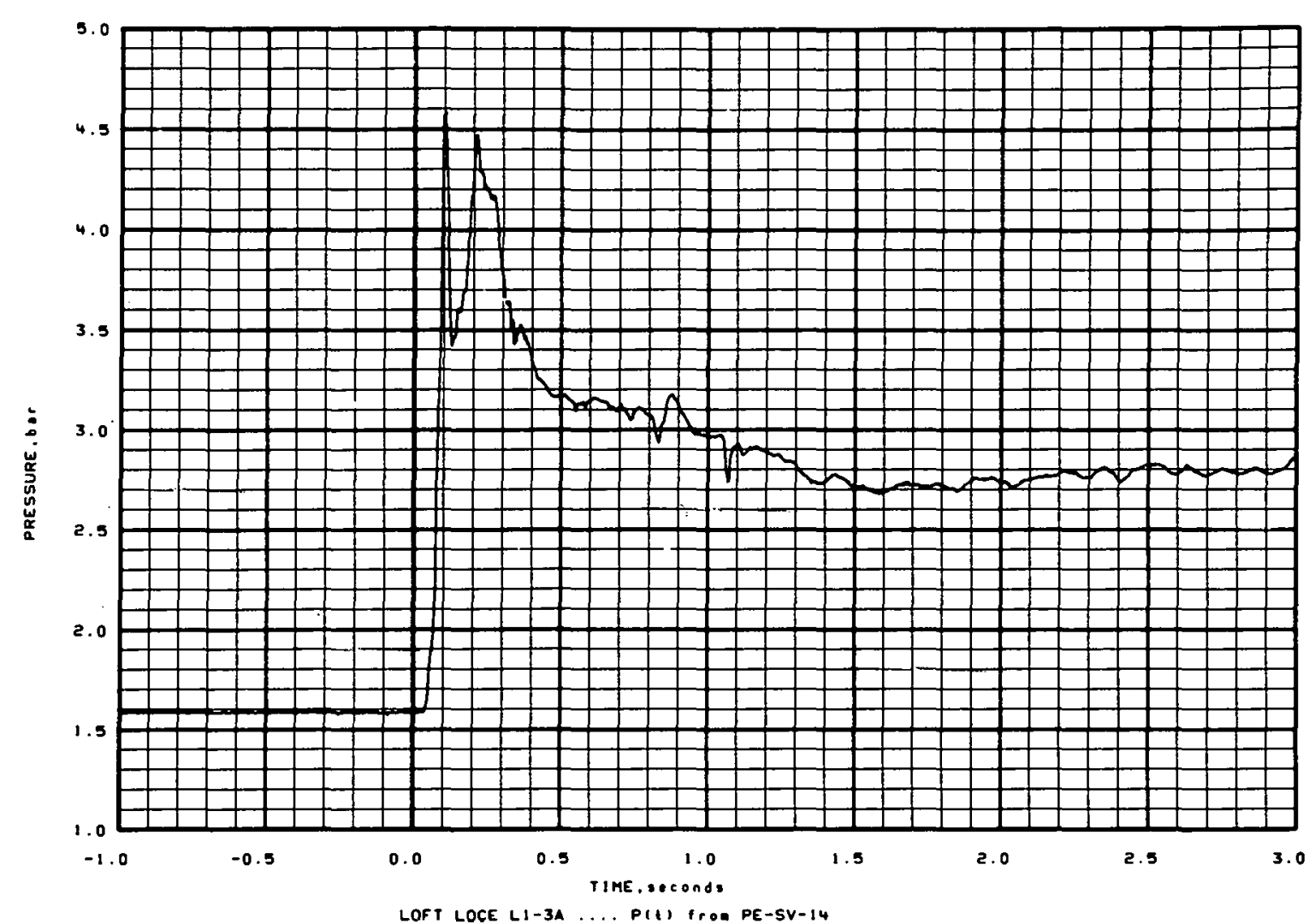

Figure $\mathrm{N}-17$

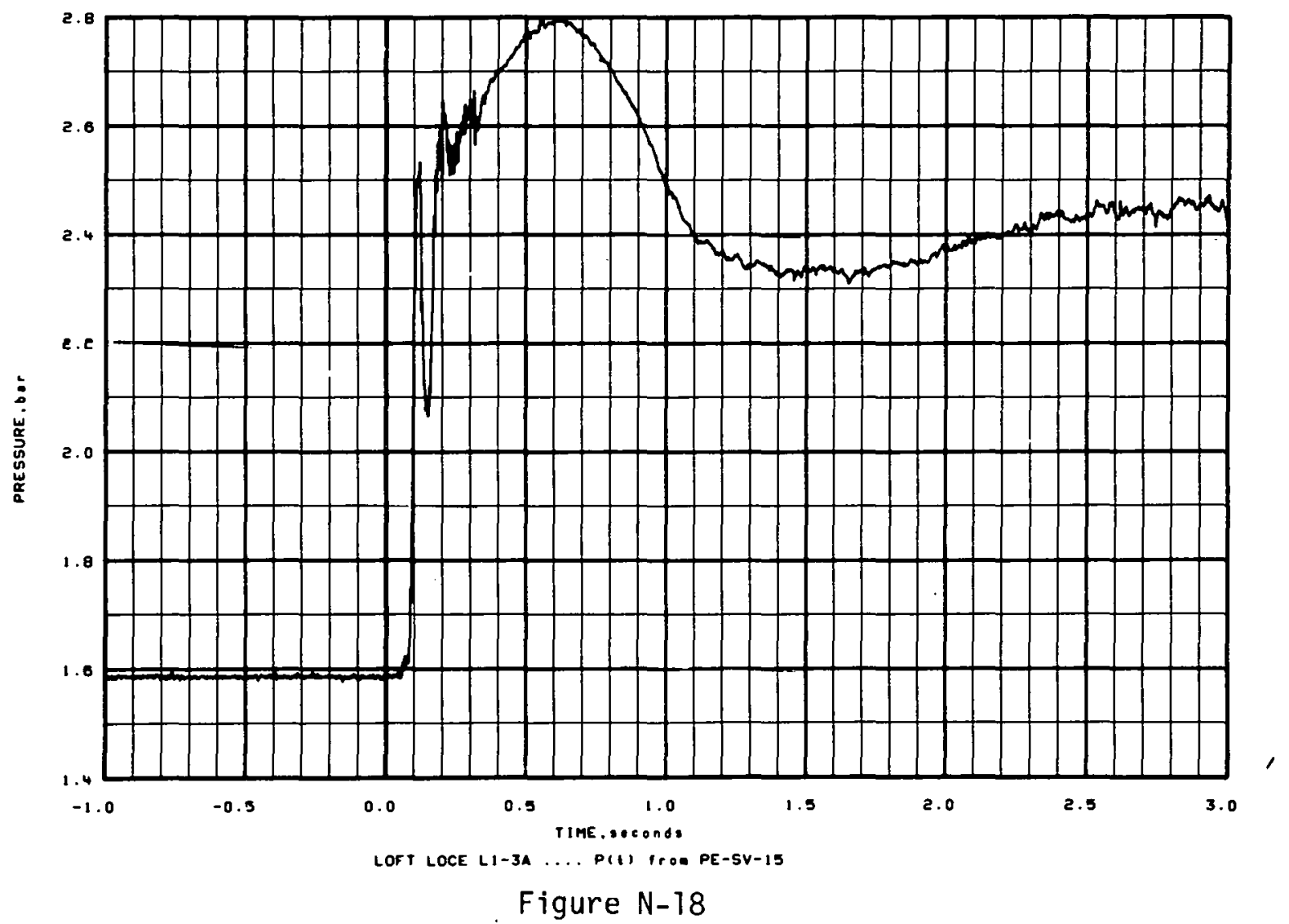




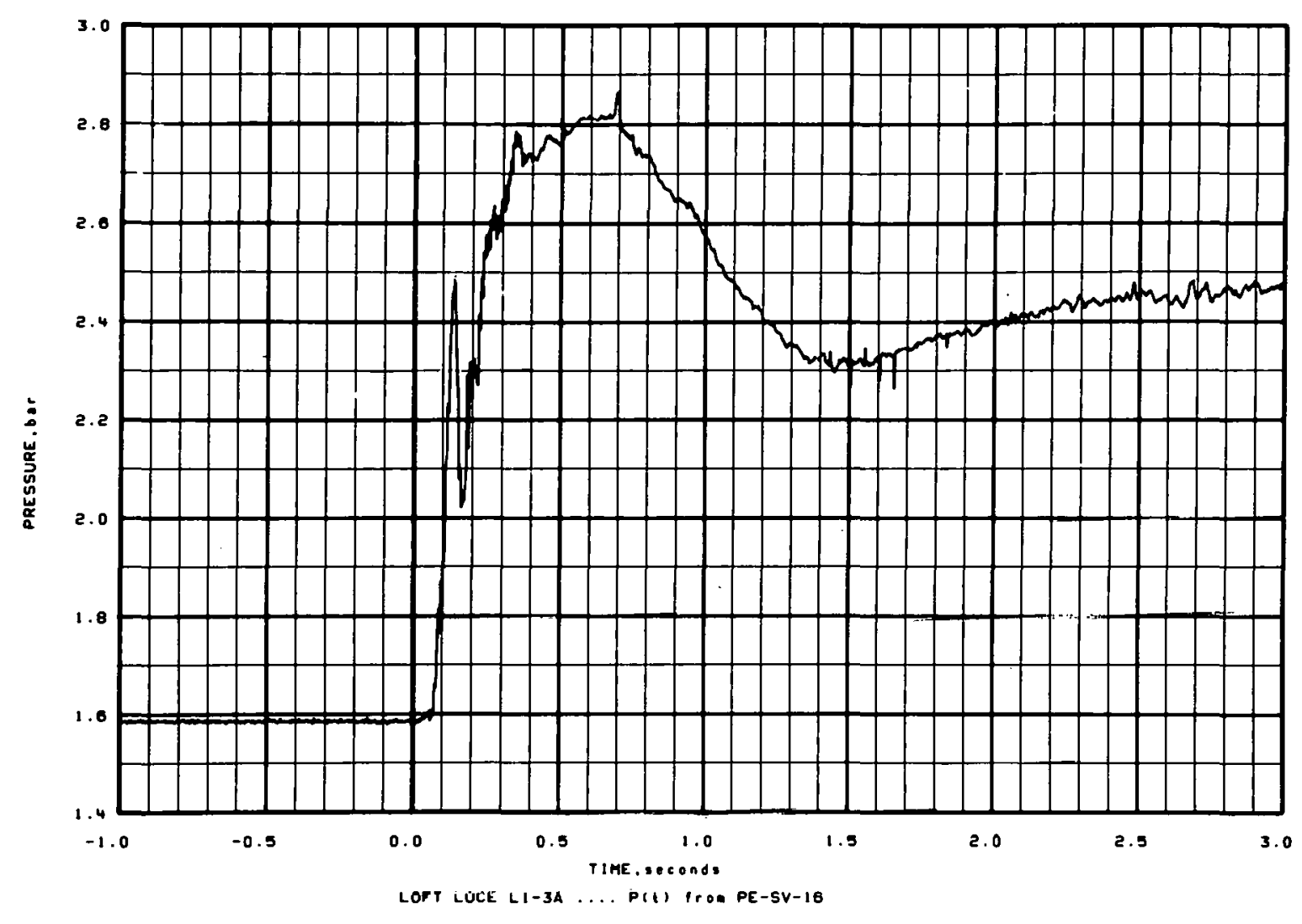

Figure $\mathrm{N}-19$

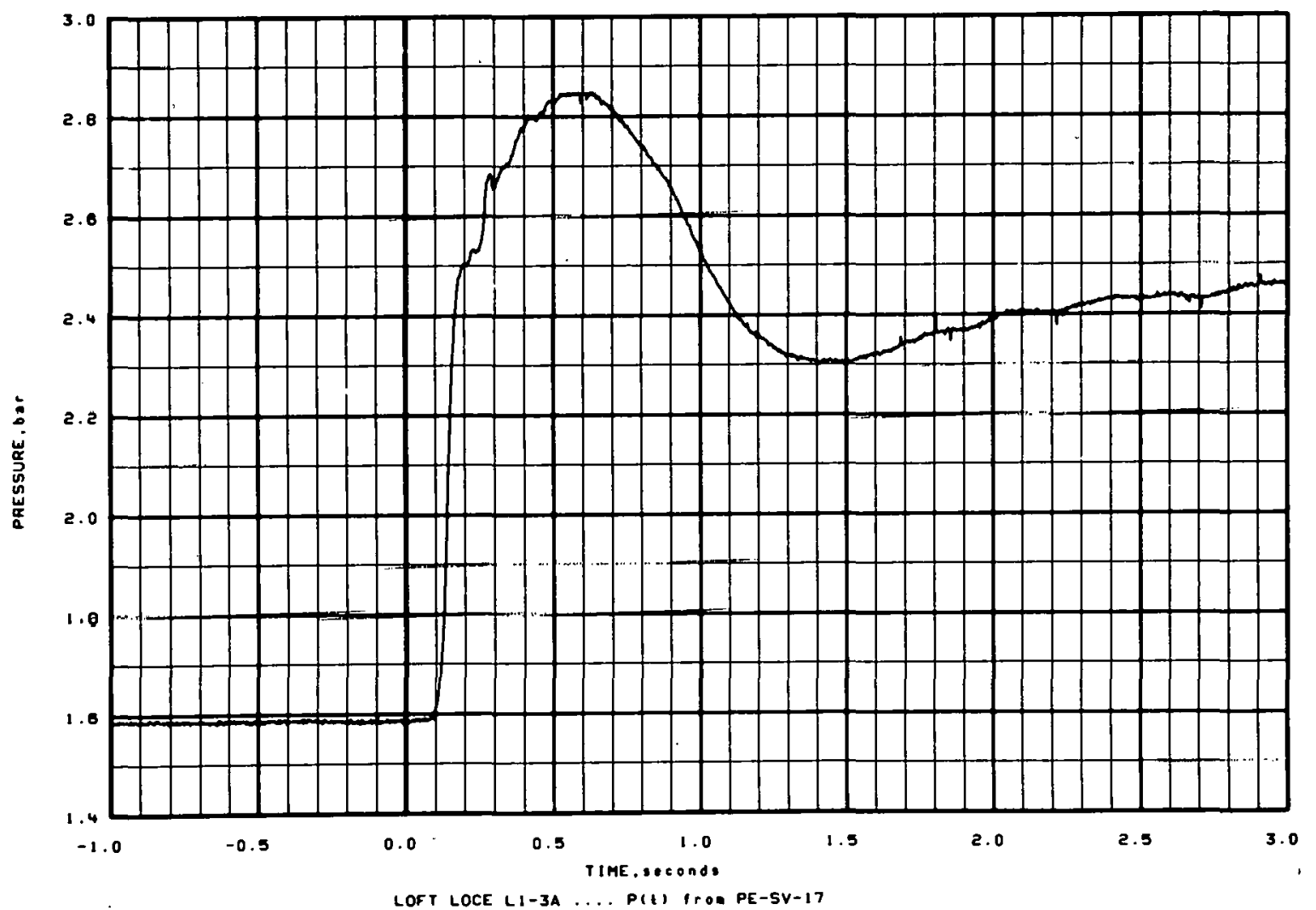

Figure $\mathrm{N}-20$ 

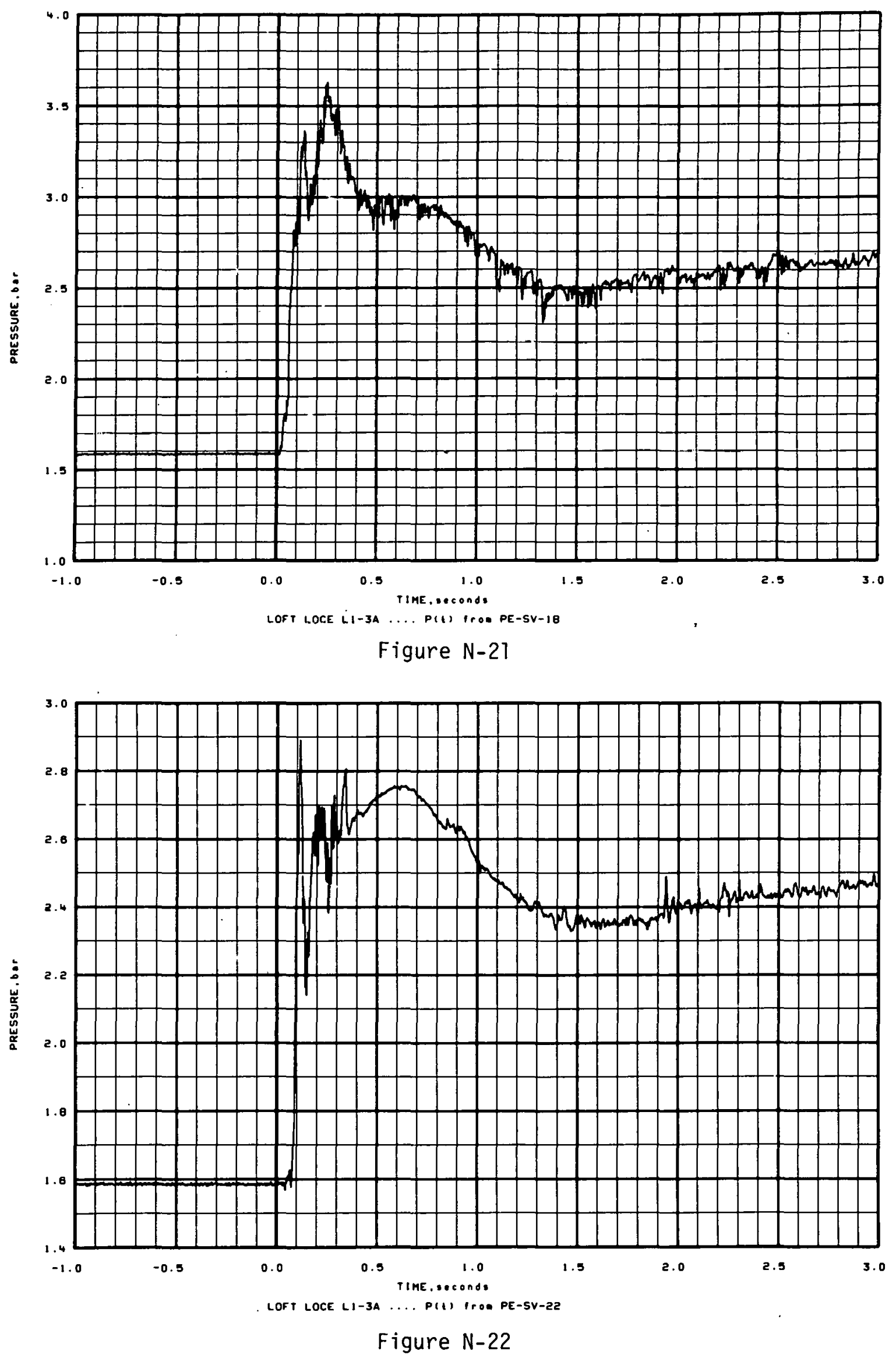


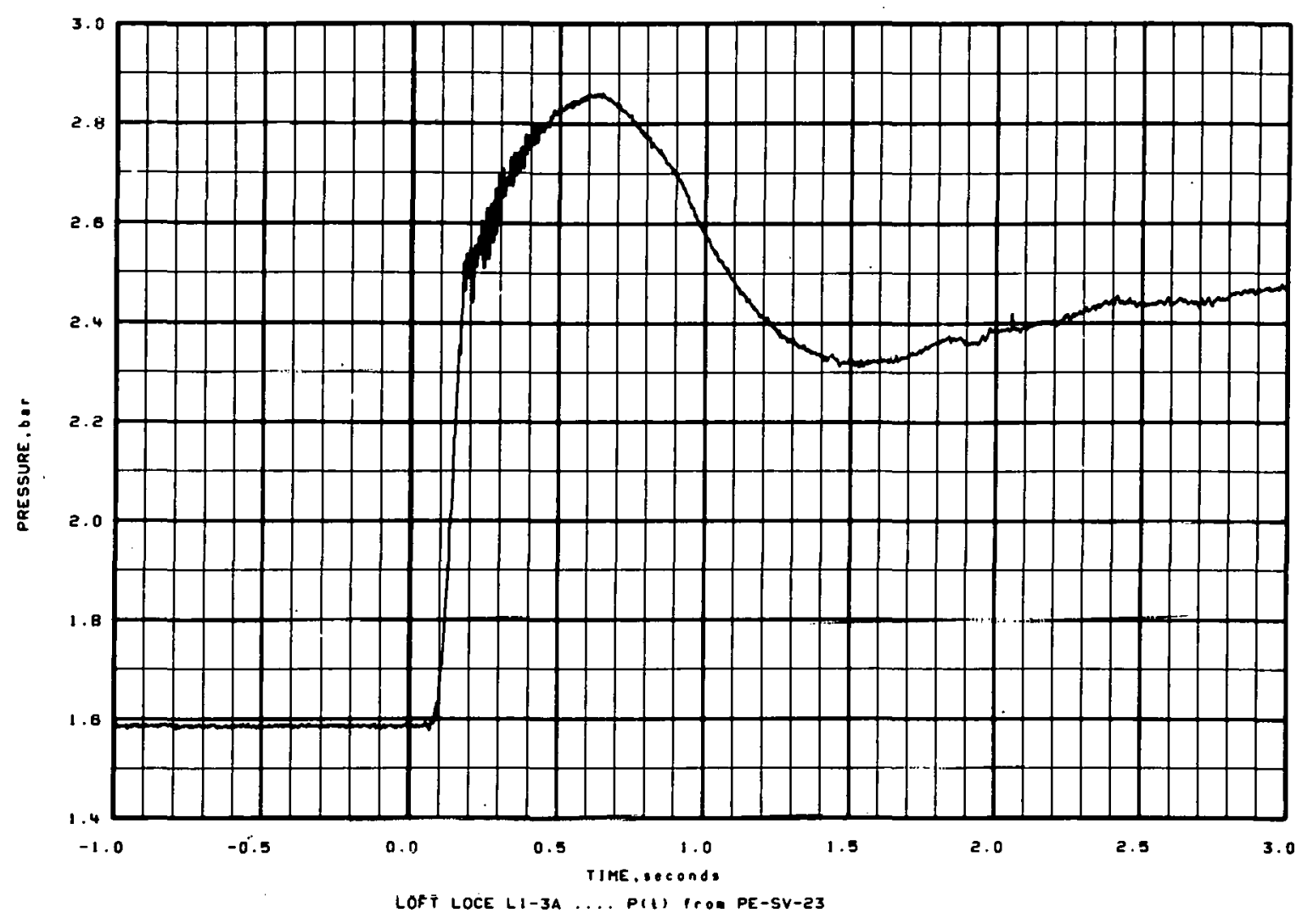

Figure N-23

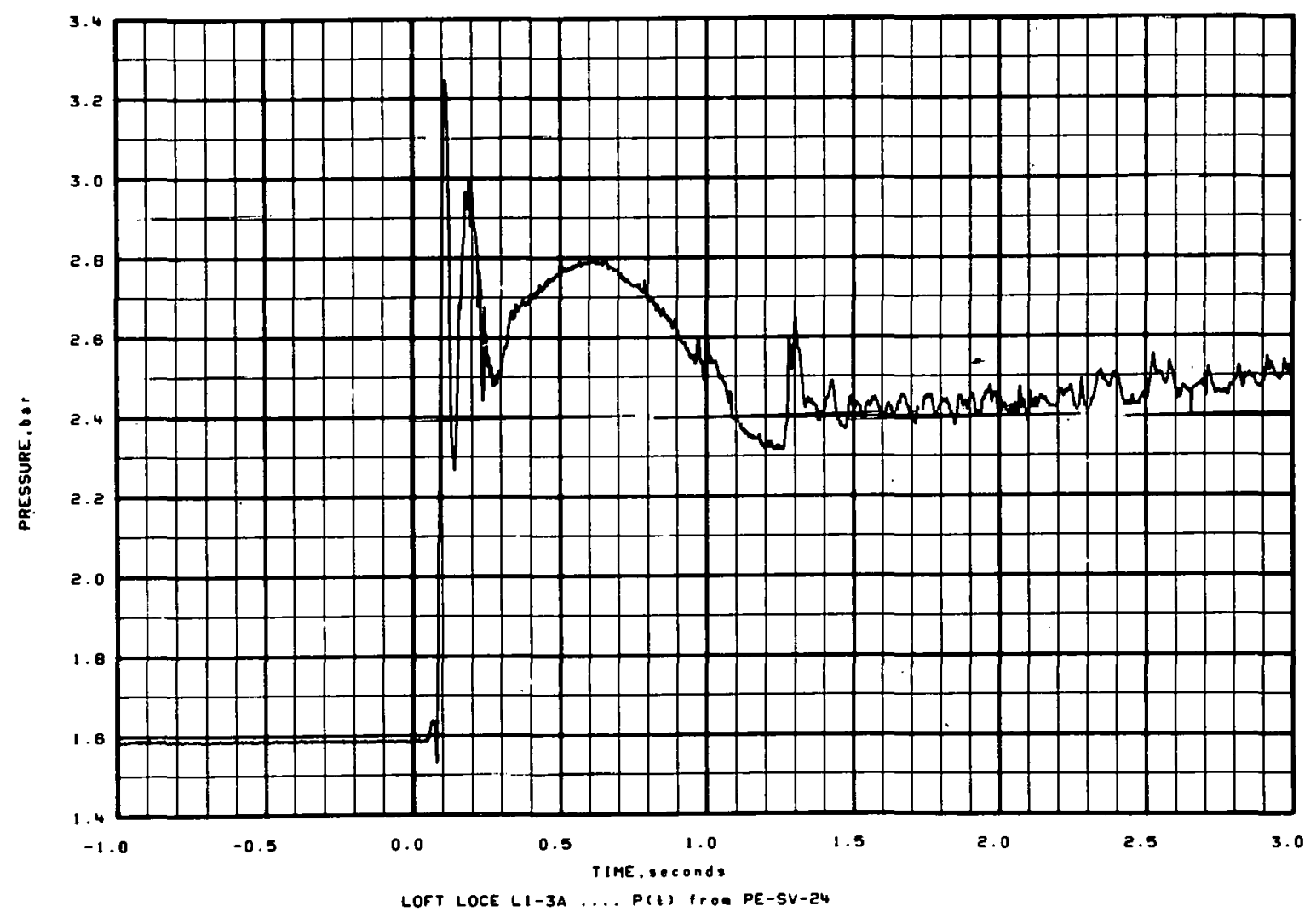

Figure N-24 


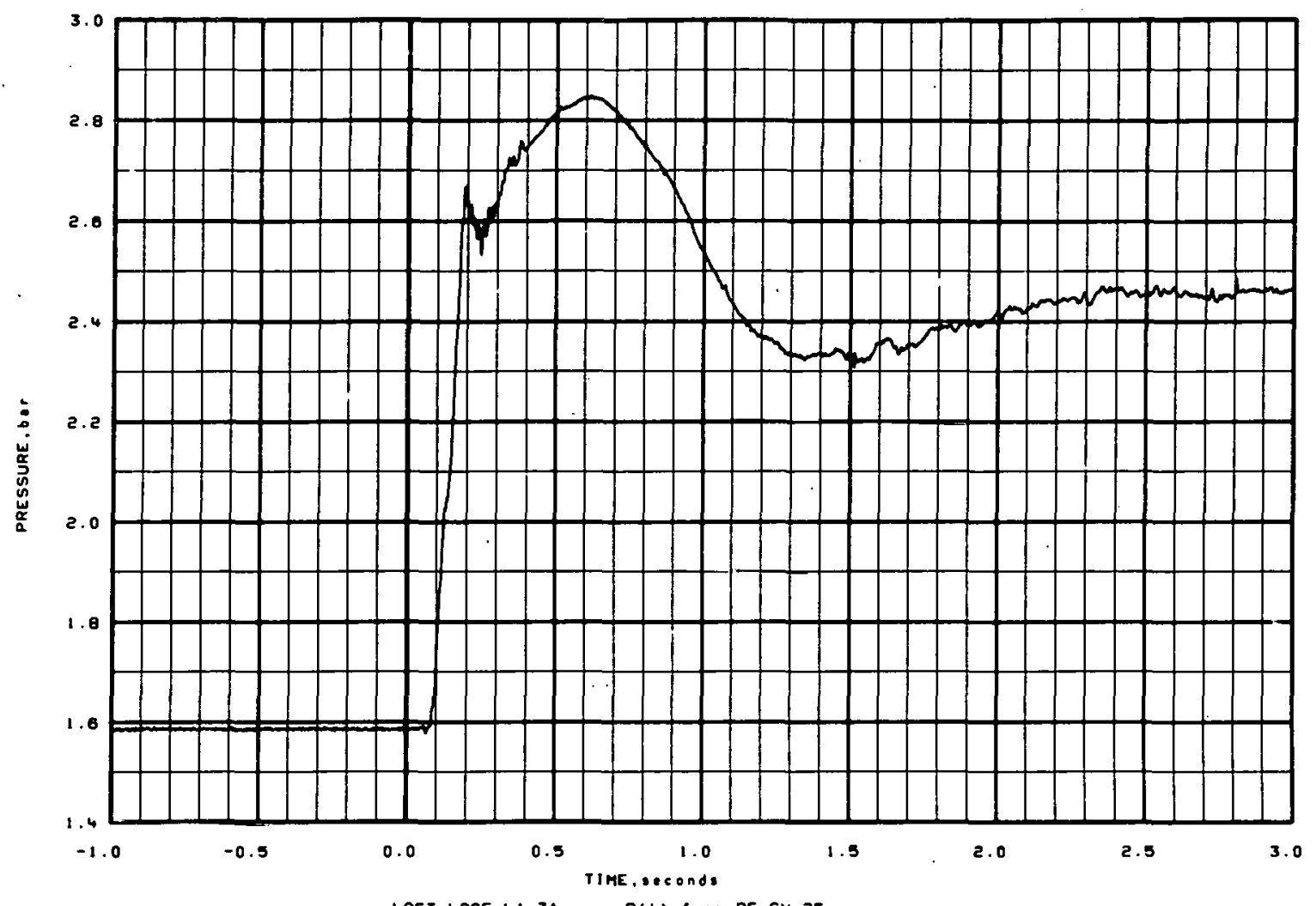

LOFT LOCE L1-3A ... P(t) fro. PE-SV-25

Figure $\mathrm{N}-25$

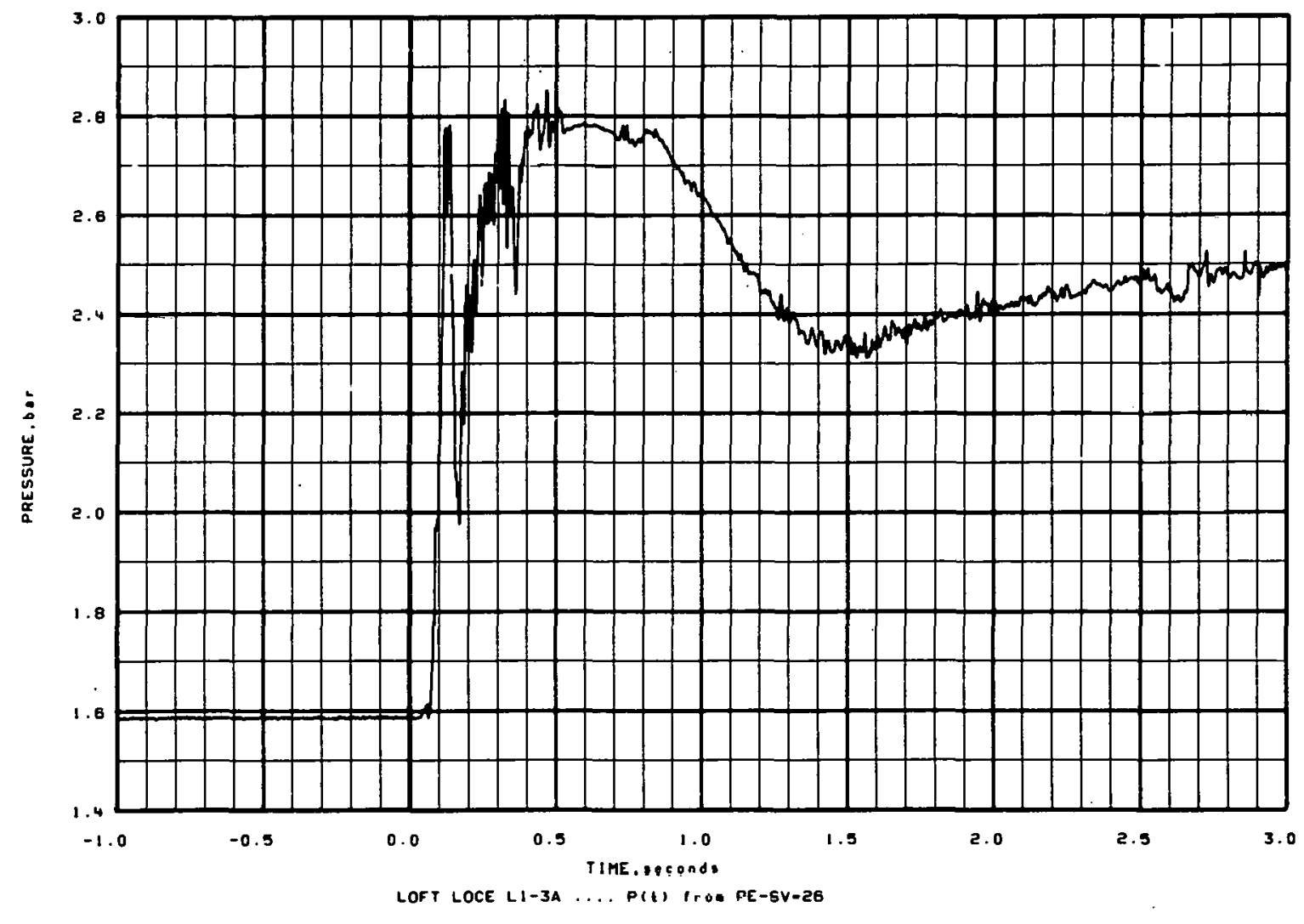

Figure $\mathrm{N}-26$ 


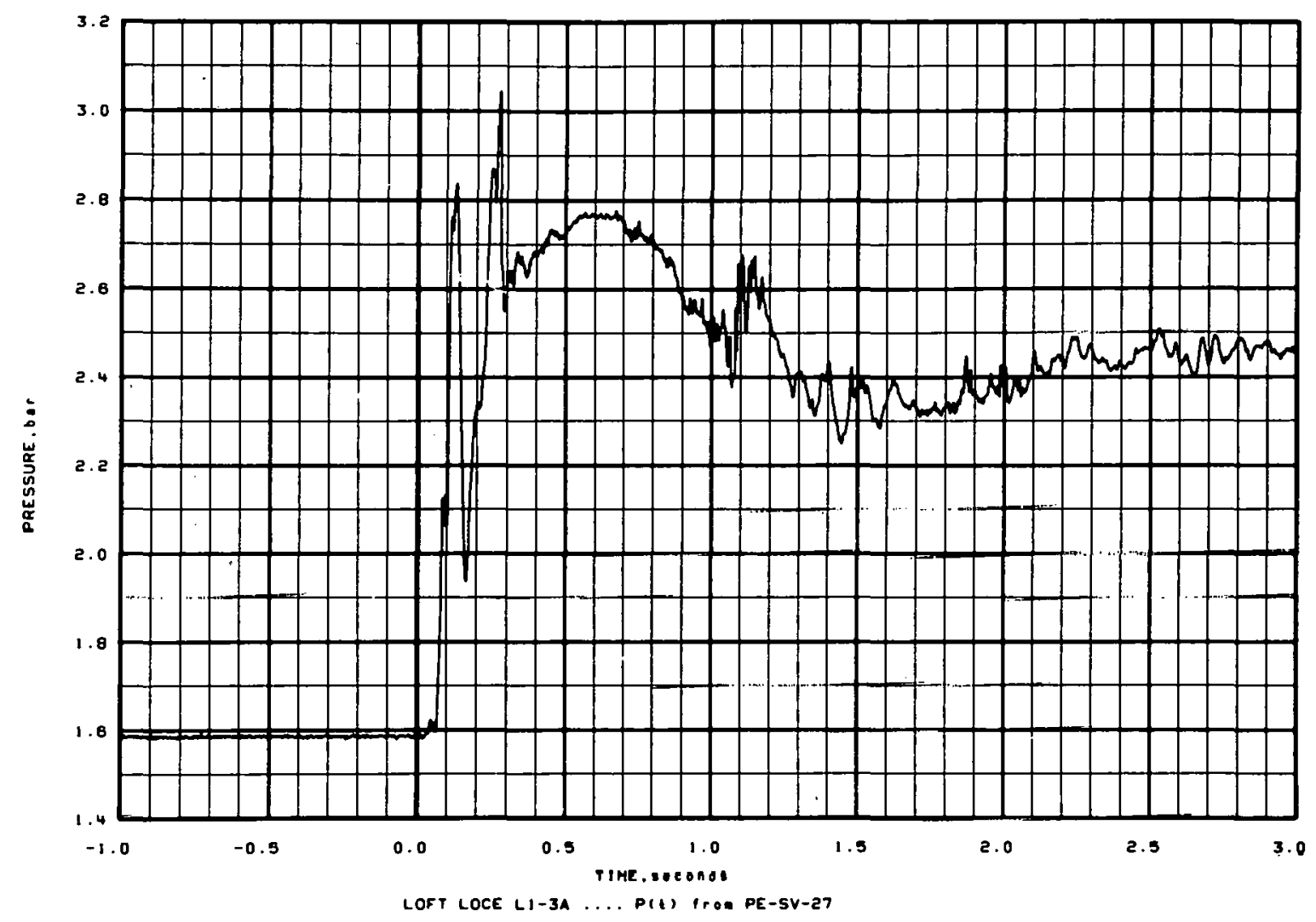

Figure $\mathrm{N}-27$

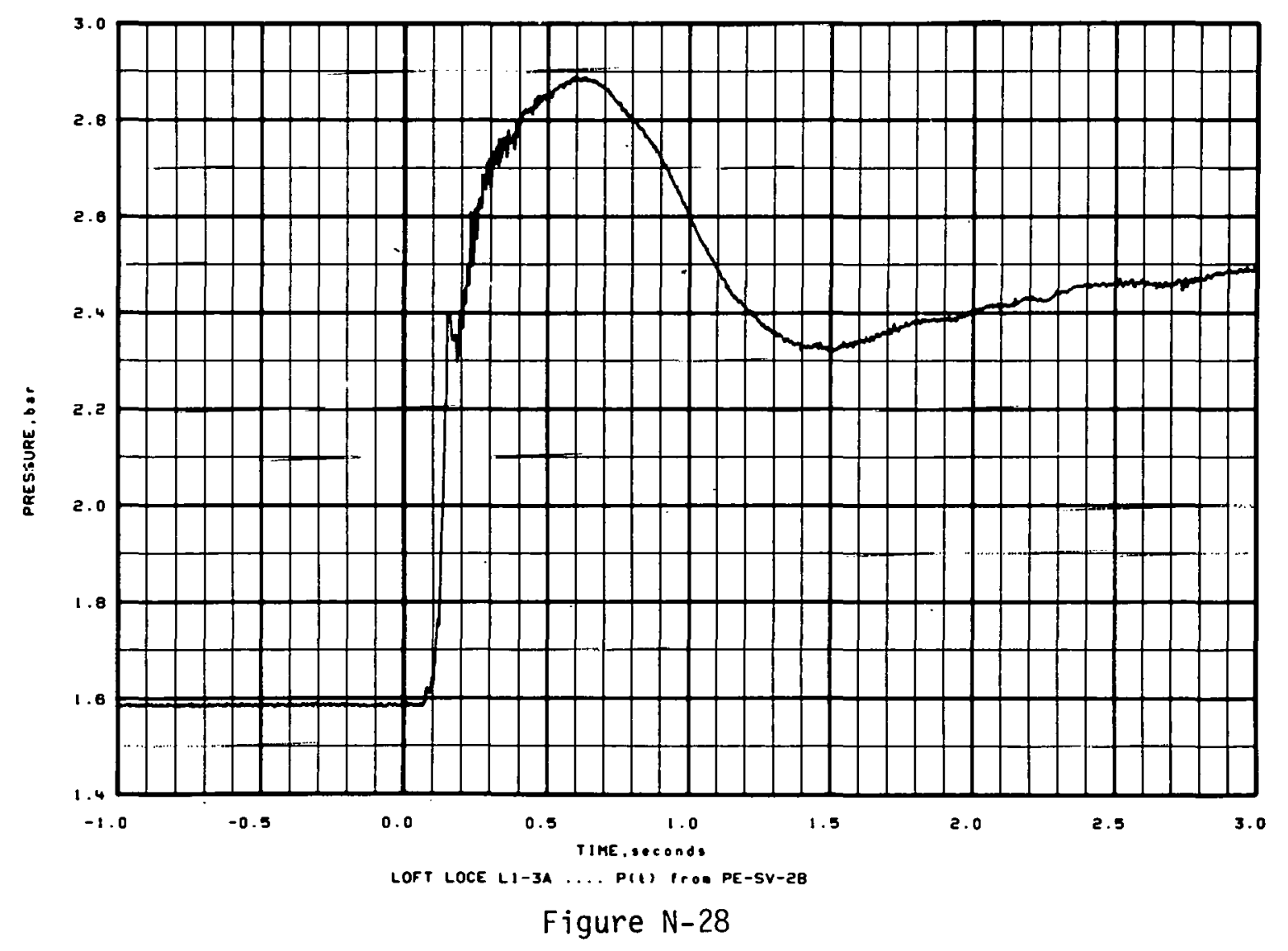



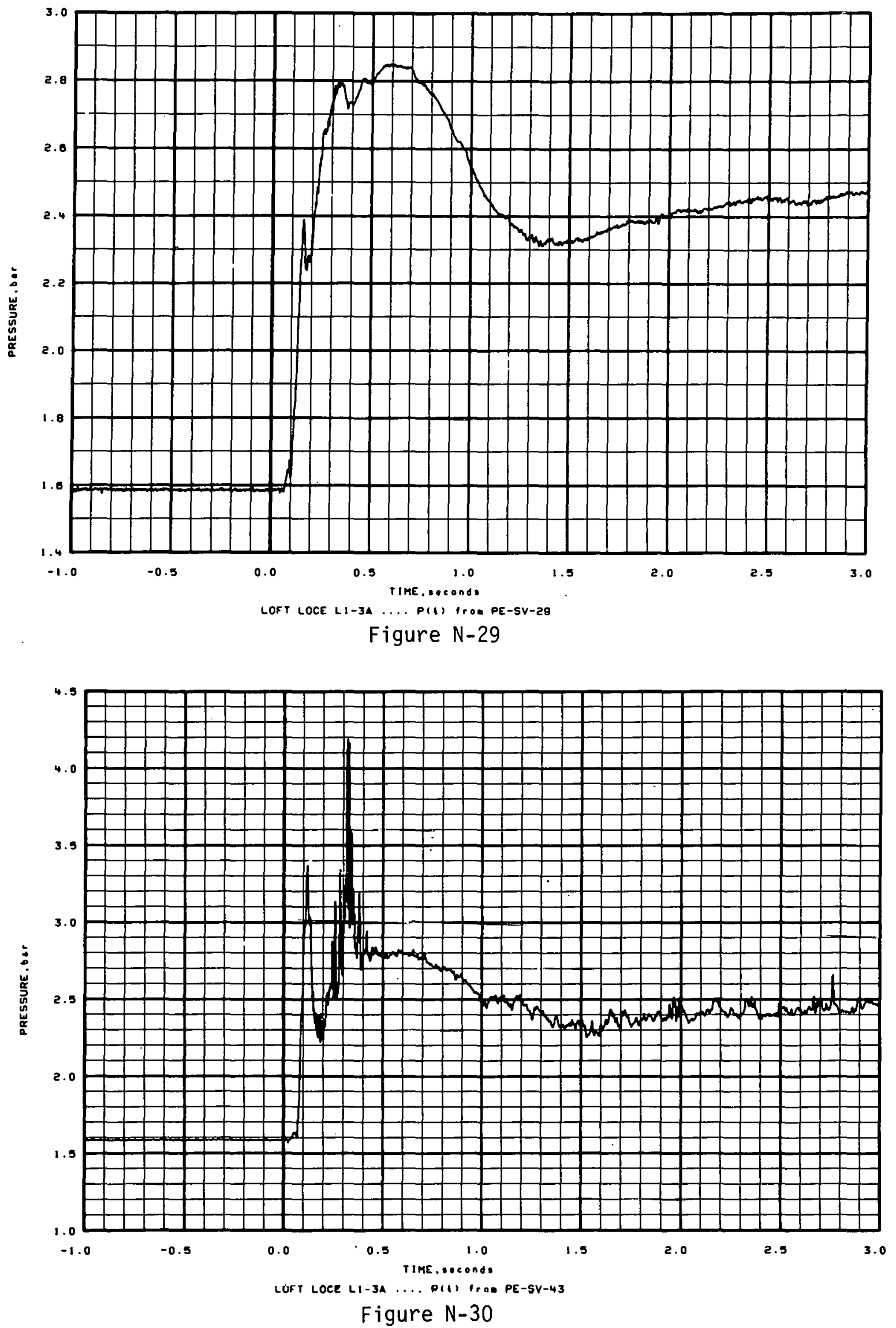

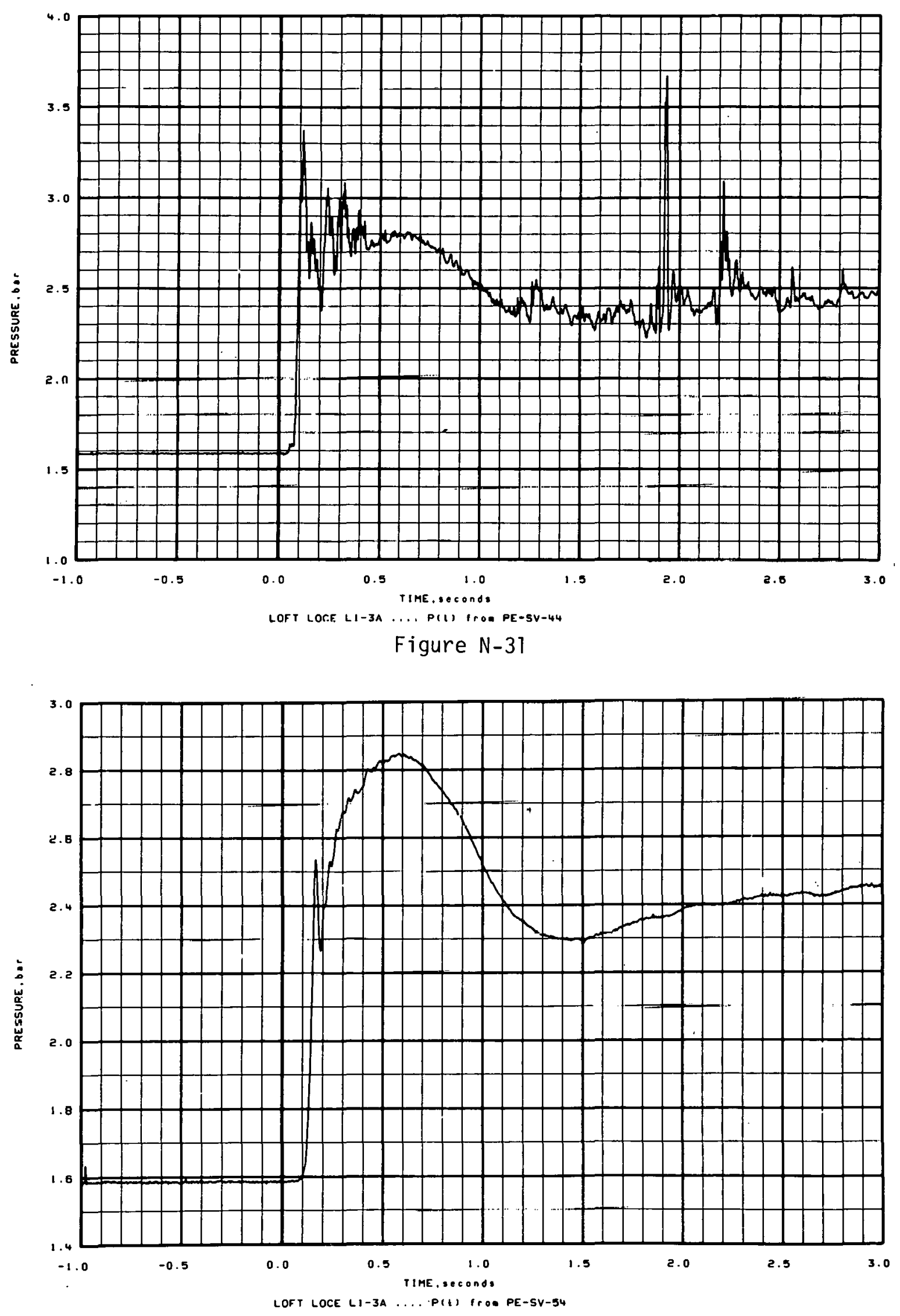

Figure $\mathrm{N}-32$ 

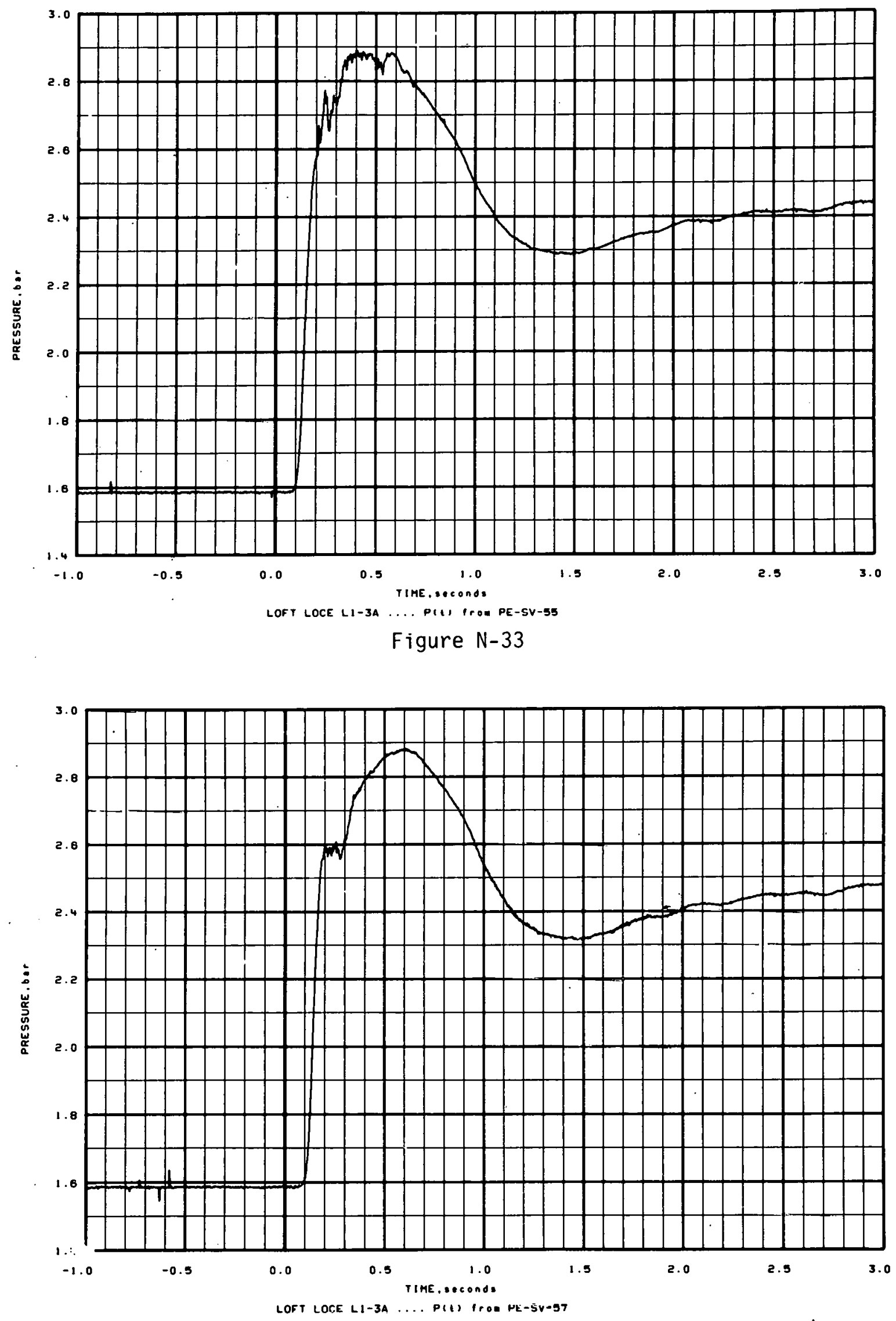

Figure N-34 

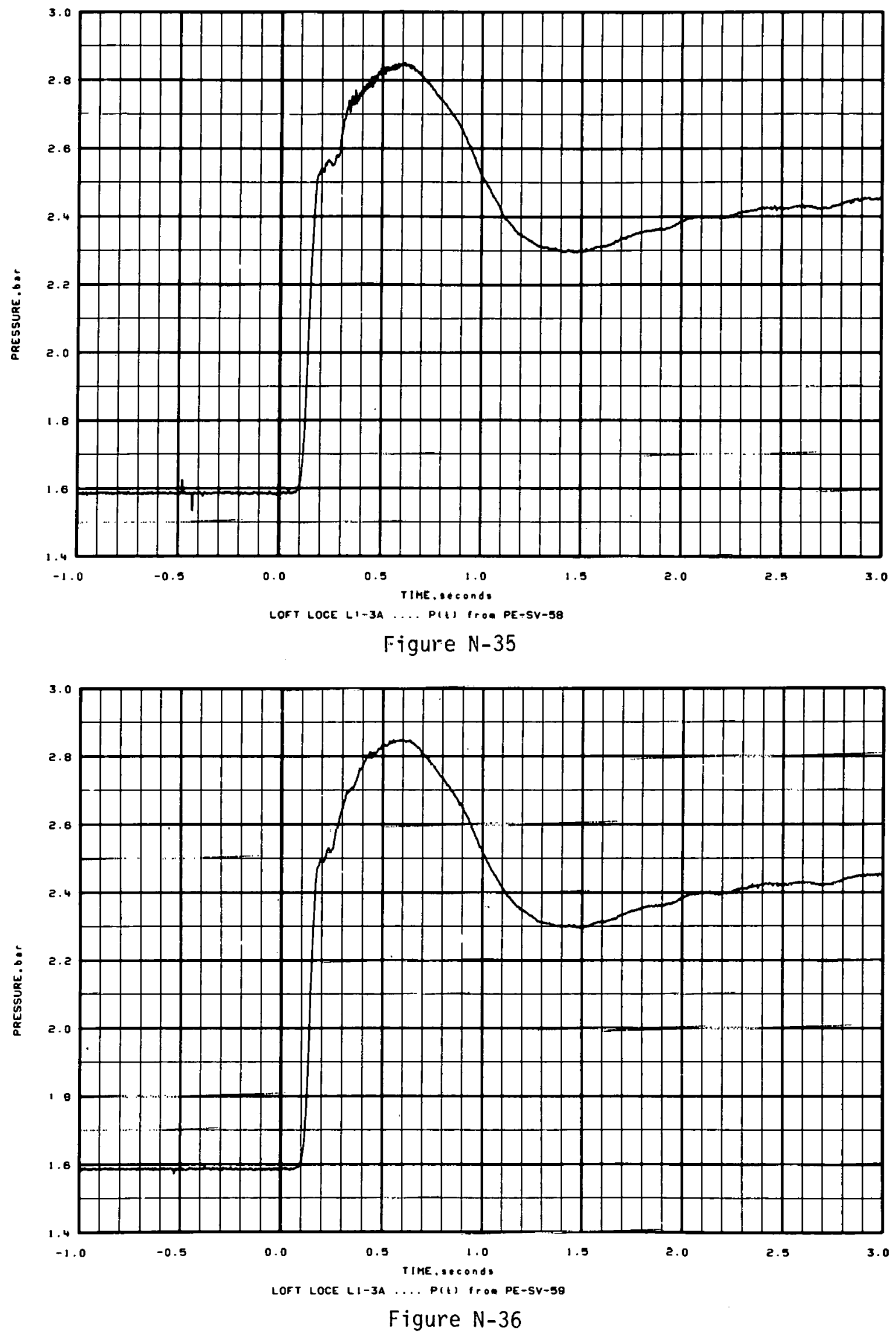


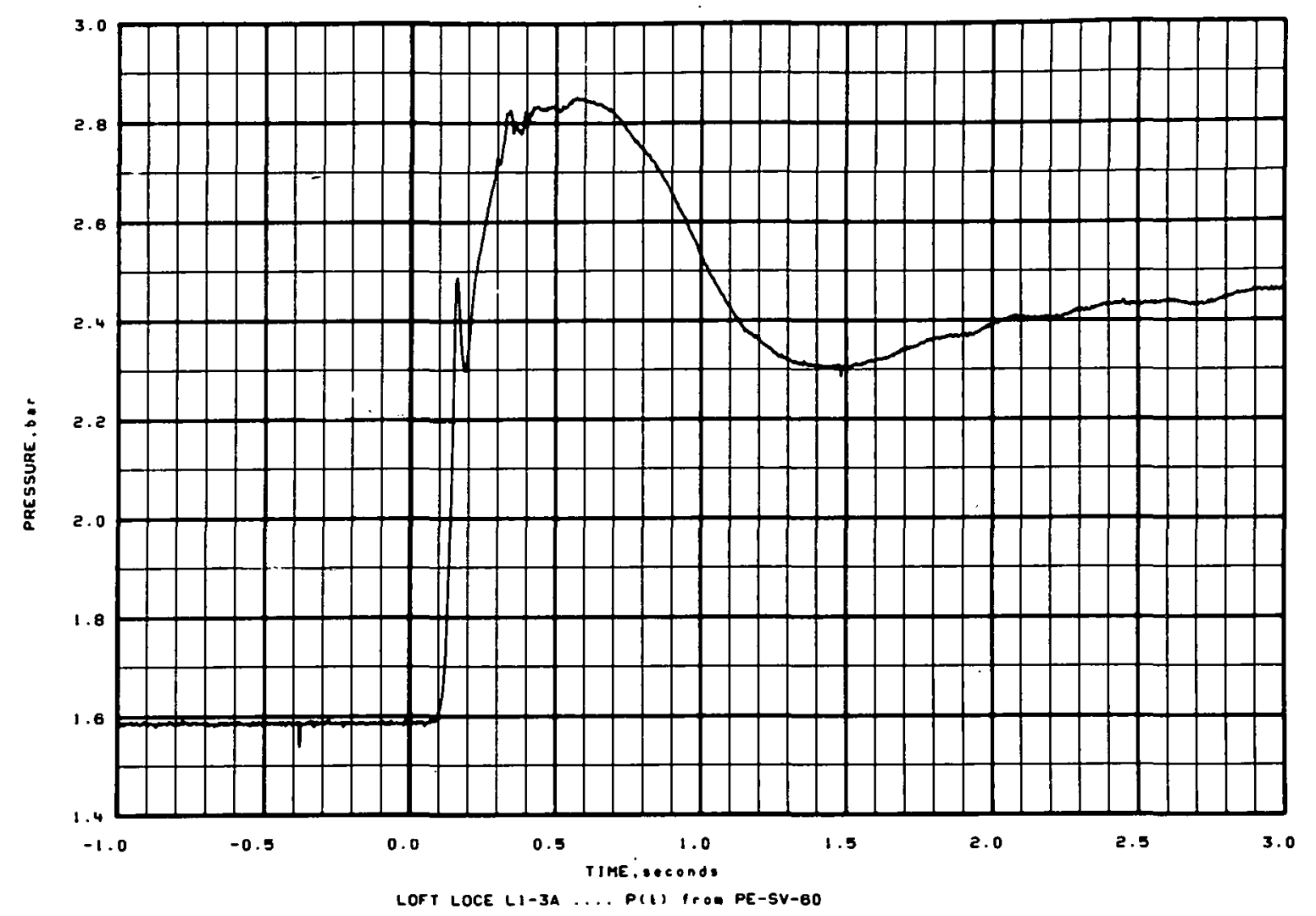

Figure N-37

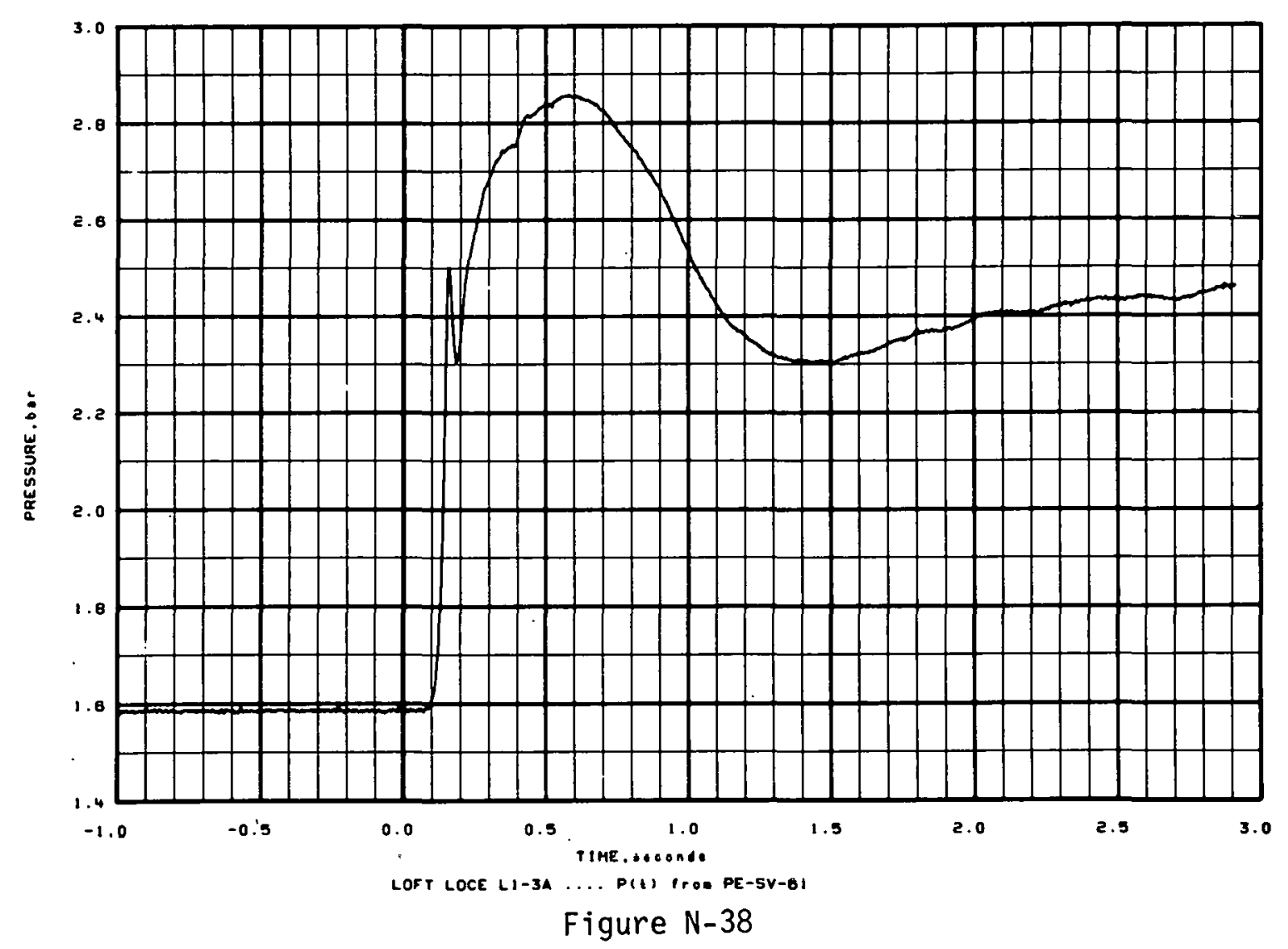


DISTRIBUTION RECORD FOR TREE-NUREG-1083

Internal Distribution

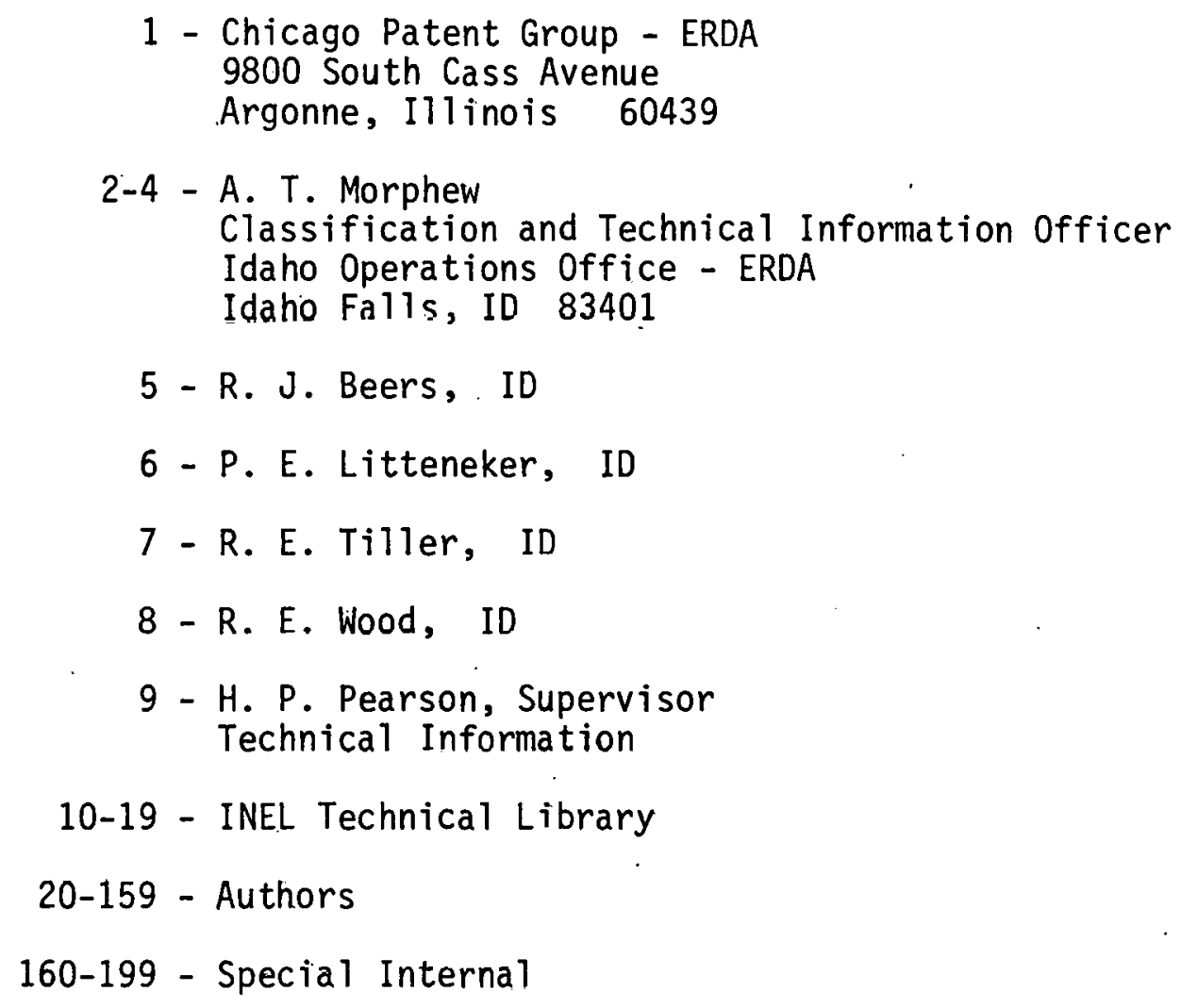

1 - Chicago Patent Group - ERDA 9800 South Cass Avenue

\section{External Distribution}

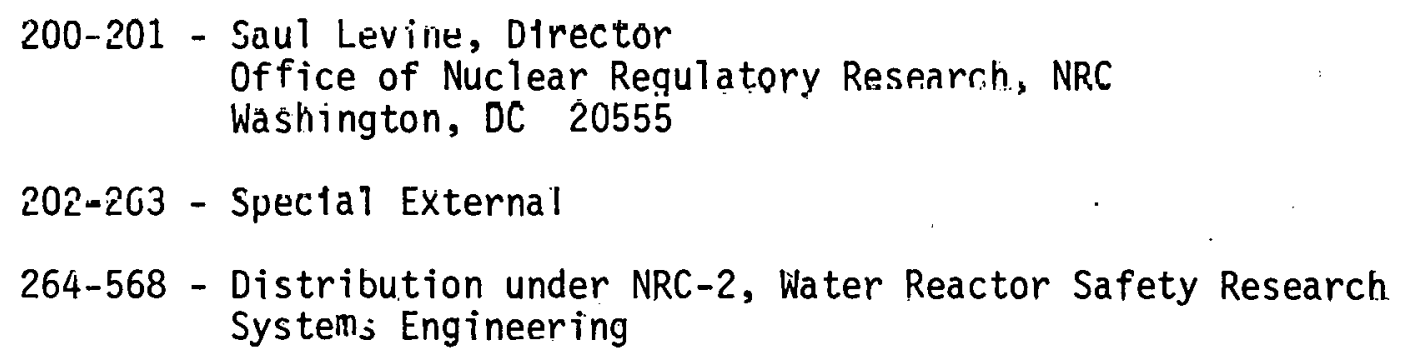

